Portland State University

PDXScholar

$5-17-2016$

\title{
On the Variability of Pacific Ocean Tides at Seasonal to Decadal Time Scales: Observed vs Modelled
}

Adam Thomas Devlin

Portland State University

Follow this and additional works at: https://pdxscholar.library.pdx.edu/open_access_etds

Part of the Oceanography Commons, and the Physics Commons

Let us know how access to this document benefits you.

Recommended Citation

Devlin, Adam Thomas, "On the Variability of Pacific Ocean Tides at Seasonal to Decadal Time Scales: Observed vs Modelled" (2016). Dissertations and Theses. Paper 2924.

https://doi.org/10.15760/etd.2920

This Dissertation is brought to you for free and open access. It has been accepted for inclusion in Dissertations and Theses by an authorized administrator of PDXScholar. Please contact us if we can make this document more accessible: pdxscholar@pdx.edu. 
On the Variability of Pacific Ocean Tides at Seasonal to Decadal Time Scales:

Observed vs Modelled

\section{by}

Adam Thomas Devlin

A dissertation submitted in partial fulfillment of the requirements for the degree of

Doctor of Philosophy

in

Applied Physics

Dissertation Committee:

David A. Jay, Chair

Ed Zaron

Stefan Talke

Aslam Khalil

Chris Butenhoff

Dacian Daescu

Portland State University

2016 
(C) 2016 Adam Thomas Devlin 


\begin{abstract}
Ocean tides worldwide have exhibited secular changes in the past century, simultaneous with a global secular rise in mean sea level (MSL). The combination of these two factors contributes to higher water levels, and may increase threats to coastal regions and populations over the next century. Equally as important as these long-term changes are the short-term fluctuations in sea levels and tidal properties. These fluctuations may interact to yield locally extreme water level events, especially when combined with storm surge. This study, presented in three parts, examines the relationships between tidal anomalies and MSL anomalies on yearly and monthly timescales, with a goal of diagnosing dynamical factors that may influence the long-term evolution of tides in the Pacific Ocean. Correlations between yearly averaged properties are denoted tidal anomaly trends (TATs), and will be used to explore interannual behavior. Correlations of monthly averaged properties are denoted seasonal tidal anomaly trends (STATs), and are used to examine seasonal behavior. Four tidal constituents are analyzed: the two largest semidiurnal (twice daily) constituents, $\mathrm{M}_{2}$ and $\mathrm{S}_{2}$, and the two largest diurnal (once daily) constituents, $\mathrm{K}_{1}$ and $\mathrm{O}_{1}$.
\end{abstract}

Part I surveys TATs and STATs at 153 Pacific Ocean tide gauges, and discusses regional patterns within the entire Pacific Ocean. TATs with statistically significant relations between MSL and amplitudes (A-TATs) are seen at $89 \%$ of all gauges; 92 gauges for $M_{2}, 66$ for $S_{2}, 82$ for $K_{1}$, and 59 for $\mathrm{O}_{1}$. TATs with statistically significant 
relations between tidal phase (the relative timing of high water of the tide) and MSL (PTATs) are observed at 55 gauges for $\mathrm{M}_{2}, 47$ for $\mathrm{S}_{2}, 42$ for $\mathrm{K}_{1}$, and 61 for $\mathrm{O}_{1}$. Significant seasonal variations (STATs) are observed at about a third of all gauges, with the largest concentration in Southeast Asia. The effect of combined A-TATs was also considered. At selected stations, observed tidal sensitivity with MSL was extrapolated forward in time to the predicted sea level in 2100 . Results suggest that stations with large positive combined A-TATs produce total water levels that are greater than those predicted by an increase in MSL alone, increasing the chances of high-water events. Conversely, negative correlation between sea level and tidal properties may mitigate somewhat against sea level rise; changes in total water levels in 2100 at stations with a negative combined A-TAT are less than that predicted by MSL rise alone. Climate change scenarios that take into account greater increases in MSL due to increased Antarctic ice melt show larger changes in total water levels over the same time period.

Part II examines the mechanisms behind the yearly (TAT) variability in the Western Tropical Pacific Ocean. Significant amplitude TATs are found at more than half of 26 gauges for each of the two strongest tidal constituents, $\mathrm{K}_{1}$ (diurnal) and $\mathrm{M}_{2}$ (semidiurnal). For the lesser constituents analyzed $\left(\mathrm{O}_{1}\right.$ and $\left.\mathrm{S}_{2}\right)$, significant trends are observed at ten gauges. Frictional mechanisms related to the El Niño Southern Oscillation (ENSO) are found to be important in influencing tides in the Western Pacific, as well as resonant triad interactions, a nonlinear coupling that exchanges energy 
between the $M_{2}, K_{1}$, and $\mathrm{O}_{1}$ tides. Both of these factors contribute to the observed tidal variability in the Solomon Sea region.

Part III analyzes the seasonal behavior of tides (STATs) at twenty tide gauges in the Southeast Asian waters, which exhibit variation by $10-30 \%$ of mean tidal amplitudes. A barotropic ocean tide model that considers the seasonal effects of MSL, stratification, and geostrophic and Ekman velocity is used to explain the observed seasonal variability in tides due to variations in monsoon-influenced climate forcing, with successful results at about half of all gauges. The observed changes in tides are best explained by the influence of non-tidal velocities (geostrophic and Ekman), though the effect of changing stratification is also an important secondary causative mechanism.

From the results of these surveys and investigations, it is concluded that shortterm fluctuations in MSL and tidal properties at multiple time scales may be as important in determining the state of future water levels as the long-term trends. Global explanations for the observed tidal behavior have not been found in this study; however, significant regional explanations are found at the yearly time scale in the Solomon Sea, and at the seasonal time scale in Southeast Asia. It is likely that tidal sensitivity to annual and seasonal variations in MSL at other locations also are driven by locally specific processes, rather than factors with basin-wide coherence. 


\section{Dedication}

Trina, I thank you for staying by my side for so long.

Rest in Peace, my dear wolf pup, and watch over me.

$11 / 17 / 2001-2 / 3 / 2016$

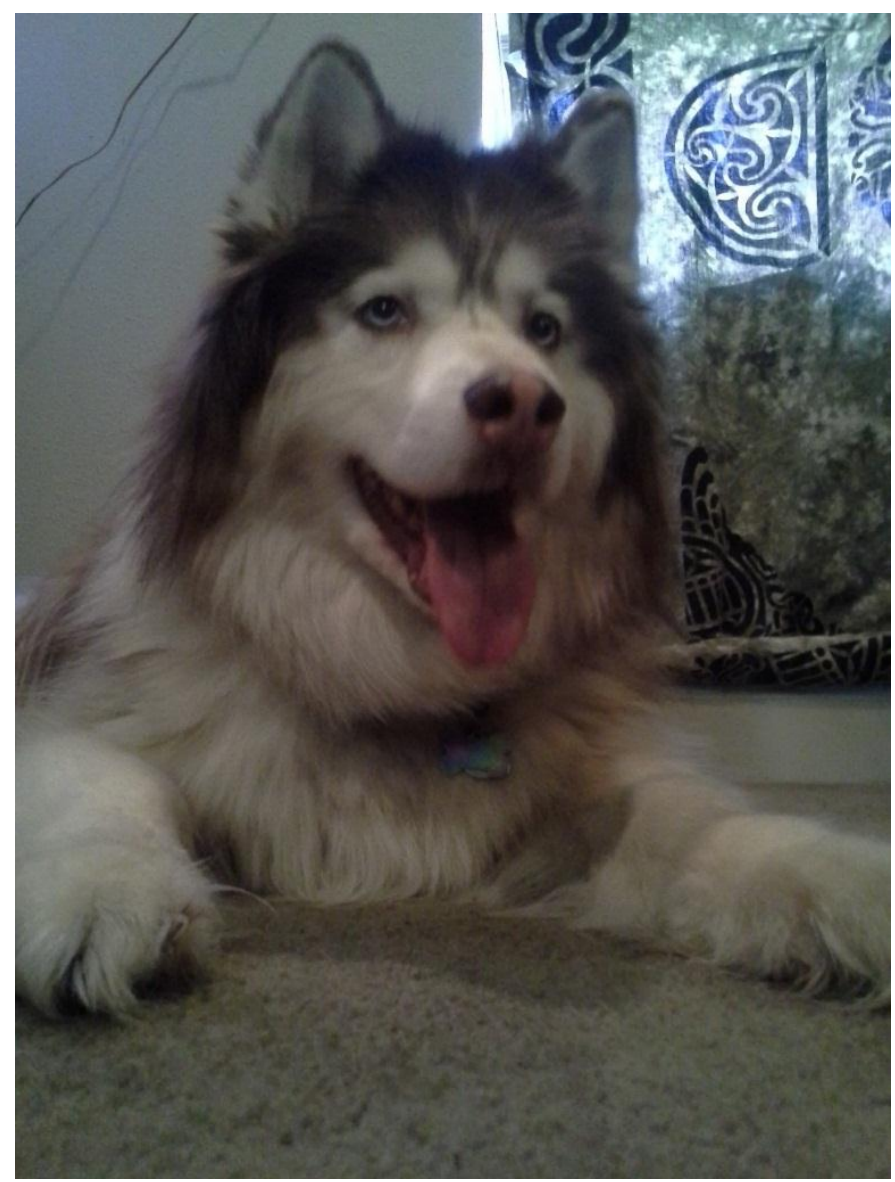

Additionally, this text is dedicated to my nieces Alana and Keira, and my nephew

Finnegan, for whom I intend to make a better world so that their smiles may never fade. 


\section{Acknowledgments}

A National Science Foundation grant provided the initial support for the current study ("Secular Changes in Pacific Tides", NSF grant \# OCE-0929055), with the objective

of better qualifying the dynamics of tidal variability in the entire Pacific Ocean. Further support for this study, particularly all the modelling efforts, was provided by the National Aeronautics and Space Administration (NASA), project: NNX13AH06G.

Heartfelt acknowledgments to my advisors, Dr. David Jay, Dr. Ed Zaron, and Dr. Stefan Talke, who have trained and coached me to this day. I hope to do you proud as I go forward. Many additional thanks to all my friends and family, too numerous to list, who helped me through to this day and always believed in me. 


\section{Table of Contents}

Abstract

Dedication

Acknowledgements $\quad \mathrm{V}$

List of Tables xiii

List of Figures $\quad$ XV

Glossary of Terms $\quad$ xx

Mathematical Symbols Used $\quad$ xxvii

$\begin{array}{ll}\text { Preface } & x x x\end{array}$

$\begin{array}{lll}\text { Chapter } 1 & \text { Introductory chapter } & 1\end{array}$

1.1 The origins of tidal analysis 1

1.2 Dynamical tide theory 2

1.3 Societal relevance $\quad 4$

1.4 Contributions of this dissertation 5

1.5 Outline of dissertation $\quad 8$

$\begin{array}{lll}\text { Chapter } 2 & \text { Tidal theory } & 13\end{array}$

2.1 The governing equations 13

$\begin{array}{ll}\text { 2.1.1 The Navier-Stokes equations } & 13\end{array}$

$\begin{array}{ll}\text { 2.1.2 The Laplace Tidal equations } & 15\end{array}$

$\begin{array}{ll}2.2 \text { The tide-generating gravitational potential } & 17\end{array}$

2.2.1 Lunar and solar motions: daily and monthly 17

2.2.2 Lunar and solar motions: yearly, perigean, and nodal 21

$\begin{array}{ll}\text { 2.2.3 Perigean Spring Tides } & 22\end{array}$

2.2.4 The harmonic development of the tide-generating potential 23 
Chapter 3 Part I: Tidal variability in the Pacific

Part I Abstract

3.1 Introduction

3.1.1 Changes in ocean tides: Hypotheses

3.1.1.1 Mean sea level (MSL) trends

3.1.1.2 Changing ocean tides

3.1.1.3 Coupled MSL and tidal change

3.1.1.4 Internal tides

3.1.1.5 Amphidromic movement

3.1.2 Climatic variability

3.1.2.1 The El Niño/Southern Oscillation (ENSO)

3.1.2.2 The monsoon

3.2.1 Data inventory

3.2.2 Tidal admittance calculations

3.2.3 Annual scale correlation of tidal variations and MSL

3.2.4 Monthly scale correlation of tidal variations and MSL

3.3.1 Yearly tidal anomaly trends (TAT) results

3.3.1.1 Northeast Pacific TATs results

3.3.1.2 Southeast Pacific TATs results 
3.3.1.4 Southwest Pacific TATs results $\quad 87$

3.3.1.4.1 Semidiurnal TATs, SW 87

3.3.1.4.2 Diurnal TATs, SW 91

3.3.2 Seasonal tidal anomaly trends (STAT) results 95

3.3.2.1 Northeast Pacific STATs results 95

$\begin{array}{ll}\text { 3.3.2.2 Southeast Pacific STATs results } & 101\end{array}$

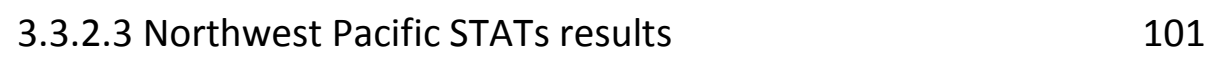

$\begin{array}{ll}\text { 3.3.2.4 Southwest Pacific STATs results } & 106\end{array}$

3.4 Discussion 112

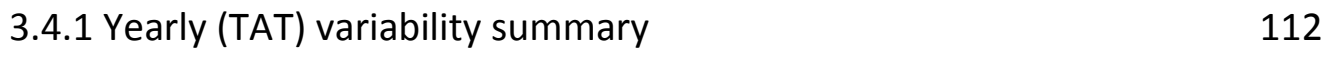

$\begin{array}{ll}3.4 .2 \text { Yearly (TAT) regional summaries } & 112\end{array}$

3.4.2.1 Summary of Northeast Pacific TATs 112

3.4.2.2 Summary of Southeast Pacific TATs 113

3.4.2.3 Summary of Northwest Pacific TATs 115

$\begin{array}{ll}\text { 3.4.2.4 Summary of Southwest Pacific TATs } & 117\end{array}$

$\begin{array}{ll}\text { 3.4.3 Combined A-TATs } & 119\end{array}$

3.4.4 Combined A-TATs coupled with future MSL rise scenarios 121

3.4.5 Summary of seasonal variability of tidal anomaly trends (STATs) 127

3.4.6 Observed tidal variability in reference to hypotheses 128

3.5 Conclusions and identification of future study efforts 129

Chapter 4 Part II: Can tidal perturbations associated with

sea level variations in the Western Pacific Ocean be used to understand future effects of tidal evolution? 156

Part II Abstract 156

$\begin{array}{ll}4.1 \text { Introduction } & 157\end{array}$ 
$\begin{array}{ll}4.2 \text { Background } & 161\end{array}$

$\begin{array}{ll}\text { 4.2.1 Changing sea level and changing tides } & 161\end{array}$

$\begin{array}{ll}\text { 4.2.2 Resonant Triads-Theory } & 164\end{array}$

$\begin{array}{ll}\text { 4.3 Methods } & 167\end{array}$

$\begin{array}{ll}\text { 4.3.1 Station selection and data } & 167\end{array}$

4.3.2 Harmonic analysis and tidal admittance 170

$\begin{array}{ll}\text { 4.3.3 Mean sea level and anomaly trends } & 171\end{array}$

$\begin{array}{ll}\text { 4.3.4 Friction and overtides } & 174\end{array}$

$\begin{array}{ll}\text { 4.3.5 Thermocline depth and EEMD analysis } & 175\end{array}$

$\begin{array}{ll}\text { 4.3.6 Analysis of resonant triads } & 176\end{array}$

$\begin{array}{ll}4.4 \text { Results } & 183\end{array}$

$\begin{array}{ll}\text { 4.4.1 Anomaly trend maps } & 183\end{array}$

4.4.1.1 Diurnal constituents $\quad 184$

$\begin{array}{ll}\text { 4.4.1.2 Semidiurnal constituents } & 187\end{array}$

4.4.1.3 Combined tidal trends $\quad 190$

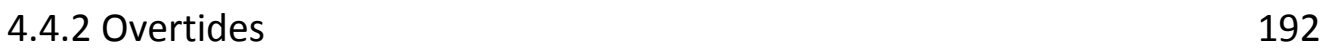

$\begin{array}{ll}\text { 4.4.3 Thermocline depth and tidal variations } & 197\end{array}$

$\begin{array}{ll}\text { 4.4.4 Spatial summary } & 199\end{array}$

$\begin{array}{ll}\text { 4.4.5 Anomaly trends over time } & 199\end{array}$

$\begin{array}{ll}\text { 4.4.6 Triad results } & 203\end{array}$

$\begin{array}{ll}\text { 4.5 Discussion } & 210\end{array}$

$\begin{array}{ll}\text { 4.5.1 Spatial Patterns } & 211\end{array}$

4.5.1.1 Australian shelf and the Great Barrier Reef 211

4.5.1.2 Solomon Islands: Overtide ratios and thermocline depth 212

$\begin{array}{ll}\text { 4.5.2 Temporal changes } & 214\end{array}$

4.5.3 Amphidromic movements 215

$\begin{array}{lr}\text { 4.5.4 Triad interactions } & 217\end{array}$

$\begin{array}{ll}\text { 4.6 Conclusions } & 218\end{array}$

ix 
Chapter 5 Part III: Seasonality of tides in Southeast Asian waters:

Observed vs. modelled

Part III Abstract 234

5.1 Introduction 236

5.1.1 Hypothesis and Approach 236

$\begin{array}{ll}\text { 5.1.2 Geography of study domain } & 238\end{array}$

$\begin{array}{ll}\text { 5.1.3 Tidal variability in Southeast Asia } & 239\end{array}$

$\begin{array}{ll}5.2 \text { Background } & 245\end{array}$

5.2.1 Atmospheric monsoon dynamics 245

$\begin{array}{ll}\text { 5.2.2 Oceanic monsoon dynamics } & 246\end{array}$

5.2.2.1 South China Sea oceanic variability 247

5.2.2.2 Java Sea oceanic variability 247

5.2.2.3 Gulf of Thailand oceanic variability 248

5.2.2.4 Malacca Strait oceanic variability 249

$\begin{array}{ll}\text { 5.2.3 Tidal Variability } & 250\end{array}$

$\begin{array}{ll}\text { 5.2.3.1 Semidiurnal tides } & 251\end{array}$

5.2.3.2 Diurnal tides $\quad 255$

$\begin{array}{ll}\text { 5.2.3.3 Seasonality of tides } & 258\end{array}$

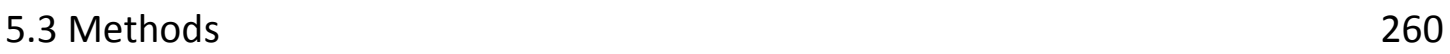

$\begin{array}{ll}\text { 5.3.1 Data Sources } & 260\end{array}$

5.3.2 Tidal admittance calculations 260

5.3.3 Seasonal tidal anomaly trends (STATs) and monsoon coherence 262

5.3.4 Barotropic ocean model setup 263

5.3.5 Model calibration and operation 265

$\begin{array}{ll}\text { 5.3.6 Model modifications } & 270\end{array}$

5.3.6.1 Sea surface height and geostrophic velocity methodology 271

5.3.6.2 Bottom drag model methodology 272 
5.3.6.2.1 Modified 'law of the wall' 272

5.3.6.2.2 Numerical solution 276

5.3.6.2.3 Linearization of friction and model calibration $\quad 279$

5.3.6.3 Ekman velocity determination $\quad 280$

$\begin{array}{ll}5.4 \text { Results } & 282\end{array}$

5.4.1 Seasonal variability of tides $\quad 282$

5.4.1.1 South China Sea $\quad 284$

5.4.1.2 Java Sea $\quad 284$

5.4.1.3 Gulf of Thailand 286

5.4.1.4 Malacca Strait $\quad 286$

5.4.2 Seasonal variability of physical properties 288

5.4.2.1 Seasonal variability of sea surface height 288

5.4.2.2 Seasonal variability of geostrophic currents 290

5.4.2.3 Seasonal variability of stratification 292

5.4.2.4 Seasonal variability of Ekman velocity 294

5.4.2.5 Seasonal variability of physical properties by region 296

$\begin{array}{ll}\text { 5.4.3 Model Results } & 299\end{array}$

5.4.3.1 SSH model results $\quad 299$

5.4.3.2 Geostrophic velocity model results 302

5.4.3.3 Drag coefficient model results $\quad 307$

5.4.3.4 Ekman velocity model results 312

5.4.4 Modelled vs. observed at tide gauges 317

5.4.5 Coupled models and accuracy of tidal reproductions 323

$\begin{array}{ll}5.5 \text { Discussion } & 324\end{array}$

$\begin{array}{ll}\text { 5.5.1 Comparison of model results } & 324\end{array}$

$\begin{array}{ll}\text { 5.5.2 Summary of model results } & 328\end{array}$

$\begin{array}{ll}\text { 5.5.3 Limitations of model results } & 329\end{array}$

5.5.4 Effect of river discharge on tidal seasonality 332 
Chapter $6 \quad$ Concluding chapter 353

$\begin{array}{ll}\text { References } & 363\end{array}$

Appendix A: Supplementary Figures for Part I (Chapter 3) 379

Appendix B: Supplementary Figures for Part II (Chapter 4) 395 


\section{List of Tables}

$\begin{array}{ll}\text { Table } 1 \text { Major tidal constituents. } & 28\end{array}$

Table 2 Station information for tidal records used in this study. 132

Table 3a Amplitude tidal anomaly trends (A-TATs). 136

Table 3b Combined amplitude tidal anomaly trends (A-TATs). 140

Table 4 Phase anomaly trends (P-TATs). 145

Table 5 Seasonal amplitude tidal anomaly trends (A-STATs). 149

Table 6 Seasonal phase tidal anomaly trends (P-STATs). 153

Table 7 Coupled changes of MSL and tidal range (TR), and total

water levels (WL), based on positive and negative combined A-TATs of Table 3b. 155

Table 8a Station information for tidal records used in Part II. 223

Table 8b Long-term (linear) trends for tidal amplitudes and phases. 224

Table 8c Long-term (linear) trends, with 95\% confidence limits, 225

for semidiurnal tidal amplitudes and phases.

Table 9 Amplitude tidal anomaly trends (A-TATs) and combined A-TATs for major diurnal and semidiurnal constituents in the Western Pacific. 226

Table 10 Phase anomaly trends (P-TATs) for major diurnal

and semidiurnal constituents in the Western Pacific.

Table 11: Amplitude and phase anomaly trends for the $K_{1}$ constituent, for before and after 1993, and the differences in the two rates.

Table 12: Amplitude and phase anomaly trends for the $\mathrm{O}_{1}$ constituent, for before and after 1993, and the differences in the two rates.

Table 13: Amplitude and phase anomaly trends for the $M_{2}$ constituent, for before and after 1993, and the differences in the two rates.

Table 14: Amplitude and phase anomaly trends for the $S_{2}$ constituent, for before and after 1993, and the differences in the two rates. 
Table 15 Phase variances and phase sum variances

of the resonant triad at Honiara and Rabaul.

Table 16 Slopes $(m / k)$ of the dispersion relations of $M_{2}, K_{1}$, and $O_{1}$

at for Honiara for typical values of non-dimensional $N$.

Table 17 PSI triad wavenumber estimates for three assumed depths. 233

Table 18 Baroclinic triad wavenumber estimates. 233

Table 19: Tide gauges used in Part III. 338

Table $20 \mathrm{M}_{2}$ amplitude and phase fitting harmonics. 339

Table $21 \mathrm{~S}_{2}$ amplitude and phase fitting harmonics. 340

Table $22 \mathrm{~K}_{1}$ amplitude and phase fitting harmonics. 341

Table $23 \mathrm{O}_{1}$ amplitude and phase fitting harmonics. 342

Table 24 Annual and semi-annual coherence of tidal amplitudes with the Western North Pacific Monsoon Index (WNPMI).

Table 25 Annual and semi-annual coherence of tidal phases

with the Western North Pacific Monsoon Index (WNPMI). 344

Table 26a M2 Model Responses (individual). 345

Table 26b M2 Model Responses (combined). 346

Table 27a $\mathrm{S}_{2}$ Model Responses (individual). 347

Table 27b $S_{2}$ Model Responses (combined). 348

Table 28a K 1 Model Responses (individual). 349

Table 28b K 1 Model Responses (combined). 350

Table 29a $\mathrm{O}_{1}$ Model Responses (individual). 351

Table 29b O $\mathrm{O}_{1}$ Model Responses (combined). 352 


\section{List of Figures}

Figure 1 Earth-Moon system.

Figure 2 Gravitational arrangement of Earth-Moon system

showing origin of diurnal tides.

Figure 3a Syzygy orientation of Earth-Moon-Sun system.

Figure 3b Quadrature orientation of Earth-Moon-Sun system.

Figure 4a Schematic of lunar perigean cycle seen from a "top view".

Figure 4b Schematic of lunar nodal cycle presented from a "side view".

Figure 5 Sample of the frequency distribution of tidal harmonics.

Figure 6 Global distribution of mean sea level (MSL) rise rates.

Figure 7a Gauge locations in the Western Pacific.

Figure 7b Gauge locations in the Eastern Pacific.

Figure 8a Amplitude of the $\mathrm{K}_{1}$ constituent at San Francisco, CA.

Figure $\mathbf{8 b}$ Admittance amplitude ratio (AR) of the $\mathrm{K}_{1}$ constituent at San Francisco, CA.

Figure 8c Mean sea level (MSL) at San Francisco, CA.

Figure $\mathbf{8 d}$ Detrended admittance amplitude ratio (AR) of the

$\mathrm{K}_{1}$ constituent at San Francisco, CA.

Figure 8e Detrended mean sea level (MSL) at San Francisco, CA.

Figure $8 f$ Detrended MSL (blue, units of $\mathrm{cm}$ ) plotted with detrended $\mathrm{K}_{1} \mathbf{A R}$

(black, units of $\mathrm{mm}$ ) at San Francisco, CA.

Figure 8g Example A-TAT of detrended MSL (meters).

scattered against detrended $\mathrm{K}_{1} \mathbf{A R}$ (millimeters) at San Francisco, CA.

Figure 8h Amplitude anomaly trends (A-TATs) for Honiara.

Figure 9a Monthly A-TAT determinations for the $M_{2}$ AR at Sedili, Malaysia.

Figure 9b A-STATs and P-STATs at Sedili, Malaysia.

Figure $10 \mathrm{M}_{2}$ A-TAT map in Northeast Pacific. 
Figure $11 \mathrm{~S}_{2}$ A-TAT map in Northeast Pacific. $\quad 70$

Figure $12 \mathrm{~K}_{1}$ A-TAT map in Northeast Pacific. $\quad 72$

Figure $13 \mathrm{O}_{1}$ A-TAT map in Northeast Pacific. 73

Figure $14 \mathrm{M}_{2}$ A-TAT map in Southeast Pacific. $\quad 75$

Figure $15 \mathrm{~S}_{2}$ A-TAT map in Southeast Pacific. 76

Figure $16 \mathrm{~K}_{1} \mathrm{~A}$-TAT map in Southeast Pacific. 78

Figure $17 \mathrm{O}_{1}$ A-TAT map in Southeast Pacific. $\quad 79$

Figure $18 \mathrm{M}_{2}$ A-TAT map in Northwest Pacific. 82

Figure $19 \mathrm{~S}_{2}$ A-TAT map in Northwest Pacific. 83

Figure $20 \mathrm{~K}_{1}$ A-TAT map in Northwest Pacific. 85

Figure $21 \mathrm{O}_{1}$ A-TAT map in Northwest Pacific. 86

Figure $22 \mathrm{M}_{2}$ A-TAT map in Southwest Pacific. $\quad 89$

Figure $23 S_{2}$ A-TAT map in Southwest Pacific. 90

Figure $24 \mathrm{~K}_{1}$ A-TAT map in Southwest Pacific. 93

Figure $25 \mathrm{O}_{1}$ A-TAT map in Southwest Pacific. 94

Figure $26 \mathrm{M}_{2}$ A-STAT map in Northeast Pacific. $\quad 97$

Figure $27 \mathrm{~S}_{2}$ A-STAT map in Northeast Pacific. 98

Figure $28 \mathrm{~K}_{1}$ A-STAT map in Northeast Pacific. 99

Figure $29 \mathrm{O}_{1}$ A-STAT map in Northeast Pacific. 100

Figure $30 \mathrm{M}_{2}$ A-STAT map in Northwest Pacific. 102

Figure $31 \mathrm{~S}_{2}$ A-STAT map in Northwest Pacific. 103

Figure $32 K_{1}$ A-STAT map in Northwest Pacific. 104

Figure $33 \mathrm{O}_{1}$ A-STAT map in Northwest Pacific. 105

$\begin{array}{ll}\text { Figure } 34 \mathrm{M}_{2} \text { A-STAT map in Southwest Pacific. } & 108\end{array}$

$\begin{array}{ll}\text { Figure } 35 \mathrm{~S}_{2} \text { A-STAT map in Southwest Pacific. } & 109\end{array}$

Figure $36 \mathrm{~K}_{1}$ A-STAT map in Southwest Pacific. 110

Figure $37 \mathrm{O}_{1}$ A-STAT map in Southwest Pacific. 111

Figure 38 Bathymetry of the western Pacific Ocean. 160 
Figure 39 Time series of yearly average MSL (in meters)

at seven Western Pacific stations.

Figure 40 Amplitude anomaly trends (A-TATs) and phase anomaly trends (P-TATs) at Honiara.

Figure $41 \mathrm{~K}_{1}$ A-TAT map in the Western Pacific. 185

Figure $42 \mathrm{O}_{1} \mathrm{~A}$-TAT map in the Western Pacific. 186

Figure $43 \mathrm{M}_{2}$ A-TAT map in the Western Pacific. 188

Figure $44 \mathrm{~S}_{2}$ A-TAT map in the Western Pacific. 189

Figure 45 Combined A-TAT map in the Western Pacific. 191

Figure 46 Overtide ratios (ORs) in the Western Pacific. 193

Figure 47 Relations of overtides and forcing tides to ENSO and MSL. 196

Figure 48 Relations of tides and thermocline depth. 198

$\begin{array}{ll}\text { Figure } 49 \mathrm{~K}_{1} \text { TAT difference map. } & 201\end{array}$

Figure $50 \mathrm{M}_{2}$ TAT difference map. $\quad 202$

Figure 51 Resonant triad interactions for Honiara and Rabaul. 205

Figure 52 Triad interaction scatterplots for Honiara and Rabaul. 206

Figure 53 Phase-lock condition at Honiara. 207

Figure 54 Map of Southeast Asia. $\quad 240$

Figure 55a Bathymetric map of Southeast Asia model domain. 241

Figure 55b Close-up map of region in the green square in Figure 55a. 242

Figure 56 Examples of observed tidal variability. 243

Figure 57a $\mathrm{M}_{2}$ tidal solutions in Southeast Asian waters from OTIS. 253

Figure 57b $S_{2}$ tidal solutions in Southeast Asian waters from OTIS. 254

Figure 58a $\mathrm{K}_{1}$ tidal solutions in Southeast Asian waters from OTIS. 256

Figure 58b $\mathrm{O}_{1}$ tidal solutions in Southeast Asian waters from OTIS. 257

Figure 59a Comparison of different ocean bathymetry sets. 268

Figure 59b Calibration model results for the $M_{2}$ tide. 269 
Figure 60 The variability of the (dimensionless) drag coefficient, $C_{d}$, with varied water depth $(H)$, and buoyancy frequency $(N)$.

Figure 61 Map of annual coherences of $\mathrm{M}_{2}$ amplitudes

with the Western North Pacific Monsoon Index (WNPMI).

Figure 62 South China Sea example tidal variability. 285

Figure 63 Java Sea example tidal variability. 285

Figure 64 Gulf of Thailand example tidal variability. 287

Figure 65 Malacca Strait example tidal variability. 287

Figure 66 Seasonal fields of sea surface height (SSH) variability. 289

Figure 67 Seasonal fields of geostrophic velocity $\left(u_{g}\right)$ variability. 291

Figure 68 Seasonal fields of effective bottom drag $\left(C_{d}\right)$ variability. 293

Figure 69 Seasonal fields of Ekman velocity variability. 295

Figure $\mathbf{7 0}$ Time series of all relevant seasonal variability in physical properties at four locations in the model domain.

Figure 71 Modelled adjustments of the $\mathrm{M}_{2}$ tidal amplitudes due to the seasonal changes in SSH.

Figure 72 Modelled adjustments of the $\mathrm{K}_{1}$ tidal amplitudes due to the seasonal changes in $\mathrm{SSH}$.

Figure 73 Modelled adjustments of the $\mathrm{M}_{2}$ tidal amplitudes due to the seasonal changes in geostrophic velocity.

Figure 74 Modelled adjustments of the $K_{1}$ tidal amplitudes due to the seasonal changes in geostrophic velocity.

Figure 75 Modelled adjustments of the $S_{2}$ tidal amplitudes due to the seasonal changes in geostrophic velocity.

Figure 76 Modelled adjustments of the $O_{1}$ tidal amplitudes due to the seasonal changes in geostrophic velocity.

Figure 77 Modelled adjustments of the $M_{2}$ tidal amplitudes due to the seasonal changes in bottom drag. 
Figure 78 Modelled adjustments of the $K_{1}$ tidal amplitudes due to the seasonal changes in bottom drag.

Figure 79 Modelled adjustments of the $S_{2}$ tidal amplitudes due to the seasonal changes in bottom drag.

Figure 80 Modelled adjustments of the $\mathrm{O}_{1}$ tidal amplitudes due to the seasonal changes in bottom drag.

Figure 81 Modelled adjustments of the $M_{2}$ tidal amplitudes due to the seasonal changes in Ekman velocity.

Figure 82 Modelled adjustments of the $K_{1}$ tidal amplitudes due to the seasonal changes in Ekman velocity.

Figure 83 Modelled adjustments of the $S_{2}$ tidal amplitudes due to the seasonal changes in Ekman velocity.

Figure 84 Modelled adjustments of the $\mathrm{O}_{1}$ tidal amplitudes due to the seasonal changes in Ekman velocity.

Figure 85 South China Sea tidal variability with modelled results.

Figure 86 Java Sea tidal variability with modelled results.

Figure 87 Gulf of Thailand tidal variability with modelled results.

Figure 88 Malacca Strait tidal variability with modelled results.

Figure 89 Weekly averaged discharge data of the Mekong River. 


\section{Glossary of Terms}

admittance (or tidal admittance): A measure of tidal forcing. It is the ratio of the observed tides to the expected tide as calculated from the gravitational tidal potential. advection, advective flow: Horizontal flow of water masses due to changes in bulk properties such as temperature or salinity.

altimetry: Having to do with satellite-based observations of the ocean.

amphidrome: A sea surface expression of a pattern of wave propagation. amplitude: The magnitude of a wave.

annual: Yearly behavior, related to orbit of the Earth around the Sun.

antipodal point: Location where the ATGF is directed away from the moon (sun). apogee: Furthest location of an eccentric planetary body.

astronomical/gravitational potential: The tidal forcing due to the gravitational attraction of heavenly bodies (Sun/Moon/etc.).

astronomical tide-generating force (ATGF): The difference between the lunar (solar) gravitational attraction at any point on the Earth's surface and at its center. barotropic fluid: Having a density only dependent on pressure.

baroclinic fluid: Having a density dependent on pressure and temperature/salinity. bathymetry: The topography of the ocean bottom, the science of measuring the ocean floor depth. 
buoyancy frequency: Brunt-Väisälä frequency, or buoyancy frequency, is the angular frequency at which a vertically displaced parcel will oscillate within a statically stable environment.

coherence: Measure of correlation at specific time scales (yearly, monthly, etc.). continuity equation: A conservation law of water mass.

Coriolis effect: The apparent deflection of moving objects when the motion is described relative to a rotating reference frame. In a reference frame with clockwise rotation, the deflection is to the left of the motion of the object in the Northern Hemisphere; in one with counter-clockwise rotation, the deflection is to the right, and vice-versa in the Southern Hemisphere.

critical latitudes: Global locations where local inertial frequencies equal the forcing frequencies; for $K_{1}$, this is near $\pm 30.1^{\circ}$ latitude; for $M_{2}$, it is near $\pm 75^{\circ}$. decadal: Time scales with range of a few years to a century. detrended: A time series with the temporal long-term trend removed. diurnal and semidiurnal: Signals with a frequency of approximately $1 /$ day or $2 /$ day. diurnal tides: Once a day tides due to interaction of Sun and Moon (lunisolar tides), major ones are $\mathrm{K}_{1}$ (period of 23.984 hours), and $\mathrm{O}_{1}$ (period of 25.819 hours). drag coefficient: In fluid dynamics, the drag coefficient is a dimensionless quantity that is used to quantify the drag or resistance of an object in a fluid environment, such as air or water. 
dynamical tide theory: The modern theory of tidal analysis.

Ekman transport: The transport of surface water due to the force of the wind. Net Ekman transport is always oriented at right angles $\left(90^{\circ}\right)$ to the wind direction. First noticed by polar explorers who noticed that icebergs drift at an angle to the wind. eddy: The swirling of a fluid and the reverse current created when the fluid flows past an obstacle. A form of turbulence.

Ensemble Empirical Mode Decomposition (EEMD): A sifting process to split signals into approximately dyadic modes - a signal of length $2^{n}$ yields $\sim n$ modes.

equilibrium tide theory: Early theory of tides, which assumes a constant-depth ocean without coastlines.

finite-difference: Mathematical modelling technique, used to approximate derivatives (rates of change).

friction velocity: Shear velocity, also called friction velocity, is a reformulation of shear stress expressed in units of velocity. It is useful as a method in fluid mechanics to compare true velocities, such as the velocity of a flow in a stream, to a velocity that relates shear between layers of flow.

geoid: The shape that the surface of the oceans would take under the influence of Earth's gravitation and rotation alone, in the absence of other influences such as winds and tides.

geostrophic velocities: An oceanic flow in which the pressure gradient is balanced by the Coriolis effect. 
gyre: A pattern of water movement in a closed recirculation.

harmonic analysis: A mathematical technique based on Fourier transforms that maps a signal in the time domain into the frequency domain.

internal wave: Internal waves are gravity waves that oscillate within a fluid medium, rather than on its surface. For internal waves to exist, the fluid must be stratified, and the density must decrease continuously or discontinuously with height due to changes in temperature and/or salinity.

internal tides: Internal tides are generated as the surface tides move stratified water up and down sloping topography, which produces a wave in the ocean interior. Munk (1981) notes, "Gravity waves in the ocean's interior are as common as waves at the sea surface-perhaps even more so, for no one has ever reported an interior calm."

intrinsic mode frequency (IMF): Nomenclature of modes split by EEMD.

Laplace tidal equations: A single set of linear partial differential equations, for tidal flow described as a barotropic two-dimensional sheet flow.

"Law of the Wall": In fluid dynamics, the law of the wall states that the average velocity of a turbulent flow at a certain point is proportional to the logarithm of the distance from that point to the "wall", or the boundary of the fluid region.

material derivative: Represents the total change of any quantity following material particles (heat, momentum, mass, etc.).

mean sea level (MSL): A reference level of local water level at a coastal location, the average (mean) level of the water undisturbed by waves or tides. 
neap tides: Times of the month when twice daily and daily ocean tides show the smallest high and low tides.

nodal points: Two points when the moon will "cross" the earth's equatorial plane each orbit; the point when the moon moves north or "up" from the point of view of an earth observer is known as the ascending node, and where it moves south or "down" is known as the descending node.

overtide: A secondary tide that are harmonics of the principal tides, which transfer tidal energy to frictional processes in coastal regions.

parametric subharmonic instability (PSI): Involves an interaction between a primary wave (such as an internal tide) and two smaller-scale waves of nearly half the frequency. perigee: Closest location of an eccentric planetary body.

perigean spring tides: Also known as a king tide, when the largest high tides and lowest low tides of the year are observed.

phase: The relative timing of a wave maximum.

primitive equations: A set of nonlinear differential equations that are used to approximate global atmospheric or oceanic flows.

psu: Practical Salinity Units. Equal to parts in a thousand, i.e., water with a salinity of 34 psu is 34 parts salt per thousand parts water, or has a salinity of $3.4 \%$.

quadrature: When the moon is half-full (waxing or waning), the sun acts at a $90^{\circ}$ angle to the moon, relative to an earth observer, and the ATGFs partially cancel each other, leading to neap tides. 
resonant triad: A nonlinear harmonic coupling of three waves whose frequencies are simple additive combinations.

sublunar (subsolar) point: Point where the ATGF is towards the moon (sun). seasonality: A pattern of monthly behavior of a climate mechanism where certain months of the year always show the same stationary relations.

seasonal tidal anomaly trends (STATs): The behavior of tidal properties over the course of the year.

sea surface height (SSH): The elevation of the water level above the mean sea level (MSL).

semidiurnal tides: Twice a day tidal components, major tides are $\mathrm{M}_{2}$ (twice a day due to the Moon) with a period of 12.42 hours, and $S_{2}$ (twice a day due to the Sun), with a period of 12.00 hours.

spring tides: The largest maxima and minima (high and low tides) in the semidiurnal and diurnal tides during the lunar month.

stratification: Occurs when water masses with different properties form layers that act as barriers to water mixing.

syzygy: Orientation where the Moon-Sun-Earth system is aligned, and the lunar and solar ATGFs reinforce one another, yielding spring tides.

thermocline: A thin but distinct layer in a large body of fluid in which temperature changes more rapidly with depth than it does in the layers above or below. In the ocean, the thermocline divides the upper mixed layer from the calm deep water below. 
tidal harmonic analysis: Method of using harmonic analysis to determine the discrete contributions of tidal frequencies to a signal at a tide gauge.

tidal constituent: A discrete tidal-related frequency.

tidal anomaly trends (TATs): The relation of variations in mean sea level to variations in tidal properties, acting on time scales of a year or longer.

wind stress: The shear stress exerted by the wind on the surface of large bodies of water. It is the force component parallel to the surface, per unit area, as applied by the wind on the water surface.

WNPMI: The Western North Pacific Monsoon Index, a climate index relating the strength of the monsoon in SE Asia, based upon the strength of wind stress. 


\section{Mathematical Symbols Used}

$a_{0}, a_{1}, a_{2}, b_{1}, b_{2}$ : Fitting coefficient for harmonic fits (in units of millimeters or degrees). $A(t)$ : Amplitude of wave determined at a series of times, $t$.

$\boldsymbol{A R}(t)$ : Amplitude ratio of magnitude of complex amplitude of observed tides to complex amplitude of theoretical values calculated from the gravitational tidal potential.

$c_{i:}$ The group velocity.

$C_{d}$ : Dimensionless drag coefficient.

Dv/Dt: The material derivative, representing the total change of any material quantity (heat, momentum, mass, etc.).

$D_{20}$ : The depth of the $20^{\circ} \mathrm{C}$ isotherm.

$d u / d z$ : The spatial derivative of the velocity, $u$, in the $z$ (vertical) direction.

$f$ : Coriolis factor (measure of vorticity of fluid parcel due to rotation of the Earth.

F: Force.

$H$ : Water depth in meters.

$i$ : Imaginary number. Equal to the square root of -1 .

$\mathbf{k}=(k, I, m)$ : Wave number in three dimensions.

I: Mixing length, chosen as appropriate to natural scaling of the system.

$I_{o z}$ : Ozmidov length scale, a mixing length that is appropriate to stratified fluids. m: Mass.

$N^{2}$ : Buoyancy frequency (see glossary).

$P D(t)$ : Phase difference of observed phase minus potential phase. 
$P$ : Pressure.

$P_{x}, P_{y}$ : Horizontal pressure gradient due to vertical elevation of the sea surface in the $(x, y)$ directions.

$P_{2}^{m}:$ The associated Legendre functions of colatitude $(\bar{\theta})$.

$R i_{g}$ : The gradient Richardson number (a metric of turbulent flows).

$r_{0}, r_{1}$ : Dissipation coefficients for tunable friction modelling.

$U:$ The astronomical tide-generating potential.

$(u, v)$ : Horizontal velocity in the $x$ and $y$ directions $(x, y)$.

$u_{t}, v_{t}$ : Time derivative (rate of change) of horizontal velocities, $(u, v)$.

$u^{*}$ : Friction velocity.

$\bar{u}:$ Vertical velocity profile.

$u_{E}, v_{E}$ : Ekman velocity in the $(x, y)$ directions.

$(x, y)$ or $(x, y, z)$ : Cartesian coordinate system (after Rene Descartes) in either 2 or 3

dimensions. $z$ is the vertical coordinate, here meaning ocean depth.

$Z(t)$ : Complex amplitude of a wave.

$Z^{*}$ : The complex conjugate of $\boldsymbol{Z}$.

$\beta=\Gamma_{\text {Abs }} / C_{\text {abs: }}$ The absolute value of the complex interaction coefficient.

$\delta_{j}$ : The interaction coefficient of the $j^{\text {th }}$ mode.

$\eta$ : Tidal elevation at any location in the model, units of meters, $\mathrm{m}$.

$\eta_{x}, \eta_{y}$ : Horizontal spatial gradient of tidal elevation (i.e., the slope of the ocean produced from a wave). 
$\kappa:$ The Von Karman constant, equal to 0.41 . Also used to indicate horizontal wavenumber in Chapter 4.

$\lambda=\lambda(x, y)$ : Dissipation coefficient, calculated at all grid cells of the model, related to friction.

$v$ : Eddy viscosity (a metric of turbulence due to stress and shear between layers). $\vartheta(t)$ : Phase of wave determined at a series of times, $t$.

$(\varphi, \vartheta):$ Latitude and longitude.

$\bar{\theta}:$ Colatitude.

$\rho_{0}$ : Reference density of the ocean $\left(1024 \mathrm{~kg} / \mathrm{m}^{3}\right)$.

$\tau_{x}, \tau_{y}:$ Wind stress in the $(x, y)$ directions.

$\zeta:$ The equilibrium tide.

$\omega:$ Angular frequency.

$\omega(\mathbf{k})$ : Dispersion relation.

$\Omega$ : Rotational rate of the Earth. 


\section{Preface}

This thesis investigates tidal variability in the Pacific Ocean at multiple time scales. Two introductory chapters are provided first (general and pedagogical introductions), then three main chapters, each of which are the subject of a publication (one is already published, two are in preparation), and a concluding chapter. The three main chapters have the following titles:

Chapter 3 (Part I): Devlin AT, Jay DA, Talke SA, and Zaron E. (2016). Tidal variability in the Pacific, in preparation (3/2016).

Chapter 4 (Part II): Devlin AT, Jay DA, Talke SA, and Zaron E. (2014). Can tidal perturbations associated with sea level variations in the Western Pacific Ocean be used to understand future effects of tidal evolution? Ocean Dynamics, 64(8), 1093-1120. DOI: $10.1007 / \mathrm{s} 10236-014-0741-6$

Chapter 5 (Part III): Devlin AT, Jay DA, Talke SA, and Zaron E. (2016). Seasonality of tides in Southeast Asian waters in preparation (3/2016).

Portions of this work have been presented at:

Coastal and Estuarine Research Federation (CERF) Fall 2015 meeting November 9-12, 2015 Portland, OR, USA, Oral presentation:

Can the seasonality of tides in SE Asia be explained by use of a barotropic model? 


\section{American Geophysical Union (AGU) Fall 2014 meeting}

December 14-18, 2014 San Francisco, CA. Poster presentation: Can tidal perturbations associated with sea level variations in the western Pacific Ocean be used to understand future effects of tidal evolution?

\section{Ocean Surface Topography Science Team (OSTST) meeting}

October 24-31, 2014, Lake Constance, Germany. Poster presentation: Can ENSO-related tidal modulations be explained using a barotropic tidal model? (presented in absentia) 


\section{Chapter 1: Introductory Chapter}

\subsection{The origins of tidal analysis}

"Fluxum \& refluxum Maris ab actionibus Solis ac Lunae oriri debere"

"The ebb and flow of the Sea ought to arise from the actions of the Moon and the Sun."

-Sir Isaac Newton, Philisophae Naturalis Principia Mathematica (1687)

Newton was the first to accurately describe the phenomenon of the ocean tides, showing that the motions of the planets, "the music of the orbs", can affect our earthly lives in a very noticeable and tangible way. The first recorded tidal measurements began soon after the publication of the Principia; the oldest extant, from Brest, France, extend back to 1711 (Cartwright, 1972). The study of the tides over history developed in concert with the observations of the sun and moon. In many ways, the study of celestial mechanics was also the birth of modern physics, and many of the mathematical techniques used today had their inception in the pursuit of "chasing the moon", finding their inspiration in the observation of ocean tides. Newton now found a practical use for his newly-conceived calculus. Leonard Euler, Daniel Bernoulli, and Colin MacLaurin shared a prize offered by the Paris Academy of Science in 1740 to best explain the ocean tides. Bessel invented the functions that bear his name to explain the eccentricity of the moon's orbit. Green, Airy, Kelvin, Poincare, Stokes and Poisson all have mathematical 
functions named after them due to their studies of the ocean, most of which are used so widely in all other areas of science that their origin is forgotten. The youngest son of Sir Charles Darwin, Sir George Darwin, detailed much of the convention used today to describe tides. William Thomson (a.k.a Lord Kelvin) developed harmonic analysis-a version of which is used in this thesis-in the 1870s. This is only a partial list of contributors. For a detailed history of tidal analysis see, e.g., Cartwright (1999) or Gutzwiller (1998).

\subsection{Dynamical tide theory}

The advent of the computer age has brought a better understanding of our global climate. Through improved observational and data processing techniques, humanity has become more cognizant of the global dynamics of the atmosphere and the ocean. Three centuries since Newton, The Principia, and the first tide gauges began the initial era of tidal observation and analysis, the ocean is now understood as a constantly-moving mass of water on a rotating Earth, with coastlines and variable topography, basin-scale cells of rotation called amphidromes and density stratification patterns that allow internal waves, nearly unseen on the surface. Observations of the ocean state are being made globally by ground-based instruments such as tide gauges, moored and free-drifting oceanic buoys and autonomous gliders, and even a suite of satellite altimeters such as the combined TOPEX/Poseidon/Jason missions which provide a continuous record of the near-global ocean surface since 1992. Yet, with this 
improved understanding has come new knowledge of the changes happening in our global climate system. Sea levels have been rising in recent decades (Church et al., 2011), which is likely tied to the warming air temperatures, leading to more glacial melt and increased warming of the ocean surface waters, which further expands sea level rise. These scenarios are further complicated by the secular and shorter-term changes in ocean tides observed worldwide.

Ocean tides are classically considered as being stationary outside of gravitational forcing, at it is due to easily predictable astronomical motions (Cartwright and Tayler, 1971). Yet, recent studies have found detectable changes in the tides in the past century and a half. Regional studies of tidal constituents (e.g., Jay, 2009; Ray 2006), and global studies (e.g., Woodworth, 2010) have found that the long-term changes in tides can be on the same order as the changes in mean sea level (MSL), and have a large degree of spatial variability by region. With an increased water depth in some regions comes a decreased frictional effect and increased tidal amplitudes, but in other areas, higher MSL floods new shallow areas, leading to increased friction and lowered tidal amplitudes. Additionally, a higher water level increases the available tidal prism and modifies standing wave resonance (Holleman and Stacey, 2014).

Mechanisms that might explain these changes include: changes in water depth that modify tidal magnitudes and timing (Pugh and Woodworth, 2014), changes in the internal tide (Colosi and Munk, 2006), and changes in water column stratification (Kang 
et al., 2002; Müller 2012b). Internal tides are another likely mechanism connecting MSL change and tidal evolution, at least between the critical latitudes for the major tidal species. Internal, or baroclinic, tides arise within the water column when the gravitational surface tide, or the barotropic tide, moves stratified water up and down sloping bathymetry. Critical latitudes indicate where local inertial frequencies equal the forcing frequencies; for $K_{1}$, this is near $\pm 30.1^{\circ}$ latitude; for $M_{2}$, it is near $\pm 75^{\circ}$. Internal tide dynamics have been studied in detail near Hawaii (Colosi and Munk, 2006; Ray and Mitchum, 1996; 1997; Chiswell, 1994; and Dushaw, et al 1995) and may provide insight into the temporal variability of tidal constituents as MSL changes elsewhere in the ocean.

\subsection{Societal relevance}

The issue of understanding why and how ocean tides change is important because the consequences have impacts that may affect many people and cultures worldwide. The well documented rise in global MSL, coupled with changing tides, can modify total water level in a complex manner. Coastal inundation is a consequence of peak sea level, not mean sea level, so the changes in tides can be as important as MSL changes. When combined with storm surges from weather patterns such as monsoons or hurricanes, the increase in mean water levels may yield increased flood risk and coastal inundation, as well as eventual loss of habitat at low-lying islands. Higher water levels may also influence oceanic mixing and nutrient concentrations, coastal erosion, 
fishing production, and shipping schedules. Additionally, there could be greatly increased costs of damage to infrastructure in coastal and island regions, along with societal impacts, such as population displacement leading to mass climate refugee migrations, and contamination of fresh water supplies. Approximately 100 million people worldwide live in coastal areas at vertical elevations within 1 meter of the current MSL. Island nations such as the Maldives and Kiribati are already making plans to evacuate their home islands for higher ground. Therefore, a better understanding of the changes that sea level rise and changing tides might bring, as well as the causative mechanisms behind the changes, will allow better planning to help mitigate the effects on coastal communities. The importance of understanding how high future water levels might get is exemplified by such recent disasters as Superstorm Sandy in 2012 that devastated the US east coast (Talke et al., 2014), or by the ocean-wide tsunami induced by the Tohoku megaquake in 2011 , and the importance for understanding the motions of ocean currents is evidenced by the Deepwater Horizon oil spill in 2010, or the radioactive leakage from the Fukushima plant in the aftermath of the Tohoku quake.

\subsection{Contributions of this dissertation}

The current state of understanding regarding tides is often called dynamic tide theory. This study develops new techniques for understanding how tides are sensitive to environmental factors such as MSL rise, both through analysis of in-situ tide gauges and through an evaluation of dynamical processes using both theoretical considerations 
and modeling. Additions to dynamical tide theory include: (1) application of a wellknown theory for the non-linear sharing of energy between waves (Craik, 1985) to help explain inter-annual variations in tidal constituents; (2) investigating the effect of sea level fluctuations on frictional interactions; (3) investigating the influence of seasonal changes in stratification and non-tidal currents (e.g., Ekman circulation and geostrophic currents) on tides. Results confirm that many physical processes within the ocean and the atmosphere can contribute to non-astronomical variation in tides. While many have looked at the long-term trends in tides and in MSL rise, less attention has been paid to the shorter-term fluctuations (seasonal to decadal). The response of tides to MSL variability is spatially complex, and it is also frequency dependent, acting at timescales from seasonal to multidecadal. This study may help to improve short-term prediction of tides at regional or even Pacific basin-wide scales via a greater understanding of the evolution of tides, particularly under a rising MSL scenario. A clearer picture of water level response may lead to better prediction of risks due to storm surges when coupled with higher tides, which may help save lives and property in coastal areas. The original motivation of this study was provided by the results of Jay (2009), in which the tides of the Eastern Pacific were found to mainly have positive long-term trends in the $K_{1}$ and $M_{2}$ tidal components, with an average increase of $2.2 \%$ per century at all stations north of $18^{\circ} \mathrm{N}$

This study introduces and develops new techniques to understand tidal variability based on comparisons of detrended tidal admittance to detrended MSL, 
quantities denoted tidal anomaly trends (TATs) at the yearly to decadal time scale, and the seasonal tidal anomaly trends (STATs) at the monthly time scales. Fluctuations in yearly averaged properties (TATs) show strong correlations to ENSO in the Western Pacific, whereas seasonal variability (STATs) is highly correlated to the Asian monsoon systems in Southeast Asian waters. The contribution of these mechanisms to the observed tidal dynamics is examined via a barotropic finite-difference ocean tide model (OTIS). This model allows for modifications of water depth, friction velocity, effective bottom drag, and Ekman velocity. However, the model is not equipped to adequately examine baroclinic mechanisms. Finally, the investigations involving the resonant triad interactions between the $\mathrm{M}_{2}, \mathrm{~K}_{1}$, and $\mathrm{O}_{1}$ tides, observed in the Solomon Sea and described in detail in in Part II, further develops the understanding of a unique nonlinear harmonic coupling phenomenon that has not been previously used in such a context. Overall, it is hoped that this work will help to better quantify sensitivities of ocean tides at multiple time scales to better predict future oceanic dynamics.

The greater region of the Western Pacific (and the far Eastern Indian) ocean analyzed in detail in Parts II and III of this study is especially important to the global climate since this region is the birthplace of many strong patterns of global variability, e.g., the El Niño/Southern Oscillation (McPhaden, 1999), the monsoon cycle, and the Madden-Julian Oscillation (MJO; Madden and Julian, 1971). This region also shows the largest MSL rates of increase in the global ocean, up to 5 times the global average MSL rise rate. In addition, the Western Pacific/Eastern Indian has a complex pattern of land 
masses and water areas, with a complex topography both above land and below water that influences oceanographic and atmospheric flows. The time scales of variability range from seasonal, expressed through the pattern of monsoon wind reversals and sea surface temperature (SST) variations, to multi-year or multi-decadal, such as the ENSO.

\subsection{Outline of dissertation}

A three-part study is presented. The outline of this document is as follows.

Chapter 2 will be a pedagogical introduction to tidal theory, including an overview of the governing equations of fluid mechanics and of tidal dynamics and a development of the harmonic tide-generating potential. Chapter 3 (Part I) is entitled, "Tidal variability in the Pacific Ocean", a survey of Pacific Ocean variability at 153 tide gauges, which begins with an extensive literature review on the recent developments concerning the global changes in MSL, the changes in tides observed at regional and global scales, and the coupled effect of rising MSL and increasing tides on total water levels. There is introductory discussion of the dynamics of internal (baroclinic) tides, the movement of tidal amphidromes, and the dynamics of climate patterns such as ENSO and the Asian monsoon system. After this background is disseminated, the data inventory and station selection criteria of the 153 Pacific tide gauges used in this survey are described and delineated by quadrants of the Pacific. The methods of using tidal admittance to calculate admittance amplitude ratios (AR) and phase differences (PD) is described as the foundation in constructing metrics of tidal variability in relation to MSL variability. 
These relationships, specifically the regressions between the two detrended quantities are defined as tidal anomaly trends (TATs) at the yearly scale, and the variation of monthly TAT determination over the course of the year are defined as seasonal tidal anomaly trends (STATs). Results are presented for yearly TATs in all quadrants, for diurnal $\left(K_{1}\right.$ and $\left.\mathrm{O}_{1}\right)$ and semidiurnal $\left(\mathrm{M}_{2}\right.$ and $\left.\mathrm{S}_{2}\right)$ components, and for amplitudes and phases. Next, the results of the STAT determinations are presented. A discussion by quadrant follows, highlighting the spatial patterns of TATs in the context of possible amphidromic migration, and discussing the spatial and temporal patterns of STATs in all quadrants, as well as qualitatively examining possible causes of the variability. The combined effect of all amplitude TATs is also examined to calculate the cumulative effect on water levels, including consideration of increased MSL rise due to accelerated Antarctic ice melt (DeConto and Pollard, 2016). The tidal variability at the yearly scale (TATs) is found to be of the greatest magnitude in the Southwest Pacific quadrant, and this region is identified as being worthy of closer study, which is the motivation for Part Il of this text. In terms of the seasonality of tidal perturbations (STATs), the most coherent and intense variability is also found in the Southwest Pacific, but more specifically confined to tide gauges in the waters of Southeast Asia, including Malaysia, Thailand, Vietnam, and Indonesia. This sub-region is identified as being the best place to focus more closely on the dynamics of seasonality, and is the subject of Part III of this text. The results of the survey in Part I are the subject of an upcoming publication. 
Chapter 4 (Part II), entitled "Can tidal perturbations associated with sea level variations in the Western Pacific Ocean be used to understand future effects of tidal evolution?", examines the yearly tidal anomaly trends (TATs) at 26 gauges in the southwestern Pacific (17 open-ocean, and 9 coastal gauges) in detail. This region shows the largest rates of MSL rise, and the most varied and largest TATs of any other region considered in Part I. In addition to the TAT variability, the long-term linear trends in tides are considered and compared to discover if the TAT variability may explain the future effects of tidal evolution, and to predict changes in total water levels (MSL plus tides). The combined effect of all tidal amplitude TATs is also examined. Additionally, the tidal anomaly trends are compared between different time periods, namely, before 1993, and after, as MSL rise has shown a marked shift in rates since this time in the region (Merrifield, 2011).

Possible mechanisms to explain the variability are explored, including the changes in shallow water overtides, and the connections of MSL and thermocline depth to changes in tides, with a detailed focus on these dynamics in the Solomon Sea, particularly during the strong El Niño event of 1997-1998. Resonant triad interactions are also found to be involved in the Solomon Sea tidal dynamics. A resonant triad is a pathway for an energy conserving, nonlinear energy exchange between multiple wave modes, in this case, between the $\mathrm{M}_{2}, \mathrm{~K}_{1}$, and $\mathrm{O}_{1}$ tides. The theory and mathematics of this complex interaction is also detailed in Part II, as well as a close analysis of the Solomon Sea triad variability at the Honiara and Rabaul tide gauges, and discussion of 
these results in a barotropic and baroclinic context. Part II is identical in structure to a previously published work (Devlin et al., 2014), and was the first part of this thesis to be written.

In Part III (Chapter 5), entitled "Seasonality of tides in Southeast Asian Waters", the monthly variability of tidal properties is investigated. Twenty tide gauges in Malaysia, Thailand, Indonesia, Singapore, and Vietnam are analyzed in detail in four subregions: The Malacca Strait (MS), the Gulf of Thailand (GOT), the South China Sea (SCS), and the Java Sea (JS). The major diurnal $\left(\mathrm{K}_{1} ; \mathrm{O}_{1}\right)$ and semidiurnal $\left(\mathrm{M}_{2} ; \mathrm{S}_{2}\right)$ tides exhibit annual and semi-annual patterns of variability as revealed by monthly harmonic analyses. MSL and tidal properties are strongly correlated to the Western North Pacific Monsoon Index (WNPMI) at the annual frequency band. Monsoon-related forcing that may explain the tidal variability are: the seasonal changes in stratification due to seasonal patterns of rainfall and runoff, seasonal changes in sea surface height (SSH) that modulate water depth and basin area, seasonal changes in geostrophic ocean currents, and seasonal patterns in wind-induced Ekman transport. More than one mechanism may be important in each of the four sub-regions examined, and the patterns of diurnal and semidiurnal tides are different. A barotropic tide model is employed to determine the causes of the observed patterns of tidal variability, and to quantify sensitivities. 
A review of monsoonal dynamics is presented first, including the regional patterns of wind, ocean currents, and surface water mass properties. This is followed by a description of the observed tidal variability in the region, the coherence of tidal properties to the monsoon index, and of the methods of analysis for the quantification of the seasonal tidal anomaly trends (STATs). Next is a detailed description of the barotropic model setup, the model calibration and operation, the methodology involved in adding climate related adjustments, and data source details for four tide models, each investigating one possible forcing mechanism (SSH, geostrophic velocity, drag coefficient, and Ekman transport), are described. Results are then documented in each sub-region (MS, GOT, SCS, and JS) for the observed tidal variability, the seasonal patterns of the climatic forcing, and for the model responses. These results are presented in both a temporal and spatial sense to determine the most important mechanisms in each sub-region. Individual model responses at each tide gauge location are compared to the observed variability, as well as the responses of combined models, which are quantified via regression statistics. Limitations of the models are then discussed, as well as other mechanisms that are not resolved in a barotropic model, such as the baroclinic effect of seasonal river discharge. The methods and results of Part III are planned to be submitted to a journal in the near future. Finally, Chapter 6 is a short conclusion that synthesizes all the results of Parts I, II, and III. 


\section{Chapter 2: Tidal Theory}

\subsection{The governing equations}

\subsubsection{The Navier-Stokes equations}

Named after Claude-Louis Navier and George Gabriel Stokes who developed them in the early 1800 s to describe the motion of a fluid substance starting from an application of Newton's second law, the Navier-Stokes equations are presented below (Temen, 2001). These equations describe a large range of applications in engineering (such as fluid flow through pipes and channels and the flow of air around an airplane wing) and observational sciences such as atmospheric science and oceanography. The Navier-Stokes equations are nonlinear partial differential equations, due to the presence of the "convective acceleration" terms. These nonlinear terms arise because they are taken with respect to a moving coordinate system, and are needed to fully describe the dynamics of most geophysical flows, typically necessitating some description of turbulence (a time-dependent, chaotic behavior described by the convective acceleration terms) to close the solution. For the study of long-waves on the ocean (ocean tides), turbulence is typically assumed to be insignificant.

The Navier-Stokes equations in an inertial reference frame are:

$$
\rho \frac{D \mathbf{v}}{D t}=-\nabla p+\nabla \cdot \mathbf{T}+\mathbf{f}
$$


Here, $\rho$ is the fluid density, $t$ is time, $\mathrm{p}$ is the pressure, $\mathbf{T}$ is the deviatoric component of the total stress tensor, $\mathbf{f}$ represents all body forces acting on the fluid (such as gravity), and $\mathbf{v}=(u, v, w)$ is the vector velocity of the fluid. The term (Dv/Dt) is known as the material derivative, representing the total change of any material quantity (such as heat, momentum, or water mass) following the flow, written out as:

$$
\frac{D \mathbf{v}}{D t}=\frac{\partial \mathbf{v}}{\partial t}+\mathbf{v} \cdot \nabla \mathbf{v}
$$

The material derivative contains all accelerations present, both time-dependent, and the spatially-dependent convective accelerations. Therefore, Eq. (1) is an expression of Newton's second law of motion ( $\Sigma \mathbf{F}=m a)$ for a continuum, with the terms on the left in Eq. (1) being equivalent to (ma), as density, $\rho$, is the corollary of mass for a fluid. The terms on the right are a sum of forces due to pressure, stresses, and body forces. In addition to the momentum equations, it is also necessary to have an expression for conversation of mass of the fluid parcel, known as the mass continuity equation, or simply the continuity equation:

$$
\frac{D \rho}{D t}+\rho(\nabla \cdot \mathbf{v})=0
$$

which is written in terms of the material derivative. For the oceanic case of an incompressible fluid, Eq. (3) reduces to: 


$$
\nabla \cdot \mathbf{v}=\mathbf{O}
$$

\subsubsection{The Laplace tidal equations}

Pierre Simon Laplace in 1776 detailed the equations of ocean tides that form the basis of equilibrium tide theory, which assumes a constant-depth ocean without coastlines (Cartwright, 1999). This simplified approximation is surprisingly accurate for most purposes (except near coastlines). Though they were developed before the Navier-Stokes equations, the Laplace tidal equations can be derived from the NavierStokes equations subject to the following assumptions: (a) molecular transport and the compressibility of water are neglected; (b) the Boussinesq approximation for buoyancy is used (fluid density differences are small enough to be neglected, except where multiplied by gravity); (c) a shallow water assumption is used to yield hydrostatic balance in the vertical momentum equation; (d) the "traditional approximation" of the Coriolis terms (vertical deflections can be neglected) is applied; and (e) the convective accelerations, though present in principle, are neglected in development of the equations.

With these assumptions, one obtains three momentum equations in three dimensions, and an expression of mass continuity; collectively, these are known as the primitive equations and do include the convective accelerations:

$$
\frac{D u}{D t}-f v=-\frac{1}{\rho_{0}} \frac{\partial P}{\partial x}+F-D
$$




$$
\begin{aligned}
& \frac{D v}{D t}+f u=-\frac{1}{\rho_{0}} \frac{\partial P}{\partial y}+F-D, \\
& \frac{-P_{z}}{\rho_{0}}-\frac{\rho g}{\rho_{0}}=0 \\
& \frac{\partial u}{\partial x}+\frac{\partial v}{\partial y}+\frac{\partial w}{\partial z}=0
\end{aligned}
$$

Here, the horizontal velocity components are $(u, v), w$ is the vertical velocity, $f=2 \Omega \sin \theta$ is the Coriolis factor, $g$ is the acceleration due to gravity, $\rho$ is the density, $\rho_{0}$ is the mean density, $P$ is the pressure, $F$ is a generalized forcing term, and $D$ is a generalized dissipation term. In order to complete the above system, it is necessary to supply an equation of state that expresses $\rho$ in terms of temperature, pressure, and salinity. The $D u / D t$ and $D v / D t$ terms are the material derivatives of Eq. (2).

Assuming the water density is constant and the horizontal velocity components are depth independent, one may vertically integrate these equations from $z=\eta$ (ocean surface) to $z=-H$ (ocean bottom) over a spherical Earth to yield the Laplace tidal equations:

$$
\frac{\partial \eta}{\partial t}+\frac{1}{r_{0} \cos \theta}\left[\frac{\partial}{\partial \varphi}(u H)+\frac{\partial}{\partial \theta}(v H \cos \theta)\right]=0
$$




$$
\begin{aligned}
& \frac{\partial u}{\partial t}-f v+\frac{1}{r_{0} \cos \theta} \frac{\partial}{\partial \varphi}(g \eta+V)=0 \\
& \frac{\partial v}{\partial t}+f u+\frac{1}{r_{0}} \frac{\partial}{\partial \theta}(g \eta+V)=0
\end{aligned}
$$

In this, the generalized dissipation, $D$, has been neglected, and the generalized forcing, $F$, has been replaced with $V$, the astronomical tide-generating potential, described in the next section. The convective terms in the material derivative have also been neglected.

\subsection{The tide-generating gravitational potential}

\subsubsection{Lunar and solar motions: daily and monthly}

The astronomical tide-generating force (ATGF) due to the moon (or the sun) at any point on the earth's surface is the difference between the lunar (solar) gravitational attraction at that point and at the earth's center, in an accelerated reference frame that moves with the center of the earth but does not rotate with respect to the fixed stars. As the earth rotates around its axis, an observer on the earth's surface will be carried through the longitude of the sublunar (subsolar) point, when the ATGF is directed towards the moon (sun), and half a lunar or solar day later, through the antipodal point, when the ATGF is directed away from the moon (sun). Figure 1 shows a schematic representation of the simple twice-a-day tide, known as the semidiurnal tide. The average magnitude of the ATGF is determined by the mass of the objects, and the square of the distance between the two bodies. While the sun is much more massive 
than the moon, the latter is so much closer to earth that the ATGF due to the moon is greater than that due to the sun by about a factor of two (the solar ATGF is $47 \%$ of the lunar ATGF).

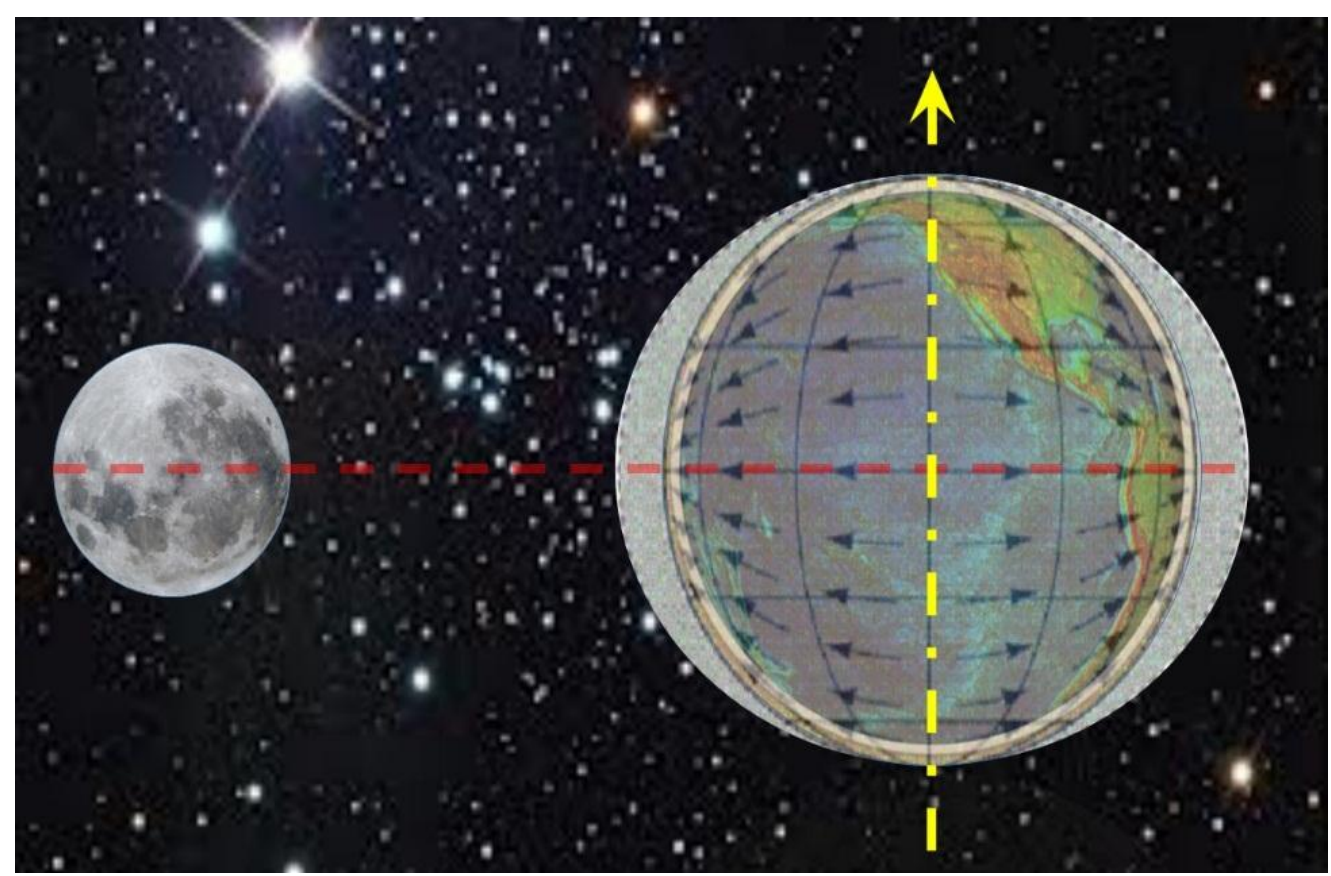

Figure 1 Earth-Moon system, showing the gravitational arrangement of a semidiurnal tide, with high tides in direct line of force with the Moon on the near and far side.

The tide-generating bodies are, however, not always in the plane of earth's orbit, and rarely in the same plane as earth's rotation, which is tilted $23.5^{\circ}$ to the ecliptic; this is especially true for the Moon. This causes an observer at a set location to see a difference between successive semidiurnal maxima and minima (high and low tides). This is known casually as the daily inequality, and it drives the diurnal (once-a-day) tides (Figure 2). This effect becomes more pronounced at higher latitudes, and nearly vanishes at the equator. Furthermore, the sun and moon are not always in the same 


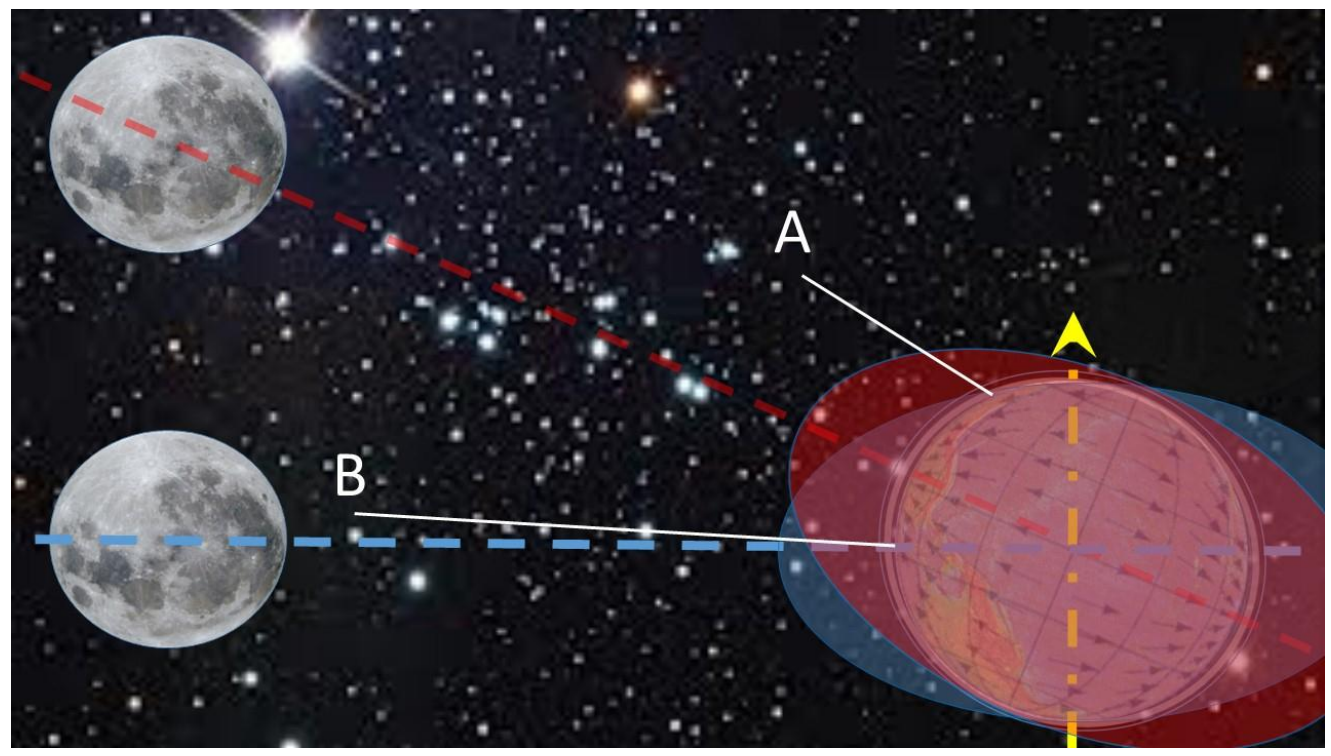

Figure 2 Gravitational arrangement of Earth-Moon system showing origin of diurnal tides due to the Moon being inclined from the Earth's plane of orbit. Diurnal tides are larger near the poles at " $\mathrm{A}$ " then near the Equator at " $\mathrm{B}$ ".

positions day to day (relative to an observer on earth), and therefore, the tides do not exactly repeat from day to day. Their positions vary approximately monthly, with periodicities between 27 and 29 days. At new moon, when the moon is directly in between the earth and the sun, or at full moon, when the earth is directly between the sun and moon, the ATGF from the two bodies reinforce one another. This orientation is known as syzygy; and produces the most extreme maxima and minima (high and low tides) in the semidiurnal and diurnal tides of the month, known as the spring tides. A week later, when the moon is half-full (waxing or waning), the sun acts at a $90^{\circ}$ angle to the moon relative to an earth observer, and the ATGFs are in a quadrature orientation that tends to partially cancel each other. 


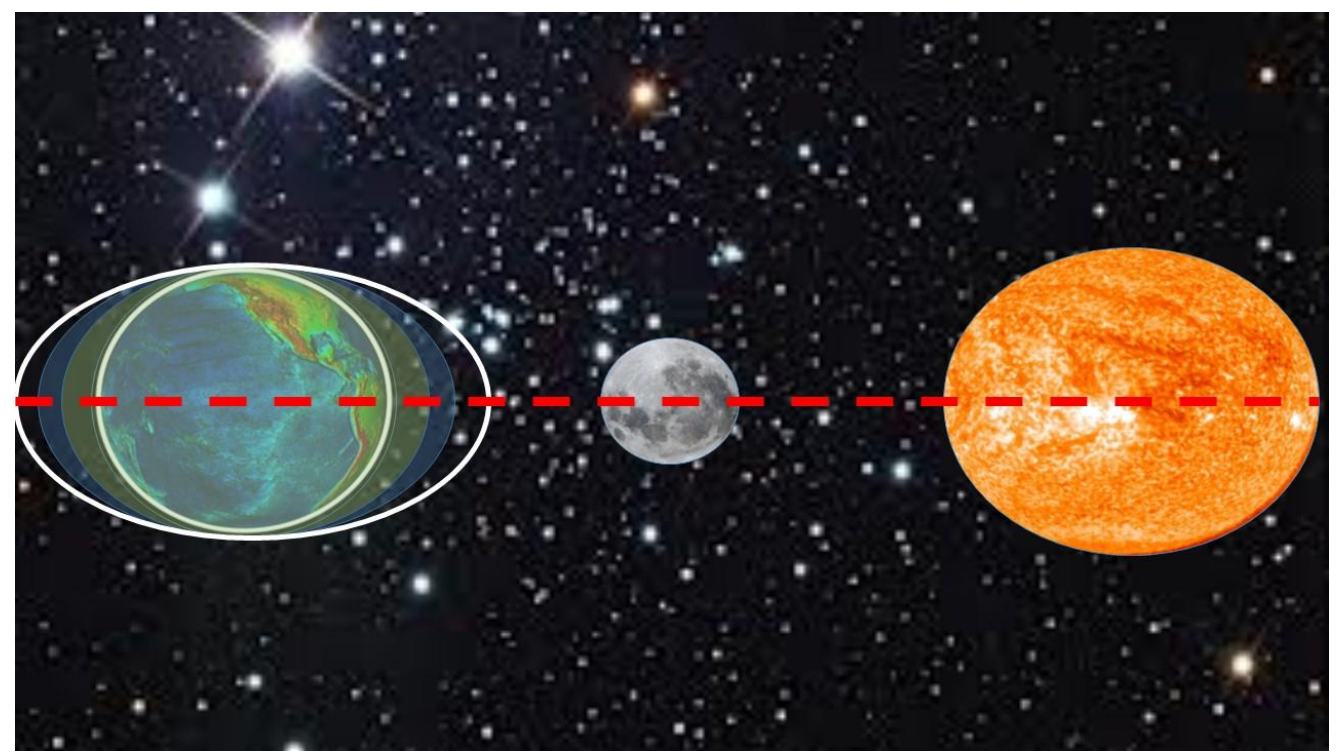

Figure 3a Syzygy orientation of Earth-Moon-Sun system, in which lines of force all act in the same direction, and corresponds to spring tides.

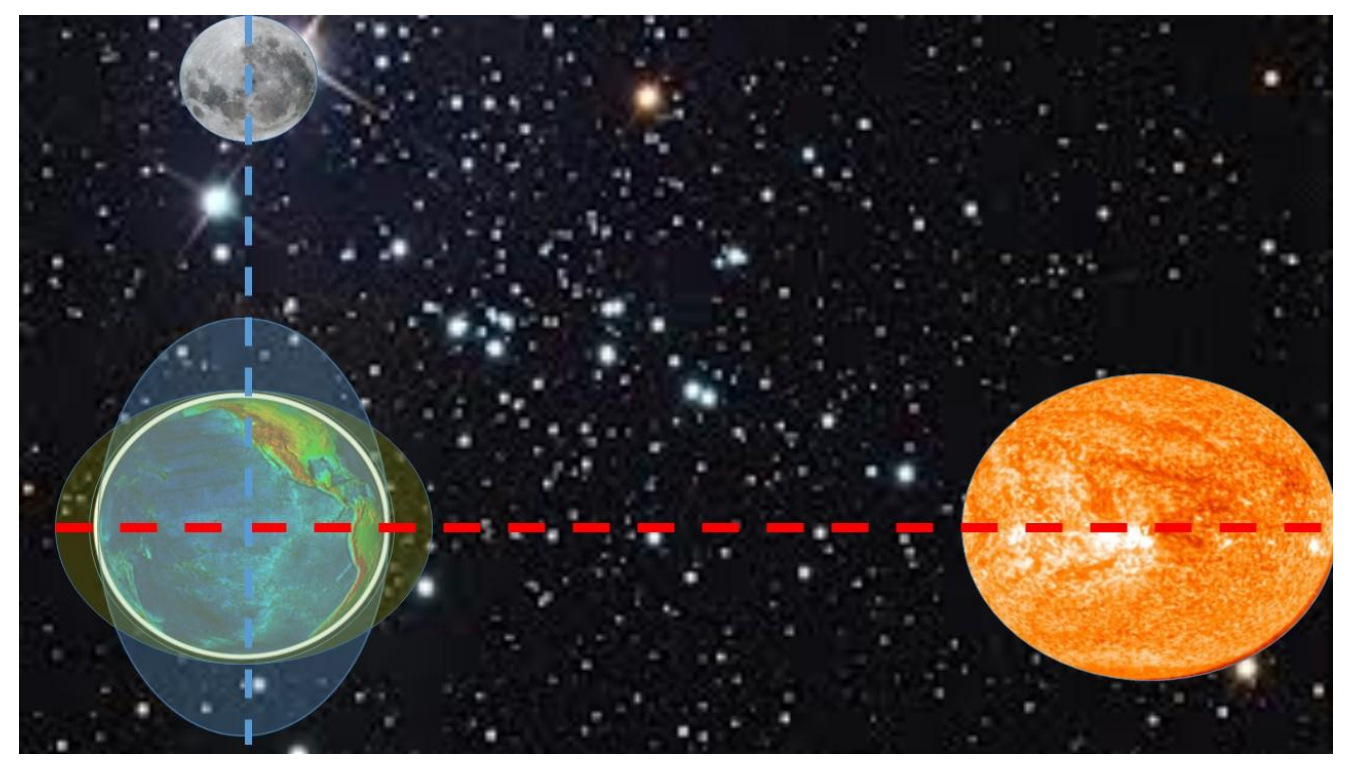

Figure 3b Quadrature orientation of Earth-Moon-Sun system, in which the line of force of the Sun and Moon are orthogonal to each other, and total tides are diminished. This corresponds to times of neap tides. 
This is because the ATGFs of the sun and the moon act in different directions. At this time, twice daily and daily ocean tides show relatively smaller tidal amplitudes, a condition known as neap tides. Figures $3 a$ and $3 b$ show these two orientations.

\subsubsection{Lunar and solar motions: yearly, perigean, and nodal}

The twice daily, daily, and monthly variations are the most apparent fluctuations of the tides, but there are also longer-period oscillations. There is the annual variation, due to the solar year of 365.25 days. Additionally, the lunar orbit is eccentric, meaning the moon will have a perigee (closest location to earth) and apogee (furthest location from earth) due to the nature of elliptical orbits. The location of the moon's perigee slowly moves over a period of about $8.85 \mathrm{yrs}$. The moon is not always in the plane of earth's rotation, which is itself tilted by $23.5^{\circ}$. The moon's inclination to the earth's equatorial plane varies by about $\pm 5^{\circ}$ over the course of its orbit. There are two points when the moon will "cross" the earth's equatorial plane each orbit. These points are called the nodal points of the orbit; the point when the moon moves north or "up" from the point of view of an earth observer is known as the ascending node, and where it moves south or "down" is known as the descending node. The locations of these points will also slowly rotate, in a retrograde manner. These points complete a rotation every 18.61 years, and the corresponding periodicity is known as the nodal cycle. The nodal variation especially modifies the diurnal tides, varying by $11 \%\left(\mathrm{~K}_{1}\right)$ and $18 \%\left(\mathrm{O}_{1}\right)$ for the two strongest daily tides over the course of the nodal cycle. The nodal and perigean variations are detailed in Figures $4 a$ and $4 b$. There is a final tidal frequency due to the 
very slow "precession of the equinoxes"; the slow retrograde motion of the Earth's rotational axis about its orbital axis. However, as this cycle has a period of $\sim 20,000$ years, this modulation has little practical importance.

\subsubsection{Perigean spring tides}

Maximum tidal ranges and extreme water levels are affected by astronomical factors. There are occasional gravitational alignments in which the moon is at perigee during a full moon (spring tides), and hence, at its closest approach to Earth, and on the most direct line of force. This may lead to what is known as perigean spring tides, also known as king tides, at which time the largest high tides and lowest low tides of the year are observed. Particularly close arrangements are yielded by the modulations of the perigean and nodal cycles, and the absolute closest approaches are known as proxigean spring tides (Wood, 1986); these occur in a quasi-periodic pattern a few times per century. Wood associated extreme high tide events of the past century with some of the most devastating storms. Proxigean spring tides occur primarily during the Northern Hemisphere winter months, when intense storms are frequent, so the added influence of maximum high tides on top of long-term increases of tides and MSL may lead to disastrous future flooding events. In this contribution, the maximum tide is approximated by the sum of four major constituents $\left(\mathrm{M}_{2}, \mathrm{~S}_{2}, \mathrm{~K}_{1}\right.$, and $\left.\mathrm{O}_{1}\right)$, assuming they are all in phase (which only occasionally happens). However, the description above suggests that a full accounting requires consideration of nodal and perigean effects. 


\subsubsection{The harmonic development of the tide-generating potential}

The above long-period orbital variations interact nonlinearly in the ATGF, both with themselves, and with the shorter period semidiurnal and diurnal variations. This causes the local ATGF to be a sum of three narrow-band processes, centered on 0,1 , and 2 cycles per day (cpd), each process being a sum of harmonics at multiples of the frequencies corresponding to the lunar day and solar day, plus sums of multiples of the long-period frequencies ( $\sim 0 \mathrm{cpd}$ band). Complete derivations are given in Cartwright (1977), Cartwright and Tayler (1971), Cartwright and Edden, (1973).

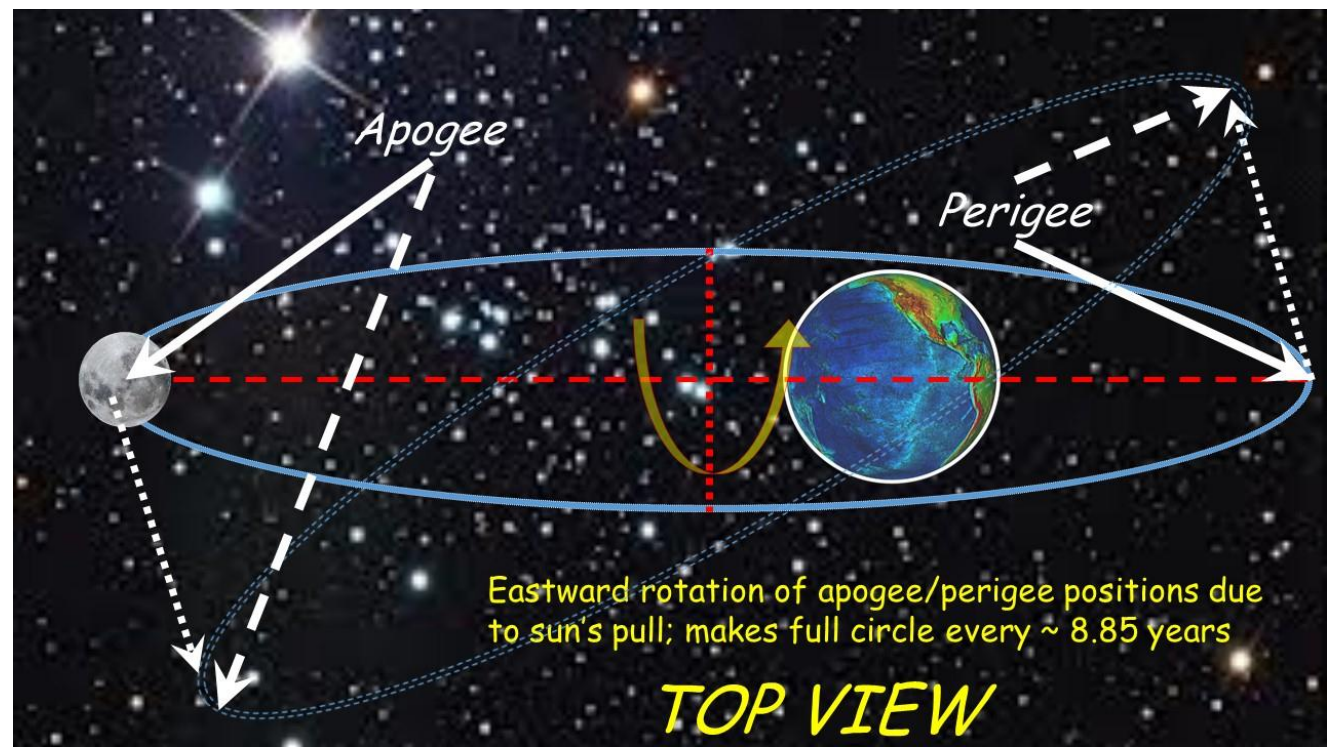

Figure 4a Schematic of lunar perigean cycle seen from a "top view". Positions of perigee (closest approach to Earth) and apogee (furthest approach) are shown, which rotate positions with a frequency of $8.85 \mathrm{yr}^{-1}$. 


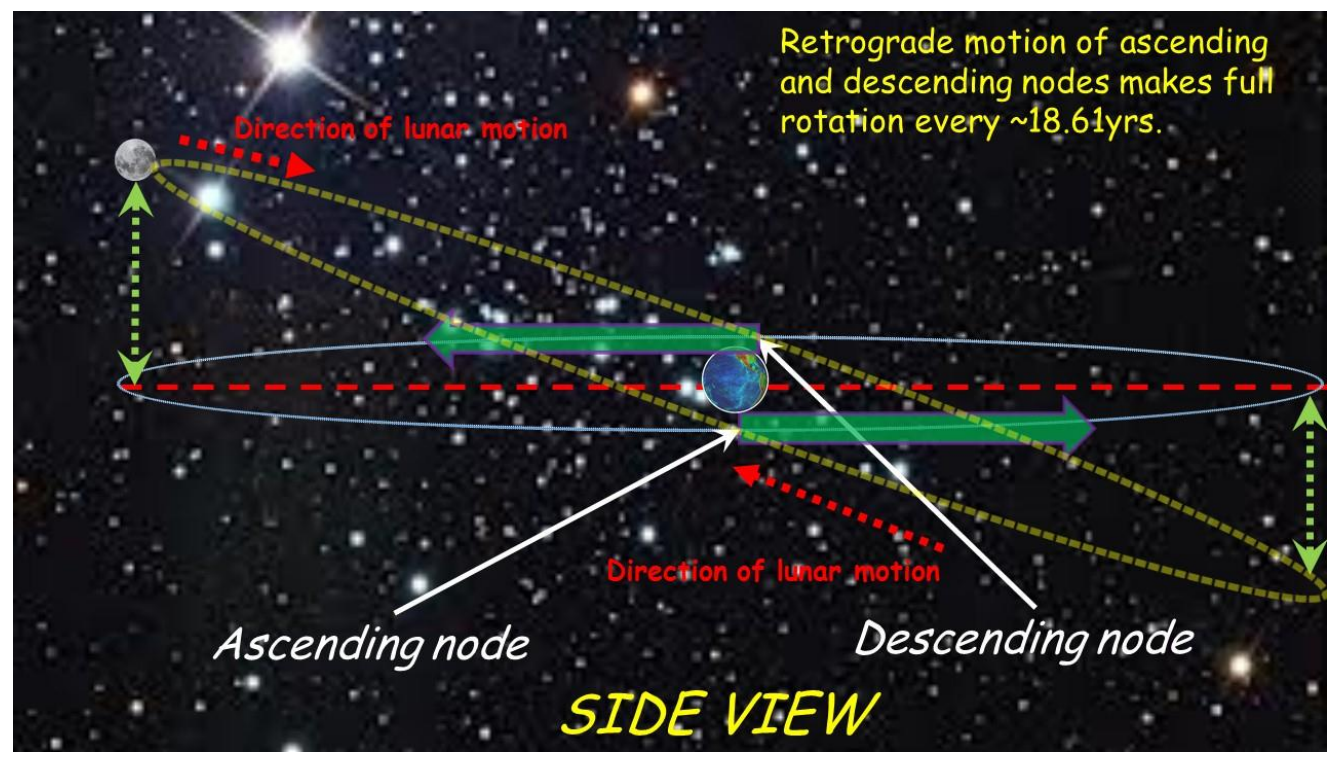

Figure $\mathbf{4 b}$ Schematic of lunar nodal cycle presented from a "side view" in the plane of Earth's orbit. The positions where the moon's orbit crosses the Earth's orbital plane are the ascending and descending nodes, and these positions rotate in a retrograde manner, with a frequency of $18.61 \mathrm{yr}^{-1}$.

To make the ATGF useful, it is thought of as a harmonic decomposition of the tide-generating potential whose spatial gradient is the ATGF. Only the horizontal components of the ATGF (tangent to the surface of the earth) are important because the vertical component is tiny compared to gravity. Therefore, we represent the tidegenerating potential as its horizontal and temporal variation, $V$, over some equipotential surface (the geoid) of the mean gravitational potential (due to the earth's shape, mass distribution, and rotation). The potential, $V / g$ (where $g$ is the local gravitational constant), will then have units of sea-surface elevation, and is called the equilibrium tide, $\zeta$. The principle term following Cartwright (1977) is: 


$$
\bar{\zeta}(\varphi, \theta, t)=\frac{V(\varphi, \theta, t)}{g}=\sum_{m=0,1,2}\left[A_{2}^{m} \cos (m \varphi)+B_{2}^{m} \sin (m \varphi)\right] P_{2}^{m}
$$

where $(\varphi, \theta)$ are latitude and longitude, and the $P_{2}{ }^{m}$ are the associated Legendre functions of colatitude $(\bar{\theta})$ :

$$
\begin{aligned}
& P_{2}^{0}=\frac{1}{3}\left(3 \cos ^{2} \bar{\theta}-1\right) \\
& P_{2}^{1}=3 \sin \bar{\theta} \cos \bar{\theta} \\
& P_{2}^{2}=3 \sin ^{2} \bar{\theta} \\
& \bar{\theta}=\left(\frac{\pi}{2}\right)-\theta
\end{aligned}
$$

The $A$ 's and $B$ 's are functions of time having the form

$$
\left.A_{n}^{m}(t)=\sum_{i} C_{i}{ }_{\sin }^{\cos }\left(\sum_{j=1}^{6} D_{j}^{i} S_{j}(t)\right)\right]
$$

The $C_{i}^{\prime}$ s are the amplitudes calculated from the Fourier analysis of the astronomically derived time-series, $V(\varphi, \theta, t) / g$, the $D_{j}^{i}$ 's are sets of (small) integers which are known as the Doodson numbers, and the $S_{j}^{\prime} S$ are the secular arguments which increase nearly linearly in time with the six associated periodicities of:

1) Lunar day (24.84 hr)

2) The lunar month( $27 \mathrm{~d})$

3) The solar year (365.25 d) 
4) The lunar perigee $(8.85 \mathrm{yr})$

5) The lunar nodal cycle (18.61 yr)

6) The solar perihelion ( $20,000 \mathrm{yr})$

The frequencies of these arguments are catalogued as three "species" of approximately 0, 1 and 2 cycles per day; each species is split into "groups", separated by 1 cycle per month; each group split into "constituents" separated by 1 cycle per year, and so forth. In this manner, a near-infinite discrete continuum of frequencies is theoretically possible, though the actual number is limited to about 475 by the requirement that all $C_{i}^{\prime}$ values for all tidal constituents be at least 1/10,000 of the largest $C_{i}^{\prime}$ value (Cartwright and Tayler, 1971). In practice, however, the number of astronomical constituents analyzed for ocean tides is usually $\sim 67$ components (including shallow-water overtides) which is a high enough level of accuracy for most endeavors. There also exists a terdiurnal tide (three times daily) that is excited through nonlinear interactions of the diurnal and semidiurnal tides. Table 1 shows a listing of the major tidal constituents listed by Doodson number, frequency, and commonly-used symbology (Darwin symbols), and Figure 5 shows some typical distributions of spectral energy of the tides at San Francisco from Fourier analysis methods. The clustering of spectral energy around the once a day frequency band gives a measure of the diurnal tide strength, and the clustering of spectral energy around the twice a day frequency band will give an indication of the semidiurnal tide strength. A spectral plot at a gauge 
that shows more energy at the once daily band will exhibit a more dominantly diurnal tidal behavior, whereas those gauges that have more energy in the twice daily band will have a more predominantly semidiurnal characteristic. For San Francisco, the spectral energy is of the same magnitude at both bands, indicating a mixed tide.

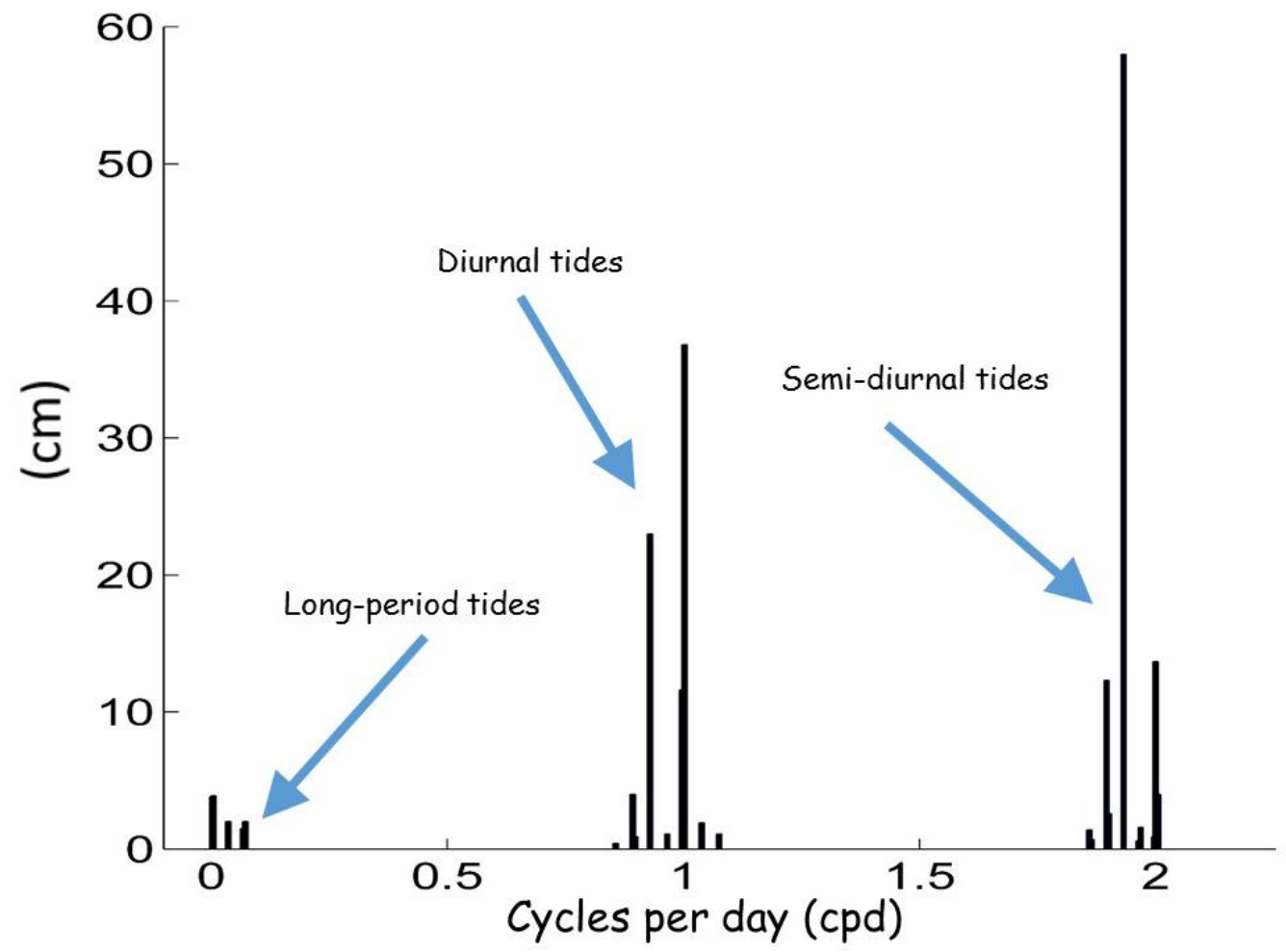

Figure 5 Sample of the frequency distribution of tidal harmonics, based upon results at San Francisco. Tidal spectrums are an interaction of three narrow-band processes, centered on 2 cycles per day (semidiurnal tides), 1 cycle per day (diurnal tides), and $\sim 0$ cycles per day (long-period tides). 
Table 1 Major tidal constituents, showing Darwin symbol notation for each tide, the tidal period in hours, the average amplitude of each constituents observed at San Francisco, California, and the corresponding Doodson number convention.

\begin{tabular}{|c|c|c|c|}
\hline $\begin{array}{c}\text { Tide name } \\
\text { (Darwin Symbol) }\end{array}$ & $\begin{array}{l}\text { Period } \\
\text { (hours) }\end{array}$ & $\begin{array}{c}\text { Avg. Amp. at } \\
\text { San Francisco (cm) }\end{array}$ & Doodson \#s \\
\hline \multicolumn{4}{|l|}{ Semidiurnal tides } \\
\hline$M_{2}$ & 12.421 & 58.0 & 255.555 \\
\hline$S_{2}$ & 12.000 & 13.7 & 273.555 \\
\hline$N_{2}$ & 12.658 & 12.3 & 245.655 \\
\hline$v_{2}$ & 12.626 & 2.6 & 247.555 \\
\hline$\mu_{2}$ & 12.872 & 0.7 & 237.555 \\
\hline $2 \mathrm{~N}_{2}$ & 12.905 & 1.4 & 235.555 \\
\hline$\lambda_{2}$ & 12.222 & 0.6 & 263.655 \\
\hline$T_{2}$ & 12.016 & 0.9 & 272.555 \\
\hline$R_{2}$ & 11.984 & 0.1 & 274.555 \\
\hline$L_{2}$ & 12.192 & 1.6 & 265.455 \\
\hline$K_{2}$ & 11.967 & 4.0 & 275.555 \\
\hline \multicolumn{4}{|l|}{ Diurnal tides } \\
\hline$K_{1}$ & 23.934 & 36.8 & 165.555 \\
\hline$O_{1}$ & 25.819 & 23.0 & 145.555 \\
\hline$P_{1}$ & 24.066 & 11.6 & 163.555 \\
\hline$Q_{1}$ & 26.868 & 4.0 & 135.655 \\
\hline$O O_{1}$ & 22.306 & 1.1 & 185.555 \\
\hline$S_{1}$ & 24.000 & 0.7 & 164.555 \\
\hline$M_{1}$ & 24.841 & 1.1 & 155.555 \\
\hline$J_{1}$ & 23.098 & 1.9 & 175.455 \\
\hline$\rho$ & 26.723 & 0.9 & 137.455 \\
\hline $2 Q_{1}$ & 28.006 & 0.4 & 125.755 \\
\hline \multicolumn{4}{|l|}{ Long-period tides } \\
\hline$M_{m}$ & 661.300 & 2.0 & 065.455 \\
\hline$S_{s a}$ & 4383.100 & 3.9 & 057.555 \\
\hline$S_{a}$ & 8766.200 & 3.8 & 056.555 \\
\hline$M_{s f}$ & 354.370 & 1.5 & 073.555 \\
\hline$M_{f}$ & 327.860 & 2.0 & 075.555 \\
\hline
\end{tabular}




\title{
Chapter 3: (Part I) Tidal variability in the Pacific
}

\begin{abstract}
Ocean tides are changing worldwide for reasons not related to astronomical forcing, concurrent with the rising trend in global sea levels due to climate change. Tidal change coupled with sea level rise may lead to increased inundation and erosion along some coasts. A better understanding of the joint changes in both sea level rise and changing tides can potentially help coastal planners mitigate the effects of climate change within coastal communities. This work examines the relationships between tidal anomalies (the deviations from long-term trends in tidal constituent properties) to mean sea level (MSL) anomalies (deviations from long-term MSL trends) as a means of diagnosing dynamical factors that might influence the longer-term evolution of tides. I hypothesize that changes in tidal properties are dynamically related to MSL changes, both directly through depth effects or indirectly due to changes in stratification (which can also affect MSL). Moreover, I hypothesize that relevant physical mechanisms may be identified through the short-term correlations between MSL and tides, and provide insight and guidance about future tidal evolution. Finally, I hypothesize that because sea level rise varies throughout the Pacific basin but is regionally coherent, trends in tidal statistics due to sea level rise will also display regional patterns. Specifically, a basin-wide survey of the entire Pacific at multiple time scales is hypothesized to be able to indicate the relevant spatial scales (local vs. amphidromic) and temporal scales (yearly vs. seasonal) of the tidal changes. To test these hypotheses, I analyze 153 tide
\end{abstract}


gauges distributed throughout the Pacific Ocean. I assess four tidal constituents: the two largest semidiurnal (twice daily) constituents, $\mathrm{M}_{2}$ and $\mathrm{S}_{2}$, and the two largest diurnal (once daily) components, $\mathrm{K}_{1}$ and $\mathrm{O}_{1}$. The correlation of MSL anomalies with tidal property anomalies are calculated and discussed for both yearly and monthly time scales. Yearly tidal variabilities are denoted tidal anomaly trends (TATs), and monthly variabilities are denoted seasonal tidal anomaly trends (STATs). Results suggest that sea level variability drives inter-annual tidal variability in a majority (89\%) of tide gauges in the Pacific. Statistically significant amplitude TATs, with a signal-to-noise ratio (SNR) of 2.0 or greater are seen at 92 gauges for $\mathrm{M}_{2}, 66$ for $\mathrm{S}_{2}, 82$ for $\mathrm{K}_{1}$, and 59 for $\mathrm{O}_{1}$. Phase TATs are significant at 55 gauges for $\mathrm{M}_{2}, 47$ for $\mathrm{S}_{2}, 42$ for $\mathrm{K}_{1}$, and 61 for $\mathrm{O}_{1}$. Seasonal variation in tidal statistics appears to be less common; statistically significant STATs are observed at only $35 \%$ of all gauges, with the largest concentration in Southeast Asia. The effect of combined A-TATs is also considered at select stations, including predictions of total water levels (change in MSL plus change in tidal range) up until 2100 based on combined effects of MSL and A-TATs. At a subset of gauges, the observed tidal anomalies in relations to MSL anomalies were projected to future expected sea levels. The change in total water levels at stations with large positive combined A-TATs are greater than that predicted by an increase in MSL alone, which may make the effects of sea level rise more damaging. Conversely, changes in total water levels at stations with negative combined A-TATs are less than that predicted by MSL rise alone, which may somewhat mitigate against future sea level rise. Climate change scenarios that consider 
greater increases in Antarctic ice melt show larger changes in total water levels over the same epoch.

Results confirm the hypotheses that: The mechanisms affecting MSL rise also appear to be affecting tidal change on a local scale, that gauges worthy of future study are identified, and that causative mechanisms are suggested at multiple time scales. These mechanisms will be tested in Parts II and III. Results are inconsistent with the hypothesis that short-term variability can predict future long-term behavior of tides; this will be explored in more detail in Part II. Overall, tidal anomalies, while forced to some extent by sea level changes, appear to be forced by locally contingent processes rather than basin-scale mechanisms. For both amplitude and phases, the Southwest Pacific shows the greatest concentration of significant TATs. 


\subsection{Introduction}

\subsubsection{Changes in ocean tides: Hypotheses}

Ocean tides exhibit changing long-term trends worldwide over the past century (Woodworth, 2010; Müller, 2011). Concurrent with these changes, mean sea levels (MSL) are increasing (Church and White, 2011). Besides the long-term trends, both MSL and tides exhibit short-term (seasonal to decadal) variability. It is hypothesized that:

1) Changes in tides are likely not caused solely by concurrent MSL rise, but may be dynamically related, either directly, or due to a common cause such as changes in stratification.

2) Non-astronomical mechanisms influencing tidal change can be identified through short-term variability of MSL and other factors, allowing for prediction of long-term tidal evolution.

3) A basin-wide survey of the Pacific will indicate the spatial scale of the mechanisms responsible for tidal changes. Basin or amphidromic scale changes will indicate a global mechanism, and changes that are more localized indicate the greater importance of regional processes.

4) The consideration of multiple time scales of tidal and MSL variability (monthly and yearly) will allow more forms of variability to be apparent. 


\subsubsection{Mean sea level (MSL) trends}

Globally averaged sea level rise is $+2.8 \pm 0.8 \mathrm{mmyr}^{-1}$ as estimated from coastal and island tide gauge measurements from 1880-2009, and $+3.3 \pm 0.4 \mathrm{mmyr}^{-1}$ for 1993 2009 as estimated from satellite altimetry (Church and White, 2011). There is suggestion that these rates may accelerate in coming decades due to global climate change mechanisms (Nicholls and Cazenave, 2010), such as eustatic MSL rise due to ice sheet melt and thermosteric MSL rise due to upper-ocean warming. The warming effect is estimated by Domingues, et al., (2008) to be contributing $+0.52 \mathrm{mmyr}^{-1}$ to total sea level rise from 1961-2003. Both the rate of ocean warming and of ice sheet melt may accelerate in coming years, which will also contribute an accelerating component to sea level rise. Church and White (2006) report a global average acceleration of $+0.013 \pm$ $0.006 \mathrm{mmyr}^{-2}$ from 1870 onwards. Jevrejeva et al. (2006) analyzed sea level records with consideration of multidecadal variability and nonlinear trends to show that simple linear trends may often miscalculate the true rate of sea level rise, and that the choice of time period analyzed greatly influences results. Holgate (2007) analyzed nine long record tide gauges to find there have been significant differences in sea level rise over the past century; in the decade centered on 1980, rates were as high as $+5.31 \mathrm{mmyr}^{-1}$, and in the decade centered on 1964, rates were -1.49 mmyr ${ }^{-1}$. A "hotspot" of accelerated sea level rise is observed by Sallenger, et al., (2012) near Cape Hatteras along the Atlantic coast of North America, where sea level rise rates are 3-4 times larger than global averages from 1980-2009, consistent with a slowdown of the Atlantic 
Meridional Overturning Current. Rahmstorf (2007) uses a semi-empirical approach integrating IPCC warming scenarios to project future global sea levels in 2100 to be 0.5 to $1.4 \mathrm{~m}$ above 1990 levels. Pfeffer et al. (2008) proposes that the possible increase of global sea levels could exceed $2 \mathrm{~m}$ by 2100 under scenarios of rapid deglaciation, especially from the effect of melting of the Greenland ice sheet, which holds 4-6 m potential sea level rise in its entirety (Rohling et al., 2008). Woodworth et al. (2009) makes a comparison of different studies that have discussed sea level acceleration and explores the global distribution of accelerations. In this, they make the case for worldwide collaboration in ensuring the richest and longest data sets of hourly water levels are available.

The true rate of sea level rise is difficult to accurately calculate because of climatic variability that may be an order of magnitude more than the long trend trends in MSL which exhibits fluctuations related to climate indices. Kolker and Hameed (2007) found that the water level variability at five Atlantic Ocean tide gauges were correlated to the meteorologically-based North Atlantic Oscillation (NAO). In the Pacific, the quasiperiodic variability of the El Niño Southern Oscillation can modulate sea levels by up to $0.1 \mathrm{~m}$ at the interannual scale, particularly during intense El Niño or La Niña events, such as the 1997-1998 El Niño (McPhaden, 1999), or the El Niño currently in process (as of March, 2016). These ENSO induced sea level changes affect the ocean in different ways by region; in most of the Western Pacific Ocean, sea levels are elevated during El Niño events due to a buildup of warm water and lowered during La Niñas. But within the 
South China Sea (SCS), the reverse is true, because warm surface water from the SCS rushes out to feed the Pacific warm pool during El Niños (Ding et al., 2001; Ding et al., 2004), and returns to the SCS during La Niñas.

The Pacific Decadal Oscillation (PDO) is another mode of oceanic variability; it has a period of about 40-60 years (Mantua et al., 1997; Mantua and Hare, 2002). It was originally discussed in relation to salmon production cycles and is defined as the leading empirical orthogonal function of North Pacific sea surface temperature anomalies. The PDO is thought to be partially coupled to ENSO and the Aleutian low (Newman et al., 2003; Schneider and Cornuelle, 2005). Other climate indices have been defined in recent years, such as the "El Niño Modoki" (Ashok, et al., 2007), and the North Pacific Gyre Oscillation (NPGO; Di Lorenzo, et al., 2008, 2010). Chambers et al. (2012) discussed the existence of a 60-year quasi-periodic oscillation in sea level records present in nearly every ocean basin that may complicate calculation of acceleration rates of MSL over the past century, but with a magnitude insufficient to explain away the long term trends. Though many of these climate indices may be useful in understanding sea level or tidal variability, a caveat must be made in remembering that any climate index is based on observations of physical properties, such as atmospheric circulation or sea surface temperature, and that the potential causes of observed variability are these properties, and not the climate indices themselves. 
There are many uncertainties in determining the future of global sea level rise, with the largest unknowns being the expected contributions of ice sheet melt and thermal expansion of ocean water under high warming scenarios, land subsidence, and future land water storage due to anthropogenic activities (Cazenave and Nerem, 2004). Accurate determination is complicated by the lack of historical data, particularly in the Southern Ocean. It can be seen from the discussion above that MSL rise is not temporally uniform, and neither is it spatially uniform. In the Southwestern Pacific, MSL rates of $+10 \mathrm{mmyr}^{-1}$ or greater are common (Figure 6). In contrast, MSL rise rates in the Northeast Pacific have been below the global average over the same time period, with some places along the West Coast of the US having constant or even negative rates. This is partly due to local tectonic rise, and partly due to prevailing wind patterns that keeps MSL elevations lower in the eastern Pacific. Merrifield (2011) examined anomalous sea surface height trends in the Pacific over the years 1993-2009 from satellite altimetry in comparison to wind stress patterns, and finds this spatial contrast in MSL rates cannot be adequately explained by the interannual variability of the El Niño Southern Oscillation (ENSO). Rather, it is thought to be due to strengthening of wind stress related to atmospheric circulation over the tropical Pacific that has accompanied recent warming trends. 


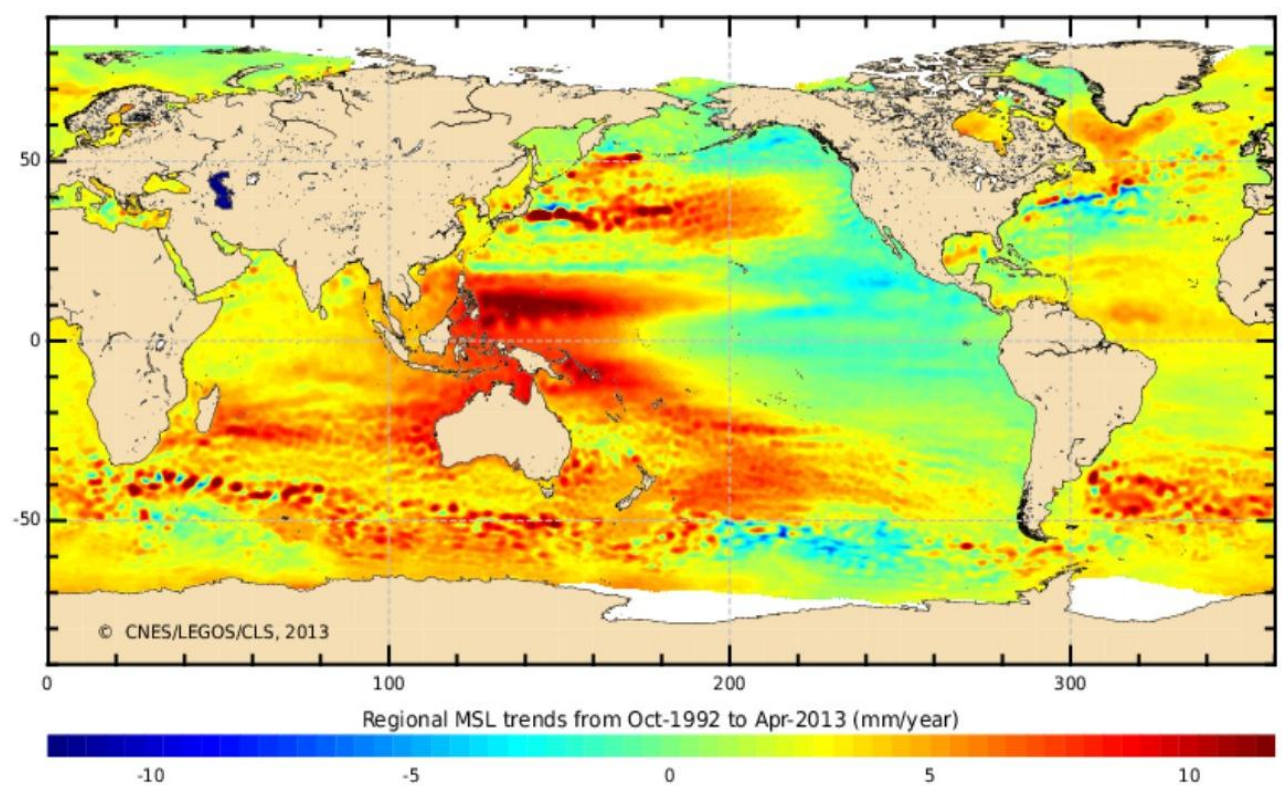

Figure 6 Global distribution of mean sea level rise rates, showing the large positive rates in the Western Pacific, and the slight negative trends in the Eastern Pacific. MSL rates are based on the time period of 1992-2013. Figure credit: ESA/CNES/LEGOS/CLS (http://www.esa-sealevel-cci.org/node/214).

It is unlikely that the extreme rise rate in the Western tropical Pacific will persist unabated, and Bromirski et al. (2011) have suggested that the suppression of sea level rise in the Northeast Pacific is due in part to the PDO, and that a trend reversal along the US West Coast is imminent. Yet, short-term MSL fluctuations offer an opportunity to examine the connections between different parts of the water level spectrum, in this case, between tidal evolution and MSL. 


\subsubsection{Changing ocean tides}

Ocean tides have historically been considered stationary in time because of their close relationship to astronomical motions (Cartwright and Tayler, 1971). Long-term tidal evolution has been observed at some stations such as Brest, France (Cartwright, 1972), and is sometimes a result of harbor modifications such as seen in systems as diverse as the Thames estuary (Bowen, 1972; Amin, 1983), the Rhine-Meuse (Vellinga et al., 2014), Neah Bay (Jay, 2009), and the Lower Columbia River (Jay et al., 2011). However, a flurry of recent work in the past decade or so has shown that tides are evolving at diverse rates worldwide without any apparent relationship to astronomical forcing. Furthermore, these changes are too widespread to be an effect of isolated mechanisms such as harbor development. Woodworth (2010) analyzed global tides, and expressed changes in tides as an annual percentage change of the mean tidal amplitude at 83 long-record ( $>50$ years) stations, and 220 shorter record ( $>30$ years) stations. Müller, et al. (2011a) examined a worldwide data set of only long period gauges, finding consistent patterns of negative and positive changes in tides in major basins, with the relative changes in amplitude of the solar semidiurnal tide, $\mathrm{S}_{2}$, being the largest. Part of the observed $\mathrm{S}_{2}$ tide may be due to the effects of generalized solar heating and irradiance, which is a daily modulation (i.e., day and night). This has been discussed in more detail by Munk and Cartwright (1966), as well as Ray (2001), Godin (1986) and Arbic (2005), and has been estimated by Zetler (1971) to contribute up to 
$17 \%$ of the solar semidiurnal tide. This irradiance contribution may increase under rapid warming scenarios.

On a regional scale, changes in $\mathrm{M}_{2}$ and $\mathrm{K}_{1}$ were observed in the Eastern Pacific by Jay (2009), with an average rate of $2.2 \%$ per century at 34 gauges from $33^{\circ} \mathrm{S}$ to $60^{\circ} \mathrm{N}$, and were posited to be due to multiple mechanisms, including baroclinic and background vorticity effects. In the Eastern Pacific, MSL rise is small, and tidal evolution is therefore important for determining future high water inundation and erosion for coastal regions. In the Gulf of Maine, Ray (2006) documents a slow increase in $\mathrm{M}_{2}$ as well as in the solar semidiurnal tide $\left(S_{2}\right)$ in the North Atlantic (Ray, 2009). Müller (2011b) also describes a rapid change in semidiurnal amplitudes and phases in the North Atlantic since 1980. Changes in tidal range and datum levels along many parts of the US coast line (Flick et al., 2003) also indicate evolution of constituents. Feng at al. (2015) investigates tide gauges along the coast of China from 1954-2012, and finds secular changes of up to 4 to $7 \mathrm{mmyr}^{-1}$ for $\mathrm{M}_{2}$ in the Bohai and Yellow Seas, as well as increases in extreme sea levels from 2 to $14 \mathrm{mmyr}^{-1}$ (Feng and Tsimplis, 2014). Rasheed and Chua (2014) analyze secular trends along the coast of Japan, and find a long-term decrease in the $M_{2}$ amplitude there. In the open ocean, Zaron and Jay (2014) analyze the secular trends at 25 gauges with records longer than 30 years, and find a statistically significant increase in $M_{2}$ and $K_{1}$ at a majority of locations, hypothesized to be due to in some locations to improvements in instrument time keeping and data processing which would reduce the apparent phase variability. At other locations, changes are hypothesized to 
be due to local morphological changes or nonlinear overtide mechanisms, while a smaller number could not be explained and were perhaps due to larger scale oceanic processes.

There are many possible mechanisms that may be contributing to these observed changes in tides, either individually or in concert. Mean sea level (MSL) may influence or be correlated with tidal evolution in a variety of ways, both locally and on basin-wide (amphidromic) scales. Changes on the continental shelves may influence tides on a basin scale through changing bed friction in shallow water (Arbic and Garrett, 2010). Alternatively, tidal changes could be related via a "coupled oscillator" concept of the interaction of coastal and open-ocean areas, which can be significant for nearresonant regions (Arbic et al., 2009; Skiba et al., 2013). Increasing water depth can modify propagation and dissipation of tidal energy (Pugh, 1987). Rising MSL may also cause changes in the tidal characteristics such as wavelength and wave speed in nearresonant shallow areas, as well as reduced energy dissipation due to reduced bottom friction. Alternatively, MSL rise may coincide with changes in stratification and/or thermocline depth. These internal changes may alter the surface manifestation of internal tides in ways that are detectable at tide gauges, e.g., at Honolulu (Colosi and Munk, 2006). Other mechanisms that may explain these changes include: changes in water depth that modify tidal magnitudes and timing (Pugh and Woodworth, 2014), and seasonal variations due to changes in water column stratification (Kang et al., 2002; 
Müller 2012b). Additionally, fluctuations in multiple constituents may be related via resonant triads, discussed in detail in Part II (Lamb, 2007).

\subsubsection{Coupled MSL and tidal change}

Coastal inundation is a consequence of peak sea level, not mean sea level, so the changes in tides may be as important as MSL changes in altering inundation risk, depending on region of the world. In the Northeast Pacific, for example, MSL rise is small and in some places negative, making the changes in tides more important than changes in MSL. In the Western Pacific, both MSL rise and tidal changes are large, making both changes important. The coupling of MSL rise with changing tides may modify total water levels in a complex manner. Increased water depths usually decrease bed friction and may increase tidal amplitudes, but at the same time, higher MSL floods new shallow areas, and may lead to increased friction and lowered tidal amplitudes. Additionally, a higher water level increases the available tidal prism and modifies standing wave resonance (Holleman and Stacey, 2014). When combined with storm surges from weather patterns such as monsoons or hurricanes, increasing tidal amplitudes and/or higher MSL may yield increased flood risk and coastal inundation, as well as eventual loss of habitat at low-lying islands. There could be greatly increased costs of damage to infrastructure in coastal and island regions, along with societal impacts such as population displacement. This was evidenced by Superstorm Sandy's arrival in NYC in 2012. The storm surge hit New York at low tide, but was much more 
disruptive than a similar hurricane that hit the area in 1821, mainly due to higher mean sea levels in the modern epoch. Had this storm hit at a high tide, the inundation would have been much worse (Talke et al., 2014).

Predictions of future inundation due to extreme events must account for both MSL rise and changes in tidal properties. Mawdsley et al., (2015) discussed secular changes in tidal range metrics such as mean tidal range (MTR), finding that the majority of tide gauges worldwide have exhibited some sort of recent changes, mainly increasing. Haigh et al. (2010) found that MSL rise rates of $+0.8-2.3 \mathrm{mmyr}^{-1}$ in the English Channel were accompanied by smaller increases in high water elevation of $+0.1-0.3$ mmyr $^{-1}$ (relative to MSL). A numerical model from Pickering et al. (2012) of the northwest European continental shelf found that a $2 \mathrm{~m}$ increase in MSL increased the spring tidal range $\left(\mathrm{M}_{2}+\mathrm{S}_{2}\right)$ from $-0.49 \mathrm{~m}$ to $+0.35 \mathrm{~m}$, depending on location, that changes in shallow water overtides were larger than expected, and that amphidromic migration was observed. Hunter (2010) examines extreme water levels in the context of increased flooding events under different sea level rise scenarios at Australian gauges, and finds such events to be more likely with higher sea levels as the lone causative factor. Hence, changing tidal processes can either mitigate or exacerbate changes to extreme water levels caused by MSL rise (Horsburgh and Wilson, 2007). It is also apparent that regional trends in total water levels will be of more consequence for future population centers than global calculations, especially in the Asian Pacific. 


\subsubsection{Internal tides}

Internal tides are a likely mechanism connecting MSL change and tidal evolution, at least between the critical latitudes for the major tidal species. Internal, or baroclinic, tides arise within the water column when the gravitational surface tide, or the barotropic tide, moves stratified water up and down sloping bathymetry. Critical latitudes indicate where local inertial frequencies equal the forcing frequencies; for $\mathrm{K}_{1}$, this is near $\pm 30.1^{\circ}$ latitude; for $M_{2}$, it is near $\pm 75^{\circ}$. Internal tide dynamics have been studied in detail near Hawaii (Ray and Mitchum, 1996; 1997; Chiswell, 1994; and Dushaw, et al 1995) and may provide insight into the temporal variability of tidal constituents as MSL changes elsewhere in the ocean. Ray and Mitchum (1997) report that time-series of the monthly variations of $\mathrm{M}_{2}$ and $\mathrm{MSL}$ were coherent at annual, inter-annual and intra-annual bands, and Mitchum and Chiswell (2000) note that higher amplitudes of $\mathrm{M}_{2}$ are associated with times of a deeper thermocline. Colosi and Munk (2006) examined the correlation between MSL and $M_{2}$ amplitude variations in the long tidal records for Honolulu (since 1905) and Hilo (since 1927). They concluded that the observed increase in the total $\mathrm{M}_{2}$ amplitude from $161 \mathrm{~mm}$ to $169 \mathrm{~mm}$ over the past century has occurred because the internal $\mathrm{M}_{2}$ wave has moved more closely into phase with the surface tide. This conclusion is dependent on the assumption that rising sea level is a proxy for a deeper thermocline, which, for a two-layer model of the ocean, can change the phase and/or the amplitudes of the internal tide. 


\subsubsection{Amphidromic movement}

The shifting of the amphidromic points, e.g., as seen around Britain and Ireland (Pugh, 2004), is likely to be associated with changes in regional tidal properties, but it is a symptom, not a cause. Amphidromes are basin-scale cells of rotation of the ocean, related to the rotation of the Earth. An amphidromic "point" (for any tidal constituent) is a location in an ocean basin where the vertical tide vanishes. All major tidal constituents have multiple amphidromic points in the Pacific Ocean. Amphidromic "anti-nodes" are, conversely, areas where tidal amplitudes are (locally) largest. Given stationary astronomical forcing, these amphidromic patterns are controlled by ocean basin shape and topography, winds, and stratification. Under rapidly rising and warming sea level scenarios, amphidromes would be expected to shift as MSL rises and as stratification strength increases. Amphidromes may shift central position, amplify, and/or rotate. Determining amphidromic movement from data is not straightforward, but some attempts based on the observations will be made within this work.

\subsubsection{Climatic variability}

\subsubsection{The El Niño/Southern Oscillation (ENSO)}

The El Niño/Southern Oscillation (ENSO) is a strong contributing factor to sea surface anomalies in the Pacific (Kohl et al. 2007; Lombard et al. 2009; Timmermann et

al. 2010). Local, short-term MSL anomalies associated with ENSO are often much larger than long-term trends in MSL rates (Merrifield et al., 2009). The 1982-1983 and the 
1997-1998 El Niño events gave rise to widespread MSL fluctuations, with some coastal localities showing yearly averaged MSL rises or falls of $200 \mathrm{~mm}$ or more (Nerem et al, 1999; White et al, 2001). ENSO related sea level variability is difficult to remove entirely from MSL time series, due to its quasi-periodic behavior, and large geographical extent that the signal affects. Hamlington, et al. (2011) present a detailed study on the capture and removal of the ENSO signal and of modulated annual variability from global sea level records for 1950 through 2009, using cyclostationary empirical orthogonal function techniques, based on the methods of Church et al. (2004). Part II of this work examines the ENSO-related variability in tides and MSL in the Western Pacific, and finds the mechanisms to be partly due to frictional interactions, and partly due to resonant triad interactions.

\subsubsection{The monsoon}

The monsoon is a seasonally-reversing pattern of wind and sea-breeze variability, with corresponding changes in precipitation (Wyrtki, 1961). The strength and timing of the monsoon cycle varies by region of the world, but monsoon effects are due to the same general mechanism, that of different cooling and heating rates between land and sea regions, due to the large heat capacity of water. The yearly monsoon cycle is thought of as having a "wet" (summer) phase, a "dry" (winter) phase, and two transition or "slack" periods. The strong and seasonally reversing winds also affect local oceanic water levels and currents, which may also modify water column mixing and 
stratification. Additionally, precipitation across a region can modify ocean water temperatures and salinity, which affects stratification and local water level. Monsoons are usually thought of as a regional phenomenon (Wang and Fan, 1999), however, some work has shown the importance of understanding the monsoons as a global pattern of variability (Trenberth et al., 2000; Webster and Yang, 1992). The relationship of the monsoons to the seasonal variability in tides is examined in detail in Part III, along with the use of a barotropic model to explain the observed variability.

\subsection{Methods}

\subsubsection{Data inventory}

This study examines 153 tide gauges in the Pacific Ocean and the far eastern Indian Ocean. The majority of the hourly tide gauge records used come from the University of Hawaii's Sea level Center (UHSLC). Beyond the UHSLC records, there are also some data from the following agencies: The Japanese Oceanographic Data Center (JODC); Canada's Fisheries and Ocean office (FOC); and Australia's National Tidal Center (AuNTC).

The factors that guided the quality control of station selection in this work were:

1) Location: All stations used are within the Pacific Ocean or far Eastern Indian Ocean. 
2) Temporal coverage: All stations used have a record length greater than one nodal cycle (18.61 years); LOR ranges from 19 to 115 yrs.

3) Completeness: All stations contain more than $80 \%$ complete data over the record.

All Pacific gauges that meet these criteria are listed in Table 2. Locations are shown in Figures 7a (Western Pacific) and 7b (Eastern Pacific). This inventory will be used to make a catalog of long-term trends (LTTs) in MSL rates, trends in tidal amplitudes and phases, and tidal anomaly trends (TATs). Relationships between detrended MSL variability and tidal property variability will be examined, based on yearly averaging and analyses. The source agency for data is also listed in Table 2 . The boxed areas in Figure 7a and 7b indicate the sub-domains in which results will be reported, as four "quadrants" of the Pacific. The northeast quadrant includes the US coast, Canada, Alaska, and Hawaii, with a total of 40 stations. The Southeast Pacific includes the coast of South America and South Pacific islands such as Tahiti and Easter Island, with a total of 20 stations. The data coverage is the sparsest in this region, both spatially and temporally. The Northwest Pacific contains 40 gauges in Japan, Taiwan, and Hong Kong. Japan provides many tide gauges, many of them 50 years or longer in record length, and geographical data coverage is particularly spatially dense here. Finally, the southwest quadrant includes Australia, New Zealand, the Philippines, Malaysia, and many island gauges, for a total of 53 gauges. There are some obvious 
geographical gaps in data coverage. There is little to no freely available modern tide gauge data in China, Russia, or Indonesia that are useful, and there are very few observations in the Southern Ocean, as there is very little land in the Southern Ocean.

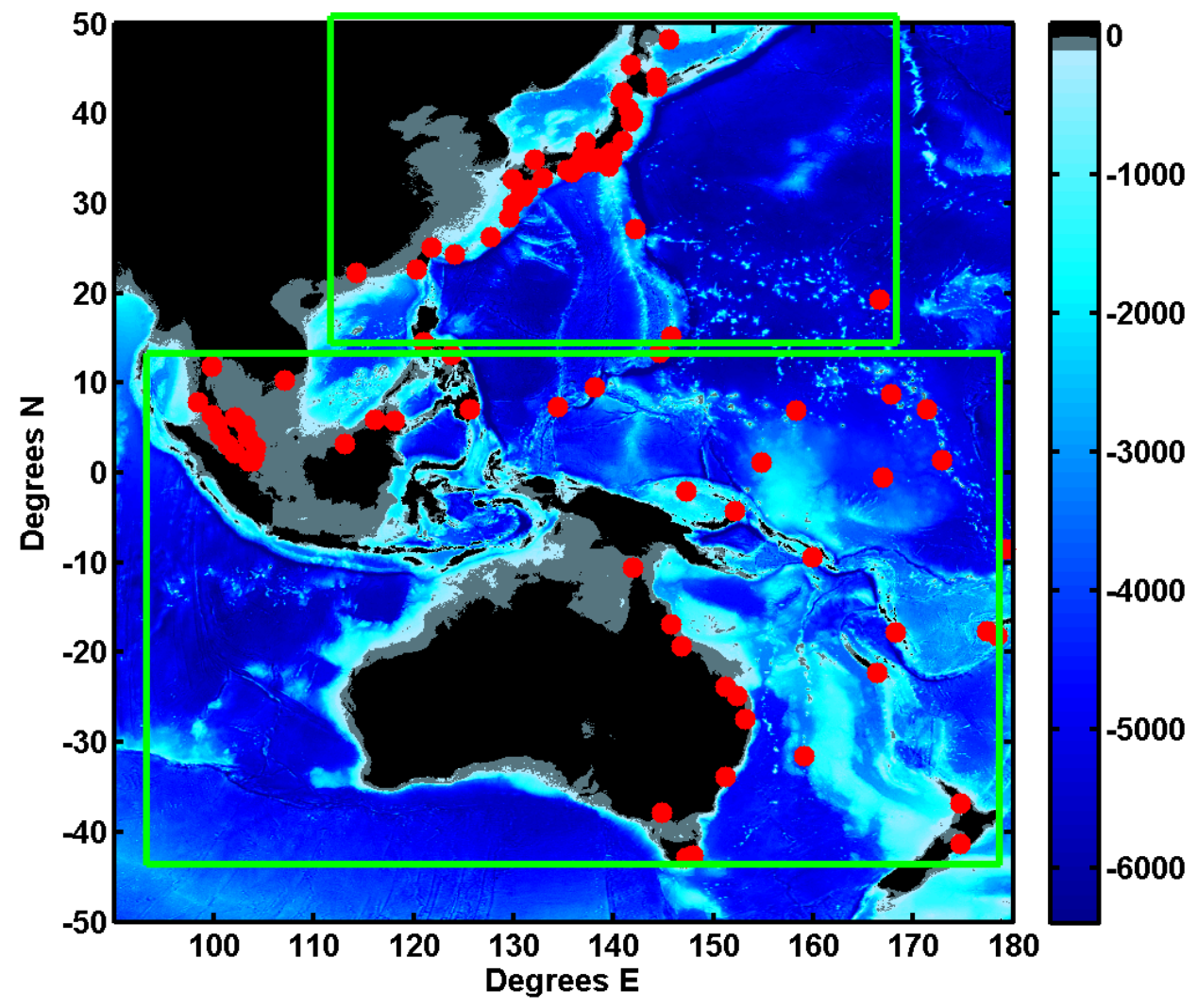

Figure 7a Gauge locations in the Western Pacific, exact locations are in Table 2. Green boxes indicate approximate domains considered in subsequent analyses. 


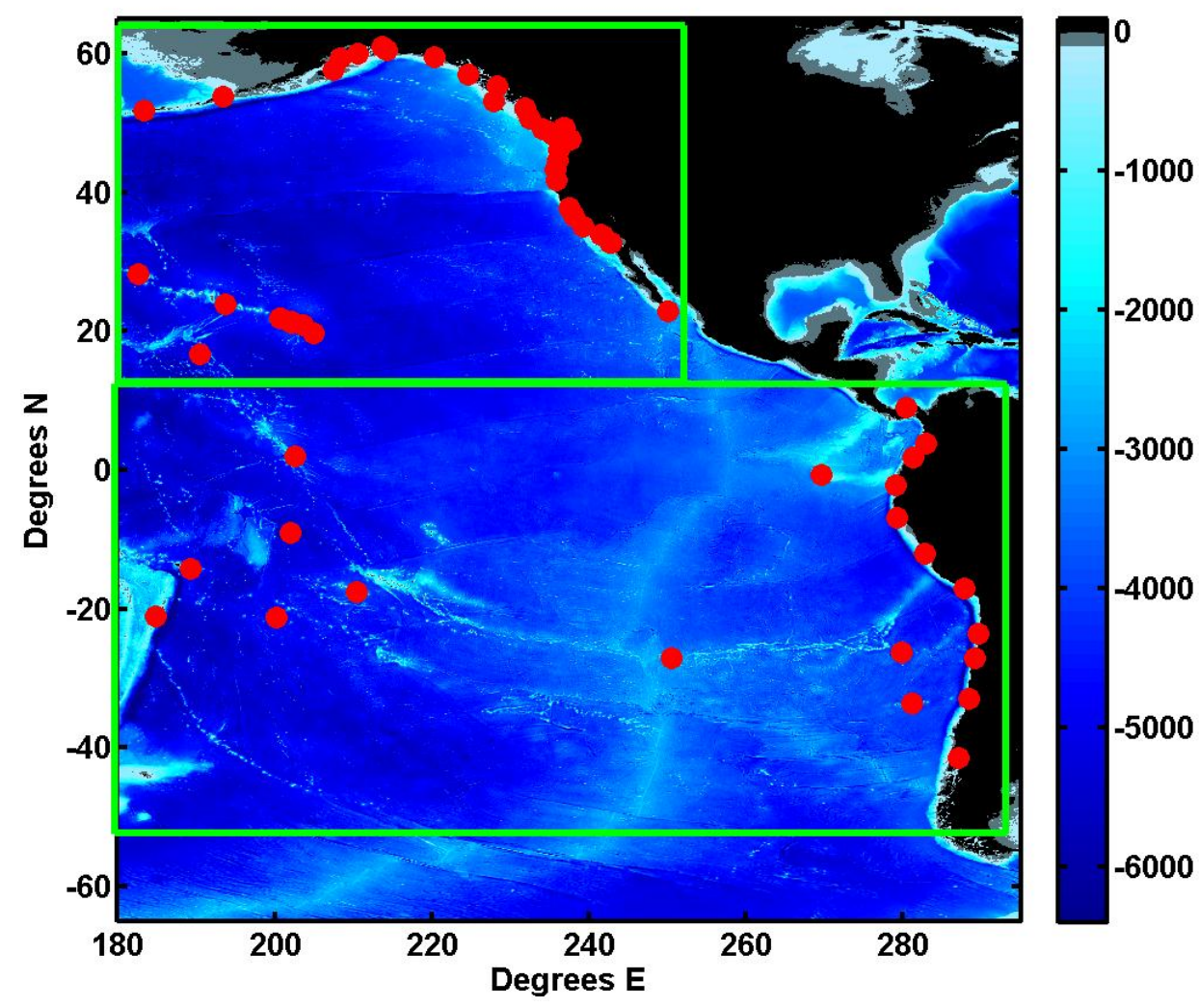

Figure 7b Gauge locations in the Eastern Pacific, exact locations are in Table 2. Green boxes indicate approximate domains considered in subsequent analyses. 


\subsubsection{Tidal admittance calculations}

Investigations of tidal trends are carried out through the use of a tidal

admittance. An admittance is the unitless ratio of an observed tidal constituent to its corresponding astronomical tide generating force (ATGF) expressed as a tidal potential, $\mathrm{V} / \mathrm{g}$. Because nodal and other low-frequency astronomical variability is present with similar strength in both the observed tidal record and in $\mathrm{V} / \mathrm{g}$, it is largely absent in admittance time series. The variations that remain are some combination of noise and non-astronomical signals, which allows useful examination of longer term climate trends.

Harmonic analysis techniques (HA) rely upon having a long enough record to be able to accurately separate relevant frequencies of interest. An inherent trade-off exists between obtaining multiple estimates (good for assessing variability) and accuracy. For analyses of record lengths much longer than the frequency of interest, the harmonic constants are well-determined and highly accurate, but the number of determinations is low. In analyses of shorter record length, frequencies can be "contaminated" by the "satellites" (constituents that have nearly the same frequency), but can yield more determinations and data points.

For all relevant stations in the Pacific, overlapping yearly tidal harmonic analyses (at monthly time steps), and monthly harmonic analyses (at weekly time steps) were carried out on hourly observed tidal records and the corresponding hourly ATGF 
generated at the same location, using the R_T_Tide tidal harmonic analysis package in MATLAB (Pawlowicz,2002; Leffler and Jay 2009). $\quad$ is determined based on the methods of Cartwright and Tayler (1971), and Cartwright and Edden (1973) using software obtained from Dr. Richard Ray of NASA (personal communication with David Jay, 2007). The result from a single harmonic analysis determines an amplitude, $A$, and phase, $\vartheta$, at the central time of the analysis window for each tidal constituent, with error estimates. Use of a moving analysis window produces time-series of amplitude and phase for both annual and monthly analyses. An example is shown for the amplitude of the $K_{1}$ constituent at San Francisco in Figure 8a, shown for both the gravitational potential (top), and the observed data (bottom). 

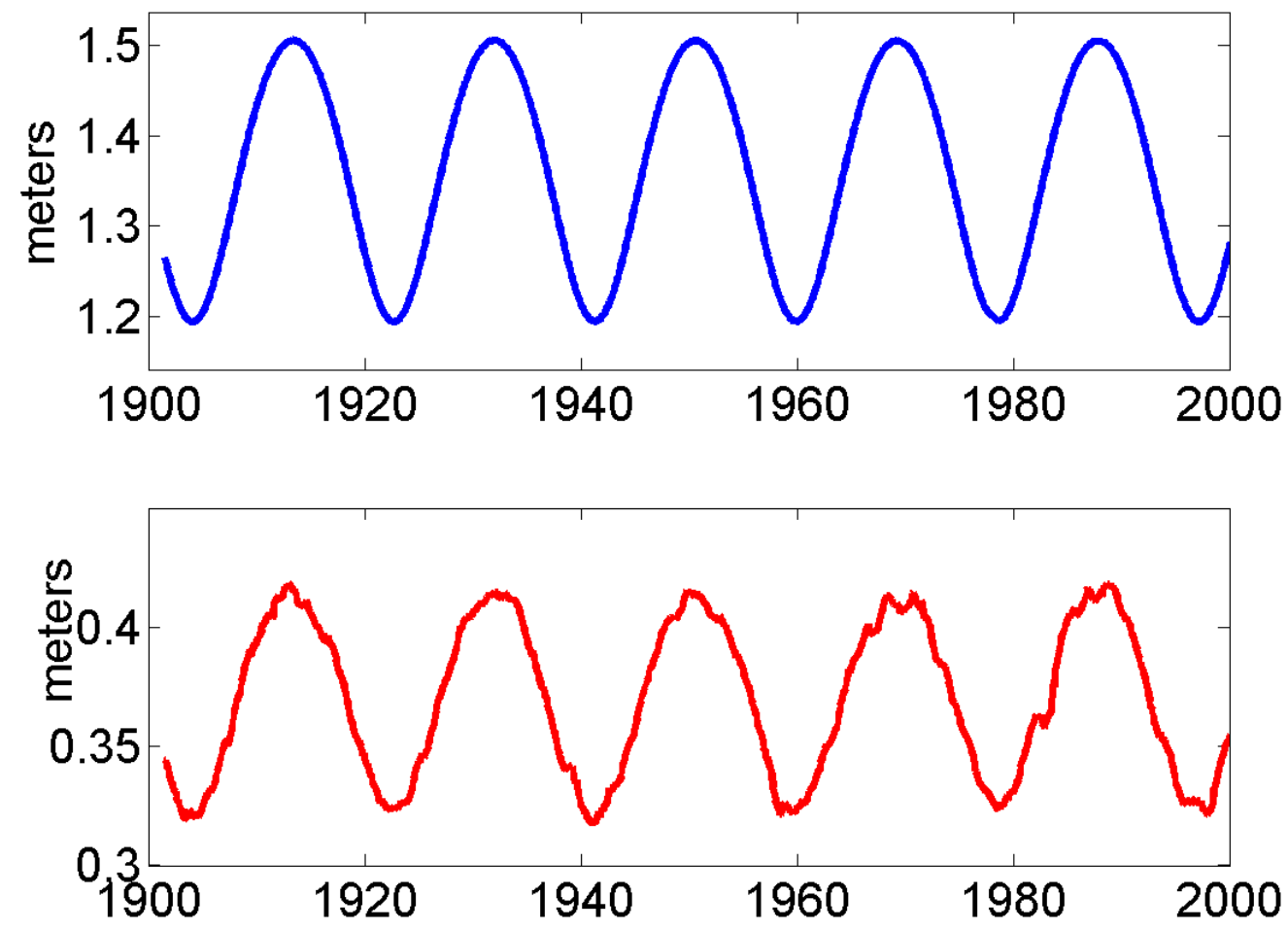

Figure 8a Amplitude of the $\mathrm{K}_{1}$ constituent at San Francisco, CA generated from tidal harmonic analysis, for the gravitational potential (top), and observed hourly tidal data (bottom). 
From amplitude $A(t)$ and phase $\vartheta(t)$ time series, one can construct complex amplitudes $Z(t)$ through:

$$
\mathbf{Z}(t)=A(t) e^{i \theta(t)}
$$

Time-series of tidal admittance ratio (AR) and phase difference (PD) for a constituent are then formed using Eqs. (8) and (9):

$$
\begin{aligned}
& \mathbf{A R}(t)=a b s\left|\frac{Z_{o b s}(t)}{Z_{p o t}(t)}\right|, \\
& \mathbf{P D}(t)=\theta_{o b s}(t)-\theta_{p o t}(t),
\end{aligned}
$$

where the subscript 'obs' or 'pot' denotes the corresponding quantity for either the observed data or the gravitational potential, respectively. Both the admittance ratio in Eq. (8) and the phase difference in Eq. (9) largely remove the nodal-cycle variability in yearly analyses, and the yearly variability in monthly analyses, allowing easier examination of the non-astronomic signals. The mean value of the tidal potential at each location is used as a scale factor to convert the AR into a "true" amplitude. The $\mathrm{K}_{1}$ AR at San Francisco generated from the potential and observed data shown in Figure 8a is presented in Figure $8 \mathrm{~b}$, with a linear trend of $+0.033 \mathrm{mmyr}^{-1}$ overlain in green. 


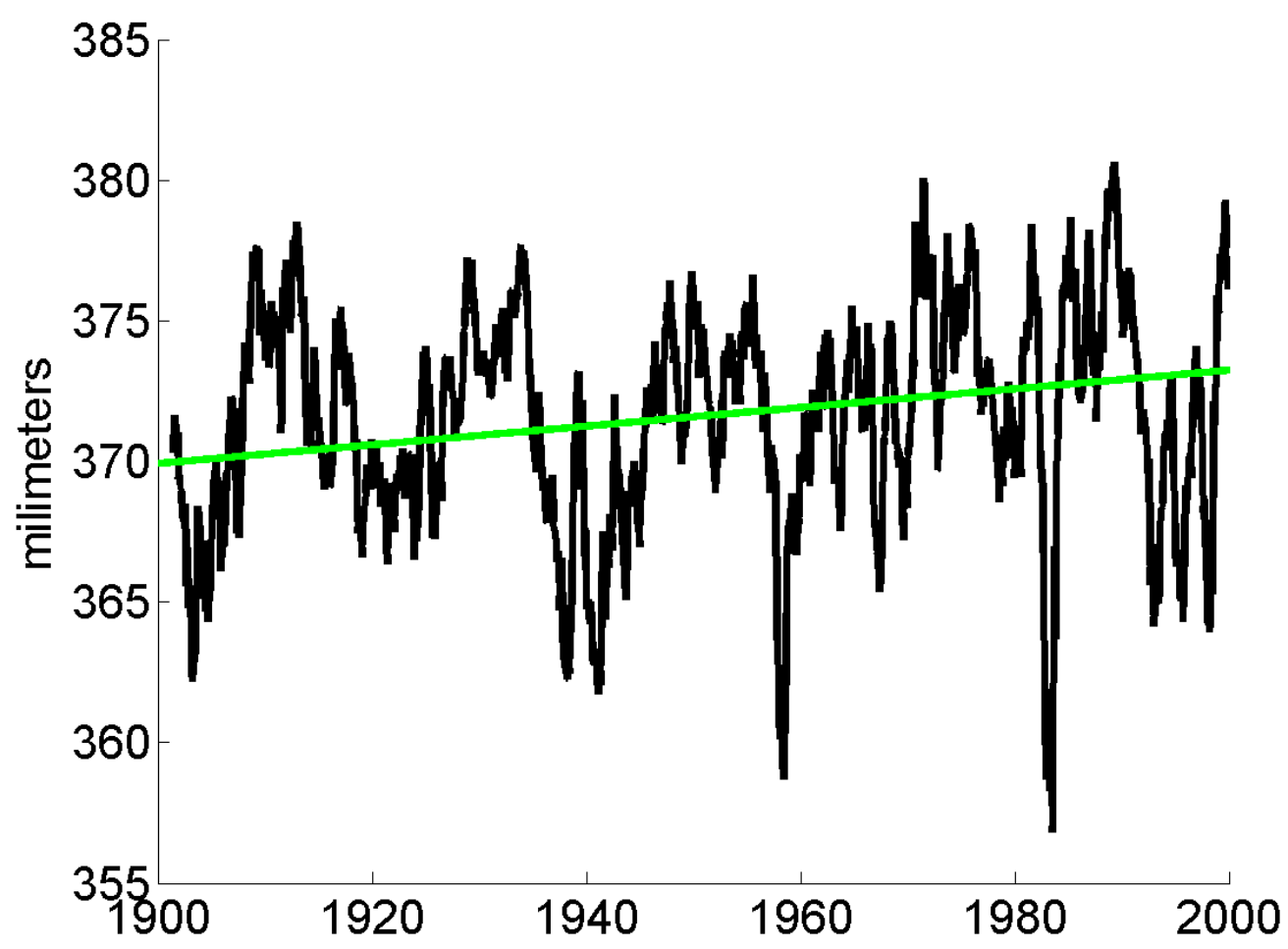

Figure $8 \mathbf{b}$ Admittance amplitude ratio (AR) of the $K_{1}$ constituent at San Francisco, CA, calculated from Eq. (8), and the potential and observed data shown in Figure 8b, with a linear trend of $+0.033 \mathrm{mmyr}^{-1}$ overlain in green.

Once the ARs and PDs are generated, MSL time-series are also generated, through either yearly or monthly averaging of hourly water level records, shown for San Francisco in Figure $8 \mathrm{c}$, with a linear trend of $+1.8 \mathrm{mmyr}^{-1}$ overlain in red. For each dataset, a mean and a long-term trend are estimated over the full length of the tide record, which is between 19 and 115 years, depending on location. The mean and trend are then removed from the time series, to allow direct comparison of their variability. The magnitude of the long-term trends is typically much less than the magnitude of the 
short-term variability, the latter of which will now be more apparent in the data. The removal of trends also removes the effects of land motion that may contaminate MSL records. Detrended quantities for our example at San Francisco are shown in Figure 8d $\left(\mathrm{K}_{1} \mathrm{AR}\right)$, and Figure 8e (MSL).

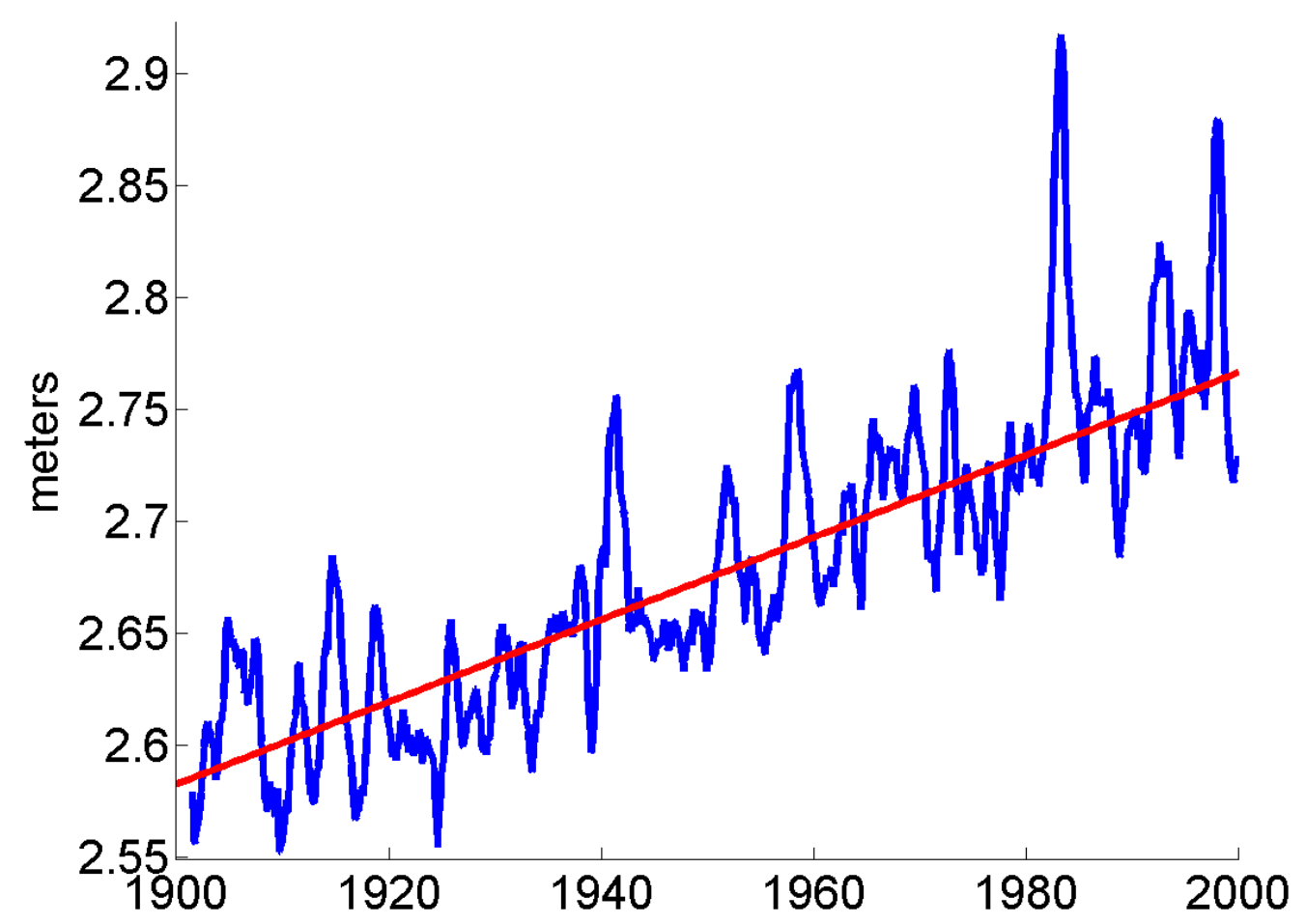

Figure 8c Mean sea level (MSL) at San Francisco, CA, yearly averaged, with a linear trend of +1.8 mmyr $^{-1}$ overlain in red. 


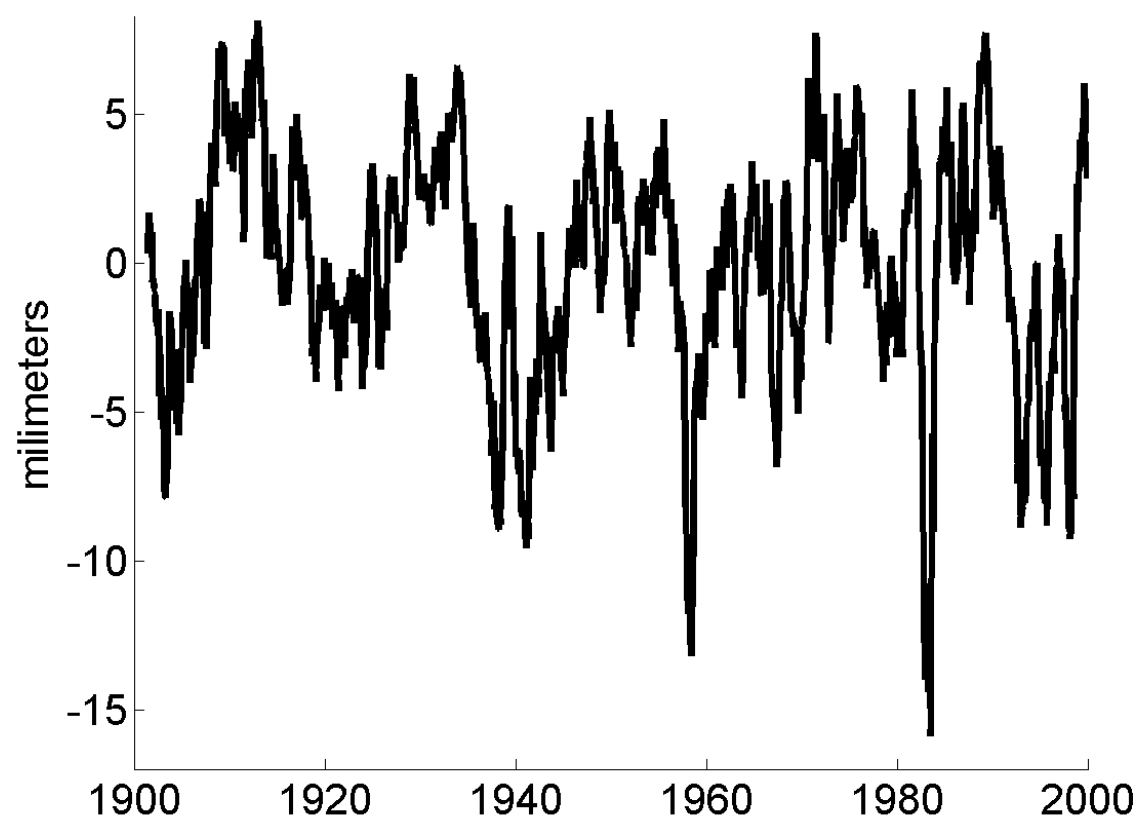

Figure $\mathbf{8 d}$ Detrended admittance amplitude ratio $(\mathbf{A R})$ of the $K_{1}$ constituent at San Francisco, CA.

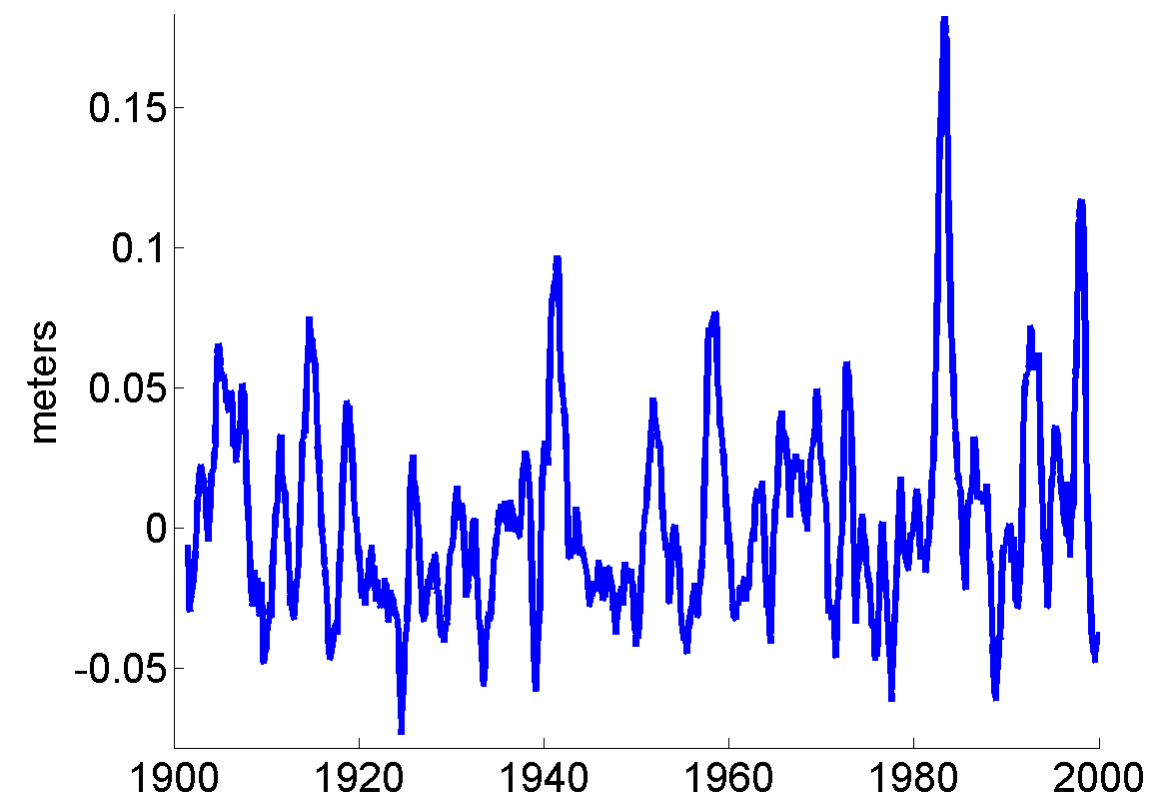

Figure 8e Detrended mean sea level (MSL) at San Francisco, CA. 


\subsubsection{Annual scale correlation of tidal variations and MSL}

The primary interest in Part I is the interannual variations and not the long-term trends. The detrended time-series of residual variations in AR and PD, and residual variations in MSL, can now be examined for coherence with one another (and with other ancillary time-series), using scatter plots, cross-correlations, and regression statistics generated from trend determination. Figure $8 \mathrm{f}$ shows the detrended $\mathrm{K}_{1} \mathbf{A R}$, and the detrended MSL at San Francisco plotted on the same axis, with the MSL anomalies in units of $\mathrm{cm}$, and the tidal amplitude anomalies in units of $\mathrm{mm}$. Figure $8 \mathrm{~g}$ shows a scatterplot between both detrended quantities at San Francisco (AR; mm vs. MSL; $\mathrm{m}$ ). I define a tidal anomaly trend (TAT) as the slope between detrended tidal properties and detrended MSL, for tidal amplitudes, these are known as amplitude tidal anomaly trends (A-TAT), expressed as the millimeter change in tidal amplitude per meter of sea level rise $\left(\mathrm{mmm}^{-1}\right)$. The same approach is used with the phase difference time-series to provide phase anomaly trends (P-TAT), with the trends expressed as degree change in tidal phase per meter of sea level rise $\left(\operatorname{degm}^{-1}\right)$. The errors of the TAT determinations are defined as the $95 \%$ confidence interval $(\mathrm{Cl})$ of the linear trend determination. Trends are deemed significant if the signal-to-noise ratio (SNR) of the linear trend to the associated error is greater than 2.0. 


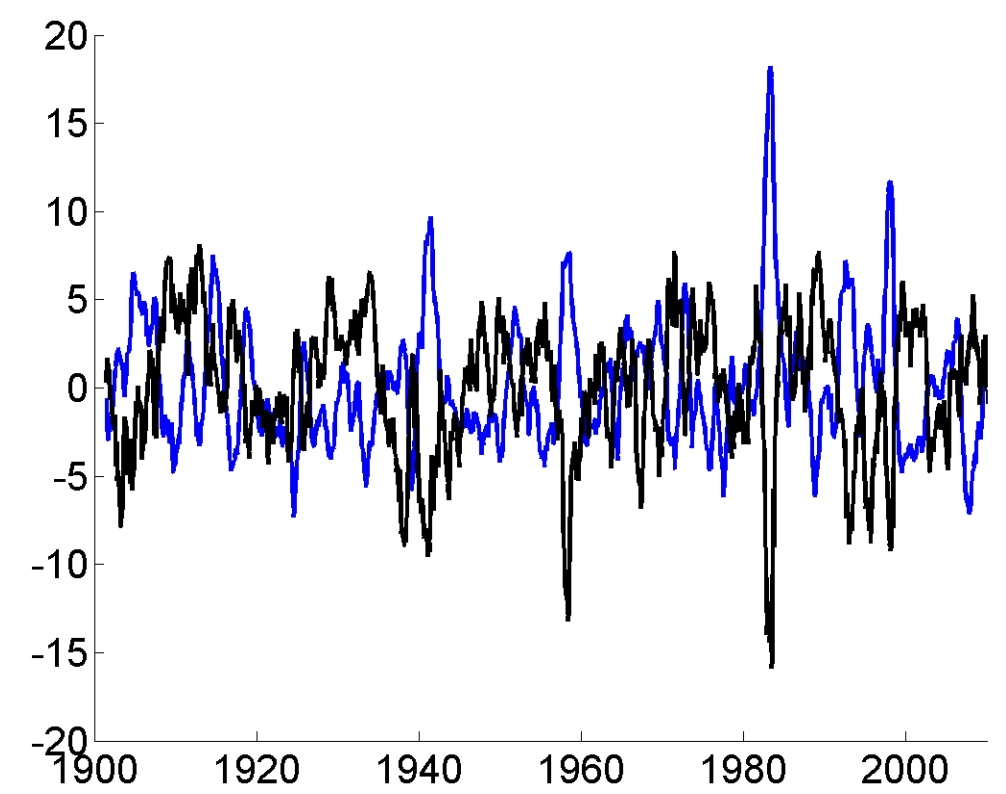

Figure $8 \mathrm{f}$ Detrended MSL (blue, units of $\mathrm{cm}$ ) plotted with detrended $\mathrm{K}_{1} \mathbf{A R}$ (black, units of $\mathrm{mm}$ ) at San Francisco, CA.

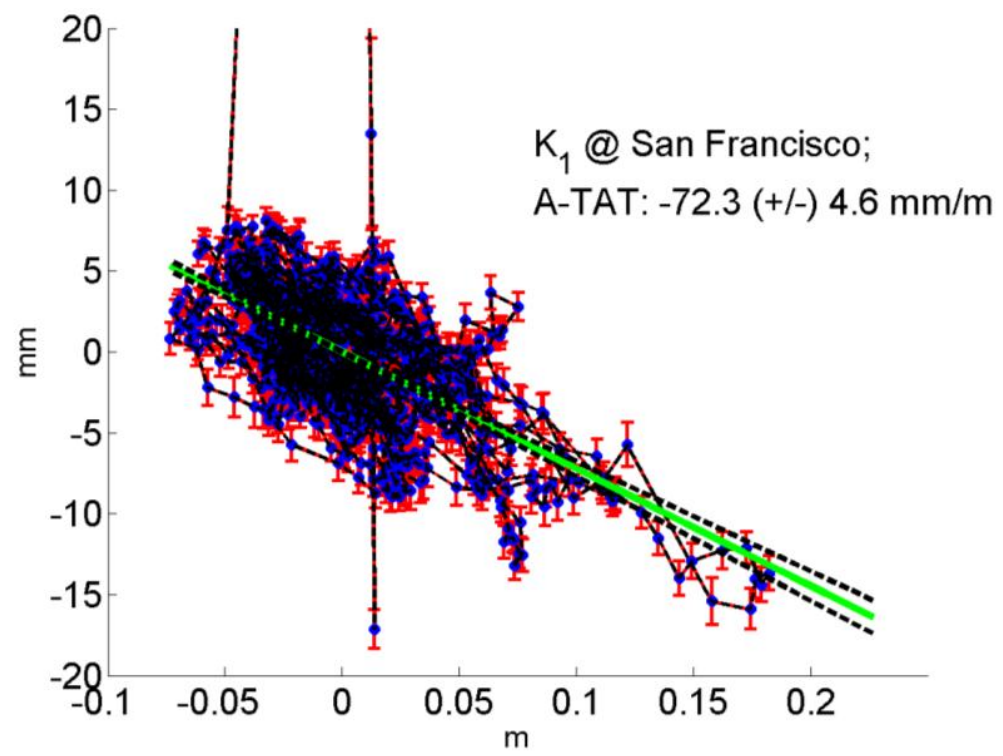

Figure 8g Example A-TAT of detrended MSL (meters) scattered against detrended $\mathrm{K}_{1} \mathbf{A R}$ (millimeters) at San Francisco, CA, with a value of $-72.3 \pm 4.6 \mathrm{mmm}^{-1}$. 
For our example of the $\mathrm{K}_{1}$ AR vs. MSL at San Francisco, it is clearly seen that the trend is negative, i.e., times of positive MSL anomaly correspond to occurrences of negative $\mathrm{K}_{1}$ AR anomaly. The A-TAT, determined from the slope, is: $-72.3 \pm 4.6 \mathrm{mmm}^{-1}$.

Next, the amplitude and phase TATs for the four major constituents are analyzed at Honiara, located on the island of Guadalcanal within the Solomon Islands (9.4167 S, 159.950 E). In Figure 8h, the A-TATs (top row) and P-TATs (bottom row) are plotted for the major diurnal $\left(\mathrm{K}_{1}\right.$ and $\left.\mathrm{O}_{1}\right)$ and semidiurnal $\left(\mathrm{M}_{2}\right.$ and $\left.\mathrm{S}_{2}\right)$ tide components vs MSL. Units for A-TATs are in millimeters of tidal amplitude change per meter of sea level rise $\left(\mathrm{mmm}^{-1}\right)$, and units of P-TATs are in degrees of tidal phase change per meter sea level rise $\left(\right.$ degm $\left.^{-1}\right)$. The $M_{2}$ results at Honiara exhibit some of the most coherent trends in the data inventory, with $r^{2}>0.89$. While the $M_{2}$ tide amplitude is relatively small at this location ( $50 \mathrm{~mm})$, the anomaly trend is large, $+65.6 \pm 3.3 \mathrm{~mm} \mathrm{~m}^{-1}\left(132 \%\right.$ of the local $\mathrm{M}_{2}$ amplitude). 

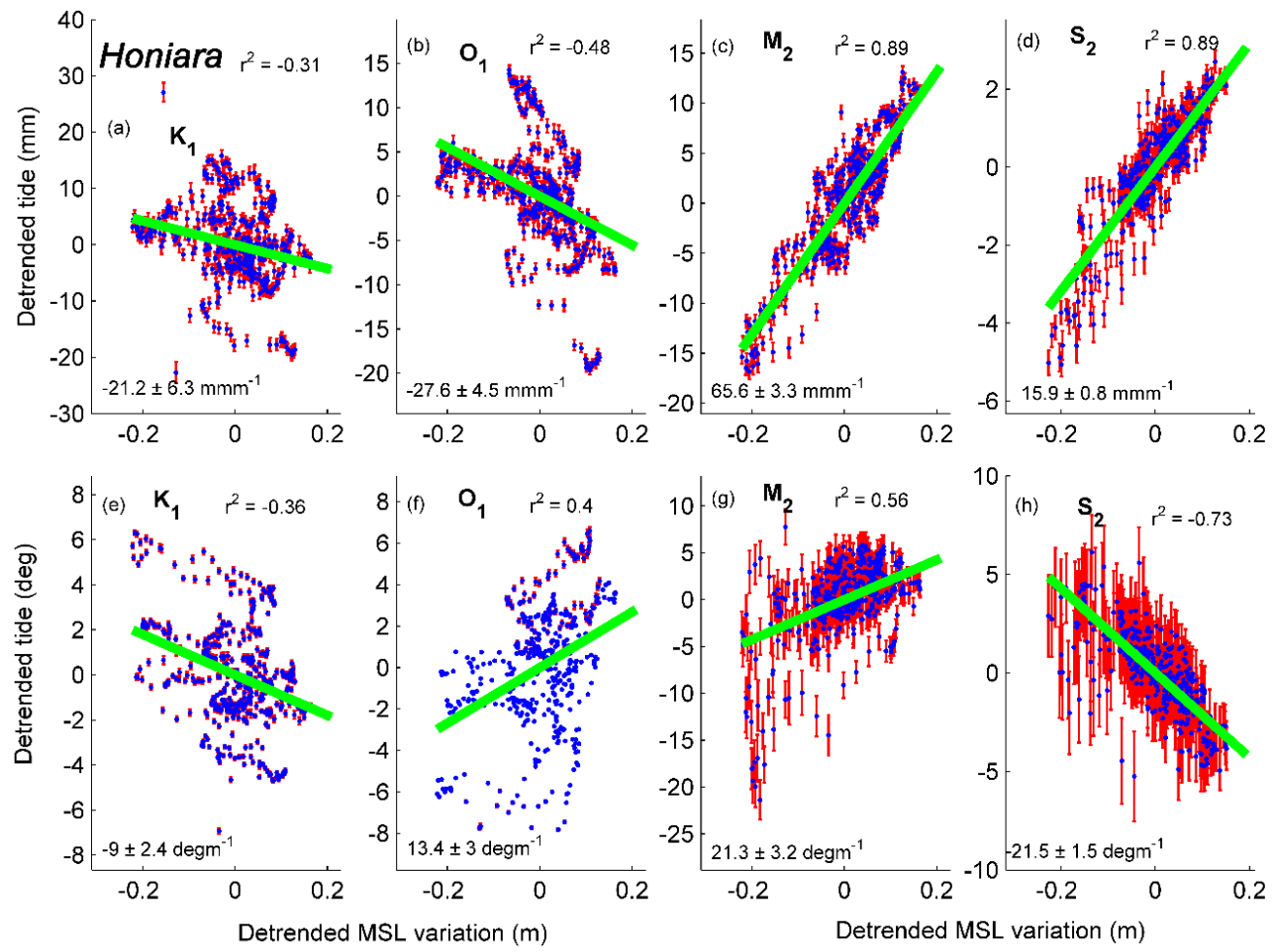

Figure 8h Amplitude anomaly trends (A-TATs) for Honiara in the Solomon Islands: (a) $\mathrm{K}_{1}$; (b) $\mathrm{O}_{1}$; (c) $\mathrm{M}$; (d) $\mathrm{S}_{2}$; and phase anomaly trend (P-TATs) for (e) $\mathrm{K}_{1}$; (f) $\mathrm{O}_{1}$; (g) $\mathrm{M}_{2}$; and (h) $\mathrm{S}_{2}$. The red bars show $95 \%$ confidence limits on each annual estimate. The green line is the robust linear regression trend, in $\mathrm{mmm}^{-1}$ or degm ${ }^{-1}$, as shown as text, with $95 \%$ confidence limits on the anomaly trend. Significance is indicated by correlation $\left(r^{2}\right)$ values within each subplot. 


\subsubsection{Monthly scale correlation of tidal variations and MSL}

Yearly analyses are only able to isolate oceanic variability at interannual or longer time scales, but the ocean varies on a shorter time scales which may be obscured by annual analyses. Here, I modify the approach detailed in Section 3.2.3 and compare monthly (rather than yearly) averages of MSL with tidal properties obtained from a 32 day harmonic analysis. As before, an admittance is constructed to eliminate the effect of satellite constituents (e.g., the effect of $\mathrm{P}_{1}$ on $\mathrm{K}_{1}$ ). Thus, the analyses performed on yearly data are expanded to yield A-TATs and P-TATs based on monthly data. After taking the admittance, variations present in the tidal property time series will be due to factors not involving astronomy, such as climatic variability due to temperature, density, and wind. The new quantities are denoted seasonal tidal anomaly trends, or STATs, with trends in admittance amplitude ratios denoted A-STATs, and trends in admittance phase differences as P-STATs.

To better understand the seasonal fluctuations, the analyses are sorted by calendar month. For all years of data, independent analyses are carried out for each month to yield 12 determinations of trend and error. An example is shown in Figure 9a for $\mathrm{M}_{2}$ amplitudes at Sedili, Malaysia. Each individual month is plotted separately, similar to the yearly determinations in Figure $8 \mathrm{~h}$, in which it can clearly be seen that the slope values corresponding to the monthly TATs change, even reversing sign, with some months showing insignificant trends. The variations in the trends over the course of the 
year are the STATs. The range of the STATs are defined as the difference between the maximum significant monthly TAT determination and the minimum significant monthly TAT determination. The range of the STATs is quite large at certain locations within the study domain, such as the example shown at Sedili, Malaysia where the difference between maximum and minimum values is near $400 \mathrm{mmm}^{-1}$. Figure $9 \mathrm{~b}$ shows a compact view of the variability shown in Figure 9a for Sedili, showing the yearly range of A-STATs in the top panel, and the P-STATs in the bottom panel. In this view, each data point corresponds to the regression slope, and the error bars correspond to the $95 \%$ confidence intervals $(\mathrm{Cl})$ of the monthly slope determinations. 

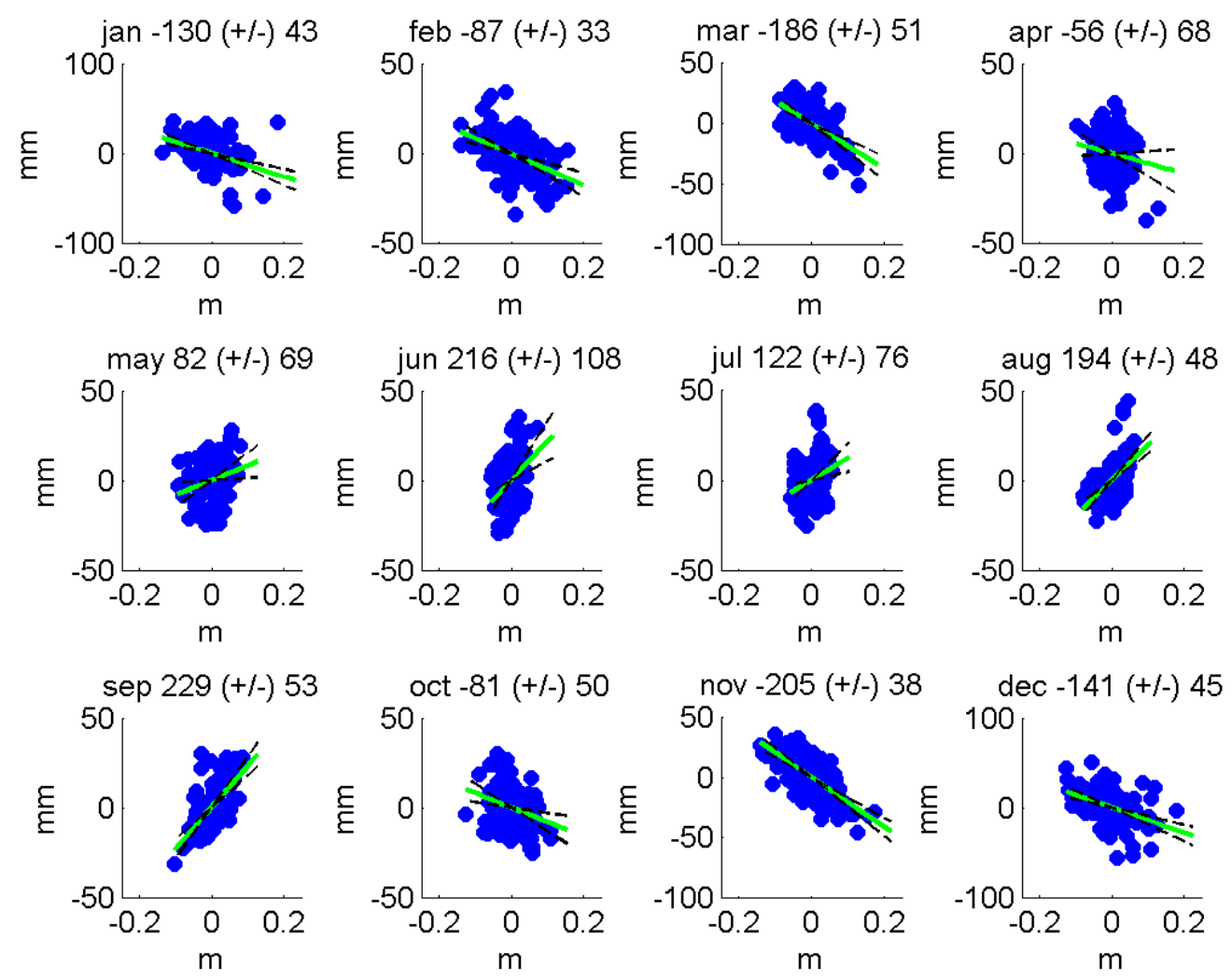

Figure 9a Monthly A-TAT determinations for the $M_{2}$ AR at Sedili, Malaysia. The anomaly of MSL is on all x-axes, in units of meters, and the anomaly of the $M_{2} A R$ is on all $y$-axes, in units of millimeters. 

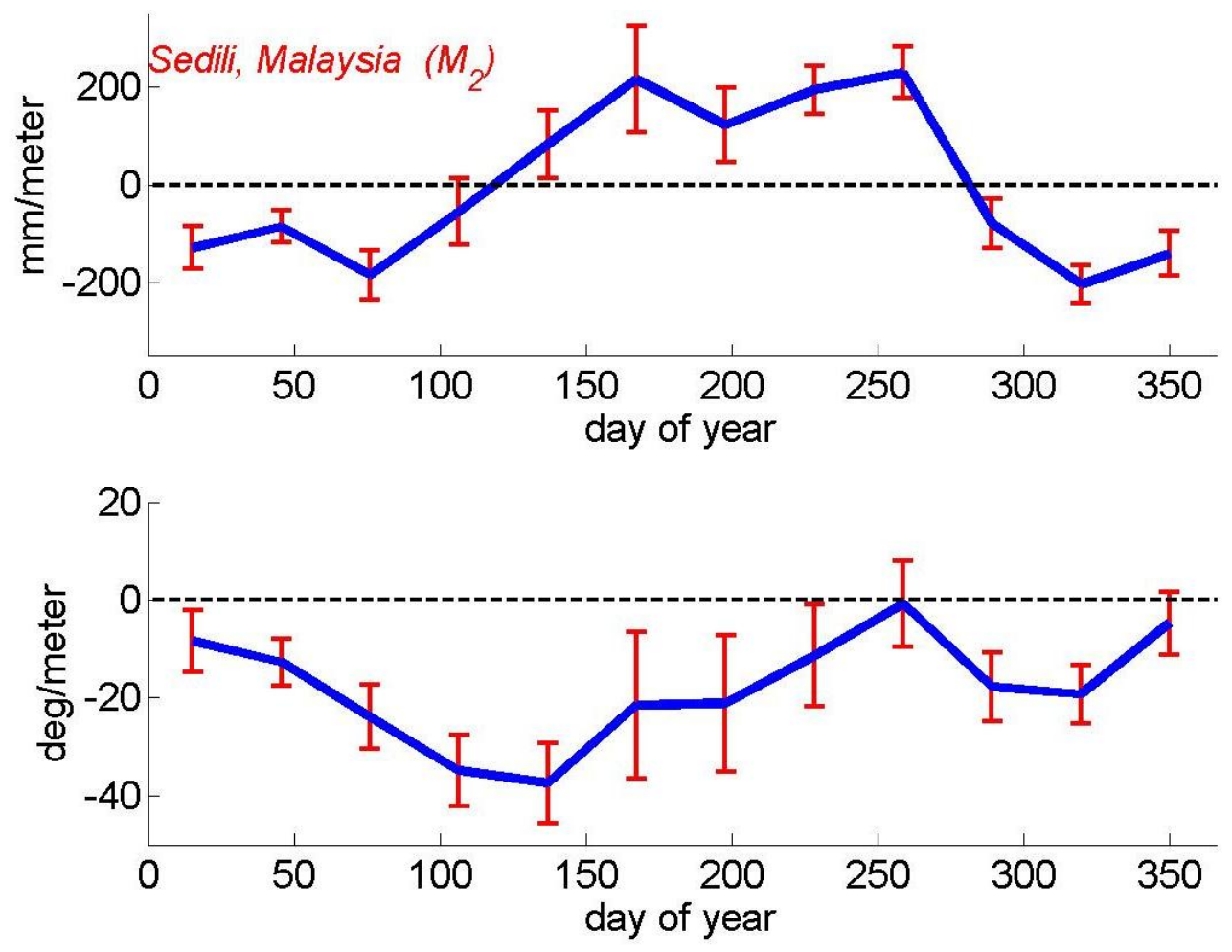

Figure 9b A-STATs and P-STATs at Sedili, Malaysia. Data points indicate slope of scatterplot, based on monthly analyses of all years of data, and error bars indicate $95 \%$ $\mathrm{Cl}$. 


\subsubsection{Error analysis}

There is an error associated with each HA determination. For the HA done on the gravitational potential, these errors are typically very small in comparison to the errors from the HA performed on the observed data. Therefore, though all errors are propagated in the calculation of the ARs and the PDs, the total error will be dominated by the errors in the observed HA determinations. Example errors bars are plotted with red in Figure 8g for San Francisco, and Figure 8h for Honiara. In general, the magnitude of the errors are larger for the phase determinations than for the amplitude determinations (see Figure 8h), and also larger for monthly analyses than for yearly analyses.

There are also errors associated with the determination of the slopes of the TATs. The slope of the detrended tidal properties in relation to the detrended MSL is calculated by robust linear fitting to all data, and the errors of this fit are determined from a $95 \%$ confidence interval $(95 \% \mathrm{Cl})$. In Figure $8 \mathrm{~g}$, the linear fit corresponds to the green lines, and the upper and lower limits of the $95 \% \mathrm{Cl}$ is shown by the black dashed lines. Finally, the significance of all TATs and STATs calculated from these methods is defined by the signal-to-noise ratio (SNR), which is the ratio of the TAT slope to the error $(95 \% \mathrm{Cl})$. If the SNR $>2.0$, then the trend determination is deemed significant. 


\subsection{Results}

\subsubsection{Yearly tidal anomaly trends (TAT) results}

The spatial distribution of anomaly trends (A-TATs and P-TATs) may help identify connections between MSL rise and tidal evolution on a basin-wide, or amphidromic scale. Figures 10-13 show the A-TATs for the $\mathrm{M}_{2}, \mathrm{~S}_{2}, \mathrm{~K}_{1}$, and $\mathrm{O}_{1}$ constituents in the Northeast Pacific, Figures 14-17 show the Southeast Pacific, Figure 18-21 show the Northwest Pacific, and Figures 22-25 show the Southwest Pacific. P-TATs plots are shown in Appendix A (Figures A1-A16), but are discussed in the text below. The magnitude of the A-TATs is shown by the color intensity of the dots according to the scale shown in the legend in all plots; positive A-TATs are in shades of red, negative ATATs are in shades of blue. For a gauge with an insignificant A-TAT ("significant" is defined as a trend having a SNR greater than 2.0), these dots are white. The approximate values of the colors are shown in the legend, and exact values and error bands are reported in Tables 3a and 3b (A-TATs, individual and combined) and 4 (PTATs). Map backgrounds show mean tidal amplitudes (in meters; green and yellow color scale) and phases (solid lines), from the TPXO7.2 tide model, (Egbert and Erofeeva, $2002,2010)$. Values in the tables are in bold text if they have an SNR of 2.0, and if the absolute magnitude is greater than $10 \mathrm{mmm}^{-1}$ for A-TATs (Table 3a), $100 \mathrm{mmm}^{-1}$ for combined A-TATs (Table $3 \mathrm{~b}$ ) and $5 \mathrm{degm}^{-1}$ for P-TATs (Table 4). 
These plots provide a measure of the expected tidal response to a $1 \mathrm{~m} \mathrm{MSL} \mathrm{rise,}$ but the range of MSL variability is typically less than $0.25 \mathrm{~m}$, so this metric assumes a linear extrapolation of these correlations. The plots also give an indication of the spatial coherence of tidal evolution. For a gauge influenced by only one amphidrome for a given constituent, a positive (negative) A-TAT and a zero P-TAT indicates that the amphidrome is moving away (towards) the gauge. Gauges that show significant P-TATs may suggest a rotational component to the movement of the amphidrome. Coherent changes in tides (as represented by A-TATs and P-TATs) on an amphidromic scale suggest amphidromic movement or rotation. If statistically significant TATs do not suggest consistent amphidromic change, then local or regional process are likely more important. Results for all constituents will be reported in the same quadrant order as shown in the tables: northeast, southeast, northwest, and then southwest.

\subsubsection{Northeast Pacific TATs results}

\subsection{Semidiurnal TATs, NE}

There is a single $M_{2}$ amphidrome that influences the Northwest quadrant, extending from Hawaii to Western North America (Figure 10). $\mathrm{M}_{2}$ A-TATs are mainly positive in the Gulf of Alaska (with the exception of Seldovia, AK, which has a strong negative A-TAT), around Victoria Island, and in southern California. San Francisco, CA has a strong negative A-TAT, as does Astoria, OR at the mouth of the Columbia River. There are also very large positive A-TATS in Hawaii at most gauges, with moderate 
negative A-TATs at Kahului and French Frigate Shoals. $M_{2}$ phase trends (P-TATs) are almost all positive with moderate magnitudes (Figure A1). S 2 -TATs are shown in Figure 11 , which also has a large amphidrome, closer to the California coast than the $\mathrm{M}_{2}$ amphidrome, and a secondary amphidrome near the Hawaiian Ridge. In the Gulf of Alaska and along the northeast US coast, trends are mostly mild and negative, though the negative A-TAT at Queen Charlotte is strong. In the open ocean, Johnston Atoll has a large negative A-TAT. There are mild positive A-TATs at San Francisco and La Jolla, CA, and also at Point Atkinson on the landward side of Victoria Island near the mouth of the Frasier River. For $\mathrm{S}_{2}$ P-TATs (Figure A2), a mainly positive response is seen in the Gulf of Alaska and at southern California stations, with insignificant changes for the majority of the US coast. Trends in Hawaii are mild and mixed positive and negative. 


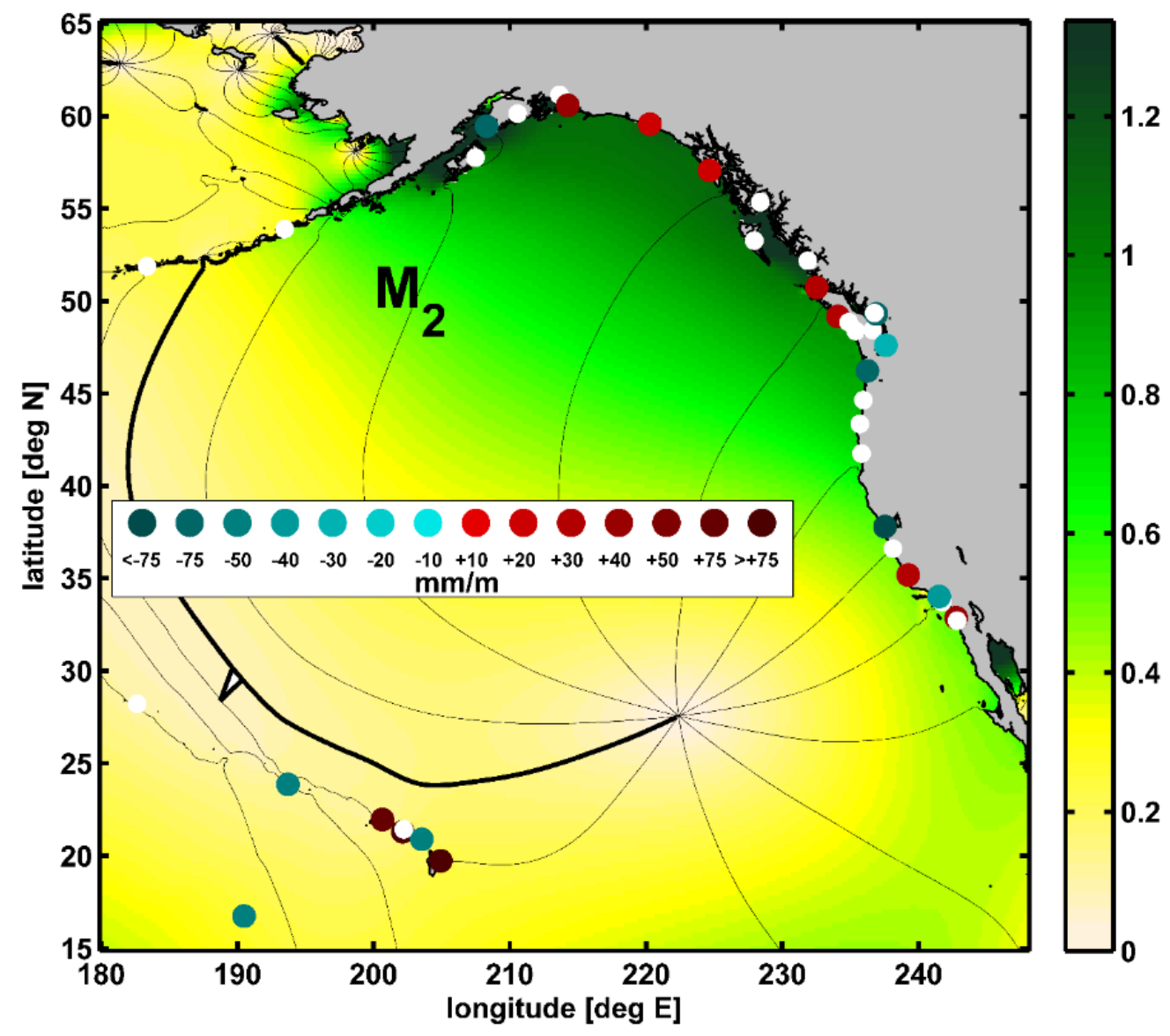

Figure $10 \mathrm{M}_{2}$ A-TAT map in Northeast Pacific, showing changes in amplitude (per m MSL rise). Map backgrounds show mean tidal amplitudes (meters) over the entire time record (color scale) and phases (solid lines), from the ocean tidal model of TPXO7.2, (Egbert and Erofeeva, 2002, 2010). Red and blue colored markers show positive and negative A-TATs, respectively. The magnitudes are indicated by color intensity, as shown by legend, in units of $\mathrm{mm}$ of tidal change per meter of sea level rise $\left(\mathrm{mmm}^{-1}\right)$. To avoid potentially spurious results due to large percentage changes in small constituents, A-TATs are only plotted if the ratio of the $95 \%$ confidence limit of the trends has an SNR $>2$. Statistically insignificant values are indicated by white circles. 


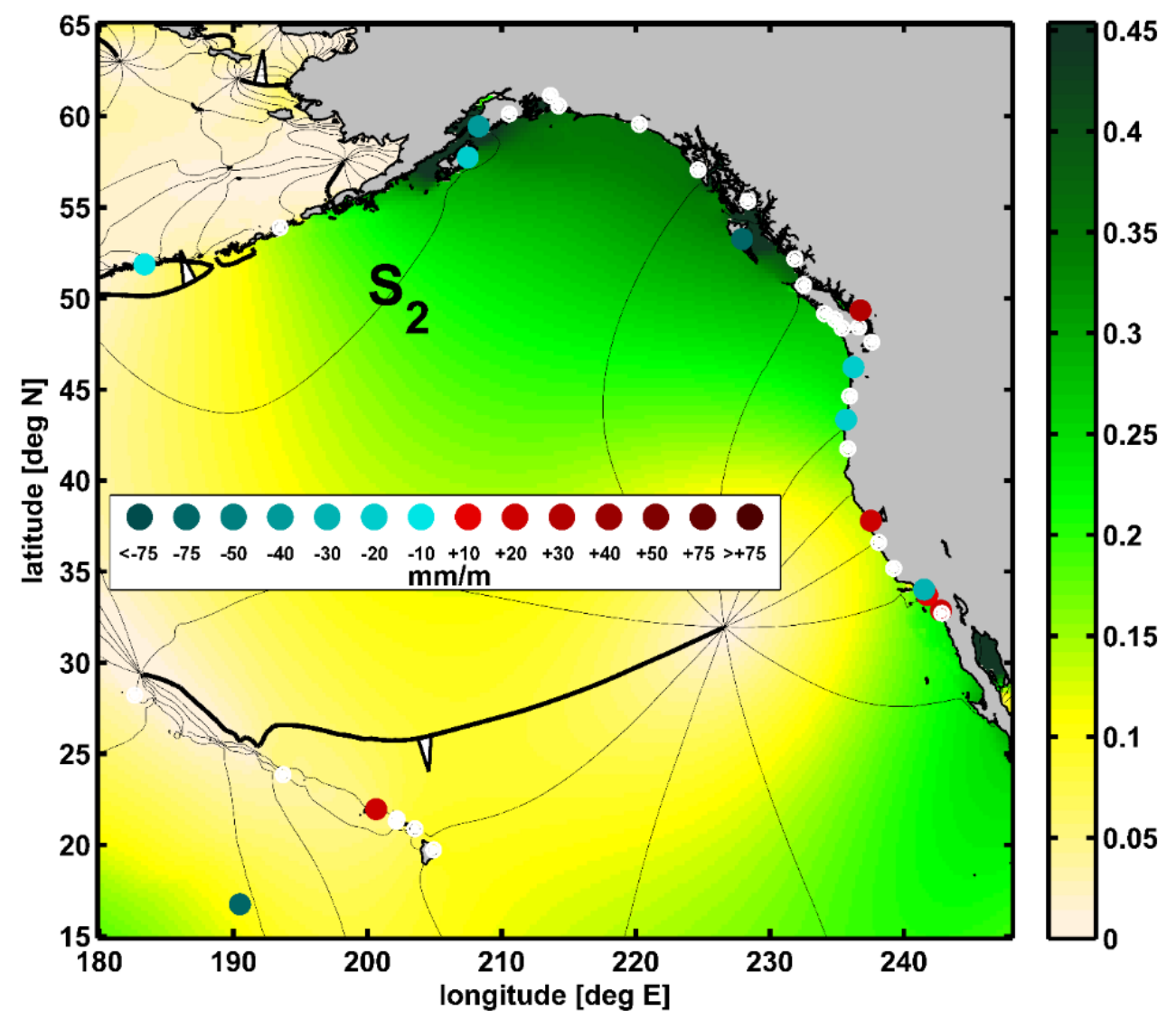

Figure $11 \mathrm{~S}_{2} \mathrm{~A}$-TAT map in Northeast Pacific showing changes in amplitude anomaly trends (for a 1 meter MSL rise); symbols are as in Figure 10, and units are $\mathrm{mmm}^{-1}$. 


\subsection{Diurnal TATs, NE}

Figure 12 shows the Northeast Pacific $\mathrm{K}_{1}$ distribution, which is influenced by one amphidromic system whose point is located just off this map. $\mathrm{K}_{1}$ A-TATs are mildly negative or insignificant for the majority of the US coast, but the negative trend at San Francisco is large. Positive A-TATs are seen in the Gulf of Alaska at Adak and Valdez, AK, and also Kahului and Hilo in Hawaii; others in these regions are negative or insignificant. $\mathrm{K}_{1}$ P-TATs in the entire region are mixed but very weak in most locations (Figure A3). Only Dutch Harbor, AK, and Charleston, OR have a P-TAT with magnitude greater than 5 degm $^{-1}$. Figure 13 shows the $\mathrm{O}_{1}$ trends and tidal distribution. $\mathrm{O}_{1}$ also shows a single amphidromic system with a center point just off this map. A-TATs for $\mathrm{O}_{1}$ are mainly negative on the US and Canadian coast, with the exceptions of Yakutat and Ketchikan, AK, and also Point Atkinson, Canada. Other gauges in the Gulf of Alaska are insignificant. Charleston, OR and San Francisco, CA have small positive trends. In Hawaii, all $\mathrm{O}_{1}$ A-TATs are positive. For $\mathrm{O}_{1}$ P-TATs (Figure A4), positive trends are seen for the northern US coast. Trends in the Gulf of Alaska and on the California coast are typically weakly negative or insignificant. Hawaii shows a mixed but weak distribution of phase trends. 


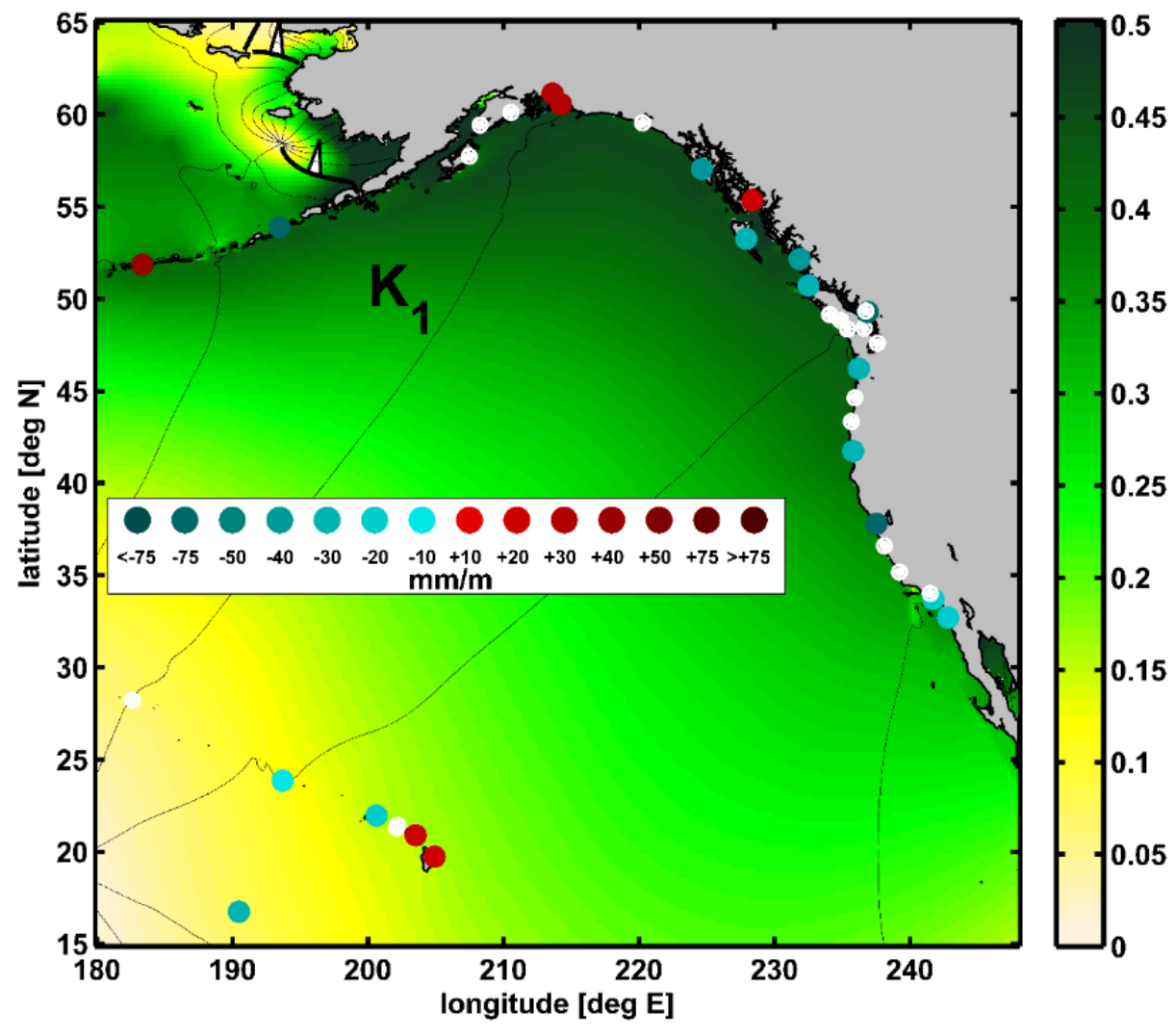

Figure $12 \mathrm{~K}_{1} \mathrm{~A}$-TAT map in Northeast Pacific showing changes in amplitude anomaly trends (for a 1 meter MSL rise); symbols are as in Figure 10, and units are $\mathrm{mmm}^{-1}$. 


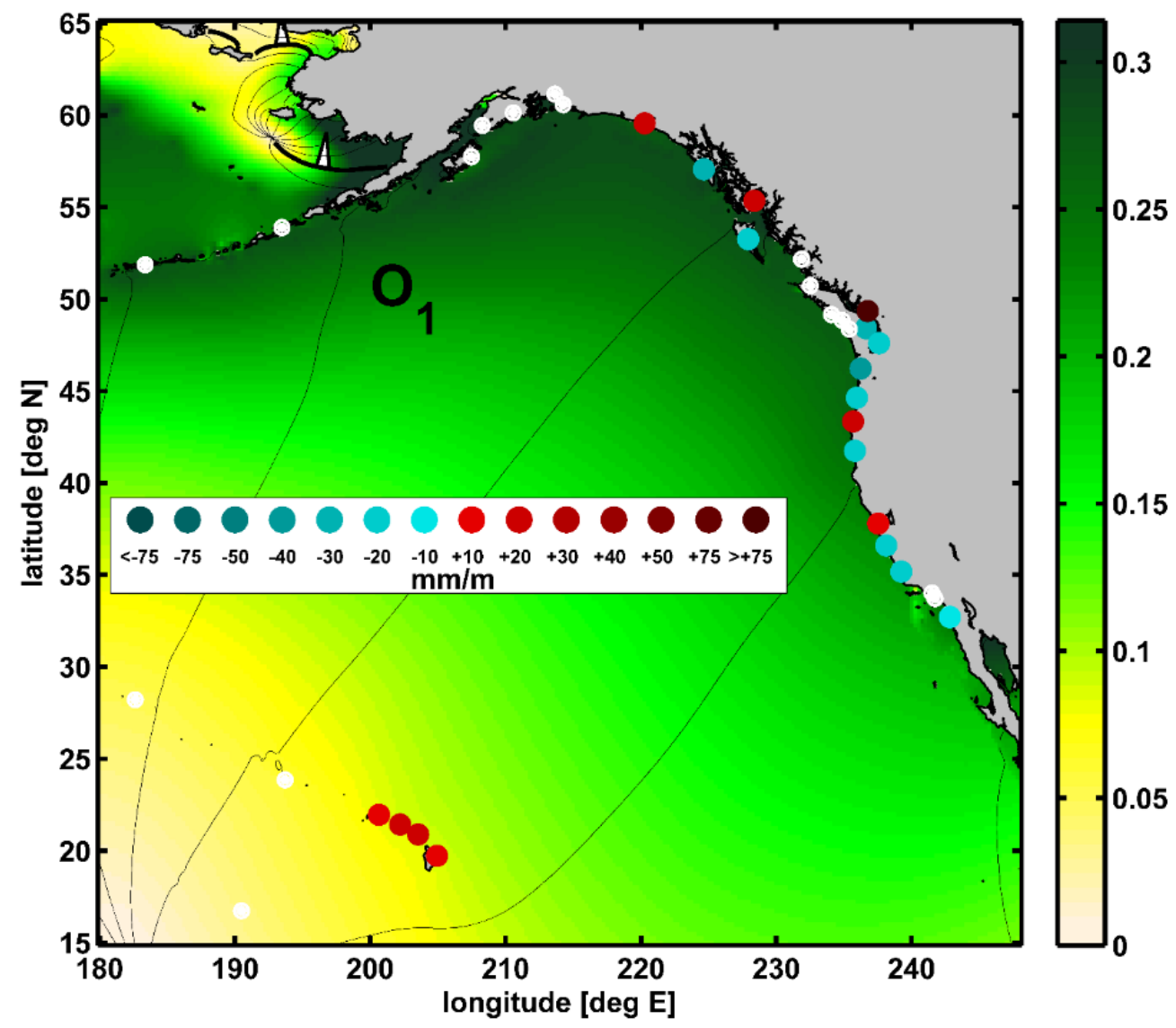

Figure $13 \mathrm{O}_{1} \mathrm{~A}$-TAT map in Northeast Pacific showing changes in amplitude anomaly trends (for a 1 meter MSL rise); symbols are as in Figure 10, and units are $\mathrm{mmm}^{-1}$. 


\subsubsection{Southeast Pacific TATs results}

\subsection{Semidiurnal TATs, SE}

In Figure 14, three distinct $\mathrm{M}_{2}$ amphidromes are located in the SE Pacific; one near Tahiti, one west of South America on the Equator, and the third one west of far southern Chile. $\mathrm{M}_{2}$ A-TATs are mixed positive and negative at both coastal and island gauges without any clear pattern. In southern Chile at Puerto Montt, there is a very large negative $\mathrm{M}_{2} \mathrm{~A}-\mathrm{TAT}$, greater than $-500 \mathrm{mmm}^{-1} . \mathrm{M}_{2}$ P-TATs are positive for the northern stations of South America, and also at Puerto Montt, and Buena Ventura. $\mathrm{M}_{2}$ P-TATs are negative for gauges centered around $-20^{\circ} \mathrm{S}$, with a very large negative P-TAT seen near Tahiti, close to the amphidromic point (Figure A5). $\mathrm{S}_{2}$ also has three amphidromic points with a similar but slightly different geographical distribution as $\mathrm{M}_{2}$ (Figure 15). Significant $S_{2}$ A-TATs are mainly negative with the exception of Caldera, and at Puerto Montt, the trend is again exceptionally large $\left(-272 \mathrm{mmm}^{-1}\right) . \mathrm{S}_{2}$ P-TATs are very similar is distribution to $\mathrm{M}_{2}$, but the trend at Tahiti is strongly positive instead of strongly negative (Figure A6). 


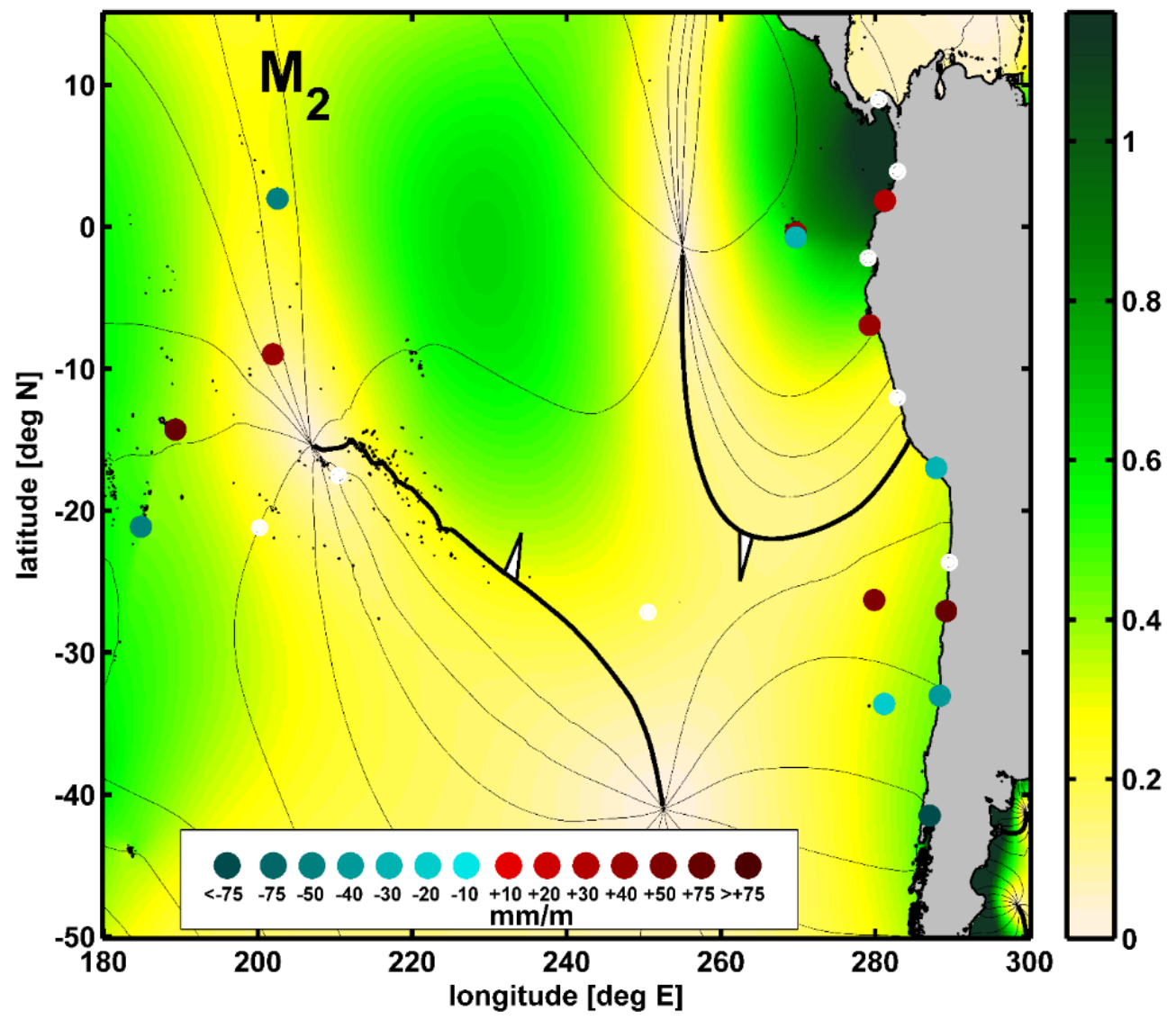

Figure $14 \mathrm{M}_{2}$ A-TAT map in Southeast Pacific showing changes in amplitude anomaly trends (for a 1 meter MSL rise); symbols are as in Figure 10, and units are $\mathrm{mmm}^{-1}$. 


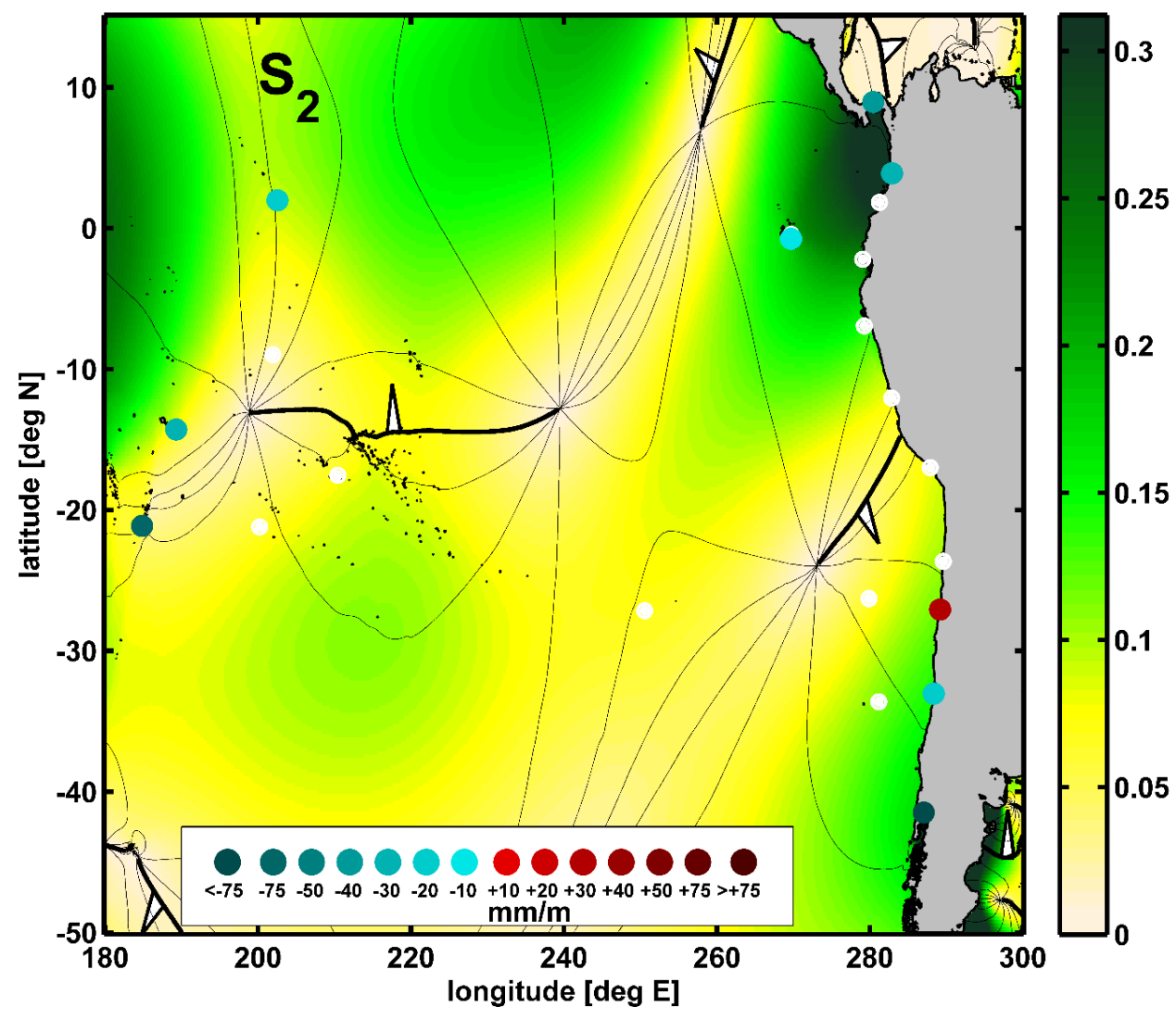

Figure $15 \mathrm{~S}_{2}$ A-TAT map in Southeast Pacific showing changes in amplitude anomaly trends (for a 1 meter MSL rise); symbols are as in Figure 10, and units are $\mathrm{mmm}^{-1}$. 


\subsection{Diurnal TATs, SE}

Figure 16 displays the $\mathrm{K}_{1}$ tidal distribution and trends in the Southeast Pacific.

There are also three $\mathrm{K}_{1}$ amphidromes in the region; one near Tahiti, one just west of the Galapagos Islands, and a third in the far Western Southern Ocean. Open-ocean A-TATs are mainly positive, as is Caldera. Other gauges on the South American coast are insignificant or weakly negative. Puerto Montt shows a very strong negative A-TAT, as was seen for the semidiurnal tides. Phase trends in $\mathrm{K}_{1}$ are mainly negative or insignificant at island gauges, with the exception of Juan Fernandez Island (Figure A7). Tahiti exhibits a very large negative P-TAT, as was also seen for semidiurnals. Coastal gauges are mainly positive or insignificant except Tumaco and Puerto Montt. Figure 17 shows the $\mathrm{O}_{1}$ tidal distribution, in which it can be seen that there are 4 clear amphidromic systems; one near Tahiti, one near the Galapagos, one in the far Southern Ocean, and one north of the Equator near the Date Line. $\mathrm{O}_{1}$ A-TATs are almost entirely insignificant or very weak. Rarontonga has a positive trend, and Valparaiso and Matarani have moderate negative trends. However, as for the case for all previous constituents, Puerto Montt has a large negative A-TAT in $\mathrm{O}_{1}$. Phase trends in $\mathrm{O}_{1}$ that are significant are mainly positive, with strong trends seen at Penrhyn, La Libertad and Santa Cruz. Significant negative trends are seen at Baltra, Tahiti, San Felix, and Nuku'alofa (Figure A8). 


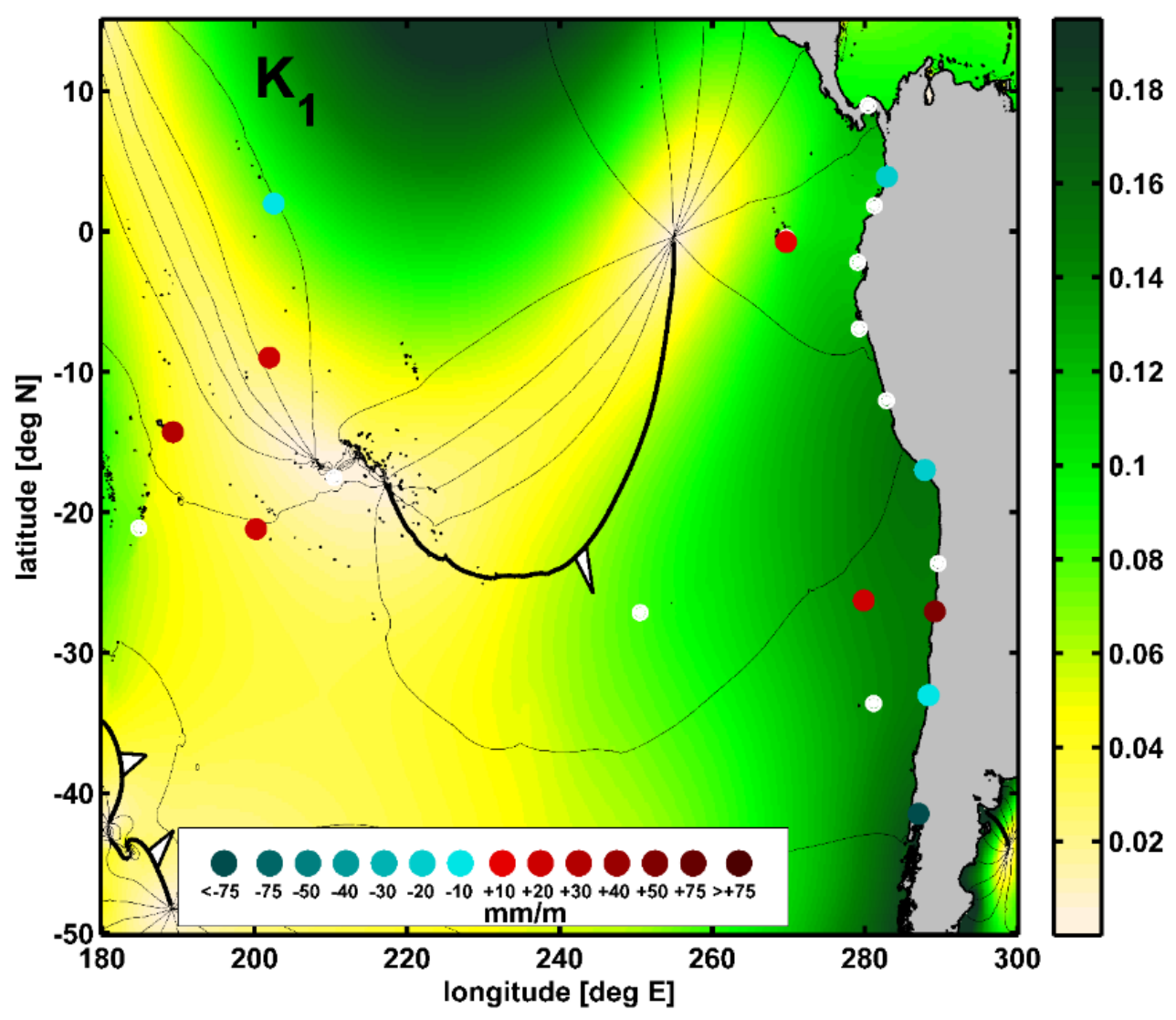

Figure $16 \mathrm{~K}_{1}$ A-TAT map in Southeast Pacific showing changes in amplitude anomaly trends (for a 1 meter MSL rise); symbols are as in Figure 10, and units are $\mathrm{mmm}^{-1}$. 


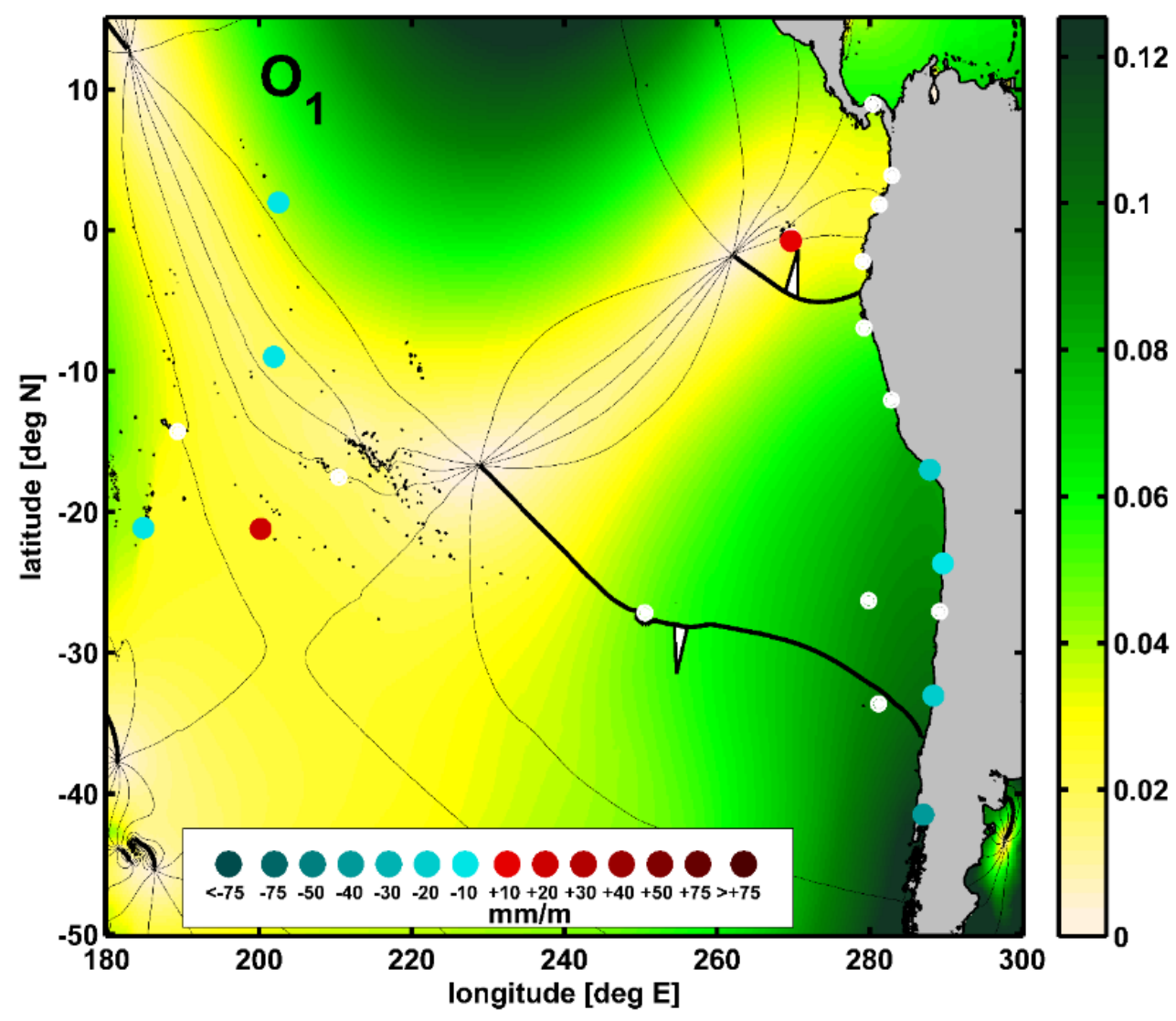

Figure $17 \mathrm{O}_{1} \mathrm{~A}$-TAT map in Southeast Pacific showing changes in amplitude anomaly trends (for a 1 meter MSL rise); symbols are as in Figure 10, and units are $\mathrm{mmm}^{-1}$. 


\subsubsection{Northwest Pacific TATs results}

\subsection{Semidiurnal TATs, NW}

Figure 18 presents the $M_{2}$ map in the Northwest Pacific. There are no openocean amphidromic points visible in this view, however, there are smaller amphidromic systems visible in the Yellow Sea, and in the north part of the domain in the Sea of Okhotsk, whose systems are likely isolated from the main basin dynamics due to the topography of the archipelagos south and north of mainland Japan.

There is an exceptionally large positive A-TAT seen in Hong Kong of $+104 \mathrm{mmm}^{-1}$, but at Keelung in northern Taiwan and at nearby Ishigaki Island, trends are strongly negative. A-TATs are negative for the majority of coastal Japan, with some having a trend of over $-80 \mathrm{mmm}^{-1}$ on the southern coast (Nishinoomote, Odomari, and Nagasaki) and surrounding Tokyo (Maisaka and Shimizuminato). However, some of the largest positive $\mathrm{M}_{2}$ A-TATs are also seen in nearby Okada, and in Tokyo harbor itself, at +109 $\mathrm{mmm}^{-1}$ and $+61 \mathrm{mmm}^{-1}$, respectively. $\mathrm{M}_{2}$ phase trends (Figure A9) are positive in northern Japan near Hokkaido and along the southern Pacific Coast, and also at gauges near Tokyo especially at Toba and Abishiri, yet the trend at Tokyo harbor itself is opposed to the surrounding trends, with a negative magnitude of over $40 \mathrm{degm}^{-1}$. Figure 19 presents the $S_{2} A$-TAT map, which shows a similar tidal map as $M_{2}$, in that the only amphidromic systems contained fully in this domain are the small ones in the Yellow Sea and Sea of Okhotsk. The trends of $\mathrm{S}_{2}$ A-TATs are negative in the large 
majority of the domain, with largest values seen at Maisaka $\left(-59 \mathrm{mmm}^{-1}\right)$, Nishinoomote $\left(-40 \mathrm{mmm}^{-1}\right)$, and Shimizuminato $\left(-35 \mathrm{mmm}^{-1}\right)$. There are some isolated but strong positive A-TATs at Hong Kong $\left(+38 \mathrm{mmm}^{-1}\right)$, Tokyo $\left(+36 \mathrm{mmm}^{-1}\right)$, Okada $\left(+37 \mathrm{mmm}^{-1}\right)$, and Shirihama (+29 $\left.\mathrm{mmm}^{-1}\right)$. The distribution of $\mathrm{S}_{2}$ P-TATs (Figure A10) is nearly identical to that seen for $M_{2}$, with largest negative values seen at Tokyo (-44 degm $\left.{ }^{-1}\right)$ and Shirihama $\left(-20 \mathrm{degm}^{-1}\right)$, and largest positive trends at Toba $\left(+24 \mathrm{degm}^{-1}\right)$ and Abishiri (+13 degm $\left.^{-1}\right)$. 


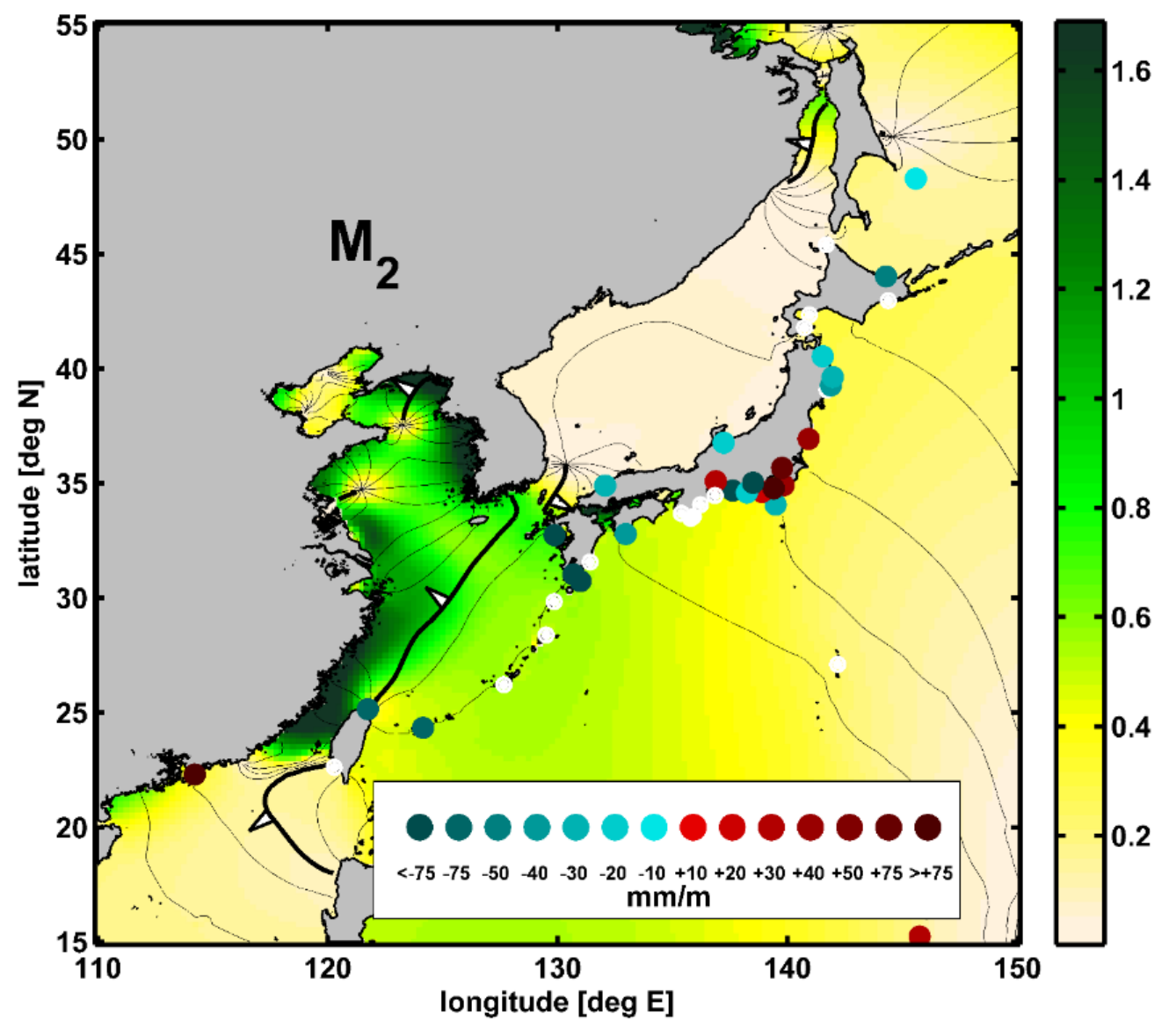

Figure $18 \mathrm{M}_{2}$ A-TAT map in Northwest Pacific showing changes in amplitude anomaly trends (for a 1 meter MSL rise); symbols are as in Figure 10, and units are $\mathrm{mmm}^{-1}$. 


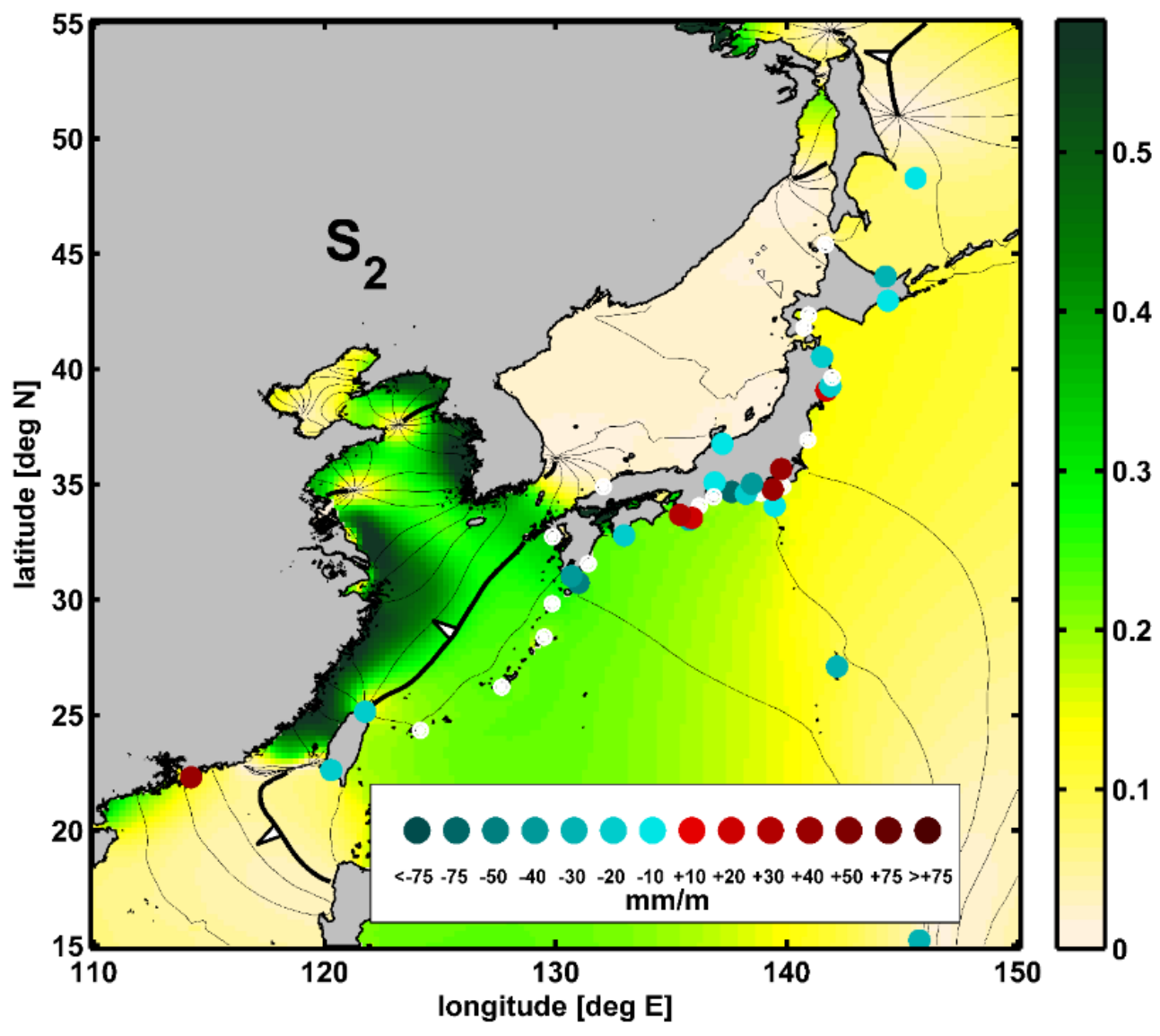

Figure $19 \mathrm{~S}_{2} \mathrm{~A}$-TAT map in Northwest Pacific showing changes in amplitude anomaly trends (for a 1 meter MSL rise); symbols are as in Figure 10, and units are $\mathrm{mmm}^{-1}$. 


\subsection{Diurnal TATs, NW}

Figure 20 shows the $\mathrm{K}_{1}$ tidal map for the Northwest Pacific, in which only one amphidromic system in the Yellow Sea is observed. Mean $\mathrm{K}_{1}$ amplitudes are very nearly the same at all gauge locations in Japan. Trends are positive at the southern islands of Japan, at Taiwan, and at isolated locations on the coast of Japan. There is a very large positive A-TAT seen in Hong Kong $\left(+116 \mathrm{mmm}^{-1}\right)$, and at Hamada in the Sea of Japan $\left(+51 \mathrm{mmm}^{-1}\right)$. The majority of gauges in coastal Japan exhibit negative A-TATs, with largest values seen at Mera $\left(-53 \mathrm{mmm}^{-1}\right)$, Maisaka $\left(-74 \mathrm{mmm}^{-1}\right)$, Wakkanai $\left(-53 \mathrm{mmm}^{-1}\right)$, and Tokyo $\left(-55 \mathrm{mmm}^{-1}\right)$. The phase trends of $\mathrm{K}_{1}$ are insignificant in the southern parts and far northern parts of the domain (Figure A11). A mixed trend without clear pattern is seen for the central coast of Japan, but the majority of significant trends are weak, with the exceptions of Tokyo $\left(-35 \mathrm{degm}^{-1}\right)$, Shirihama $\left(-15 \mathrm{degm}^{-1}\right)$, Toyama $\left(-19 \mathrm{degm}^{-1}\right)$, Kushiro $\left(-13 \mathrm{degm}^{-1}\right)$, and Toba $\left(+12 \mathrm{degm}^{-1}\right)$. Figure 21 shows the $\mathrm{O}_{1}$ tidal map, with a similar amphidromic distribution as $\mathrm{K}_{1}$. As with $\mathrm{K}_{1}, \mathrm{O}_{1}$ amplitudes vary only by small amounts along the coast of Japan. $\mathrm{O}_{1}$ A-TATs are almost ubiquitously negative at gauges with significant trends, with the notable exceptions of Hakodate in northern Japan (+36 $\mathrm{mmm}^{-1}$ ) and Okada $\left(+39 \mathrm{mmm}^{-1}\right)$. There is also a large positive A-TAT in Hong Kong of $+40 \mathrm{mmm}^{-1}$, as was seen with all other constituents, but the noise level in this determination is very large, and this trend is just below the significance line. Strong negative $\mathrm{O}_{1}$ A-TATs are seen at Kushiro $\left(-67 \mathrm{mmm}^{-1}\right)$, Maisaka $\left(-53 \mathrm{mmm}^{-1}\right)$, and Tokyo ($60 \mathrm{mmm}^{-1}$ ). $\mathrm{O}_{1}$ P-TATs (Figure A12) are more coherent than was seen for $\mathrm{K}_{1}$, with 
moderate positive trends generally seen at southern islands of Japan, at far northern gauges, and clustered around and to the west of Tokyo, but again, the trend at Tokyo harbor itself is opposite to the surrounding gauges, with a negative P-TAT of -25 degm $^{-1}$. Shirihama also shows a strongly negative P-TAT $\left(-20\right.$ degm $\left.^{-1}\right)$.

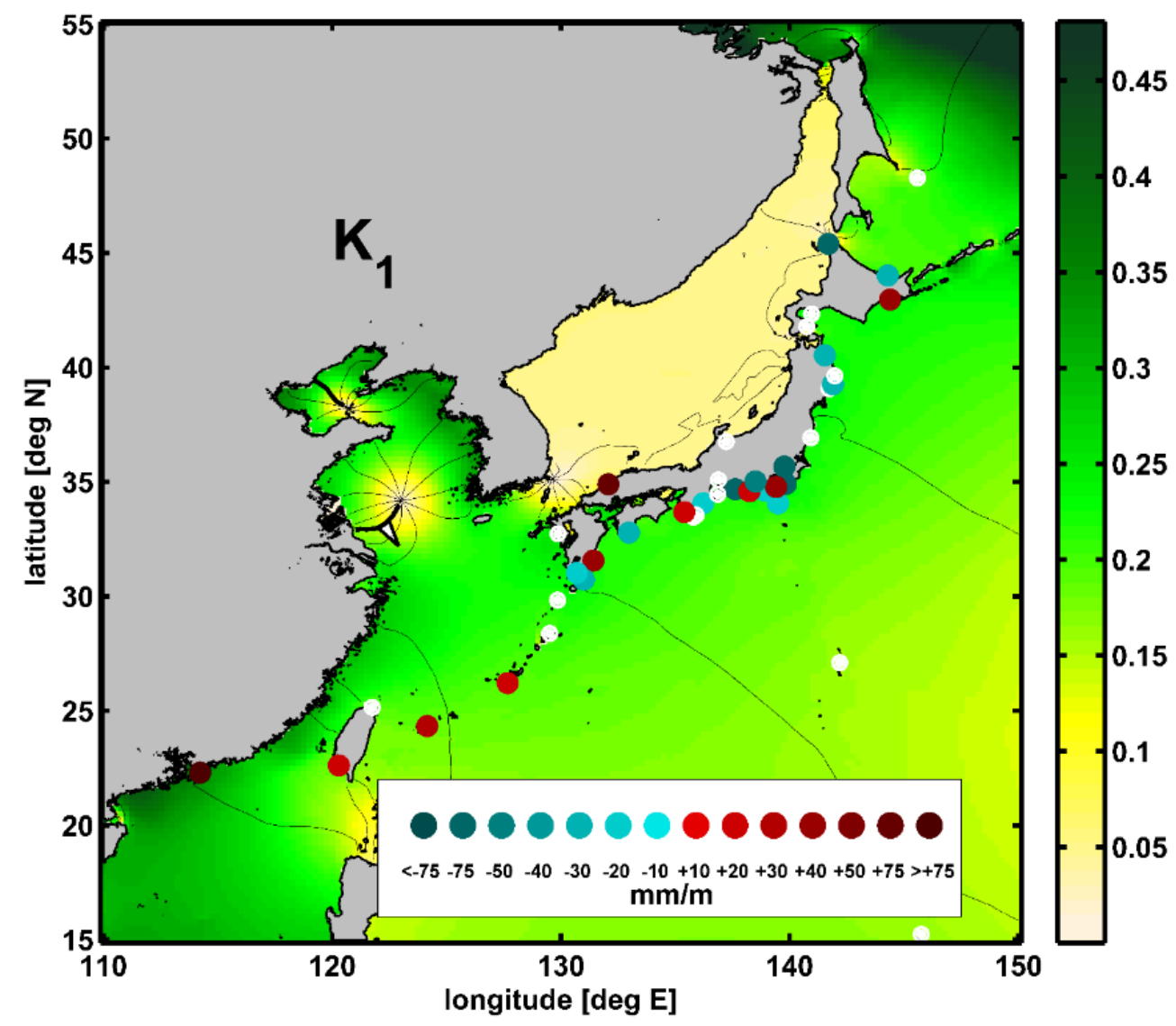

Figure $20 \mathrm{~K}_{1}$ A-TAT map in Northwest Pacific showing changes in amplitude anomaly trends (for a 1 meter MSL rise); symbols are as in Figure 10, and units are $\mathrm{mmm}^{-1}$. 


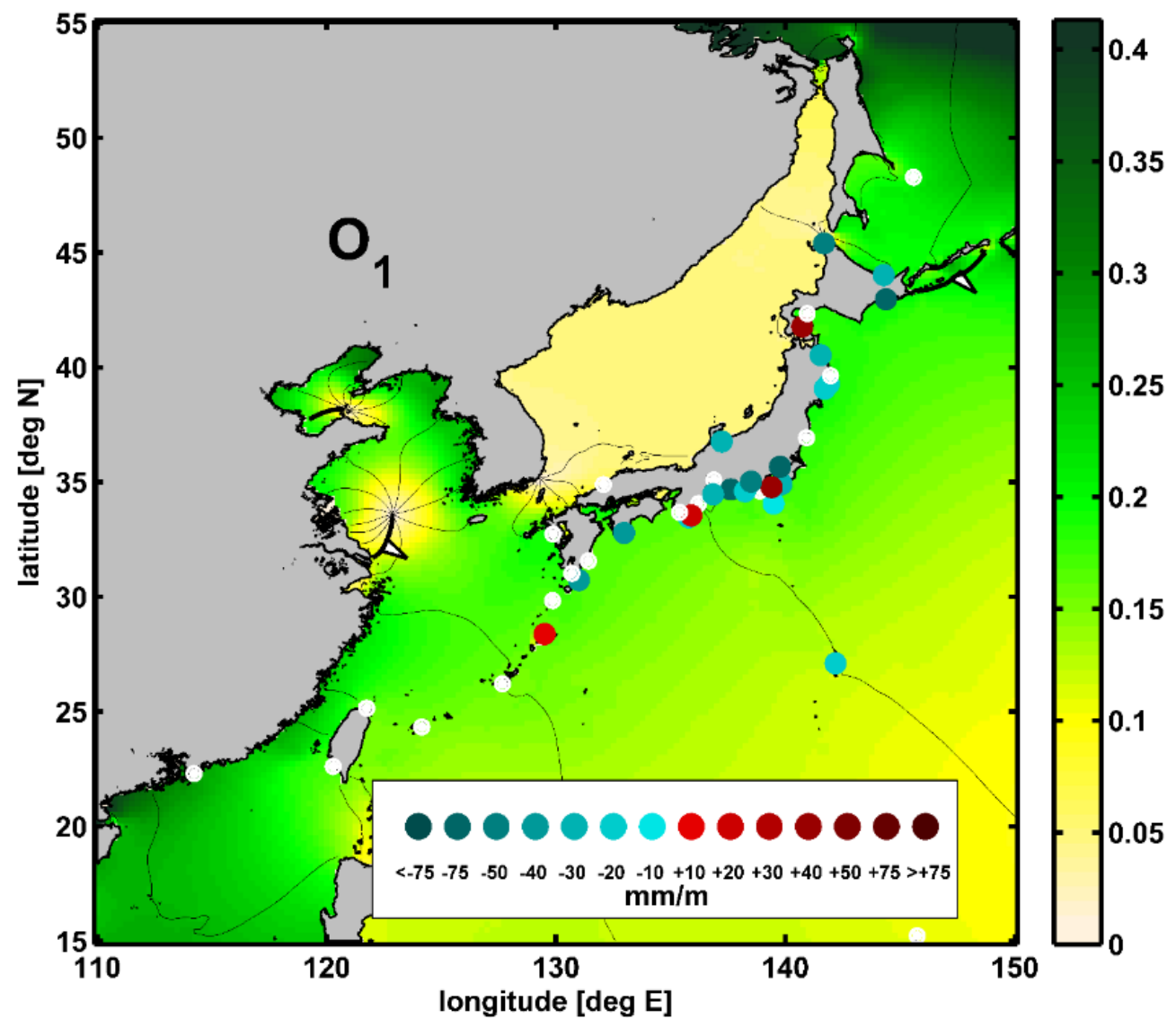

Figure $21 \mathrm{O}_{1}$ A-TAT map in Northwest Pacific showing changes in amplitude anomaly trends (for a 1 meter MSL rise); symbols are as in Figure 10, and units are $\mathrm{mmm}^{-1}$. 


\subsubsection{Southwest Pacific TATs results}

\subsection{Semidiurnal TATs, SW}

$M_{2}$ amplitudes are generally larger than diurnal amplitudes in the Southwest Pacific study area, with the largest amplitudes occurring around New Zealand and the northern coast of Australia (Figure 22). An amphidromic point is located just to the east of Pago Pago, with an anti-node along the equator west of the date line. Very low $\mathrm{M}_{2}$ amplitudes are seen in and around the Solomon Sea. Honiara and Rabaul are near the $\mathrm{M}_{2}$ amphidrome in the Solomon Sea and have small mean $\mathrm{M}_{2}$ amplitudes ( $\left.\sim 50 \mathrm{~mm}\right)$, but display large relative trends ( $+132 \%$ for Honiara and $+240 \%$ for Rabaul), though the strong phase trends at these two gauges have opposite magnitudes. The tidal variability at Honiara was shown earlier in Figure $8 \mathrm{~h}$ as an example of some of the most coherent trends. Most significant positive A-TATs are south of the equator, and most negative ATATs are north of the equator. The trends at nearly all gauges in Malaysia ( -40 to -150 $\left.\mathrm{mmm}^{-1}\right)$, and in the Philippines $\left(-80\right.$ to $-145 \mathrm{mmm}^{-1}$ ) are strongly negative. Largest positive A-TATs are seen at Suva $\left(+60 \mathrm{mmm}^{-1}\right)$, Pago Pago $\left(+62 \mathrm{mmm}^{-1}\right)$, Port Villa $(+82$ $\left.\mathrm{mmm}^{-1}\right)$, and Brisbane $\left(+153 \mathrm{mmm}^{-1}\right)$. Phase trends in $\mathrm{M}_{2}$ (Figure $\mathrm{A} 13$ ) are positive in Tasmania, Honiara, and most gauges north of the equator, with many large trends in Malaysia, with an anomalously large phase trend in Ko Lak, Thailand of +54 degm $^{-1}$. In the equatorial Pacific at Manus Island, Rabaul, and Kapingamarangi, trends are strongly negative $\left(\sim-40\right.$ degm $\left.^{-1}\right)$. Figure 23 displays the $S_{2}$ tidal map. $S_{2}$ is much smaller than $M_{2}$ 
at most locations, but with a similar large amplification on the northwest coast of Australia. Also similar is the location of the amphidromic points, with another lineshaped amphidrome (located westward of the similar structure of $\mathrm{M}_{2}$ and more closely following the Mariana trench), and an amphidromic point very near Pago Pago, but different from $\mathrm{M}_{2}$, there is another amphidrome near Tasmania. There is again a strong concentration of negative A-TATs in Malaysia $\left(-18\right.$ to $\left.-59 \mathrm{mmm}^{-1}\right)$ and in the Philippines $\left(-30\right.$ and $\left.-40 \mathrm{mmm}^{-1}\right)$, yet Legaspi has an opposed strong positive trend of $+77 \mathrm{mmm}^{-1}$. Other strong positive trends of note are seen at Brisbane $\left(+35 \mathrm{mmm}^{-1}\right)$, Kapingamarangi $\left(+44 \mathrm{mmm}^{-1}\right)$, Noumea $\left(+31 \mathrm{mmm}^{-1}\right)$, and Honiara $\left(+42 \mathrm{mmm}^{-1}\right)$, and large strong negative trends are seen at Rabaul $\left(-33 \mathrm{mmm}^{-1}\right)$ and Gladstone, $\mathrm{AU}\left(-78 \mathrm{mmm}^{-1}\right)$. $\mathrm{S}_{2} \mathrm{P}-$ TATs (Figure A14) are similar to the patterns shown by $\mathrm{M}_{2}$, but are generally weaker and less significant. Saipan and Kapingamarangi are notable in having strong negative trends of -43 and -45 degm $^{-1}$, respectively, as are Davao $\left(-37\right.$ degm $\left.^{-1}\right)$, Brisbane $\left(-23 \operatorname{degm}^{-1}\right)$, and Honiara $\left(-21 \mathrm{degm}^{-1}\right)$. Strong positive phase trends are seen at Hobart, AU (+68 $\left.\operatorname{degm}^{-1}\right)$, Port Villa $\left(+30 \operatorname{degm}^{-1}\right)$, and Yap $\left(+22 \operatorname{degm}^{-1}\right)$ 


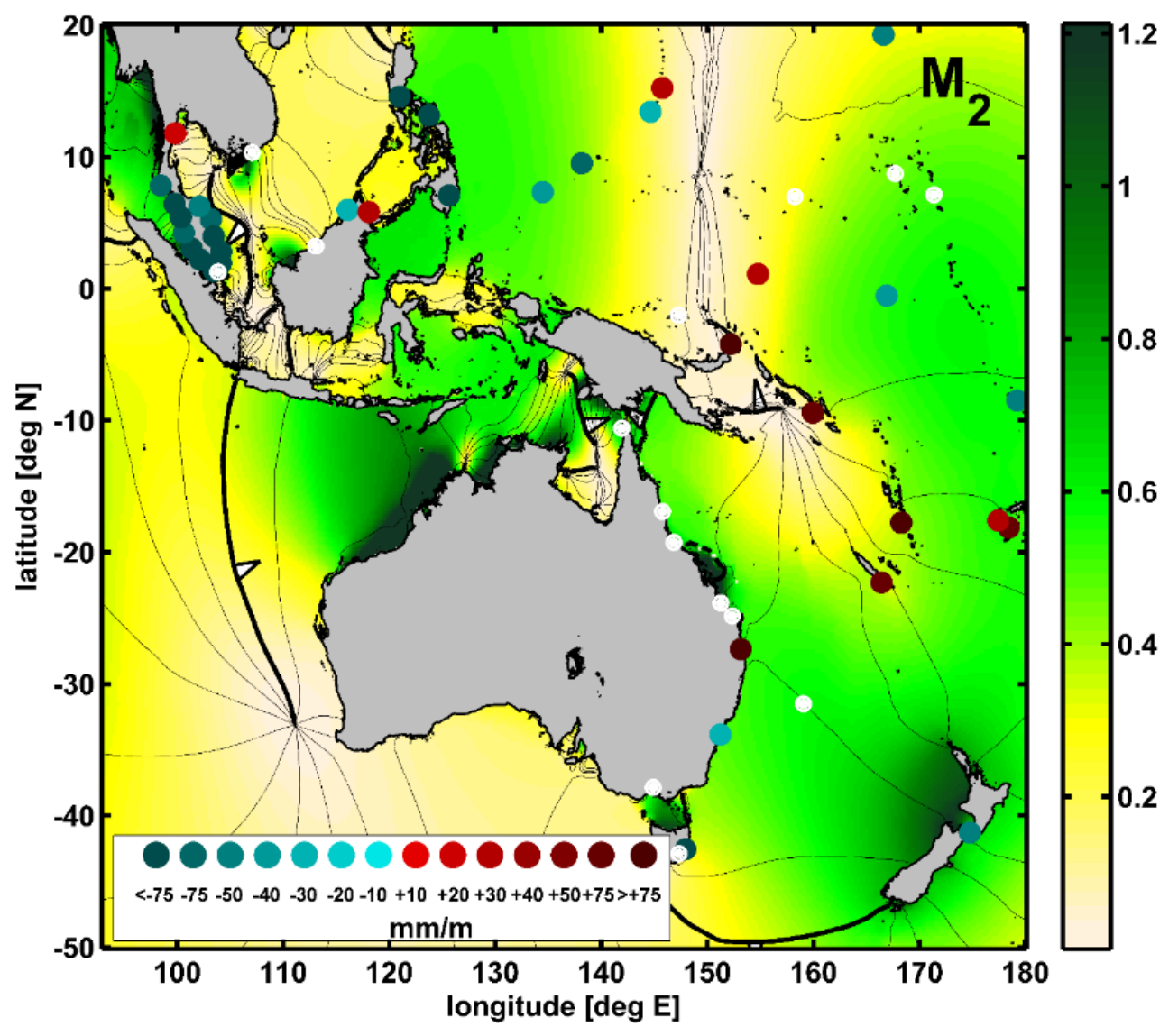

Figure $22 \mathrm{M}_{2}$ A-TAT map in Southwest Pacific showing changes in amplitude anomaly trends (for a 1 meter MSL rise); symbols are as in Figure 10, and units are $\mathrm{mmm}^{-1}$. 


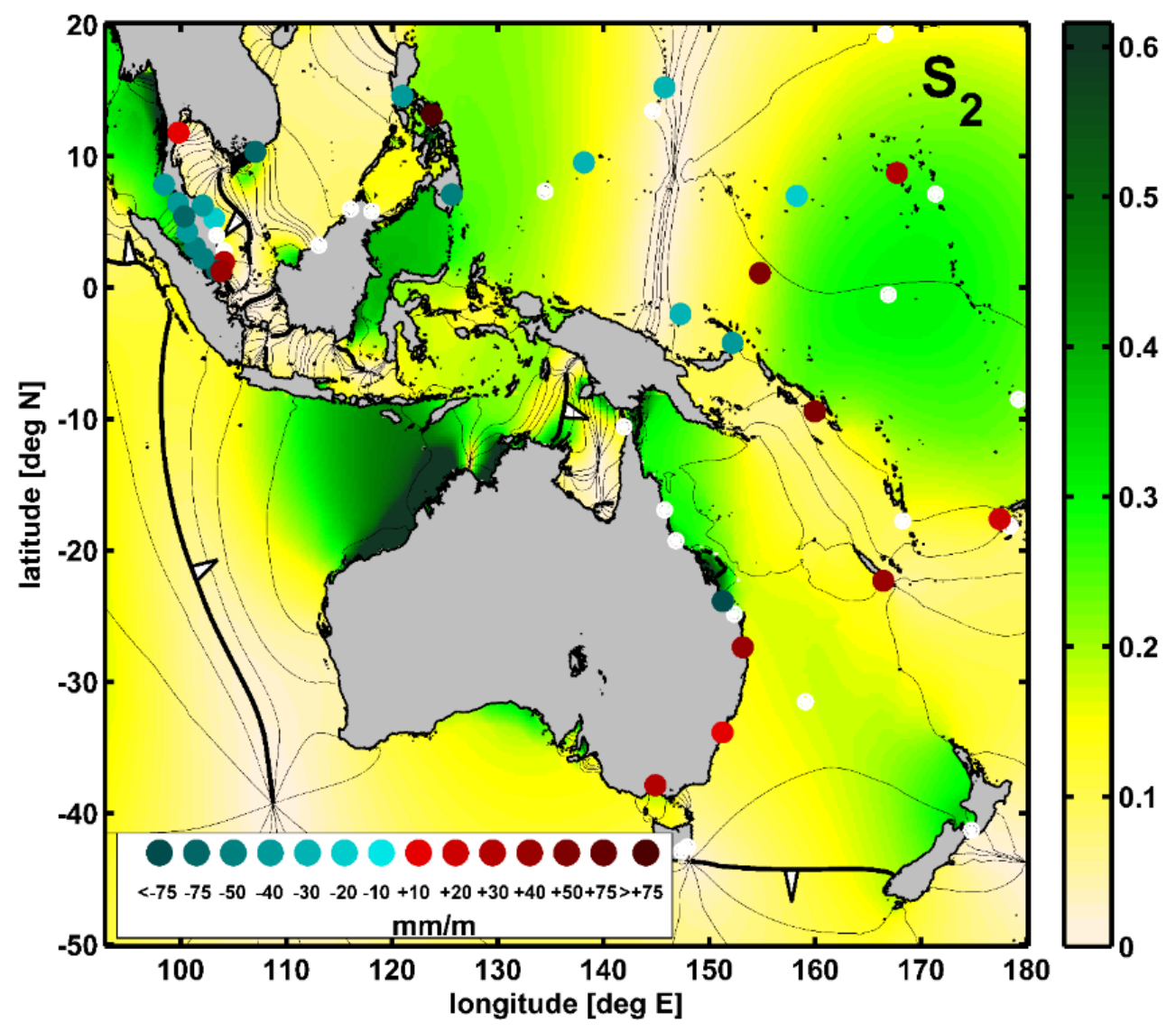

Figure $23 \mathrm{~S}_{2}$ A-TAT map in Southwest Pacific showing changes in amplitude anomaly trends (for a 1 meter MSL rise); symbols are as in Figure 10, and units are $\mathrm{mmm}^{-1}$. 


\subsection{Diurnal TATs, SW}

$\mathrm{K}_{1}$ has its largest amplitudes in the Western Pacific between New Guinea and Singapore and between $10^{\circ} \mathrm{N}$ and $10^{\circ} \mathrm{S}$, with much lower amplitudes eastward in the open ocean to the east (Figure 24). Based on the tidal potential, diurnal tides are expected to be small near the equator (see Figure 2), and the large amplitudes seen (4-5 times that predicted by astronomical forcing) around Indonesia and Papua New Guinea may represent a near-resonance. Diurnal tides are large within the Coral Sea, but are very small around New Zealand, where semidiurnal tides prevail. Large positive A-TATs are seen at both island and shelf stations, significant negative A-TATs are mainly seen at island gauges, and also in coastal Malaysia and Thailand $\left(-14\right.$ to $\left.-85 \mathrm{mmm}^{-1}\right)$. There is a concentration of positive A-TATs at Australian gauges, and strong positive trends are also observed in Malaysia ( $+50 \mathrm{mmm}^{-1}$ at Sandakan and $+287 \mathrm{mmm}^{-1}$ at Bintulu) and also at Davao in the Philippines $\left(+191 \mathrm{mmm}^{-1}\right)$. Almost all significant negative A-TATs are north of $\sim 10^{\circ} \mathrm{S}$. The strongest positive P-TATs (Figure A15) are seen at Guam (+22 degm $\left.^{-1}\right)$ and Tioman in Malaysia $\left(+82 \mathrm{degm}^{-1}\right)$, and strong negative trends in phase are seen at the islands near the center of the map, with another notable negative trend observed at Davao of -97 degm $^{-1}$.

The amplitude and phase distributions and amphidromic patterns for $\mathrm{O}_{1}$ are similar to those for $\mathrm{K}_{1}$, though $\mathrm{O}_{1}$ amplitudes are generally smaller (Figure 25). Like $\mathrm{K}_{1}$, $\mathrm{O}_{1}$ is resonant near Papua New Guinea and in the Indonesian archipelago. Significant 
positive A-TATs are also found at most Australian shelf stations, and at gauges in the South China Sea, with strong positive trends at Vung Tau, Vietnam $\left(+44 \mathrm{mmm}^{-1}\right)$ and Bintulu, Malaysia $\left(+231 \mathrm{mmm}^{-1}\right)$. Other gauges in Malaysia show some of the strongest negative $\mathrm{O}_{1}$ A-TATs $\left(-60\right.$ to $\left.-90 \mathrm{mmm}^{-1}\right)$. Strong negative A-TATs are also seen at Gladstone $\left(-302 \mathrm{mmm}^{-1}\right)$, Manila $\left(-84 \mathrm{mmm}^{-1}\right)$, Guam $\left(-42 \mathrm{mmm}^{-1}\right)$, Nauru $\left(-35 \mathrm{mmm}^{-1}\right)$, and Honiara $\left(-27 \mathrm{mmm}^{-1}\right)$. Phase trends in $\mathrm{O}_{1}$ (Figure A16) are strongly negative at Malakal (-33 degm $\left.{ }^{-1}\right)$, Kapingamarangi $\left(-25\right.$ degm $\left.^{-1}\right)$, and at scattered gauges in Malaysia. $\mathrm{O}_{1}$ P-TATs are strongly positive at Legaspi $\left(+21 \mathrm{degm}^{-1}\right)$, Ko Lak, Thailand $\left(+24 \mathrm{degm}^{-1}\right)$, Pago Pago $\left(+22 \mathrm{degm}^{-1}\right)$, Suva $\left(+25 \mathrm{degm}^{-1}\right)$, and very strong at Yap Island $\left(+54 \mathrm{degm}^{-1}\right)$. 


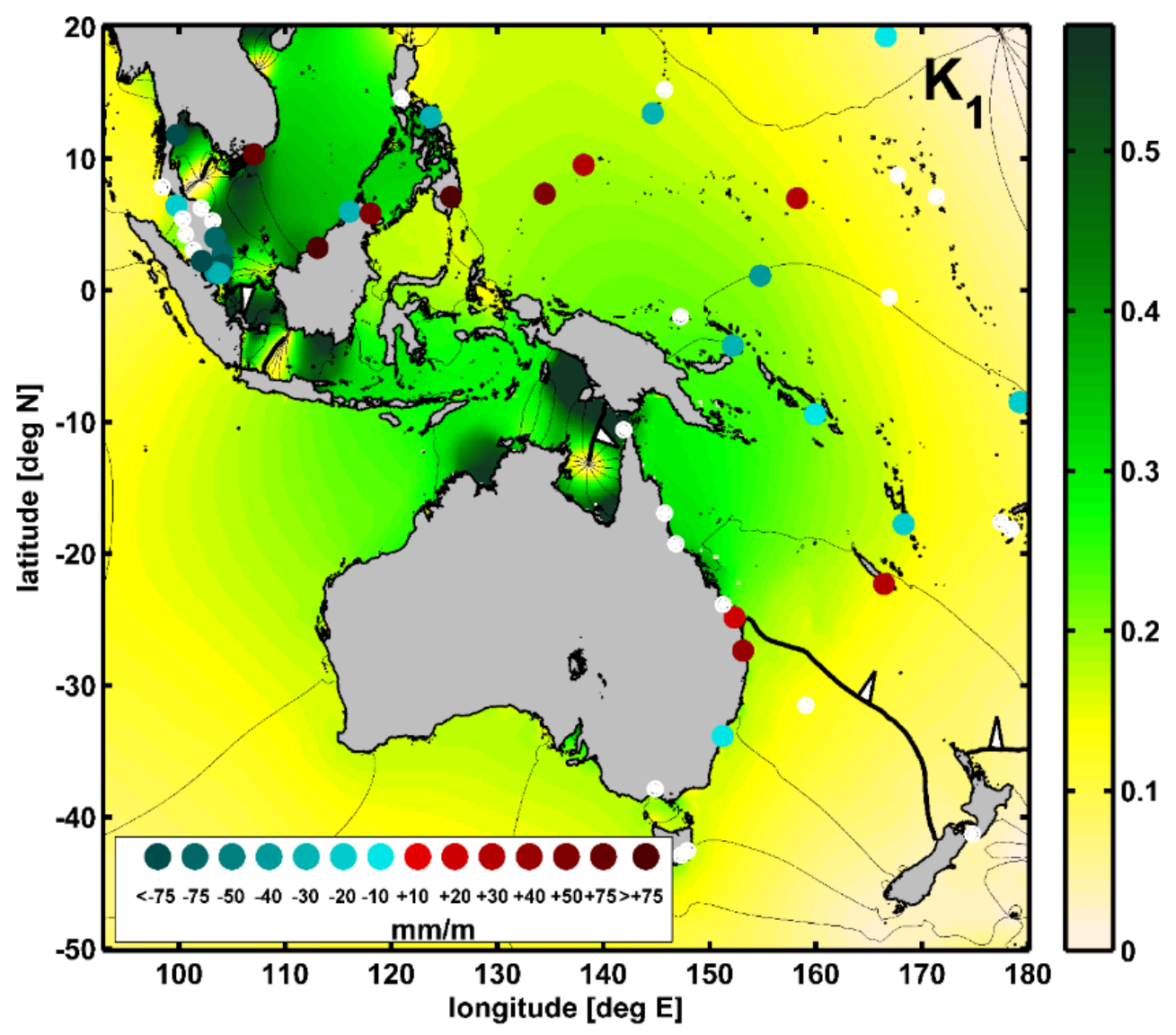

Figure $24 \mathrm{~K}_{1} \mathrm{~A}$-TAT map in Southwest Pacific showing changes in amplitude anomaly trends (for a 1 meter MSL rise); symbols are as in Figure 10, and units are $\mathrm{mmm}^{-1}$. 


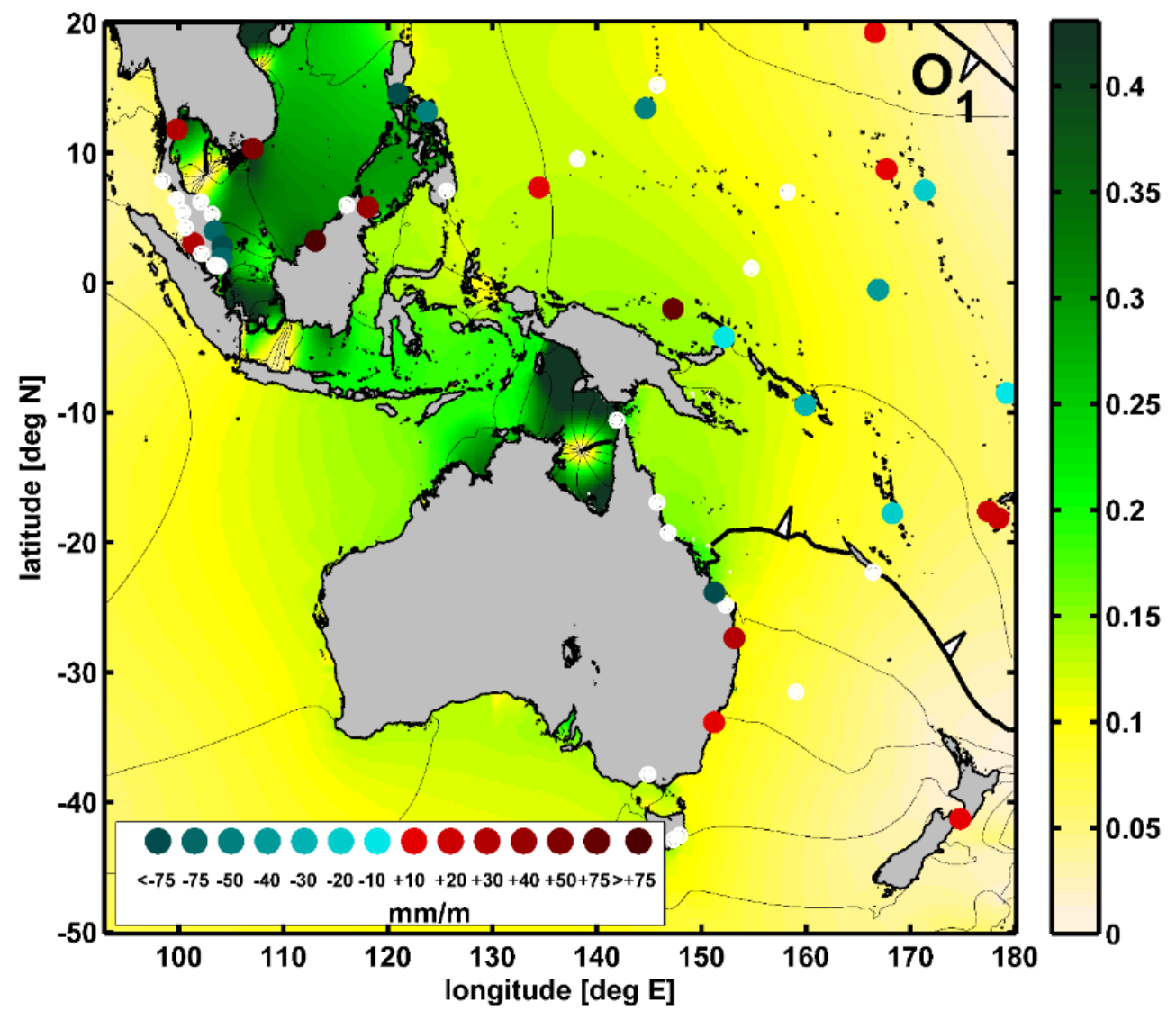

Figure $25 \mathrm{O}_{1}$ A-TAT map in Southwest Pacific showing changes in amplitude anomaly trends (for a 1 meter MSL rise); symbols are as in Figure 10, and units are $\mathrm{mmm}^{-1}$. 


\subsubsection{Seasonal tidal anomaly trends (STAT) results}

The seasonal tidal patterns will be analyzed through the use of seasonal tidal anomaly trends (STATs). Locations that exhibit seasonality show seasonally variable STATs. The difference between the maximum monthly STAT and the minimum monthly STAT will be denoted the range of the STAT. For the sake of brevity, only stations with a seasonal range of greater than $50 \mathrm{mmm}^{-1}$ for A-STATs will be plotted on the figures, and only those with a range of greater than $100 \mathrm{mmm}^{-1}$ in statistically significant monthly TAT determinations (SNR > 2.0) or $100 \mathrm{degm}^{-1}$ will be listed in tables and discussed in the text. P-STAT plots are not provided, as the monthly phase variability is highly variable at most locations with large errors. Also not shown are A-STAT plots for the Southeast Pacific, as only a few gauges in this data-poor region exhibited any measurable seasonality which are discussed and listed in tables. Table 5 lists the significant A-STATs for all constituents, Table 6 lists the P-STATs. In the tables, the maximum monthly TAT achieved, the minimum monthly TAT, and the difference (range) between the two is listed (see Figures 9a and 9b). For maximums and minimums, the month number (1-12) of determination is listed in italicized parentheses after the value to explore the possible cycles of seasonality by region.

\subsubsection{Northeast Pacific STATs results}

Figures 26-29 display the significant A-STATs in the Northeast Pacific. There are ten gauges with $\mathrm{M}_{2}$ A-STATs (Figure 26) greater than $100 \mathrm{mmm}^{-1}$; one in Mexico (Cabo 
San Lucas), three in the US (San Francisco, Astoria, and La Jolla), and six in Canada (Vancouver, Point Atkinson, Bella Bella, Queen Charlotte, Port Hardy, and Bamfield). The difference in monthly trends is very extreme at Point Atkinson and Queen Charlotte, 557 and $473 \mathrm{mmm}^{-1}$, respectively. Maximum values mainly occur in late fall and winter months, minimums in spring months (Table 5). For $\mathrm{S}_{2}$ (Figure 27), there are significant A-STATs at 6 gauges: Ketchikan, AK, Seattle, WA, and 4 in Canada (Point Atkinson, Queen Charlotte, Port Hardy, and Bamfield). Largest seasonal differences are seen at Queen Charlotte $\left(362 \mathrm{mmm}^{-1}\right)$ and Port Hardy $\left(448 \mathrm{mmm}^{-1}\right)$. Maximums and minimums do not show any clear regional trends in seasonal occurrence. Figure 28 shows the $\mathrm{K}_{1} \mathrm{~A}$ STATs. As was seen for the semidiurnal constituents, significant seasonality greater than $100 \mathrm{mmm}^{-1}$ is concentrated in the northern US (Neah Bay, WA, Seattle, WA, and Astoria, OR), and Canada (Vancouver, Point Atkinson, Queen Charlotte, and Port Hardy) for a total of seven gauges. Point Atkinson has a large seasonal difference of $552 \mathrm{mmm}^{-1} . \mathrm{K}_{1}$ P-STATs are also strongly seasonal at Port Hardy and Point Atkinson. Maximum trend values in A-STATs occur mostly in September or October, with minimums during May or June. Finally, for $\mathrm{O}_{1}$ A-STATs (Figure 29), significant seasonal variation is seen at five Canadian gauges, the same four in Canada as $\mathrm{K}_{1}$, with the addition of Bella Bella, but no clear pattern in seasonal timing of maximums and minimums is evident. For P-STATs, there is no significant seasonality seen in this quadrant, except for $\mathrm{K}_{1}$ at Point Atkinson and Port Hardy. 


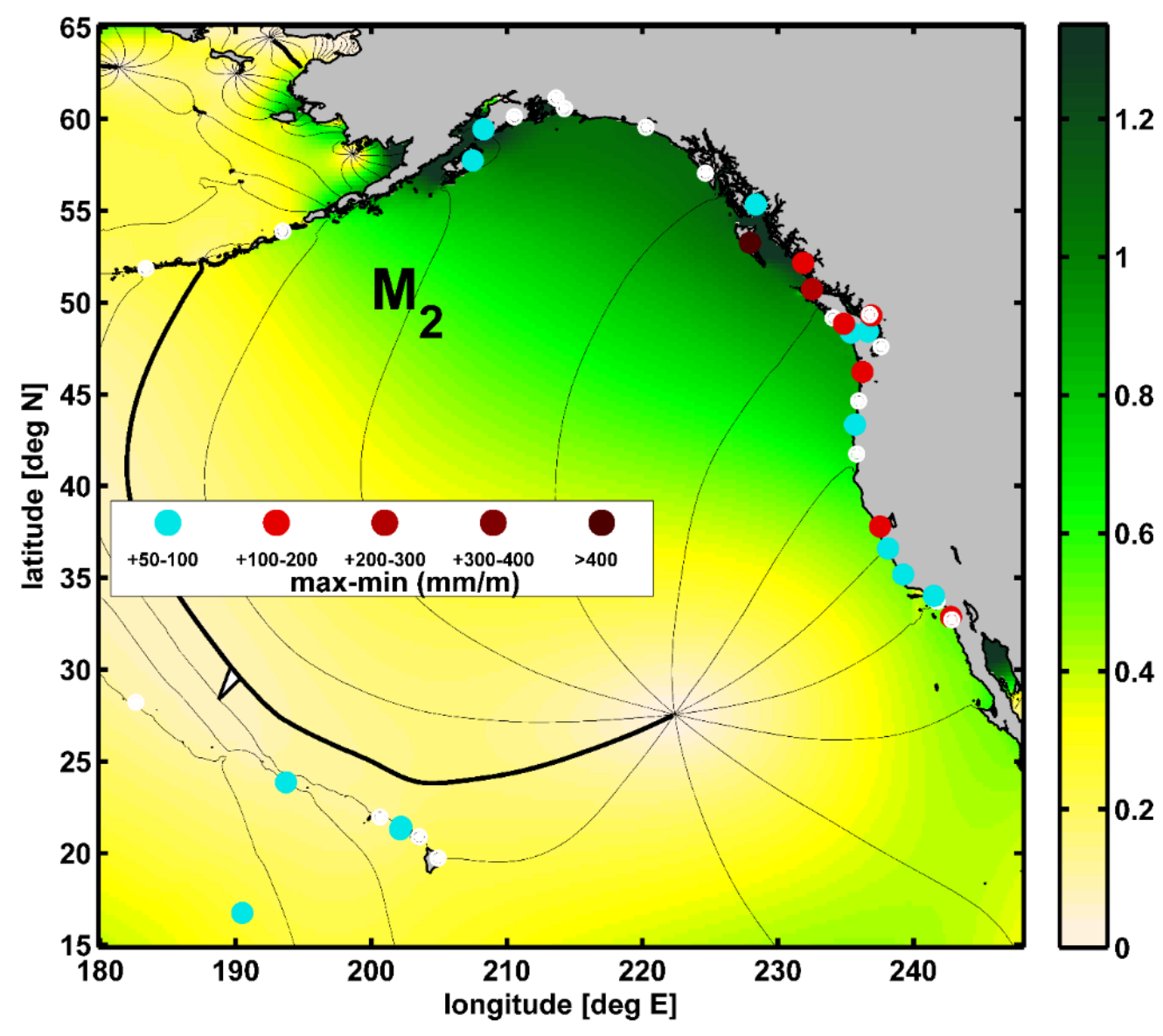

Figure $26 \mathrm{M}_{2}$ A-STAT map in Northeast Pacific, showing range of monthly TAT determinations of amplitude anomaly trends (for a 1 meter MSL rise). Range is defined as the difference of the maximum monthly TAT minus the minimum monthly TAT; units are in $\mathrm{mmm}^{-1}$. Statistically insignificant values are indicated by white circles. 


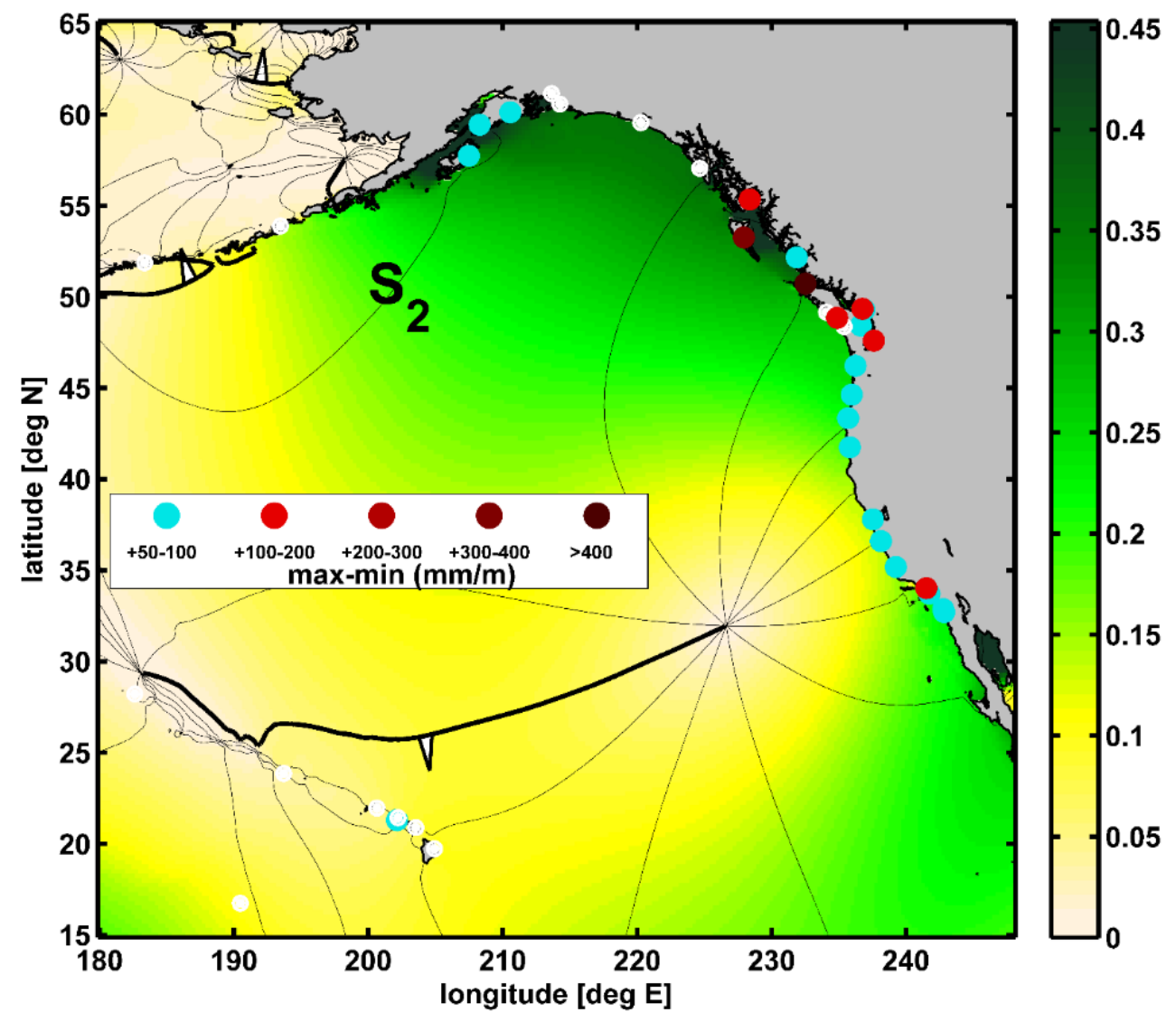

Figure $27 \mathrm{~S}_{2}$ A-STAT map in Northeast Pacific, showing range of monthly TAT determinations of amplitude anomaly trends (for a 1 meter MSL rise). Range is defined as the difference of the maximum monthly TAT minus the minimum monthly TAT; units are in $\mathrm{mmm}^{-1}$. Statistically insignificant values are indicated by white circles. 


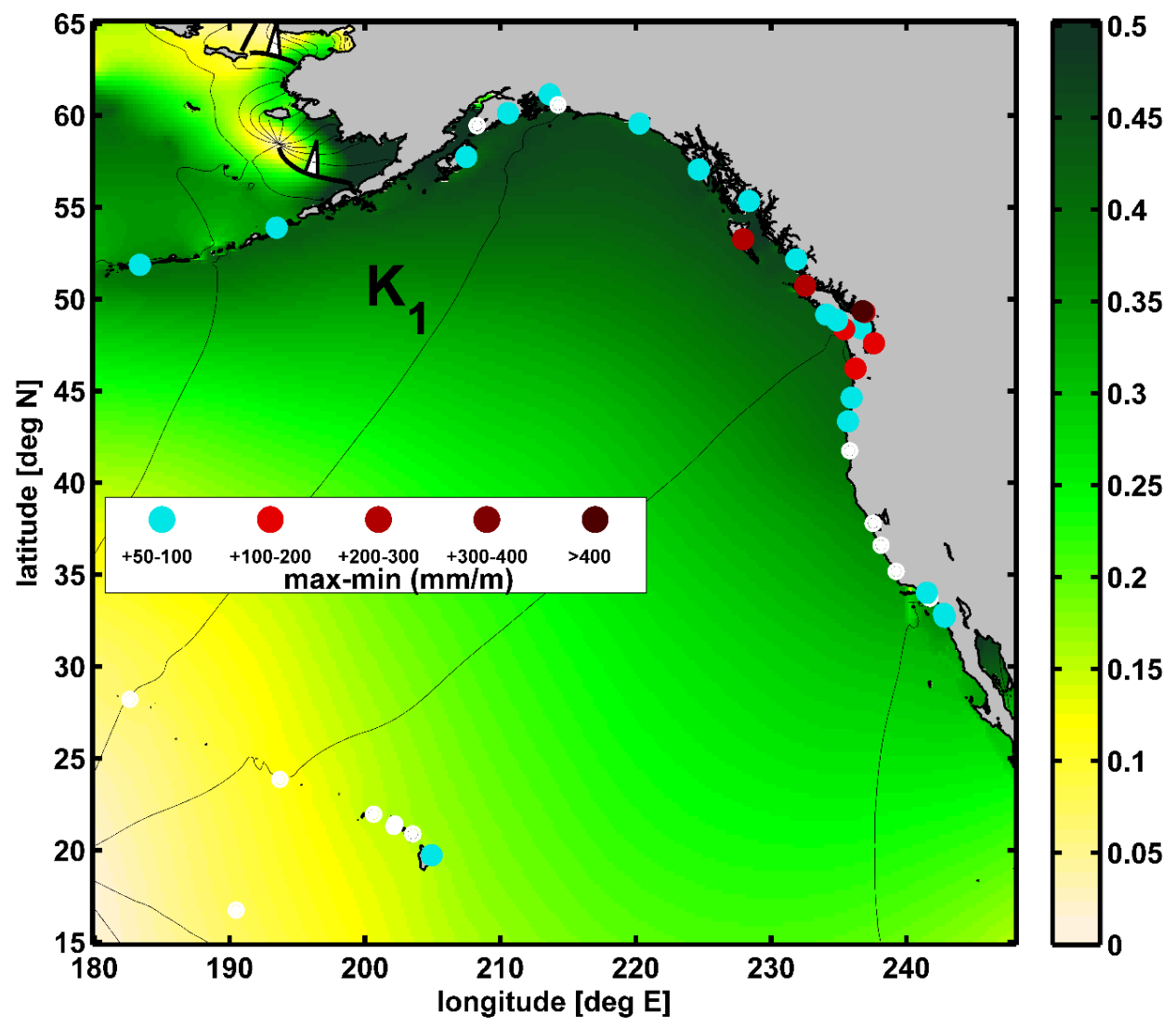

Figure $28 \mathrm{~K}_{1}$ A-STAT map in Northeast Pacific, showing range of monthly TAT determinations of amplitude anomaly trends (for a 1 meter MSL rise). Range is defined as the difference of the maximum monthly TAT minus the minimum monthly TAT; units are in $\mathrm{mmm}^{-1}$. Statistically insignificant values are indicated by white circles. 


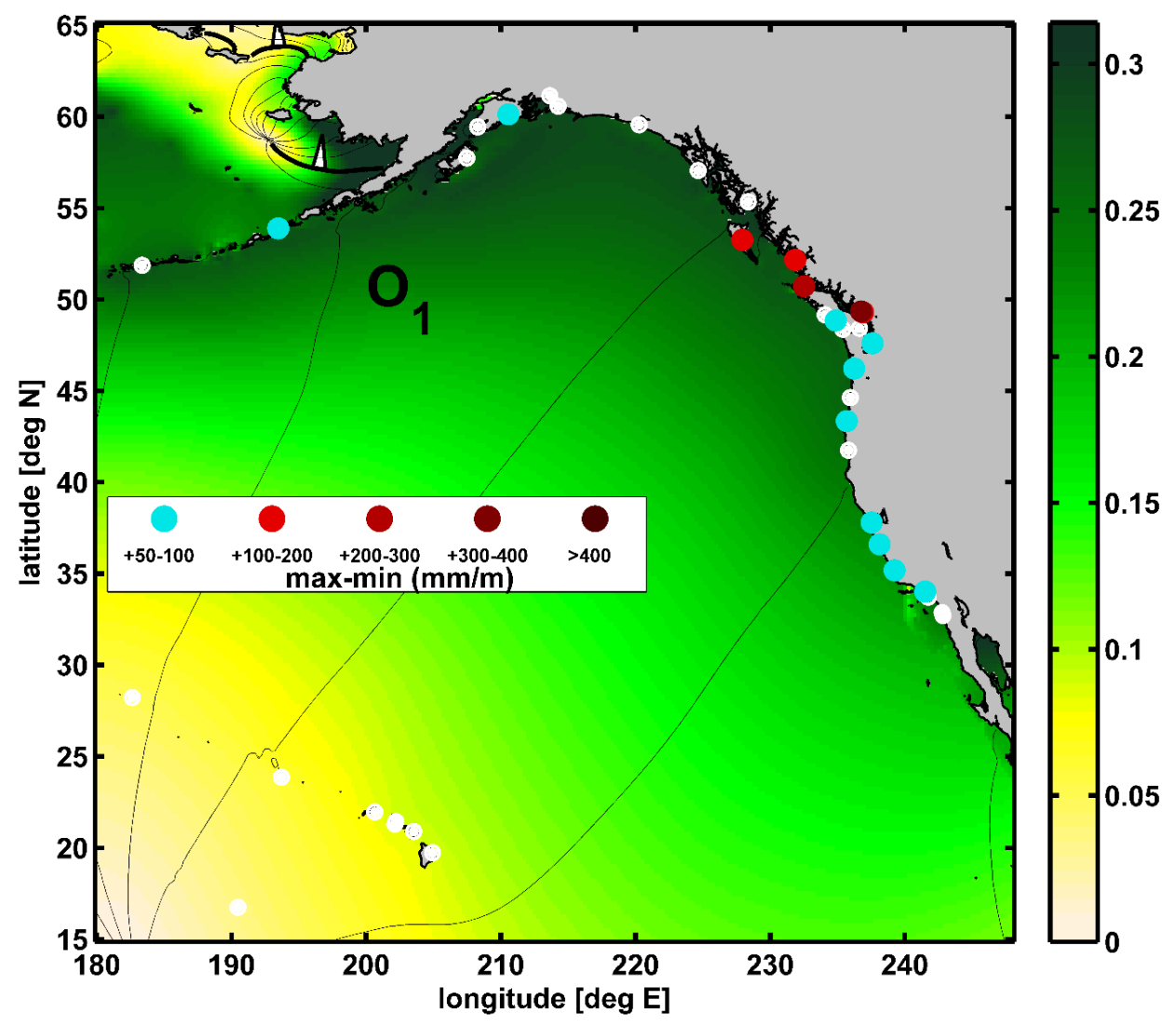

Figure $29 \mathrm{O}_{1}$ A-STAT map in Northeast Pacific, showing range of monthly TAT determinations of amplitude anomaly trends (for a 1 meter MSL rise). Range is defined as the difference of the maximum monthly TAT minus the minimum monthly TAT; units are in $\mathrm{mmm}^{-1}$. Statistically insignificant values are indicated by white circles. 


\subsubsection{Southeast Pacific STATs results}

In the Southeast region of the Pacific, no plots are presented, since there was very little significant seasonality seen for any A-STATs. For $\mathrm{M}_{2}$, only Puerto Montt, Tahiti and Buena Ventura, Colombia showed significant seasonal ranges of 345, 228, and 106 $\mathrm{mmm}^{-1}$, respectively (Table 5). Puerto Montt also showed seasonality in the $\mathrm{S}_{2}$ A-STAT of $419 \mathrm{mmm}^{-1}$, and in the $\mathrm{K}_{1}$ A-STAT of $100 \mathrm{mmm}^{-1}$. Additionally, Tahiti also has a strong phase seasonality in $\mathrm{K}_{1}, \mathrm{M}_{2}$, and $\mathrm{S}_{2}$.

\subsubsection{Northwest Pacific STATs results}

Figures 30-33 display the significant A-STATs in the Northwest Pacific. Only Keelung $\left(100 \mathrm{mmm}^{-1}\right)$ in Taiwan, and also Toba $\left(114 \mathrm{mmm}^{-1}\right)$ and Tokyo $\left(247 \mathrm{mmm}^{-1}\right)$ in Japan show strong seasonality in $\mathrm{M}_{2}$ A-TATs (Figure 30), which both have maxima during July and minima during February. There are no significant P-STATs in $\mathrm{M}_{2}$. For $\mathrm{S}_{2}$ A-STATs (Figure 31), only Tokyo $\left(175 \mathrm{mmm}^{-1}\right)$ and Nagasaki $\left(101 \mathrm{mmm}^{-1}\right)$ in southern Japan exhibit strong seasonality in amplitude, however, seven gauges show significant phase variability, all of which achieve a maximum during June and reach a minimum during January. Four gauges show seasonality greater than $100 \mathrm{mmm}^{-1}$ in $\mathrm{K}_{1}$ A-STATs (Figure 32); Hamada, Hakodate, Hachinohe, and Miyako, with maximums mainly in late summer or fall and minimums in spring. Three gauges show significant phase seasonality (Hakodate, Abishiri, Hamada), with maxima in September and minima during April or May. For $\mathrm{O}_{1}$ A-STATs (Figure 33), there are four gauges with moderate seasonality 
(Kaohsiung, Kushiro, Wakkanai, and Tokyo) in amplitude but timings are mixed, and six gauges with seasonality in phase (Abishiri, Hamada, Ofunato, Wakkanai, Nagasaki, and Nishinoomote), all of which reach maximum during March or April, with less coherent timing of minima.

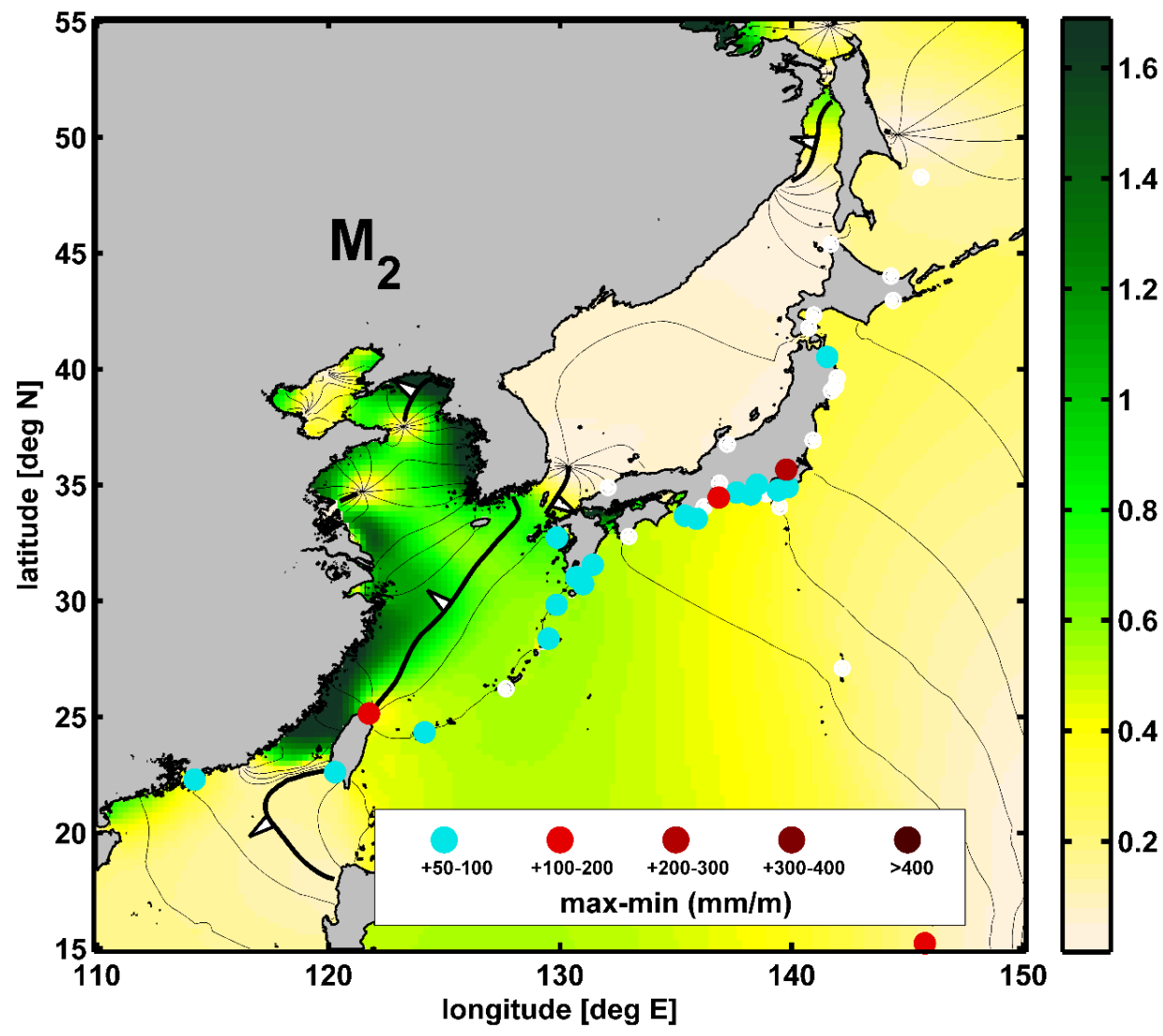

Figure $30 \mathrm{M}_{2}$ A-STAT map in Northwest Pacific, showing range of monthly TAT determinations of amplitude anomaly trends (for a 1 meter MSL rise). Range is defined as the difference of the maximum monthly TAT minus the minimum monthly TAT; units are in $\mathrm{mmm}^{-1}$. Statistically insignificant values are indicated by white circles. 


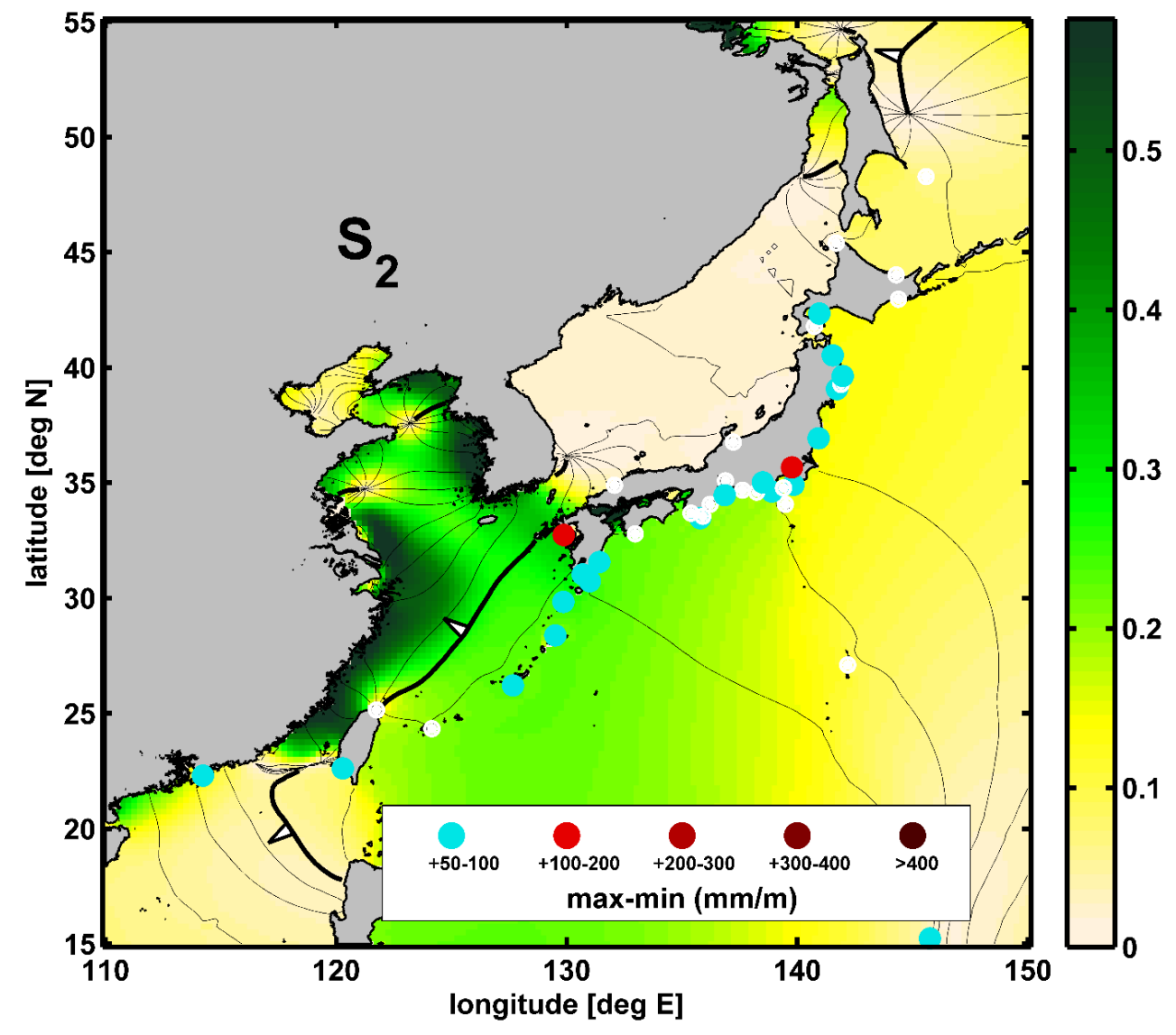

Figure $31 \mathrm{~S}_{2} \mathrm{~A}$-STAT map in Northwest Pacific, showing range of monthly TAT determinations of amplitude anomaly trends (for a 1 meter MSL rise). Range is defined as the difference of the maximum monthly TAT minus the minimum monthly TAT; units are in $\mathrm{mmm}^{-1}$. Statistically insignificant values are indicated by white circles. 


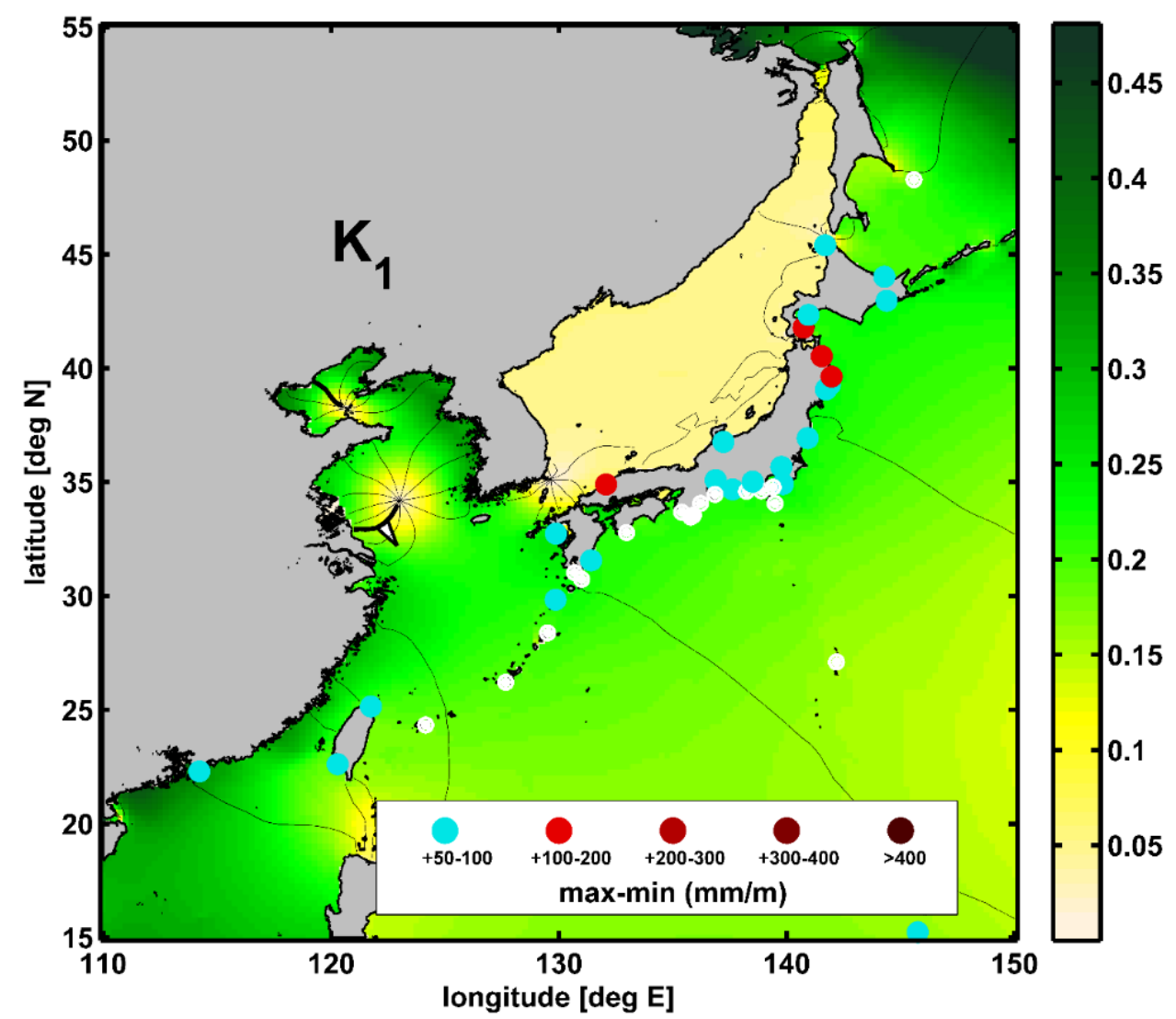

Figure $32 \mathrm{~K}_{1} \mathrm{~A}-\mathrm{STAT}$ map in Northwest Pacific, showing range of monthly TAT determinations of amplitude anomaly trends (for a 1 meter MSL rise). Range is defined as the difference of the maximum monthly TAT minus the minimum monthly TAT; units are in $\mathrm{mmm}^{-1}$. Statistically insignificant values are indicated by white circles. 


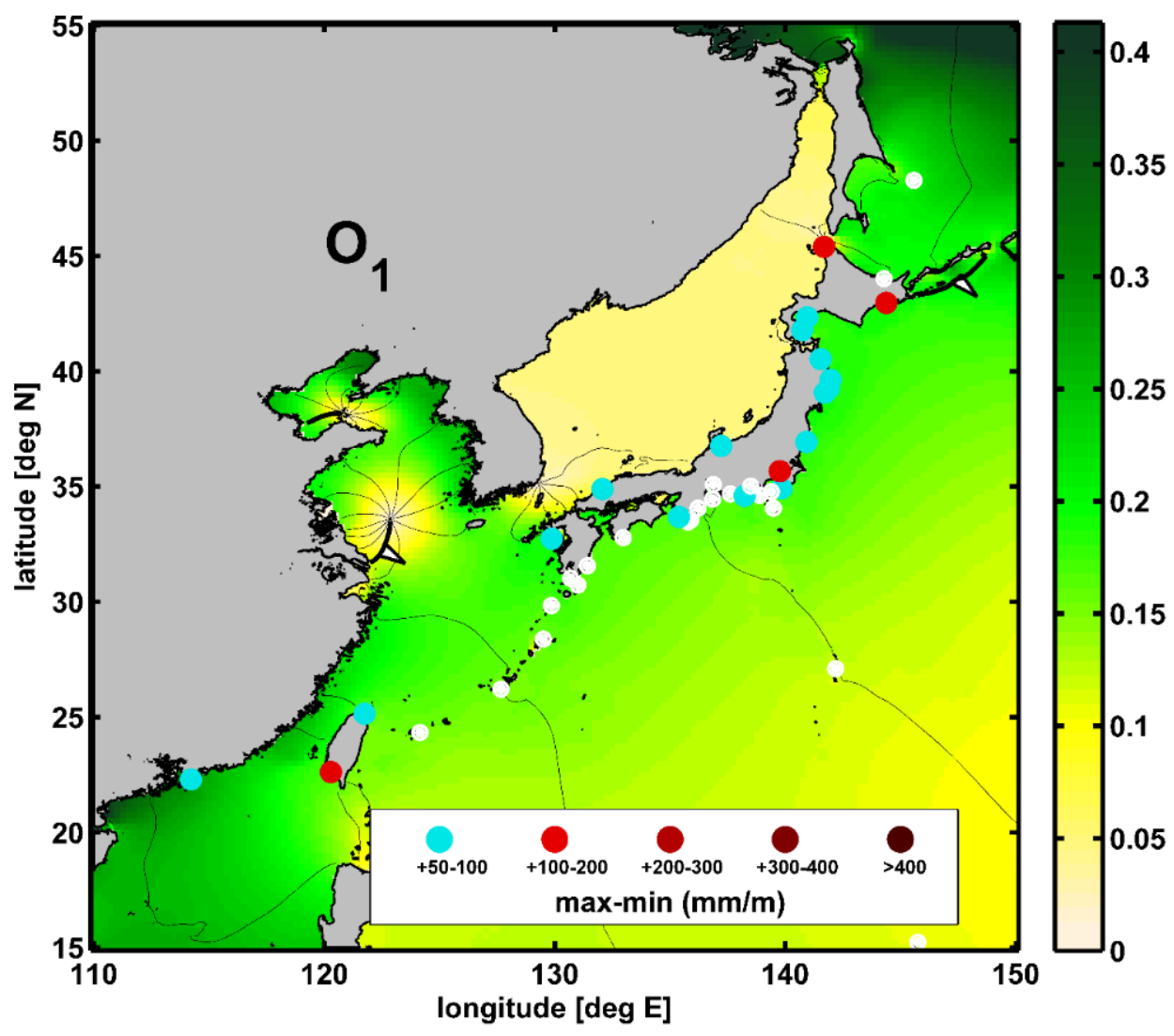

Figure $33 \mathrm{O}_{1} \mathrm{~A}-\mathrm{STAT}$ map in Northwest Pacific, showing range of monthly TAT determinations of amplitude anomaly trends (for a 1 meter MSL rise). Range is defined as the difference of the maximum monthly TAT minus the minimum monthly TAT; units are in $\mathrm{mmm}^{-1}$. Statistically insignificant values are indicated by white circles. 


\subsubsection{Southwest Pacific STATs results}

The Southwest Pacific STATs, shown in Figures 34-37, exhibit more strong seasonality than any other quadrant. Figure 34 displays the $M_{2}$ A-STATs, of which 22 are moderately to strongly seasonal, with variability seen at both island and coastal gauges. Pohnpei, Port Villa, and Suva are both over $200 \mathrm{mmm}^{-1}$, and two of three Philippine gauges also show moderate variation. There is a high concentration of strongly seasonal behavior at the majority of gauges in Malaysia, Thailand, and Vietnam, with some locations exceeding a seasonal difference in tidal anomaly trends of $400 \mathrm{mmm}^{-1}$. The timings of extrema are also very coherent, as the majority of these gauges reach maximum A-STAT determinations in August, and minimum determinations in March. Timings are not coherent in other regions for $\mathrm{M}_{2}$. For $\mathrm{S}_{2}$ A-STATs (Figure 35), 14 gauges have seasonality greater than $100 \mathrm{mmm}^{-1}$, with a similar distribution as $\mathrm{M}_{2}$. Temporal coherence of extreme values are similarly coherent in Southeast Asian waters, as was for $M_{2}$. At most locations, maximum values are found during late spring or early summer, with minimums during winter. Phase seasonality is significant at eight gauges, with the strongest seasonality is again seen in and around Malaysia and Vietnam. Phase seasonality is also temporally coherent in Southeast Asian waters, with all significant gauges having maxima in March or April, and minima during June.

Seasonal behavior of $\mathrm{K}_{1}$ A-STATs (Figure 36 ) show that 20 gauges have strong seasonality. Guam has a seasonal difference of $110 \mathrm{mmm}^{-1}$; Brisbane, Hobart, and 
Booby Island, Australia have differences of $135-222 \mathrm{mmm}^{-1}$. The remainder of significantly seasonal behavior is seen in the Southeast Asian waters, with seasonal differences exceeding $300 \mathrm{mmm}^{-1}$ at some locations, many greater than $200 \mathrm{mmm}^{-1}$. Temporal coherence in the Southeast Asian waters is not as clear as was for the semidiurnals, but the majority of maxima happen during late summer, and most minima happen during fall or early winter. Phase variability is also strong at 10 gauges in this region, all in Malaysia or Vietnam, with most maxima are found during March, and most minima during June. There is a very complex spatial variability to this behavior, and it suggests that the $\mathrm{K}_{1}$ tidal variability is very complex in both amplitude and phase. Finally, Figure 37 shows the $\mathrm{O}_{1}$ amplitude seasonality; 13 gauges are moderate to strong. Yap and Suva exhibit seasonality of 148 and $119 \mathrm{mmm}^{-1}$, respectively; all other locations of strongly seasonal behavior are in Malaysian waters, exceeding $200 \mathrm{mmm}^{-1}$ at some locations. As for $\mathrm{K}_{1}$, temporal patterns of maxima/minima are much more varied (Table 5), but generally, maxima occur during spring months, and minima during winter months. Phase variability is strong and significant at four Malaysian gauges in $\mathrm{O}_{1}$. Maxima are mainly in summer, but minima are mixed in their timing. 


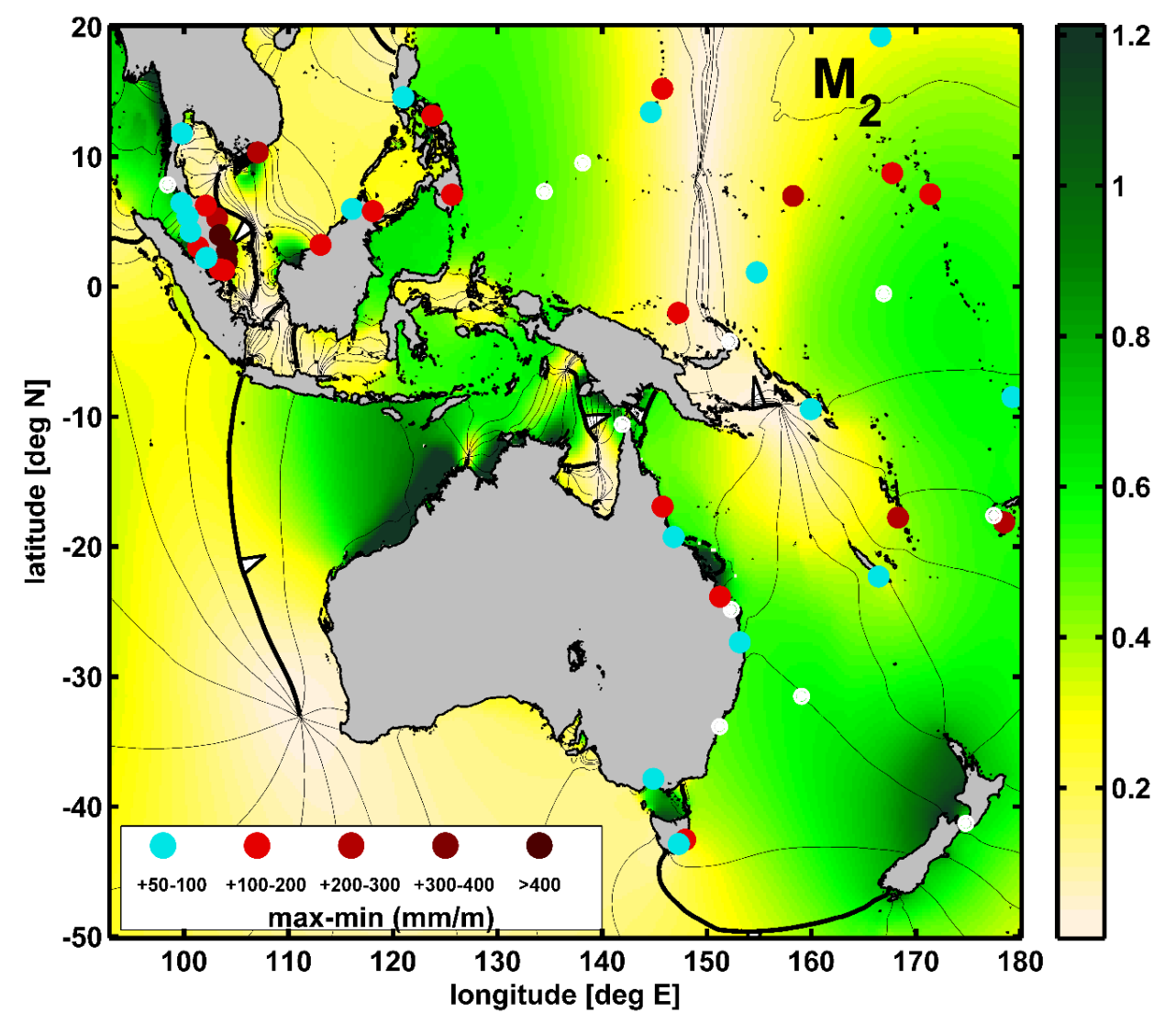

Figure $34 \mathrm{M}_{2}$ A-STAT map in Southwest Pacific, showing range of monthly TAT determinations of amplitude anomaly trends (for a 1 meter MSL rise). Range is defined as the difference of the maximum monthly TAT minus the minimum monthly TAT; units are in $\mathrm{mmm}^{-1}$. Statistically insignificant values are indicated by white circles. 


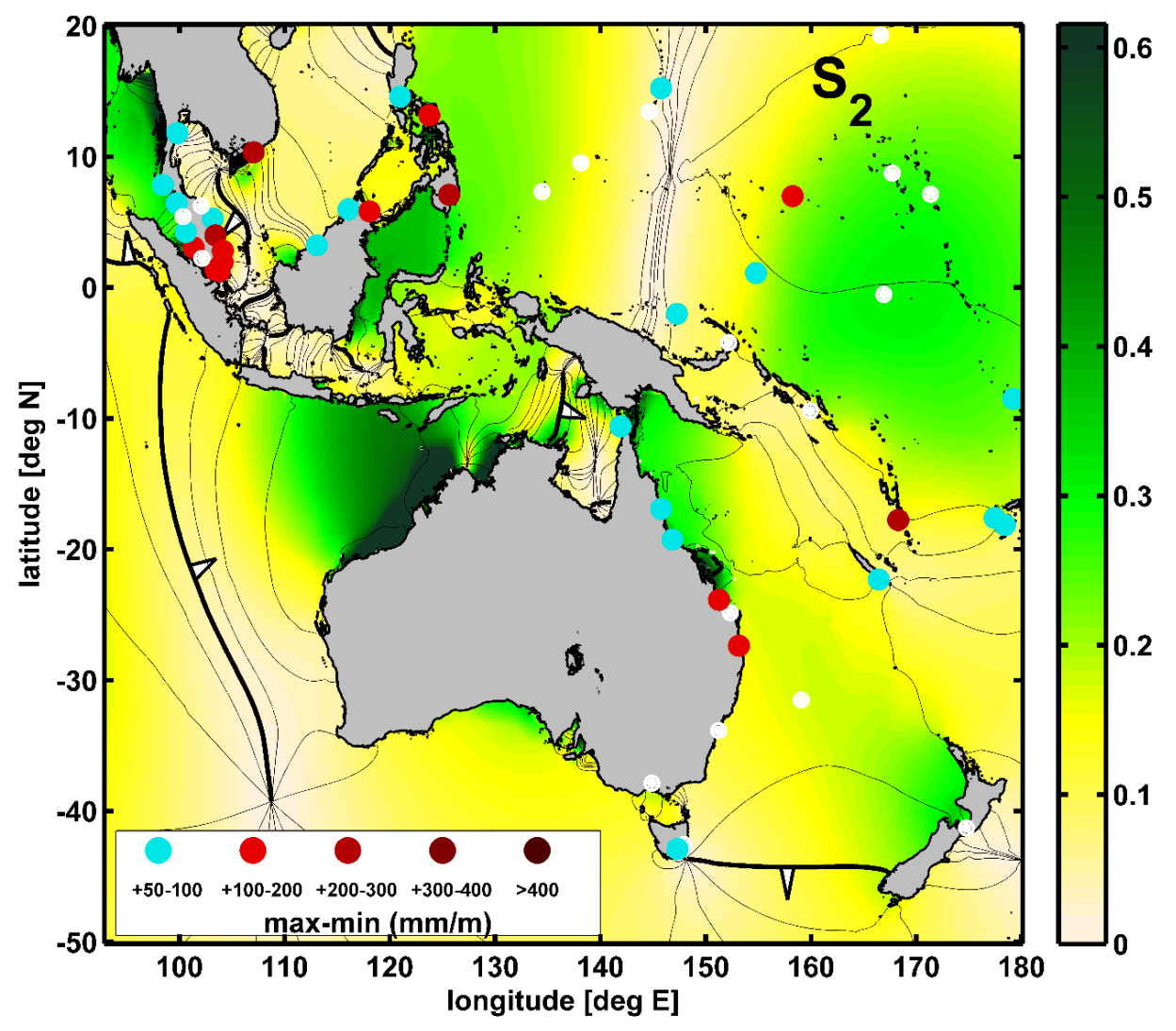

Figure $35 \mathrm{~S}_{2}$ A-STAT map in Southwest Pacific, showing range of monthly TAT determinations of amplitude anomaly trends (for a 1 meter MSL rise). Range is defined as the difference of the maximum monthly TAT minus the minimum monthly TAT; units are in $\mathrm{mmm}^{-1}$. Statistically insignificant values are indicated by white circles. 


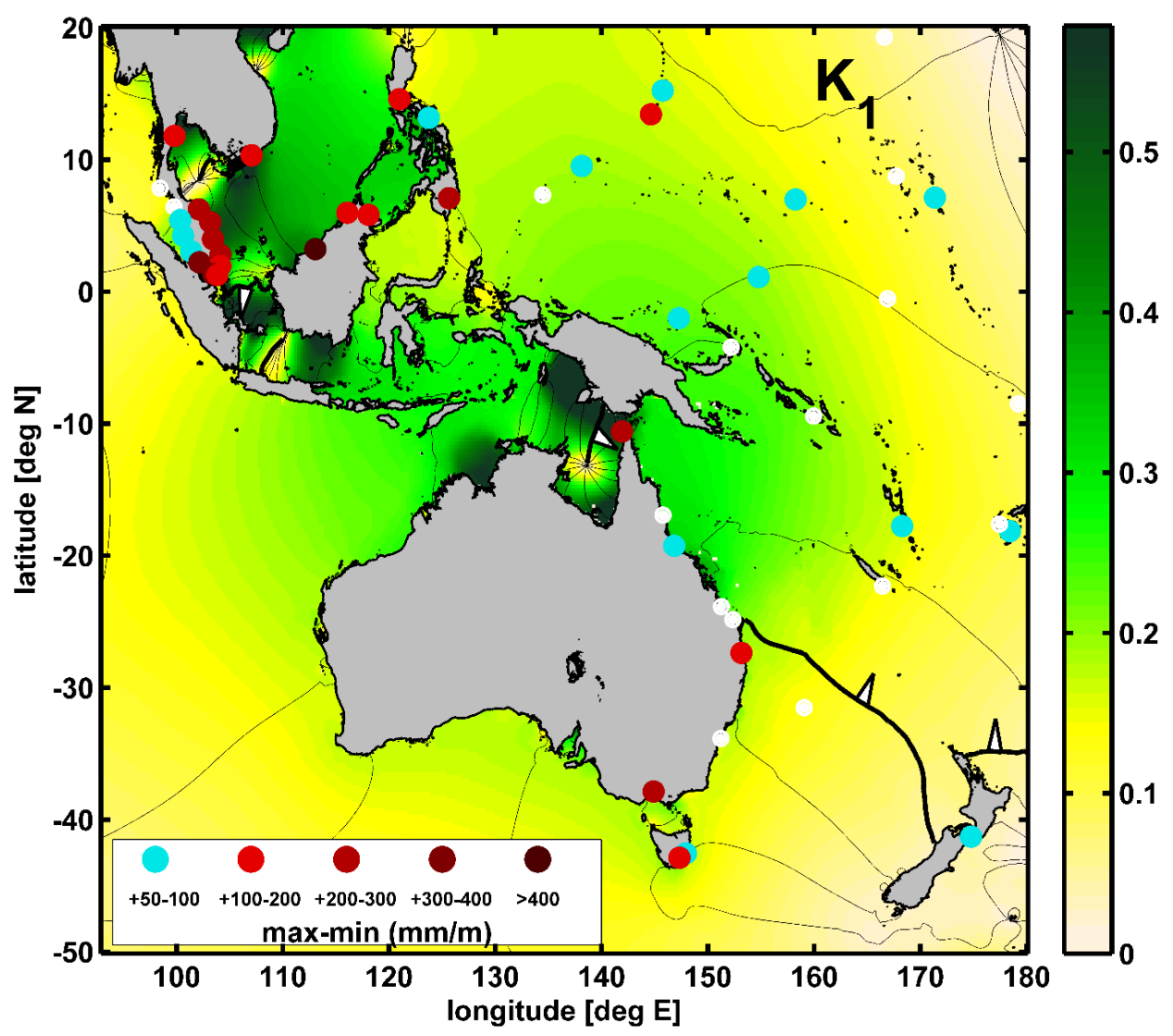

Figure $36 \mathrm{~K}_{1}$ A-STAT map in Southwest Pacific, showing range of monthly TAT determinations of amplitude anomaly trends (for a 1 meter MSL rise). Range is defined as the difference of the maximum monthly TAT minus the minimum monthly TAT; units are in $\mathrm{mmm}^{-1}$. Statistically insignificant values are indicated by white circles. 


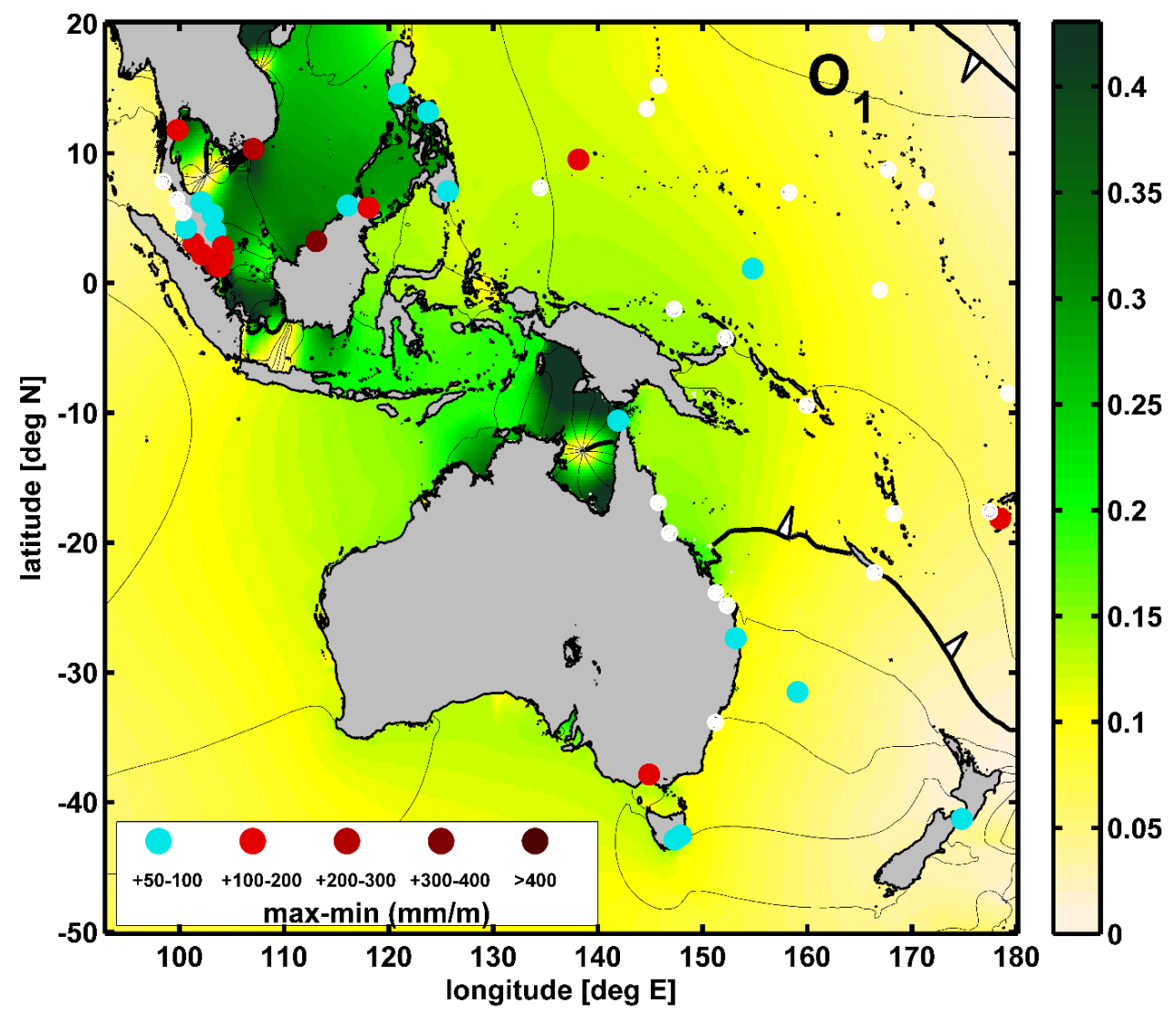

Figure $37 \mathrm{O}_{1} \mathrm{~A}$-STAT map in Southwest Pacific, showing range of monthly TAT determinations of amplitude anomaly trends (for a 1 meter MSL rise). Range is defined as the difference of the maximum monthly TAT minus the minimum monthly TAT; units are in $\mathrm{mmm}^{-1}$. Statistically insignificant values are indicated by white circles. 


\subsection{Discussion}

\subsubsection{Yearly (TAT) variability summary}

Tidal anomaly trends (TATs) based on yearly analyses are significant at 93 gauges in the total domain for $\mathrm{M}_{2}$ A-TATs, with 20 in the NE, 12 in the SE, 23 in the NW, and 38 in the SW. $\mathrm{M}_{2}$ P-TATs are significant at 55 gauges (13 NE; $7 \mathrm{SE} ; 14 \mathrm{NW} ; 21 \mathrm{SW}$ ). $\mathrm{S}_{2} \mathrm{~A}$ TATs are significant at 66 total gauges (12 NE; 6 SE; 19 NW; 29 SW), and P-STATs are significant at 47 gauges (10 NE; $7 \mathrm{SE} ; 8 \mathrm{NW} ; 22 \mathrm{SW}$ ). For the diurnal constituents, $\mathrm{K}_{1} \mathrm{~A}-$ TATs are significant at 82 gauges (20 NE; 7 SE; 26 NW and 29 SW), P-STATs are significant at 42 gauges ( $2 \mathrm{NE} ; 10 \mathrm{SE} ; 11 \mathrm{NW}$, and $19 \mathrm{SW}$ ). Lastly, $\mathrm{O}_{1} \mathrm{~A}$-TATS are significant at 59 gauges (15 NE; 4 SE; 19 NW; and 21 SW), and P-TATs are significant at 61 gauges (9 NE; 8 SE; 21 NW; and 23 SW).

\subsubsection{Yearly (TAT) regional summaries}

\subsubsection{Summary of Northeast Pacific TATs}

The Northeast Pacific shows moderate tidal anomaly trends. The semidiurnal response is strong in Hawaii, and along the majority of the northern US and Canadian coasts. The majority of $\mathrm{M}_{2}$ A-TATs are positive, and are mainly negative for $\mathrm{S}_{2}$ A-TATs. Phase responses are mainly positive for $\mathrm{M}_{2}$ and $\mathrm{S}_{2}$. An eastward or southeastward advection of the $\mathrm{M}_{2}$ amphidrome near Hawaii might explain the mainly positive trends seen the Gulf of Alaska, though there are also gauges in the Gulf that show negative responses. The more likely explanation in Hawaii is a changing $M_{2}$ internal (baroclinic) 
tide (Colosi and Munk, 2006). Diurnal responses (the $\mathrm{K}_{1}$ and $\mathrm{O}_{1} \mathrm{~A}$-TATs) are largest in the Gulf of Alaska, with more negative than positive responses seen. In Hawaii, diurnal responses are mainly positive. Phase trends for diurnal constituents are mainly insignificant or weak, but there is a concentration of positive P-TATs for both diurnals along the northern US coast. Very strong tidal anomaly trends are seen at Astoria, OR, San Francisco, CA, and near Victoria Island in Canada; these trends are likely due in part to the flows of the Columbia, Sacramento, and Frasier Rivers, respectively. In the context of amphidromic movement, the consistently positive $\mathrm{O}_{1}$ A-TATs in Hawaii may indicate a southwestern migration of the amphidrome just off the bottom left corner of this map, though $\mathrm{K}_{1}$ trends in Hawaii do not support such a conclusion for $\mathrm{K}_{1}$.

\subsubsection{Summary of Southeast Pacific TATs}

The Southeast Pacific has the least coverage of any quadrant examined ( 20 gauges), and a very sparse spatial distribution of gauges. The strongest A-TATs were seen for the semidiurnal constituents at both island gauges and gauges along the South American coast. Both $\mathrm{M}_{2}$ and $\mathrm{S}_{2}$ have complex amphidromic systems in this area, the interactions of which are hard to determine from the scattered distribution of tide gauge data in time and space, but migrations of the amphidromic points may be contributing to the tidal trends. The $\mathrm{S}_{2} \mathrm{~A}$-TATs around the amphidrome near Tahiti are generally negative, which may indicate a westward migration of this amphidromic point. A southeast deflection of the $M_{2}$ amphidrome near Tahiti may explain the positive A- 
TATs nearby, but not the gauges located further away, and a westward motion of the amphidrome near the Galapagos Islands might contribute to the positive trends seen in the coastal region nearby, though the trends at the two Galapagos gauges (Baltra and Santa (ruz) are opposed. For diurnals, an east or northeast advection of the amphidrome near Tahiti would correspond to the positive changes seen at both islands and coasts for $\mathrm{K}_{1}$. No clear pattern of amplitude changes can be seen for $\mathrm{O}_{1}$, though large P-TATs near the amphidromic point may indicate a change of rotational characteristics. Phase trends are generally larger for the diurnal constituents than the amplitude trends, and are exceptionally large at Tahiti, which is located very near the amphidromic points of all constituents, further suggesting possible amphidromic migrations or interactions occurring in the region.

The tidal trends at Puerto Montt in southern Chile are very different from those of other gauges in the Pacific. The A-TATs in all constituents are strongly negative, with the semidiurnal trends being $-568 \mathrm{mmm}^{-1}$ for $\mathrm{M}_{2}$, and $-272 \mathrm{mmm}^{-1}$ for $S_{2}$. This behavior may possibly be due to a resonant effect; the tide gauge at Puerto Montt is part of one of the largest fjord systems in the world with complex oceanographic characteristics; for a detailed explanation of the region, see Pantoja et al. (2011). This basin structure, in which inlets are deep, long, and narrow, may trap and amplify long-period oceanic waves such as tides. The fjord system may have a resonant period near 12 hours. If so, then MSL rise is changing the basin geometry and bringing it away from semidiurnal resonance. Indeed, mean semidiurnal amplitudes are very large at this tide gauge as 
compared to tidal amplitudes found from satellite solutions just offshore, and tidal ranges of $7 \mathrm{~m}$ and tidal currents of $4 \mathrm{~ms}^{-1}$ are seen at Puerto Montt (Cáceres et al., 2003), so a resonant mechanism is plausible within the Chilean inland seas, such as is found in the Bay of Fundy. Aiken (2008) simulated barotropic tides in the region, finding that the inland seas act like a forced damped channel with a resonant period near that of the semidiurnal tides $\left(\sim 10 \mathrm{~h}^{-1}\right)$. It is also possible that an eastward migration of the far southern semidiurnal amphidromes could contribute to negative $\mathrm{M}_{2}$ and $\mathrm{S}_{2}$ ATATs. The closest gauges to Puerto Montt on the $\mathrm{M}_{2}$ map also indicate a negative trends, but at nowhere near the magnitude of that seen at Puerto Montt, so the amphidromic motion is at best a partial solution to the question of this extreme variability, with the more likely explanation being a departure from resonance in the semi-enclosed seas of Chile.

\subsubsection{Summary of Northwest Pacific TATs}

The Northwest Pacific shows moderate to strong tidal amplitude and phase anomaly trends at numerous stations for all constituents investigated. For $M_{2}$ A-TATs, negative trends are observed in southern Japan and at island stations further south, but are very strongly positive along the central coast of Japan and at Hong Kong. For $\mathrm{S}_{2}$, trends are more consistently negative, but also weaker in magnitude. Semidiurnal PTATs are generally weak or insignificant, and without any clear geographical pattern. Diurnal tidal amplitude anomaly trends are mainly weakly negative, but $\mathrm{K}_{1} \mathrm{~A}$-TATs are 
consistently positive in the southern part of the domain, including a very strong positive trend at Hong Kong. Phase trends are spatially variable for $\mathrm{K}_{1}$, but $\mathrm{O}_{1}$ shows a geographical concentration of positive P-TATs along the central coast of Japan. All of Japan is essentially part of one amphidromic system in all constituents, with relatively uniform tidal amplitudes and nearly concurrent phases over large areas, particularly for diurnal constituents, so amphidromic motion is not a likely cause of the tidal trends observed here. However, the gauges in Taiwan and Hong Kong are more closely influenced by the tidal dynamics of the surrounding marginal waterways such as the Taiwan Strait, Luzon Strait, and the South China Sea than the greater Pacific, and even small migrations of the amphidromes within these waterways may be of consequence.

Tidal trends in both amplitude and phase tend to be largest along the central coast of Japan, near Tokyo. This offshore area has regions of very complex ocean bathymetry, and is also likely influenced by the effect of the Kuroshio Current, which branches south of Tokyo, and exhibits annual and interannual variability (Mizuno and White, 1983). Though amplitude and phase trends are relatively coherent in the tightly concentrated tide gauge distribution surrounding Tokyo, the tidal trends seen at the gauge at Tokyo harbor itself are among the strongest of any in the domain, and are mainly opposite in sign to the trends observed at the nearby gauges. Tokyo and surrounding ports have undergone massive harbor development over the past 50 years, and this is the most likely cause for the variability (Min-Sheng, 2000), so the correlation with MSL fluctuations is possibly coincidental. The combination of this unique behavior, 
and the effect of the local bathymetry and currents makes the region around Tokyo a good candidate for further study. Another interesting case is that of Hong Kong, which has very large positive A-TATs in all constituents, the combined effect of which approach $+300 \mathrm{~mm}$ for a $1 \mathrm{~m} \mathrm{MSL}$ rise. If these trends persist as MSL increases, coastal regions might see inundation greatly increased at high tides, unless harbor modifications are the cause and the correlation with MSL is coincidental.

\subsubsection{Summary of Southwest Pacific TATs}

The foregoing analyses suggest that the area richest in tidal variability in all constituents is the Southwestern Pacific. More gauges in this quadrant showed significant tidal anomaly trends here, and the magnitude of variability is larger here than anywhere else. There is a near-even distribution of significant trends (positive and negative) at both island and coastal locales. Semidiurnal tidal trends are very strong and coherent in the Solomon Sea at Honiara, Manus, and Rabaul. Australian and Philippine trends are also very strong, but are mixed in orientation. A concentration of large magnitude significant TATs (both amplitude and phase) are found in the SE Asian waters, including the Gulf of Thailand, the South China Sea, and the Malacca Strait which connects to the Indian Ocean. Though magnitudes of TATS are large, there is also a large spread in the data (leading to large uncertainties); these are related to the seasonal modification of tidal anomaly trends (i.e., STATs). 
For the rest of the domain, amphidromic migration modified by local processes (e.g., harbor modification) is the mostly likely explanation. For $\mathrm{M}_{2}$, (Figure 22) an eastward movement of the amphidrome east of Pago Pago, along with a counterclockwise rotation that expands the anti-node (centered on the Equator) westward and southwest-ward, would agree with most of the observed $M_{2}$ TATs. The long, narrow $\mathrm{M}_{2}$ amphidrome (more or less aligned with the Mariana Trench) is not changing in any obvious manner. The $S_{2}$ patterns (Figure 23) of A-TATs and P-TATs show some similarities to those for $M_{2}$ (e.g., at Yap, Kapingamarangi, and Noumea), but also many differences (e.g., Legaspi, Rabaul and Pago Pago). Honiara has a similar $\mathrm{M}_{2} \mathrm{~A}-\mathrm{TAT}$ to other regional gauges, but an opposite P-TAT. The overall pattern of change for $\mathrm{S}_{2}$ may echo $\mathrm{M}_{2}$, with an amphidromic point east of Pago Pago moving westward, and a central anti-node rotating counter-clockwise. However, $\mathrm{S}_{2}$ has a significant radiational component that is absent for $M_{2}$ (Godin, 1986; Ray, 2001; Arbic, 2005), which may explain the differences between the two constituents. Still, there is a suggestion of strong regional coherence for the semidiurnals, as with the diurnals.

The observed TATs for $\mathrm{K}_{1}$ (Figure 24) are consistent with a westward or slightly northwest-ward advection and counter-clockwise rotation of the amphidrome in the far northeastern corner, and an eastward movement and clockwise rotation of an amphidrome east of Pago Pago (off the map) associated with positive MSL fluctuations. These combined motions are consistent with the observed increase in the $K_{1}$ amplitudes within the Coral Sea, as evidenced by the TATs in the area. The $\mathrm{O}_{1}$ tidal field shows a 
similar movement in amphidromic points as $\mathrm{K}_{1}$ (Figure 25). Unlike $\mathrm{K}_{1}$, there is an additional amphidromic point off the New Zealand coast. A westward movement in this point would explain trends observed at the Australian shelf and Auckland. Thus, changes in diurnal tides may be on an amphidromic scale, though modulated by other local factors at some stations. Note that amphidromic movements are not a cause of the observed TATs, but are rather symptoms of tidal evolution that represent a redistribution the tidal fields driven by other factors.

\subsubsection{Combined A-TATs}

The changes in tidal amplitudes have been considered individually, but the combined effect of all constituents, and therefore the change in total tidal range, is important for possible total peak water levels under future sea level rise scenarios. Table $3 \mathrm{~b}$ lists the effect of combined $\mathrm{M}_{2}, \mathrm{~S}_{2}, \mathrm{~K}_{1}$, and $\mathrm{O}_{1}$ significant A-TATs, with all errors propagated through, and significance defined as before (SNR $>2.0)$. There are over 40 stations where the combined tidal response is greater than $100 \mathrm{~mm}$ for a 1 meter MSL fluctuation ( $10 \%$ of the sea level change), these values are listed in bold text in Table $3 \mathrm{~b}$. The combined A-TATs in Hawaii (Honolulu and Hilo) both show a combined trend of over $100 \mathrm{mmm}^{-1}$, but the large majority of this is the $\mathrm{M}_{2}$ trend, and is likely due to baroclinic mechanisms (Colosi and Munk, 2006). San Francisco, CA, Astoria, OR, and Vancouver and Queen Charlotte, Canada all show a combined negative trend of -120 to $-170 \mathrm{mmm}^{-1}$ for a 1 meter sea level rise. These are mainly river-influenced stations, 
and the lowered amplitudes may be due to increased river flow providing friction (Godin, 1991).

Combined A-TATs at Caldera, Chile are positive, with a total of $+126 \mathrm{mmm}^{-1}$. The anomalously large negative TATs seen in the semidiurnal constituents at Puerto Montt, Chile combine to show a combined response of $-955 \mathrm{mmm}^{-1}$ for a 1 meter sea level rise. However, these steep trends are likely an effect of Puerto Montt moving away from resonance locally, and it is not clear if this steepness can be expected to hold. Further study would be needed to understand the behavior at this station, and there is a lack of nearby tide gauges with which to verify the magnitude of these trends. Ten gauges in the Northwest Pacific show a significant combination of A-TATs. Positive combinations are seen at Okada $\left(+218 \mathrm{mmm}^{-1}\right)$ and Hong Kong $\left(+296 \mathrm{mmm}^{-1}\right)$, which may be of importance in the near future for peak water levels in both of these cities, especially densely populated Hong Kong. Seven gauges that showed a significant combined A-TAT in Japan showed negative responses from -100 to $-294 \mathrm{mmm}^{-1}$, seen in both southern Japan, and along the central coast.

In the Southwest Pacific, 20 gauges show a significant combined A-TAT. At island gauges, Noumea is positive $\left(+130 \mathrm{mmm}^{-1}\right)$, and Guam is negative $\left(-104 \mathrm{mmm}^{-1}\right)$. At coastal tide gauges in the South China Sea, combined trends range from $-309 \mathrm{mmm}^{-1}$ (Tioman, Malaysia), to $+496 \mathrm{mmm}^{-1}$ (Bintulu, Malaysia), suggesting a complex scenario of tidal dynamics that is not well explained by simple linear relations. Elsewhere in the 
Southwest Pacific, there are significant combined A-TATs at Brisbane $\left(+249 \mathrm{mmm}^{-1}\right)$ and Williamstown $\left(-271 \mathrm{mmm}^{-1}\right)$, Australia, and a combined negative tidal response at Manila $\left(-174 \mathrm{mmm}^{-1}\right)$ and Legaspi $\left(-133 \mathrm{mmm}^{-1}\right)$, Philippines. Large combined trends were also observed at Cairns and Gladstone, but errors were also very large, and these trends did not meet the signal-to-noise ratio condition of SNR $>2.0$.

\subsubsection{Combined A-TATs coupled with future MSL rise scenarios}

Consideration will now be given to the effects of these combined A-TATs on future total water levels, when the effects of tidal variations are coupled with sea level rise predictions. A comparison is made for sea level rise based on the global MSL rate as calculated from satellite altimetry of $+3.3 \mathrm{mmyr}^{-1}$ (Church and White, 2011), and for recent predictions of sea level increase based on improved models of Antarctic ice melt scenarios (DeConto and Pollard, 2016). Four stations where the combined trends in ATATs are strongly positive are given focus: Honolulu (+101 $\left.\pm 11 \mathrm{mmm}^{-1}\right)$, Noumea (+130 $\left.\pm 21 \mathrm{mmm}^{-1}\right)$, Brisbane $\left(+249 \pm 38 \mathrm{mmm}^{-1}\right)$, and Hong Kong $\left(+296 \pm 43 \mathrm{mmm}^{-1}\right)$. In addition, four stations where the combined A-TATs are strongly negative are considered: Tioman $\left(-309 \pm 49 \mathrm{mmm}^{-1}\right)$, Sedili $\left(-241 \pm 49 \mathrm{mmm}^{-1}\right)$, Odomari $(-177 \pm 14$ $\left.\mathrm{mmm}^{-1}\right)$, and Nishinoomote $\left(-219 \pm 42 \mathrm{mmm}^{-1}\right)$. Using these values and the expected sea level rise scenarios, the change in tidal range by the end of the century $(2100)$ is calculated, with the assumption that the magnitude of the combined A-TATs will remain 
constant under future higher MSL conditions, and that the rate of increase of total sea level rise can be approximated as a linear function.

In addition to the short-term variability associated with the combined A-TATs, there is also a long-term component of the tidal amplitude trends. The long-term trends are not used in the total water level calculations, as the primary focus here is the behavior of tides with short-term variation in MSL, and the long-term changes are the result of a variety of factors, not just MSL change. Many of the long-term changes in tides may be due to anthropogenic factors, such as massive harbor development, which is likely not to be continued on such a scale in future centuries. Furthermore, some of the stations considered have shorter records, and the calculated long-term trends may not reflect the true long-term behavior, as a longer record length is usually needed to insure an accurate long-term prediction. These long-term rates are still reported to show that the effect of the long-term changes do not overwhelm the effect of the combined A-TATs, but do act in the same direction (positive or negative). Different time scales of the water level spectrum (long-term vs. interannual) may, in general, act in the same direction, or may oppose each other; this point is demonstrated further in Chapter 4 (Part II).

I estimate possible future effects of sea level rise on tides and total water levels as follows. The change in mean sea level $(\triangle M S L)$ is found from the linear rate of $M S L$ rise, multiplied by the length of time for the prediction. Assuming that the A-TAT values 
derived from the historical record are relevant for future, I combine the four A-TATS (sum of contributions of the four major constituents) to obtain a composite tidal anomaly trend. The change in tidal range $(\Delta T R)$ is found by multiplying the change in MSL by the value of the combined A-TAT: $\left(\triangle T R=A-T A T^{*} \Delta M S L\right)$. The change in total sea level $(\Delta \mathrm{TSL}$ ) will then be equal to the sum of these two components ( $\Delta \mathrm{TSL}=\Delta \mathrm{MSL}+$ $\Delta T R$ ), to obtain the total potential change in water levels, assuming constant-valued ATATs. Using the current global rates of sea level rise determined by satellite altimetry of $+3.3 \mathrm{mmyr}^{-1}$ (Church and White, 2011), global sea level will increase by $+0.28 \mathrm{~m}$ by 2100 (relative to 2015). While the phases of $\mathrm{K}_{1}, \mathrm{O}_{1}, \mathrm{M}_{2}$ and $\mathrm{S}_{2}$ are rarely aligned in such a way that they all constructively interfere, their summation provides a useful proxy or 'envelope' of possible tidal amplitudes. A major assumption is that the combined tidal anomaly trends and the combined secular trends are aligned, i.e., occur in the same direction and with the same causality, which is true at all the stations considered. For simplicity, another assumption made here is that sea level rise will be evenly distributed globally and that local changes due to isostatic rebound, plate tectonics, or other vertical land movement are not significant at the stations evaluated (both these factors are important but beyond the scope of this analysis). The calculated increase in MSL, the calculated increase or decrease in tidal range based on the combined A-TATs due to MSL rise, and the effect on total peak water levels are reported in Table 7. The combined long-term trends in tidal amplitudes are also listed in Table 7 for reference. 
Results suggest that the predicted change in tidal range by 2100 (calculated from 2015 ) is $+28 \mathrm{~mm}$ at Honolulu, $+37 \mathrm{~mm}$ at Noumea, $+70 \mathrm{~mm}$ at Brisbane, and $+83 \mathrm{~mm}$ in Hong Kong. The coupled effect of MSL rise and tidal range changes may increase the peak water level by $+0.31 \mathrm{~m}$ in Honolulu, $+0.32 \mathrm{~m}$ in Noumea, $+0.35 \mathrm{~m}$ in Brisbane, and $+0.36 \mathrm{~m}$ in Hong Kong by 2100 . At the four stations that have a negative combined ATAT, the linear MSL assumption will yield a decrease in tidal range by 2100 of $-87 \mathrm{~mm}$ at Tioman, $-67 \mathrm{~mm}$ at Sedili, $-50 \mathrm{~mm}$ at Odomari, and $-61 \mathrm{~mm}$ at Nishinoomote. The coupled change in water levels will be: $+0.19 \mathrm{~m}$ at Tioman, $+0.21 \mathrm{~m}$ at Sedili, $+0.23 \mathrm{~m}$ at Odomari, and $+0.22 \mathrm{~m}$ at Nishinoomote.

The preceding predictions assume that MSL rise will remain linear, but this assumption does not take into account the possible effect of accelerated ice melt in Antarctica. DeConto and Pollard (2016) use computer models that consider coupled ice sheet and climate dynamics as well as improved ice melt mechanisms, such as the influence of increased atmospheric warming due to increased carbon dioxide concentrations, increased oceanic warming, hydrofracturing of buttressing ice shelfs, and structural collapse of marine-terminating ice cliffs. These models were also used to reconstruct the global MSL during past warm climate events, which were used to calibrate the future forecast models, and compared to the geological record, to better predict future global MSL increase. The periods considered were the Pliocene epoch (about 3 million years ago), and the more recent Last Interglacial epoch ( 130,000 to 155,000 years ago). For forecasting purposes, DeConto and Pollard (2016) ran multiple 
large-ensemble models, based on Representative Carbon Pathway (RCP) scenarios as detailed by Meinshausen, et al. (2011). Two of these scenarios, one that considers moderate future $\mathrm{CO}_{2}$ emissions and faster drawdown (RCP4.5), and one that considers much higher future $\mathrm{CO}_{2}$ emissions and longer drawdown (RCP8.5) are used here to calculate future increases in tidal range. Deconto and Pollard (2016) calculated future sea levels up to 2100 and 2500 , but only the 2100 scenarios are considered here.

For the large ensemble RCP4.5 model, a global MSL increase of $+0.49 \mathrm{~m}$ is found by 2100 , and for RCP8.5, an increase of +1.05 m occurs by 2100 . For stations with a positive combined A-TAT, the corresponding increase in tidal range by 2100 under the RCP4.5 scenario will be: $+49 \mathrm{~mm}$ in Honolulu, $+64 \mathrm{~mm}$ in Noumea, $+122 \mathrm{~mm}$ in Brisbane, and $+145 \mathrm{~mm}$ in Hong Kong, which will yield a total increase in peak water levels of: $+0.54 \mathrm{~m},+0.55 \mathrm{~m},+0.61 \mathrm{~m}$, and $+0.64 \mathrm{~m}$, respectively. For the RCP8.5 scenario, the tidal range increases will be: $+107 \mathrm{~mm}$ in Honolulu, $+137 \mathrm{~mm}$ in Noumea, $+261 \mathrm{~mm}$ in Brisbane, and $+311 \mathrm{~mm}$ in Hong Kong, yielding a total change in peak water levels of: $+1.16 \mathrm{~m},+1.19 \mathrm{~m},+1.31 \mathrm{~m}$, and $+1.36 \mathrm{~m}$, respectively. At the stations with negative combined A-TATs, the change in tidal range by 2100 under the RCP4.5 scenario is: -151 $\mathrm{mm}$ at Tioman, -118 at Sedili, $-87 \mathrm{~mm}$ at Odomari, and $-107 \mathrm{~mm}$ at Nishinoomote, yielding a total change in peak water levels of: $+0.34 m,+0.37 m,+0.40 m$, and $+0.38 m$, respectively. For the $\mathrm{RCP} 8.5$ scenario, the tidal range changes are: $-324 \mathrm{~mm}$ at Tioman, $-253 \mathrm{~mm}$ at Sedili, $-185 \mathrm{~mm}$ at Odomari, and $-230 \mathrm{~mm}$ at Nishinoomote, yielding 
changes in total peak water level of: $+0.73 \mathrm{~m},+0.80 \mathrm{~m},+0.87 \mathrm{~m}$, and $+0.82 \mathrm{~m}$, respectively.

While the changes in maximum tidal range and highest astronomical tide (HAT) are only $10-30 \%$ of the increase in MSL, this is still important, as this will considerably increase the occurrence of exceedance of any fixed water level, above and beyond the changes that MSL rise alone will bring. Moreover, changes in only four tidal constituents were considered, and inclusion of all of the major constituents might well result in increased changes in the combined A-TAT values. It can be seen that the consideration of possible ice-melt scenarios greatly change the predictions of future sea level rise by 2100 when including the localized effect of the combined A-TATs, as these two factors are cumulative. The RCP scenarios show changes in total water level that are larger than the linear MSL assumption, which may have an increased detrimental effect on the coasts in future decades. Conversely, locations where the combined ATATs are negative, such as along the coast of Japan and in Southeast Asia, the future increase in MSL may decrease tidal range, lessening the effects of peak water levels by $10-30 \%$. Since MSL rise is always positive, the changes in total water level will still be largely positive, though the total effect will be diminished, which may give these coastal locations more time to respond to future inundation. 


\subsubsection{Summary of seasonal variability of tidal anomaly trends (STATs)}

Most locations did not show any significant seasonal variability $\left(<100 \mathrm{~mm}^{-1}\right.$ range), indicating that the response of tidal properties to MSL fluctuations is relatively constant throughout the year. There are, however, some very notable and regionally consistent exceptions to this generalization (Tables 5 and 6). Forty gauges exhibit significant A-STATs in $M_{2}$. Ten of these are in the Northeast Pacific, the majority of which are influenced by major rivers (e.g., the Columbia at Astoria, the Sacramento at San Francisco, and the Frasier at gauges in British Columbia). Since river flow is a seasonal process strongly affecting water level, this is the likely explanation for the observed seasonality at these locations. There are a handful of gauges in Japan and in the Southeast Pacific that also exhibit some measure of seasonality. Explanations for this behavior are not readily apparent, though some of the seasonal variability of coastal Japan may be tied to the seasonal modulations of the strong offshore Kuroshio Current (Mizuno and White, 1983). The majority of locations that have a seasonal variation are located in the Southwest Pacific, with some variability at island gauges and in the Philippines, and the strongest seasonality seen in the seas around Malaysia. The seasonality in $\mathrm{S}_{2}$ A-STATs are significant at 23 locations, with the majority again located around the Canadian coast, in the Philippines, and in Malaysia. There are 32 gauges with significant seasonality of $\mathrm{K}_{1} \mathrm{~A}$-STATs and, similar to the semidiurnal behavior, the strongest examples are at Canadian and northern US gauges, and around Malaysia, but there is also seasonal behavior seen at Australian and Philippine gauges not present in 
other constituents. Finally, the $\mathrm{O}_{1}$ seasonality of amplitude tidal anomaly trends are significant at 23 gauges, again, mainly at Canadian and Malaysian gauges. Seasonality in the Southeast and Northwest Pacific are essentially nonexistent, though there are some isolated examples in Japan, particularly at Tokyo. The seasonality of phase anomaly trends (P-STATs) was highly variable with large errors at most locations, but the majority of significant seasonality in phase was also seen around Malaysia for all constituents, though a number of gauges in Japan have significant phase seasonality, particularly for the $S_{2}$ and $\mathrm{O}_{1}$ constituents. Since the amplitudes of these are generally lower than the dominant $\mathrm{M}_{2}$ and $\mathrm{K}_{1}$ constituents, phases are more often more variable. The temporal patterns of occurrence of maximum and minimum monthly STAT determinations at many of these gauges are regionally coherent, such as the phase variability seen around Japan in $S_{2}$. However, the most consistent temporal coherence was for gauges in the Southeast Asian waters for amplitudes and phases, with the semidiurnal constituents more coherent than diurnals. Patterns are similar enough across a large geographical region to suggest a common causative mechanism, requiring careful study. This is carried out in Part III (Chapter 5) of this thesis.

\subsubsection{Observed tidal variability in reference to hypotheses}

In relation to the original hypotheses (stated in Section 3.1.1), \#1 is supported (MSL and tidal changes may be related), because the mechanisms affecting MSL rise also appear to be causative factors of tidal changes, albeit only locally variable ones. This 
also provides an answer to hypothesis \#3 (a survey will indicate the relevant spatial scale of the variability), in that tidal variability is better explained as a collection of local mechanisms than as a global-scale mechanism. The second part of hypothesis \#3 is also confirmed, as this survey did indicate gauges that were deserving of future study, some of which will be analyzed in more detail in Parts II and III of this thesis, and others will be addressed in future studies. The results of this survey do not support hypothesis \#2 (long-term tidal evolution can be identified through short-term variability), as the shortterm variability does not show any obvious overlap with the patterns of long-term trends. This point will be further discussed in Part II.

There is considerable difference between the magnitudes and spatial distribution of the TATs and STATs. Whereas TATs are observed to be locally significant in each quadrant, the STATs are mainly concentrated in a few regions, being relatively constant elsewhere. Therefore, hypothesis \#4 (that multiple time scales will reveal more variability) is supported, in that patterns of tidal variability are different, but still significant, on the two time scales (yearly and monthly).

\subsection{Conclusions and identification of future study efforts}

Ocean tides show long-term increases at many locations worldwide. The tidal changes can be as important as MSL rise for determining future extreme water levels. However, shorter-term tidal variability (yearly and monthly) related to short-term MSL fluctuations may also significantly affect maximal water levels and coastal 
inundation/erosion at this time scale, particularly when coupled with storm surges and climatic events such as ENSO. Tidal variability at 153 tide gauge stations in the Pacific Ocean was analyzed in relation to MSL variability at both the yearly and seasonal time scales. In terms of yearly variability, there are 93 and 66 significant amplitude trends for $\mathrm{M}_{2}$ and $\mathrm{S}_{2}$, and 82 and 59 significant trends for $\mathrm{K}_{1}$ and $\mathrm{O}_{1}$, respectively. Phase trends are significant at 55 and 47 gauges for $\mathrm{M}_{2}$ and $\mathrm{S}_{2} ; 42$ and 61 for $\mathrm{K}_{1}$ and $\mathrm{O}_{1}$, respectively. Trends in the Southwest Pacific are more widespread and of greater magnitude than in all other regions, and this region also exhibits the largest MSL rise rates $\left(+5-10 \mathrm{mmyr}^{-1}\right)$. The observed changes in tides in the Southwest Pacific at the yearly timescale due to MSL variations are the focus of Part II of this text. Part II also examines possible forcing mechanisms behind the observed changes, which include frictional effects (due to changing water levels in shallow regions or due to stratification), baroclinic (internal tide) mechanisms, and resonant triad interactions. Additionally, the connections of yearly MSL and tidal variability with ENSO variations will be explored for two time periods (pre-1993 and post-1993). Other locations that could warrant future study would be the river influenced gauges in the Northeast Pacific, such as Astoria, San Francisco, and Vancouver. The anomalous variability at Tokyo harbor and surrounding gauges (which appear to be opposed in behavior) also warrants future study, and it is likely that the harbor modifications could be affecting all gauges in the Tokyo area, though long-term modulation of the Kuroshio Current system could also be a factor. In the Southeastern Pacific, the very large negative A-TATs seen at Puerto Montt in 
southern Chile also warrant future study. It is hypothesized that it is partly due to amphidromic movement, but mostly due to resonant changes in the enclosed basin. Finally, the large combined A-TATs observed at Hong Kong will also be looked at in detail in a future study, as well as another study that will give detailed consideration of other large combined A-TATs under future Antarctic ice melt scenarios.

Significant seasonal tidal anomaly trends (STATs) were observed at about a quarter of all gauges, mostly confined to specific locations, such as around US and Canadian gauges which are influenced by seasonal river flow characteristics, and in the waters of Southeast Asia, including Vietnam, Malaysia, Thailand, Singapore, and Indonesia. The Southeast Asia area is under the influence of the monsoon system of rains and winds, which is a likely causal mechanism. The seasonality of all constituent amplitudes in Malaysia and neighboring countries is exceptionally strong and coherent, as is the majority of phase seasonality, in both a spatial and temporal context. This subregion of the southwest Pacific is investigated closely in Part III (Chapter 5) of this text. The variations in MSL and tidal properties by season will be analyzed separately, and a barotropic ocean tide model will be utilized to explore possible monsoon-related mechanisms, including: MSL seasonality, seasonality of geostrophic currents and Ekman currents, and seasonal patterns of stratification. 
Table 2 Station information for tidal records used in this study. Information given is: station name, latitude/longitude, country, start year of record used, end year of record used, and source agency. Locations are shown in Figure 7a and 7b. ${ }^{a}$

\begin{tabular}{|c|c|c|c|c|c|c|}
\hline Station Name & Lat.(N) & Long. (E) & Country & $\begin{array}{l}\text { Start } \\
\text { Year }\end{array}$ & $\begin{array}{l}\text { End } \\
\text { Year }\end{array}$ & Source \\
\hline \multicolumn{7}{|l|}{ NORTHEAST PAC } \\
\hline Fr. Frigate Shoals & 23.87 & -166.28 & USA & 1974 & 2014 & UHI \\
\hline Cabo San Lucas & 22.88 & -109.92 & Mexico & 1973 & 2014 & UHI \\
\hline Kodiak Island, AK & 57.73 & -152.52 & USA & 1975 & 2014 & UHI \\
\hline Adak, AK & 51.87 & -176.63 & USA & 1950 & 2014 & UHI \\
\hline Dutch Harbor, AK & 53.88 & -166.53 & USA & 1985 & 2014 & UHI \\
\hline Midway & 28.22 & -177.37 & USA & 1947 & 2014 & UHI \\
\hline Johnston & 16.75 & -169.52 & USA & 1947 & 2014 & UHI \\
\hline Honolulu, HI & 21.3 & -157.87 & USA & 1905 & 2014 & UHI \\
\hline Nawiliwilli Bay, HI & 21.97 & -159.35 & USA & 1954 & 2014 & UHI \\
\hline Kahului, HI & 20.9 & -156.47 & USA & 1950 & 2014 & UHI \\
\hline Hilo, HI & 19.73 & -155.07 & USA & 1927 & 2014 & UHI \\
\hline Mokuoloe, $\mathrm{HI}$ & 21.43 & -157.8 & USA & 1957 & 2014 & UHI \\
\hline Tofino & 49.15 & -125.92 & Canada & 1949 & 2014 & FOC \\
\hline Victoria & 48.42 & -123.37 & Canada & 1909 & 2014 & FOC \\
\hline San Francisco, CA & 37.8 & -122.47 & USA & 1899 & 2014 & UHI \\
\hline La Jolla, CA & 32.87 & -117.25 & USA & 1925 & 2014 & UHI \\
\hline Monterey, CA & 36.6 & -121.88 & USA & 1973 & 2014 & UHI \\
\hline Crescent City, CA & 41.75 & -124.18 & USA & 1933 & 2014 & UHI \\
\hline Neah Bay, WA & 48.37 & -124.62 & USA & 1934 & 2014 & UHI \\
\hline Sitka, AK & 57.05 & -135.35 & USA & 1938 & 2014 & UHI \\
\hline Seward, AK & 60.12 & -149.43 & USA & 1979 & 2014 & UHI \\
\hline Seldovia, AK & 59.43 & -151.72 & USA & 1980 & 2014 & UHI \\
\hline Valdez, AK & 61.13 & -146.37 & USA & 1973 & 2014 & UHI \\
\hline Port San Luis, CA & 35.18 & -120.77 & USA & 1983 & 2014 & UHI \\
\hline Los Angeles, CA & 33.72 & -118.27 & USA & 1924 & 2014 & UHI \\
\hline San Diego, CA & 32.72 & -117.17 & USA & 1906 & 2014 & UHI \\
\hline Yakutat, AK & 59.55 & -139.73 & USA & 1961 & 2014 & UHI \\
\hline Ketchikan, AK & 55.33 & -131.63 & USA & 1949 & 2014 & UHI \\
\hline Astoria, OR & 46.22 & -123.77 & USA & 1925 & 2014 & UHI \\
\hline Charleston, OR & 43.35 & -124.32 & USA & 1978 & 2014 & UHI \\
\hline Santa Monica, CA & 34.02 & -118.5 & USA & 1973 & 2014 & UHI \\
\hline Cordova, AK & 60.57 & -145.75 & USA & 1978 & 2014 & UHI \\
\hline South Beach, OR & 44.63 & -124.05 & USA & 1967 & 2014 & UHI \\
\hline
\end{tabular}




\begin{tabular}{|c|c|c|c|c|c|c|}
\hline Seattle & 47.6 & -122.4 & USA & 1899 & 2011 & UHI \\
\hline Vancouver & 49.29 & -123.11 & Canada & 1943 & 2014 & FOC \\
\hline Point Atkinson & 49.34 & -123.25 & Canada & 1960 & 2014 & FOC \\
\hline Bella Bella & 52.16 & -128.14 & Canada & 1962 & 2014 & FOC \\
\hline Queen Charlotte & 53.25 & -132.07 & Canada & 1966 & 2014 & FOC \\
\hline Port Hardy & 50.72 & -127.49 & Canada & 1965 & 2014 & FOC \\
\hline Bamfield & 48.84 & -125.14 & Canada & 1971 & 2014 & FOC \\
\hline \multicolumn{7}{|l|}{ SOUTHEAST PAC } \\
\hline Baltra & -0.43 & -90.28 & Ecuador & 1985 & 2014 & UHI \\
\hline Papeete (Tahiti) & -17.53 & -149.57 & Fr. Poly. & 1969 & 2014 & UHI \\
\hline Juan Fernandez Is. & -33.62 & -78.83 & Chile & 1988 & 2014 & UHI \\
\hline Easter Is. & -27.15 & -109.45 & Chile & 1970 & 2014 & UHI \\
\hline Rarotonga & -21.2 & -159.78 & Cook Is. & 1977 & 2014 & UHI \\
\hline Penrhyn & -8.98 & -158.05 & Cook Is. & 1977 & 2014 & UHI \\
\hline Santa Cruz & -0.75 & -90.32 & Ecuador & 1978 & 2014 & UHI \\
\hline San Felix & -26.28 & -80.13 & Chile & 1987 & 2014 & UHI \\
\hline Nuku' alofa & -21.13 & -175.17 & Tonga & 1990 & 2014 & $\mathrm{UHI}$ \\
\hline Antofagasta & -23.65 & -70.4 & Chile & 1945 & 2014 & UHI \\
\hline Valparaiso & -33.03 & -71.63 & Chile & 1944 & 2014 & UHI \\
\hline Lobos de Afuera & -6.93 & -80.72 & Peru & 1982 & 2010 & UHI \\
\hline Buena Ventura & 3.9 & -77.1 & Colombia & 1953 & 2011 & UHI \\
\hline Caldera & -27.07 & -70.83 & Chile & 1980 & 2014 & $\mathrm{UHI}$ \\
\hline La Libertad & -2.2 & -80.92 & Ecuador & 1949 & 2014 & UHI \\
\hline Callao & -12.05 & -77.15 & Peru & 1950 & 2014 & UHI \\
\hline Matarani & -17 & -72.12 & Peru & 1992 & 2014 & UHI \\
\hline Balboa & 8.97 & -79.57 & Panama & 1907 & 2014 & UHI \\
\hline Tumaco & 1.83 & -78.73 & Colombia & 1951 & 2012 & $\mathrm{UHI}$ \\
\hline Puerto Montt & -41.48 & -72.97 & Chile & 1980 & 2014 & $\mathrm{UHI}$ \\
\hline \multicolumn{7}{|l|}{ NORTHWEST PAC. } \\
\hline Chichijima & 27.1 & 142.18 & Japan & 1975 & 2014 & UHI \\
\hline Hong Kong & 22.3 & 114.22 & China & 1962 & 2014 & UHI \\
\hline Kaohsiung & 22.62 & 120.28 & Taiwan & 1980 & 2014 & $\mathrm{UHI}$ \\
\hline Keelung & 25.15 & 121.75 & Taiwan & 1980 & 2014 & $\mathrm{UHI}$ \\
\hline Nakanoshima & 29.83 & 129.85 & Japan & 1984 & 2014 & UHI \\
\hline Abashiri & 44.02 & 144.28 & Japan & 1968 & 2014 & $\mathrm{UHI}$ \\
\hline Hamada & 34.9 & 132.07 & Japan & 1984 & 2014 & $\mathrm{UHI}$ \\
\hline Toyama & 36.77 & 137.22 & Japan & 1967 & 2014 & UHI \\
\hline Kushiro & 42.97 & 144.38 & Japan & 1963 & 2014 & $\mathrm{UHI}$ \\
\hline Ofunato & 39.07 & 141.72 & Japan & 1962 & 2014 & UHI \\
\hline Mera & 34.92 & 139.83 & Japan & 1965 & 2014 & $\mathrm{UHI}$ \\
\hline Kushimoto & 33.47 & 135.78 & Japan & 1961 & 2014 & UHI \\
\hline
\end{tabular}




\begin{tabular}{|c|c|c|c|c|c|c|}
\hline Aburatsu & 31.57 & 131.42 & Japan & 1961 & 2014 & UHI \\
\hline Naha & 26.22 & 127.67 & Japan & 1966 & 2014 & UHI \\
\hline Maisaka & 34.68 & 137.62 & Japan & 1968 & 2014 & UHI \\
\hline Miyakejima & 34.07 & 139.48 & Japan & 1964 & 2014 & UHI \\
\hline Naze & 28.38 & 129.5 & Japan & 1957 & 2014 & $\mathrm{UHI}$ \\
\hline Wakkanai & 45.4 & 141.68 & Japan & 1967 & 2014 & UHI \\
\hline Nagasaki & 32.73 & 129.87 & Japan & 1985 & 2014 & UHI \\
\hline Nishinoomote & 30.73 & 131 & Japan & 1965 & 2014 & UHI \\
\hline Hakodate & 41.78 & 140.73 & Japan & 1964 & 2014 & UHI \\
\hline Ishigaki & 24.33 & 124.15 & Japan & 1969 & 2014 & UHI \\
\hline Hachinohe & 40.53 & 141.53 & Japan & 1980 & 2014 & UHI \\
\hline Hanasaki & 48.28 & 145.58 & Japan & 1977 & 2009 & JODC \\
\hline Kamaishi & 39.27 & 141.89 & Japan & 1956 & 2010 & JODC \\
\hline Minamizu & 34.63 & 138.89 & Japan & 1965 & 2008 & JODC \\
\hline Miyako & 39.63 & 141.97 & Japan & 1967 & 2009 & JODC \\
\hline Muoran & 42.34 & 140.95 & Japan & 1967 & 2008 & JODC \\
\hline Nagoya & 35.08 & 136.88 & Japan & 1961 & 2009 & JODC \\
\hline Omaezaki & 34.6 & 138.23 & Japan & 1961 & 2009 & JODC \\
\hline Onahama & 36.93 & 140.92 & Japan & 1967 & 2009 & JODC \\
\hline Owase & 34.07 & 136.22 & Japan & 1967 & 2009 & JODC \\
\hline Toba & 34.47 & 136.85 & Japan & 1969 & 2009 & JODC \\
\hline Tokyo & 35.67 & 139.77 & Japan & 1968 & 2009 & JODC \\
\hline Urigami & 33.55 & 135.9 & Japan & 1969 & 2009 & JODC \\
\hline Odomari & 31.02 & 130.69 & Japan & 1965 & 2009 & JODC \\
\hline Okada & 34.78 & 139.4 & Japan & 1963 & 2009 & JODC \\
\hline Shimizuminato & 35.02 & 138.5 & Japan & 1965 & 2009 & JODC \\
\hline Shirihama & 33.68 & 135.38 & Japan & 1968 & 2009 & JODC \\
\hline Tosashimizu & 32.78 & 132.97 & Japan & 1961 & 2009 & JODC \\
\hline \multicolumn{7}{|l|}{ SOUTHWEST PAC. } \\
\hline Pohnpei & 6.98 & 158.25 & Micronesia & 1974 & 2014 & UHI \\
\hline Nauru & -0.53 & 166.92 & Rep of Nauru & 1975 & 2014 & UHI \\
\hline Majuro & 7.12 & 171.37 & Rep Marshall Is & 1968 & 2014 & UHI \\
\hline Malakal & 7.33 & 134.47 & Rep of Belau & 1969 & 2014 & UHI \\
\hline Yap & 9.52 & 138.13 & Fd St Micronesia & 1969 & 2014 & UHI \\
\hline Honiara & -9.42 & 159.95 & Solomon Islands & 1974 & 2014 & UHI \\
\hline Rabaul & -4.2 & 152.18 & Pap. New Guinea & 1966 & 1997 & UHI \\
\hline Christmas Island & 1.98 & -157.47 & Rep of Kiribati & 1974 & 2014 & UHI \\
\hline Suva & -18.13 & 178.43 & Fiji & 1972 & 2014 & UHI \\
\hline Noumea & -22.3 & 166.43 & France & 1967 & 2014 & UHI \\
\hline Funafuti & -8.5 & 179.22 & Fiji & 1977 & 2014 & UHI \\
\hline Saipan & 15.23 & 145.75 & N. Mari. Islands & 1978 & 2014 & UHI \\
\hline
\end{tabular}




\begin{tabular}{|c|c|c|c|c|c|c|}
\hline Kapingamarangi & 1.1 & 154.78 & Fd St Micronesia & 1978 & 2009 & UHI \\
\hline Port Villa & -17.77 & 168.3 & Vanuatu & 1993 & 2014 & UHI \\
\hline Wake & 19.28 & 166.62 & USA & 1950 & 2014 & UHI \\
\hline Guam & 13.43 & 144.65 & Guam & 1948 & 2014 & $\mathrm{UHI}$ \\
\hline Kwajalein & 8.73 & 167.73 & Marshall Islands & 1946 & 2014 & UHI \\
\hline Pago Pago & -14.28 & -170.68 & USA & 1948 & 2014 & UHI \\
\hline Manus Island & -2.02 & 147.27 & Pap. New Guinea & 1993 & 2014 & CSIRIO \\
\hline Wellington & -41.28 & 174.78 & New Zealand & 1944 & 2014 & UHI \\
\hline Cendering & 5.27 & 103.18 & Malaysia & 1984 & 2014 & UHI \\
\hline Johor Bahru & 1.47 & 103.8 & Malaysia & 1984 & 2014 & UHI \\
\hline Kuantan & 3.98 & 103.43 & Malaysia & 1984 & 2014 & UHI \\
\hline Tioman & 2.8 & 104.13 & Malaysia & 1985 & 2014 & UHI \\
\hline Sedili & 1.93 & 104.12 & Malaysia & 1986 & 2014 & UHI \\
\hline Kukup & 1.33 & 103.45 & Malaysia & 1985 & 2014 & UHI \\
\hline Getting & 6.23 & 102.1 & Malaysia & 1986 & 2014 & UHI \\
\hline Ko Lak & 11.8 & 99.82 & Thailand & 1985 & 2014 & UHI \\
\hline Tanjong Pagar & 1.27 & 103.85 & Singapore & 1988 & 2014 & UHI \\
\hline Kelang & 3.05 & 101.37 & Malaysia & 1984 & 2014 & UHI \\
\hline Kaling & 2.22 & 102.15 & Malaysia & 1984 & 2014 & UHI \\
\hline Langkawi & 6.43 & 99.75 & Malaysia & 1985 & 2014 & UHI \\
\hline Lumut & 4.23 & 100.62 & Malaysia & 1984 & 2014 & UHI \\
\hline Penang & 5.42 & 100.35 & Malaysia & 1984 & 2014 & UHI \\
\hline Ko Taphao Noi & 7.83 & 98.43 & Thailand & 1985 & 2014 & UHI \\
\hline Vung Tau & 10.33 & 107.07 & Vietnam & 1986 & 2014 & UHI \\
\hline Kota Kinabalu & 5.98 & 116.07 & Malaysia & 1987 & 2014 & UHI \\
\hline Bintulu & 3.22 & 113.07 & Malaysia & 1992 & 2014 & UHI \\
\hline Sandakan & 5.82 & 118.07 & Malaysia & 1993 & 2014 & UHI \\
\hline Brisbane & -27.37 & 153.17 & Australia & 1984 & 2014 & UHI \\
\hline Bundaberg & -24.83 & 152.35 & Australia & 1984 & 2014 & $\mathrm{UHI}$ \\
\hline Ft. Denison (Sydney) & -33.85 & 151.23 & Australia & 1965 & 2014 & UHI \\
\hline Townsville & -19.25 & 146.83 & Australia & 1984 & 2014 & UHI \\
\hline Spring Bay & -42.55 & 147.93 & Australia & 1985 & 2014 & $\mathrm{UHI}$ \\
\hline Booby Island & -10.6 & 141.92 & Australia & 1988 & 2014 & UHI \\
\hline Hobart & -42.88 & 147.33 & Australia & 1985 & 2012 & UHI \\
\hline Manila & 14.58 & 120.97 & Philippines & 1984 & 2012 & UHI \\
\hline Legaspi & 13.15 & 123.75 & Philippines & 1984 & 2014 & $\mathrm{UHI}$ \\
\hline Davao & 7.08 & 125.63 & Philippines & 1984 & 2014 & UHI \\
\hline Lord Howe Is. & -31.52 & 159.07 & Australia & 1991 & 2014 & UHI \\
\hline Lautoka & -17.6 & 177.43 & Fiji & 1992 & 2014 & UHI \\
\hline Cairns & -16.92 & 145.77 & Australia & 1984 & 2014 & AuNTC \\
\hline Gladstone & -23.85 & 151.26 & Australia & 1978 & 2014 & AuNTC \\
\hline
\end{tabular}




\section{Williamstown}

$-37.86$

144.89

Australia

1966

2014 AuNTC

a -Source agency abbreviations: UHI: University of Hawaii Sea level Center; FOC: Fisheries and Oceans Canada; LINZ: Land Information New Zealand; CSIRO: Commonwealth Scientific and Research Organization; AuNTC: Australian National Tidal Center. Bold text entries indicate gauges used in Part II, and published in Devlin et al (2014). Italicized text entries indicate gauges used in Part III.

Table 3a Amplitude tidal anomaly trends (A-TATs) with 95\% confidence limits ${ }^{\mathrm{a}}$.

\begin{tabular}{|c|c|c|c|c|c|c|c|c|}
\hline$\underline{\text { Station Name }}$ & $K_{1}$ & $( \pm)$ & $\mathrm{O}_{1}$ & $( \pm)$ & $M_{2}$ & $( \pm)$ & $S_{2}$ & $( \pm)$ \\
\hline \multicolumn{9}{|l|}{$\frac{\text { NORTHEAST }}{\text { PAC. }}$} \\
\hline $\begin{array}{c}\text { French Frigate } \\
\text { Sh. }\end{array}$ & -9.4 & 3.7 & -2.0 & 2.8 & -43.2 & 9.4 & 0.3 & 4.3 \\
\hline Cabo San Lucas & -12.7 & 3.2 & 2.0 & 2.5 & 21.2 & 12.7 & 31.8 & 8.3 \\
\hline $\begin{array}{c}\text { Kodiak Island, } \\
\text { AK }\end{array}$ & 7.1 & 7.0 & -1.6 & 5.7 & -1.9 & 12.4 & -14.5 & 5.9 \\
\hline Adak, AK & 35.4 & 8.5 & -9.7 & 6.1 & 0.3 & 3.9 & -8.8 & 3.4 \\
\hline $\begin{array}{c}\text { Dutch Harbor, } \\
\text { AK }\end{array}$ & -52.0 & 9.9 & -1.0 & 6.8 & -12.8 & 7.1 & 7.7 & 3.9 \\
\hline Midway & 1.3 & 3.1 & -3.4 & 2.6 & -4.9 & 6.3 & 3.9 & 2.8 \\
\hline Johnston & -25.9 & 3.8 & 0.9 & 2.3 & -42.7 & 10.2 & -53.5 & 6.8 \\
\hline Honolulu, $\mathrm{HI}$ & 2.9 & 2.8 & -0.4 & 2.1 & 97.2 & 10.0 & 1.6 & 4.0 \\
\hline $\begin{array}{c}\text { Nawiliwilli Bay, } \\
\text { HI }\end{array}$ & -14.1 & 4.2 & 7.0 & 2.7 & 74.8 & 11.5 & 15.7 & 5.4 \\
\hline Kahului, $\mathrm{HI}$ & 14.0 & 4.3 & 11.6 & 3.0 & -40.1 & 4.3 & -1.7 & 2.2 \\
\hline Hilo, $\mathrm{HI}$ & 10.9 & 3.0 & 6.8 & 2.1 & 95.4 & 6.4 & 5.9 & 3.1 \\
\hline Mokuoloe, HI & 6.8 & 6.6 & 19.7 & 5.2 & 2.0 & 14.6 & -7.4 & 7.4 \\
\hline Tofino & -4.7 & 5.7 & 2.3 & 5.4 & 22.1 & 6.0 & -0.7 & 4.9 \\
\hline Victoria & -19.1 & 11.9 & -22.4 & 7.0 & -14.5 & 7.4 & -3.9 & 3.3 \\
\hline $\begin{array}{c}\text { San Francisco, } \\
\text { CA }\end{array}$ & -72.3 & 4.6 & 5.6 & 2.6 & -106.5 & 12.1 & 14.3 & 3.4 \\
\hline La Jolla, CA & -5.8 & 3.2 & 4.2 & 2.3 & 33.0 & 5.8 & 13.4 & 3.8 \\
\hline Monterey, CA & -9.0 & 5.1 & -18.7 & 3.9 & -10.4 & 7.7 & -6.5 & 3.9 \\
\hline $\begin{array}{c}\text { Crescent City, } \\
\text { CA }\end{array}$ & -21.8 & 4.8 & -13.1 & 3.2 & -1.4 & 4.9 & -1.6 & 3.6 \\
\hline Neah Bay, WA & -8.0 & 5.8 & 3.9 & 4.3 & -20.5 & 14.4 & -2.7 & 5.4 \\
\hline Sitka, AK & -38.6 & 6.1 & -20.7 & 5.7 & 15.8 & 6.1 & -7.1 & 4.7 \\
\hline Seward, AK & 4.4 & 5.9 & -3.6 & 5.3 & -1.4 & 7.0 & -9.8 & 5.3 \\
\hline Seldovia, AK & 9.8 & 9.4 & 3.6 & 6.8 & -54.2 & 18.4 & -33.8 & 12.5 \\
\hline Valdez, AK & 20.7 & 7.2 & -4.1 & 4.8 & 0.2 & 8.5 & 3.0 & 6.2 \\
\hline
\end{tabular}




\begin{tabular}{|c|c|c|c|c|c|c|c|c|}
\hline $\begin{array}{c}\text { Port San Luis, } \\
\text { CA }\end{array}$ & -10.7 & 7.2 & -12.3 & 3.9 & 21.5 & 6.3 & 3.3 & 5.4 \\
\hline Los Angeles, CA & -12.1 & 3.5 & -1.6 & 2.4 & -1.1 & 5.1 & 8.8 & 2.9 \\
\hline San Diego, CA & -10.4 & 3.1 & -4.9 & 2.4 & 2.2 & 11.6 & 6.5 & 5.6 \\
\hline Yakutat, AK & 9.9 & 5.5 & 13.8 & 5.0 & 14.6 & 7.1 & 1.8 & 5.0 \\
\hline Ketchikan, AK & 11.7 & 5.4 & 15.1 & 4.6 & 18.6 & 10.0 & 12.2 & 7.5 \\
\hline Astoria, OR & -22.1 & 5.3 & -36.7 & 5.6 & -66.4 & 9.9 & -10.8 & 5.1 \\
\hline Charleston, OR & -4.5 & 5.5 & 12.7 & 5.2 & -4.7 & 9.2 & -10.8 & 3.5 \\
\hline $\begin{array}{c}\text { Santa Monica, } \\
\text { CA }\end{array}$ & -2.5 & 12.8 & 7.5 & 5.4 & -38.3 & 6.8 & -22.8 & 7.3 \\
\hline Cordova, AK & 20.0 & 5.1 & 1.2 & 4.0 & 34.6 & 7.5 & 0.8 & 4.8 \\
\hline $\begin{array}{c}\text { South Beach, } \\
\text { OR }\end{array}$ & -9.6 & 5.0 & -10.4 & 4.3 & 11.8 & 5.9 & 1.5 & 3.5 \\
\hline Seattle & -4.5 & 8.9 & -14.6 & 6.6 & -22.6 & 6.2 & -3.7 & 5.3 \\
\hline Vancouver & -66.7 & 16.5 & -18.2 & 11.2 & -53.5 & 15.2 & -6.3 & 5.8 \\
\hline Point Atkinson & -8.1 & 8.0 & 83.4 & 6.1 & -5.7 & 7.1 & 29.6 & 3.3 \\
\hline Bella Bella & -33.1 & 6.9 & -10.1 & 5.8 & 7.2 & 12.2 & 0.1 & 6.6 \\
\hline $\begin{array}{c}\text { Queen } \\
\text { Charlotte }\end{array}$ & -29.3 & 8.5 & -18.1 & 6.3 & -63.6 & 31.8 & -58.8 & 14.3 \\
\hline Port Hardy & -23.7 & 3.5 & -0.4 & 2.3 & 24.9 & 7.9 & 4.7 & 3.3 \\
\hline Bamfield & -5.8 & 6.5 & 4.2 & 4.5 & 8.5 & 8.8 & 5.1 & 4.7 \\
\hline \multicolumn{9}{|l|}{$\frac{\text { SOUTHEAST }}{\text { PAC. }}$} \\
\hline Baltra & 4.4 & 3.9 & -3.8 & 2.6 & 32.3 & 7.3 & 2.5 & 3.1 \\
\hline Papeete (Tahiti) & 2.9 & 4.2 & 1.3 & 2.8 & -21.8 & 17.6 & 5.4 & 4.5 \\
\hline Juan Fern. Is. & -4.6 & 6.5 & -2.0 & 3.6 & -16.5 & 4.9 & -3.5 & 5.1 \\
\hline Easter Is. & 5.6 & 7.0 & 1.7 & 5.2 & 12.8 & 12.8 & 7.4 & 5.9 \\
\hline Rarotonga & 10.3 & 3.5 & 14.5 & 3.3 & 17.7 & 12.0 & 6.8 & 4.2 \\
\hline Penrhyn & 13.4 & 3.1 & -6.8 & 3.0 & 32.9 & 5.0 & -3.5 & 3.0 \\
\hline Santa Cruz & 5.3 & 2.2 & 4.3 & 2.0 & -29.5 & 8.9 & -8.4 & 3.6 \\
\hline San Felix & 14.3 & 4.1 & 1.1 & 2.8 & 45.3 & 11.3 & 8.5 & 4.3 \\
\hline Nuku' alofa & 5.4 & 4.1 & -8.3 & 3.5 & -42.0 & 10.6 & -52.9 & 8.7 \\
\hline Antofagasta & -1.7 & 2.9 & -5.7 & 2.4 & -12.4 & 7.5 & -5.2 & 3.2 \\
\hline Valparaiso & -8.5 & 3.3 & -12.5 & 2.5 & -32.8 & 8.8 & -18.8 & 3.8 \\
\hline $\begin{array}{l}\text { Lobos de } \\
\text { Afuera }\end{array}$ & 0.7 & 4.0 & -2.0 & 2.1 & 31.6 & 10.5 & -4.9 & 3.9 \\
\hline Buena Ventura & -12.5 & 3.3 & 3.2 & 2.9 & -12.6 & 15.1 & -26.3 & 8.9 \\
\hline Caldera & 40.3 & 6.7 & 5.4 & 4.2 & 51.2 & 10.7 & 29.2 & 4.5 \\
\hline La Libertad & 1.0 & 2.5 & 0.6 & 1.6 & -3.2 & 13.1 & -8.0 & 4.0 \\
\hline Callao & -4.1 & 3.4 & 0.0 & 3.1 & -7.3 & 5.1 & -3.6 & 2.3 \\
\hline Matarani & -18.6 & 4.3 & -10.6 & 4.0 & -20.2 & 9.3 & 13.6 & 7.1 \\
\hline Balboa & 3.2 & 3.0 & -2.8 & 3.2 & -20.7 & 17.9 & -33.2 & 8.9 \\
\hline Tumaco & 1.5 & 2.2 & -0.1 & 2.2 & 20.5 & 9.1 & 2.2 & 5.0 \\
\hline
\end{tabular}




\begin{tabular}{|c|c|c|c|c|c|c|c|c|}
\hline Puerto Montt & -77.4 & 10.5 & -38.3 & 5.7 & -567.9 & 60.1 & -272.0 & 26.9 \\
\hline \multicolumn{9}{|l|}{$\frac{\text { NORTHWEST }}{\text { PAC. }}$} \\
\hline Chichijima & -1.8 & 7.6 & -10.6 & 5.0 & -7.1 & 8.6 & -20.0 & 5.5 \\
\hline Hong Kong & 116.4 & 22.9 & 38.2 & 19.7 & 103.9 & 28.5 & 37.5 & 9.6 \\
\hline Kaohsiung & 11.0 & 5.0 & -6.0 & 7.0 & -7.1 & 8.0 & -17.7 & 4.7 \\
\hline Keelung & -11.2 & 7.2 & 0.1 & 5.8 & -54.9 & 9.9 & -17.8 & 8.5 \\
\hline Nakanoshima & -8.4 & 12.3 & -0.1 & 13.5 & 31.8 & 27.7 & 27.3 & 14.6 \\
\hline Abashiri & -29.7 & 12.9 & -25.3 & 11.4 & -41.9 & 9.9 & -24.5 & 6.4 \\
\hline Hamada & 51.0 & 19.0 & 29.0 & 22.7 & -24.8 & 7.1 & -5.4 & 5.4 \\
\hline Toyama & -11.4 & 7.0 & -20.1 & 7.0 & -19.3 & 4.6 & -6.9 & 3.1 \\
\hline Kushiro & 32.0 & 9.1 & -67.8 & 10.8 & -5.2 & 6.6 & -8.9 & 3.5 \\
\hline Ofunato & 4.1 & 6.0 & -15.2 & 6.7 & 8.8 & 7.3 & 13.4 & 3.4 \\
\hline Mera & -53.1 & 13.0 & -23.3 & 10.0 & 33.5 & 8.1 & 5.3 & 5.6 \\
\hline Kushimoto & -4.6 & 5.2 & -14.7 & 4.9 & -7.7 & 16.5 & -23.5 & 7.8 \\
\hline Aburatsu & 33.9 & 5.6 & 5.2 & 4.5 & 0.5 & 10.6 & 8.3 & 5.5 \\
\hline Naha & 16.3 & 5.2 & 3.7 & 4.3 & 11.0 & 8.8 & 3.8 & 5.2 \\
\hline Maisaka & -73.9 & 9.0 & -53.4 & 9.1 & -107.6 & 15.5 & -59.2 & 9.3 \\
\hline Miyakejima & -11.9 & 3.2 & -6.3 & 2.2 & -24.7 & 4.2 & -8.6 & 2.2 \\
\hline Naze & -4.4 & 3.8 & 8.0 & 3.5 & 12.6 & 9.9 & 9.5 & 5.6 \\
\hline Wakkanai & -53.3 & 13.4 & -41.8 & 10.3 & -8.3 & 7.6 & 6.1 & 4.6 \\
\hline Nagasaki & -18.2 & 9.6 & 1.6 & 11.0 & -84.8 & 22.6 & -0.2 & 18.5 \\
\hline Nishinoomote & -26.5 & 11.2 & -33.4 & 8.6 & -119.1 & 34.0 & -40.4 & 19.2 \\
\hline Hakodate & -1.4 & 9.7 & 35.9 & 9.3 & 7.3 & 8.6 & -8.6 & 5.3 \\
\hline Ishigaki & 29.6 & 6.4 & -5.1 & 5.3 & -60.6 & 12.4 & -12.0 & 6.2 \\
\hline Hachinohe & -27.2 & 8.3 & -25.1 & 7.5 & -13.3 & 5.9 & -14.4 & 4.2 \\
\hline Hanasaki & 0.9 & 1.3 & 0.8 & 1.8 & -6.7 & 1.8 & -3.3 & 0.9 \\
\hline Kamaishi & -21.9 & 3.7 & -12.3 & 3.6 & -31.7 & 6.1 & -12.6 & 2.8 \\
\hline Minamizu & -12.3 & 5.2 & -9.9 & 5.7 & 13.7 & 4.9 & -1.5 & 3.6 \\
\hline Miyako & -8.3 & 5.5 & 0.6 & 5.8 & -22.6 & 7.0 & -4.8 & 4.0 \\
\hline Muoran & -6.4 & 9.9 & 20.5 & 12.6 & -14.6 & 10.6 & -9.4 & 9.2 \\
\hline Nagoya & 0.7 & 3.0 & -5.4 & 2.8 & 21.6 & 5.3 & -9.3 & 2.8 \\
\hline Omaezaki & 18.7 & 4.6 & -12.5 & 4.9 & -17.7 & 5.0 & -11.0 & 3.3 \\
\hline Onahama & 5.8 & 7.1 & 7.9 & 7.6 & 32.8 & 11.0 & 6.3 & 5.5 \\
\hline Owase & -10.4 & 3.6 & -8.2 & 4.5 & 0.7 & 4.0 & -5.9 & 3.4 \\
\hline Toba & -14.9 & 9.6 & -20.9 & 8.5 & -29.6 & 46.3 & -40.0 & 22.1 \\
\hline Tokyo & -55.2 & 5.0 & -59.7 & 4.8 & 61.4 & 12.2 & 36.3 & 7.0 \\
\hline Urigami & 2.0 & 4.0 & 12.3 & 3.3 & -16.6 & 8.8 & 15.5 & 5.3 \\
\hline Odomari & -13.0 & 4.9 & -7.5 & 4.8 & -124.6 & 9.9 & -32.1 & 7.4 \\
\hline Okada & 33.0 & 6.4 & 39.2 & 6.1 & 108.9 & 14.3 & 37.4 & 5.4 \\
\hline Shimizuminato & -45.4 & 11.1 & -46.8 & 11.0 & -86.0 & 25.2 & -35.0 & 13.8 \\
\hline
\end{tabular}




\begin{tabular}{|c|c|c|c|c|c|c|c|c|}
\hline Shirihama & 11.2 & 4.2 & -6.8 & 4.2 & 4.3 & 13.6 & 28.6 & 6.7 \\
\hline Tosashimizu & -24.5 & 5.2 & -32.9 & 5.4 & -36.1 & 8.0 & -12.9 & 4.9 \\
\hline \multicolumn{9}{|l|}{$\frac{\text { SOUTHWEST }}{\text { PAC. }}$} \\
\hline Pohnpei & 25.4 & 3.7 & 1.8 & 2.5 & -9.6 & 12.1 & -17.2 & 8.2 \\
\hline Nauru & -4.9 & 4.8 & -34.8 & 11.5 & -32.1 & 13.3 & 5.4 & 9.6 \\
\hline Majuro & 7.9 & 4.7 & -13.2 & 3.1 & -36.3 & 20.1 & -4.4 & 12.8 \\
\hline Malakal & 42.0 & 3.8 & 7.4 & 3.6 & -34.5 & 6.3 & -4.3 & 3.3 \\
\hline Yap & 20.6 & 3.8 & 1.5 & 6.1 & -53.5 & 6.2 & -26.9 & 3.5 \\
\hline Honiara & -9.7 & 3.2 & -26.9 & 2.0 & 64.1 & 3.0 & 42.2 & 1.8 \\
\hline Rabaul & -25.6 & 3.8 & -7.6 & 3.4 & 97.9 & 7.6 & -33.3 & 4.2 \\
\hline $\begin{array}{l}\text { Christmas } \\
\text { Island }\end{array}$ & -9.0 & 2.4 & -6.2 & 2.0 & -45.9 & 7.5 & -10.7 & 3.8 \\
\hline Suva & -2.9 & 4.9 & 18.7 & 6.3 & 59.6 & 17.0 & -7.1 & 12.5 \\
\hline Noumea & 23.0 & 4.2 & 2.0 & 3.3 & 74.5 & 18.7 & 30.8 & 8.1 \\
\hline Funafuti & -10.8 & 2.6 & -5.5 & 1.5 & -44.5 & 9.3 & 8.5 & 5.9 \\
\hline Saipan & -11.1 & 9.0 & 4.4 & 3.8 & 28.0 & 12.7 & -25.4 & 7.2 \\
\hline Kapingamarangi & -30.8 & 6.0 & -23.9 & 13.5 & 29.8 & 9.6 & 43.9 & 4.3 \\
\hline Port Villa & -11.7 & 4.9 & -10.5 & 4.5 & 82.5 & 19.5 & 14.2 & 12.9 \\
\hline Wake & -7.6 & 3.0 & 8.4 & 2.8 & -46.9 & 12.7 & -5.6 & 5.6 \\
\hline Guam & -29.8 & 4.6 & -41.8 & 3.3 & -28.6 & 6.4 & -4.1 & 2.8 \\
\hline Kwajalein & 1.0 & 2.6 & 8.5 & 1.9 & -4.4 & 6.5 & 24.9 & 4.9 \\
\hline Pago Pago & 20.8 & 2.9 & -0.6 & 1.6 & 61.5 & 8.2 & -20.2 & 2.6 \\
\hline Manus Island & -15.8 & 10.1 & 57.8 & 17.9 & -26.1 & 14.0 & -24.2 & 6.2 \\
\hline Wellington & -0.6 & 3.8 & 8.4 & 4.0 & -40.7 & 18.7 & -3.5 & 4.9 \\
\hline Cendering & -15.8 & 14.9 & -17.8 & 12.4 & -65.2 & 9.7 & -18.6 & 7.7 \\
\hline Johor Bahru & -72.5 & 22.2 & -46.8 & 37.2 & -145.7 & 25.9 & -0.2 & 12.3 \\
\hline Kuantan & -63.4 & 14.5 & -60.7 & 17.2 & -137.0 & 25.7 & -16.0 & 11.6 \\
\hline Tioman & -55.0 & 19.3 & -92.7 & 25.0 & -150.3 & 35.2 & -11.0 & 13.6 \\
\hline Sedili & -85.3 & 21.6 & -63.3 & 26.4 & -118.6 & 33.1 & 26.2 & 10.1 \\
\hline Kukup & -30.5 & 13.6 & -50.2 & 29.4 & -79.9 & 16.8 & -50.1 & 22.7 \\
\hline Getting & -20.7 & 11.8 & -15.6 & 8.7 & -41.3 & 11.4 & -34.0 & 6.5 \\
\hline Ko Lak & -81.8 & 16.7 & 26.2 & 11.6 & 14.7 & 5.1 & 9.3 & 4.2 \\
\hline Tanjong Pagar & -29.3 & 14.0 & 2.7 & 32.0 & 1.2 & 15.1 & 38.0 & 6.6 \\
\hline Kelang & 20.1 & 12.3 & 27.0 & 11.3 & -151.8 & 13.0 & -46.9 & 10.7 \\
\hline Kaling & -78.3 & 11.6 & -17.3 & 25.7 & -78.7 & 8.9 & -41.1 & 13.8 \\
\hline Langkawi & -13.8 & 4.4 & -8.0 & 4.8 & -81.3 & 13.4 & -34.6 & 6.8 \\
\hline Lumut & -3.8 & 9.9 & -8.7 & 8.9 & -71.6 & 7.2 & -37.6 & 6.3 \\
\hline Penang & -3.0 & 6.6 & -4.8 & 5.4 & -90.0 & 10.7 & -50.9 & 7.3 \\
\hline Ko Taphao Noi & -0.9 & 3.9 & 2.4 & 2.5 & -54.9 & 11.1 & -39.6 & 10.3 \\
\hline Vung Tau & 59.3 & 16.8 & 43.6 & 11.0 & -1.7 & 37.5 & -59.0 & 14.5 \\
\hline
\end{tabular}




\begin{tabular}{|c|c|c|c|c|c|c|c|c|}
\hline Kota Kinabalu & $\mathbf{- 2 5 . 1}$ & $\mathbf{1 1 . 5}$ & -11.3 & 9.3 & $\mathbf{- 2 1 . 4}$ & $\mathbf{5 . 1}$ & -4.2 & 3.3 \\
\hline Bintulu & $\mathbf{2 8 7 . 1}$ & $\mathbf{4 4 . 8}$ & $\mathbf{2 3 1 . 7}$ & $\mathbf{5 2 . 2}$ & -23.4 & 13.8 & 1.1 & 6.9 \\
\hline Sandakan & $\mathbf{4 9 . 5}$ & $\mathbf{1 1 . 0}$ & $\mathbf{3 4 . 1}$ & $\mathbf{1 4 . 4}$ & $\mathbf{2 4 . 8}$ & $\mathbf{9 . 2}$ & -1.6 & 9.1 \\
\hline Brisbane & $\mathbf{3 1 . 9}$ & $\mathbf{1 0 . 7}$ & $\mathbf{2 8 . 6}$ & $\mathbf{8 . 4}$ & $\mathbf{1 5 3 . 4}$ & $\mathbf{3 1 . 0}$ & $\mathbf{3 5 . 0}$ & $\mathbf{1 7 . 3}$ \\
\hline Bundaberg & $\mathbf{1 0 . 6}$ & $\mathbf{4 . 6}$ & -0.9 & 3.4 & -13.7 & 7.8 & -5.3 & 6.0 \\
\hline $\begin{array}{c}\text { Ft. Denison } \\
\text { (Sydney) }\end{array}$ & -0.8 & 0.3 & 1.2 & 0.3 & $\mathbf{- 2 2 . 9}$ & $\mathbf{0 . 7}$ & 1.0 & 0.3 \\
\hline Townsville & -1.4 & 4.7 & -1.6 & 3.6 & 1.5 & 10.9 & -5.0 & 5.8 \\
\hline Spring Bay & 19.8 & 11.8 & -19.3 & 12.1 & $\mathbf{- 8 4 . 0}$ & $\mathbf{3 1 . 5}$ & 3.3 & 7.7 \\
\hline Booby Island & 25.4 & 24.6 & -7.1 & 16.8 & -6.5 & 15.2 & -11.7 & 7.4 \\
\hline Hobart & -20.1 & 11.2 & 13.9 & 13.7 & 19.7 & 15.8 & 9.7 & 6.9 \\
\hline Manila & 34.0 & 25.3 & $\mathbf{- 8 4 . 3}$ & $\mathbf{1 3 . 7}$ & $\mathbf{- 9 2 . 7}$ & $\mathbf{1 4 . 6}$ & $\mathbf{- 3 1 . 1}$ & $\mathbf{8 . 1}$ \\
\hline Legaspi & $\mathbf{- 2 4 . 3}$ & $\mathbf{7 . 1}$ & $\mathbf{- 4 0 . 7}$ & $\mathbf{6 . 2}$ & $\mathbf{- 1 4 4 . 9}$ & $\mathbf{2 0 . 8}$ & $\mathbf{7 7 . 2}$ & $\mathbf{1 2 . 7}$ \\
\hline Davao & $\mathbf{1 9 1 . 9}$ & $\mathbf{2 2 . 2}$ & -23.1 & 12.9 & $\mathbf{- 7 9 . 7}$ & $\mathbf{1 4 . 9}$ & $\mathbf{- 4 1 . 3}$ & $\mathbf{1 4 . 4}$ \\
\hline Lord Howe Is. & 4.8 & 7.2 & 14.0 & 7.2 & -7.2 & 12.7 & 3.8 & 9.6 \\
\hline Lautoka & 4.2 & 3.3 & 10.5 & 2.9 & $\mathbf{2 2 . 7}$ & $\mathbf{1 0 . 9}$ & $\mathbf{1 7 . 8}$ & $\mathbf{8 . 4}$ \\
\hline Cairns & 557.3 & 560.1 & -134.8 & 162.4 & 42.3 & 26.6 & 4.9 & 13.9 \\
\hline Gladstone & 47.3 & 438.9 & $\mathbf{- 3 0 2 . 0}$ & $\mathbf{1 3 3 . 7}$ & -0.3 & $\mathbf{2 2 . 4}$ & $\mathbf{- 7 7 . 9}$ & $\mathbf{2 0 . 9}$ \\
\hline Williamstown & -218.5 & 117.4 & -85.1 & 60.7 & 10.2 & $\mathbf{8 . 6}$ & $\mathbf{2 2 . 2}$ & $\mathbf{5 . 6}$ \\
\hline
\end{tabular}

a -All values are expressed as millimeter change in tide per meter rise in MSL $\left(\mathrm{mm} \mathrm{m}^{-1}\right)$. Significant values are in bold text, based on a SNR $>2$, and an absolute magnitude of $>10 \mathrm{mmm}^{-1}$

Table 3b Combined amplitude tidal anomaly trends (A-TATs) with 95\% confidence limits ${ }^{a}$.

\begin{tabular}{|c|c|c|}
\hline Station Name & Combined & $\mathbf{( \pm )}$ \\
\hline NORTHEAST PAC. & & \\
\hline French Frigate Sh. & -54.4 & 11.3 \\
\hline Cabo San Lucas & 42.3 & 15.7 \\
\hline Kodiak Island, AK & -10.9 & 16.4 \\
\hline Adak, AK & 17.1 & 11.6 \\
\hline Dutch Harbor, AK & -58.1 & 14.5 \\
\hline Midway & -3.1 & 8.0 \\
\hline Johnston & $\mathbf{- 1 2 1 . 3}$ & $\mathbf{1 3 . 1}$ \\
\hline Honolulu, HI & $\mathbf{1 0 1 . 3}$ & $\mathbf{1 1 . 3}$ \\
\hline Nawiliwilli Bay, HI & $\mathbf{8 3 . 4}$ & 13.6 \\
\hline Kahului, HI & -16.3 & 7.2 \\
\hline Hilo, HI & $\mathbf{1 1 9 . 0}$ & $\mathbf{7 . 9}$ \\
\hline
\end{tabular}




\begin{tabular}{|c|c|c|}
\hline Mokuoloe, $\mathrm{HI}$ & 21.1 & 18.4 \\
\hline Tofino & 19.0 & 11.1 \\
\hline Victoria & -59.9 & 16.0 \\
\hline San Francisco, CA & -158.9 & 13.7 \\
\hline La Jolla, CA & 44.8 & 8.0 \\
\hline Monterey, CA & -44.5 & 10.8 \\
\hline Crescent City, CA & -37.9 & 8.4 \\
\hline Neah Bay, WA & -27.4 & 16.9 \\
\hline Sitka, AK & -50.6 & 11.4 \\
\hline Seward, AK & -10.3 & 11.8 \\
\hline Seldovia, AK & -74.6 & 25.1 \\
\hline Valdez, AK & 19.8 & 13.6 \\
\hline Port San Luis, CA & 1.8 & 11.7 \\
\hline Los Angeles, CA & -6.0 & 7.2 \\
\hline San Diego, CA & -6.6 & 13.5 \\
\hline Yakutat, AK & 40.0 & 11.4 \\
\hline Ketchikan, AK & 57.7 & 14.4 \\
\hline Astoria, OR & -136.0 & 13.6 \\
\hline Charleston, OR & -7.4 & 12.4 \\
\hline Santa Monica, CA & -56.0 & 17.1 \\
\hline Cordova, AK & 56.6 & 11.0 \\
\hline South Beach, OR & -6.7 & 9.5 \\
\hline Seattle & -45.4 & 13.8 \\
\hline Vancouver & -144.8 & 25.8 \\
\hline Point Atkinson & 99.2 & 12.8 \\
\hline Bella Bella & -35.9 & 16.6 \\
\hline Queen Charlotte & -169.8 & 36.5 \\
\hline Port Hardy & 5.5 & 9.5 \\
\hline Bamfield & 11.9 & 12.8 \\
\hline \multicolumn{3}{|l|}{ SOUTHEAST PAC. } \\
\hline Baltra & 35.3 & 9.2 \\
\hline Papeete (Tahiti) & -12.2 & 18.8 \\
\hline Juan Fernandez Is. & -26.6 & 10.3 \\
\hline Easter Is. & 27.5 & 16.6 \\
\hline Rarotonga & 49.2 & 13.6 \\
\hline Penrhyn & 36.0 & 7.2 \\
\hline Santa Cruz & -28.4 & 10.0 \\
\hline San Felix & 69.3 & 13.1 \\
\hline Nuku' alofa & -97.8 & 14.7 \\
\hline Antofagasta & -25.0 & 9.0 \\
\hline Valparaiso & -72.5 & 10.5 \\
\hline
\end{tabular}

141 


\begin{tabular}{|c|c|c|}
\hline Lobos de Afuera & 25.4 & 12.1 \\
\hline Buena Ventura & -48.2 & 18.0 \\
\hline Caldera & 126.2 & 14.1 \\
\hline La Libertad & -9.5 & 14.1 \\
\hline Callao & -15.1 & 7.3 \\
\hline Matarani & -35.7 & 13.1 \\
\hline Balboa & -53.5 & 20.5 \\
\hline Tumaco & 24.2 & 10.9 \\
\hline Puerto Montt & -955.5 & 66.9 \\
\hline \multicolumn{3}{|l|}{ NORTHWEST PAC. } \\
\hline Chichijima & -39.5 & 13.7 \\
\hline Hong Kong & 296.1 & 42.7 \\
\hline Kaohsiung & -19.8 & 12.6 \\
\hline Keelung & -83.8 & 16.0 \\
\hline Nakanoshima & 50.6 & 36.2 \\
\hline Abashiri & -121.4 & 20.9 \\
\hline Hamada & 49.9 & 30.9 \\
\hline Toyama & -57.7 & 11.3 \\
\hline Kushiro & -49.9 & 16.0 \\
\hline Ofunato & 11.1 & 12.1 \\
\hline Mera & -37.5 & 19.1 \\
\hline Kushimoto & -50.5 & 19.6 \\
\hline Aburatsu & 47.9 & 14.0 \\
\hline Naha & 34.9 & 12.2 \\
\hline Maisaka & -294.2 & 22.2 \\
\hline Miyakejima & -51.5 & 6.1 \\
\hline Naze & 25.7 & 12.5 \\
\hline Wakkanai & -97.4 & 19.1 \\
\hline Nagasaki & -101.6 & 32.7 \\
\hline Nishinoomote & -219.4 & 41.5 \\
\hline Hakodate & 33.2 & 16.8 \\
\hline Ishigaki & -48.2 & 16.2 \\
\hline Hachinohe & -80.1 & 13.3 \\
\hline Hanasaki & -8.3 & 3.0 \\
\hline Kamaishi & -78.5 & 8.4 \\
\hline Minamizu & -10.0 & 9.8 \\
\hline Miyako & -35.1 & 11.3 \\
\hline Muoran & -9.9 & 21.3 \\
\hline Nagoya & 7.5 & 7.3 \\
\hline Omaezaki & -22.4 & 9.0 \\
\hline Onahama & 52.7 & 16.1 \\
\hline
\end{tabular}




\begin{tabular}{|c|c|c|}
\hline Owase & -23.9 & 7.8 \\
\hline Toba & -105.5 & 52.9 \\
\hline Tokyo & -17.2 & 15.7 \\
\hline Urigami & 13.3 & 11.5 \\
\hline Odomari & -177.2 & 14.1 \\
\hline Okada & 218.6 & 17.6 \\
\hline Shimizuminato & -213.2 & 32.7 \\
\hline Shirihama & 37.3 & 16.2 \\
\hline Tosashimizu & -106.5 & 12.0 \\
\hline \multicolumn{3}{|l|}{ SOUTHWEST PAC. } \\
\hline Pohnpei & 0.5 & 15.3 \\
\hline Nauru & -66.5 & 20.6 \\
\hline Majuro & -46.0 & 24.5 \\
\hline Malakal & 10.6 & 8.8 \\
\hline Yap & -58.2 & 10.1 \\
\hline Honiara & 69.6 & 5.2 \\
\hline Rabaul & 31.5 & 10.1 \\
\hline Christmas Island & -71.8 & 9.0 \\
\hline Suva & 68.3 & 22.6 \\
\hline Noumea & 130.2 & 21.1 \\
\hline Funafuti & -52.3 & 11.4 \\
\hline Saipan & -4.1 & 17.5 \\
\hline Kapingamarangi & 19.0 & 18.2 \\
\hline Port Villa & 74.5 & 24.3 \\
\hline Wake & -51.7 & 14.5 \\
\hline Guam & -104.4 & 9.0 \\
\hline Kwajalein & 30.0 & 8.7 \\
\hline Pago Pago & 61.5 & 9.2 \\
\hline Manus Island & -8.3 & 25.6 \\
\hline Wellington & -36.4 & 20.1 \\
\hline Cendering & -117.4 & 23.1 \\
\hline Johor Bahru & -265.3 & 51.9 \\
\hline Kuantan & -277.2 & 36.1 \\
\hline Tioman & -309.0 & 49.2 \\
\hline Sedili & -241.0 & 48.5 \\
\hline Kukup & -210.7 & 43.0 \\
\hline Getting & -111.6 & 19.7 \\
\hline Ko Lak & -31.6 & 21.4 \\
\hline Tanjong Pagar & 12.5 & 38.6 \\
\hline Kelang & -151.6 & 23.7 \\
\hline Kaling & -215.4 & 32.6 \\
\hline
\end{tabular}




\begin{tabular}{|c|c|c|}
\hline Langkawi & $\mathbf{- 1 3 7 . 7}$ & $\mathbf{1 6 . 4}$ \\
\hline Lumut & $\mathbf{- 1 2 1 . 7}$ & $\mathbf{1 6 . 4}$ \\
\hline Penang & $\mathbf{- 1 4 8 . 7}$ & $\mathbf{1 5 . 5}$ \\
\hline Ko Taphao Noi & -93.0 & 15.8 \\
\hline Vung Tau & 42.2 & 44.9 \\
\hline Kota Kinabalu & -62.1 & 16.0 \\
\hline Bintulu & $\mathbf{4 9 6 . 4}$ & $\mathbf{7 0 . 5}$ \\
\hline Sandakan & $\mathbf{1 0 6 . 9}$ & $\mathbf{2 2 . 3}$ \\
\hline Brisbane & $\mathbf{2 4 8 . 8}$ & $\mathbf{3 8 . 0}$ \\
\hline Bundaberg & -9.4 & 11.4 \\
\hline Ft. Denison (Sydney) & -21.4 & 0.8 \\
\hline Townsville & -6.5 & 13.7 \\
\hline Spring Bay & -80.2 & 36.6 \\
\hline Booby Island & 0.2 & 34.3 \\
\hline Hobart & 23.1 & 24.7 \\
\hline Manila & $\mathbf{- 1 7 4 . 1}$ & $\mathbf{3 3 . 3}$ \\
\hline Legaspi & $\mathbf{- 1 3 2 . 7}$ & $\mathbf{2 6 . 1}$ \\
\hline Davao & 47.9 & 33.0 \\
\hline Lord Howe Is. & 15.4 & 19.0 \\
\hline Lautoka & 55.2 & 14.4 \\
\hline Cairns & 469.8 & 583.9 \\
\hline Gladstone & -332.9 & 459.8 \\
\hline Williamstown & $\mathbf{- 2 7 1 . 2}$ & $\mathbf{1 3 2 . 6}$ \\
\hline
\end{tabular}

a -All values are expressed as millimeter change in tide per meter rise in MSL $\left(\mathrm{mmm}^{-1}\right)$. Significant values are in bold text, based on a SNR $>2$, and an absolute combined magnitude of $>100 \mathrm{mmm}^{-1}$ 
Table 4 Phase anomaly trends (P-TATs) with 95\% confidence limits for major diurnal and semidiurnal constituents

\begin{tabular}{|c|c|c|c|c|c|c|c|c|}
\hline Station Name & $K_{1}$ & $( \pm)$ & $\mathbf{O}_{1}$ & ( \pm ) & $\mathrm{M}_{2}$ & $( \pm)$ & $S_{2}$ & ( \pm ) \\
\hline \multicolumn{9}{|l|}{ NORTHEAST PAC. } \\
\hline French Frigate Sh. & -0.3 & 2.1 & 7.6 & 2.7 & -1.3 & 4.9 & -3.9 & 10.5 \\
\hline Cabo San Lucas & 0.5 & 1.4 & 8.6 & 1.4 & 6.3 & 1.7 & 11.8 & 1.6 \\
\hline Kodiak Island, AK & -0.2 & 1.0 & 0.9 & 1.3 & 0.6 & 0.7 & -0.3 & 0.9 \\
\hline Adak, AK & -4.8 & 1.2 & -10.0 & 1.2 & -4.3 & 2.2 & 18.6 & 7.0 \\
\hline Dutch Harbor, AK & 16.7 & 2.6 & 20.0 & 2.3 & 17.8 & 3.2 & 35.4 & 10.7 \\
\hline Midway & -0.1 & 2.3 & 4.3 & 2.6 & -6.5 & 3.4 & -27.8 & 8.3 \\
\hline Johnston & -3.4 & 3.3 & 7.7 & 3.9 & 16.9 & 4.3 & -3.0 & 4.5 \\
\hline Honolulu, $\mathrm{HI}$ & -2.7 & 1.7 & -2.7 & 2.0 & -0.1 & 3.6 & 1.5 & 5.2 \\
\hline Nawiliwilli Bay, HI & 4.7 & 1.6 & 0.1 & 2.0 & 10.7 & 4.2 & 16.3 & 6.1 \\
\hline Kahului, HI & 4.9 & 1.4 & -4.7 & 1.8 & -6.5 & 2.2 & -10.5 & 2.3 \\
\hline Hilo, HI & 1.7 & 1.1 & 6.6 & 1.6 & 9.0 & 2.2 & 16.3 & 2.3 \\
\hline Mokuoloe, HI & -3.8 & 2.1 & -4.1 & 2.1 & 15.6 & 7.6 & -5.7 & 5.1 \\
\hline Tofino & -0.1 & 1.5 & 0.1 & 1.6 & 2.5 & 1.3 & 2.1 & 1.7 \\
\hline Victoria & 2.5 & 0.8 & 3.8 & 0.9 & 5.2 & 1.3 & 8.3 & 2.0 \\
\hline San Francisco, CA & 3.5 & 0.8 & 6.2 & 1.0 & 3.4 & 1.3 & 5.4 & 2.0 \\
\hline La Jolla, CA & -1.6 & 1.0 & -3.3 & 0.8 & 5.7 & 1.3 & 1.0 & 2.0 \\
\hline Monterey, CA & -3.2 & 0.9 & -4.5 & 1.0 & 6.6 & 0.5 & 4.5 & 1.5 \\
\hline Crescent City, CA & 4.3 & 1.1 & 4.8 & 1.0 & 4.3 & 1.2 & 2.7 & 1.7 \\
\hline Neah Bay, WA & 1.3 & 1.1 & 2.3 & 1.1 & 0.6 & 6.6 & 1.2 & 1.2 \\
\hline Sitka, AK & -4.8 & 0.9 & -0.4 & 1.2 & -1.0 & 0.8 & 1.0 & 0.9 \\
\hline Seward, AK & -1.9 & 0.8 & -2.9 & 0.9 & -1.1 & 0.7 & -3.3 & 0.9 \\
\hline Seldovia, AK & -1.0 & 1.2 & 1.2 & 1.4 & 2.1 & 1.0 & 1.7 & 1.4 \\
\hline Valdez, AK & -0.3 & 0.8 & -2.1 & 0.9 & 0.5 & 0.5 & 2.7 & 1.0 \\
\hline Port San Luis, CA & -3.9 & 1.4 & -3.7 & 1.1 & 2.6 & 0.8 & -0.4 & 2.1 \\
\hline Los Angeles, CA & 3.0 & 0.6 & 0.1 & 0.7 & 4.2 & 0.8 & 1.1 & 0.9 \\
\hline San Diego, CA & -2.6 & 1.3 & -3.6 & 1.3 & -2.3 & 2.5 & -5.0 & 3.5 \\
\hline Yakutat, AK & -1.1 & 1.1 & -1.3 & 1.1 & -1.9 & 1.1 & -1.4 & 1.4 \\
\hline Ketchikan, AK & -0.1 & 0.8 & 0.5 & 0.9 & 1.6 & 0.8 & 2.2 & 1.0 \\
\hline Astoria, OR & 1.8 & 0.8 & 6.1 & 1.4 & 0.9 & 0.7 & 0.6 & 1.3 \\
\hline Charleston, OR & 5.5 & 0.9 & 6.2 & 1.2 & 1.0 & 0.8 & 5.4 & 12.9 \\
\hline Santa Monica, CA & 0.1 & 2.1 & 1.8 & 1.2 & 4.3 & 0.8 & -5.3 & 3.2 \\
\hline Cordova, AK & -2.1 & 0.9 & -2.6 & 0.9 & 0.6 & 0.7 & -0.5 & 0.8 \\
\hline South Beach, OR & -3.1 & 0.9 & 0.6 & 0.9 & 0.9 & 0.8 & 1.2 & 1.3 \\
\hline Seattle & 1.9 & 0.8 & 2.1 & 1.1 & 5.8 & 0.8 & 3.1 & 1.2 \\
\hline Vancouver & 3.0 & 1.6 & 5.2 & 1.9 & -1.2 & 1.9 & -2.5 & 2.5 \\
\hline Point Atkinson & -2.7 & 0.6 & 1.5 & 0.7 & -4.0 & 0.4 & -2.5 & 0.7 \\
\hline Bella Bella & -3.0 & 0.7 & -0.7 & 1.1 & 1.5 & 0.8 & 2.9 & 1.3 \\
\hline
\end{tabular}




\begin{tabular}{|c|c|c|c|c|c|c|c|c|}
\hline Queen Charlotte & -0.9 & 0.8 & 0.9 & 0.9 & 0.8 & 0.8 & -1.4 & 0.9 \\
\hline Port Hardy & -1.0 & 0.4 & -0.1 & 0.5 & 18.4 & 3.7 & 8.6 & 0.5 \\
\hline Bamfield & -0.7 & 1.1 & -0.1 & 1.3 & 2.6 & 0.8 & 3.9 & 1.3 \\
\hline \multicolumn{9}{|l|}{ SOUTHEAST PAC. } \\
\hline Baltra & -11.1 & 4.4 & -27.3 & 14.3 & -2.1 & 1.6 & -0.3 & 1.7 \\
\hline Papeete (Tahiti) & -173.4 & 44.7 & -26.3 & 8.4 & -116.0 & 25.6 & 30.9 & 5.0 \\
\hline Juan Fernandez Is. & 14.7 & 3.0 & 8.9 & 3.1 & 12.7 & 4.0 & 11.8 & 5.2 \\
\hline Easter Is. & -6.6 & 2.8 & -2.1 & 3.4 & 3.6 & 2.7 & 1.6 & 4.0 \\
\hline Rarotonga & 6.4 & 10.9 & 1.3 & 6.7 & -13.0 & 2.4 & -6.3 & 4.0 \\
\hline Penrhyn & -38.9 & 6.8 & 43.1 & 11.9 & 1.8 & 5.0 & -26.6 & 8.1 \\
\hline Santa Cruz & -2.9 & 3.0 & 26.1 & 7.0 & -0.4 & 0.5 & 0.4 & 0.7 \\
\hline San Felix & -15.4 & 2.3 & -10.0 & 3.0 & -21.5 & 4.0 & -19.8 & 5.1 \\
\hline Nuku' alofa & -6.4 & 3.1 & -16.1 & 4.5 & -5.0 & 1.2 & -18.7 & 7.2 \\
\hline Antofagasta & -1.9 & 1.4 & 1.5 & 1.9 & -4.4 & 2.2 & -0.5 & 3.0 \\
\hline Valparaiso & -2.1 & 0.8 & -3.4 & 1.0 & -0.9 & 0.9 & -4.2 & 1.3 \\
\hline Lobos de Afuera & 0.3 & 1.9 & 0.5 & 2.9 & -0.2 & 1.8 & 3.7 & 2.1 \\
\hline Buena Ventura & 5.9 & 2.1 & -40.6 & 42.2 & 8.3 & 2.1 & 12.4 & 2.7 \\
\hline Caldera & -0.2 & 1.6 & -1.8 & 2.4 & -0.7 & 2.2 & -5.0 & 2.9 \\
\hline La Libertad & 4.4 & 1.1 & 11.4 & 3.2 & 3.7 & 1.1 & 4.2 & 1.1 \\
\hline Callao & -4.9 & 1.4 & -2.6 & 2.3 & 1.2 & 2.6 & -2.9 & 2.7 \\
\hline Matarani & 1.4 & 5.5 & 6.4 & 7.1 & 3.5 & 10.5 & -3.2 & 7.0 \\
\hline Balboa & 3.1 & 2.1 & 5.5 & 23.7 & 7.3 & 2.4 & 8.9 & 2.6 \\
\hline Tumaco & 6.7 & 2.1 & -1.8 & 5.5 & -1.7 & 2.6 & 2.5 & 3.0 \\
\hline Puerto Montt & 6.0 & 1.7 & 1.8 & 1.9 & 5.0 & 2.3 & 1.8 & 3.2 \\
\hline \multicolumn{9}{|l|}{ NORTHWEST PAC. } \\
\hline Chichijima & 2.8 & 2.3 & -1.3 & 2.2 & -12.7 & 2.0 & 6.3 & 2.6 \\
\hline Hong Kong & -2.3 & 1.3 & -6.2 & 1.8 & -1.1 & 2.6 & -5.1 & 3.1 \\
\hline Kaohsiung & 1.8 & 2.1 & -4.6 & 2.7 & 2.3 & 4.4 & -7.3 & 5.5 \\
\hline Keelung & -4.1 & 2.7 & -6.2 & 2.0 & -10.4 & 6.8 & -17.8 & 9.7 \\
\hline Nakanoshima & 5.2 & 2.9 & 9.3 & 4.6 & -1.4 & 2.7 & 3.9 & 3.5 \\
\hline Abashiri & 3.6 & 4.4 & 10.6 & 3.4 & 20.7 & 5.0 & 12.7 & 5.9 \\
\hline Hamada & 4.6 & 12.5 & -24.1 & 10.0 & 10.2 & 6.2 & 11.4 & 24.3 \\
\hline Toyama & -19.0 & 7.1 & -1.9 & 6.8 & 2.9 & 4.4 & -13.4 & 9.4 \\
\hline Kushiro & -13.0 & 2.2 & -15.3 & 3.4 & 4.3 & 1.3 & 3.5 & 1.4 \\
\hline Ofunato & -8.8 & 1.8 & -0.2 & 2.3 & -3.2 & 1.3 & -3.8 & 1.5 \\
\hline Mera & 1.8 & 2.0 & 9.4 & 2.6 & -5.5 & 1.4 & -1.0 & 1.8 \\
\hline Kushimoto & 0.7 & 1.6 & -1.3 & 2.2 & 9.7 & 2.3 & 7.1 & 3.4 \\
\hline Aburatsu & -7.8 & 1.4 & -13.5 & 1.6 & 1.6 & 1.1 & 0.2 & 1.5 \\
\hline Naha & 1.6 & 2.4 & 5.2 & 2.1 & 3.5 & 2.4 & 9.0 & 2.9 \\
\hline Maisaka & 7.6 & 2.8 & 13.1 & 3.3 & 6.6 & 2.7 & 8.0 & 2.7 \\
\hline Miyakejima & 1.0 & 0.7 & 2.2 & 0.7 & 2.1 & 0.5 & 2.3 & 0.6 \\
\hline Naze & 1.2 & 3.8 & 2.2 & 3.1 & -8.8 & 1.8 & -10.9 & 7.3 \\
\hline
\end{tabular}




\begin{tabular}{|c|c|c|c|c|c|c|c|c|}
\hline Wakkanai & 5.7 & 8.3 & -8.4 & 9.5 & 5.5 & 13.3 & 6.4 & 14.6 \\
\hline Nagasaki & 2.1 & 3.4 & 0.3 & 4.1 & -4.4 & 1.6 & 1.3 & 2.5 \\
\hline Nishinoomote & 6.5 & 4.6 & 5.4 & 4.1 & -1.7 & 6.1 & 2.8 & 6.6 \\
\hline Hakodate & -3.5 & 4.1 & -14.5 & 5.9 & -2.5 & 2.3 & -4.9 & 2.7 \\
\hline Ishigaki & -3.9 & 2.5 & -4.3 & 2.2 & 1.1 & 1.5 & 0.1 & 2.1 \\
\hline Hachinohe & -5.3 & 2.5 & 4.9 & 2.8 & -0.2 & 1.3 & -3.1 & 2.2 \\
\hline Hanasaki & 0.1 & 0.4 & -1.4 & 0.3 & -0.6 & 0.3 & 0.2 & 0.4 \\
\hline Kamaishi & 4.3 & 1.9 & 1.7 & 1.6 & 6.1 & 2.9 & 2.6 & 3.0 \\
\hline Minamizu & 2.9 & 1.3 & 5.8 & 1.6 & 2.2 & 0.8 & 2.7 & 1.3 \\
\hline Miyako & -3.1 & 1.6 & -6.2 & 2.0 & -1.2 & 1.0 & 1.1 & 1.5 \\
\hline Muoran & -0.1 & 2.6 & 6.3 & 3.0 & 4.9 & 3.7 & 7.3 & 4.1 \\
\hline Nagoya & -3.6 & 0.9 & -2.3 & 1.1 & -1.9 & 0.8 & -2.6 & 1.1 \\
\hline Omaezaki & -5.3 & 1.4 & -9.5 & 1.9 & -3.1 & 0.8 & -2.3 & 1.0 \\
\hline Onahama & 2.3 & 1.7 & 2.0 & 2.1 & 0.8 & 1.2 & 1.3 & 1.9 \\
\hline Owase & 0.3 & 1.1 & -3.2 & 1.7 & 1.9 & 1.3 & 2.1 & 1.1 \\
\hline Toba & 11.8 & 4.0 & 12.3 & 4.3 & 16.5 & 5.5 & 24.1 & 6.7 \\
\hline Tokyo & -34.9 & 2.4 & -25.0 & 2.6 & -40.8 & 3.6 & -44.1 & 3.8 \\
\hline Urigami & 6.1 & 1.1 & 6.6 & 1.7 & -8.1 & 1.6 & -4.9 & 1.7 \\
\hline Odomari & 8.0 & 1.3 & 3.6 & 1.3 & 6.0 & 1.1 & 4.9 & 1.4 \\
\hline Okada & 1.6 & 1.4 & 6.7 & 1.6 & 8.0 & 1.3 & 7.2 & 1.6 \\
\hline Shimizuminato & 1.2 & 3.5 & 9.6 & 3.9 & 8.2 & 4.6 & 6.8 & 4.9 \\
\hline Shirihama & -15.3 & 2.1 & -19.5 & 2.2 & -24.2 & 3.4 & -19.5 & 3.0 \\
\hline Tosashimizu & -1.0 & 1.3 & -2.9 & 1.4 & 6.8 & 1.2 & 8.3 & 1.5 \\
\hline \multicolumn{9}{|l|}{ SOUTHWEST PAC. } \\
\hline Pohnpei & -18.3 & 2.2 & 7.6 & 1.8 & 11.2 & 2.8 & -13.9 & 3.2 \\
\hline Nauru & 3.5 & 3.5 & -5.7 & 7.1 & 2.4 & 1.0 & -0.5 & 0.9 \\
\hline Majuro & -17.2 & 2.8 & 7.6 & 3.2 & 2.0 & 2.2 & 0.4 & 2.3 \\
\hline Malakal & 5.5 & 1.5 & -32.9 & 1.4 & -3.9 & 1.4 & -6.4 & 1.4 \\
\hline Yap & 9.0 & 1.5 & 54.0 & 2.8 & 16.6 & 1.7 & 21.5 & 2.0 \\
\hline Honiara & -1.8 & 0.5 & 3.0 & 9.0 & 20.2 & 3.1 & -20.6 & 1.5 \\
\hline Rabaul & -1.8 & 1.6 & 2.9 & 1.6 & -38.8 & 13.9 & 4.6 & 3.2 \\
\hline Christmas Island & 2.1 & 3.9 & 17.4 & 5.1 & 9.6 & 5.5 & 5.5 & 7.2 \\
\hline Suva & -2.2 & 3.4 & 24.8 & 7.8 & -10.1 & 4.4 & -0.1 & 5.0 \\
\hline Noumea & 3.7 & 1.9 & -2.0 & 2.8 & 1.4 & 2.5 & 1.2 & 3.2 \\
\hline Funafuti & -0.6 & 2.0 & 1.3 & 2.4 & -2.0 & 1.8 & -2.8 & 2.0 \\
\hline Saipan & -6.5 & 3.6 & -13.5 & 3.0 & 0.3 & 4.9 & -43.3 & 9.7 \\
\hline Kapingamarangi & -18.6 & 2.7 & -25.7 & 5.3 & -41.6 & 4.4 & -44.7 & 3.6 \\
\hline Port Villa & 0.1 & 2.0 & -5.3 & 3.1 & -7.3 & 2.7 & 29.6 & 7.2 \\
\hline Wake & -1.0 & 3.1 & 9.6 & 3.2 & 19.3 & 2.2 & 7.1 & 2.4 \\
\hline Guam & 21.8 & 1.9 & 0.4 & 2.0 & 0.6 & 1.6 & 18.0 & 3.1 \\
\hline Kwajalein & 7.6 & 1.7 & -2.6 & 1.7 & -1.8 & 0.7 & -3.8 & 0.9 \\
\hline Pago Pago & 2.7 & 2.5 & 22.0 & 3.1 & 13.8 & 1.5 & -4.9 & 2.6 \\
\hline
\end{tabular}




\begin{tabular}{|c|c|c|c|c|c|c|c|c|}
\hline Manus Island & -0.2 & 2.1 & 10.3 & 4.1 & -43.9 & 4.9 & 21.8 & 8.6 \\
\hline Wellington & 7.4 & 8.0 & -16.4 & 7.7 & 2.0 & 3.8 & -7.2 & 11.0 \\
\hline Cendering & -11.0 & 4.6 & 6.2 & 3.8 & -0.1 & 1.5 & -9.2 & 2.6 \\
\hline Johor Bahru & 4.7 & 4.2 & 15.7 & 5.1 & -1.1 & 3.2 & -12.9 & 3.2 \\
\hline Kuantan & -3.8 & 4.3 & 6.3 & 3.3 & 10.2 & 1.9 & 2.7 & 3.5 \\
\hline Tioman & 82.3 & 32.5 & 0.9 & 4.1 & 6.3 & 1.8 & -5.8 & 3.2 \\
\hline Sedili & -16.6 & 4.0 & -1.0 & 41.3 & -14.7 & 2.7 & -23.5 & 3.7 \\
\hline Kukup & 6.0 & 3.8 & -2.2 & 5.7 & -1.5 & 1.5 & -5.0 & 2.2 \\
\hline Getting & -16.0 & 6.0 & -0.3 & 5.8 & 2.0 & 6.6 & -22.1 & 9.5 \\
\hline Ko Lak & 12.4 & 2.9 & 23.5 & 2.4 & 54.3 & 6.7 & 34.0 & 20.2 \\
\hline Tanjong Pagar & 12.6 & 5.1 & 9.1 & 5.7 & 4.3 & 2.7 & 2.8 & 3.2 \\
\hline Kelang & -0.3 & 41.9 & -0.8 & 13.5 & 0.9 & 1.4 & 2.2 & 2.4 \\
\hline Kaling & -14.0 & 14.4 & 0.6 & 3.4 & 0.2 & 1.6 & -6.1 & 3.4 \\
\hline Langkawi & 1.0 & 1.6 & -9.9 & 4.0 & 4.4 & 1.4 & -1.2 & 7.7 \\
\hline Lumut & -6.1 & 2.1 & -27.9 & 11.7 & 1.6 & 1.4 & -1.0 & 2.1 \\
\hline Penang & -0.2 & 1.9 & -9.2 & 5.2 & 5.2 & 1.4 & 1.6 & 2.1 \\
\hline Ko Taphao Noi & -2.1 & 1.7 & 7.2 & 2.6 & 7.5 & 1.5 & 4.0 & 2.3 \\
\hline Vung Tau & -0.7 & 3.9 & 4.5 & 2.9 & 4.4 & 5.0 & 12.3 & 10.8 \\
\hline Kota Kinabalu & 4.3 & 1.7 & -2.0 & 2.5 & 5.6 & 1.6 & 3.0 & 2.3 \\
\hline Bintulu & -1.1 & 3.9 & -19.0 & 5.0 & 0.6 & 4.2 & -13.4 & 6.1 \\
\hline Sandakan & 0.5 & 1.8 & 10.1 & 1.9 & 15.7 & 2.6 & 11.6 & 2.0 \\
\hline Brisbane & -4.5 & 9.8 & -17.2 & 3.3 & -13.4 & 2.9 & -22.9 & 3.4 \\
\hline Bundaberg & 0.4 & 1.3 & -0.1 & 1.6 & -1.1 & 1.6 & -2.7 & 1.9 \\
\hline Ft. Den. (Sydney) & 0.8 & 0.6 & 0.1 & 0.5 & -2.7 & 1.1 & 0.3 & 1.1 \\
\hline Townsville & 2.3 & 0.7 & 1.4 & 1.3 & 1.8 & 1.2 & 3.3 & 0.9 \\
\hline Spring Bay & 3.3 & 4.5 & 6.2 & 6.7 & 7.3 & 2.9 & 13.7 & 14.0 \\
\hline Booby Island & 2.5 & 1.2 & -3.0 & 0.8 & -3.4 & 1.4 & -1.3 & 3.7 \\
\hline Hobart & 13.7 & 4.8 & 12.2 & 7.1 & 17.4 & 8.4 & 67.6 & 32.6 \\
\hline Manila & 18.8 & 3.1 & 3.4 & 5.4 & 6.8 & 5.3 & -3.5 & 8.5 \\
\hline Legaspi & 11.9 & 2.5 & 21.4 & 3.0 & -21.9 & 3.8 & -3.1 & 4.2 \\
\hline Davao & -96.9 & 13.9 & 9.3 & 5.6 & -5.1 & 4.4 & -37.3 & 6.7 \\
\hline Lord Howe Is. & -0.8 & 3.8 & -2.9 & 5.0 & -0.3 & 2.2 & -4.3 & 2.9 \\
\hline Lautoka & 6.8 & 1.5 & -12.0 & 2.5 & -2.2 & 1.2 & 13.5 & 3.1 \\
\hline Cairns & 1.7 & 2.3 & -1.9 & 2.6 & 13.5 & 3.3 & -0.9 & 3.8 \\
\hline Gladstone & 8.2 & 2.2 & 8.7 & 3.4 & -0.8 & 2.4 & -2.2 & 3.4 \\
\hline Williamstown & -2.3 & 5.2 & -10.1 & 6.6 & -5.1 & 5.7 & -24.0 & 7.2 \\
\hline
\end{tabular}

a -All values are expressed as degree change in tide per meter rise in MSL $\left(\mathrm{degm}^{-1}\right)$. Significant values are in bold text, based on a SNR $>2$, and an absolute magnitude of $>5 \mathrm{degm}^{-1}$. 
Table 5 Seasonal amplitude tidal anomaly trends (A-STATs), showing maximum monthly TAT determinations in units of $\mathrm{mmm}^{-1}$, along with month number of occurrence as italicized text in parentheses (\#1-12), and total seasonal range between maximum and minimum values.

\begin{tabular}{|c|c|c|c|}
\hline & Max. & Min. & Range \\
\hline \multicolumn{4}{|l|}{$M_{2}$ Northeast } \\
\hline Cabo San Lucas & $87.1(9)$ & $-41.8(2)$ & 128.9 \\
\hline San Francisco, CA & $7.3(10)$ & $-182.7(4)$ & 189.9 \\
\hline La Jolla, CA & $68.3(11)$ & $-47.0(5)$ & 115.2 \\
\hline Astoria, OR & $-5.8(9)$ & $-179.8(6)$ & 174.0 \\
\hline Vancouver & $12.5(7)$ & $-97.2(2)$ & 109.7 \\
\hline Point Atkinson & $512.9(1)$ & $-43.8(9)$ & 556.7 \\
\hline Bella Bella & $45.9(1)$ & $-69.3(10)$ & 115.2 \\
\hline Queen Charlotte & $179.8(12)$ & $-292.8(5)$ & 472.6 \\
\hline Port Hardy & $107.7(5)$ & $-127.5(7)$ & 235.3 \\
\hline Bamfield & $174.4(7)$ & $-17.1(3)$ & 191.5 \\
\hline \multicolumn{4}{|l|}{$M_{2}$ Southeast } \\
\hline Papeete (Tahiti) & $26.1(12)$ & $-202.2(6)$ & 228.2 \\
\hline Buena Ventura & $49.3(10)$ & $-56.5(3)$ & 105.8 \\
\hline Puerto Montt & $-182.7(6)$ & $-528.0(2)$ & 345.3 \\
\hline \multicolumn{4}{|l|}{$\underline{M_{2} \text { Northwest }}$} \\
\hline Keelung & $37.1(5)$ & $-63.4(4)$ & 100.6 \\
\hline Toba & 86.7 (7) & $-26.8(2)$ & 113.5 \\
\hline Tokyo & $223.8(7)$ & $-23.6(2)$ & 247.4 \\
\hline \multicolumn{4}{|l|}{ M2 Southwest } \\
\hline Pohnpei & $128.8(6)$ & $-76.0(11)$ & 204.8 \\
\hline Majuro & $19.9(12)$ & $-123.8(5)$ & 143.7 \\
\hline Suva & $112.9(4)$ & $-88.1(10)$ & 201.1 \\
\hline Noumea & $79.8(9)$ & $-20.1(4)$ & 99.9 \\
\hline Saipan & $61.0(7)$ & $-58.9(11)$ & 119.9 \\
\hline Port Villa & $217.8(2)$ & $-29.8(5)$ & 247.6 \\
\hline Kwajalein & $50.0(2)$ & $-56.1(3)$ & 106.1 \\
\hline Manus Island & $50.6(8)$ & $-67.3(5)$ & 117.9 \\
\hline Cendering & $135.8(8)$ & $-113.0(3)$ & 248.8 \\
\hline Johor Bahru & $46.3(8)$ & $-165.4(3)$ & 211.7 \\
\hline Kuantan & $179.0(8)$ & $-240.5(3)$ & 419.4 \\
\hline Tioman & 209.2 (8) & $-254.8(3)$ & 464.0 \\
\hline Sedili & 229.7 (9) & $-204.4(3)$ & 434.1 \\
\hline Kukup & $4.5(1)$ & $-123.5(6)$ & 128.0 \\
\hline Getting & 49.5 (8) & $-123.8(2)$ & 173.3 \\
\hline
\end{tabular}




\begin{tabular}{|c|c|c|c|}
\hline Tanjong Pagar & 74.6 (8) & $-119.3(11)$ & 193.9 \\
\hline Kelang & $-72.1(2)$ & -185.8 (7) & 113.7 \\
\hline Vung Tau & 98.4 (8) & $-176.9(2)$ & 275.3 \\
\hline Bintulu & $30.3(2)$ & -100.4 (9) & 130.7 \\
\hline Sandakan & $130.4(6)$ & $-39.5(3)$ & 169.9 \\
\hline Spring Bay & 39.1 (11) & $-119.8(2)$ & 158.9 \\
\hline Legaspi & $-31.1(1)$ & -228.7 (4) & 197.6 \\
\hline Davao & $15.7(1)$ & $-129.2(8)$ & 144.9 \\
\hline \multicolumn{4}{|l|}{$\underline{S_{2} \text { Northeast }}$} \\
\hline Ketchikan, AK & $56.3(4)$ & $-45.1(6)$ & 101.4 \\
\hline Seattle & $84.5(7)$ & $-58.8(10)$ & 143.4 \\
\hline Point Atkinson & 159.4 (7) & $-13.8(1)$ & 173.2 \\
\hline Queen Charlotte & $122.3(12)$ & $-239.4(5)$ & 361.7 \\
\hline Port Hardy & $167.6(4)$ & $-280.8(7)$ & 448.3 \\
\hline Bamfield & $95.2(7)$ & $-18.2(6)$ & 113.3 \\
\hline \multicolumn{4}{|l|}{$\underline{S_{2} \text { Southeast }}$} \\
\hline Puerto Montt & $-34.9(10)$ & $-453.3(1)$ & 418.5 \\
\hline \multicolumn{4}{|l|}{$\underline{S_{2} \text { Northwest }}$} \\
\hline Nagasaki & 39.1 (11) & $-62.3(1)$ & 101.5 \\
\hline Tokyo & $153.0(7)$ & $-21.6(1)$ & 174.5 \\
\hline \multicolumn{4}{|l|}{$\underline{S_{2} \text { Southwest }}$} \\
\hline Pohnpei & $27.3(11)$ & $-77.0(4)$ & 104.3 \\
\hline Port Villa & $98.7(11)$ & $-110.6(5)$ & 209.3 \\
\hline Johor Bahru & 46.0 (9) & $-136.9(11)$ & 182.9 \\
\hline Kuantan & $134.8(5)$ & $-77.4(2)$ & 212.2 \\
\hline Tioman & $97.9(5)$ & $-76.1(2)$ & 173.9 \\
\hline Sedili & $93.1(5)$ & $-72.3(12)$ & 165.4 \\
\hline Kukup & 43.3 (9) & $-102.9(2)$ & 146.2 \\
\hline Tanjong Pagar & $74.9(6)$ & $-82.0(11)$ & 157.0 \\
\hline Kelang & $-18.8(8)$ & $-133.3(1)$ & 114.5 \\
\hline Vung Tau & $53.1(7)$ & $-149.5(6)$ & 202.6 \\
\hline Sandakan & $64.4(6)$ & $-56.9(11)$ & 121.2 \\
\hline Brisbane & $51.5(12)$ & $-50.8(7)$ & 102.3 \\
\hline Legaspi & $150.5(4)$ & $-4.9(12)$ & 155.4 \\
\hline Davao & $57.5(11)$ & $-215.6(7)$ & 273.1 \\
\hline \multicolumn{4}{|l|}{$\underline{K_{1} \text { Northeast }}$} \\
\hline Neah Bay, WA & 93.7 (9) & $-7.3(5)$ & 101.0 \\
\hline Astoria, OR & 26.7 (9) & $-74.7(6)$ & 101.4 \\
\hline Seattle & $67.9(10)$ & $-34.5(7)$ & 102.3 \\
\hline Vancouver & $99.1(10)$ & $-118.0(5)$ & 217.1 \\
\hline Point Atkinson & $499.2(9)$ & $-52.0(5)$ & 551.2 \\
\hline Queen Charlotte & $39.4(3)$ & $-246.0(5)$ & 285.5 \\
\hline
\end{tabular}




\begin{tabular}{|c|c|c|c|}
\hline Port Hardy & $191.8(3)$ & $-36.6(6)$ & 228.4 \\
\hline \multicolumn{4}{|l|}{$\underline{K_{1} \text { Southeast }}$} \\
\hline Puerto Montt & 30.6 (9) & $-69.3(2)$ & 99.9 \\
\hline \multicolumn{4}{|l|}{$\underline{K_{1} \text { Northwest }}$} \\
\hline Hamada & $65.1(10)$ & $-35.0(2)$ & 100.1 \\
\hline Hakodate & $43.8(9)$ & $-67.1(4)$ & 110.9 \\
\hline Hachinohe & $55.2(5)$ & $-116.0(10)$ & 171.2 \\
\hline Miyako & $57.0(8)$ & $-45.9(3)$ & 102.9 \\
\hline \multicolumn{4}{|l|}{$\underline{K_{1} \text { Southwest }}$} \\
\hline Guam & $38.4(6)$ & $-72.3(12)$ & 110.7 \\
\hline Cendering & $154.9(8)$ & $-127.6(3)$ & 282.5 \\
\hline Johor Bahru & $81.2(2)$ & $-218.5(9)$ & 299.8 \\
\hline Kuantan & 89.7 (8) & $-169.3(10)$ & 259.0 \\
\hline Tioman & $61.0(8)$ & $-146.2(6)$ & 207.2 \\
\hline Sedili & $13.4(4)$ & $-126.1(9)$ & 139.5 \\
\hline Kukup & $126.7(3)$ & $-200.4(9)$ & 327.2 \\
\hline Getting & $60.0(8)$ & $-191.9(12)$ & 251.9 \\
\hline Ko Lak & 46.9 (8) & $-121.1(3)$ & 168.0 \\
\hline Tanjong Pagar & $49.3(4)$ & $-123.5(9)$ & 172.8 \\
\hline Kaling & 79.5 (3) & -264.0 (9) & 343.5 \\
\hline Vung Tau & $73.3(3)$ & $-54.3(10)$ & 127.6 \\
\hline Kota Kinabalu & $44.7(10)$ & $-95.5(9)$ & 140.1 \\
\hline Bintulu & 419.2 (9) & $16.8(1)$ & 402.3 \\
\hline Sandakan & $104.5(4)$ & $-40.7(7)$ & 145.2 \\
\hline Brisbane & $81.3(4)$ & $-54.7(9)$ & 136.0 \\
\hline Booby Island & $137.3(4)$ & $-84.6(7)$ & 221.9 \\
\hline Hobart & $82.2(2)$ & $-62.9(8)$ & 145.1 \\
\hline Manila & $101.5(9)$ & $-49.8(4)$ & 151.3 \\
\hline Davao & $318.7(1)$ & $69.9(7)$ & 248.8 \\
\hline \multicolumn{4}{|l|}{$\underline{O_{1} \text { Northeast }}$} \\
\hline Vancouver & $48.7(3)$ & $-66.3(5)$ & 115.1 \\
\hline Point Atkinson & $280.2(9)$ & $-21.2(1)$ & 301.4 \\
\hline Bella Bella & $67.7(2)$ & $-33.8(10)$ & 101.5 \\
\hline Queen Charlotte & $24.5(1)$ & $-75.7(9)$ & 100.2 \\
\hline Port Hardy & $109.5(3)$ & $-182.4(6)$ & 291.9 \\
\hline \multicolumn{4}{|l|}{$\underline{O}_{1}$ Northwest } \\
\hline Kaohsiung & $47.9(5)$ & $-53.4(9)$ & 101.3 \\
\hline Kushiro & $-9.1(5)$ & $-132.6(9)$ & 123.5 \\
\hline Wakkanai & 33.7 (9) & $-72.5(3)$ & 106.2 \\
\hline Tokyo & $-0.4(3)$ & $-102.4(7)$ & 102.0 \\
\hline \multicolumn{4}{|l|}{$\underline{O}_{1}$ Southwest } \\
\hline Yap & $68.4(6)$ & $-79.3(12)$ & 147.7 \\
\hline
\end{tabular}




\begin{tabular}{|c|c|c|c|}
\hline Suva & $89.7(2)$ & $-29.4(11)$ & $\mathbf{1 1 9 . 0}$ \\
\hline Johor Bahru & $86.5(9)$ & $-108.8(2)$ & $\mathbf{1 9 5 . 3}$ \\
\hline Tioman & $29.8(3)$ & $-132.3(9)$ & $\mathbf{1 6 2 . 1}$ \\
\hline Sedili & $16.5(8)$ & $-117.2(6)$ & $\mathbf{1 3 3 . 7}$ \\
\hline Kukup & $78.5(3)$ & $-144.7(7)$ & $\mathbf{2 2 3 . 2}$ \\
\hline Ko Lak & $82.0(7)$ & $-36.0(2)$ & $\mathbf{1 1 8 . 0}$ \\
\hline Tanjong Pagar & $50.7(6)$ & $-61.8(1)$ & $\mathbf{1 1 2 . 5}$ \\
\hline Kelang & $82.1(5)$ & $-26.2(7)$ & $\mathbf{1 0 8 . 3}$ \\
\hline Kaling & $32.9(1)$ & $-134.0(7)$ & $\mathbf{1 6 6 . 8}$ \\
\hline Vung Tau & $108.2(7)$ & $-92.4(9)$ & $\mathbf{2 0 0 . 6}$ \\
\hline Bintulu & $320.8(9)$ & $-11.9(1)$ & $\mathbf{3 3 2 . 7}$ \\
\hline Sandakan & $62.2(1)$ & $-91.2(8)$ & $\mathbf{1 5 3 . 4}$ \\
\hline
\end{tabular}

a -All values are expressed as millimeter change in tide per meter rise in MSL $\left(\mathrm{mmm}^{-1}\right)$. 
Table 6 Seasonal phase tidal anomaly trends (P-STATs), showing maximum monthly TAT determinations in units of degm ${ }^{-1}$, along with month number of occurrence as italicized text in parentheses (1-12), and total seasonal range between maximum and minimum values.

\begin{tabular}{|c|c|c|c|}
\hline & Max. & Min. & Range \\
\hline \multicolumn{4}{|l|}{$M_{2}$ Southeast } \\
\hline Tahiti & $-46.9(3)$ & $-150.4(11)$ & 103.5 \\
\hline \multicolumn{4}{|l|}{$\underline{S_{2} \text { Southeast }}$} \\
\hline Tahiti & $37.3(1)$ & $-77.2(6)$ & 114.5 \\
\hline \multicolumn{4}{|l|}{$\underline{S_{2} \text { Northwest }}$} \\
\hline Nakanoshima & $51.9(6)$ & $-86.3(12)$ & 138.2 \\
\hline Kushiro & $94.4(6)$ & $-33.0(1)$ & 127.4 \\
\hline Ofunato & $120.7(6)$ & $-46.0(1)$ & 166.7 \\
\hline Hakodate & $144.5(6)$ & $-22.8(1)$ & 167.3 \\
\hline Hachinohe & $74.6(6)$ & $-48.0(1)$ & 122.6 \\
\hline Kamaishi & $125.3(6)$ & $-25.0(1)$ & 150.3 \\
\hline Miyako & $123.0(6)$ & $-28.2(1)$ & 151.1 \\
\hline Muoran & $138.9(6)$ & $-28.1(1)$ & 167.0 \\
\hline \multicolumn{4}{|l|}{$\underline{S_{2} \text { Southwest }}$} \\
\hline Cendering & 27.5 (4) & $-151.9(6)$ & 179.4 \\
\hline Johor Bahru & $23.7(3)$ & $-137.8(6)$ & 161.5 \\
\hline Kuantan & $40.3(3)$ & $-195.2(6)$ & 235.5 \\
\hline Tioman & $28.3(3)$ & $-198.5(6)$ & 226.8 \\
\hline Sedili & $10.5(3)$ & $-189.2(6)$ & 199.7 \\
\hline Getting & 56.9 (4) & $-86.1(6)$ & 143.1 \\
\hline Manila & 37.1 (9) & $-94.9(6)$ & 132.0 \\
\hline Davao & $-2.4(4)$ & $-120.3(12)$ & 117.9 \\
\hline \multicolumn{4}{|l|}{$\underline{K_{1} \text { Northeast }}$} \\
\hline Point Atkinson & $115.2(10)$ & $-10.9(1)$ & 126.1 \\
\hline Port Hardy & $31.9(3)$ & $-89.7(7)$ & 121.6 \\
\hline \multicolumn{4}{|l|}{$\underline{K_{1} \text { Southeast }}$} \\
\hline Tahiti & $125.0(3)$ & $-108.4(12)$ & 233.5 \\
\hline \multicolumn{4}{|l|}{$\underline{K_{1} \text { Northwest }}$} \\
\hline Abashiri & 110.9 (9) & $-37.1(5)$ & 148.0 \\
\hline Hamada & 109.6 (9) & $-98.8(4)$ & 208.4 \\
\hline Hakodate & $66.3(6)$ & $-98.5(4)$ & 164.8 \\
\hline \multicolumn{4}{|l|}{$K_{1}$ Southwest } \\
\hline Cendering & 47.5 (3) & $-111.9(6)$ & 159.4 \\
\hline Kuantan & $56.8(3)$ & $-95.2(6)$ & 152.0 \\
\hline
\end{tabular}




\begin{tabular}{|c|c|c|c|}
\hline Tioman & 49.4 (3) & $-114.9(6)$ & 164.3 \\
\hline Sedili & 35.1 (3) & $-94.9(6)$ & 130.1 \\
\hline Kukup & $58.8(8)$ & $-48.6(4)$ & 107.4 \\
\hline Getting & $36.0(2)$ & $-104.8(6)$ & 140.7 \\
\hline Kelang & $40.8(5)$ & $-66.1(9)$ & 106.9 \\
\hline Vung Tau & $38.1(3)$ & $-82.2(9)$ & 120.3 \\
\hline Sandakan & 73.5 (8) & $-123.9(9)$ & 197.4 \\
\hline Davao & $-3.3(2)$ & $-105.0(10)$ & 101.7 \\
\hline \multicolumn{4}{|l|}{$\underline{O}_{1}$ Northwest } \\
\hline Abashiri & $46.1(5)$ & $-54.3(9)$ & 100.3 \\
\hline Hamada & $61.0(4)$ & $-58.5(3)$ & 119.5 \\
\hline Ofunato & $110.8(3)$ & $-36.2(8)$ & 147.0 \\
\hline Wakkanai & 96.0 (4) & $-36.1(12)$ & 132.1 \\
\hline Nagasaki & $63.1(4)$ & $-60.1(7)$ & 123.2 \\
\hline Nishinoomote & $62.4(4)$ & $-41.2(7)$ & 103.7 \\
\hline \multicolumn{4}{|l|}{$\underline{O}_{1}$ Southwest } \\
\hline Getting & $71.9(6)$ & $-55.2(9)$ & 127.0 \\
\hline Ko Lak & 120.2 (7) & $5.4(9)$ & 114.9 \\
\hline Lumut & $139.6(6)$ & $-88.6(3)$ & 228.1 \\
\hline Manila & $-4.5(8)$ & $-109.0(1)$ & 104.5 \\
\hline
\end{tabular}

a -All values are expressed as degree change in tide per meter rise in MSL $\left(\right.$ degm $\left.^{-1}\right)$. 
Table 7 Coupled changes of MSL and tidal range (TR), and total water levels (WL), based on positive and negative combined A-TATs of Table 3b, and on MSL rise scenarios, calculated to $2100 .^{a}$

\begin{tabular}{|c|c|c|c|c|c|c|c|c|c|c|}
\hline $\begin{array}{c}\text { Stati } \\
\text { on }\end{array}$ & $\begin{array}{c}\text { Lin. } \\
\Delta \mathrm{MSL} \\
(\mathrm{m})\end{array}$ & $\begin{array}{c}\Delta \mathrm{TR} \\
(\mathrm{mm})\end{array}$ & $\begin{array}{c}\mathrm{Comb} \\
\mathrm{WL} \\
(\mathrm{m})\end{array}$ & $\begin{array}{c}\mathrm{RCP} \\
4.5 \\
\Delta \mathrm{MSL} \\
(\mathrm{m})\end{array}$ & $\begin{array}{c}\Delta \mathrm{TR} \\
(\mathrm{mm})\end{array}$ & $\begin{array}{c}\text { Comb } \\
\mathrm{WL} \\
(\mathrm{m})\end{array}$ & $\begin{array}{c}\mathrm{RCP} \\
8.5 \\
\Delta \mathrm{MSL} \\
(\mathrm{m})\end{array}$ & $\begin{array}{c}\Delta \mathrm{TR} \\
(\mathrm{mm})\end{array}$ & $\begin{array}{c}\text { Comb } \\
\mathrm{WL} \\
(\mathrm{m})\end{array}$ & $\begin{array}{c}\text { Comb } \\
\text { LLT of } \\
\text { tides } \\
\left(\mathrm{mmyr} \mathrm{r}^{1}\right)\end{array}$ \\
\hline $\begin{array}{c}\text { Hono } \\
\text { lulu }\end{array}$ & 0.28 & 28 & $\mathbf{0 . 3 1}$ & 0.49 & 49 & $\mathbf{0 . 5 4}$ & 1.05 & 107 & $\mathbf{1 . 1 6}$ & +0.25 \\
\hline $\begin{array}{c}\text { Nou } \\
\text { mea }\end{array}$ & 0.28 & 37 & $\mathbf{0 . 3 2}$ & 0.49 & 64 & $\mathbf{0 . 5 5}$ & 1.05 & 137 & $\mathbf{1 . 1 9}$ & +0.38 \\
\hline $\begin{array}{c}\text { Brisb } \\
\text { ane }\end{array}$ & 0.28 & 70 & $\mathbf{0 . 3 5}$ & 0.49 & 122 & $\mathbf{0 . 6 1}$ & 1.05 & 261 & $\mathbf{1 . 3 1}$ & +0.09 \\
\hline $\begin{array}{c}\text { Hong } \\
\text { Kong }\end{array}$ & 0.28 & 83 & $\mathbf{0 . 3 6}$ & 0.49 & 145 & $\mathbf{0 . 6 4}$ & 1.05 & 311 & $\mathbf{1 . 3 6}$ & +0.53 \\
\hline $\begin{array}{c}\text { Tiom } \\
\text { an }\end{array}$ & 0.28 & -87 & $\mathbf{0 . 1 9}$ & 0.49 & -151 & $\mathbf{0 . 3 4}$ & 1.05 & -324 & $\mathbf{0 . 7 3}$ & -0.54 \\
\hline Sedili & 0.28 & -67 & $\mathbf{0 . 2 1}$ & 0.49 & -118 & $\mathbf{0 . 3 7}$ & 1.05 & -253 & $\mathbf{0 . 8 0}$ & -0.70 \\
\hline $\begin{array}{c}\text { Odo } \\
\text { mari }\end{array}$ & 0.28 & -50 & $\mathbf{0 . 2 3}$ & 0.49 & -87 & $\mathbf{0 . 4 0}$ & 1.05 & -185 & $\mathbf{0 . 8 7}$ & -0.08 \\
\hline $\begin{array}{c}\text { Nishi } \\
\text { noo } \\
\text { mote }\end{array}$ & 0.28 & -61 & $\mathbf{0 . 2 2}$ & 0.49 & -107 & $\mathbf{0 . 3 8}$ & 1.05 & -230 & $\mathbf{0 . 8 2}$ & -0.13 \\
\hline
\end{tabular}

a -Three cases are included, one based on a linear global MSL rise of $+3.3 \mathrm{mmyr}^{-1}$, based on satellite altimetry observations from 1992-2014 (Church and White, 2011), and two based on the RCP4.5 and RCP8.5 scenarios of MSL rise (DeConto and Pollard, 2016). The MSL ( $\triangle M S L$ ) and tidal range changes are calculated to the end of the century (2100). The final column lists the rate of combined long-term trends (LTTS) of tidal amplitudes for reference. 


\title{
Chapter 4: (PART II) Can tidal perturbations associated with sea level variations in the Western Pacific Ocean be used to understand future effects of tidal evolution?
}

\begin{abstract}
This study examines connections between mean sea level (MSL) variability and diurnal and semidiurnal tidal constituent variations at 17 open-ocean and 9 continental shelf tide gauges in the Western Tropical Pacific Ocean, a region showing anomalous rise in MSL over the last 20 years and strong interannual variability. Detrended MSL fluctuations are correlated with detrended tidal amplitude and phase fluctuations, defined as tidal anomaly trends (TATs), to quantify the response of tidal properties to MSL variation; both positive and negative responses occur. Significant amplitude TATs are found for each of the two strongest tidal constituents, $\mathrm{K}_{1}$ (diurnal) and $\mathrm{M}_{2}$ (semidiurnal) at 14 and 17 gauges, respectively. Lesser constituents $\left(\mathrm{O}_{1}\right.$ and $\left.\mathrm{S}_{2}\right)$ show significant trends at ten gauges. Changing overtides suggest TATs are influenced by changing shallow water friction over the equatorial Western Pacific and the eastern coast of Australia, especially near the Great Barrier Reef. There is a strong connection between semidiurnal TATs at stations around the Solomon Islands and changes in thermocline depth, overtide generation, and the El Niño/Southern Oscillation (ENSO). Furthermore, the $\mathrm{O}_{1}, \mathrm{~K}_{1}$ and $\mathrm{M}_{2}$ TATs in the Solomon Sea are related to each other in a manner that suggests transfer of energy from $M_{2}$ to the two diurnals via resonant triad interactions; these cause major tidal variability on sub-decadal time scales, especially for $M_{2}$. The response of tides to MSL variability is not only spatially complex, it is frequency dependent; therefore, short-term responses may not predict long-term behavior.
\end{abstract}




\subsection{Introduction}

This study examines the connections between mean sea level (MSL) and variations in major diurnal and semidiurnal tidal constituent properties at open-ocean and continental shelf tide gauges in the Western Tropical Pacific Ocean, a region showing anomalous MSL rise over the last 20 years (Merrifield, 2011). Additionally, this domain exhibits large excursions of interannual sea level and tidal variability, especially during El Niño and La Niña events. We attempt to answer the question posed in the title, can we use the relations of the observed short-term MSL fluctuations to the shortterm tidal variations to understand the future effects of tidal evolution, and to predict changes in total water level (MSL + tides) under higher MSL conditions? MSL rise rates have increased since 1993 at 15 of 26 gauges used in this study, observed at both deep ocean island stations and at continental shelf gauges (Figure 39; Tables 8a, 8b, and 8c). This rapid increase in Western Pacific MSL rate of change provides an opportunity to seek connections between MSL rise and tidal evolution. If MSL rise is a primary driver of changes in the tides, as suggested by Arbic and Garrett (2010), then this area should exhibit unusually large rates of tidal evolution over the same time period, with a relatively simple spatial pattern. Alternatively, if changes in internal wave propagation (as in Hawaii, Colosi and Munk, 2006) are dominant, then smaller-scale, less spatially coherent tidal evolution would be expected. Shallow water frictional processes can also alter tidal constituents and may be altered by MSL variations (Amin, 1983), but this local process would not likely drive regional trends. Finally, the existence of multiple 
mechanisms could lead to complex patterns of tidal evolution, and this is, in fact, what our examination of Pacific Island gauges suggests. Furthermore, the results of our analyses suggest that different processes are active in different parts of the frequency spectrum, and so the behavior of short-term fluctuations do not, in general, allow a clear prediction of what may be expected for long-term trends of tidal properties.

We examine the interactions of detrended tidal anomalies - the deviations from long-term trends in tidal constituent properties -in relation to detrended MSL anomalies (deviations from long-term MSL trends) as a means of diagnosing dynamical factors that might influence the longer-term evolution of tides. Specifically, we examine MSL anomalies and tidal anomalies at 26 tide gauges in the Western Pacific region, at both island gauges, and at nearby continental shelves. We focus on four constituents, the two largest semidiurnal (twice daily) constituents, $M_{2}$ (twice daily lunar tide) and $S_{2}$ (twice daily solar tide), and the two largest diurnal (once daily) components, $\mathrm{K}_{1}$ (lunisolar diurnal) and $\mathrm{O}_{1}$ (lunar diurnal). In addition, a subset of gauges with a minimum length-of-record ( $L O R) \geq 40 \mathrm{yr}$ is used to determine whether any changes in tidal trends are associated with the onset of anomalous regional MSL rise in recent decades. We will compare the long-term linear trends of both MSL and tidal properties (amplitude and phase), as well as the shorter-term fluctuations of MSL anomalies and tidal property anomalies from these long term trends (LTTS). Under rapidly rising and warming sea level scenarios, tidal amphidromes may change as MSL rises and stratification increases (Pugh, 2004, Müller 2012b). Amphidromes may shift center 
position, amplify, and/or rotate. For all four tides, we compare the changes in amplitudes and phases with changes in MSL in the context of possible amphidromic migrations. We also attempt to identify the mechanisms behind the observed trends in tidal properties in several ways. First, we consider non-linear, shallow-water overtides as a tool for understanding changing friction over continental shelves and in shallow water regions in relation to changing tides. Then, we compare the variations of tidal trends at select stations to fluctuations in regional thermocline depth. Finally, we consider the possibility of a resonant triad interaction between the $K, \mathrm{O}_{1}$, and $\mathrm{M}_{2}$ tides. 


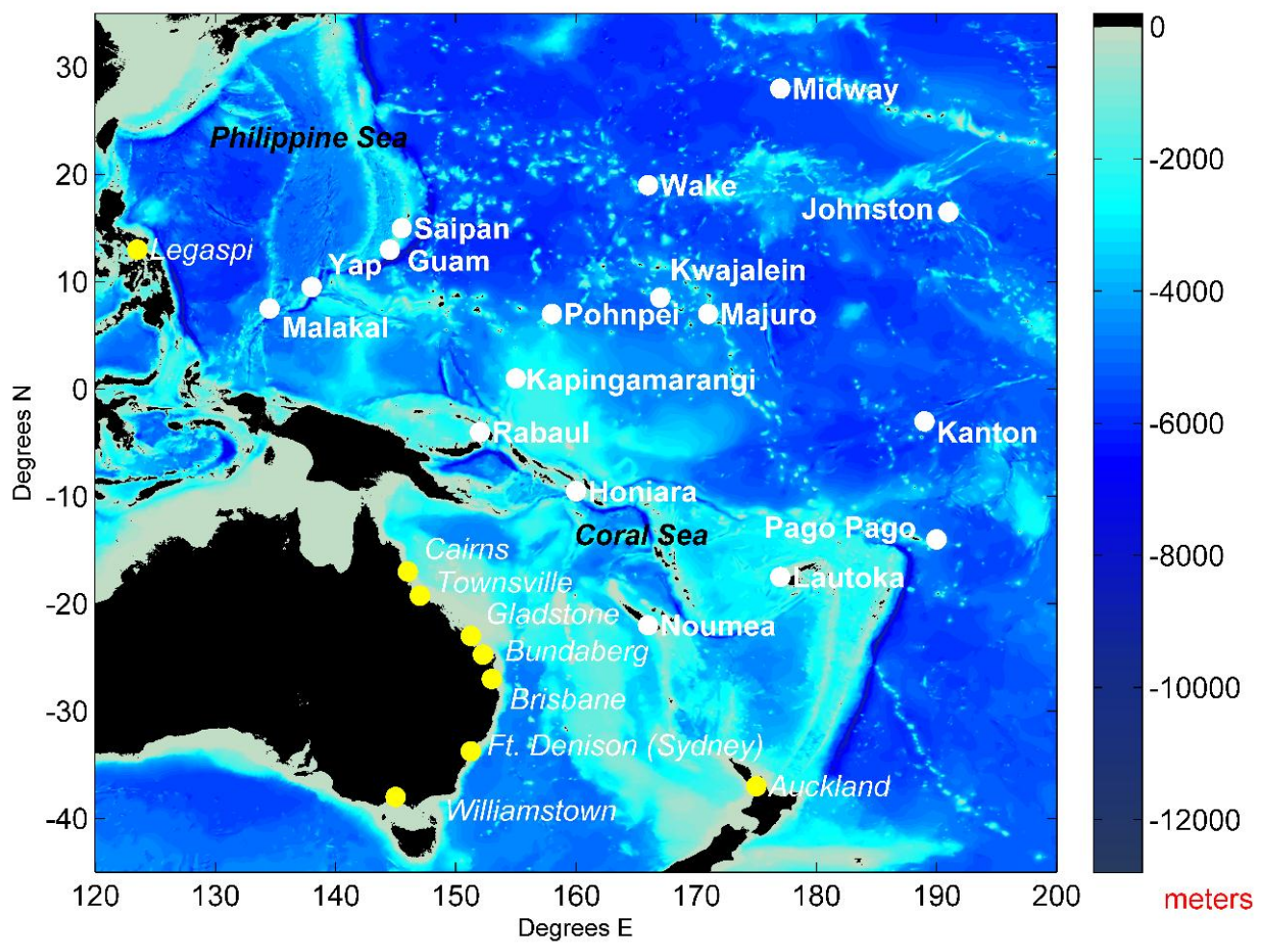

Figure 38 Bathymetry of the Western Pacific Ocean, with tide gauge stations used in this study shown as white dots and bold text for island gauges, and yellow dots and italicized text for coastal gauges; the depth scale is shown at right, in meters. 


\subsection{Background}

\subsubsection{Changing sea level and changing tides}

Ocean tides are usually considered stationary in time because of their close relationship to astronomical forcing. However, recent work has shown that tides are evolving at diverse rates in different parts of the ocean without any apparent relationship to astronomical forcing (Woodworth, 2010). Changes in major tidal constituents such as $\mathrm{M}_{2}, \mathrm{~S}_{2}, \mathrm{~K}_{1}$ and $\mathrm{O}_{1}$ are observed in the Eastern Pacific (Jay, 2009), the Gulf of Maine (Ray, 2006), and the North Atlantic (Ray, 2009; Müller, 2011b). Changes in tidal range and datum levels along many parts of the US coast line (Flick et al., 2003) also indicate evolution of constituents. While several mechanisms have been suggested that are independent of mean sea level (MSL) rise (Jay, 2009), MSL may influence or be correlated with tidal evolution in a variety of ways, both locally and on amphidromic scales, as well as over a multitude of frequency bands, from seasonal to multi-decadal. One possibility is that changes in continental shelf depth influence tides on a basin scale (Arbic and Garrett, 2010, Arbic et al., 2009), through changing bed friction in shallow water. Rising MSL also alters tidal wavelength and wave speed in shallow water areas, and reduces energy dissipation due to the reduced effect of bottom friction (Pugh, 1987). Alternatively, MSL rise may coincide with changes in stratification and/or thermocline depth. These internal changes may alter the surface manifestation of internal tides in ways that are detectable at tide gauges, e.g., at Honolulu (Colosi and Munk, 2006). Finally, fluctuations in multiple constituents may be related via resonant 
triads (Lamb, 2007). These factors, individually or in combination, could lead to a migration of the tidal amphidromes that would appear as a change in tidal properties at fixed observation stations.

The long-term global average trend in MSL is $2.8 \pm 0.3 \mathrm{mmyr}^{-1}$, as determined from tide gauge records (Church and White, 2006; 2011). Satellite observations show that the global MSL rise since 1993 has been $3.3 \pm 0.4 \mathrm{mmyr}^{-1}$ (Nicholls and Cazenave, 2010), suggesting a recent acceleration. However, MSL rise is spatially non-uniform. Five-year running means suggest that the MSL trend in the Western Tropical Pacific has approached +10 mmyr $^{-1}$ at some locations since 1993 (Merrifield, 2011). In contrast, MSL rise rates in the Northeastern Pacific have been below the global average over the same time period (National Research Council Ocean Science Board, 2012), with some places along the West Coast of the US having constant or slightly negative rates since 1980, partly due to prevailing wind patterns. While it is unlikely that the extreme rise rate in the Western tropical Pacific will persist, and Bromirski et al. (2011) have suggested that a trend reversal along the US West Coast is imminent, such decadal-scale variations in MSL rise rates offer an opportunity to examine the connections between different parts of the water level spectrum, in this case, between tidal evolution and MSL.

MSL also exhibits fluctuations related to climate cycles. The El Niño/Southern Oscillation (ENSO) is a strong contributing factor to sea surface anomalies in the Pacific 
(Kohl et al. 2007; Lombard et al. 2009; Timmermann et al. 2010), and local, short-term MSL anomalies associated with ENSO are often much larger than long-term trends. The 1982-1983 and the 1997-1998 El Niño events gave rise to widespread MSL fluctuations, with some coastal localities showing yearly averaged MSL rises or falls of $200 \mathrm{~mm}$ or more (Nerem et al, 1999; White et al, 2001). ENSO-related sea surface height (SSH) trends are, however, an order of magnitude too small (over a 15 yr time period) and too transient to account for the observed MSL rise for the Western tropical Pacific region (Merrifield, 2011). Instead, Merrifield argues that the unusually rapid MSL rise in the Western tropical Pacific is correlated with changing wind stress patterns in the region after 1993. ENSO related sea level variability is difficult to remove entirely from MSL time series, due to its quasi-periodic behavior, and large geographical extent that the signal affects. Hamlington, et al. (2011) present a detailed study on the identification and removal of the ENSO signal from global sea level records for 1950 through 2009, using cyclostationary empirical orthogonal function techniques, based on the methods of Church et al. (2004).

Predictions of future inundation due to extreme events must account for both MSL rise and changes in tidal properties. For example, Haigh et al. (2010) found that MSL rise rates of $+0.8-2.3$ mmyr $^{-1}$ in the English Channel were accompanied by smaller increases in high water elevation of $+0.1-0.3 \mathrm{mmyr}^{-1}$ (relative to $\mathrm{MSL}$ ). A numerical model from Pickering et al. (2012) found that a $2 \mathrm{~m}$ increase in MSL increased the spring tidal range from $-0.49 m$ to $+0.35 m$, depending on location. Hence, changing tidal 
processes can either mitigate or exacerbate changes to extreme water levels caused by MSL rise (Horsburgh and Wilson, 2007).

Changing internal tides are a likely mechanism connecting MSL change and the tidal evolution, at least between the critical latitudes for the major tidal species, $\pm 30^{\circ}$ latitude for $K_{1}$ and, and $\pm 75^{\circ}$ for $M_{2}$. Ray and Mitchum (1997) report that time-series of the monthly variations of $\mathrm{M}_{2}$ and $\mathrm{MSL}$ were coherent at annual, inter-annual and intraannual bands, and Mitchum and Chiswell (2000) note that higher amplitudes of $\mathrm{M}_{2}$ are associated with times of a deeper thermocline. Colosi and Munk (2006) conclude that the observed increase in the total $\mathrm{M}_{2}$ amplitude from $161 \mathrm{~mm}$ to $169 \mathrm{~mm}$ at Honolulu over the past century occurred because the internal $M_{2}$ wave moved more closely into phase with the surface tide. This conclusion is dependent on the assumption that rising sea level is a proxy for a deeper thermocline, which then alters the phase and/or the amplitudes of the internal tide.

\subsubsection{Resonant triads: Theory}

Resonant triad interactions are a possible mechanism for coherent fluctuations of multiple tidal constituents. Resonant (and near-resonant) triad interactions were first described in the context of light waves by Armstrong et al (1962), discussed generally by Bretherton (1964), and solutions for water waves are detailed by Craik (1985). Resonant triads arise from the (nonlinear) convective acceleration terms and are essential to energy transfer across the oceanic tidal spectrum (Hibiya et al 2002; Gerkama et al, 
2006), including shoaling surface gravity waves in shallow water (Frelich and Guza, 1984), and are involved in parametric subharmonic instabilities (PSI) at or near critical latitudes (MacKinnon and Winters, 2005).

A resonant triad is a pathway for an energy conserving, nonlinear energy exchange between multiple wave modes. The three complex plane waves involved in a triad have the form:

$$
\begin{aligned}
& Z_{j}(t)=A_{j} \exp \left[\mathrm{i} \theta_{j}(t)\right] \\
& \text { with }: \theta_{j}=\left(\mathbf{k}_{j} \cdot \mathbf{x}-\omega_{j} t\right)=\left(k_{j} x+l_{j} y+m_{j} z-w_{j} t\right) .
\end{aligned}
$$

The $\omega_{j}^{\prime}$ s are the frequencies of each wave; $\mathbf{k}_{j}=\left(k_{j}, l_{j}, m_{j}\right)$ are the wavevectors of each wave, and each wave has a dispersion relation given by $\omega_{\mathrm{j}}\left(\mathbf{k}_{\mathrm{j}}\right)$. For three interacting waves, the main resonance conditions are (Craik, 1985; Simmons, 1969) that the waves are phase locked (i.e., the sum of the phases is a constant), and that the frequencies and wavenumbers are also matched via a summation. Thus:

$$
\begin{aligned}
& \theta_{1}+\theta_{2}+\theta_{3}=C \\
& \omega_{1} \pm \omega_{2} \pm \omega_{3}=\Delta \omega \\
& \mathbf{k}_{1} \pm \mathbf{k}_{2} \pm \mathbf{k}_{3}=\Delta \mathbf{k}[\text { for }: \mathbf{k}=(k, l, m)]
\end{aligned}
$$

Small frequency and wavenumber mismatches ( $\Delta \omega$ and $\Delta \mathbf{k}$ ) allow for the possibility of near-resonant triads (Craik, 1985); exact triads have $\Delta \omega=0$ and $\Delta \mathbf{k}=0$. Near-resonant triads are possible in the ocean for internal tide generation at or near topographic 
features (Lamb, 2007). These relationships hold for a single triad of three waves, but are applicable to multiple triads of three waves, or even groups of four waves (tetrads). While Eq. (11b) is satisfied exactly $(\Delta \omega=0)$ by a number of tidal constituent combinations, Eq. (11c) is geometry-dependent. The dispersion relationship, $\omega_{i}\left(\mathbf{k}_{\mathbf{i}}\right)$, for planar and linear internal waves in the ocean is given by (Gill, 1982):

$$
\omega_{j}\left(\mathbf{k}_{j}\right)^{2}=\frac{N^{2}\left(k_{j}^{2}+l_{j}^{2}\right)+f^{2} m_{j}^{2}}{k_{j}^{2}+l_{j}^{2}+m_{j}^{2}},
$$

where $N$ indicates the buoyancy frequency, and $f$ is the Coriolis frequency; $f$ is a constant for each gauge, while $N$ is dependent on the local depth profile of temperature and salinity, and may vary seasonally.

There are more than 450 tidal frequencies in the ocean (Cartwright and Tayler, 1971); many of these frequencies could in theory form triads that satisfy Eq. (11b), but most such triads are based on minor tidal constituents and are unlikely to be energetic enough to be measurable. The triad most likely to be detected consists of $\mathrm{K}_{1}, \mathrm{O}_{1}$ and $\mathrm{M}_{2}$. The $\mathrm{K}_{1}$ and $\mathrm{O}_{1}$ tidal frequencies are close to each other, being equidistant (plus or minus $\sim 2 \%$ ) from half the $M_{2}$ frequency; in terms of $M_{2}$, they are:

$$
\begin{aligned}
& \omega_{M_{2}}=\omega_{K_{1}}+\omega_{O_{1}}, \\
& \left(\omega_{K_{1}}=0.52 \omega_{M_{2}}\right) ;\left(\omega_{O_{1}}=0.48 \omega_{M_{2}}\right)
\end{aligned} .
$$


We note that shallow water (frictional) overtides satisfy Eqs. (11a) and (11b), and may satisfy Eq. (11c), but this is not a requirement.

Ball (1964) details how triad interactions can occur at the interface of a two-layer fluid, e.g., at the thermocline. The strength of the interactions is dependent on the depths of the layers as well as the stratification and the angles of incidence of each wave relative to the thermocline interface. Recent upper-layer warming in the Western Pacific (Domingues et al, 2008) may be leading to a deepening thermocline and stronger stratification (Müller, 2012b), which makes the ocean effectively two-layered, and enhanced triad interactions may occur at the interface. MSL rise may also cause an extension in a basin's areal extent, as new areas are inundated. The close frequencies of $\mathrm{K}_{1}$ and $\mathrm{O}_{1}$ will yield similar wavenumber magnitudes for any given mode. In addition, because they are both nearly half the $\mathrm{M}_{2}$ frequency, internal modes of $\mathrm{K}_{1}$ and $\mathrm{O}_{1}$ may exchange energy via $M_{2}$. Alternatively, remote changes in barotropic $M_{2}$ may alter lowmode diurnal internal tides via parametric subharmonic instability (MacKinnon and Winters, 2005). Both possibilities are explored below.

\subsection{Methods}

\subsubsection{Station selection and data}

Twenty-two of the 26 tidal records used in this study were selected from the University of Hawaii Sea Level Center (UHSLC) archives. The Australian stations of Cairns, Gladstone, and Williamstown were provided by the Australian National Tidal 
Center (AuNTC), and Auckland, New Zealand was provided by Land Information New Zealand (LINZ). The factors that guided our station selection were:

1) Location: All stations are in or near the area of anomalous MSL rise.

2) Temporal coverage: All stations used have an LOR (length of record) greater than one nodal cycle (18.6yrs); LOR ranged from 19 to $107 y$ rs.

3) Completeness: The data were more than $80 \%$ complete over the record.

There were 17 island and 9 coastal stations that met these criteria, allowing comparison of open-ocean and continental shelf dynamics. Locations are shown in Figure 38, along with bathymetry. Figure 39 shows yearly average MSL time series at seven long-term gauges (Guam, Pago Pago, Kwajalein, Malakal, Yap, Honiara, and Kanton). These suggest a break in sea level trend at or around 1993 (broken vertical line). All of these seven gauges and more than half of the 26 total gauges of our study show an increase in MSL rate after this point up to the present. The longer-period gauges used will be subject to larger timing errors in the earlier years of the records, but these clock errors have improved in the recent decades with the advent of precise GPS clocks. A detailed discussion of the effect of clock errors in the Western Pacific can be found in: (Zaron and Jay, 2014).

Table 8a shows the gauges used (location name and country), start and end year of the complete length of record (LOR), and a descriptor indicating the environment where the gauge is located. For islands, delineation is made between low-lying atolls, 
steep islands with active volcanism, and non-volcanic mountainous terrain. Locations where a coral reef surrounds one or both sides of the island are also indicated. For coastal locations, we note whether the gauge location involves a river estuary, or a coastal enclosed bay. The last three columns of Table 8a show the MSL rates, in units of mmyr ${ }^{-1}$, shown first for the entire record, and then for the years before 1993, and after 1993. Rates are only reported for the early years if there exists at least a full nodal period of data ( 19 years), otherwise, they are not calculated, since these determinations may be inaccurate.

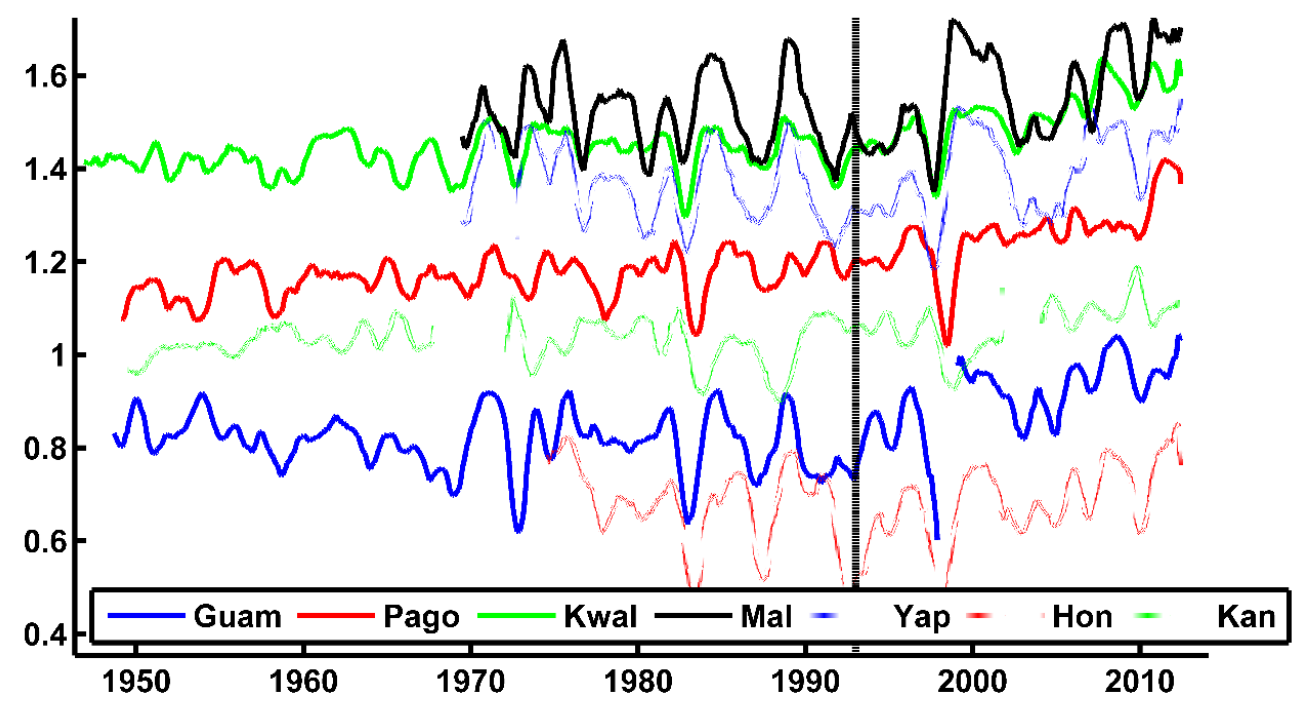

Figure 39 Time series of yearly average MSL (in meters) at seven Western Pacific stations: Guam, Pago Pago, Kwajalein, Malakal, Yap, Honiara, and Kanton, showing differences in sea level evolution before and after 1993 (indicated by the dashed vertical line). 


\subsubsection{Harmonic analysis and tidal admittance}

To account for nodal cycle variability, we investigate tidal trends through the use

of a tidal admittance, the details of which are described in full detail Part I of this thesis, Section 3.2.2, though the relevant equations are repeated below. For all stations, overlapping yearly tidal harmonic analyses (at monthly time steps) were carried out on hourly records and hourly ATGF. Results from a single harmonic analysis determine an amplitude, $A$, and phase, $\vartheta$, at the central time of the analysis window for each tidal constituent with error estimates for both. Use of a moving analysis window produces time-series of amplitude and phase; both monthly (767hr) and annual analyses were used. From amplitude $A(t)$ and phase $\theta(t)$ time series one can construct complex amplitudes, $\mathbf{Z}(t)$,

$$
\mathbf{Z}(t)=A(t) e^{-i \theta(t)}
$$

We form time-series of tidal admittance ratio (AR) and phase difference (PD) for any constituent using Eqs. (15) and (16),

$$
\begin{aligned}
& \mathbf{A R}(t)=\frac{A_{o b s}(t)}{A_{p o t}(t)}, \\
& \mathbf{P D}(t)=\theta_{o b s}(t)-\theta_{p o t}(t),
\end{aligned}
$$

where the subscripts 'obs' or 'pot' denote the observed data or the equilibrium amplitude, respectively. Both the admittance ratio in Eq. (15) and the phase difference 
in Eq. (16) largely remove the nodal-cycle variability, allowing easier examination of the non-tidal signals.

\subsubsection{Mean sea level and tidal anomaly trends}

The 26 gauges used have a variable time coverage; some have less than 40 years of data, others have 100 years or more. MSL time-series are generated by taking overlapping yearly averages of the original hourly water level data at monthly intervals, without corrections for local ground motion or inverted barometer effects. AR and PD time series are generated by overlapping yearly harmonic analyses. We remove trends from the yearly AR, PD, and MSL time-series for each location and constituent over the entire record. The removed trends are found by linear regression, reported in Table 8a (MSL) and Tables $8 \mathrm{~b}$ and $8 \mathrm{c}$ (ARs and PDs). While the long-term trends are an important concern that must still be considered in the overall picture of the ocean, our primary focus here is the interannual variations of MSL and the tides.

The removal of the long-term trends leaves a time-series of residual variations in AR, PD, and MSL. The mean value of the tidal potential amplitude at each location is used as a scale factor to convert the non-dimensional detrended AR into a dimensional amplitude, which is then regressed against detrended MSL to yield an A-TAT, expressed as millimeter change per meter of sea level rise $\left(\mathrm{mmm}^{-1}\right)$. The same approach is used with the phase difference time-series to provide phase anomaly trends (P-TATs), with the trends expressed as degree change per meter of sea level rise $\left(\mathrm{degm}^{-1}\right)$. 
Sample results (Figure 40) show the A-TATs (top 4 panes, (a) - (d)) and P-TATs (bottom 4 panes, $(e)-(h)$ ) for the diurnal $\left(K_{1}\right.$ and $\left.\mathrm{O}_{1}\right)$ and semidiurnal $\left(M_{2}\right.$ and $\left.S_{2}\right)$ tides vs. MSL at Honiara, Solomon Islands (9.4167 S, $159.950 \mathrm{E})$. Figure 40 is identical to Figure 8h shown in Part I of this thesis. The scatter plots at Honiara exhibit some of the most coherent trends in our data set, for $M_{2}$, with $r^{2}>0.89$. While the $M_{2}$ tide amplitude is relatively small at this location $(\sim 50 \mathrm{~mm})$, the anomaly trend is large, +65.6 $\pm 3.3 \mathrm{~m} \mathrm{~mm}^{-1}$ (132\% of the local $\mathrm{M}_{2}$ amplitude per meter of MSL rise). The $\mathrm{S}_{2}$ trend in amplitude is not as coherent, but is still significant, as are the $\mathrm{K}_{1}$ and $\mathrm{O}_{1} \mathrm{~A}-\mathrm{TATs}$. Trends in $\mathrm{M}_{2}$ and $\mathrm{S}_{2}$ phase are smaller but still significant. The diurnal P-TATs are not significant. A-TATs and P-TATs are reported in Tables 9 and 10, and plots similar to Figure 40 for semidiurnal and diurnal tides at all 26 stations are provided in supplementary materials (Figures B1-1 through B1-26). 

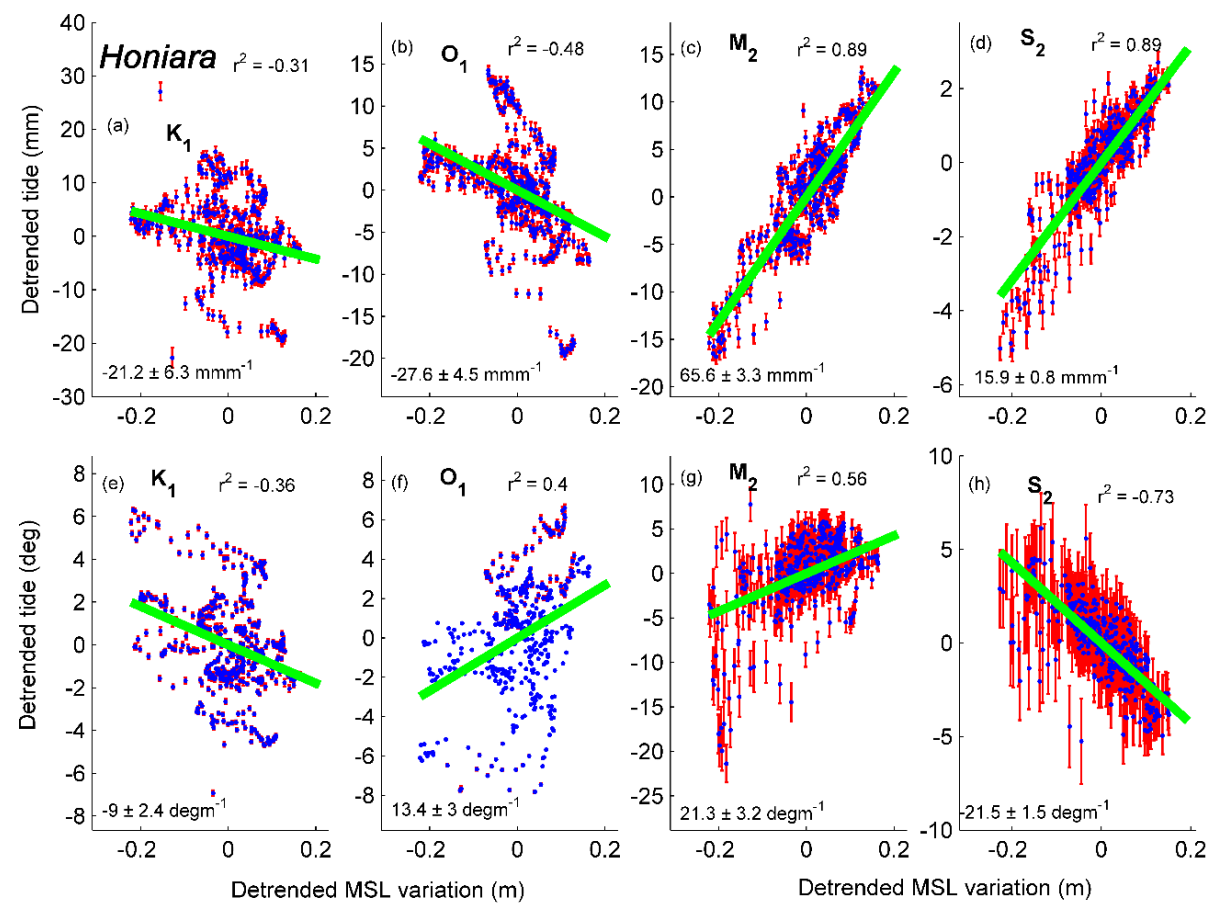

Figure 40 Amplitude anomaly trends (A-TATs) for Honiara in the Solomon Islands: (a) $\mathrm{K}_{1}$; (b) $\mathrm{O}_{1}$; (c) $\mathrm{M}$; (d) $\mathrm{S}_{2}$; and phase anomaly trend (P-TATs) for (e) $\mathrm{K}_{1}$; (f) $\mathrm{O}_{1}$; (g) $\mathrm{M}_{2}$; and (h) $\mathrm{S}_{2}$. The red bars show $95 \%$ confidence limits on each annual estimate. The green line is the robust linear regression trend, in $\mathrm{mmm}^{-1}$ or degm ${ }^{-1}$, as shown as text, with $95 \%$ confidence limits on the anomaly trend. Significance is indicated by correlation $\left(r^{2}\right)$ values within each subplot. 


\subsubsection{Friction and overtides}

Overtide generation is superficially similar to a resonant triad interaction, since both may satisfy a similar frequency condition to Eq. (11b), (i.e., $\omega_{1}+\omega_{2}=\omega_{3}$ ). Overtides can be linked to bottom topography, but may also result from internal waves of large amplitude (Legg and Klymak, 2008), or from strong flow curvature (Parker, 1991). The largest overtide at most locations is $M_{4}$, twice the frequency of $M_{2} ; M_{4}\left(\omega_{3}\right)$ results from the non-linear interaction of the $M_{2}$ tidal currents with itself $\left(\omega_{1}+\omega_{2}\right)$. However, unlike resonant triads, the wavenumber condition Eq. (11c) is not a requirement. The driving non-linearity (quadratic bed friction) is not the same as that for resonant triads (convective accelerations). Still, a frictional triad may interact with a resonant triad, as can a mean flow or an eddy field (Lelong and Kunze, 2013). Constituent interactions are therefore part frictional and part resonant. If overtides change substantially over time, it may indicate changes in non-linear frictional interaction (Parker, 1991). Because $M_{4}$ is not represented in the astronomical potential, it is normalized by an appropriate overtide ratio $(O R)$ to its forcing constituent, $M_{2}$,

$$
O R_{M_{4}}(t)=\frac{A_{M_{4}}(t)}{\left[A_{M_{2}}(t)\right]^{2}}
$$

Here, $\mathrm{OR}_{\mathrm{m} 4}$ indicates the overtide ratio of $\mathrm{M}_{4}$. This ratio is analogous to an admittance calculation and will remove known long-period variations such as the nodal cycle.

Additional overtides investigated are: $S_{4}$ (interaction of $S_{2}$ with itself), $M K_{3}$ (interaction 
of $M_{2}$ and $K_{1}$ ), $M_{6}$ (third harmonic of $M_{2}$ ), $M S_{4}$ (interaction of $M_{2}$ and $S_{2}$ ), and $M_{3}$ (interaction of $\mathrm{O}_{1}$ and $\mathrm{M}_{2}$ ). In each case, the overtide "ratio" is that between the overtide amplitude and the product of the amplitudes of the forcing waves. Overtides are small and may not be resolvable against background noise; we consider only overtides with a signal-to-noise ratio greater than 2.0. Temporal trends are normalized as the percentage change (per year) from local means of the overtide ratios (ORs). Additionally, we compare time-series of $\mathrm{M}_{4}$ and $\mathrm{M}_{6}$ overtide ratios at Honiara and Rabaul, two stations where the local overtides are anomalously large, to local MSL variations, and to ENSO through the use of the Multivariate EI Niño Index (MEI), as defined by the National Oceanic and Atmospheric Administration (NOAA) climate data center: http://www.ncdc.noaa.gov. Note that the Rabaul station was decommissioned in 1997.

\subsubsection{Thermocline depth and EEMD analysis}

Observed tidal properties are compared to estimated thermocline depths to diagnose the possible role of internal processes in tidal anomaly trends. Thermocline depths are synthesized from the NOAA Tropical Atmosphere Ocean project (TAO) buoys: (http://www.pmel.noaa.gov/tao). The TAO array, established in the early 1990s, is a network of 70 buoys extending from $8^{\circ} \mathrm{N}$ to $8^{\circ} \mathrm{S}$ and from $137^{\circ} \mathrm{E}$ to $95^{\circ} \mathrm{W}$. These buoys record sea surface temperature (SST), wind speed, air pressure, and subsurface water temperature. From the temperature profile, the depth of the $20^{\circ} \mathrm{C}$ isotherm, $D_{20}$, is 
estimated and used as a proxy for thermocline depth. $D_{20}$ time-series are compared to tidal property (AR and PD) time-series for gauges at Honiara, Pago Pago, and Kapingamarangi, where some of the largest TATs (relative to local mean tides) are seen for the semidiurnal tides $\left(\mathrm{M}_{2}\right.$ and $\left.\mathrm{S}_{2}\right)$. Monthly averaged $\mathrm{D}_{20}$ data are compared to monthly $\mathrm{M}_{2}$ and $\mathrm{S}_{2}$ admittance data, calculated using 767 hour analysis, allowing examination of seasonal, as well as interannual, variations.

The $\mathrm{D}_{20}$ and monthly A-TAT time-series are separated into quasi-orthogonal scales using an EEMD (Ensemble Empirical Mode Decomposition) analysis (Huang, et al., 1998; Huang and Wu, 2008). EEMD uses a sifting process to split signals into approximately dyadic modes - a signal of length $2^{n}$ yields $\sim n$ modes. We selectively recombine modes to preserve the desired scales of variation (from about annual to decadal scale), while removing higher frequency variability and the long-term trend. In the language of EEMD, the decomposition of the variables are expressed as intrinsic mode frequencies, or IMFs. For all variables considered, we will use a decomposition of 10 IMFs, with IMF \#10 being the actual long-term trend of the time series.

\subsubsection{Analysis of resonant triads}

Resonant triad interactions are nonlinear and occur through the convective accelerations. They are described by coupled evolution equations for the amplitude "envelopes" of the three interacting waves, assumed to vary on a "slow" timescale, $\tau$, which is much longer than the actual wave periods. These non-dimensional evolution 
equations relate the rate of change of the complex amplitude of one wave to the product of the other two waves' complex amplitudes (Craik, 1985):

$$
\begin{aligned}
& \left(\partial_{\tau}+\mathbf{c}_{j} \cdot \nabla\right) \mathbf{Z}_{j}=i \delta_{j} \mathbf{Z}_{k}^{*} \mathbf{Z}_{l}^{*}, \\
& j \neq k \neq l
\end{aligned}
$$

where $\mathbf{c}_{\mathbf{j}}$ is the group velocity, $\mathbf{Z}_{\mathbf{j}}$ is the complex amplitude, $\mathbf{Z}_{\mathbf{j}}{ }^{*}$ is the complex conjugate of $\mathbf{Z}_{\mathbf{j}}$, and $\delta_{\mathrm{j}}$ the interaction coefficient of the ${ }^{\text {th }}$ mode. The $\delta_{\mathrm{j}}$ describe the strength of the wave interactions; each is the sum of a number of bilinear correlations between waves. We neglect the spatial gradient terms (a "local" assumption), assume that amplitudes and phases will be slowly-varying, and also assume that only one triad-the one linking the $\mathrm{M}_{2}, \mathrm{~K}_{1}$ and $\mathrm{O}_{1}$ tides-is active. Note that the triad relationships involve the slow (interannual or decadal) modulations of the tidal harmonics, not the fast timescale of the tidal frequencies themselves (approximately once and twice daily), and the yearly admittance ratios and phase difference have already removed the fast-scale variations of the tides. Thus, our time-series for AR and PD can be used to represent slow-scale variation of amplitudes and phases, respectively. We rewrite Eq. (10) to show the form of the slowly varying complex triad modes,

$$
Z_{j}(\tau)=\mathbf{A R}_{j}(\tau) \exp \left[-i\left(\omega_{j} \tau+\mathbf{P D}_{j}(\tau)\right)\right]
$$

where the AR's and the PD's are time-dependent and real-valued. Thus, taking the time 
derivative of the LHS under the local assumption of Eq. (18) yields three terms:

$\frac{d}{d \tau}\left(\mathrm{Z}_{j}(\tau)\right)=\left[\frac{d Z_{j}(\tau)}{d \tau}\right] Z_{j}(\tau)=\left[\frac{1}{\mathbf{A R}_{j}(\tau)} \frac{d}{d t} \mathbf{A} \mathbf{R}_{j}(\tau)-i \omega_{j}-i \frac{d}{d \tau} \mathbf{P D}_{j}(\tau)\right] Z_{j}(\tau)$

Equating this expression to the RHS, combining complex exponential terms, and separating the real and imaginary terms (via the Euler formula) into two equations leads to:

$\left[\frac{1}{\mathbf{A} \mathbf{R}_{j}(\tau)} \frac{d}{d \tau} \mathbf{A} \mathbf{R}_{j}\right] \mathbf{A} \mathbf{R}_{j}(\tau)=\delta_{j}\left(\mathbf{A} \mathbf{R}_{k}(\tau) \mathbf{A} \mathbf{R}_{l}(\tau)\right) \sin (\Phi(\tau)+\Delta \omega \tau)$

$\left[\omega+\frac{d}{d \tau} \mathbf{P D}_{j}(\tau)\right] \mathbf{A} \mathbf{R}_{j}(\tau)=\delta_{j}\left(\mathbf{A R}_{k}(\tau) \mathbf{A} \mathbf{R}_{l}(\tau)\right) \cos (\Phi(\tau)+\Delta \omega \tau)$

Here, the $\Delta \omega$ term is the sum of the frequencies as in Eq. (11b): $\Delta \omega=\omega_{1}+\omega_{2}+\omega_{3}$; for the $\mathrm{M}_{2}+\mathrm{K}_{1}+\mathrm{O}_{1}$ triad, $\Delta \omega=0$. The $\Phi(\tau)$ term is the sum of the three phase differences:

$\Phi(\tau)=P_{1}(\tau)+P_{2}(\tau)+P_{3}(\tau)$

Sets of equations like Eqs. (20a; b) can, in principle, be solved using inverse scattering methods (Zakharov and Manakov, 1973; Kaup, 1980), but sufficient environmental information to do so is rarely present in an oceanographic context. We manipulate Eqs. (20a; b), therefore, to obtain a tool for diagnosis of triad interactions; Eq. (20a) and Eq. (20b) can be then rewritten in terms of $M_{2}, K_{1}$, and $O_{1}$ as: 


$$
\begin{aligned}
& C_{\operatorname{Re}}\left[\operatorname{Re}\left\{\mathbf{A R}_{M_{2}}(\tau)\right\}\right]=\Gamma_{\operatorname{Re}}\left[\operatorname{Re}\left\{\mathbf{A R}_{K_{1}}(\tau) \mathbf{A} \mathbf{R}_{O_{1}}(\tau)\right\}\right] \sin (\Phi(\tau)) \\
& C_{\operatorname{Im}}\left[\operatorname{Im}\left\{\mathbf{A R}_{M_{2}}(\tau)\right\}\right]=\Gamma_{\operatorname{Im}}\left[\operatorname{Im}\left\{\mathbf{A} \mathbf{R}_{K_{1}}(\tau) \mathbf{A} \mathbf{R}_{O_{1}}(\tau)\right\}\right] \cos (\Phi(\tau))
\end{aligned}
$$

$C_{R e}$ and $C_{I m}$ represent the terms in brackets on the LHS of Eqs. (20a; b), and $\Gamma=\Gamma_{R e}+i^{*} \Gamma_{I m}$ is a complex interaction coefficient related to the phase speeds and dispersion relations of the interaction. Finally, we can examine the absolute variation by combining both expressions of Eqs. (20a) and (20b) or (21a) and (21b) into a single equation,

$$
\mathbf{A R}_{M_{2}}(\tau)=\beta \mathbf{A R}_{K_{1}}(\tau) \mathbf{A} \mathbf{R}_{O_{1}}(\tau)
$$

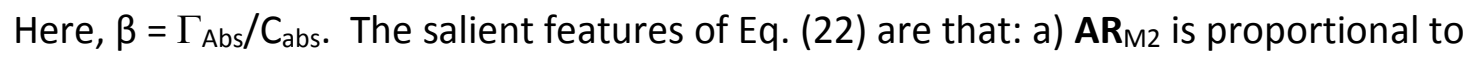
the product on the RHS, and b) $\Gamma_{A b s} / C_{a b s}=\beta<0$, so that energy lost from $M_{2}$ is taken up by the two diurnals. A complete triad problem requires two more equations similar to Eq. (22), but we shall only focus on the one that uses $M_{2}$ as the primary wave. Here, we use Eq. (22) as a diagnostic tool to identify and describe qualitatively the $\mathrm{M}_{2}-\mathrm{K}_{1}-\mathrm{O}_{1}$ triad. The other diagnostic tool comes from Eq. (11a), a "phase-lock" constraint,

$$
\Phi(\tau)=\mathbf{P D}_{1}(\tau)+\mathbf{P D}_{2}(\tau)+\mathbf{P D}_{3}(\tau)=\text { const }
$$

For the PD variations, we convert variations from degrees to minutes. Also, $\beta$ in Eq. (22)

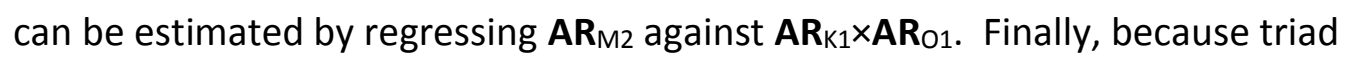
interactions may occur on multiple timescales, it is logical to compare variations on multiple scales. Trends were extracted, and modes of variability separated via EEMD. 
Applying this approach, we compare the two sides of Eq. (22) using IMFs \#4-10 of all quantities. To illustrate the possible importance of triad interactions, we examine below the coupled variations of $\mathrm{M}_{2}, \mathrm{~K}_{1}$, and $\mathrm{O}_{1}$ at Honiara and Rabaul.

Because the data we analyze are surface water levels and not internal wave amplitudes at the thermocline level, we cannot use Eqs. (18-23) without additional assumptions. We assume that, for nearly linear internal waves, the induced surface displacement is governed by the depth of the interface and the ratio of the restoring forces between surface and internal waves. If the changes in interfacial depth and stratification are small, then the surface displacements measured at tide gauges will be proportional to the interfacial amplitudes (and their variations) described by Eqs. (1920). This approach allows us to analyze interactions between baroclinic and surface tides, because the surface displacements of both involve similar potential energies. The method outlined here also assumes that the wavenumber vectors for each wave are constant, with amplitudes and phases that evolve slowly. Rising MSL renders a constant wavenumber assumption questionable, especially for the vertical wavenumbers $\left(m_{\mathrm{i}}\right)$. Still, it is of interest to identify wavenumbers for which triads are possible, assuming stationary wavenumbers. For the triad of interest $\left(\mathrm{K}_{1}, \mathrm{O}_{1}\right.$, and $\left.\mathrm{M}_{2}\right)$, Eq. (11b) is exact, but Eqs. (11a), (11c) and (12) must still be satisfied. To simplify finding wavenumber vectors that satisfy the triad restraints, the dispersion relation, Eq. (12), can be recast as an aspect ratio or slope factor (Gill, 1982): 


$$
\sqrt{\frac{\left(\omega_{i}^{2}+N^{2}\right)}{\left(f^{2}+\omega_{i}^{2}\right)}}=\frac{m_{i}}{\kappa_{i}}
$$

using a general horizontal wavenumber $k_{i}^{2}=\left(k_{i}^{2}+l_{i}^{2}\right)$. The Coriolis frequency, $f$, will be dependent only on latitude, but $N^{2}$ will depend on temporally variable temperature and salinity profiles. However, because all three waves involved in the triad are present at the same place, all three will have the same $N$ at any time. Choosing one vertical wavenumber, $\left(m_{1}\right), \kappa_{1}$ is determined from Eq. (24). We then select $\left(m_{2}, k_{2}, m_{3}\right.$, and $\left.k_{3}\right)$ combinations that are consistent with Eq. (24) and then test their consistency with Eq. (11). Because higher modes can be involved in a resonant triad, there could be several wavenumber solutions that satisfy Eqs. (11a; c) and (12); however, higher modes are usually less energetic. We therefore only consider (vertical) modes 1 to 3 , along with the zero-mode (barotropic) waves.

We use the Honiara and Rabaul records to illustrate the role of triad interactions in tidal evolution, because both stations show strong fluctuations in $\mathrm{M}_{2}, \mathrm{~K}_{1}$ and $\mathrm{O}_{1}$ that are relatively coherent with MSL variations. Application of Eqs. (21-24) then requires determination of a locally appropriate density profile. $N$ profiles are estimated from temperature-salinity (T-S) profiles obtained from the World Ocean Atlas 2009 (Locarnini, et al., 2010), using the TEOS-10 (Thermodynamics Equations of Seawater) standard (Millero, et al., 2008). For convenience, we express all frequencies non-dimensionally, relative to the $M_{2}$ forcing frequency. Thus, the $M_{2}$ frequency $=1 ; K_{1}=0.52 ; O_{1}=0.48$. 
The Coriolis frequency, $f$, at Honiara $\left(9.5^{\circ} \mathrm{S}\right)$, is $\sim 0.17$; and at Rabaul is $\sim 0.07$. For both stations, non-dimensional $N$ in the thermocline ranges from about 10 to 100 . With $N>>$ $\omega>>$, Eq. (24) can be simplified, for conceptual purposes, to:

$$
\frac{N}{\omega_{i}} \cong \frac{m_{i}}{\kappa_{i}}
$$

for $i=1,2, \ldots$ This form emphasizes the fact that $K_{1}$ and $O_{1}$ will have similar wavenumbers for any given internal wave mode.

Because we consider only the barotropic waves and the first three internal modes; there are only four choices for each $m_{i} ; m=0,1,2,3$, when non-dimensionalized by depth. Inserting these values of $m_{i}$ into $m_{i} / \kappa_{i}$ ratio (Eqs. $24 ; 25$ ) gives values for the $\kappa_{\mathrm{i}}$, which may examined for conformity with wavenumber resonance condition Eq. (11c) for each mode. The vertical to horizontal aspect ratio of the ocean is small, so the $m_{i} \gg$ $\kappa_{\mathrm{i}}$. Because $\mathrm{M}_{2}$ amplitudes are quite small in the Solomon Sea relative to the diurnal constituents, it seems likely that the most easily detected triad is the barotropic $M_{2}$ wave interacting with a first-mode internal $K_{1}$, and an oppositely propagating first-mode internal $\mathrm{O}_{1}$. This is a form of parametric sub-harmonic instability that has been analyzed in the context of a resonant triad (but not specifically the $\mathrm{M}_{2}-\mathrm{K}_{1}-\mathrm{O}_{1}$ triad) in the South China Sea (Xie, 2008) and also near the Hawaiian Ridge (Carter and Gregg, 2006). 


\subsection{Results}

\subsubsection{Anomaly trend maps}

The spatial distribution of anomaly trends (A-TATs and P-TATs) may help identify connections between MSL variability and tidal evolution on a basin-wide, or amphidromic scale. Figures 41 to 44 show the A-TATs for each constituent. P-TATs are not shown on the plots, but are discussed below in the context of possible amphidromic migration. Exact values and error bands are reported in Tables 9 (A-TATs) and 10 (PTATs). Significant values are those with an SNR $>2.0$, and an absolute magnitude of 10 $\mathrm{mmm}^{-1}$ for A-TATs, and an absolute magnitude of 5 degm $^{-1}$ for P-TATs. The magnitude of the A-TATs is shown by the color intensity of the dots, with the color indicating positive (red) or negative (blue). For a gauge with an insignificant A-TAT, the dot is white.

These plots provide a picture of the tidal response to a $1 \mathrm{~m} \mathrm{MSL} \mathrm{rise} \mathrm{and} \mathrm{an}$ indication of the spatial coherence of tidal evolution. For a gauge influenced by only one amphidrome, a positive (negative) A-TAT and a zero P-TAT indicates that the amphidrome is moving away (towards) the gauge. Gauges that show significant P-TATs suggest a rotational component to the movement of the amphidrome. If changes in tides (as represented by A-TATs and P-TATs) are coherent on an amphidromic scale, they should suggest consistent amphidromic movement or rotation. If statistically 
significant TATs do not suggest consistent amphidromic change, then local or regional process are likely more important.

\subsubsection{Diurnal constituents}

$\mathrm{K}_{1}$ has its largest amplitudes along the Western Pacific equator, with much lower amplitudes eastward in the open-ocean (Figure 41). Based on the tidal potential, diurnal tides are expected to be small near the equator, and the large amplitudes seen (4-5 times that predicted by astronomical forcing) around Indonesia and Papua New Guinea may represent a resonance. Diurnal tides are larger within the Coral Sea, but are very small around New Zealand, where semidiurnal tides prevail. Amphidromic points are marked by " $\mathrm{A}$ " and " $\mathrm{B}$ ".

There are statistically significant ( $S N R>2.0$ ) positive $K_{1}$ amplitude tidal anomaly trends at 14 of 26 gauges. Large positive A-TATs are seen at both island and shelf stations, while significant negative A-TATs are only seen at island gauges. There is a concentration of positive A-TATs at Australian gauges. All negative A-TATs are north of $\sim 10^{\circ} \mathrm{S}$. For the $\mathrm{K}_{1} \mathrm{P}$-TATs, 11 of 26 stations are significant. The strongest positive P-TAT is seen at Guam, and other strong negative trends in phase are seen at the islands near the center of the map.

The amplitude and phase distributions and amphidromic patterns for $\mathrm{O}_{1}$ are similar to those for $\mathrm{K}_{1}$, though $\mathrm{O}_{1}$ amplitudes are generally smaller (Figure 42 ). Like $\mathrm{K}_{1}$, $\mathrm{O}_{1}$ is resonant near Papua New Guinea and the Indonesian archipelago. Amphidromic 
points are again marked by "A" and "B". Significant positive A-TATs are also found at most Australian shelf stations. In total for $\mathrm{O}_{1}$, there are 10 significant A-TATs, and 13 significant P-TATs.

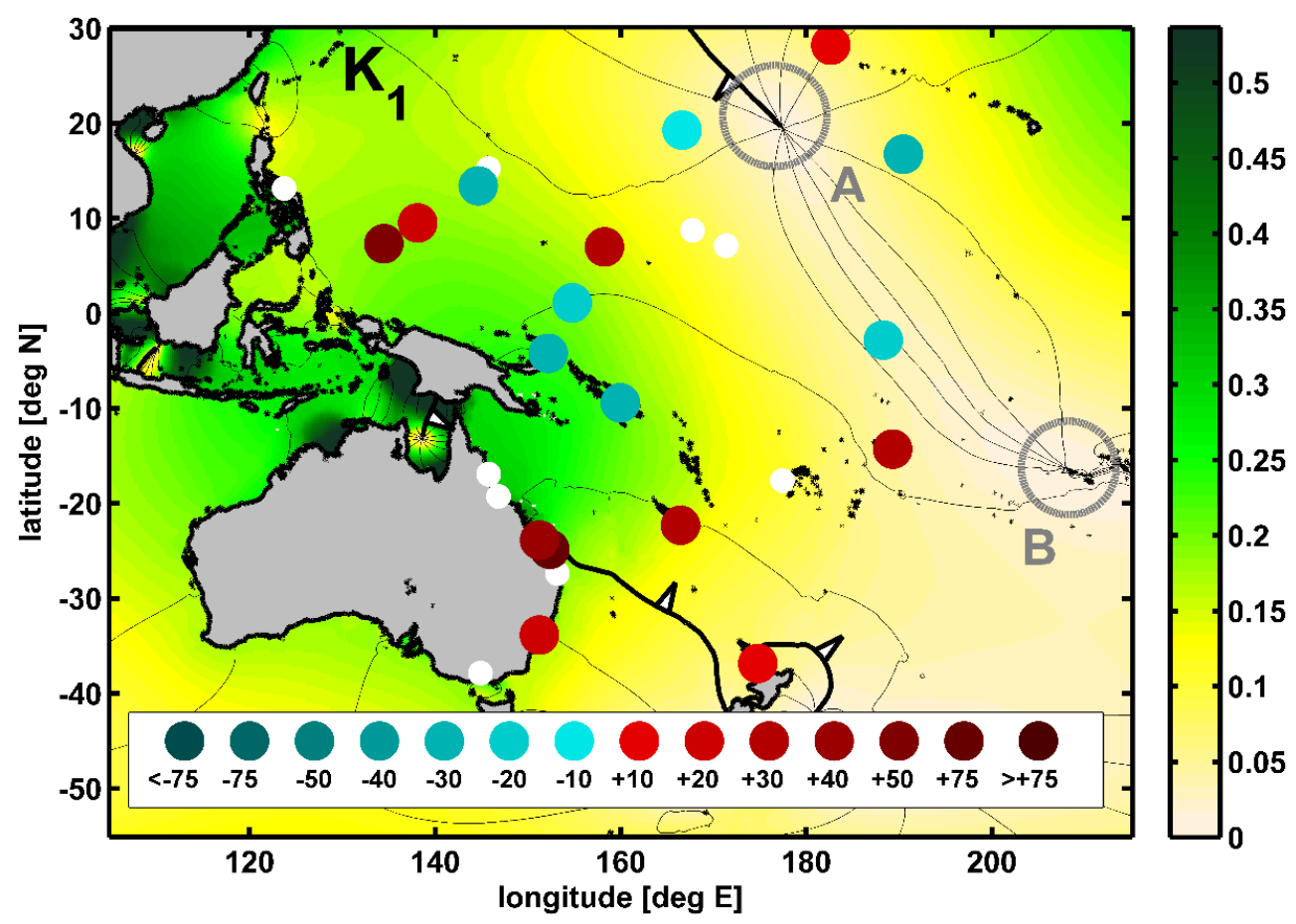

Figure $41 \mathrm{~K}_{1} \mathrm{~A}$-TAT map in the Western Pacific, showing changes in amplitude (per m MSL rise). Map backgrounds show mean tidal amplitudes (meters) over the entire time record (color scale) and phases (solid lines), from the ocean tidal model of TPXO7.2, (Egbert and Erofeeva, 2002, 2010). Red and blue colored markers show positive and negative A-TATs, respectively. The magnitudes are indicated by color intensity, as shown by legend at the bottom, in units of $\mathrm{mm}$ of tidal change per meter of sea level rise $\left(\mathrm{mmm}^{-1}\right)$. To avoid potentially spurious results due to large percentage changes in small constituents, A-TATs are only plotted if the ratio of the $95 \%$ confidence limit of the trends has an SNR $>$ 2.0. Statistically insignificant values are indicated by white circles. 


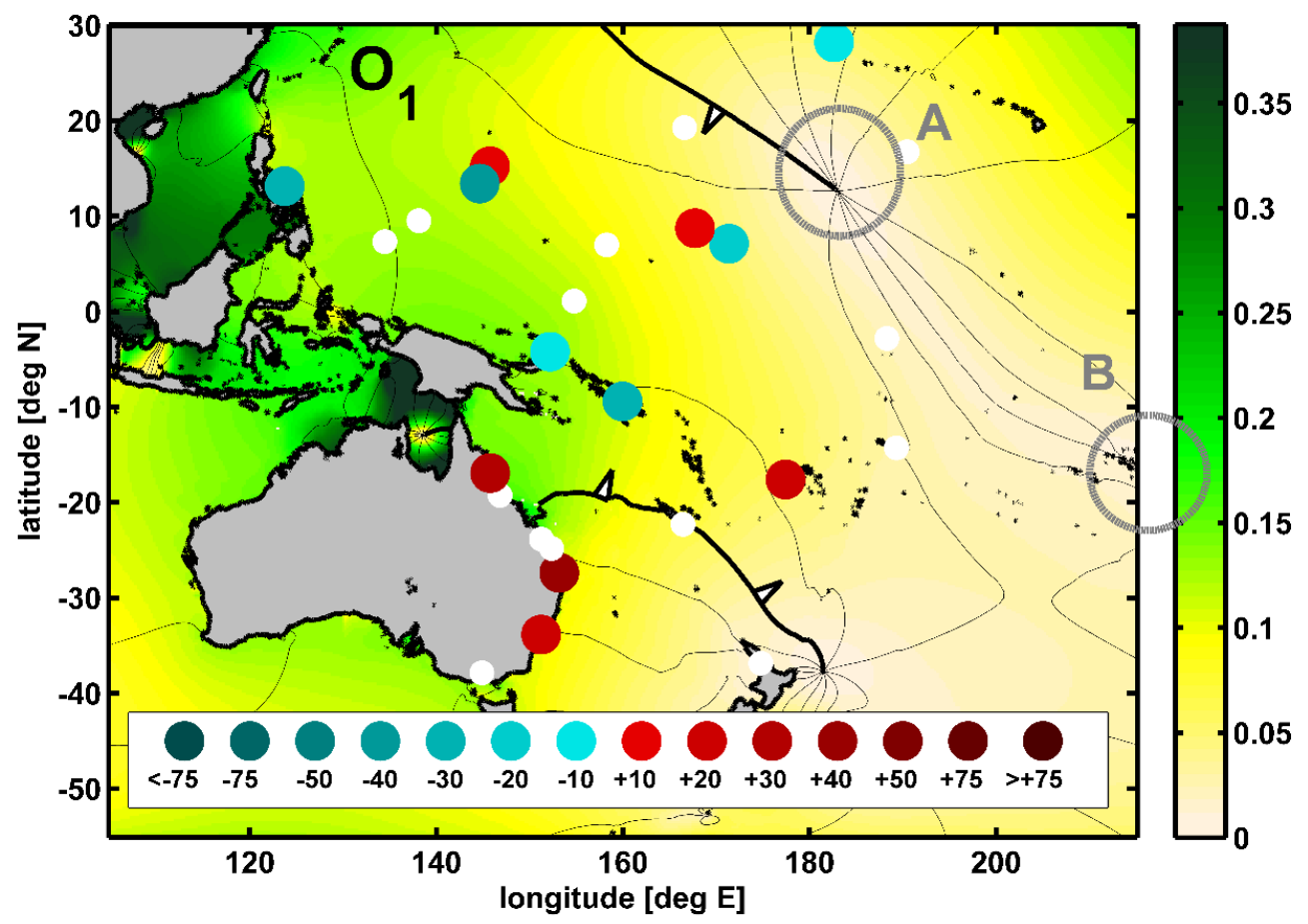

Figure $42 \mathrm{O}_{1} \mathrm{~A}$-TAT map in the Western Pacific, showing changes in amplitude anomaly trends (for a 1 meter MSL rise); symbols are as in Figure 41, and units are $\mathrm{mmm}^{-1}$. 


\subsubsection{Semidiurnal constituents}

$M_{2}$ amplitudes are generally larger than diurnal amplitudes in the study area, with the largest amplitudes occurring around New Zealand and the northern coast of Australia (Figure 43). An amphidromic point is located just to the east of Pago Pago (marked by "B"), with an anti-node (high amplitude) along the equator west of the date line. There is a line-shaped amphidrome near the Mariana Trench, marked by " $A$ ". Very low $\mathrm{M}_{2}$ amplitudes are seen in and around the Solomon Sea.

There are significant $\mathrm{M}_{2} \mathrm{~A}$-TATs at 17 of 26 stations and significant $\mathrm{M}_{2}$ P-TATs at 14 of 26 stations. Positive and negative A-TATs are observed at both island gauges and shelf gauges. Honiara and Rabaul, which are near the $M_{2}$ amphidrome in the Solomon Sea, have small mean $\mathrm{M}_{2}$ amplitudes ( $\left.50 \mathrm{~mm}\right)$, but display large relative trends; $(+132 \%$ for Honiara and $+240 \%$ for Rabaul), though the strong phase trends at these two gauges have opposite magnitudes. With the exception of Auckland, all significant positive ATATs are south of the equator, and all negative A-TATs are north of the equator.

$\mathrm{S}_{2}$ is much smaller than $\mathrm{M}_{2}$ at most locations, but with a similar (large) amplification on the northwest coast of Australia (Figure 44). Also similar is the location of the amphidromic points, with " $\mathrm{A}$ " indicating another line-shaped amphidrome (which more closely follows the Mariana trench), and an amphidromic point at " $\mathrm{B}$ " very near Pago Pago. There are 10 significant A-TATs, and 16 significant P-TATs in $\mathrm{S}_{2}$. 


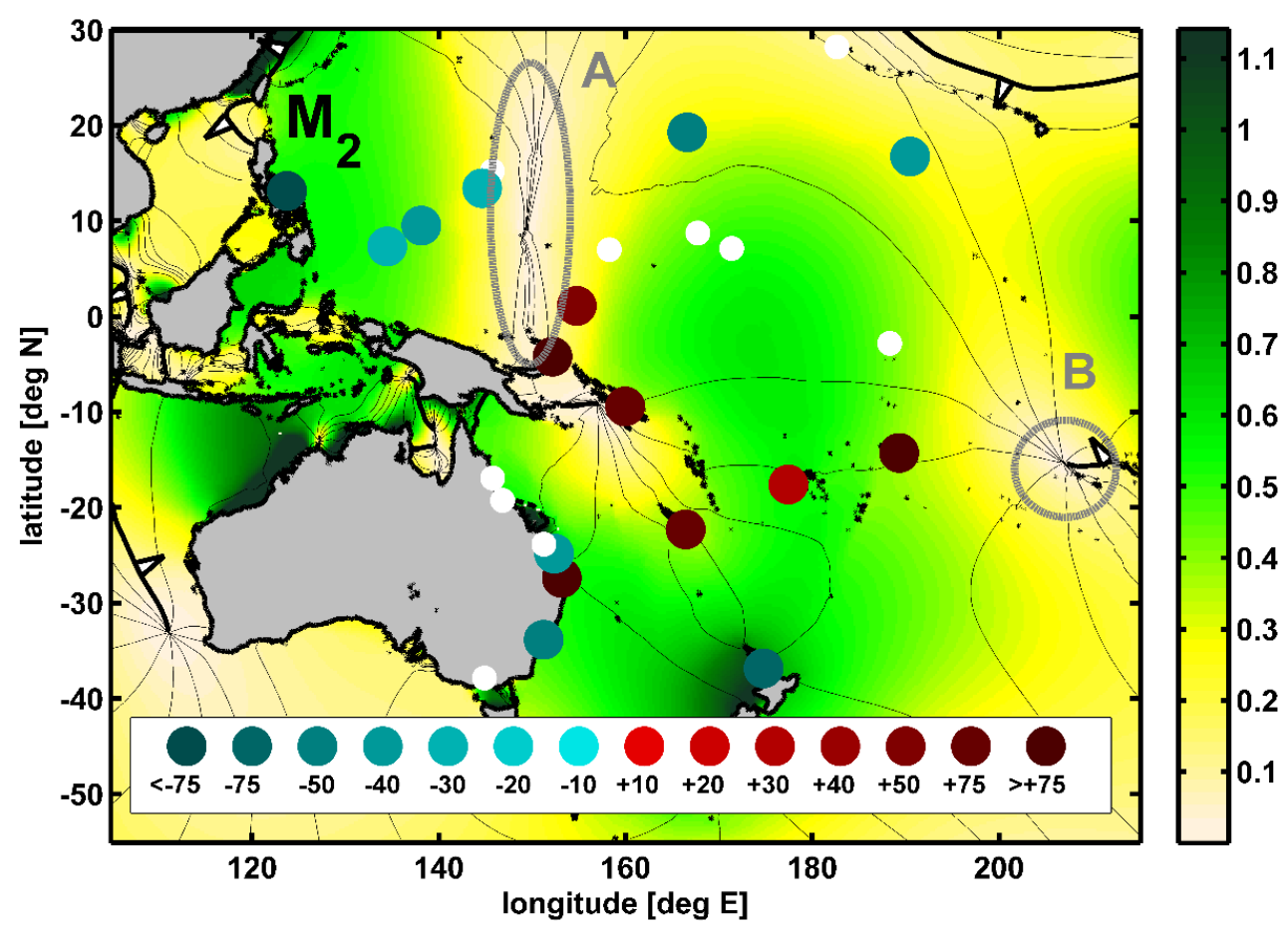

Figure $43 \mathrm{M}_{2}$ A-TAT map in the Western Pacific, showing changes in amplitude anomaly trends (for a 1 meter MSL rise); symbols are as in Figure 41, and units are $\mathrm{mmm}^{-1}$. 


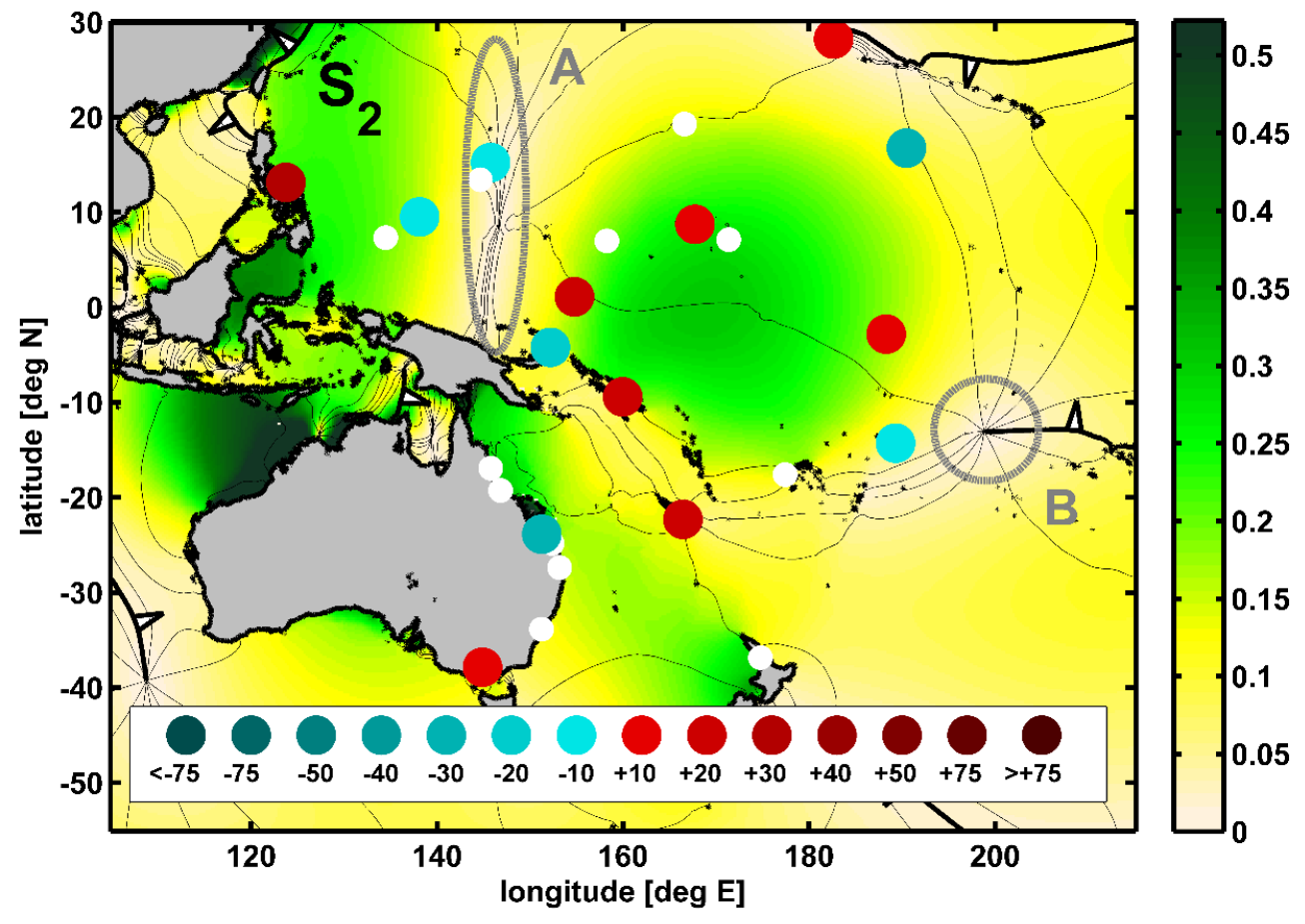

Figure $44 \mathrm{~S}_{2} \mathrm{~A}$-TAT map in the Western Pacific, showing changes in amplitude anomaly trends (for a 1 meter MSL rise); symbols are as in Figure 41, and units are $\mathrm{mmm}^{-1}$. 


\subsubsection{Combined tidal trends}

We show the combined A-TATs in Figure 45; exact values and confidence limits are tabulated in Table 9. Conceptually, a large and positive combined A-TAT describes locations in which the tidal range increases strongly during periods with a positive sea level anomaly, whereas a negative combined A-TAT implies decreased tidal range for a positive MSL anomaly. Therefore, shelf locations such as Brisbane, or island stations such as Pago Pago or Noumea could see large tidal range increases for a positive sea level anomaly. By contrast, stations such as Legaspi, Guam, and Johnston could see decreased tidal range for a positive sea level anomaly. Large positive tidal range responses are all south of $9^{\circ} \mathrm{N}$, while all but one of the large negative changes are north of this latitude. 


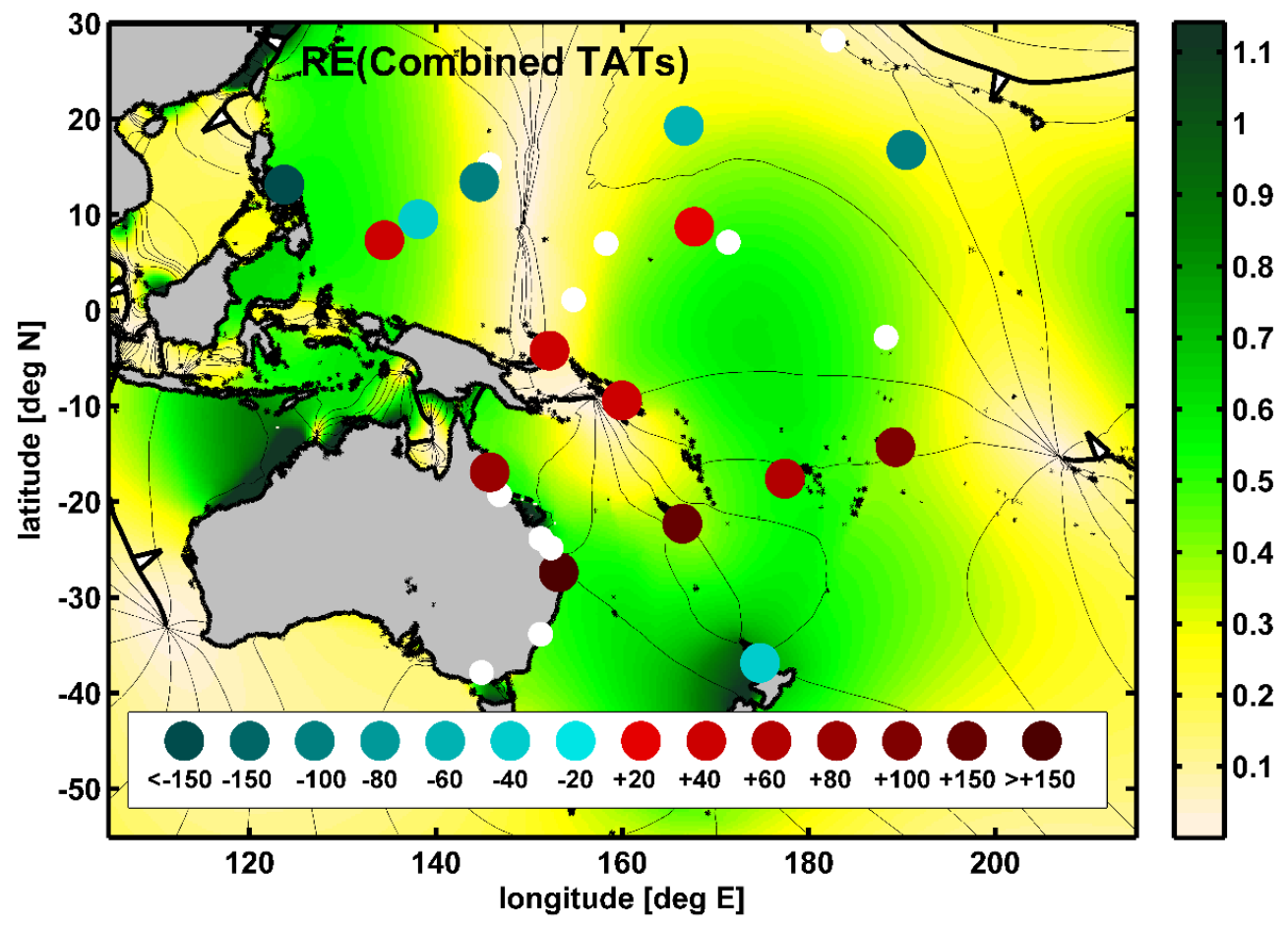

Figure 45 Combined A-TAT map in the Western Pacific, showing changes in amplitude anomaly trends (for a 1 meter MSL rise); symbols as in Figure 4, and units are $\mathrm{mmm}^{-1}$. Tidal magnitudes were added together as complex quantities, and the real part of the result is plotted. 


\subsubsection{Overtides}

Figure 46(a-d) summarizes the spatial distribution of overtide ratios (ORs) for: $M_{4}, M_{6}, S_{4}$, and $M_{3}$; significant long-term trends are shown as colored dots. $M_{4}$ and $\mathrm{MO}_{3}$ plots are shown in supplementary materials (Figure B2 and B3). Significant changes over time for these four ORs are mainly seen at coastal shelf stations, with a few islands showing some moderate change over time. The largest $M_{4}$ and $M_{6}$ overtide ratios are found in the Solomon and Coral Seas, and in general, regions of high $\mathrm{M}_{4}$ and $M_{6}$ ratios correspond to areas where lower $M_{2}$ amplitude are found (Figure 43). Mean $S_{4}$ ratios are generally smaller than those for $M_{4}$ and $M_{6}$, and fewer gauges show changes over time; those that do are decreasing. Again, the $\mathrm{S}_{4}$ ratio is large in areas where $\mathrm{S}_{2}$ amplitudes are small (Figure 44). $\mathrm{MK}_{3}$ is also generally smaller than other overtides, but shows larger relative changes at many stations. Examination of the numerators and denominators of the ORs shows that in almost all cases the trend is driven by changes in the observed overtides (numerator), not by changes in the forcing (denominator). This suggests a mechanism of changing ORs in the area being driven by frictional processes rather than by secular increases or spatial shifts of the gravitationally forced tides. 

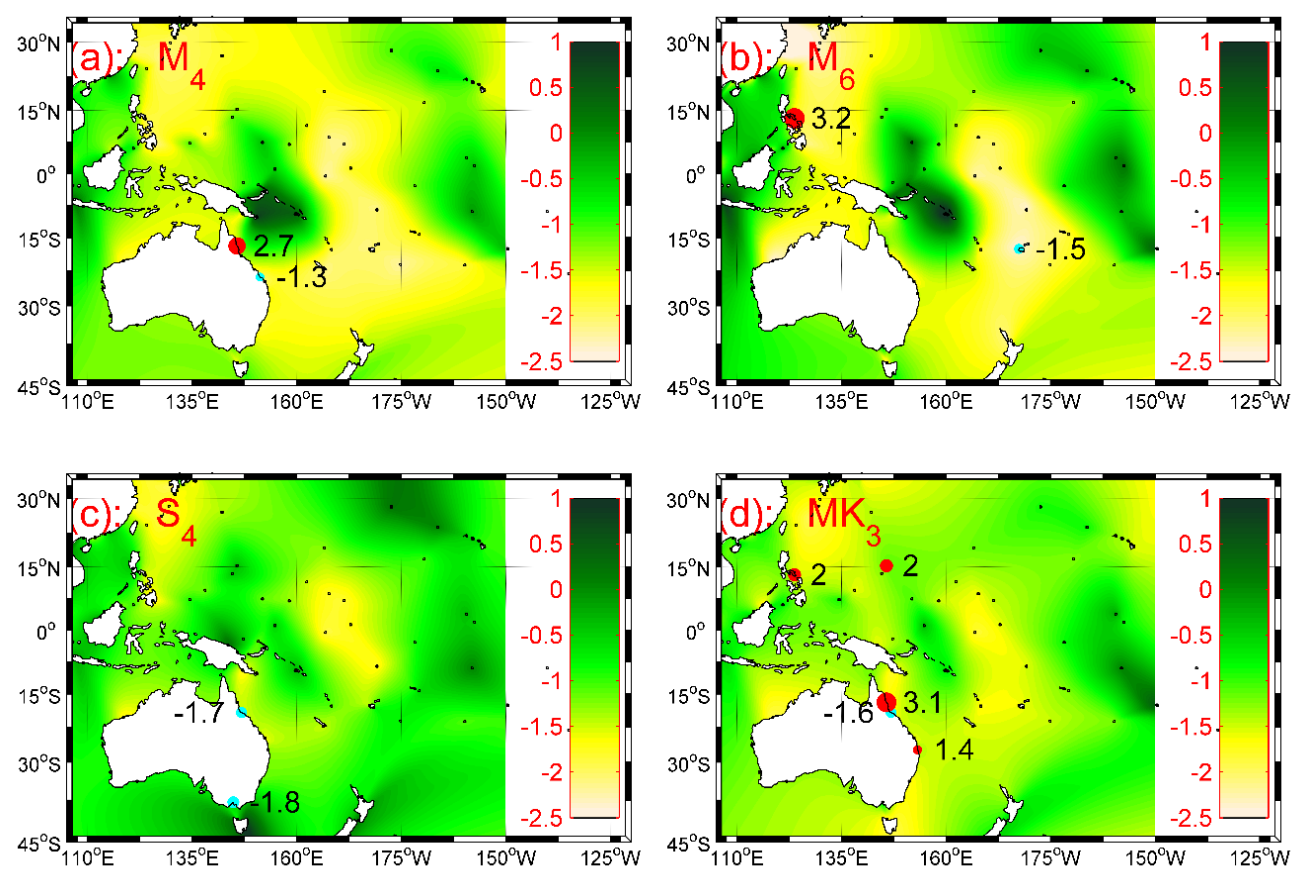

Figure 46 Overtide ratios (ORs) in the Western Pacific for: (a) $\mathrm{M}_{4} / \mathrm{M}_{2}{ }^{2} ;$ (b) $\mathrm{M}_{6} / \mathrm{M}_{2}{ }^{3}$; (c) $\mathrm{S}_{4} / \mathrm{S}_{2}{ }^{2}$; and (d) $\mathrm{MK}_{3} /\left(\mathrm{K}_{1} \mathrm{M}_{2}\right)$; the background color scale represents the mean OR on a logarithmic scale. For stations that show a significant change over time in this ratio, numbers and colored markers indicate change in the ORs, in units of $1 / \mathrm{m}$, (or $1 / \mathrm{m}^{2}$ for $M_{6}$ ) expressed as percentage change per year. 
We next consider the fluctuations in ORs at Honiara and Rabaul (which show some of the largest OR values), as well as the simultaneous changes in forcing tides, in MSL, and in the Multivariate EI Niño Index (MEI). Figure 47 shows the time-series of the ORs for $\mathrm{M}_{4}$ and, $\mathrm{M}_{6} ; \mathrm{AR}$ amplitudes for $\mathrm{M}_{2}, \mathrm{~K}_{1}$ and $\mathrm{O}_{1} ; \mathrm{MSL}$; and the MEl. These two gauges show the largest ORs in the region, and very large fluctuations are associated with high values of the $\mathrm{MEI}$ index (El Niño events). $\mathrm{M}_{2}$ amplitudes are much smaller than predicted by astronomy at these gauges ( $2 \%$ of the gravitational potential prediction), suggesting the possibility of increased relative error. However, the coherence between the two records at several frequencies suggests that this is unlikely $-M_{2}$ at these two gauges show an $r^{2}=+0.8$ correlation to each other, $M_{4}$ overtide ratios at Honiara and Rabaul show an $r^{2}=+0.4$ correlation to each other, and $M_{6}$ ratios have a very strong correlation $\left(r^{2}=+0.85\right)$. MSL signals at the two gauges are also well correlated $\left(r^{2}=+0.80\right) . M_{4}$ ratios are fairly well correlated to the MEI $\left(r^{2}=+0.4\right.$ for Honiara and $r^{2}=+0.64$ for Rabaul). $M_{6}$ at Honiara shows an $r^{2}=+0.7$ correlation to MEI, while Rabaul shows a correlation of $r^{2}=+0.65$ for $M_{6}$ to MEl. Both gauges show very strong correlations $\left(r^{2}=-0.85\right.$ for Honiara; $r^{2}=-0.75$ for Rabaul) of local MSL to the MEI.

Figure 47 suggests that there is a threshold relationship between the occurrence of large ORs, local MSL, and the MEI. As shown by the yellow boxes, significant increases in ORs by a factor of 3 to 10 occur when the MEl is high and MSL is low, under El Niño conditions. Increased OR values during El Niño periods of low MSL could result 
from several factors, including increased friction over reefs and in shallow lagoonal areas. Most of Indonesia and Australia receive less rain during El Niño events (Roplewski and Halpert, 1987, Figure 21). Honiara and Rabaul are on the edge of this ENSO-induced drought region, and MSL rapidly decreases at both these gauges during EI Niño events. $M_{4}$ and $M_{6}$ ORs have started to decrease in recent years at Honiara, while $M_{2}$ has shown a strong increase. This is likely due to the fact that sea level has risen rapidly in recent years, reducing bed friction. 


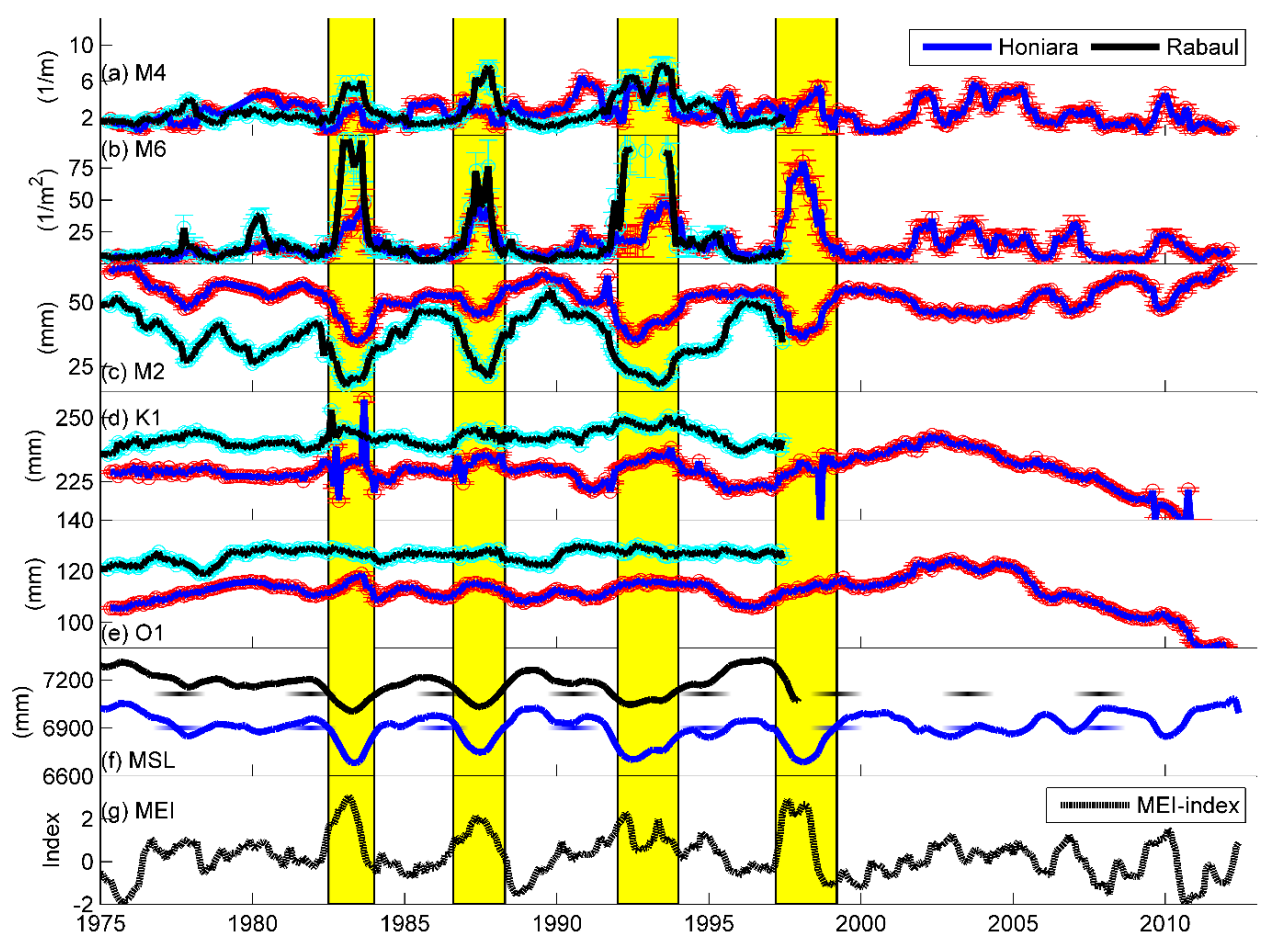

Figure 47 Relations of overtides and forcing tides to ENSO and MSL. Time-series for Honiara (blue line with red error bars) and Rabaul (black line with cyan error bars) of: (a) $M_{4}$ and (b) $M_{6}$ overtide ratios; and detrended (c) $M_{2}$ amplitude; (d) $K_{1}$ amplitude; and (e) $\mathrm{O}_{1}$ amplitude; (f) MSL at Honiara (blue) and Rabaul (black); and (g) the Multivariate EI Niño Index (MEI). Horizontal lines in (f) indicate approximate threshold values of MSL at the two gauges, vertical lines indicate times of ENSO events (yellow shading), when MSL is forced below this threshold. To standardize to a common water level datum, MSL is expressed as difference from the Revised Local Reference (RLR) datum (for 1983), as defined by the Permanent Service for Mean Sea Level (PSMSL), http://www.psmsl.org/; MSL is $6.232 \mathrm{~m}$ on RLR at Honiara and $6.401 \mathrm{~m}$ at Rabaul. 


\subsubsection{Thermocline depth and tidal variations}

Thermocline depth, MSL, and tidal properties are closely linked at certain stations. Figure 48 shows EEMD decomposed time-series (seasonal scales and longer) of $D_{20}$ from the TAO buoys (as detailed in section 3.5), along with the $M_{2}$ and $S_{2}$ tidal amplitude variations (determined from monthly admittance amplitudes); for all relevant time series, we only use IMFs \#4-9 so the long-term trends are not included. This analysis is performed at Honiara, Kapingamarangi, and Pago Pago; buoys and gauge locations are shown in Figure $48 \mathrm{a}$. The $\mathrm{D}_{20}$ variations at the three TAO buoys nearest Honiara are mutually coherent; we take, therefore, a mean of these three equidistant buoys (Figure 48b). For the other two gauges, only one TAO buoy is used to determine thermocline depths. Figure $48 \mathrm{c}$ and $48 \mathrm{~d}$ show this $\mathrm{D}_{20}$ time-series with $\mathrm{M}_{2}$ and $\mathrm{S}_{2}$ variations at Honiara and Kapingamarangi; both gauges show positive correlations of thermocline depth fluctuations to $\mathrm{M}_{2}$ and $\mathrm{S}_{2}$ fluctuations, with $\mathrm{r}^{2}$ being between +0.69 and +0.89 in all cases. For Pago Pago, the coherence between the time-series is insignificant $\left(r^{2}<+0.1\right)$. It is unclear whether this is the result of the distance between buoy 5 and Pago Pago, or whether different processes are at work at this station. The thermocline, as represented by $D_{20}$, shoaled during the 1997-1998 ENSO event. At the same time, there was drop in tidal admittance for $\mathrm{M}_{2}$ and $\mathrm{S}_{2}$ at Honiara, Kapingamarangi, and Pago Pago, but available data do not provide any apparent connection of the tides to changes in thermocline depth at Pago Pago. 

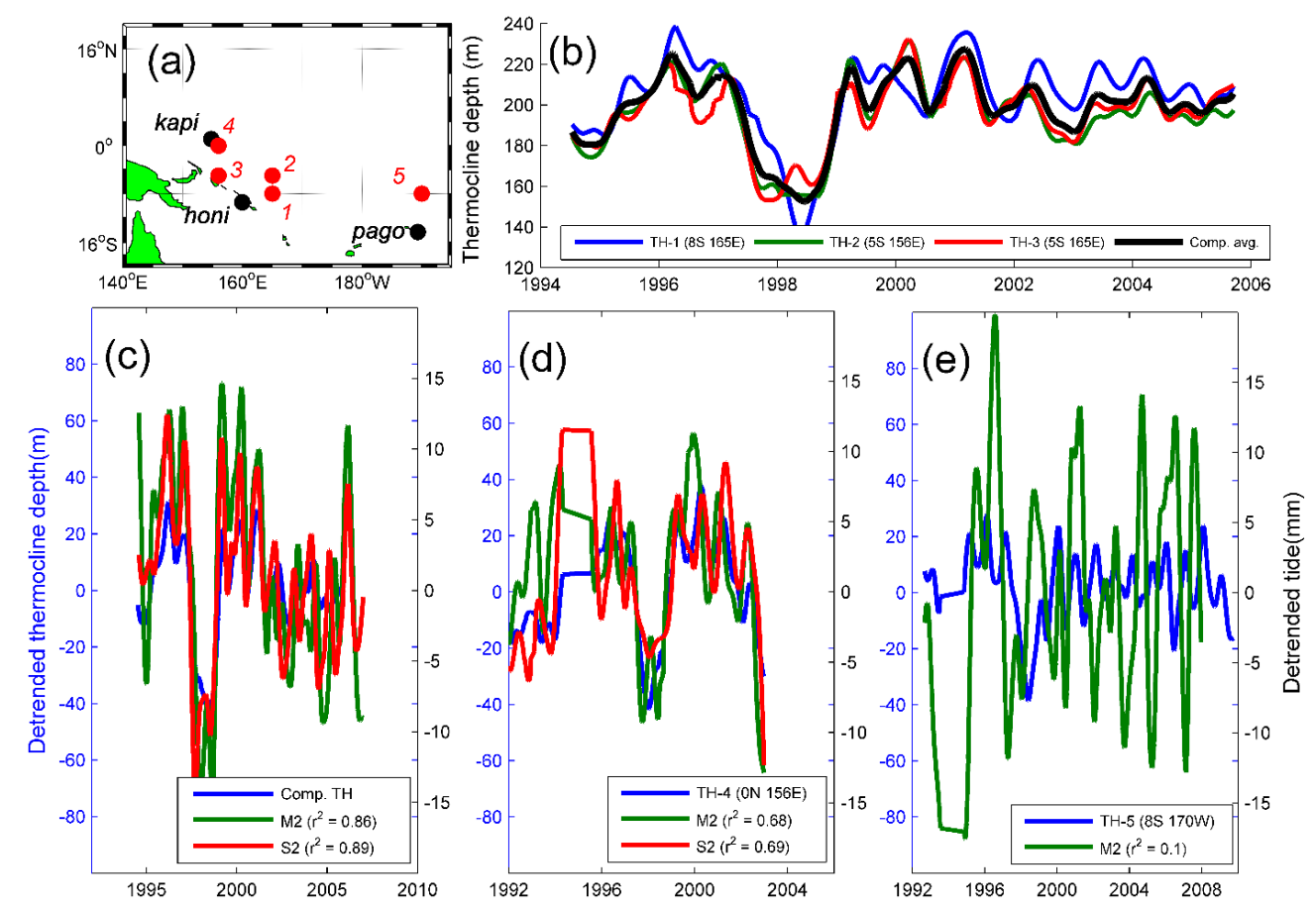

Figure 48 Relations of tides and thermocline depth. (a) map of Solomon Islands region, with locations of tide gauges and TAO buoys used for thermocline analyses; (b) time series of $D_{20}$ at buoys 1-3 in blue, red and green, each about equidistant from Honiara, and the composite average of all three (black dotted line); (c) time series of composite $D_{20}$ (blue), $M_{2}$ (green) and $S_{2}$ (red) amplitude variations at Honiara; (d) time series of $D_{20}$ (blue) at buoy 4, $\mathrm{M}_{2}$ (green) and $\mathrm{S}_{2}$ (red) amplitude variations at Kapingamarangi; and (e) $\mathrm{D}_{20}$ for Pago Pago (blue) and $\mathrm{M}_{2}$ amplitude (green) at buoy 5. All datasets represent an IMF decomposition of monthly time series, using IMFs \#4-9 out of 10 so that the long term trends are not apparent. 


\subsubsection{Spatial summary}

The long-term trends of the $\mathrm{M}_{2}$ tide are mainly positive, while diurnals are mixed, but generally negative, in Australian and New Zealand waters. For the A-TATs, $M_{2}$ is mainly negative, while the diurnal A-TATs are all positive. Overtides in the Coral Sea region are generally growing, despite extensive harbor development at some locations. These changes suggest regionally driven tidal evolution involving a combination of frictional and resonant triad interaction, perhaps tied to the reef systems in the Coral Sea. The waters around the Solomon Islands show $\mathrm{M}_{2}$ A-TATs to be increasing, while $\mathrm{K}_{1}, \mathrm{O}_{1}$, and the main overtide ratios are decreasing, with all variations coherent with, and likely driven by, variations in the depth of the thermocline.

\subsubsection{Anomaly trends over time}

The majority of the Western Pacific stations used in this study show larger yearly MSL rise rates after 1993 than before (Table 8a; Figure 39). This rather abrupt increase in MSL rise in the southwest Pacific after 1993 provides an opportunity to test the relationship between MSL rise and tidal evolution. If TATs are sensitive to absolute MSL or rate of change of MSL, we might expect to see differences in TATs between these two epochs at gauges that show MSL acceleration. If TATs are the same in both time periods for such gauges, then they are likely independent of MSL. Thus, analyses were performed to evaluate differences in TATs before and after 1993. Twenty out of 26 stations have enough data both before and after 1993 to cover a nodal period and allow 
meaningful comparison. Results of the "before and after" 1993 analyses for these 20 gauges are summarized in Table $11\left(\mathrm{~K}_{1}\right)$, Table $12\left(\mathrm{O}_{1}\right)$, Table $13\left(\mathrm{M}_{2}\right)$, and Table $14\left(\mathrm{~S}_{2}\right)$. To illustrate spatial trends in these shifts, figures are provided for $K_{1}$ (Figure 49) and $M_{2}$ (Figure 50), analogous to Figure 41 through 44, but now the color intensity of the dots represent the difference in A-TATs between the two time eras.

There are strong positive $\mathrm{K}_{1} \mathrm{~A}$-TAT temporal shifts at three shelf gauges, and at two islands; there is a negative shift at only one shelf gauge. $M_{2}$ A-TAT shifts tend to be generally larger than $K_{1}$. Most shelf gauges show significant $M_{2}$ shifts, positive at four, and negative at two stations. Two island gauges show positive shifts, with only one negative result. In general, shelf gauges show larger magnitude shifts than island gauges, where it is harder to distinguish the two periods (pre and post-1993). O O A-TATs shifts are also mainly positive after 1993 , but S $_{2}$ A-TATs and P-TATs have shifted only slightly. It is concluded that TATs are more sensitive to absolute MSL than to MSL rates. 


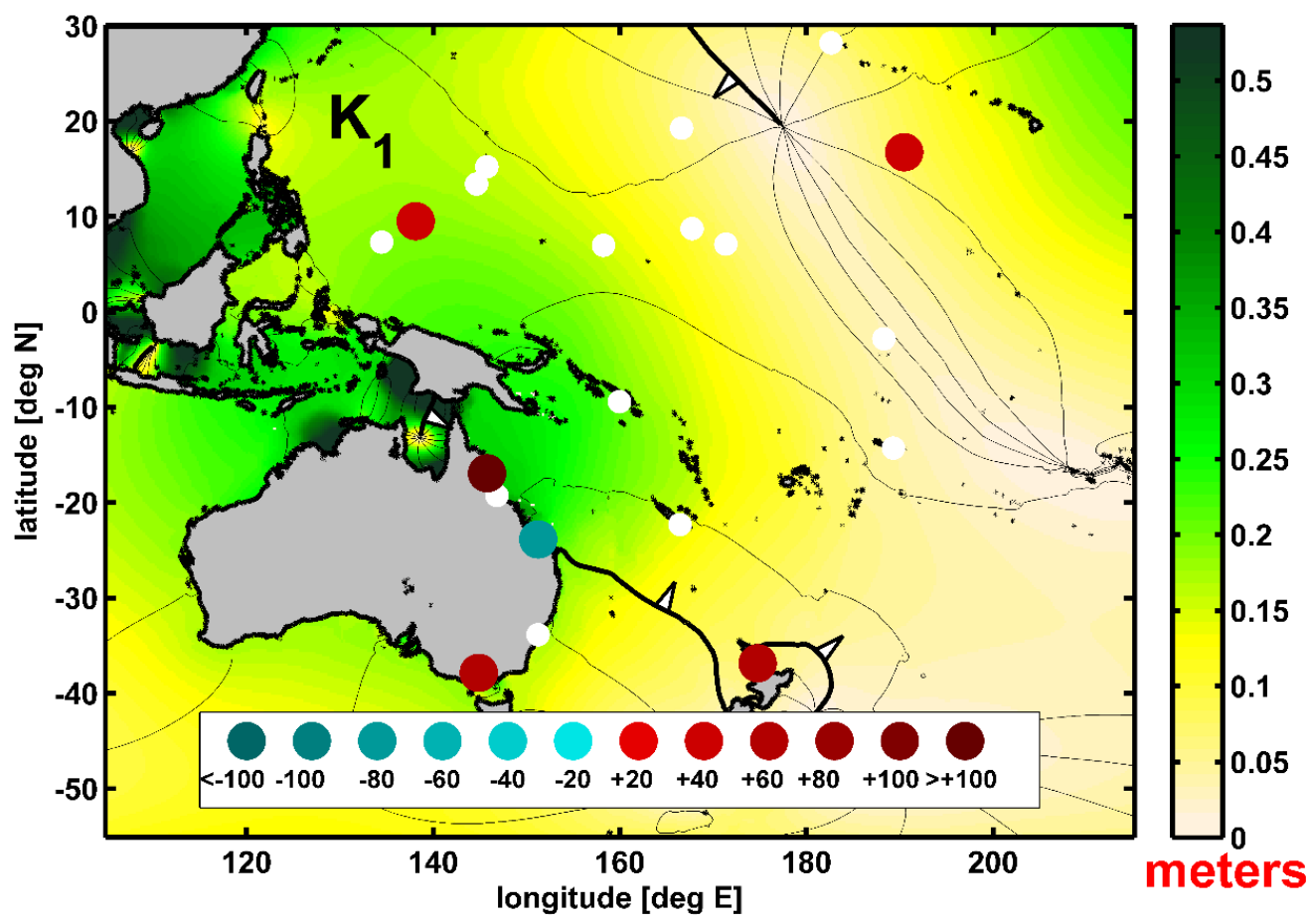

Figure $49 \mathrm{~K}_{1}$ TAT difference map, showing differences in A-TATs and P-TATs between years before 1993 and after 1993 (for a 1m MSL rise); symbols are as in Figures 41-44. 


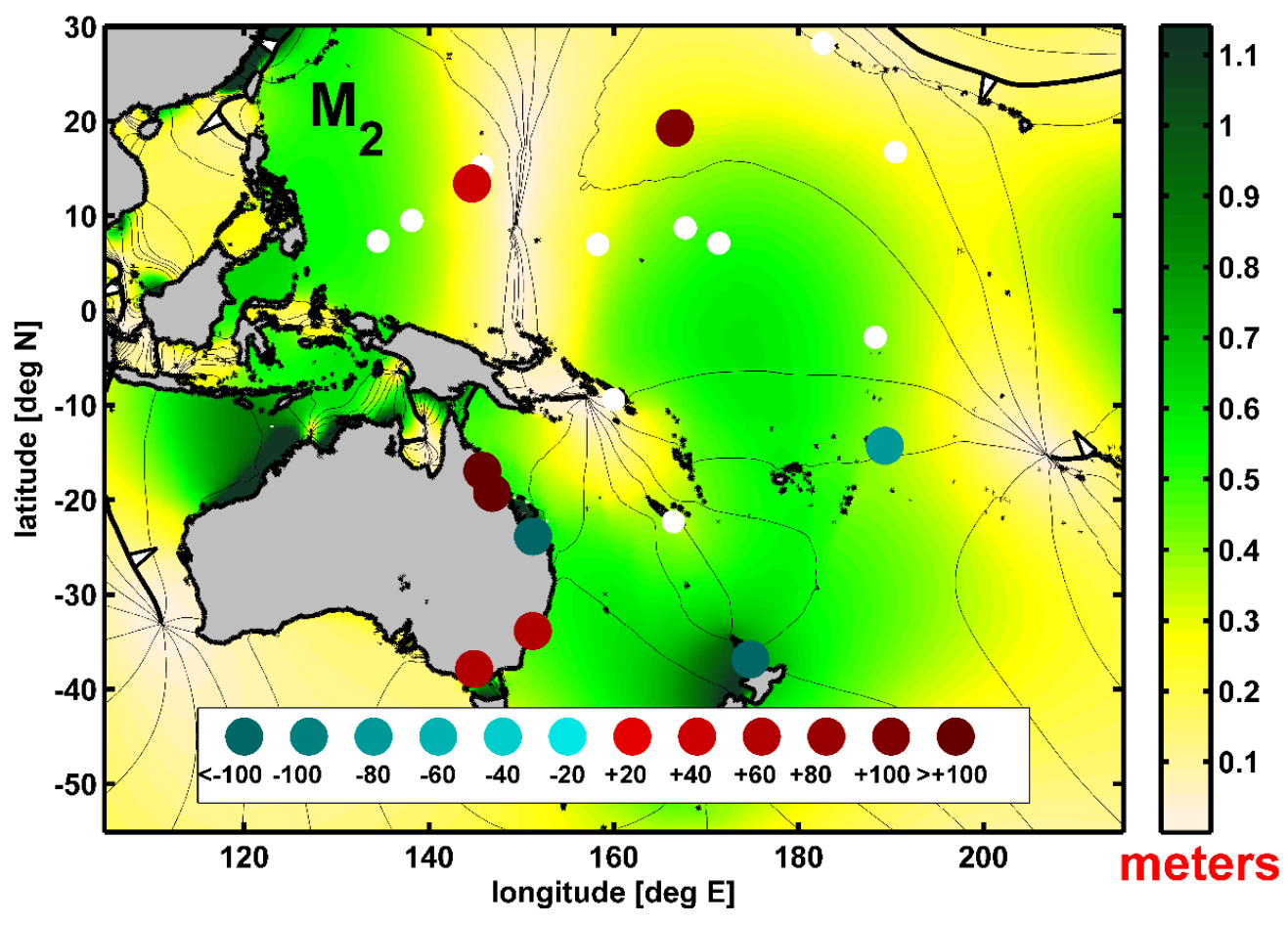

Figure $50 \mathrm{M}_{2}$ TAT difference map, showing differences in A-TATs and P-TATs between years before 1993 and after 1993 (for a 1 m MSL rise); symbols are as in Figures 41-44. 


\subsubsection{Triad results}

The Honiara and Rabaul tidal records show striking examples of what appears to be $\mathrm{M}_{2}-\mathrm{K}_{1}-\mathrm{O}_{1}$ triad interactions (Figures 51 and 52). Figure $51(\mathrm{a})$ shows $\mathrm{K}_{1} \mathrm{O}_{1}$ vs. $\mathrm{M}_{2}$ at Honiara; Figure 51(b) shows Rabaul. $\mathrm{M}_{2}$ amplitudes are small, $51 \mathrm{~mm}$ at Honiara and 40 $\mathrm{mm}$ at Rabaul, and their temporal variability is high (Figures 47 and 48 ). Diurnal tides are larger; $\mathrm{K}_{1}$ amplitudes are $229 \mathrm{~mm}$ and $240 \mathrm{~mm}$ at Honiara and Rabaul, while $\mathrm{O}_{1}$ amplitudes are $112 \mathrm{~mm}$ and $126 \mathrm{~mm}$, respectively. Since we multiply the $\mathrm{K}_{1}$ and $\mathrm{O}_{1} \mathrm{ARs}$ together, the magnitude of the RHS of Eq. (22) will be much larger than the $\mathrm{M}_{2} \mathbf{A R}$ appearing on the LHS, meaning that the interaction coefficients, $\beta$, must be small as well as negative (Figure 51). As noted above, $\beta$ can be estimated by regression, using Eq. (22); see Figure 52. If a triad resonance is active, the variations of the summed variables (LHS and RHS sides of Eq. (22)) should be less than the variations in the LHS and RHS individually, a condition that is generally fulfilled for both stations in Figure 51, though some deviations are seen during El Niño. Also, the $r^{2}$ values of -0.59 (Honiara) and -0.72 (Rabaul) in Figure 52 suggest that resonant triad dynamics explain a substantial fraction, though not all, of the variations in the major constituents at these stations. A fraction of this energy may be lost to overtide generation during El Niño events. Finally, the variations in $\mathbf{A} \mathbf{R}_{\mathrm{M} 2}$ are impressive: $\pm 30+\%$. Thus, for a small constituent like $\mathbf{M}_{2}$, triad interactions can lead to very large time variations, in relative terms. 
Also, it is evident from Figure 53 and Table 15 that the phase-lock condition Eq. (11a) is generally approximately met for IMF\#s 4-10. While $\Phi(\tau)$ is not constant, particularly during the ENSO events, it is less variable than the individual phases. For most of the record, the $\mathrm{O}_{1}$ and $\mathrm{K}_{1}$ PDs are negatively correlated, with $\mathrm{M}_{2}$ making up the difference between the two. During El Niño events, in contrast, there are large $M_{2}$ phase excursions that perturb the phase lock. The sum of the variances is larger than the variance of $\Phi$, and the phase lock is more closely met after 1993 than before, despite very large fluctuations in the $\mathrm{O}_{1}$ PD. Interestingly, the $1998 \mathrm{El}$ Niño does not cause large excursions in the $\mathrm{M}_{2} \mathbf{P D}$, even though large $\mathrm{M}_{4}$ amplitudes are seen at Honiara. 

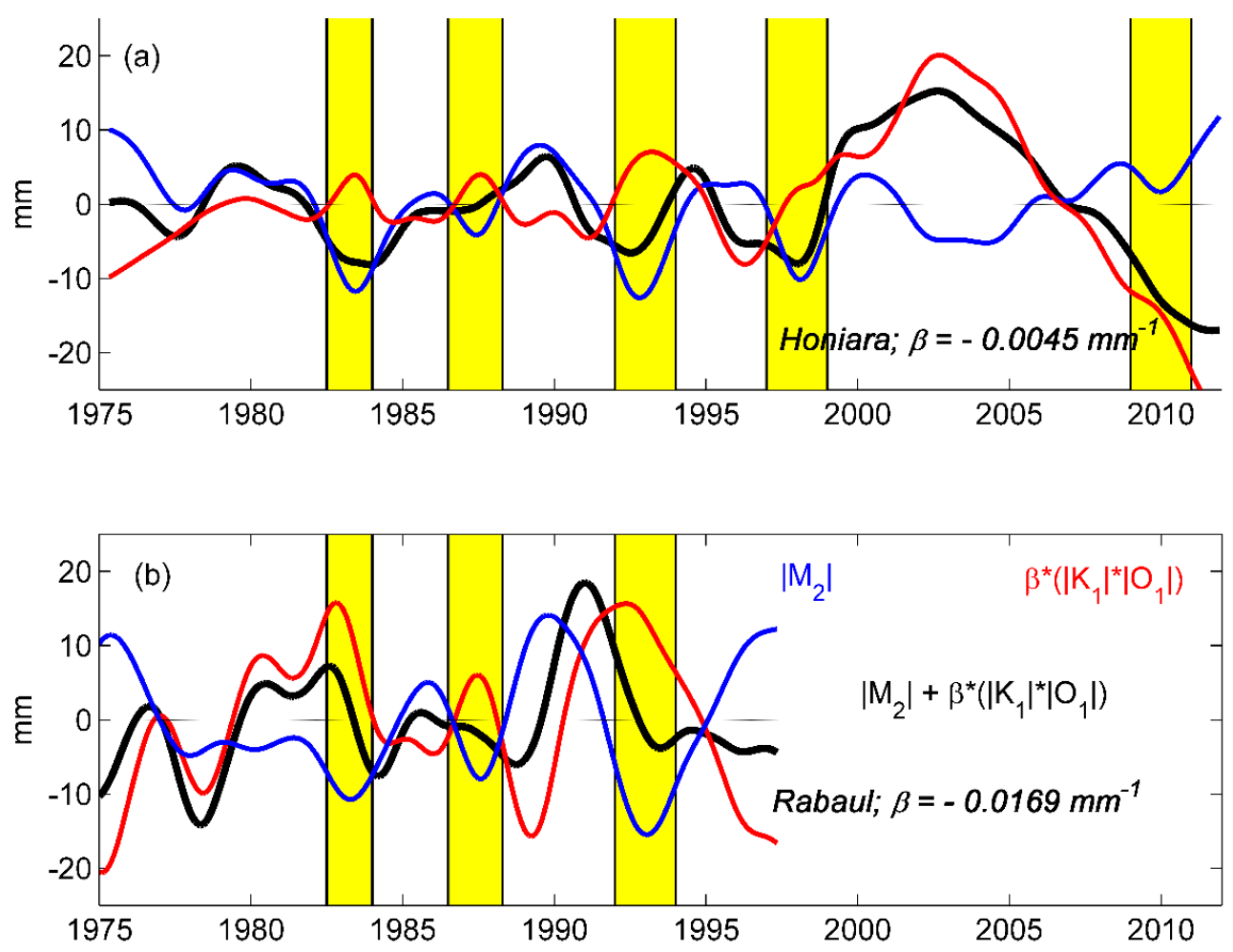

Figure 51 Resonant triad interactions for Honiara (a) and Rabaul (b) in the Solomon Sea region, represented in terms of the IMF decomposition (IMFs \#4-10) of the LHS (blue, $\left|\mathrm{M}_{2}\right|$ ) and RHS (red, $\beta\left|\mathrm{O}_{1}\right|\left|\mathrm{K}_{1}\right|$ ) of (13). As in Figure 47, stronger ENSO-related fluctuations are highlighted in yellow. 

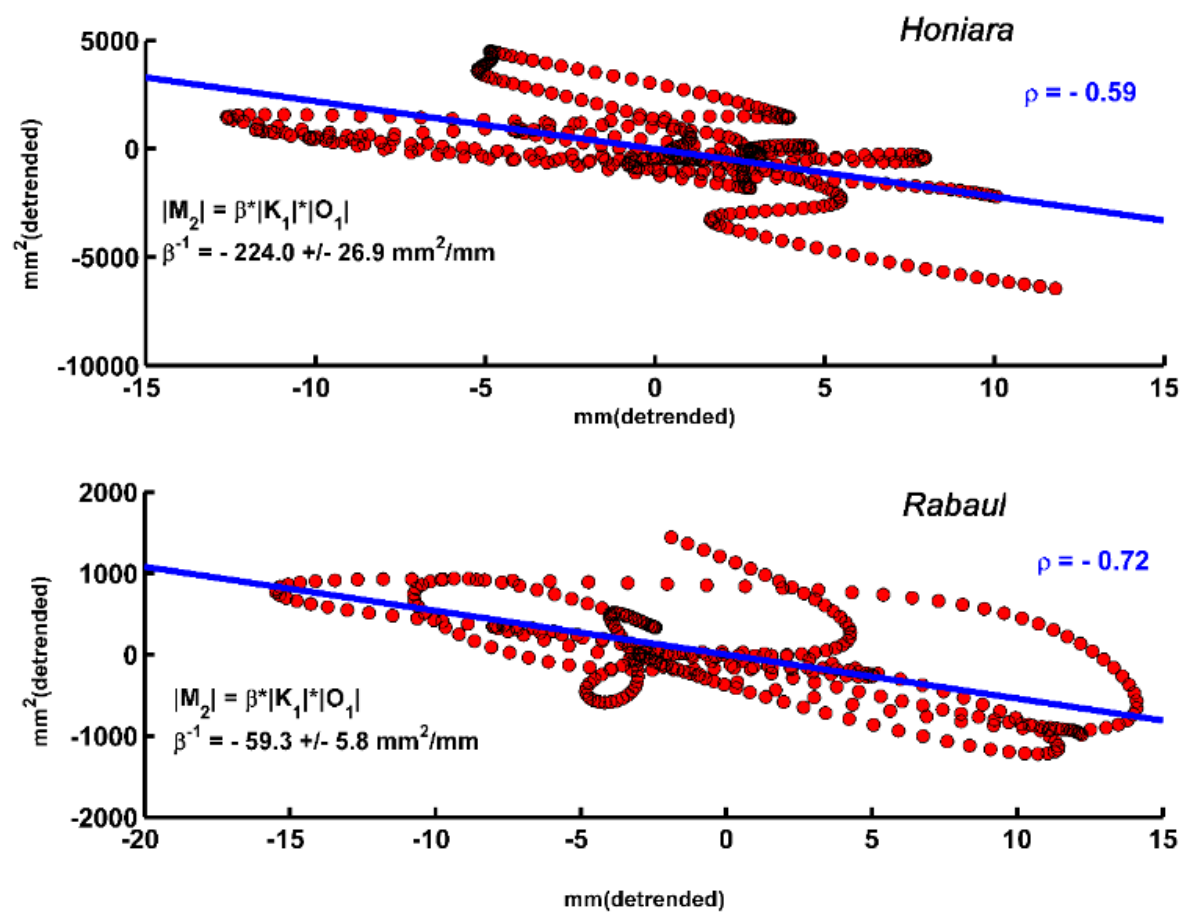

Figure 52 Triad interaction scatterplots for Honiara (a) and Rabaul (b), Solomon Sea region: scatterplots of the IMF decomposition (IMFs \#4-10) of $\left|M_{2}\right|$ vs. $\left|O_{1}\right|\left|K_{1}\right|$ to determine $\beta$ in Eq. (13); 95\% confidence limits and correlation ( $\rho$ ) values are given. 


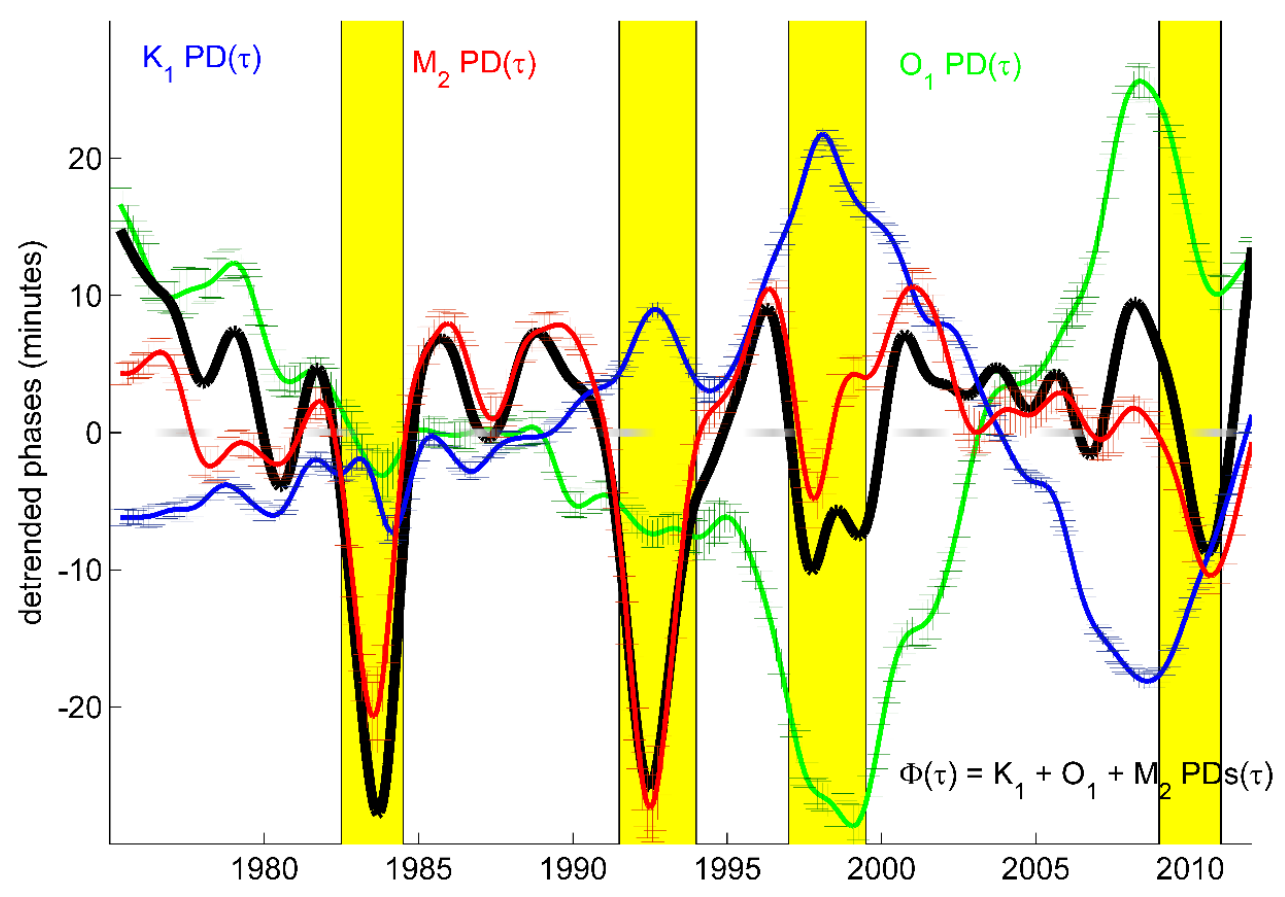

Figure 53 Phase-lock condition at Honiara, showing the IMF decomposition (IMFs \#4-10) of the individual PD variations of $\mathrm{M}_{2}$ (blue), $\mathrm{K}_{1}$ (red), and $\mathrm{O}_{1}$ (green), along with errors. The sum of the phase differences, $\Phi$, is shown in black. 
To confirm that the variations shown in Figures 51-53 indeed represent a triad interaction, we should verify that the resonance conditions of Eq. (11) and Eq. (12) are satisfied. For $\mathrm{M}_{2}, \mathrm{~K}_{1}$, and $\mathrm{O}_{1}$, the frequency condition, Eq. (11b), is satisfied by definition, and the phase-lock condition, Eq. (11a), is shown in Figure 53. There are, however, only a few wave combinations that will satisfy the resonance condition, Eq. (11c), that $\Sigma \boldsymbol{k}_{i}=0$. For simplicity, we consider only cases in which Eq. (11c) can be satisfied in two dimensions (2D). We exclude 3D solutions on the grounds that they would require a rather special geometry and that the matching conditions would likely be transient -- small changes in thermocline depth could cause large changes in the angles between the matching wavenumber vectors. Given fixed geometry, it seems unlikely that the resonance would endure. There are only two possible 2D interactions between waves of zero or low vertical wavenumber. The most likely situation is a parametric sub-harmonic instability (PSI): a barotropic $\mathrm{M}_{2}$ wave interacting with firstmode $\mathrm{K}_{1}$ and $\mathrm{O}_{1}$ internal waves. The other possibility is a second mode $\mathrm{M}_{2}$ wave interacting with first and third mode diurnal waves, the case examined numerically by Lamb (2007).

For the PSI case, the vertical wavenumber for $\mathrm{M}_{2}$ is $m_{\mathrm{M} 2}=0$; and $\kappa_{\mathrm{M} 2}$ will be small relative to the $\kappa_{\mathrm{i}}$ for the diurnals, because barotropic tidal wavelengths are much longer than internal wavelengths. As detailed above, we find values of the $m_{i} / \kappa_{i}$ ratio for the internal waves from Eq. (20). Table 16 shows these ratios for a range of values of $N$ of 10-100. The $m_{i}$ for $K_{1}$ and $\mathrm{O}_{1}$ will be equal and of opposite sign, while their $\kappa_{i}$ 's will 
differ by $\sim 8 \%$. An exact triad would occur when the small difference between the two diurnal $\kappa_{i}$ matches the $\kappa_{\mathrm{M} 2}$. For the barotropic forcing wave, $\mathrm{M}_{2}$, we find $\kappa$ from the dispersion relation: $\kappa=\omega / \operatorname{sqrt}(g H)$, where $g$ is the gravitational acceleration, $\omega$ is the frequency of $M_{2}$, and $H$ is the bottom depth, taken to be $\sim 500 \mathrm{~m}$ based on the average depth near Honiara. These values yield a $\kappa=2.0 \times 10^{-6} \mathrm{~m}^{-1}$. However, the depth in this area is highly variable, and water depths of up to $5 \mathrm{~km}$ are found within a wavelength of Honiara. If, on the other hand, the triad interaction is localized near the gauge, the relevant depth could be as little as $100-200 \mathrm{~m}$. Thus, a plausible range of $\kappa$ values for barotropic $\mathrm{M}_{2}$ is $\sim 0.7$ to $4 \times 10^{-6} \mathrm{~m}^{-1}$. For the $\mathrm{K}_{1}$ and $\mathrm{O}_{1}$ first-mode internal waves, the internal wave relation gives $\kappa=\omega / c_{p h}$, where $c_{p h}$ is the phase speed of each wave. We use the $N$ profile near Honiara (with $10<N<100$ ) to find a typical first-mode diurnal $c_{p h}$ $\sim 2.7 \pm 0.1 \mathrm{~ms}^{-1}$ for both $\mathrm{K}_{1}$ and $\mathrm{O}_{1}$ (Rainville and Pinkel, 2006). The resulting first-mode wavenumbers are: $\kappa^{\sim 2.7}$ and $2.5 \times 10^{-5} \mathrm{~m}^{-1}$ for $\mathrm{K}_{1}$ and $\mathrm{O}_{1}$, respectively. The difference between these two $\kappa$ values, $\sim 2 \times 10^{-6} \mathrm{~m}^{-1}$, gives an exact resonant triad $(\Delta \kappa=0)$ for a barotropic $\mathrm{M}_{2}$ wave corresponding to depth of $500 \mathrm{~m}$, as well as near-resonant triads for depths ranging from 100 to $5000 \mathrm{~m}$ (Table 17). Given the uncertainty in and temporal variability of $N$, an exact resonant triad is likely present only on a transient basis, and a near-resonant triad is probably the usual situation. It is encouraging, however, that such a simple configuration is possible in $2 \mathrm{D}$, and Table 17 indicates that $\Delta \kappa$ remains small for a range of possible values of $N$. 
There is only one $2 \mathrm{D}$, low-mode $\mathrm{M}_{2}-\mathrm{K}_{1}-\mathrm{O}_{1}$ triad that does not involve a barotropic wave: $1^{\text {st }}(m= \pm 1)$ and $2^{\text {nd }}$ mode $(m= \pm 2)$ waves of the same sign, coupled with a $3^{\text {rd }}$ mode wave $(m=\mp 3)$ of opposite sign. To satisfy the wavenumber condition Eq. (11c), the second mode wave must be $M_{2}$, the case studied by Lamb (2007). There are two "flavors" of this triad, because there are two diurnals $\left(\mathrm{K}_{1}\right.$ and $\left.\mathrm{O}_{1}\right)$, one third mode and one first mode. Which diurnal should be chosen as the first mode depends on the fit to Eq. (11c); the correct choice will minimize $\Delta \kappa$. Table 18 lists the $\kappa_{\mathrm{i}}$ and $\Delta \kappa$ for these two possibilities. The $\Delta \kappa$ is minimized by factor of 5 for a $\mathrm{K}_{1}$ mode 3 and an $\mathrm{O}_{1}$ mode 1 over the reverse situation, but both show a very small $\Delta \kappa$. While both the Lamb analysis and Table 18 suggest that this triad is possible, measurable surface deflections seem unlikely for an $M_{2}$ wave with $m= \pm 2$, given the small barotropic $M_{2}$ in the Solomon Sea. Thus, it seems a less likely candidate to account for the triad features seen in Figures 51-53.

\subsection{Discussion}

We observed above that fluctuations in observed tidal properties are associated with sea level anomalies. At three stations (Honiara, Kapingamarangi, and Rabaul), semidiurnal tidal properties (influenced by both local and amphidromic scale processes) and overtide generation (a local, frictional process) are strongly correlated with anomalies in sea level and stratification. These observations leave open, however, the question of whether constituent variability is primarily related to local processes, to 
basin-scale phenomena, or to some combination thereof. Furthermore, it is yet to be determined if the observed tidal variability is influenced only at the interannual time scale, or if there is also a combination of dynamics across multiple frequency bands, including the long-term trends of MSL. In the following discussion we attempt to identify the mechanisms behind the observed TATs.

\subsubsection{Spatial patterns}

Here we summarize and interpret spatial patterns in selected areas, focusing on two regions that exhibit reasonably coherent changes; a) the eastern coast of Australia and the Great Barrier Reef; and b) the Solomon Sea. We will also consider not just the anomaly trends (TATs), but also the long term trends (LTTs) in tidal constituents.

\subsubsection{Australian shelf and the Great Barrier Reef}

Anomaly trends for the Australian stations are relatively coherent. A-TATs are positive for $\mathrm{K}_{1}$ and $\mathrm{O}_{1}$ along the eastern Australian coast, and (with the exception of Brisbane) negative for $\mathrm{M}_{2}$ A-TATs. Stations north of Brisbane lie on the semi-enclosed Coral Sea behind the Great Barrier Reef (GBF) where the regional bathymetry is highly variable, from deep ( $>4000 \mathrm{~m}$ ) to inter-tidal. The pattern of TATs suggests larger diurnal and smaller semidiurnal tides in this region as MSL rises. The large trends in A-TATs at Auckland show a heightened sensitivity of tidal dynamics to water level; though New Zealand has its own $M_{2}$ amphidrome, the dynamics are still likely connected to the 
Australian waters across the Coral Sea. Auckland shows a negative $\mathrm{M}_{2} \mathrm{~A}-\mathrm{TAT}$ and a negative LTT in $\mathrm{M}_{2}$, but for diurnals the A-TAT is positive and the LTT negative.

Overtide ratios (Figure 46) for $\mathrm{M}_{4}$ and $\mathrm{MK}_{3}$ are increasing for most Australian stations north of Brisbane, with some of the largest long-term trends seen at Cairns $\left(+3 \% \mathrm{yr}^{-1}\right.$ for $\mathrm{M}_{4}$, and $+4 \% \mathrm{yr}^{-1}$ for $\left.\mathrm{MK}_{3}\right)$. Decreases are seen only at Townsville for $\mathrm{S}_{4}$ and $\mathrm{MK}_{3}\left(-2 \% \mathrm{yr}^{-1}\right)$ and at Bundaberg and Gladstone for $\mathrm{M}_{4}\left(-2 \% \mathrm{yr}^{-1}\right)$. Overtides are typically driven by frictional interactions, and friction at harbor stations is usually reduced, not increased, by navigational development (e.g., Jay et al., 2011), which may help explain the decreasing trends at Townsville, Bundaberg, and Gladstone. These harbors are amongst the busiest in Australia, and have had an extensive history of development over the last 50 years. This would not, however, explain the overtide increases seen at other nearby Australian gauges. It is likely that the regional overtide changes are related to larger scale processes, perhaps a coupling of resonant triads and overtides. Tidal evolution at the Australian gauges on the Coral Sea may be a response in part to MSL rise over the complex topography of the Great Barrier and other reef systems (Hughes et al, 2003; Wolanski, 1994).

\subsubsection{Solomon Islands: Overtide ratios and thermocline depth}

The Honiara and Rabaul tide gauges are located in an area of water shallower $(\sim 300-700 \mathrm{~m})$ than at nearby island stations. To the direct west of the island chain is the deep Solomon Sea basin, which is connected to the waters of Honiara and Rabaul via a 
semi-enclosed basin directly east of Papua New Guinea known as "The Slot". Much deeper water lies both north and south of Honiara and Rabaul, but the only open-water connection to the north is a through a narrow deep channel east of the Honiara gauge. The connecting waters south of Honiara and Rabaul have very strong currents due to the motion of the South Equatorial Current (SEC) that runs through the area, both on the surface, and in the deeper thermocline layer. The local bathymetry (Figure 38) is irregular and steep, with relatively narrow deep-water connections between neighboring deep-water basins. This region also has some of the strongest ORs for $\mathrm{M}_{4}$, and $M_{6}$, an order of magnitude greater than neighboring stations. The connections detailed above between the temporal fluctuations in the ORs, MSL, and the El Niño (Figure 47) highlight the heightened sensitivity of tides to water level in this area. Thus, changes in friction, related to changes in lagoonal inundation or "sill depth" that connect the deep and interconnecting basins in the complex bathymetric region may be tied to changing ORs, since the large MSL fluctuations due to ENSO represent a larger relative change in water level. The $\mathrm{M}_{2} \mathrm{~A}$-TAT is positive at Honiara and Rabaul, while both the diurnals show negative A-TATs. Long-term trends are negative at Honiara for $\mathrm{M}_{2}, \mathrm{~K}_{1}$, and $\mathrm{O}_{1}$. At Rabaul, the long-term trends are negative in $\mathrm{M}_{2}$ and positive for the diurnals, but this trend is only estimated up to 1997 when the Rabaul gauge was decommissioned so a direct comparison of LTTs will not be accurate.

The similarity of behavior between TATs and $D_{20}$ variations (Figure 48 ) suggests that the semidiurnal tidal properties in this region may be dependent on local 
thermocline depth. These results are (at least partially) consistent with the processes inferred for Hawaii; i.e., that increased $\mathrm{M}_{2}$ amplitude is correlated with times of deeper thermocline, due to changing internal wave phases (Mitchum and Chiswell, 2000; Colosi and Munk, 2006). In principle, changing thermocline depth could change ORs by altering internal tidal wave steepness. However, the observation (above) that changes in ORs are driven by changes in the overtides (not the parent constituents) suggests a frictional mechanism. That is, it seems unlikely that the $M_{2}$ wave would become significantly steeper at several stations without modifying $M_{2}$ amplitudes at any of them. Moreover, the deeper thermocline during El Niño does not suggest internal tide steepening. Finally, scaling relationships suggest that changes in friction associated with lowered sea levels are a more likely cause of increased ORs than internal wave steepening. In any event, evidence for a direct relationship between overtides, the thermocline, local MSL and the forcing tides can only so far be provided for the gauges near the Solomon Islands (Rabaul, Honiara, Kapingamarangi), presumably due in part to the variable topography and shallower relative water level amplifying both the overtide and thermocline mechanisms.

\subsubsection{Temporal changes}

Analyses of TATs before and after 1993 show that most stations on the Australian shelf exhibit larger A-TATs before than after 1993 for $\mathrm{M}_{2}$, and also for $\mathrm{K}_{1}$ (Figure 49 and 50; Tables 11-14). No other region in this study showed such spatial 
coherence in the shifting of TATs. Overall, these results are locally interesting, but do not conclusively show that the rate of MSL during different epochs is directly influencing the response of the tides to MSL variability, since the majority of all gauges analyzed show more or less unchanged TATs before 1993 and after. Gauges that do show a significant shift in TATs are likely due to local dynamical factors mentioned above (overtide and thermocline variability), as well as the fact that the post-1993 period captures the 1997-1998 El Niño event, the strongest such event in the modern record, which produced the largest interannual variability in both MSL and the tidal dynamics, particularly in this region. Therefore, the comparison of the tidal variability between these two time periods with different MSL rates is either not able to isolate the effect of long-term sea level change, or it is not the mechanism for the observed tidal variability at this time scale.

\subsubsection{Amphidromic movements}

The observed TATs for $\mathrm{K}_{1}$ (Figure 41) are consistent with a westward, slightly northwest-ward movement and counter-clockwise rotation of amphidrome " $A$ ", and an eastward movement and clockwise rotation of amphidrome " $\mathrm{B}$ " associated with positive MSL fluctuations. These combined motions would also allow an increase in the $K_{1}$ amplitudes within the Coral Sea, as observed in TATs for the area. Though diurnal ATATs are decreasing at nearby Honiara and Rabaul, these gauges are within a semienclosed basin, and are essentially separated from the Coral Sea and the open Pacific. 
The $\mathrm{O}_{1}$ tidal field shows a similar movement of amphidromic points as $\mathrm{K}_{1}$ (Figure 42 ). Unlike $K_{1}$, there is an additional amphidromic point off the New Zealand coast. A westward movement of this point would explain trends observed at the Australian shelf and Auckland. Thus, we conclude that changes in diurnal tides within amphidromes " $A$ " and " $\mathrm{B}$ " are amphidromic scale, though modulated by other local factors at some stations.

For $\mathrm{M}_{2}$, (Figure 43) an eastward movement of amphidrome " $\mathrm{B}$ ", along with a counterclockwise rotation that expands the anti-node near Pago Pago westward and southwest-ward would agree with most of the observed $M_{2}$ TATs. The long, narrow amphidrome, " $A$ " (more or less aligned with the Mariana Trench) is not changing in an obvious pattern. The $S_{2}$ patterns (Figure 44) of A-TATs and P-TATs show some similarities to those for $\mathrm{M}_{2}$ (e.g., at Yap, Kapingamarangi, and Noumea), but also many differences (e.g., Legaspi, Rabaul and Pago Pago). Honiara has a similar $\mathrm{M}_{2}$ A-TAT to other regional gauges, but an opposite P-TAT. The overall pattern of change for $\mathrm{S}_{2}$ may echo $\mathrm{M}_{2}$, with an amphidromic point east of Pago Pago moving westward, and a central anti-node rotating counter-clockwise. It is not surprising that the $\mathrm{M}_{2}$ and $\mathrm{S}_{2}$ behavior show some difference, because $S_{2}$ has a significant radiational component that is absent for $M_{2}$ (Godin, 1986; Ray, 2001; Arbic, 2005). Still, there is a strong suggestion of regional coherence for the semidiurnals, as with the diurnals. 
If these suggestions of amphidromic-scale tidal evolution are real, they require an explanation relevant to such a scale. The two most likely candidates are the barotropic "back-effect" mechanism suggested by Arbic and Garrett (2010) and altered stratification (Müller, 2012b). The first requires continental shelf areas over which friction or depth are changing, which seems more relevant to amphidrome " $\mathrm{B}$ ", for both the diurnals and the semidiurnals. Altered stratification may have occurred over large areas in both amphidromes " $\mathrm{A}$ " and " $\mathrm{B}$ ", and there is a clear connection between stratification and tidal properties at Honiara and Kapingamarangi. At least the latter is affected by amphidrome " $A$ " for both diurnals and semidiurnals. Thus, altered stratification seems the more likely agent of tidal evolution in amphidrome " $A$ ". We note that amphidromic movements are not a cause of the observed TATs, but are rather symptoms of tidal evolution that represent a re-distribution of the tidal fields driven by other factors.

\subsubsection{Triad interactions}

Honiara and Rabaul in the Solomon Sea show resonant triad behavior at sub-

decadal and longer timescales, with some fluctuations during ENSO events. Estimates of possible wave vectors show there are multiple situations that can satisfy the resonance conditions, Eqs. (11) and (12). Triads that involve higher-mode internal tides are, however, unlikely to be observed at a coastal tide gauge. Thus, the triad interaction 
that we do see is possibly a parametric subharmonic instability (PSI) interaction of barotropic $\mathrm{M}_{2}$ with first-mode internal $\mathrm{K}_{1}$ and $\mathrm{O}_{1}$.

There are also frictional triad interactions in the Solomon Sea that are correlated with MSL fluctuations, likely due to decreased lagoonal depths during periods of lowered MSL (Figure 47). Thus, the frictionally-driven overtides of $M_{4}$ and $M_{6}$ strongly vary with $\mathrm{MSL}$ (and thermocline depth) even though $\mathrm{MO}_{3}$ and $\mathrm{MK}_{3}$ do not. This likely reflects the fact that $M_{2}$ is decreased and the diurnals $\left(K_{1}\right.$ and $\left.O_{1}\right)$ increased by a deeper thermocline. These opposite fluctuations compensate each other in $\mathrm{MO}_{3}$ and $\mathrm{MK}_{3}$, while $M_{4}$ and $M_{6}$ variations are proportional to the square and cube (respectively) of $M_{2}$.

Resonant triad behavior at Honiara shows a difference in behavior before and after 1993, with larger excursions from stability after 1993. These excursions are caused by decreases in the $\mathrm{K}_{1}$ and $\mathrm{O}_{1}$ amplitudes that are not fully compensated by changes in $M_{2}$. These may be caused by the rising MSL in the area. Also, the resonant triad behavior during the ENSO event in 2009 and 2010 was less dramatic than in the four previous El Niños, perhaps because the most recent El Niño was weaker. Determining whether MSL rise has fundamentally altered Solomon Sea triad behavior awaits the next major El Niño.

\subsection{Conclusions}

Tidal anomalies are related to MSL anomalies via tidal anomaly trends for both amplitude and phase (A-TATs and P-TATs) over much of the Western tropical Pacific, at 
both coastal and open-ocean stations. Comparison of periods before and after 1993 at stations with records $>40$ yrs long shows considerable temporal variability. However, complex spatial patterns, differences between constituents, and differences between TATs and long term trends make it difficult to draw conclusions regarding causes of tidal evolution. Observed trends so far suggest the existence of multiple mechanisms with spatial scales from strictly local (e.g., lagoonal depth and harbor modification) to amphidromal, as evidenced in the apparent movement and rotation of both diurnal and semidiurnal amphidromes. Comparison of the long-term trends (LTTs) in MSL and tidal properties with the short-term variability of MSL and tides, as exhibited by the A-TATs and P-TATs, do not show ubiquitous overlap of behavior. At some locations, the LTTS and TATs are correlated, and at others, anti-correlated. This suggests that multiple dynamics are active in different parts of the frequency spectrum, with temporal scales from interannual to decadal, and as of yet, no significant prediction about the future behavior of tidal constituents may be inferred from the analysis of interannual tidal and MSL fluctuations. Thus, the question posed in the title must be answered in the negative, at least for now, though further analysis with longer records from a different part of the world ocean might suggest a different answer.

Two regions were studied in detail; the Solomon Sea, and the Coral Sea area including the east coast of Australia and New Zealand. Both areas show regionally coherent changes, but with different manifestations. In both cases, there is considerable variability between stations related to local processes. To the extent that 
the reefs of the Coral Sea are a factor, changes in the Australia-New Zealand area may be unusual - regionally coherent but not likely applicable in other settings.

To summarize the available evidence:

1. Internal tides: The surface manifestation of internal tides, generated across steep topography, can affect major tidal constituents over the entire region investigated, which is between the critical latitudes for both diurnal and semidiurnal tides. There has been a deepening and strengthening of the thermocline in the area (documented for 1993-2003 by Church et al., 2011), which necessarily changes internal tides and may affect surface tides (Müller, 2012b). The $\mathrm{M}_{2}$ and $\mathrm{S}_{2}$ constituents are strongly (positively) correlated with nearby thermocline depth in the region surrounding the Solomon Islands as well as MSL, and diurnal tides show a negative (decreasing) response to increasing MSL and deepening thermocline. Thus, changing stratification appears to be the most likely agent of large-scale tidal evolution in the northern part of the study area (amphidrome " $A$ " for both diurnals and semidiurnal). It may affect amphidrome " $B$ " in the southern part of the study area, but we have no definite evidence of this.

2. Changing friction: Frictional interactions are most prominent for overtides but affect the main tidal species as well. A-TATs, and LTTs of the major tides sometimes reinforce each other, but also show opposing behavior at some locations. These two calculations of trends have different time scales, and are likely due to unrelated 
mechanisms. The similarity in trends between coastal and island stations gives some support to the hypothesis that changes in amphidrome "B" may be driven by continental shelf processes, which can have a back-effect upon open-ocean trends (Arbic and Garrett, 2010). Comparison of TATs for the pre- and post-1993 periods shows that trends have changed for many Australian shelf stations, including sign reversals. Changes in ORs over time also suggest a frictional component to changing tides in the region of study. Particularly over the Australian shelf, this appears to have a regional rather than local origin.

3. Resonant triad interactions: Triad interactions of the diurnal and semidiurnal tides $\left(K_{1}, O_{1}\right.$, and $\left.M_{2}\right)$, may both be mediated by and enhanced by variations in thermocline properties (Ball, 1964). The strength of these interactions can be modulated by changing water depth (MSL), which changes bottom friction, and also the deepening of the thermocline, which changes both surface-layer depth and stratification. Triads can involve a transfer of tidal energy across multiple frequencies, and is therefore a likely candidate to connect the other variability explored in this work, as illustrated by analysis of the Honiara and Rabaul in the Solomon Sea region. Whether triad interactions are relevant on a regional basis, or only locally important, remains unclear.

It is likely the above mechanisms are not altogether independent, and the situation in the Solomon Sea suggests that there is a connection between triad and 
frictional interactions, with $\mathrm{M}_{2}$ energy feeding both the resonant and frictional triads. This results in large ( $\pm 30 \%$ ) interannual fluctuations in $M_{2}$ amplitude. Variations in thermocline depth may be tied to changes in shallow water frictional interactions, because a shallower total depth makes fluctuations in the upper-layer thickness larger, in percentage terms, than at deep water stations. The amphidromic movements associated with MSL will likely have secondary regional effects as the basin-wide water levels and tidal admittances adjust to changes in sea level and in thermocline profile. Further work is underway to test the contribution of each of these mechanisms through modeling in coordination with analyses of satellite altimetry data, as well as investigations focusing on sub-annual (seasonal) dynamics based on monthly analyses. 
Table 8a Station information for tidal records used in this study, showing country, start and end year of record, metadata about gauge locations, and mean sea level (MSL) rates for the entire record, and for before and after 1993 (where applicable). Locations are shown in Figure $38^{a}$

\begin{tabular}{|c|c|c|c|c|c|c|c|}
\hline Station & Country & $\begin{array}{l}\text { Start } \\
\text { Year }\end{array}$ & $\begin{array}{l}\text { End } \\
\text { Year }\end{array}$ & Locale & $\begin{array}{c}\text { MSL } \\
\text { Rates }\end{array}$ & $\begin{array}{c}\text { Pre- } \\
1993\end{array}$ & $\begin{array}{l}\text { Post- } \\
1993\end{array}$ \\
\hline Pohnpei & Micronesia & 1974 & 2012 & volc & $2.22 \pm 0.01$ & $-2.20 \pm 0.28$ & $4.71 \pm 0.27$ \\
\hline Majuro & Marshall Is. & 1974 & 2012 & atoll & $3.91 \pm 0.15$ & $2.66 \pm 0.45$ & $7.02 \pm 0.41$ \\
\hline Malakal & Belau & 1974 & 2012 & $\mathrm{mtn}$ & $2.98 \pm 0.15$ & $-1.56 \pm 0.44$ & $\begin{array}{c}10.36 \pm \\
0.42\end{array}$ \\
\hline Yap & Micronesia & 1974 & 2012 & $\mathrm{mtn}$ & $1.99 \pm 0.12$ & $-2.91 \pm 0.34$ & $7.30 \pm 0.34$ \\
\hline Honiara & Solomon Is. & 1975 & 2012 & volc & $0.88 \pm 0.08$ & $-5.15 \pm 0.24$ & $8.51 \pm 0.20$ \\
\hline Rabaul & Pap. N. Gui. & 1966 & 1997 & volc & $-3.16 \pm 0.09$ & $-5.94 \pm 0.10$ & $\mathrm{~N} / \mathrm{A}$ \\
\hline Kanton & Kiribati & 1949 & 2012 & atoll & $0.89 \pm 0.05$ & $0.12 \pm 0.08$ & $4.69 \pm 0.29$ \\
\hline Noum. & France & 1967 & 2012 & reef & $1.37 \pm 0.09$ & $0.53 \pm 0.20$ & $5.93 \pm 0.34$ \\
\hline Saipan & N. Mar. Is. & 1978 & 2012 & $\mathrm{mtn}$ & $2.27 \pm 0.10$ & $\mathrm{~N} / \mathrm{A}$ & N/A \\
\hline Kapinga & Micronesia & 1978 & 2009 & atoll & $2.82 \pm .12$ & N/A & N/A \\
\hline Lautoka & Fiji & 1992 & 2012 & volc & $5.58 \pm 0.10$ & N/A & $\mathrm{N} / \mathrm{A}$ \\
\hline Midway & USA & 1947 & 2012 & atoll & $0.86 \pm 0.02$ & $-0.25 \pm 0.04$ & $5.40 \pm 0.17$ \\
\hline Wake & USA & 1950 & 2012 & atoll & $1.99 \pm 0.05$ & $1.42 \pm 0.07$ & $1.12 \pm 0.36$ \\
\hline Johns. & USA & 1947 & 2012 & atoll & $0.85 \pm 0.05$ & $0.51 \pm 0.06$ & $3.04 \pm 0.59$ \\
\hline Guam & USA & 1948 & 2012 & $\mathrm{mtn}$ & $1.32 \pm 0.04$ & $-0.89 \pm 0.06$ & $9.32 \pm 0.31$ \\
\hline Kwaj. & Marshall Is. & 1946 & 2012 & atoll & $1.72 \pm 0.07$ & $0.71 \pm 0.10$ & $8.07 \pm 0.50$ \\
\hline Pago & USA & 1948 & 2012 & volc & $2.13 \pm 0.05$ & $1.45 \pm 0.08$ & $6.44 \pm 0.37$ \\
\hline Bris. & Australia & 1984 & 2012 & est & $2.75 \pm 0.10$ & $\mathrm{~N} / \mathrm{A}$ & N/A \\
\hline Bunda. & Australia & 1984 & 2012 & est & $1.90 \pm 0.08$ & N/A & $\mathrm{N} / \mathrm{A}$ \\
\hline Ft. Den & Australia & 1914 & 2012 & est & $0.92 \pm 0.12$ & $1.06 \pm 0.22$ & $2.84 \pm 0.56$ \\
\hline Towns. & Australia & 1985 & 2012 & bay & $0.81 \pm 0.16$ & N/A & N/A \\
\hline Legaspi & Philippines & 1984 & 2007 & bay & $8.97 \pm 0.42$ & N/A & N/A \\
\hline Cairns & Australia & 1985 & 2010 & inlet & $2.14 \pm 0.33$ & $\mathrm{~N} / \mathrm{A}$ & N/A \\
\hline Glads. & Australia & 1978 & 2010 & bay & $2.47 \pm 0.58$ & $\mathrm{~N} / \mathrm{A}$ & $\mathrm{N} / \mathrm{A}$ \\
\hline Willia. & Australia & 1966 & 2010 & bay & $1.39 \pm 0.07$ & $0.09 \pm 0.17$ & $2.48 \pm 0.25$ \\
\hline Auck. & New Zealand & 1904 & 2010 & bay & $1.48 \pm 0.09$ & $1.33 \pm 0.07$ & $3.75 \pm 0.18$ \\
\hline
\end{tabular}

a -Expressed in $\mathrm{mm} \mathrm{yr}^{-1}$. N/A indicates there was not a full nodal cycle ( $\sim 18.6$ years) of data before 1993 available. Location abbreviations: volc: volcanic; $m t n$ : mountainous; est: estuary. 
Table 8b Long-term (linear) trends, with 95\% confidence limits, for diurnal tidal amplitudes and phases ${ }^{a}$

\begin{tabular}{|c|c|c|c|c|}
\hline $\begin{array}{l}\text { Tidal Comp: } \\
( \pm 95 \% \mathrm{Cl})\end{array}$ & $\begin{array}{c}K_{1} \\
\text { A-LTT }\end{array}$ & $\begin{array}{c}K_{1} \\
\text { P-LTT }\end{array}$ & $\begin{array}{c}O_{1} \\
\text { A-LTT }\end{array}$ & $\begin{array}{c}O_{1} \\
\text { P-LTT }\end{array}$ \\
\hline Station & $\left(\mathrm{mmcy}^{-1}\right)$ & $\left(\right.$ degcy $\left.^{-1}\right)$ & $\left(\mathrm{mmcy}^{-1}\right)$ & $\left(\right.$ degcy $\left.^{-1}\right)$ \\
\hline Pohnpei & $-7.5 \pm 2.5$ & $-7.5 \pm 1.7$ & $4.4 \pm 1.3$ & $5.7 \pm 1.1$ \\
\hline Majuro & $0.4 \pm 2.6$ & $17.7 \pm 2.7$ & $3.7 \pm 1.5$ & $23.2 \pm 2.4$ \\
\hline Malakal & $15.7 \pm 4.8$ & $2.6 \pm 1.3$ & $-1.0 \pm 3.0$ & $-5.5 \pm 2.8$ \\
\hline Yap & $14.0 \pm 3.2$ & $4.1 \pm 1.3$ & $21.8 \pm 4.6$ & $16.3 \pm 4.7$ \\
\hline Honiara & $-2.1 \pm 4.9$ & $15.6 \pm 1.9$ & $-4.8 \pm 4.5$ & $22.5 \pm 9.8$ \\
\hline Rabaul & $23.6 \pm 3.9$ & $1.0 \pm 1.3$ & $5.4 \pm 3.1$ & $0.0 \pm 1.4$ \\
\hline Kanton & $3.0 \pm 1.0$ & $-2.4 \pm 2.6$ & $4.0 \pm 0.9$ & $6.4 \pm 2.4$ \\
\hline Noumea & $6.9 \pm 1.2$ & $0.6 \pm 0.5$ & $0.3 \pm 0.9$ & $0.9 \pm 1.2$ \\
\hline Saipan & $-11.2 \pm 4.9$ & $0.7 \pm 1.7$ & $1.3 \pm 2.3$ & $-0.2 \pm 2.0$ \\
\hline Kapinga & $19.8 \pm 6.3$ & $1.7 \pm 3.1$ & $-1.5 \pm 12.5$ & $7.2 \pm 5.9$ \\
\hline Lautoka & $1.8 \pm 2.2$ & $-3.5 \pm 15.1$ & $2.8 \pm 2.3$ & $-8.1 \pm 8.4$ \\
\hline Midway & $1.5 \pm 0.7$ & $0.2 \pm 0.4$ & $1.6 \pm 0.5$ & $-2.3 \pm 0.5$ \\
\hline Wake & $-3.4 \pm 0.6$ & $-0.7 \pm 0.6$ & $0.9 \pm 0.6$ & $2.0 \pm 0.7$ \\
\hline Johnston & $-3.9 \pm 0.8$ & $-7.0 \pm 0.5$ & $-2.0 \pm 0.4$ & $1.8 \pm 0.6$ \\
\hline Guam & $4.7 \pm 1.9$ & $4.3 \pm 0.9$ & $-3.4 \pm 1.6$ & $3.5 \pm 0.7$ \\
\hline Kwajalein & $1.6 \pm 0.6$ & $0.4 \pm 0.5$ & $-1.0 \pm 0.5$ & $0.2 \pm 0.4$ \\
\hline Pagopago & $2.2 \pm 0.9$ & $0.3 \pm 0.7$ & $2.2 \pm 0.9$ & $3.8 \pm 0.9$ \\
\hline Brisbane & $-12.9 \pm 3.7$ & $2.5 \pm 1.1$ & $-4.9 \pm 3.3$ & $6.2 \pm 1.5$ \\
\hline Bundaberg & $-8.7 \pm 3.1$ & $0.3 \pm 1.1$ & $-8.3 \pm 2.4$ & $0.5 \pm 1.1$ \\
\hline Ft Denison & $-1.1 \pm 0.4$ & $-0.4 \pm 0.2$ & $-0.2 \pm 0.4$ & $-0.9 \pm 0.2$ \\
\hline Townsville & $3.3 \pm 1.7$ & $-1.6 \pm 0.3$ & $2.6 \pm 1.2$ & $1.1 \pm 0.5$ \\
\hline Legaspi & $-14.8 \pm 6.9$ & $0.1 \pm 2.7$ & $-28.7 \pm 7.2$ & $9.4 \pm 3.8$ \\
\hline Cairns & $8.8 \pm 5.7$ & $-0.1 \pm 0.8$ & $10.2 \pm 3.1$ & $0.4 \pm 0.9$ \\
\hline Gladstone & $-2.2 \pm 3.3$ & $0.1 \pm 0.7$ & $-8.9 \pm 2.3$ & $1.7 \pm 1.1$ \\
\hline WIImstwn & $18.2 \pm 1.6$ & $5.1 \pm 1.3$ & $7.8 \pm 1.6$ & $9.6 \pm 1.7$ \\
\hline Auckland & $-1.4 \pm 0.4$ & $1.2 \pm 0.3$ & $-0.8 \pm 0.3$ & $19.5 \pm 1.3$ \\
\hline
\end{tabular}

a -Expressed as mm per century $\left(\mathrm{mmcy}^{-1}\right)$ for amplitudes, or degrees per century $\left(\mathrm{degcy}^{-1}\right)$ for phases. Significant values are shaded grey, and have SNR $>2$, and an absolute magnitude of $>10 \mathrm{mmcy}^{-1}$ or degcy ${ }^{-1}$. 
Table 8c Long-term (linear) trends, with 95\% confidence limits, for semidiurnal tidal amplitudes and phases ${ }^{a}$

\begin{tabular}{|c|c|c|c|c|}
\hline $\begin{array}{l}\text { Tidal Comp: } \\
\text { ( } \pm 95 \% \mathrm{Cl})\end{array}$ & $\begin{array}{c}M_{2} \\
\text { A-LTT }\end{array}$ & $\begin{array}{c}M_{2} \\
\text { P-LTT }\end{array}$ & $\begin{array}{c}S_{2} \\
\text { A-LTT }\end{array}$ & $\begin{array}{c}S_{2} \\
\text { P-LTT }\end{array}$ \\
\hline Station & $\left(\mathrm{mmcy}^{-1}\right)$ & $\left(\right.$ degcy $\left.^{-1}\right)$ & $\left(\mathrm{mmcy}^{-1}\right)$ & $\left(\right.$ degcy $\left.^{-1}\right)$ \\
\hline Pohnpei & $22.0 \pm 6.7$ & $8.0 \pm 1.8$ & $18.2 \pm 4.4$ & $1.8 \pm 2.0$ \\
\hline Majuro & $44.9 \pm 8.3$ & $0.8 \pm 1.2$ & $35.8 \pm 3.8$ & $4.6 \pm 0.9$ \\
\hline Malakal & $62.3 \pm 5.8$ & $0.1 \pm 1.2$ & $29.5 \pm 2.3$ & $-0.7 \pm 1.4$ \\
\hline Yap & $41.3 \pm 6.1$ & $10.5 \pm 1.8$ & $16.2 \pm .31$ & $10.6 \pm 2.2$ \\
\hline Honiara & $-6.2 \pm 5.4$ & $17.8 \pm 2.8$ & $4.0 \pm 2.7$ & $6.8 \pm 1.7$ \\
\hline Rabaul & $-13.1 \pm 13.1$ & $-0.8 \pm 12.8$ & $14.4 \pm 5.6$ & $0.8 \pm 2.5$ \\
\hline Kanton & $27.8 \pm 4.8$ & $-5.0 \pm 0.8$ & $15.3 \pm 1.3$ & $-1.5 \pm 0.6$ \\
\hline Noumea & $25.3 \pm 6.1$ & $-2.5 \pm 0.7$ & $19.3 \pm 2.5$ & $-4.6 \pm 0.8$ \\
\hline Saipan & $33.2 \pm 6.7$ & $7.6 \pm 2.6$ & $-15.8 \pm 3.9$ & $-13.4 \pm 5.2$ \\
\hline Kapinga & $49.7 \pm 9.7$ & $7.9 \pm 5.7$ & $35.1 \pm 6.6$ & $10.3 \pm 5.7$ \\
\hline Lautoka & $36.7 \pm 7.1$ & $-5.2 \pm 0.9$ & $12.4 \pm 6.0$ & $14.1 \pm 5.2$ \\
\hline Midway & $7.4 \pm 1.2$ & $-5.5 \pm 0.7$ & $-0.3 \pm 0.5$ & $-17.2 \pm 1.7$ \\
\hline Wake & $-11.9 \pm 2.7$ & $2.4 \pm 0.5$ & $5.7 \pm 1.1$ & $2.1 \pm 0.5$ \\
\hline Johnston & $2.6 \pm 1.7$ & $-4.1 \pm 0.7$ & $8.1 \pm 1.4$ & $-11.3 \pm 0.7$ \\
\hline Guam & $-0.5 \pm 2.4$ & $1.6 \pm 0.6$ & $0.1 \pm 0.9$ & $7.7 \pm 1.2$ \\
\hline Kwajalein & $-7.3 \pm 1.7$ & $0.4 \pm 0.2$ & $-0.1 \pm 1.4$ & $-1.8 \pm 0.2$ \\
\hline Pagopago & $10.1 \pm 2.5$ & $-0.2 \pm 0.5$ & $1.0 \pm 0.8$ & $-1.8 \pm 0.2$ \\
\hline Brisbane & $15.6 \pm 13.6$ & $13.9 \pm 1.1$ & $12.3 \pm 7.2$ & $9.1 \pm 1.5$ \\
\hline Bundaberg & $2.3 \pm 5.6$ & $1.9 \pm 1.2$ & $7.9 \pm 4.4$ & $2.5 \pm 1.4$ \\
\hline Ft Denison & $-27.8 \pm 10.0$ & $-2.0 \pm 0.2$ & $-5.1 \pm 0.4$ & $-3.5 \pm 0.2$ \\
\hline Townsville & $66.8 \pm 3.2$ & $-3.0 \pm 0.4$ & $9.9 \pm 2.0$ & $1.9 \pm 0.4$ \\
\hline Legaspi & $-69.3 \pm 27.6$ & $-4.1 \pm 4.1$ & $-13.1 \pm 15.1$ & $-0.1 \pm 3.4$ \\
\hline Cairns & $49.5 \pm 12.5$ & $-1.4 \pm 1.4$ & $15.4 \pm 6.0$ & $-3.1 \pm 1.7$ \\
\hline Gladstone & $14.1 \pm 8.2$ & $1.6 \pm 0.7$ & $57.3 \pm 6.7$ & $2.3 \pm 0.8$ \\
\hline WIImstwn & $34.8 \pm 2.1$ & $11.7 \pm 1.2$ & $6.6 \pm 1.5$ & $18.9 \pm 1.8$ \\
\hline Auckland & $-31.7 \pm 2.0$ & $0.6 \pm 0.2$ & $-3.6 \pm 0.7$ & $1.6 \pm 1.5$ \\
\hline
\end{tabular}

a -Expressed as $\mathrm{mm}$ per century $\left(\mathrm{mmcy}^{-1}\right)$ for amplitudes, or degrees per century (degcy ${ }^{-1}$ ) for phases. Significant values are shaded grey, and have SNR $>2$, and an absolute magnitude of $>10 \mathrm{mmcy}^{-1}$ or degcy $^{-1}$. 
Table 9 Amplitude tidal anomaly trends (A-TATs) with 95\% confidence limits and combined A-TATs for major diurnal and semidiurnal constituents ${ }^{\mathrm{a}}$.

\begin{tabular}{|c|c|c|c|c|c|}
\hline $\begin{array}{l}\text { Trend: } \\
( \pm 95 \% \mathrm{Cl})\end{array}$ & $\begin{array}{c}K_{1} \\
\text { A-TAT }\end{array}$ & $\begin{array}{c}O_{1} \\
\text { A-TAT }\end{array}$ & $\begin{array}{c}M_{2} \\
\text { A-TAT }\end{array}$ & $\begin{array}{c}S_{2} \\
\text { A-TAT }\end{array}$ & $\begin{array}{l}\text { Comb. } \\
\text { A-TATs }\end{array}$ \\
\hline Station & $\left(\mathrm{mmm}^{-1}\right)$ & $\left(\mathrm{mmm}^{-1}\right)$ & $\left(\mathrm{mmm}^{-1}\right)$ & $\left(\mathrm{mmm}^{-1}\right)$ & $\left(\mathrm{mmm}^{-1}\right)$ \\
\hline Pohnpei & $22.9 \pm 3.6$ & $0.2 \pm 2.3$ & $-4.1 \pm 12.2$ & $-5.6 \pm 3.2$ & $13.5 \pm 13.3$ \\
\hline Majuro & $7.6 \pm 6.8$ & $-17.7 \pm 4.2$ & $-21.6 \pm 23.3$ & $-0.9 \pm 5.0$ & $-32.6 \pm 25.2$ \\
\hline Malakal & $46.4 \pm 3.8$ & $6.3 \pm 3.4$ & $-28.5 \pm 7.2$ & $-2.2 \pm 1.5$ & $21.9 \pm 9.0$ \\
\hline Yap & $19.6 \pm 4.0$ & $3.6 \pm 5.8$ & $-39.6 \pm 7.9$ & $-9.7 \pm 1.5$ & $-26.1 \pm 10.7$ \\
\hline Honiara & $-21.2 \pm 6.3$ & $-27.6 \pm 4.5$ & $65.6 \pm 3.3$ & $15.9 \pm 0.8$ & $32.7 \pm 8.4$ \\
\hline Rabaul & $-24.3 \pm 3.1$ & $-8.4 \pm 2.9$ & $91.1 \pm 7.5$ & $-11.7 \pm 1.8$ & $46.7 \pm 8.8$ \\
\hline Kanton & $-14.0 \pm 3.6$ & $-2.4 \pm 3.7$ & $33.0 \pm 18.3$ & $8.7 \pm 2.2$ & $25.3 \pm 19.1$ \\
\hline Noumea & $23.6 \pm 4.2$ & $2.9 \pm 3.3$ & $70.9 \pm 19.0$ & $12.9 \pm 3.3$ & $110.4 \pm 20.0$ \\
\hline Saipan & $-10.6 \pm 8.2$ & $8.9 \pm 3.8$ & $17.0 \pm 11.1$ & $-8.1 \pm 2.6$ & $7.2 \pm 14.6$ \\
\hline Kapinga & $-18.3 \pm 5.8$ & $-20.7 \pm 12.5$ & $47.6 \pm 7.7$ & $17.4 \pm 1.6$ & $26.1 \pm 15.8$ \\
\hline Lautoka & $5.4 \pm 3.3$ & $12.3 \pm 2.9$ & $21.9 \pm 10.6$ & $6.4 \pm 3.8$ & $46.0 \pm 12.1$ \\
\hline Midway & $7.4 \pm 3.1$ & $-7.7 \pm 2.4$ & $6.6 \pm 6.0$ & $2.9 \pm 1.1$ & $9.1 \pm 7.2$ \\
\hline Wake & $-9.0 \pm 2.6$ & $4.1 \pm 2.6$ & $-43.6 \pm 11.8$ & $-2.4 \pm 2.1$ & $-50.9 \pm 12.6$ \\
\hline Johnston & $-26.1 \pm 3.4$ & $2.1 \pm 2.1$ & $-38.4 \pm 8.9$ & $-21.9 \pm 2.6$ & $-84.3 \pm 10.1$ \\
\hline Guam & $-29.0 \pm 4.2$ & $-35.9 \pm 2.9$ & $-23.3 \pm 5.8$ & $1.3 \pm 0.9$ & $-86.9 \pm 7.7$ \\
\hline Kwajalein & $-1.1 \pm 2.6$ & $8.2 \pm 2.0$ & $-2.7 \pm 6.6$ & $9.1 \pm 2.0$ & $13.4 \pm 7.6$ \\
\hline Pagopago & $20.3 \pm 3.1$ & $2.7 \pm 1.5$ & $82.7 \pm 7.7$ & $-9.9 \pm 1.1$ & $95.8 \pm 8.5$ \\
\hline Brisbane & $19.4 \pm 10.2$ & $30.3 \pm 8.4$ & $177.6 \pm 28.8$ & $15.2 \pm 8.4$ & $242.4 \pm 32.8$ \\
\hline Bundaberg & $50.8 \pm 10.6$ & $1.9 \pm 6.8$ & $-32.2 \pm 15.4$ & $-9.3 \pm 4.9$ & $11.2 \pm 20.5$ \\
\hline Ft. Denison & $18.1 \pm 4.8$ & $10.2 \pm 4.1$ & $-47.9 \pm 11.0$ & $-0.5 \pm 1.8$ & $-20.1 \pm 12.8$ \\
\hline Townsville & $10.4 \pm 11.6$ & $1.0 \pm 7.2$ & $-4.7 \pm 19.6$ & $-6.0 \pm 4.4$ & $0.7 \pm 24.3$ \\
\hline Legaspi & $-11.2 \pm 7.1$ & $-29.1 \pm 6.2$ & $-152.0 \pm 21.2$ & $26.0 \pm 4.5$ & $-166.2 \pm 23.6$ \\
\hline Cairns & $15.8 \pm 16.4$ & $27.1 \pm 8.0$ & $35.5 \pm 36.0$ & $1.7 \pm 6.9$ & $80.1 \pm 40.9$ \\
\hline Gladstone & $38.3 \pm 10.5$ & $6.8 \pm 7.7$ & $-34.1 \pm 26.8$ & $-23.1 \pm 8.5$ & $-12.1 \pm 31.0$ \\
\hline Wllmstown & $1.0 \pm 6.3$ & $-0.1 \pm 6.2$ & $9.2 \pm 8.2$ & $9.2 \pm 2.2$ & $19.3 \pm 12.3$ \\
\hline Auckland & $6.0 \pm 3.0$ & $-0.8 \pm 2.3$ & $-58.2 \pm 17.2$ & $3.4 \pm 2.5$ & $-49.5 \pm 17.8$ \\
\hline
\end{tabular}

a -All values are expressed as millimeter change in tide per meter rise in MSL $\left(\mathrm{mmm}^{-1}\right)$. Significant values are shaded grey, based on a SNR $>2$, and an absolute magnitude of $>10 \mathrm{mmm}^{-1}$. 
Table 10 Phase anomaly trends (P-TATs) with 95\% confidence limits for major diurnal and semidiurnal constituents ${ }^{\mathrm{a}}$.

\begin{tabular}{|c|c|c|c|c|}
\hline $\begin{array}{l}\text { Trend: } \\
( \pm 95 \% \mathrm{Cl})\end{array}$ & $\begin{array}{c}\mathrm{K}_{1} \\
\text { P-TAT }\end{array}$ & $\begin{array}{c}O_{1} \\
\text { P-TAT }\end{array}$ & $\begin{array}{c}M_{2} \\
\text { P-TAT }\end{array}$ & $\begin{array}{c}S_{2} \\
\text { P-TAT }\end{array}$ \\
\hline Station & $\left(\right.$ degm $\left.^{-1}\right)$ & $\left(\right.$ degm $\left.^{-1}\right)$ & $\left(\operatorname{degm}^{-1}\right)$ & $\left(\right.$ degm $\left.^{-1}\right)$ \\
\hline Pohnpei & $-18.9 \pm 2.1$ & $8.7 \pm 1.6$ & $12.1 \pm 2.9$ & $-13.9 \pm 3.1$ \\
\hline Majuro & $-26.6 \pm 6.4$ & $22.0 \pm 6.0$ & $-0.3 \pm 2.9$ & $-0.2 \pm 2.2$ \\
\hline Malakal & $6.7 \pm 1.4$ & $-31.3 \pm 1.3$ & $-3.7 \pm 1.3$ & $-6.5 \pm 1.4$ \\
\hline Yap & $11.0 \pm 1.4$ & $57.6 \pm 2.6$ & $17.4 \pm 1.8$ & $23.0 \pm 2.1$ \\
\hline Honiara & $1.8 \pm 0.6$ & $2.3 \pm 7.9$ & $28.2 \pm 2.8$ & $-16.9 \pm 1.6$ \\
\hline Rabaul & $-2.0 \pm 1.2$ & $4.2 \pm 1.5$ & $-39.6 \pm 10.8$ & $3.6 \pm 2.4$ \\
\hline Kanton & $-2.8 \pm 10.5$ & $32.0 \pm 10.9$ & $-7.4 \pm 3.6$ & $4.9 \pm 2.6$ \\
\hline Noumea & $2.8 \pm 1.9$ & $-3.3 \pm 4.3$ & $1.0 \pm 2.5$ & $1.2 \pm 3.1$ \\
\hline Saipan & $-1.6 \pm 3.0$ & $-12.9 \pm 2.9$ & $3.7 \pm 4.3$ & $-28.2 \pm 9.1$ \\
\hline Kapinga & $-13.3 \pm 2.8$ & $-27.2 \pm 5.4$ & $-32.6 \pm 4.5$ & $-37.0 \pm 4.0$ \\
\hline Lautoka & $23.8 \pm 39.2$ & $-10.0 \pm 12.8$ & $-2.2 \pm 1.3$ & $14.5 \pm 3.4$ \\
\hline Midway & $0.8 \pm 2.1$ & $-1.1 \pm 2.2$ & $-12.3 \pm 3.1$ & $-49.8 \pm 7.2$ \\
\hline Wake & $0.6 \pm 2.7$ & $10.8 \pm 3.2$ & $17.6 \pm 2.1$ & $7.8 \pm 2.3$ \\
\hline Johnston & $-3.4 \pm 2.9$ & $6.0 \pm 3.4$ & $15.8 \pm 3.7$ & $-3.0 \pm 3.9$ \\
\hline Guam & $18.9 \pm 1.6$ & $-4.3 \pm 1.6$ & $-1.9 \pm 1.4$ & $15.9 \pm 2.8$ \\
\hline Kwajalein & $7.6 \pm 1.8$ & $-3.6 \pm 1.7$ & $-1.6 \pm 0.7$ & $-3.2 \pm 0.9$ \\
\hline Pagopago & $2.9 \pm 2.5$ & $23.6 \pm 3.3$ & $17.8 \pm 1.5$ & $-6.7 \pm 3.0$ \\
\hline Brisbane & $-6.9 \pm 2.8$ & $-15.1 \pm 3.3$ & $-11.9 \pm 2.9$ & $-20.7 \pm 3.8$ \\
\hline Bundaberg & $-4.4 \pm 4.2$ & $0.6 \pm 3.3$ & $-3.9 \pm 3.6$ & $-6.3 \pm 4.0$ \\
\hline Ft. Denison & $10.9 \pm 1.9$ & $2.2 \pm 2.4$ & $13.2 \pm 2.6$ & $17.4 \pm 2.3$ \\
\hline Townsville & $6.3 \pm 1.7$ & $-0.5 \pm 2.8$ & $-0.1 \pm 1.8$ & $2.7 \pm 1.7$ \\
\hline Legaspi & $3.2 \pm 2.9$ & $16.9 \pm 2.7$ & $-17.3 \pm 3.5$ & $-7.9 \pm 3.2$ \\
\hline Cairns & $1.7 \pm 2.3$ & $-1.9 \pm 2.6$ & $11.9 \pm 3.8$ & $-2.3 \pm 4.8$ \\
\hline Gladstone & $8.2 \pm 2.2$ & $8.7 \pm 3.4$ & $-0.9 \pm 2.6$ & $-2.1 \pm 3.1$ \\
\hline Wllmstown & $-2.3 \pm 5.2$ & $-10.1 \pm 6.6$ & $-10.2 \pm 5.2$ & $-32.0 \pm 6.7$ \\
\hline Auckland & $1.9 \pm 2.9$ & $22.4 \pm 11.6$ & $1.2 \pm 1.4$ & $60.3 \pm 11.6$ \\
\hline
\end{tabular}

a -All values are expressed as degree change in tide per meter rise in MSL $\left(\right.$ degm $\left.^{-1}\right)$. Significant values are shaded grey, based on a SNR $>2$, and an absolute magnitude of $>5$ degm $^{-1}$. 
Table 11 Amplitude and phase anomaly trends with 95\% confidence limits for the $K_{1}$ constituent, for before and after 1993, and the differences in the two rates (italics) ${ }^{a}$

\begin{tabular}{|c|c|c|c|c|c|c|}
\hline Station & & $\begin{array}{l}K_{1} \text { A-TAT } \\
\left(\mathrm{mmm}^{-1}\right)\end{array}$ & & & $\begin{array}{l}K_{1} \text { P-TAT } \\
\left(\text { degm }^{-1}\right)\end{array}$ & \\
\hline & Pre-1993 & Post-1993 & Diffs. & Pre-1993 & Post-1993 & Diffs. \\
\hline Pohnpei & $24.9 \pm 5.9$ & $20.8 \pm 5.1$ & $-4.0 \pm 7.8$ & $-13.3 \pm 2.6$ & $-16.5 \pm 2.4$ & $-3.2 \pm 3.5$ \\
\hline Majuro & $20.7 \pm 5.9$ & $3.3 \pm 14.6$ & $\begin{array}{c}-17.4 \pm \\
15.7\end{array}$ & $-15.7 \pm 3.7$ & $5.7 \pm 10.1$ & $21.4 \pm 10.8$ \\
\hline Malakal & $42.2 \pm 5.2$ & $52.8 \pm 5.6$ & $10.6 \pm 7.6$ & $8.9 \pm 2.5$ & $6.0 \pm 1.7$ & $-2.9 \pm 3.0$ \\
\hline Yap & $4.9 \pm 5.5$ & $30.8 \pm 6.1$ & $25.9 \pm 8.2$ & $14.7 \pm 2.6$ & $9.5 \pm 1.5$ & $-5.2 \pm 3.0$ \\
\hline Honiara & $-12.5 \pm 3.9$ & $-13.0 \pm 17.4$ & $-0.5 \pm 17.8$ & $-1.7 \pm 0.8$ & $-1.9 \pm 4.3$ & $-0.3 \pm 4.4$ \\
\hline Kanton & $-20.1 \pm 3.0$ & $-21.5 \pm 8.4$ & $-1.4 \pm 9.0$ & $33.7 \pm 8.2$ & $-77.0 \pm 24.1$ & $\begin{array}{c}-110.7 \pm \\
25.5 \\
\end{array}$ \\
\hline Noumea & $10.7 \pm 4.3$ & $27.6 \pm 12.0$ & $16.9 \pm 12.7$ & $6.5 \pm 2.5$ & $3.0 \pm 3.5$ & $-3.5 \pm 4.3$ \\
\hline Saipan & $\begin{array}{c}-14.0 \pm \\
11.8\end{array}$ & $-4.4 \pm 11.4$ & $9.5 \pm 16.4$ & $-2.3 \pm 4.3$ & $2.5 \pm 3.2$ & $4.8 \pm 5.4$ \\
\hline Midway & $14.3 \pm 4.6$ & $4.4 \pm 5.4$ & $-10.0 \pm 7.1$ & $0.0 \pm 3.0$ & $4.6 \pm 3.9$ & $4.6 \pm 4.9$ \\
\hline Wake & $-10.1 \pm 3.0$ & $-3.7 \pm 5.4$ & $6.4 \pm 6.2$ & $-0.3 \pm 3.0$ & $1.8 \pm 6.1$ & $2.1 \pm 6.8$ \\
\hline Johnston & $-26.9 \pm 3.7$ & $-6.5 \pm 8.8$ & $20.5 \pm 9.5$ & $-5.6 \pm 3.5$ & $-1.7 \pm 4.6$ & $4.0 \pm 5.8$ \\
\hline Guam & $-36.8 \pm 6.3$ & $-21.8 \pm 8.0$ & $15.0 \pm 10.2$ & $17.4 \pm 2.5$ & $17.7 \pm 2.3$ & $0.2 \pm 3.4$ \\
\hline Kwajalein & $-4.6 \pm 3.9$ & $1.3 \pm 4.9$ & $6.0 \pm 6.3$ & $4.6 \pm 2.7$ & $5.9 \pm 3.3$ & $1.3 \pm 4.3$ \\
\hline Pagopago & $20.8 \pm 5.1$ & $15.6 \pm 3.4$ & $-5.2 \pm 6.1$ & $4.8 \pm 3.5$ & $5.0 \pm 4.8$ & $0.3 \pm 5.9$ \\
\hline $\begin{array}{c}\text { Ft. } \\
\text { Denison }\end{array}$ & $11.5 \pm 5.4$ & $33.1 \pm 10.8$ & $21.7 \pm 12.1$ & $8.9 \pm 2.2$ & $12.5 \pm 4.7$ & $3.6 \pm 5.2$ \\
\hline Townsville & $42.9 \pm 8.5$ & $9.1 \pm 15.4$ & $\begin{array}{c}-33.7 \pm \\
17.6 \\
\end{array}$ & $9.4 \pm 2.3$ & $8.0 \pm 1.8$ & $-1.3 \pm 2.9$ \\
\hline Cairns & $\begin{array}{c}-67.9 \pm \\
32.5\end{array}$ & $45.9 \pm 12.1$ & $\begin{array}{c}113.8 \pm \\
34.7\end{array}$ & $-5.6 \pm 2.3$ & $4.6 \pm 2.0$ & $10.1 \pm 3.0$ \\
\hline Gladstone & $66.0 \pm 13.3$ & $4.2 \pm 14.1$ & $\begin{array}{c}-61.8 \pm \\
19.4\end{array}$ & $10.6 \pm 3.0$ & $5.6 \pm 2.1$ & $-5.0 \pm 3.7$ \\
\hline WImstwn & $-11.1 \pm 7.2$ & $30.0 \pm 11.3$ & $41.1 \pm 13.4$ & $-7.8 \pm 6.4$ & $3.5 \pm 6.3$ & $11.3 \pm 9.0$ \\
\hline Auckland & $-2.0 \pm 2.9$ & $47.1 \pm 9.7$ & $49.1 \pm 10.1$ & $26.7 \pm 4.7$ & $5.8 \pm 10.3$ & $\begin{array}{c}-20.9 \pm \\
11.3 \\
\end{array}$ \\
\hline
\end{tabular}

a -Tables are shaded with either a dark grey (for A-TATs), or light grey (for P-TATs) to show locations where there is a significant difference in the TATs between the two time periods, "significant" here is defined as more than $\pm 10 \mathrm{mmm}^{-1}$ or $\pm 10 \mathrm{degm}^{-1}$ (beyond combined error bands), as well as a signal-to-noise ratio greater than $2(S N R>2)$. 
Table 12 Amplitude and phase anomaly trends with 95\% confidence limits for the $\mathrm{O}_{1}$ constituent, for before and after 1993, and differences in the two rates (in italics) ${ }^{a}$

\begin{tabular}{|c|c|c|c|c|c|c|}
\hline Station & & $\begin{array}{l}O_{1} \text { A-TAT } \\
\left(\mathrm{mmm}^{-1}\right)\end{array}$ & & & $\begin{array}{l}\text { O }_{1} \text { P-TAT } \\
\left(\text { degm }^{-1}\right)\end{array}$ & \\
\hline & Pre-1993 & Post-1993 & Diffs. & Pre-1993 & Post-1993 & Diffs. \\
\hline Pohnpei & $2.4 \pm 3.3$ & $-3.1 \pm 3.3$ & $-5.5 \pm 4.7$ & $8.0 \pm 3.6$ & $8.6 \pm 1.7$ & $0.6 \pm 4.0$ \\
\hline Majuro & $-22.2 \pm 3.6$ & $-3.6 \pm 10.4$ & $18.6 \pm 11.0$ & $11.6 \pm 4.1$ & $-5.9 \pm 9.1$ & $\begin{array}{c}-17.5 \pm \\
10.0\end{array}$ \\
\hline Malakal & $12.8 \pm 4.8$ & $-1.7 \pm 5.4$ & $-14.5 \pm 7.2$ & $-25.1 \pm 1.6$ & $-34.4 \pm 2.3$ & $-9.3 \pm 2.8$ \\
\hline Yap & $-4.1 \pm 7.8$ & $13.4 \pm 9.4$ & $17.5 \pm 12.2$ & $60.8 \pm 4.4$ & $51.4 \pm 3.2$ & $-9.4 \pm 5.4$ \\
\hline Honiara & $-24.2 \pm 2.8$ & $-25.4 \pm 14.8$ & $-1.2 \pm 15.1$ & $2.0 \pm 14.6$ & $-4.3 \pm 4.6$ & $6.3 \pm 15.3$ \\
\hline Kanton & $-10.6 \pm 2.4$ & $12.7 \pm 15.4$ & $23.3 \pm 15.6$ & $-12.9 \pm 7.9$ & $\begin{array}{c}149.8 \pm \\
26.8\end{array}$ & $\begin{array}{c}162.7 \pm \\
27.9\end{array}$ \\
\hline Noumea & $-2.7 \pm 3.5$ & $-6.3 \pm 7.9$ & $-3.7 \pm 8.6$ & $-10.3 \pm 4.0$ & $0.7 \pm 19.8$ & $11.0 \pm 20.2$ \\
\hline Saipan & $18.8 \pm 4.0$ & $2.9 \pm 4.6$ & $-15.9 \pm 6.1$ & $-6.3 \pm 4.4$ & $-17.5 \pm 3.9$ & $-11.3 \pm 5.9$ \\
\hline Midway & $-3.5 \pm 3.5$ & $-9.0 \pm 4.3$ & $-5.5 \pm 5.5$ & $-1.3 \pm 2.9$ & $1.9 \pm 5.2$ & $3.2 \pm 5.9$ \\
\hline Wake & $5.9 \pm 3.2$ & $4.4 \pm 4.7$ & $-1.5 \pm 5.7$ & $13.3 \pm 3.9$ & $3.2 \pm 5.9$ & $-10.1 \pm 7.1$ \\
\hline Johnston & $-0.3 \pm 2.4$ & $10.1 \pm 5.0$ & $10.5 \pm 5.5$ & $4.8 \pm 3.9$ & $6.6 \pm 6.5$ & $1.8 \pm 7.6$ \\
\hline Guam & $-39.6 \pm 3.9$ & $-14.6 \pm 5.8$ & $24.9 \pm 7.0$ & $-3.3 \pm 2.4$ & $-7.4 \pm 3.1$ & $-4.1 \pm 3.9$ \\
\hline Kwajalein & $13.0 \pm 2.4$ & $3.0 \pm 5.3$ & $-10.0 \pm 5.8$ & $-0.6 \pm 2.5$ & $-3.1 \pm 3.3$ & $-2.5 \pm 4.1$ \\
\hline Pagopago & $7.8 \pm 2.5$ & $-3.1 \pm 1.9$ & $-11.0 \pm 3.1$ & $24.1 \pm 4.8$ & $23.8 \pm 6.2$ & $-0.3 \pm 7.8$ \\
\hline $\begin{array}{c}\text { Ft. } \\
\text { Denison }\end{array}$ & $2.7 \pm 4.5$ & $37.7 \pm 9.2$ & $35.0 \pm 10.2$ & $0.6 \pm 2.7$ & $2.6 \pm 6.5$ & $2.0 \pm 7.0$ \\
\hline Townsville & $27.7 \pm 9.8$ & $-8.9 \pm 9.3$ & $\begin{array}{c}-36.6 \pm \\
13.5\end{array}$ & $8.2 \pm 4.6$ & $-9.6 \pm 2.6$ & $-17.8 \pm 5.3$ \\
\hline Cairns & $4.2 \pm 14.3$ & $29.8 \pm 9.1$ & $25.6 \pm 16.9$ & $-2.5 \pm 4.4$ & $-2.4 \pm 3.0$ & $0.1 \pm 5.3$ \\
\hline Gladstone & $7.3 \pm 11.9$ & $11.0 \pm 12.8$ & $3.6 \pm 17.5$ & $16.1 \pm 4.4$ & $-1.0 \pm 5.6$ & $-17.1 \pm 7.1$ \\
\hline WImstwn & $-10.4 \pm 6.5$ & $31.7 \pm 13.1$ & $42.1 \pm 14.6$ & $-15.1 \pm 7.2$ & $-3.5 \pm 11.2$ & $11.6 \pm 13.7$ \\
\hline Auckland & $-0.5 \pm 2.6$ & $6.3 \pm 4.5$ & $6.8 \pm 5.2$ & $0.3+12.0$ & $8.0 \pm 15.3$ & $7.7 \pm 19.4$ \\
\hline
\end{tabular}

a -Tables are shaded with either a dark grey (for A-TATs), or light grey (for P-TATs) to show locations where there is a significant difference in the TATs between the two time periods, "significant" here is defined as more than $\pm 10 \mathrm{mmm}^{-1}$ or $\pm 10 \mathrm{degm}^{-1}$ (beyond combined error bands), as well as a signal-to-noise ratio greater than $2(S N R>2)$. 
Table 13 Amplitude and phase anomaly trends with 95\% confidence limits for the $M_{2}$ constituent, for before and after 1993, and differences in the two rates (in italics) ${ }^{a}$

\begin{tabular}{|c|c|c|c|c|c|c|}
\hline Station & & $\begin{array}{l}\mathrm{M}_{2} \text { A-TAT } \\
\left(\mathrm{mmm}^{-1}\right)\end{array}$ & & & $\begin{array}{l}\mathrm{M}_{2} \text { P-TAT } \\
\left(\text { degm }^{-1}\right)\end{array}$ & \\
\hline & Pre-1993 & Post-1993 & Diffs. & Pre-1993 & Post-1993 & Diffs. \\
\hline Pohnpei & $-10.1 \pm 21.6$ & $5.5 \pm 14.0$ & $15.6 \pm 25.7$ & $22.6 \pm 7.4$ & $8.0 \pm 2.4$ & $-14.6 \pm 7.8$ \\
\hline Majuro & $-29.4 \pm 35.3$ & $5.0 \pm 31.6$ & $34.4 \pm 47.4$ & $4.8 \pm 4.4$ & $6.2 \pm 2.8$ & $1.4 \pm 5.2$ \\
\hline Malakal & $-27.9 \pm 13.4$ & $-27.4 \pm 7.4$ & $0.5 \pm 15.3$ & $0.7 \pm 2.5$ & $-3.8 \pm 1.4$ & $-4.5 \pm 2.9$ \\
\hline Yap & $-28.0 \pm 16.1$ & $-46.4 \pm 7.9$ & $-18.4 \pm 18.0$ & $21.5 \pm 2.9$ & $12.3 \pm 2.0$ & $-9.2 \pm 3.5$ \\
\hline Honiara & $62.8 \pm 5.0$ & $65.6 \pm 5.1$ & $2.8 \pm 7.1$ & $39.0 \pm 4.3$ & $26.8 \pm 4.5$ & $-12.2 \pm 6.2$ \\
\hline Kanton & $55.6 \pm 18.5$ & $58.1 \pm 39.4$ & $2.5 \pm 43.5$ & $6.0 \pm 2.8$ & $-33.3 \pm 4.2$ & $-39.3 \pm 5.0$ \\
\hline Noumea & $63.0 \pm 22.8$ & $-10.3 \pm 46.4$ & $-73.2 \pm 51.7$ & $-5.2 \pm 3.3$ & $8.7 \pm 4.6$ & $13.9 \pm 5.7$ \\
\hline Saipan & $5.9 \pm 13.2$ & $28.2 \pm 13.7$ & $22.3 \pm 19.0$ & $20.3 \pm 4.6$ & $-7.4 \pm 6.9$ & $-27.7 \pm .8 .3$ \\
\hline Midway & $11.8 \pm 8.6$ & $8.2 \pm 8.5$ & $-3.6 \pm 12.1$ & $-7.1 \pm 5.3$ & $-6.7 \pm 2.5$ & $0.3 \pm 5.9$ \\
\hline Wake & $-66.5 \pm 12.0$ & $24.7 \pm 22.7$ & $91.2 \pm 25.7$ & $17.5 \pm 2.5$ & $14.1 \pm 4.6$ & $-3.3 \pm 5.2$ \\
\hline Johnston & $-32.4 \pm 8.8$ & $-33.3 \pm 13.0$ & $-0.9 \pm 15.7$ & $15.8 \pm 4.5$ & $0.2 \pm 4.8$ & $-15.6 \pm 6.6$ \\
\hline Guam & $-34.8 \pm 8.7$ & $-5.8 \pm 10.5$ & $29.0 \pm 13.6$ & $5.9 \pm 2.0$ & $-7.1 \pm 2.4$ & $-13.0 \pm 3.1$ \\
\hline Kwajalein & $1.3 \pm 10.5$ & $6.9 \pm 11.7$ & $5.6 \pm 15.7$ & $-2.7 \pm 1.1$ & $1.7 \pm 1.2$ & $4.4 \pm 1.6$ \\
\hline Pagopago & $105.6 \pm 11.0$ & $32.3 \pm 13.1$ & $-73.4 \pm 17.1$ & $20.7 \pm 2.5$ & $13.9 \pm 1.9$ & $-6.9 \pm 3.1$ \\
\hline $\begin{array}{c}\text { Ft. } \\
\text { Denison }\end{array}$ & $-64.9 \pm 13.6$ & $-13.9 \pm 12.7$ & $51.0 \pm 18.6$ & $12.0 \pm 3.1$ & $2.5 \pm 3.3$ & $-9.5 \pm 4.5$ \\
\hline Townsville & $-78.2 \pm 30.3$ & $22.4 \pm 24.6$ & $100.5 \pm 39.0$ & $1.0 \pm 3.7$ & $-3.4 \pm 1.5$ & $-4.4 \pm 4.0$ \\
\hline Cairns & $\begin{array}{c}-169.1 \pm \\
52.4\end{array}$ & $131.4 \pm 20.8$ & $300.5 \pm 56.4$ & $-10.3 \pm 8.5$ & $15.5 \pm 3.4$ & $25.8 \pm 9.2$ \\
\hline Gladstone & $-19.8 \pm 18.2$ & $-153.7 \pm 55.4$ & $\begin{array}{c}-133.9 \pm \\
58.3\end{array}$ & $8.6 \pm 3.9$ & $0.9 \pm 1.9$ & $-7.7 \pm 4.3$ \\
\hline Wlmstwn & $-2.9 \pm 6.2$ & $41.2 \pm 13.3$ & $44.1 \pm 14.7$ & $-16.1 \pm 8.9$ & $-2.9 \pm 3.2$ & $13.2 \pm 9.5$ \\
\hline Auckland & $-27.0 \pm 19.4$ & $-185.5 \pm 39.5$ & $\begin{array}{c}-158.5 \pm \\
44.0\end{array}$ & $39.6 \pm 7.3$ & $6.4 \pm 2.7$ & $-33.2 \pm 7.8$ \\
\hline
\end{tabular}

a -Tables are shaded with either a dark grey (for A-TATs), or light grey (for P-TATs) to show locations where there is a significant difference in the TATs between the two time periods, "significant" here is defined as more than $\pm 10 \mathrm{mmm}^{-1}$ or $\pm 10 \mathrm{degm}^{-1}$ (beyond combined error bands), as well as a signal-to-noise ratio greater than $2(S N R>2)$. 
Table 14 Amplitude and phase anomaly trends with 95\% confidence limits for the $S_{2}$ constituent, for before and after 1993, and differences in the two rates (in italics) ${ }^{a}$

\begin{tabular}{|c|c|c|c|c|c|c|}
\hline Station & & $\begin{array}{c}\text { S2 A-TAT } \\
\left(\mathbf{m m m}^{-1}\right)\end{array}$ & & & $\begin{array}{c}\text { S2 P-TAT } \\
\left(\text { degm }^{-1}\right)\end{array}$ & \\
\hline & Pre-1993 & Post-1993 & Diffs. & Pre-1993 & Post-1993 & Diffs. \\
\hline Pohnpei & $-2.3 \pm 4.0$ & $-3.1 \pm 4.1$ & $-0.8 \pm 5.7$ & $-5.0 \pm 5.9$ & $-18.1 \pm 2.9$ & $-13.1 \pm 6.6$ \\
\hline Majuro & $-3.6 \pm 9.3$ & $5.2 \pm 4.7$ & $8.8 \pm 10.2$ & $6.1 \pm 3.9$ & $1.3 \pm 2.4$ & $-4.8 \pm 4.6$ \\
\hline Malakal & $-3.8 \pm 3.0$ & $0.0 \pm 1.3$ & $3.7 \pm 3.3$ & $-0.2 \pm 2.3$ & $-6.3 \pm 1.6$ & $-6.1 \pm 2.8$ \\
\hline Yap & $-5.2 \pm 2.6$ & $-12.8 \pm 1.7$ & $-7.7 \pm 3.1$ & $29.5 \pm 3.6$ & $17.8 \pm 1.8$ & $-11.7 \pm 4.0$ \\
\hline Honiara & $16.3 \pm 1.2$ & $16.4 \pm 1.1$ & $0.1 \pm 1.6$ & $-21.5 \pm 1.9$ & $-16.8 \pm 2.1$ & $4.7 \pm 2.8$ \\
\hline Kanton & $-0.1 \pm 2.9$ & $12.8 \pm 1.9$ & $12.9 \pm 3.5$ & $7.6 \pm 2.8$ & $-1.8 \pm 3.4$ & $-9.5 \pm 4.4$ \\
\hline Noumea & $8.9 \pm 4.4$ & $6.2 \pm 6.7$ & $-2.7 \pm 8.0$ & $0.8 \pm 5.0$ & $-3.5 \pm 4.2$ & $-4.3 \pm 6.5$ \\
\hline Saipan & $-10.4 \pm 3.6$ & $-3.5 \pm 3.6$ & $6.9 \pm 5.1$ & $-24.3 \pm 12.5$ & $-13.3 \pm 11.0$ & $10.9 \pm 16.6$ \\
\hline Midway & $1.9 \pm 1.5$ & $0.5 \pm 1.9$ & $-1.4 \pm 2.4$ & $-30.3 \pm 10.4$ & $-65.1 \pm 12.2$ & $-34.8 \pm 16.0$ \\
\hline Wake & $-5.1 \pm 2.2$ & $-0.2 \pm 4.6$ & $4.9 \pm 5.1$ & $5.3 \pm 2.5$ & $2.1 \pm 4.6$ & $-3.1 \pm 5.2$ \\
\hline Johnston & $-21.8 \pm 2.6$ & $-13.0 \pm 5.1$ & $8.9 \pm 5.7$ & $-3.9 \pm 4.6$ & $3.3 \pm 6.6$ & $7.2 \pm 8.0$ \\
\hline Guam & $-1.4 \pm 1.5$ & $3.2 \pm 1.4$ & $4.6 \pm 2.1$ & $15.9 \pm 4.4$ & $22.1 \pm 4.6$ & $6.2 \pm 6.4$ \\
\hline Kwajalein & $8.6 \pm 3.3$ & $2.8 \pm 3.1$ & $-5.8 \pm 4.5$ & $-0.4 \pm 1.4$ & $-3.1 \pm 1.6$ & $-2.7 \pm 2.1$ \\
\hline Pagopago & $-6.3 \pm 1.6$ & $-10.8 \pm 1.9$ & $-4.5 \pm 2.5$ & $-5.4 \pm 4.8$ & $-1.6 \pm 4.1$ & $3.8 \pm 6.3$ \\
\hline $\begin{array}{c}\text { Ft. } \\
\text { Denison }\end{array}$ & $-2.9 \pm 2.1$ & $1.4 \pm 3.4$ & $4.3 \pm 4.0$ & $17.2 \pm 2.7$ & $2.8 \pm 3.5$ & $-14.5 \pm 4.4$ \\
\hline Townsville & $-20.6 \pm 8.8$ & $4.3 \pm 4.3$ & $24.8 \pm 9.8$ & $1.4 \pm 2.9$ & $3.4 \pm 2.1$ & $1.9 \pm 3.6$ \\
\hline Cairns & $4.9 \pm 8.4$ & $-0.8 \pm 5.1$ & $-5.7 \pm 9.8$ & $-27.8 \pm 5.8$ & $7.8 \pm 3.2$ & $35.6 \pm 6.6$ \\
\hline Gladstone & $-30.7 \pm 7.7$ & $-34.2 \pm 11.1$ & $-3.5 \pm 13.5$ & $8.8 \pm 4.4$ & $-5.2 \pm 3.1$ & $-14.1 \pm 5.4$ \\
\hline WImstwn & $6.3 \pm 2.1$ & $13.4 \pm 4.2$ & $7.1 \pm 4.7$ & $-30.7 \pm 9.1$ & $-29.5 \pm 7.2$ & $1.2 \pm 11.6$ \\
\hline Auckland & $-0.6 \pm 2.9$ & $1.5 \pm 2.3$ & $2.0 \pm 3.7$ & $43.2 \pm 7.3$ & $7.8 \pm 2.7$ & $-35.4 \pm 7.8$ \\
\hline
\end{tabular}

a -Tables are shaded with either a dark grey (for A-TATs), or light grey (for P-TATs) to show locations where there is a significant difference in the TATs between the two time periods, "significant" here is defined as more than $\pm 10 \mathrm{mmm}^{-1}$ or $\pm 10 \mathrm{degm}^{-1}$ (beyond combined error bands), as well as a signal-to-noise ratio greater than $2(S N R>2)$. 
Table 15 Phase variances and phase sum variances (of the IMF 4-10 combination) for Honiara and Rabaul. For Honiara, we calculate the variances for the entire time record as well as splitting the record about the year $1993^{\mathrm{a}}$.

\begin{tabular}{|c|c|c|c|c|c|}
\hline Honiara & $\begin{array}{l}\text { K1 phase } \\
\text { variance }\end{array}$ & $\begin{array}{l}\mathrm{O}_{1} \text { phase } \\
\text { variance }\end{array}$ & $\begin{array}{l}\mathbf{M}_{2} \text { phase } \\
\text { variance }\end{array}$ & $\begin{array}{c}\text { Sum of } \\
\text { variances }\end{array}$ & $\Phi(\tau)$ variance \\
\hline (1974-2012) & 0.49 & 0.62 & 0.71 & 1.06 & 0.42 \\
\hline (1974-1993) & 0.11 & 0.12 & 0.89 & 0.91 & 0.48 \\
\hline (1993-2012) & 0.47 & 0.54 & 0.51 & 0.88 & 0.31 \\
\hline \multicolumn{6}{|l|}{$\underline{\text { Rabaul }}$} \\
\hline (1966-1997) & 0.15 & 0.20 & 1.56 & 1.58 & 0.68 \\
\hline
\end{tabular}

a- All variances are expressed as a percentage of a full cycle, with $\Phi$ being relative to $K_{1}$. Values shaded grey in the last column indicate that the variance is less in the combined quantity than in the sum of the individual quantities.

Table 16 Slopes $(m / k)$ of the dispersion relations of $M_{2}, K_{1}$, and $\mathrm{O}_{1}$ at for Honiara for typical values of non-dimensional $N$.

\begin{tabular}{|c|c|c|c|}
\hline$N / \omega_{m 2}$ & $\begin{array}{l}(m / k) \\
\text { for } M_{2}\end{array}$ & $\begin{array}{l}(m / \kappa) \\
\text { for } K_{1}\end{array}$ & $\begin{array}{l}(\mathrm{m} / \mathrm{k}) \\
\text { for } \mathrm{O}_{1}\end{array}$ \\
\hline 10 & 10.0 & 20.2 & 22.1 \\
\hline 23 & 27.6 & 45.5 & 49.8 \\
\hline 32 & 32.1 & 64.0 & 70.1 \\
\hline 71 & 71.8 & 143.8 & 157.5 \\
\hline 100 & 101.4 & 203.6 & 222.9 \\
\hline
\end{tabular}


Table 17 PSI triad wavenumber estimates for three assumed depths ${ }^{\mathrm{a}}$.

\begin{tabular}{|c|c|c|c|c|}
\hline Depth, $(\mathrm{m})$ & $(k, m)$ for $M_{2}$ & $(k, m)$ for $K_{1}$ & $(k, m)$ for $O_{1}$ & $\Delta \mathbf{k}$ \\
\hline 500 & $\left(2.0 \times 10^{-6} \mathrm{~m}^{-1}, \sim 0\right)$ & $\left(-2.7 \times 10^{-5} \mathrm{~m}^{-1}, \pm 1\right)$ & $\left(+2.5 \times 10^{-5} \mathrm{~m}^{-1}, \pm 1\right)$ & $\sim 0$ \\
5000 & $\left(0.7 \times 10^{-6} \mathrm{~m}^{-1}, \sim 0\right)$ & $\left(-2.7 \times 10^{-5} \mathrm{~m}^{-1}, \pm 1\right)$ & $\left(+2.5 \times 10^{-5} \mathrm{~m}^{-1}, \pm 1\right)$ & $1.3 \times 10^{-6} \mathrm{~m}^{-1}$ \\
& & & & \\
100 & $\left(4.0 \times 10^{-6} \mathrm{~m}^{-1}, \sim 0\right)$ & $\left(-2.7 \times 10^{-5} \mathrm{~m}^{-1}, \pm 1\right)$ & $\left(+2.5 \times 10^{-5} \mathrm{~m}^{-1}, \pm 1\right)$ & $2.0 \times 10^{-6} \mathrm{~m}^{-1}$ \\
& & & & \\
\hline
\end{tabular}

a - Calculations of wavenumbers for the case of a barotropic $M_{2}$, and a first mode baroclinic $K_{1}$, and $\mathrm{O}_{1}$ at Honiara, Solomon Islands. Three cases are shown for three depths typical of the region; the mean depth of $500 \mathrm{~m}$ gives an exact triad $(\Delta \mathrm{k})$. For much deeper $(5000 \mathrm{~m})$ and much shallower $(100 \mathrm{~m})$ water, a nearresonant triad is possible. Horizontal wavenumbers ( $k^{\prime} s$, and $\Delta k$ ) are dimensional (meters) and mode numbers are non-dimensional.

Table 18 Baroclinic triad wavenumber estimates.

\begin{tabular}{|c|c|c|c|}
\hline$(k, m)$ for $M_{2}$ & $(k, m)$ for $K_{1}$ & $(k, m)$ for $O_{1}$ & $\Delta \mathbf{k}$ \\
& & & \\
$\left( \pm 1.1 \times 10^{-4} \mathrm{~m}^{-1}, \pm 2\right)$ & $\left( \pm 8.4 \times 10^{-5} \mathrm{~m}^{-1}, \pm 3\right)$ & $\left( \pm 2.5 \times 10^{-5} \mathrm{~m}^{-1}, \pm 1\right)$ & $1.0 \times 10^{-6} \mathrm{~m}^{-1}$ \\
& & & \\
$\left( \pm 1.1 \times 10^{-4} \mathrm{~m}^{-1}, \pm 2\right)$ & $\left( \pm 2.7 \times 10^{-5} \mathrm{~m}^{-1}, \pm 1\right)$ & $\left( \pm 7.8 \times 10^{-5} \mathrm{~m}^{-1}, \pm 3\right)$ & $5.0 \times 10^{-6} \mathrm{~m}^{-1}$ \\
& & &
\end{tabular}

a - As in Table 17, this time for the 3-2-1 triad of Lamb (2007) (with a mode $2 \mathrm{M}_{2}$ wave), at Honiara, Solomon Islands. The first of the two estimates assumes that $\mathrm{K}_{1}$ is mode 3 and $\mathrm{O}_{1}$ is mode 1 ; the second assumes that $\mathrm{K}_{1}$ is mode 1 and $\mathrm{O}_{1}$ is mode 3 . 


\title{
Chapter 5: (PART III) Seasonality of Tides in Southeast Asian Waters: Observed vs. Modeled
}

\begin{abstract}
Tidal amplitudes and phases exhibit strong oscillations (annual and semi-annual) in the waters of four sub-regions in Southeast Asia: the Malacca Strait, the Gulf of Thailand, the Java Sea, and the South China Sea. Results of monthly harmonic analyses at twenty tide gauges in Malaysia, Thailand, Indonesia, Singapore, and Vietnam reveal that the major diurnal $\left(K_{1}\right.$, and $\left.\mathrm{O}_{1}\right)$ and semidiurnal $\left(\mathrm{M}_{2}\right.$, and $\left.\mathrm{S}_{2}\right)$ ocean tides demonstrate strong seasonal behavior, seen in both amplitude (up to $100 \mathrm{~mm}$ ) and phase (up to 40 degrees). Tidal properties are also coherent at the annual band with the Western North Pacific Monsoon Index (WNPMI), indicating that mechanisms associated with the monsoons are the likely cause of the tidal variability. The tidal responses are different in each of the sub-regions, and the behavior of the diurnal and semidiurnal tides is distinct at most stations. Three hypotheses are tested in this work: First, that the observed seasonal tidal variability is due to changes in stratification, which may affect bottom drag; second, that seasonal changes in non-tidal velocity (i.e., geostrophic and Ekman velocities) induced by the persistent monsoonal winds change the damping of tides by altering friction; and third, that changes in tides are due to changes in mean sea level (MSL). A barotropic, depth-averaged tide model is employed to investigate observed patterns of tidal variability due to seasonal variations in: mean sea level (MSL), stratification-related drag coefficient, $\left(C_{d}\right)$, and geostrophic and Ekman
\end{abstract}


velocities $\left(u_{g}\right.$ and $\left.u_{E}\right)$. Results show that the semidiurnal constituents are better modeled than diurnal constituents, and the best semidiurnal model response occurs in the southern Gulf of Thailand and Singapore. Tidal variability is best (though still incompletely) explained at the most gauges by the combined models of geostrophic and Ekman velocities, though the addition of the drag coefficient model to the two velocity models at a few stations yields highly accurate reconstructions of tidal variability. 


\subsection{Introduction}

Tidal properties exhibit variability on multiple time scales, due to changes in physical properties of the ocean and the atmosphere that are not attributed to astronomical variations. Previous work, presented in Part II, and in Devlin et al. (2014), examined yearly and decadal variability, whereas this chapter focuses on the factors affecting the seasonal variability of tides. The methodology in Devlin et al., (2014) assumed that the changes in tides were related, directly or indirectly, to the variations in mean sea level (MSL). In this work, forcing mechanisms will be examined in more detail to explain the observed tidal seasonality in Southeast Asia, and will be explored by use of a barotropic tide model.

\subsubsection{Hypothesis and Approach}

We hypothesize that the observed tidal seasonality is due to:

H1) Seasonal changes in stratification due to the buoyancy input from monsoon rainfall and river discharge, which may cause changes in effective turbulent dissipation and damping of the tides.

H2) Seasonal changes in non-tidal velocities (geostrophic currents and Ekman transport), induced by the persistent monsoonal winds, which may alter bed friction.

H3) Seasonal changes in MSL. 
The contribution of these mechanisms to the observed tidal dynamics is examined via a barotropic finite-difference ocean tide model (OTIS). The model is modified to test for the effects of changing water depth, geostrophic velocity, bottom drag due to stratification, and Ekman velocity. Because the modifications are semianalytical, the individual effects of changing these physical mechanisms can be tested. However, the model alterations can only indirectly examine baroclinic mechanisms, and some important processes (such as the effects of internal waves) are beyond the scope of this work. Similarly, the spatial resolution of the model is inadequate for resolving smaller scale processes such as river-tide interaction in harbors, where many tide gauges are located (see Moftakhari et al., 2013, 2016). However, the effect of the discharge of the Mekong River in Vietnam will be qualitatively compared to tidal variability.

The drag coefficient is calculated in the barotropic model, according to the basic relation between friction velocity, $u^{*}$, and the vertical average of the horizontal velocity profile, $\bar{u}$ :

$$
C_{d}=\frac{u^{*^{2}}}{\bar{u}^{2}}
$$

The vertical profile of $u$ is determined through a recursive "modified law of the wall" (Perlin et al, 2005) analysis, using the stratification-related Ozmidov length scale as the natural mixing length (Ozmidov, 1965). 
Analysis of seasonal changes in geostrophic velocities assumes a steady, geostrophic balance, such that the pressure gradient $\left(P_{x}, P_{y}\right)$ balances with the Coriolis parameter, $f$ :

$$
\begin{aligned}
& f v=\frac{P_{x}}{\rho} \\
& f u=-\frac{P_{y}}{\rho}
\end{aligned}
$$

where $\rho$ is the reference density of the ocean. Finally, the assumption of an Ekman velocity (or ageostrophic velocity) related mechanism relies on the balance between ocean surface currents and surface wind stress (Ekman, 1905):

$$
\begin{aligned}
& -f v_{E}=\frac{\tau_{x}}{H \rho} ; \\
& f u_{E}=\frac{\tau_{y}}{H \rho}
\end{aligned}
$$

The Ekman balance of (28) assumes that winds are blowing steadily, for a few days at least. Monsoon winds exhibit relatively steady winds that persist for months, so this assumption should be valid for the study domain.

\subsubsection{Geography of study domain}

In terms of land geography, the study area is part of Southeast Asia (Figure 54). This part of the Pacific Ocean is denoted the "Southeast Asian waters," meaning all the 
partly enclosed seas between the greater Pacific and Indian Oceans. The countries included in this region are: Indonesia, consisting of Java, Sumatra, southern Borneo, and other minor islands; Malaysia, whose territories are found partly on the island of Borneo and partly on the Malay Peninsula; Singapore, Thailand, Brunei, Vietnam, Cambodia, China, Australia, and the Philippines. This system of seas and connecting sills, one of the most complex of any on Earth, also constitutes the main equatorial connection between the Pacific and Indian Ocean, known as the Indonesian Throughflow (Hirst and Godfrey, 1993). In the present study, the focus will be narrowed to the dynamics of sub-regions of SE Asian waters that might affect the observed tidal variability at the gauges analyzed, namely, the Malacca Strait (MS), the Gulf of Thailand (GOT), the Java Sea (JS) and the South China Sea (SCS).

\subsubsection{Tidal variability in Southeast Asia}

Twenty gauges of Southeast Asia will be used to explore the relations of the seasonal variability of tides to the seasonal variability in ocean currents, MSL, and stratification introduced by the monsoon forcing. The majority of the gauges used are in Malaysia (MLY); both on the Malay Peninsula, and on the island of Borneo; with two additional gauges in Thailand (THL); one gauge in Vietnam (VTM) near the Mekong River delta; one at Tanjong Pagar in Singapore (SNG), and two in Indonesia (IND) on the island of Java. 


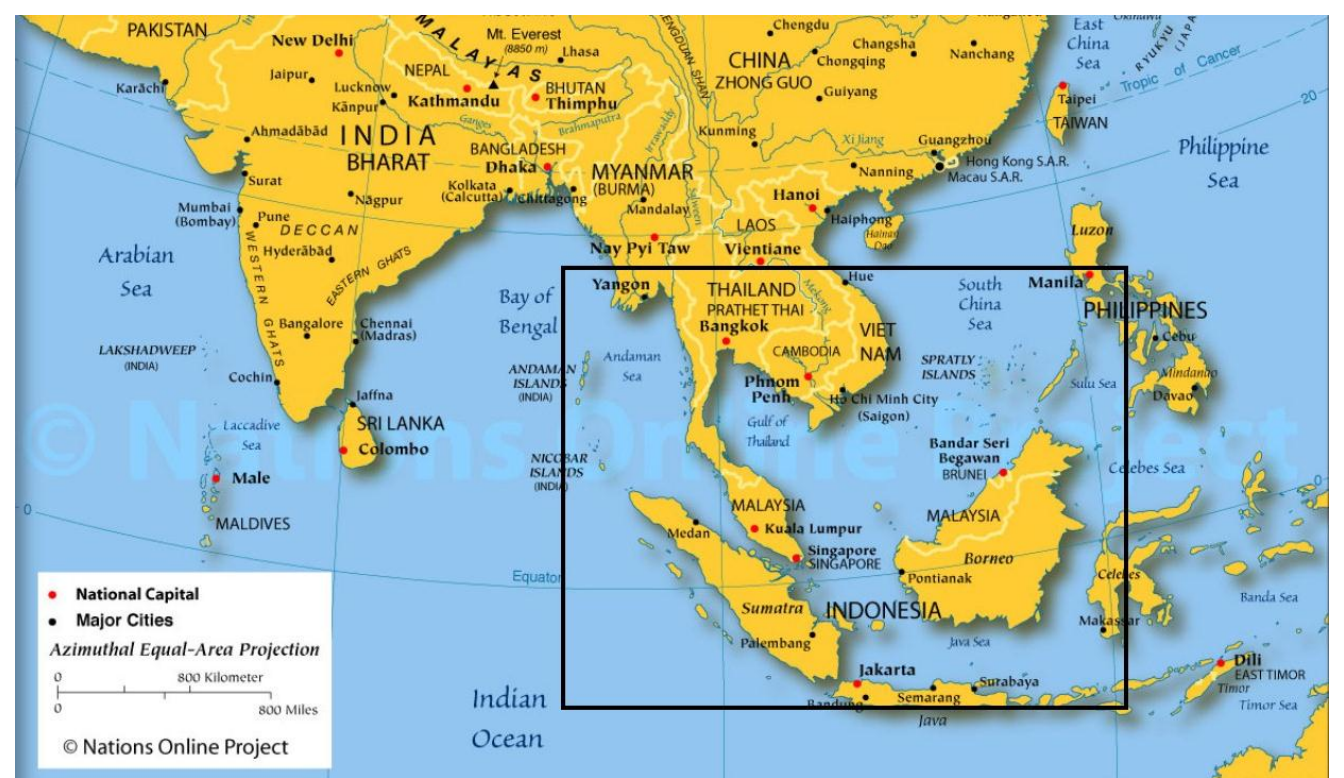

Figure 54 Map of Southeast Asia. Model domain considered in study is in the black outline.

The model region is shown with bathymetry in Figures 55a and Figure 55b. Note the different depth scales of the two figures. The gauges used (Table 19) all have a length of record (LOR) of about 30 years, from about 1984-2014. Exceptions are: the two gauges in Indonesia, which cover from 1984-2004; Vung Tau, Vietnam, which covers from 1986-2002 and 2007-2012; and the three Malaysian gauges located in Borneo, with data from 1992 to 2014. Within this region, we will demarcate four sub-regions with different tidal property responses. The first sub-region of eight gauges includes all locations laying on the Malacca Strait on the west side of the Malay Peninsula, including the very tip where Singapore is located. The second sub-region of six gauges covers the east side of the Malay Peninsula and the western coast of the Gulf of Thailand. The 
third sub-region is the western part of the South China Sea, which has four gauges located in Vietnam and Borneo, and the fourth sub-region is the Java Sea, in which there are two gauges.

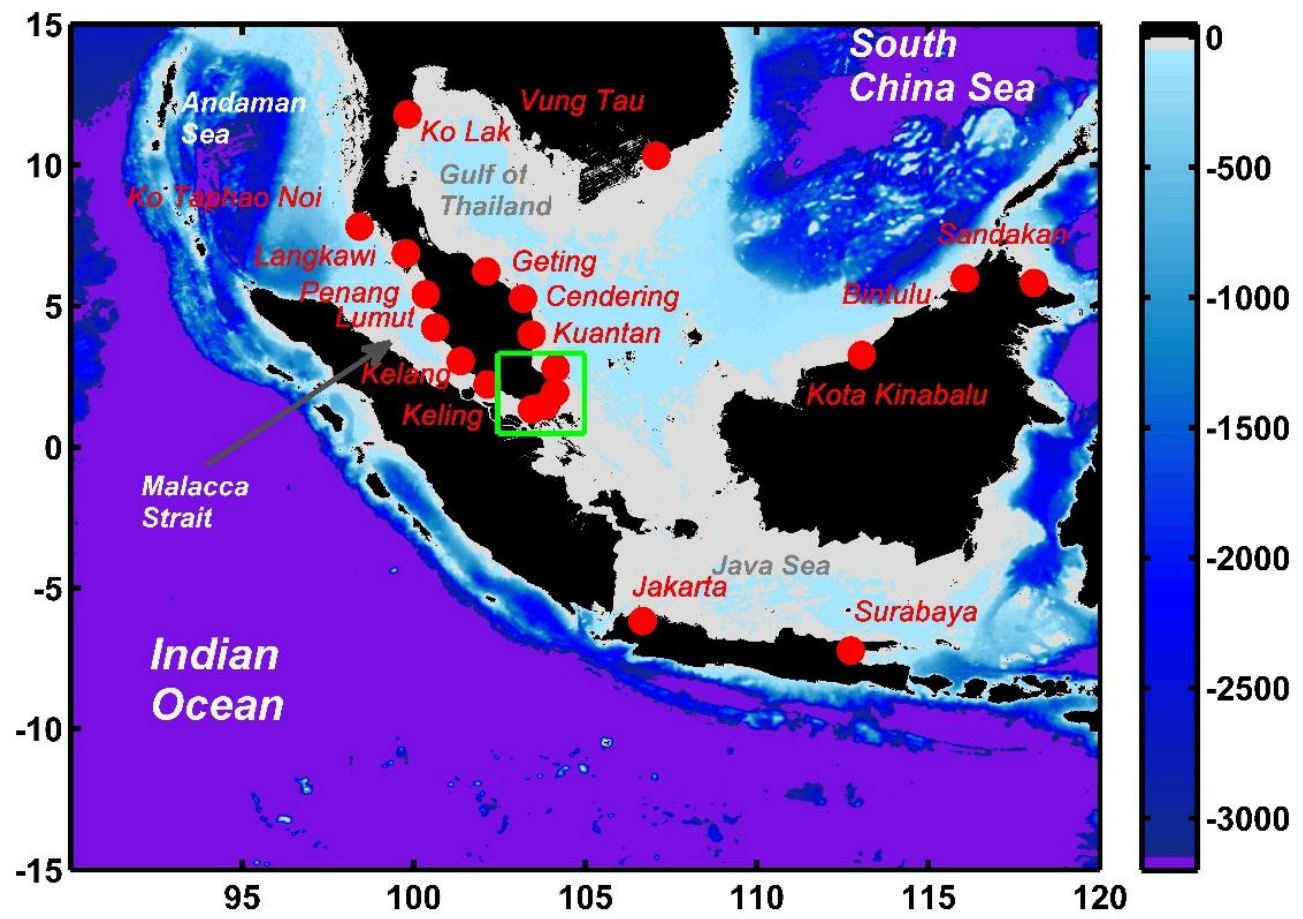

Figure 55a Bathymetric map of Southeast Asia model domain, showing major ocean basins and tide gauge locations. Units of depth are in meters. The region in the green square is expanded in Figure 55b. 


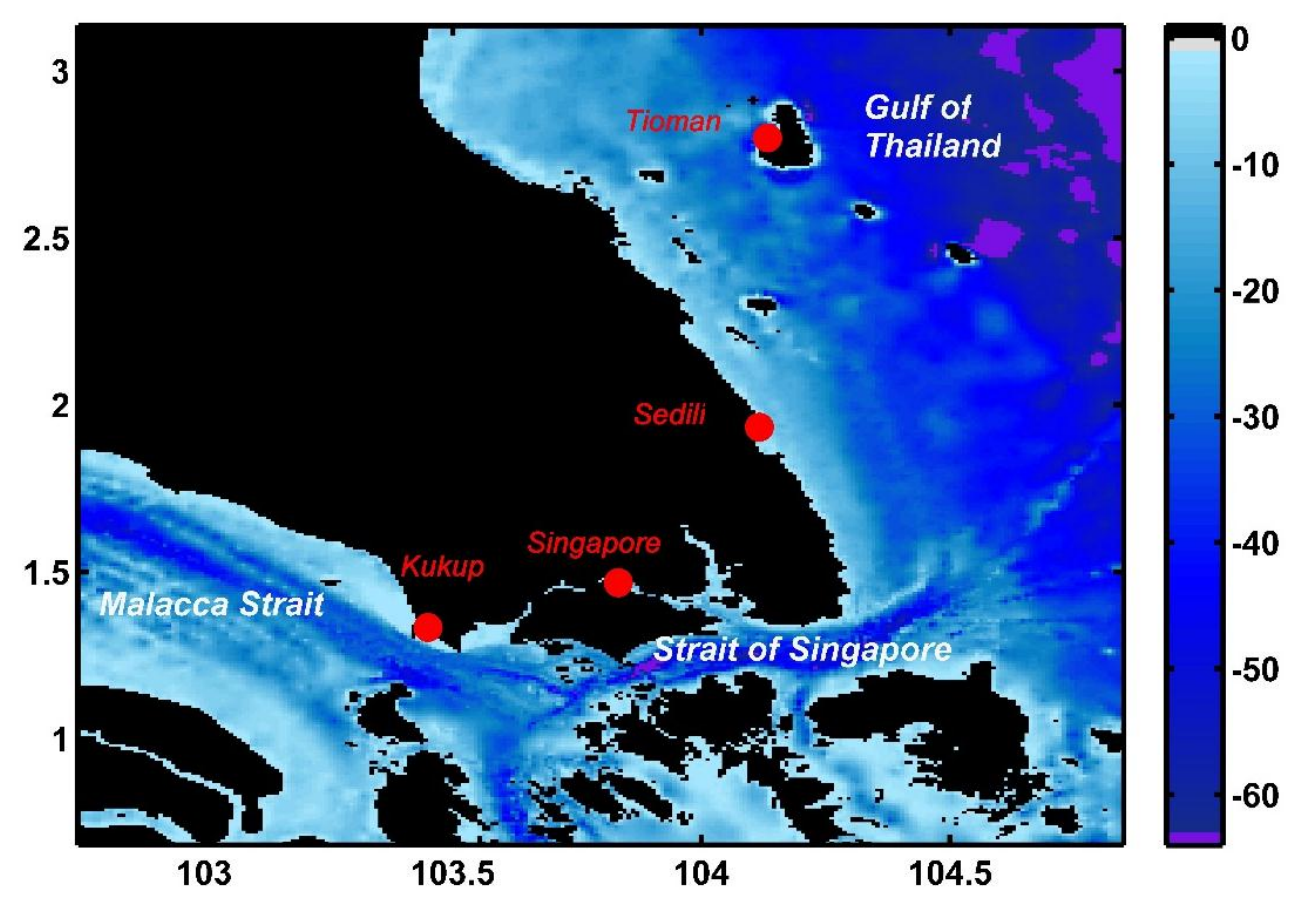

Figure 55b Close-up map of region in the green square in Figure 55a, showing the bathymetry of the Strait of Singapore and nearby tide gauges. Units of depth are in meters.

To motivate the study that follows, I show a few examples of seasonal variability, which is quite distinct between sub-regions (Figure 56). Fig 56 (a) and (c) shows the seasonality of the $\mathrm{M}_{2}$ admittance amplitude and phase difference variations in the Gulf of Thailand at Sedili (GOT). Fig 56 (b) and (d) shows the $K_{1}$ admittance amplitude and phase difference variations in the Malacca Strait at Kelang (MS). For all plots, all years of monthly harmonic analysis results are collapsed into day of year on the x-axis, while departure from the long-term average is plotted on the $y$-axis. 

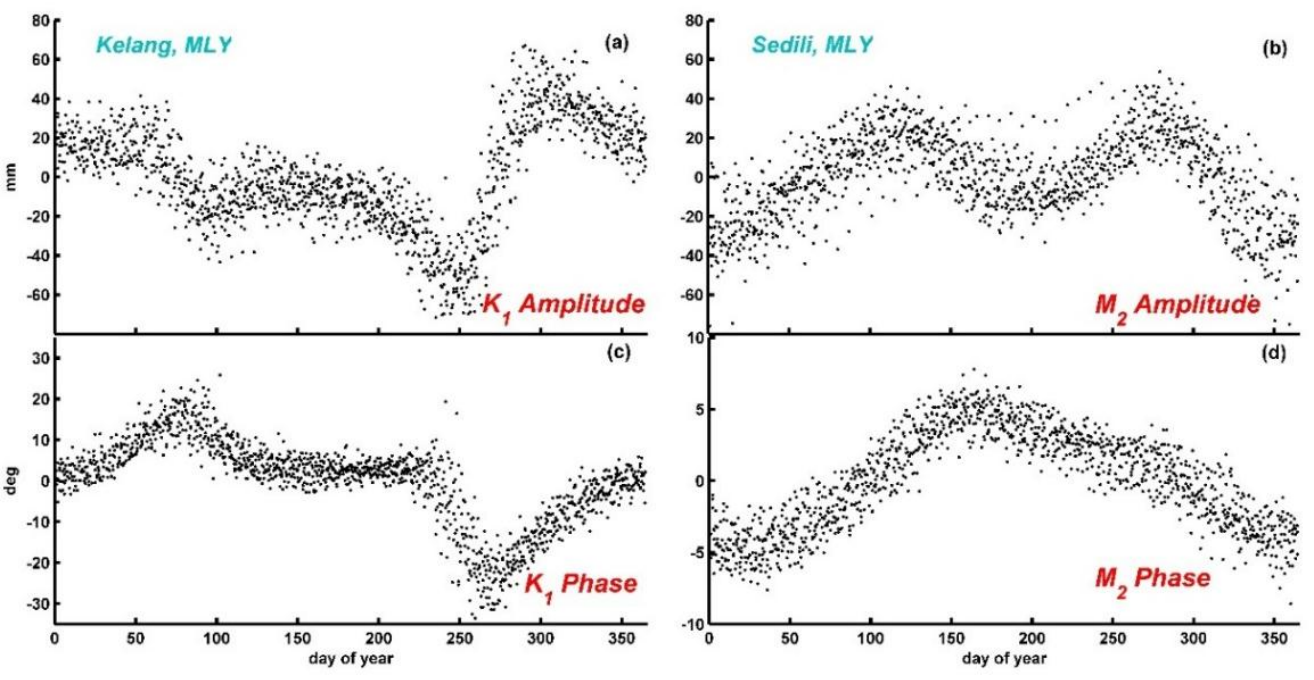

Figure 56 Examples of observed tidal variability. In (a) and (c) is shown the seasonality of the $\mathrm{M}_{2}$ admittance amplitude and phase difference variations in the Gulf of Thailand at Sedili, MLY. In (b) and (d) is shown the $K_{1}$ admittance amplitude and phase difference variations in the Malacca Strait at Kelang, MLY. All variations are shown relative to the mean amplitudes and phases; units are in millimeters for amplitudes, and degrees for phases.

The seasonal patterns at most gauges exhibit a mix of semi-annual and annual behavior, though it is spatially and temporally variable. There are considerable differences in the magnitudes, as well as differences in the timing of the maxima and minima between even closely neighboring tide gauges. While complex, this pattern of change has a likely general cause, the monsoon, with specific causes indicated by hypotheses $\mathrm{H} 1, \mathrm{H} 2$ and $\mathrm{H} 3$, which are tested below. The entire study domain is under strong influence of the Asian monsoon, with spatially variable seasonal changes in winds, rainfall, and ocean surface circulation, all of which may affect stratification and 
water mass transport, any or all of which all may in turn affect the tides. Both diurnal and semidiurnal tidal variability show annual coherence to the Western North Pacific Monsoon Index (WNPMI) in the majority of the study domain, defined as the difference of winds at the $850 \mathrm{hPa}$ level between two geographical regions, one centered over $25^{\circ} \mathrm{N}$ and $125^{\circ} \mathrm{E}$, the other centered on $10^{\circ} \mathrm{N}$ and $115^{\circ} \mathrm{E}$ (Wang and Fan, 1999). This suggests that the annual changes in the monsoon dynamics may be important to seasonal changes in tides.

This text is organized into the following sections: (a) a background on the dynamics of the monsoons; (b) the spatial distributions of the major diurnal and semidiurnal constituents; (c) methods, including the calculation of tidal admittance from observed water level data and the tidal model computations, the construction of physical property fields (stratification and currents) from gridded climate property products, and the addition of these fields into the tide model forcing; (d) the observed seasonal variation in tidal amplitudes and phases, the patterns of variation in SSH, geostrophic and Ekman (ageostrophic) currents, and stratification to be calculated via climate reanalysis data; (e) the spatial results of the models for all physical property adjustments for the major diurnal and semidiurnal tides; ( $f$ ) comparisons of model results with observed tidal variations; (g) discussion; and (h) conclusions. 


\subsection{Background}

\subsubsection{Atmospheric monsoon dynamics}

The monsoon (from the Arabic word mawsim, meaning "season") is a seasonallyreversing pattern of wind variability due to large-scale sea breeze effects, with corresponding changes in precipitation. The monsoon development is steered by the position of an equatorial pressure trough which crosses the Equator twice each year, yielding winds that are relatively constant, particularly over the sea. The strength and timing of the monsoon cycle varies regionally, but the same general mechanism is involved globally; i.e., uneven heating between land and sea. During warmer months, land surfaces heat up more rapidly than ocean regions so that air temperatures rise quickly, which lowers the air pressure over land. The sea surface temperature (SST) of adjacent ocean waters adjusts more slowly, maintaining a higher air pressure, which will cause an on-shore air flow of moist air. These air masses eventually rise, recirculate, and return to the ocean, leading to greatly increased precipitation over land. In the cooler months, the reverse occurs, with wind flowing predominantly from land to sea, since the land will now cool more rapidly than the ocean, with the majority of precipitation falling on ocean areas. In this way, the yearly monsoon cycle is generally thought of as having a "wet" (summer) phase, a "dry" (winter) phase, and two transition or "slack" periods, which yields dominantly annual and/or semi-annual climate patterns, depending on region. These strong and seasonally reversing winds, along with heavy 
and unevenly distributed precipitation and river discharge across a region can modify ocean water temperatures and salinity, which may affect stratification, ocean currents, and water level. Much of the information presented here stems from Wyrtki (1961), still a seminal source of information regarding oceanic variability in Southeast Asia.

\subsubsection{Oceanic monsoon dynamics}

Monsoonal variations in atmospheric circulation directly influence regional oceanic circulation. The monsoon winds change direction twice a year, and the oceanic circulation also reverses in large areas of the Southeast Asian waters, yielding seasonal cycles in water mass transports between basins and seas. Local sea level and regional sea surface topography are also influenced by the wind, and the sea surface, the mass transports, and the currents all may influence each other.

The Southeast Asian waters are a source of warm and less-saline water that is transported to both the Pacific and the Indian Oceans, and replaced by more saline water. The majority of the region experiences warm water temperatures, with a small annual variation, but the seasonality of salinity is much more important to changes in water density. Freshwater input to the seas is mainly supplied by the rains of the monsoon seasons and river discharge. The spatial pattern of precipitation is not uniform across the region, nor is its seasonal behavior, as some areas have two distinct rainy seasons, while others only have one longer rainy season, with the rest of the year being relatively dry. 


\subsubsection{South China Sea oceanic variability}

The axis of the South China Sea (SCS) is well aligned with the direction of monsoon winds; i.e., along a northeast-southwest line between Singapore and Taiwan, such that monsoon winds drive strong seasonal ocean circulation patterns. In the northern SCS, sea level has a distinct annual cycle, with rising water levels during the southern monsoon, and falling during northern monsoon, though during the southern monsoon, sea levels in the southern SCS are lower. Water that cannot flow back into the Java Sea returns to the central SCS, which is wide enough to develop large horizontal eddies, especially during the northern monsoon.

In general, the annual cycle in the northern SCS is controlled by rainfall and evaporation. In the central SCS, annual salinity variations are dominated by surface current variations, and by the inflow of low salinity water from the Mekong River. In the southern SCS, there are two rainy seasons; a weaker one in April and May, and a stronger one from October to January. Salinity variations also have two minima, but these do not show direct relationships to rainfall maxima, indicating that river runoff is a more important controlling factor on salinity than rainfall itself.

\subsubsection{Java Sea oceanic variability}

As with the SCS, the Java Sea (JS) lies directly along the main axis of the monsoon wind forcing, and the strong wind-induced surface currents may extend all the way to the bottom, almost completely mixing the water column. Higher sea levels are seen 
from February to July in the JS than in the SCS, with the opposite being true from August to November. The winds over the JS blow WNW from November to March, and ESE from May to September, with the ocean currents moving with the wind in both cases. In April and October at the change of the monsoon winds, the currents also reverse. The JS is also a source of low salinity waters. Runoff from the rivers of Borneo, Sumatra, and Java reduce the salinity of the coastal regions. The rainy season is from October to March, and the maximum river discharge follows about a month later.

\subsubsection{Gulf of Thailand oceanic variability}

In the Gulf of Thailand (GOT), water mass movements during the southwest monsoon (May to September) are generally anti-cyclonic, during the northeast monsoon, they are cyclonic (February to April). Circulation modelling studies (Chen at al., 2005) show that the currents in the Strait of Singapore (at the tip of the Malay Peninsula) are complicated and variable. In addition to tidal forcing, there is a strong hydrodynamic pressure gradient along the length of the Strait, which reverses semiannually, coinciding with the seasonal monsoon changes. These strong pressure gradients in the narrow Singapore Strait cause tidal currents of up to $3 \mathrm{~ms}^{-1}$, with the peak magnitudes seen at the height of monsoon seasons.

The salinity of the Gulf of Thailand is almost always below 32 psu due to river flow from the Chao Phraya River at the head of the Gulf, and from other rivers of peninsular Malaysia that feed the Gulf of Thailand, e.g., the Kelantan. The salinity 
minimum occurs in January, with a maximum observed in September at the end of the rainy season, followed by a quick drop in surface salinity. During October to January, the low salinity water off the mouth of the Mekong flows into the Gulf of Thailand, lowering salinity there.

\subsubsection{Malacca Strait oceanic variability}

Currents in the Malacca Strait (MS) are driven by interactions between the tides, winds, and bathymetry. Winds can both increase (in the northern MS), and decrease (in the southern MS) tidal currents, with this effect being greatest during times between the monsoons, when the persistent directional winds are weakest, and other more variable winds dominate. The strong tidal transport assists mixing, and the water column is mixed for the majority of the year, especially in the southern MS where currents are stronger, up to $1.0 \mathrm{~ms}^{-1}$. Studies of three dimensional current simulations in the Malacca Strait (Rizal, at al., 2010) show that there is always a steady current flowing northwest through the Malacca Strait at the bottom, but surface currents exhibit a large difference between February and August, at the height of the northeast and southwest monsoon, respectively. In general, the sea levels in the southern MS are closely related to the levels in the SCS, while in the northern MS, they are related to the Andaman Sea. There are two rainy seasons in the Malacca Strait, without any true dry season, and water masses passing through the strait have their salinity constantly 
lowered by heavy rainfall and river discharge. Additionally, strong tidal currents cause a complete mixing of the water.

\subsubsection{Tidal variability}

Four major tidal constituents are analyzed: the major semidiurnal lunar $\left(M_{2}\right)$ and solar $\left(\mathrm{S}_{2}\right)$ tides with periods of 12.421 and 12 hours, respectively, and the major diurnal lunisolar tides $\left(\mathrm{K}_{1}\right.$ and $\left.\mathrm{O}_{1}\right)$, with periods of 23.984 and 25.819 hours, respectively. Harmonic analysis of the major semidiurnal and diurnal tides in the Southeast Asian waters show that the spatial patterns of tidal variability are complex. The region is equatorial, and the diurnal (once a day) astronomical tide-generating potential vanishes at the equator, which suggests that diurnal tides should be small (see Figure 2 in Part I), yet in many regions, they are of comparable strength to the semidiurnal (twice a day) tides. Depending on location, one may find: a predominantly semidiurnal tide (Indian Ocean); a predominantly diurnal tide (northern Gulf of Thailand and the northern Java Sea between Borneo and Sumatra); a mixed tide with mostly semidiurnal tides (near Singapore), or a mixed tide with mostly diurnal tides (majority of the South China Sea and the Java Sea). For a map of the dominant tidal distributions, see Figure 8.2 in Wyrtki (1961). In addition to this complexity, the admittance amplitudes and phase differences of the tides exhibit seasonal variability, but temporal patterns differ in magnitude and timing between tide gauges, even closely neighboring ones. Semidiurnal and diurnal behavior at any one station tends to be generally consistent, i.e., $\mathrm{S}_{2}$ behavior 
mirrors $\mathrm{M}_{2}$, and $\mathrm{O}_{1}$ mirrors $\mathrm{K}_{1}$. However, there are some strong exceptions to this, as is seen at the gauges within the Malacca Strait for the diurnal constituents.

\subsubsection{Semidiurnal tides}

The $\mathrm{M}_{2}$ semidiurnal wave entering the Luzon Strait from the Pacific Ocean advances into the South China Sea slowly, and with a relatively small amplitude of about $200 \mathrm{~mm}$, reaching the Sunda Shelf 6 hours later. There are significant semidiurnal internal waves mediated through the Luzon Strait (Niwa and Hibaya, 2002; Chao, et al., 2007). The velocity of the tidal wave decreases when meeting the shelf, and the refraction yields high amplitudes of a meter or more off the coast of Borneo and Vietnam near the Mekong River delta. Approximately 8 hours after meeting the shelf, the tidal wave reaches the eastern coast of the Malay Peninsula, and splits into two branches, one flowing north into the Gulf of Thailand, the other flowing south towards the Java Sea. The northward flowing branch forms a clockwise amphidrome in the Gulf of Thailand, with an average amplitude of 100 to $200 \mathrm{~mm}$ for $\mathrm{M}_{2}$. The southern branch diminishes quickly as it joins the last influences of the semidiurnal wave of the Indian Ocean arriving from the eastern Java Sea, and between Borneo and Sumatra the tides are mainly diurnal. The rotation of the northern semidiurnal amphidrome should be noted, as theory would suggest that a northern hemisphere amphidrome should rotate counter-clockwise, not clockwise. This is partly explained by the fact that the natural oscillation period of the whole GOT is near the semidiurnal period, that the gently 
sloping bottom of the GOT "guides" the semidiurnal wave, and because of the direction and propagation of the incoming semidiurnal tidal wave from the SCS (Yanagi and Takao, 1998). Within the Malacca Strait, there are amplifications of the semidiurnal tides at each end of the Strait, with a region of lesser amplification in between. In the Java Sea, semidiurnal constituents are very small. The $S_{2}$ amplitudes exhibit the same regional amplifications, with amplitudes generally about half of $\mathrm{M}_{2}$. In Figures 57a and 57b, the $M_{2}$ and $S_{2}$ tidal amplitudes calculated from the TPXO7.2 global tide model are shown. 


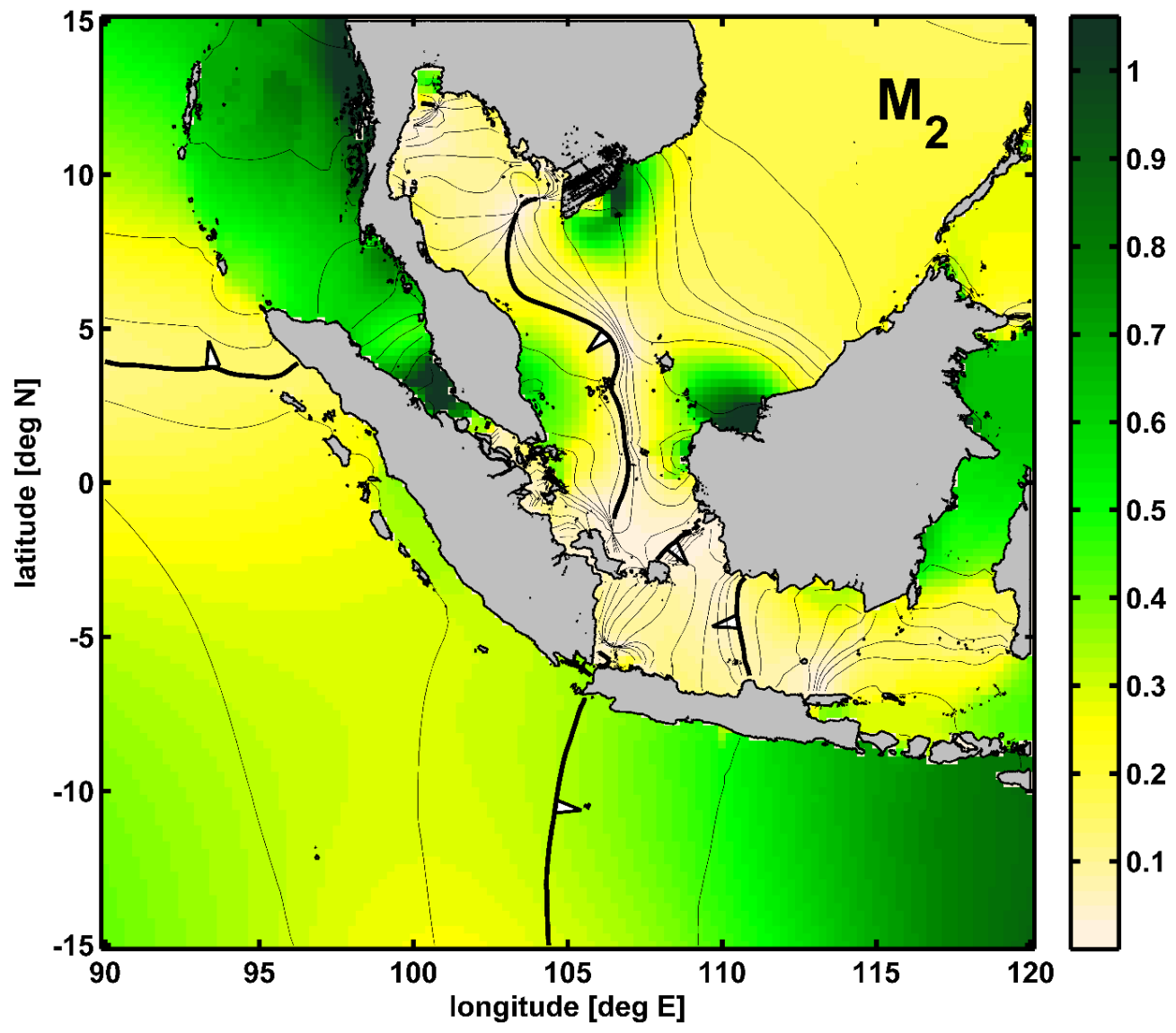

Figure 57a $\mathrm{M}_{2}$ tidal solutions in Southeast Asian waters from OTIS. Tidal amplitudes are generated from the TPXO7.2 global dataset. Units are in meters. 


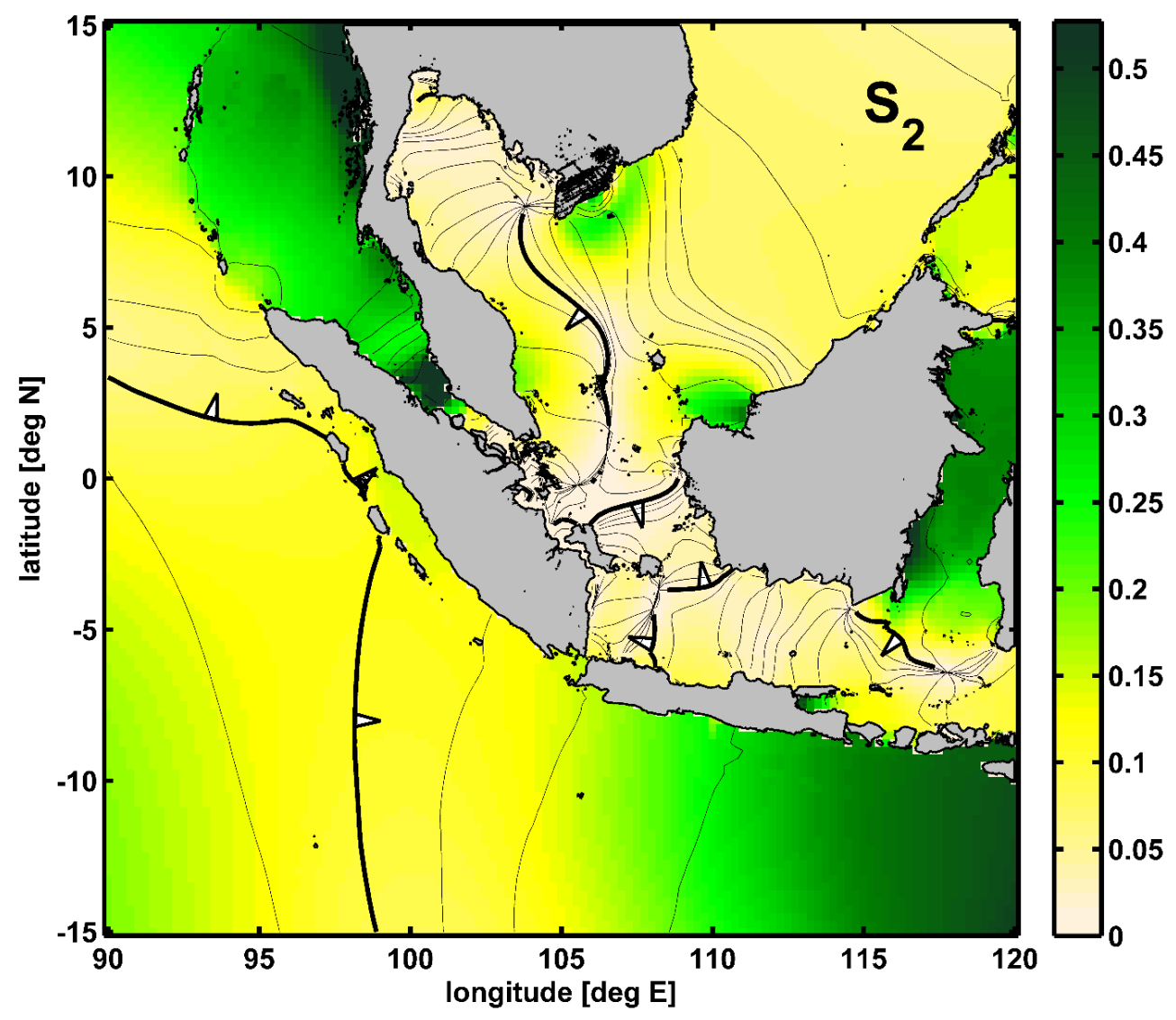

Figure 57b $\mathrm{S}_{2}$ tidal solutions in Southeast Asian waters from OTIS. Tidal amplitudes are generated from the TPX07.2 global dataset. Units are in meters. 


\subsubsection{Diurnal tides}

The Pacific diurnal tidal wave also enters the South China Sea through the Luzon Strait, with an average amplitude of about $500 \mathrm{~mm}$, and there are also diurnal internal tides generated here (Jan et al.,2007). High water reaches the Sunda Shelf 13 hours after passing Luzon, with a small amphidromic system forming near the Gulf of Tonkin near Vietnam where $K_{1}$ amplitudes can exceed $1 \mathrm{~m}$. Similar to the $\mathrm{M}_{2}$ wave, upon reaching the Malay coast, it splits into northward and southward travelling waves. The northward flowing branch forms an amphidrome in the Gulf of Thailand, this one circulating counter-clockwise. The amphidromic point is deflected westward of center, slightly lowering diurnal amplitudes on the north part of the Malay coast, with the maximum amplitudes found at the head of the Gulf near Bangkok. The southern wave advances slowly, but with rapidly increasing amplitude, surpassing $1 \mathrm{~m}$ off the coast of Sumatra, and maintaining at about $800 \mathrm{~mm}$ throughout the Java Sea. The interaction of the diurnal tidal wave of the Pacific and of the Indian occurs near Singapore, as does the interaction of the semidiurnal waves, which yields a very complicated tidal pattern in a very small geographical region. In the Malacca Strait, $\mathrm{K}_{1}$ is largest in the southern part of the Strait, and small elsewhere heading towards the Andaman Sea. The $\mathrm{K}_{1}$ amplitudes are also large in the northwestern and eastern Java Sea. The $\mathrm{O}_{1}$ tidal amplitudes mimic the $K_{1}$ spatial patterns, and average amplitudes are of near equal amplitude in most regions. The notable exception to this is that there is no $\mathrm{O}_{1}$ 
maximum in the eastern Java Sea. In Figures $58 \mathrm{a}$ and $58 \mathrm{~b}$, the $\mathrm{K}_{1}$ and $\mathrm{O}_{1}$ tides from the TPX07.2 global tide model are shown.

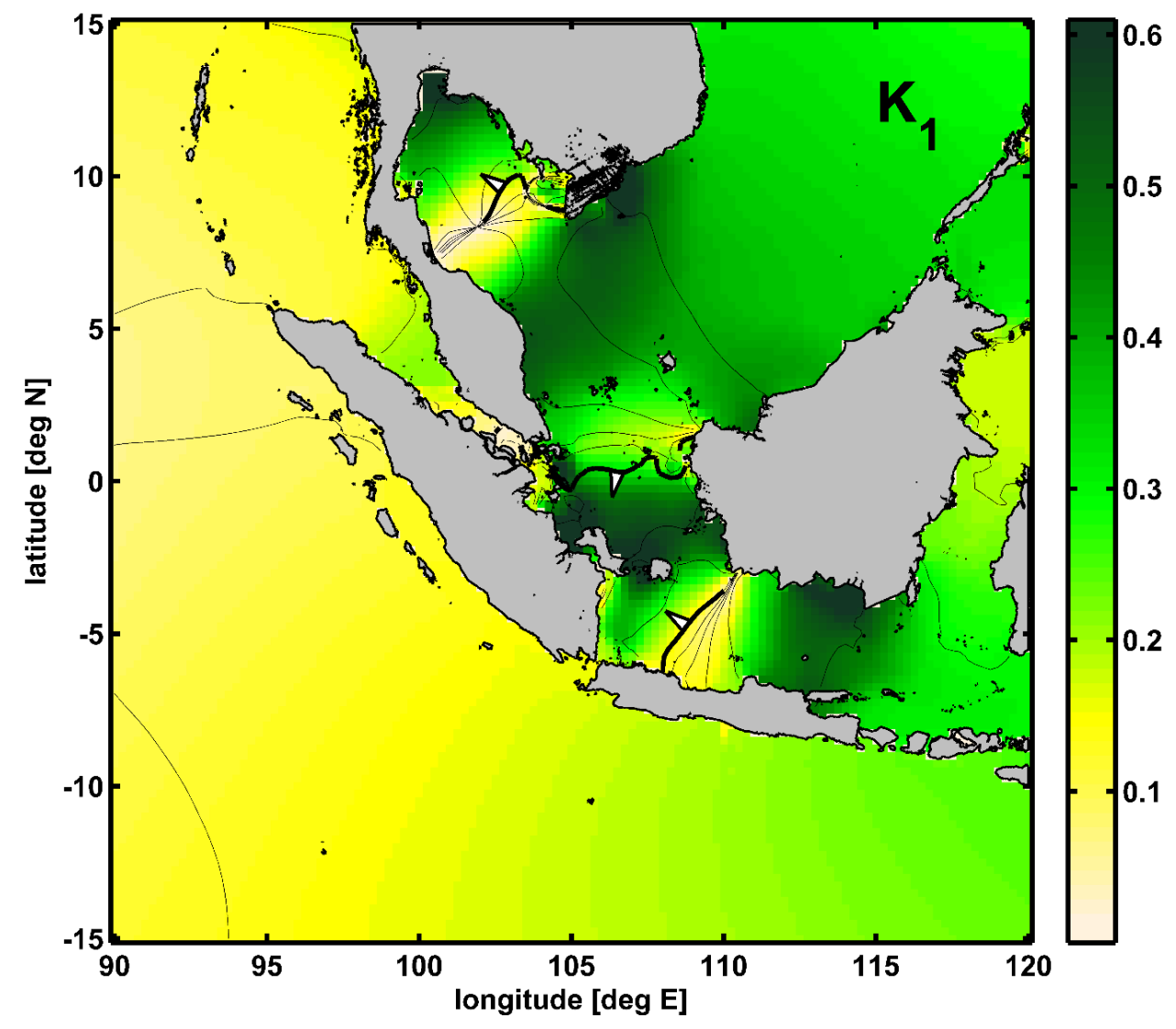

Figure 58a $\mathrm{K}_{1}$ tidal solutions in Southeast Asian waters from OTIS. Tidal amplitudes are generated from the TPX07.2 global dataset. Units are in meters. 


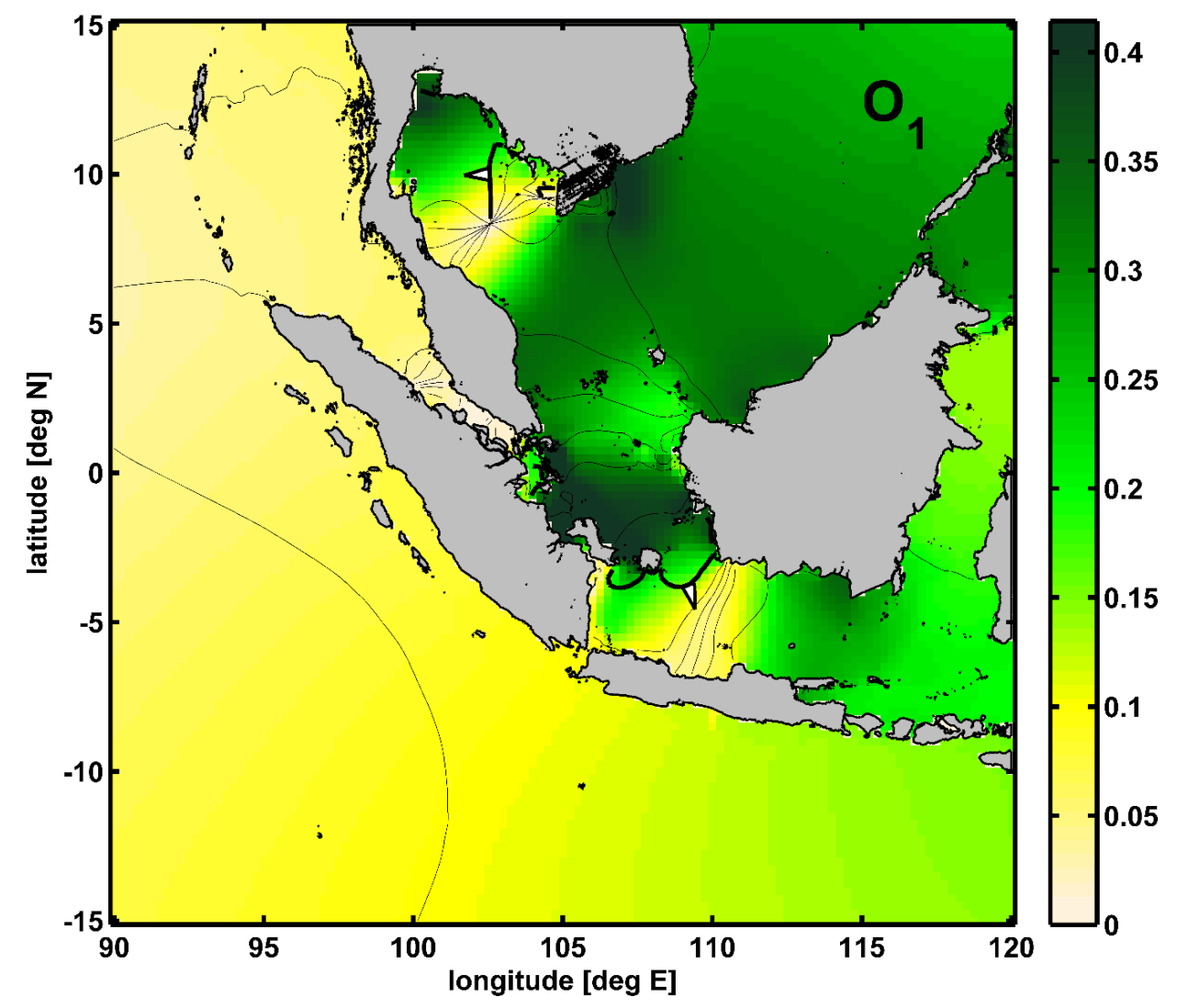

Figure 58b $\mathrm{O}_{1}$ tidal solutions in Southeast Asian waters from OTIS. Tidal amplitudes are generated from the TPX07.2 global dataset. Units are in meters. 


\subsubsection{Seasonality of tides}

Seasonal variability in tidal components has been investigated in a small number of studies in the past, and there has been little consensus as to the mechanisms causing such variability, usually being attributed to a nonlinear interaction with the tide, such as meteorological effects or mean currents, or to noise present in shorter harmonic analysis records producing leakage between constituents (Cartwright and Amin, 1986). The variation in $\mathrm{M}_{2}$ as prescribed by gravitational forcing is only about $0.7 \%$ (Hartmann and Wenzel, 1995), as parameterized by annual satellite constituents $\left(\alpha_{2}, \beta_{2}\right)$, but there are many tide gauge records worldwide that show a seasonal modification in tidal properties that are too large to be explained by noise or gravitational forcing. The earliest known study of the seasonality of tides was given by Corkan (1934), in which the monthly variations of semidiurnal tides in British waters during the 1920s were analyzed, and found to be up to $2 \%$ of the mean tidal amplitude. Additionally, Corkan found significant annual variations in $\mathrm{M}_{2}$ in a survey of worldwide tide gauge data spanning 1918-1931 in: the Bay of Fundy (St. John, NB), the Azore islands (Ponta Delgada), the northwest coast of Australia (Port Hedland), Johor Bahru (Singapore), and Newchang, China (Yellow Sea). North Sea seasonality has been documented by Pugh and Vassie (1976), and also in the Bristol Channel by Alcock and Pugh (1980). Tidal variability of diurnal and semidiurnal components also exhibits seasonality on the European Shelf, analyzed by Leeuwenburgh, et al. (1999), and attributed to nonlinear surge-tide interaction. A detailed study of the Korean waters by Kang et al. (1995) 
revealed strong seasonal variations in $\mathrm{M}_{2}$ of up to $4 \%$ of the mean tide, with magnitudes up to $50 \mathrm{~mm}$. It was supposed there that the seasonality may be partly attributed to noise, but mainly attributed to an unexplained 'interacting effect', such as meteorological factors, or to the strong seasonal variations in the strength of the Kuroshio Current and the Tsushima Current. The interaction of mean currents with tidal currents may significantly alter the frictional terms (Hunter, 1975), and the interaction of tides with river discharge may also induce a significant nonlinearity in the seasonal cycle, investigated by Godin (1985; 1991), and more recently, by Guo et al. (2015) for the Yangtze River. The seasonal variability of the global altimetry-derived $\mathrm{M}_{2}$ internal tide is reported by Müller et al. (2012a), thought to be due to solar radiative forcing and to wind-forced oceanic circulation. A study by Müller (2012b) examined the effect of modifying the influence of vertical eddy viscosity and bottom drag, finding that barotropic transport can be seasonally modified by $5 \%$, and that the influence of seasonal stratification can be a major factor contributing to seasonal tidal modulation in shallow waters. A commonality in studies of seasonal tidal behavior is a strong stationarity of the seasonal signals, being very consistent and reproducible from year to year. The explanation of this variability, if assumed to be meteorological based, is likely attributed to aspects of these systems that also exhibit such predictable seasonal behavior, such as the wind and precipitation patterns of the monsoons. 


\subsection{Methods}

\subsubsection{Data sources}

All hourly tide gauge records come from the University of Hawaii's Sea Level Center (UHSLC). Utilizing the World Ocean Atlas 2013 (WOA13; Levitus et al., 2013) climatology, a picture of the seasonal stratification changes in the area via the buoyancy frequency $(N)$ will be created. Additionally, data products from satellite altimetry will be utilized to construct monthly fields of SSH and geostrophic currents from the entire satellite era (1992-2013). The altimeter products were produced by Ssalto/Duacs and distributed by AVISO, with support from Cnes (http://www.aviso.altimetry.fr/duacs/). Finally, the Ekman velocities are found via wind stress data of the European Center for Medium-range Weather Forecasting (ECMWF) reanalysis (Dee et al., 2011). These relevant climatology fields will be used in a barotropic tide model (Egbert and Erofeeva, 2002) to perform model adjustments, with yearly average fields subtracted out, to yield monthly perturbation fields.

\subsubsection{Tidal admittance calculations}

Investigations of tidal trends are carried out through the use of a tidal

admittance. See section 3.2.2 above for more detail on this methodology, but the main equations are repeated below. For all relevant stations, monthly harmonic analyses were carried out on hourly records and hourly $V / g$, using the R_T_Tide tidal harmonic 
analysis package in MATLAB (Pawlowicz, 2002; Leffler and Jay 2009). From amplitude $A(\mathrm{t})$ and phase $\vartheta(\mathrm{t})$ time series, one can construct complex amplitudes $Z(\mathrm{t})$ through:

$$
\mathbf{Z}(t)=A(t) e^{i \theta(t)}
$$

Time-series of tidal admittance amplitude ratio (AR) and phase difference (PD) for a constituent are formed using:

$$
\begin{aligned}
& \mathbf{A R}(t)=a b s\left|\frac{Z_{o b s}(t)}{Z_{p o t}(t)}\right|, \\
& \mathbf{P D}(t)=\theta_{o b s}(t)-\theta_{p o t}(t)
\end{aligned}
$$

where the subscript 'obs' or 'pot' denotes the corresponding quantity for either the observed data or the gravitational potential, respectively. Both the admittance ratio in Eq. (30) and the phase difference in Eq. (31) largely remove the yearly tidal variability in monthly analyses, allowing easier examination of the non-tidal signals. The technique of using admittances has the benefit that the variations present in the tidal property time series will be due to factors not involving astronomy, such as climatic variability. These two quantities, AR and PD, will be the main tools used to explore tidal variability in this study. 


\subsubsection{Seasonal tidal anomaly trends (STATs) and monsoon coherence}

Sections 3.2.3 and 3.2.4 above detailed the methodology of TATs and STATs.

These preliminary examinations revealed that the seasonal variability in TATs is largest in the Southeast Asian waters, with some locations exhibiting a reversal of trend. The range of the monthly TAT determinations were denoted seasonal tidal anomaly trends (STATs). This was the motivation for the present study. To better understand the seasonal fluctuations, and the mechanisms behind them, methods are employed which involve considering separately the direct seasonal variation in MSL, in tidal properties, and in climate-related variables that may be directly forcing the tidal seasonality. For monthly averaged MSL, and for monthly tidal admittance amplitude ratio (AR) and phase difference (PD) data, all station years are collapsed into a phase space of yearly behavior, and binned by day-of-year. The fitting algorithm below is applied which considers both annual and semi-annual harmonics:

$$
\begin{aligned}
& \left.\left.F(t)=a_{0}+a_{1} \sin (2 \pi t) / 365.25\right)+b_{1} \cos (2 \pi t) / 365.25\right) \\
& \left.\left.+a_{2} \sin (4 \pi t) / 365.25\right)+b_{2} \cos (4 \pi t) / 365.25\right)
\end{aligned}
$$

where $t$ is in days. It is this seasonal mix of annual and semi-annual behavior that this study will attempt to replicate in the models.

The observed tidal data is also compared to the Western North Pacific Monsoon Index (WNPMI), using coherence estimates to isolate the possible correlations between 
the dynamics of the monsoon and the seasonal patterns in tidal properties, centered at the annual frequency band.

\subsubsection{Barotropic ocean model setup}

The mechanisms responsible for the observed STATs are explored using the OTIS (Oregon State Tidal Inversion Software) tidal model (Egbert et al., 1994; Egbert and Erofeeva, 2002). OTIS uses barotropic global solutions determined from satellite altimetry as boundary conditions for modelling regional domains of interest. The global tide models have an accuracy of $\pm 1 \mathrm{~cm}$ or better in the open ocean (Ablain et al., 2015) with greater deviations near coastlines, particularly around complex topography (Ray, et al., 2011). The equations that are solved at each grid cell in OTIS are derived from the Laplace tidal equations to yield the linear shallow water equations (LSWE) on a sphere for tidal elevations and horizontal currents in two dimensions:

$$
\begin{aligned}
& u_{t}-f v+g\left(\eta+\frac{\Phi}{g}\right)_{x}+\lambda u=0 \\
& v_{t}+f u+g\left(\eta+\frac{\Phi}{g}\right)_{y}+\lambda v=0 \\
& \eta_{t}+(H u)_{x}+(H v)_{y}=0
\end{aligned}
$$

Here, $\mathbf{u}=(u, v)$ are the barotropic horizontal currents in the $(x, y)$ directions, $\eta$ is the sea surface elevation, $f$ is the Coriolis coefficient, $g$ is the acceleration due to gravity, $\Phi$ is the equilibrium tidal potential with corrections for ocean self-attraction and solid Earth loading (Egbert, et al., 1994), and $H=H(x, y)$ is the spatially-variable mean depth of the 
water column, which is provided from the US Navy's DBDB2 ocean bathymetry dataset, calculated at a resolution of $(1 / 30)^{\circ}$. Subscripts indicate partial derivatives. The terms $(H u)$ and $(H v)$ indicate volume transports. Note that equations (33a-c) are written in rectangular coordinates for simplicity alone. The actual operation of the model solves the governing equations in a spherical polar coordinate system. The $\lambda$ term is a dissipation coefficient, defined as:

$$
\lambda=\lambda(x, y)=\frac{C_{d}\left|u_{f}\right|}{H},
$$

where $u_{f}$ is the friction velocity, equal to the time-averaged total velocity vector including tidal velocities (Egbert and Erofeeva, 2002), $C_{d}$ is a non-dimensional drag coefficient, usually set to a global default value of $0.001-0.003$, and $H$ is the depth. Adjustments to the model detailed below utilize spatially variable versions of $u_{f}$ or $C_{d}$. Note the dependence of the friction term $\lambda$ on the depth; in shallow waters, sea level variations can therefore affect damping. However, as is later discussed, uncertainty in bathymetry also appears to have a large effect.

The equations governing tidal motions (Eqs. (33a) and (33b)) can be modified by altering the $\lambda$ term (Eq. 33d), for example by modifying the friction velocity field, $u_{f}$, (Synder et al., 1979). The friction velocity, $u_{f}$, is given by:

$$
u_{f}=\left(u_{0}^{2}+\sum_{\omega} u_{\omega}^{2}\right)^{1 / 2}
$$


where $u_{0}$ is the non-tidal velocity, and $u_{\omega}$ are the tidal velocities. To include the effect of the geostrophic and Ekman velocity in the models, $u_{g}$ and $u_{E}$ are added to the non-tidal (uo) component of $u_{f}$.

\subsubsection{Model calibration and operation}

The boundaries of the model domain used will be the box outlined in Figure 54, between $+15^{\circ}$ and $-15^{\circ} \mathrm{N}$ latitude, and between $90^{\circ}$ and $120^{\circ} \mathrm{E}$. For all model setups, 13 runs are performed; one for each month of year, based on monthly averages of adjustment variables, and one for the annual averages of the same variables. The model domain is chosen so as to fully enclose the regions of interest, with domain boundaries drawn along as much of the open-ocean as possible to achieve accurate forcing at the boundaries. Model resolution is chosen to be $(1 / 30)^{\circ}$, identical to that of the DBDB2 bathymetry. There are multiple bathymetric data sets available in addition to the US Navy's DBDB2 dataset, such as the General Bathymetric Chart of the Ocean (GEBCO, Fisher et al., 1982), and version 15.1 of Smith and Sandwell's global bathymetry (SS, Smith and Sandwell; 1994, 1997). The choice of using the DBDB2 bathymetry was based on calibration runs that inter-compared the modelled tides using different bathymetry, which differs significantly different among the DBDB2, GEBCO, and SS products. Figure 59a shows an example of these bathymetric discrepancies, showing the Smith and Sandwell 15.1 dataset subtracted from the DBDB2 dataset, and then divided by the base bathymetry of DBDB2 to yield a fractional depth difference, relative 
to total water column depth. The two bathymetry sets are nearly equal in deep water areas, but within the interior shallow seas, the differences are significant, particularly in the Malacca Strait and the Java Sea. The effect of the different bathymetry on the model response is shown in Figure 59b. The behavior of the $M_{2}$ tide is shown as a difference of responses between the two bathymetric datasets, in units of millimeters, with all other model parameters identical. The majority of deep-water locations show little to no change, but differences in model response are significant in parts of the Gulf of Thailand, the Java Sea, and the Malacca Strait, with some areas exhibiting a difference of more than $200 \mathrm{~mm}$. It is clear from this exercise that the choice of depth data used can greatly affect tidal solutions. From a set of calibration models such as this, it was determined that the DBDB2 dataset was the best in the regions of interest to the modelling effort (i.e., the shallow-water regions of the Gulf of Thailand, Java Sea, and Malacca Strait.

The output of the annual average tide model is subtracted from the outputs of the monthly model runs to yield the seasonal perturbations of the tides due to each mechanism. There are two types of model modifications. First, there are global adjustments such as the default global drag coefficient, $C_{d}$, the minimum value of friction velocity, $u_{f}$. Second, there are field adjustments, which are calculated at all model grid points, which are described in the next section. Before the field adjustment modifications are added, the model is calibrated for the domain of interest by adjustment of these global variables. Comparisons are made between the annual 
means of the tidal amplitudes from all stations, as determined from the observed tide gauge data, and the output of each calibration model at the nearest grid cells to the tide gauge locations. Values of the global model variables are then adjusted until the root mean square error (RMSE) of the differences between the observed and modelled tidal amplitudes were as small as possible for all tidal constituents. Calibration runs yielded the best results (lowest RMSE) for the minimum friction velocity $\left(u_{f}\right)$ equal to $0 \mathrm{~ms}^{-1}$, and for the global drag coefficient $\left(C_{d}\right)$ equal to $1 \times 10^{-3}$. 


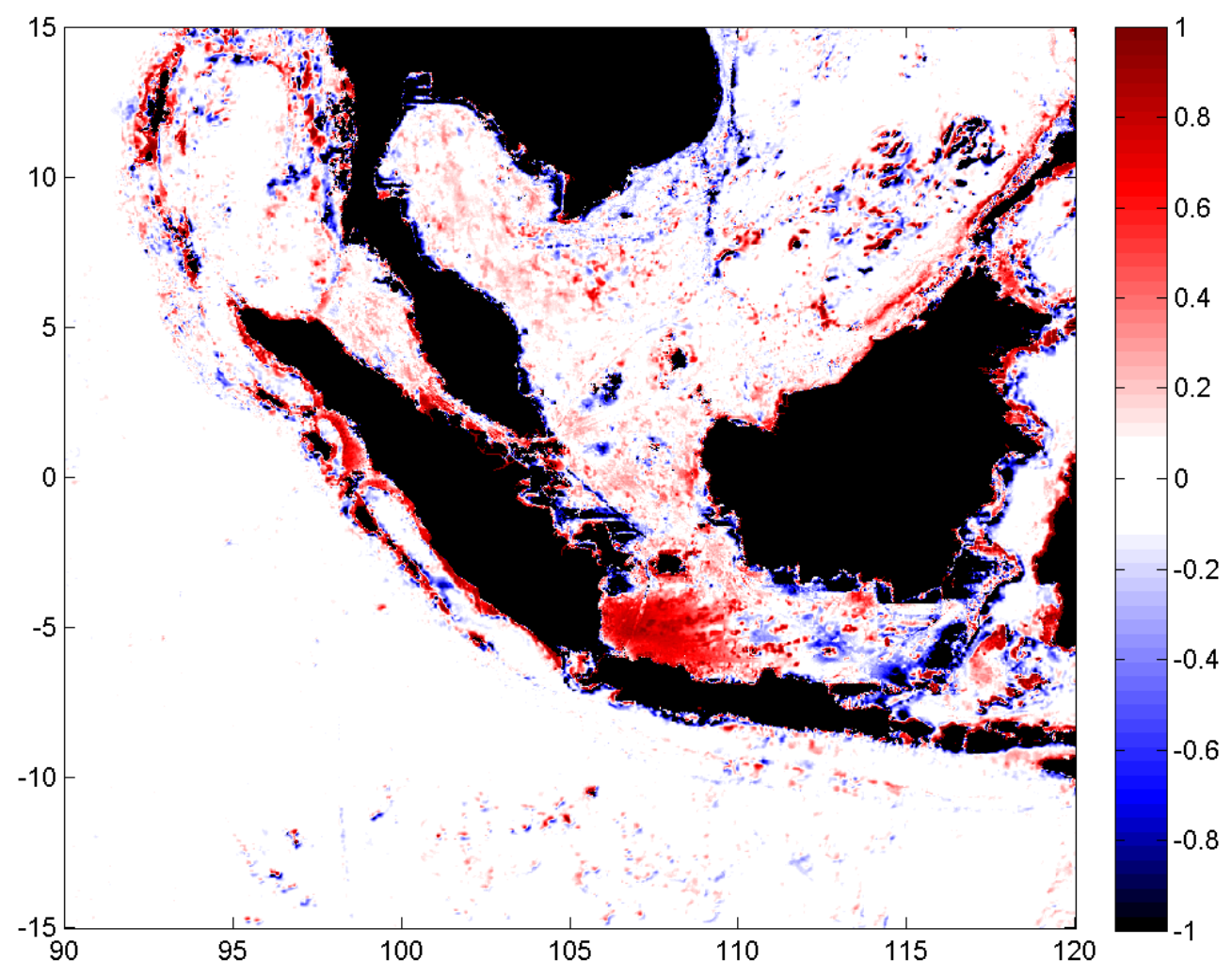

Figure 59a Comparison of different ocean bathymetry sets available to the barotropic model. The Smith and Sandwell bathymetry (Smith and Sandwell, 1997) version 15.1 is subtracted from the US Navy's DBDB2 bathymetry. Differences are expressed as a relative (fractional) change, as compared to the total water depth of the DBDB2 bathymetry. 


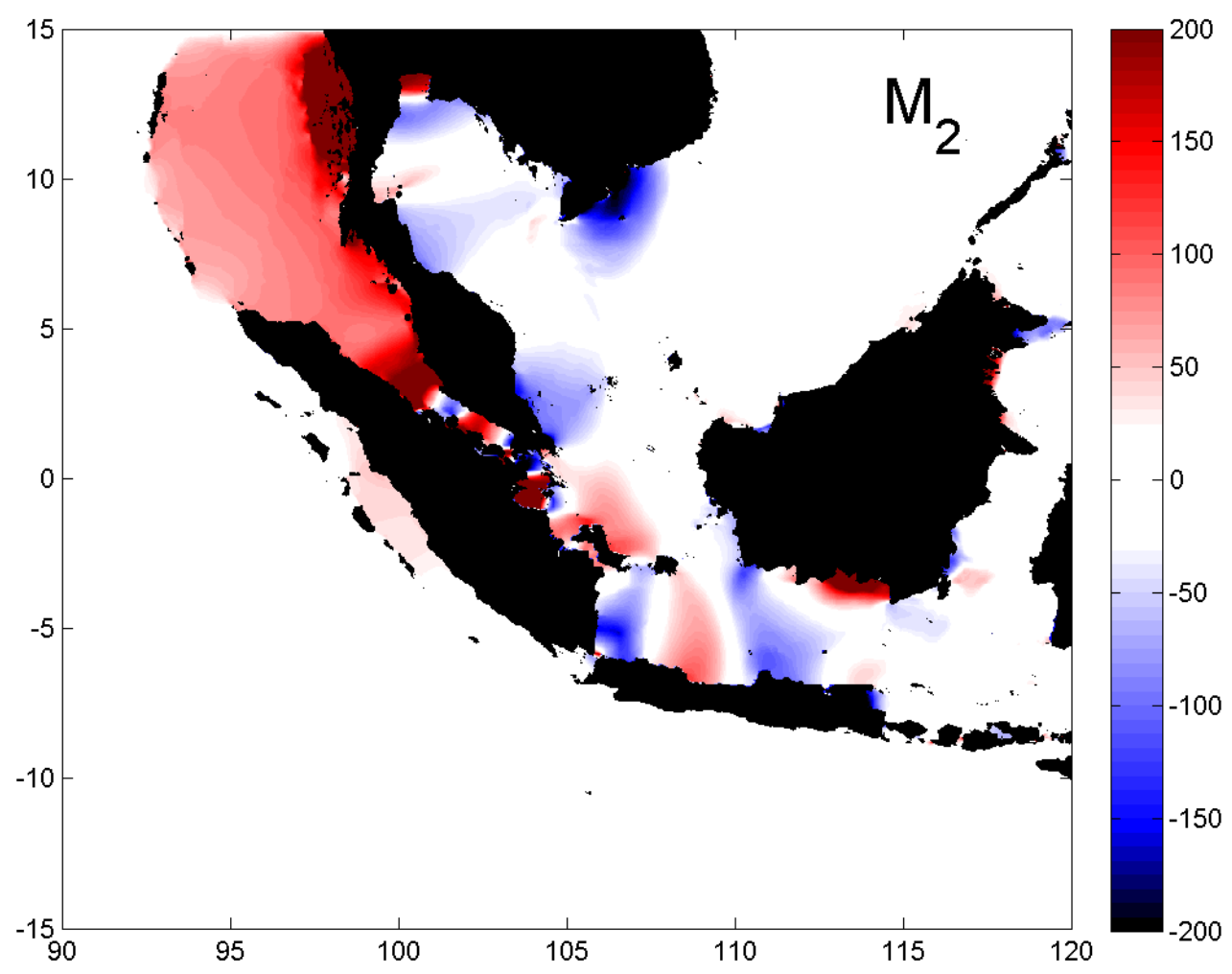

Figure 59b Calibration model results for the $M_{2}$ tide using the two different bathymetries (Smith and Sandwell 15.1 and DBDB2) compared in Figure 59a. Differences are expressed in units of millimeters. 


\subsubsection{Model modifications}

The field modifications available to the model are:

1) Seasonal variation of water depth, $H$. This modification takes the form of a spatiallyvariable perturbation of mean water depth; $H \rightarrow H+\delta \eta$, where $\delta \eta$ is the spatiallyvariable SSH perturbation field for each month, determined from the altimetry-derived mean absolute dynamic topography (MADT) dataset from AVISO by computing yearly and monthly climatology over 1992-2014.

2) Seasonal modulation of $C_{d}$ using buoyancy frequency profiles. Temperature and salinity data from the World Ocean Atlas 2013 (WOA13) climatology are used to test the effects of spatially variable bottom friction in response to variable thermocline depth and stratification. The determination of $C_{d}$ uses a modified "law of the wall" analysis (Perlin et al., 2005), the derivation of which is shown below.

3) Seasonal variation of geostrophic velocity. This modification takes the form of a spatially-variable addition to the minimum friction velocity in the model, which is by default a scalar constant value. Friction velocities added to the model will be determined from the absolute value of the geostrophic currents: $u_{0} \rightarrow \delta u_{0}=\left|\mathbf{u}_{\text {geo }}\right|=$ $\left|u_{g e o}{ }^{2}+v_{g e o}{ }^{2}\right|^{1 / 2}$. The geostrophic currents are obtained from the MADT dataset, covering the years 1992-2014, to produce monthly and yearly climatology.

4) Seasonal variation of the Ekman velocities can also be added into the model via the friction velocity term in a similar manner to the geostrophic velocities: $u_{0} \rightarrow \delta u_{0}=\left|\mathbf{u}_{\mathrm{ek}}\right|=$ 
$\left|u_{e k}{ }^{2}+v_{e k}{ }^{2}\right|^{1 / 2}$. The Ekman velocities are determined by Eqs. (28), and are depthdependent. The wind stress fields are obtained from the ECMWF gridded dataset of climate reanalysis.

Combined model outputs are also used to determine the most accurate combination of climatic forcing mechanisms for the observed seasonal tidal variability. The details of each of these modifications are shown below

\subsubsection{Sea surface height and geostrophic velocity methodology}

The MADT dataset, as well as the zonal and meridional geostrophic current vector fields, $(u, v)$, are provided as weekly averaged snapshots constructed from satellite altimetry observations of the ocean surface taken by the interlaced missions of TOPEX/POSEIDON, Jason-1, and Jason-2, which provide a continuous record back to 1992. For this work, weekly snapshots of SSH and geostrophic currents are binned by month of the year, and averaged over all years to provide a seasonal perturbation field. The resolution of these fields is $(1 / 4)^{\circ}$, and these are extrapolated over land nodes via a successive relaxation technique, then interpolated onto the OTIS model domain resolution, which is the same as the resolution of the DBDB2 bathymetry $(1 / 30)^{\circ}$. The fields of seasonal SSH are added directly to the water depth data in OTIS, and the geostrophic currents are added to the non-tidal component of the friction velocity, $u_{0}$, within the iterative code of OTIS (usually set by default to zero). Geostrophic current velocities provided by Aviso at the equator are computed in a $5^{\circ}$ band around the 
Equator, using second derivative methods inspired by Lagerloef et al. (1999), in which altimetry based geostrophic currents were calibrated against in-situ drifter observations. This adjustment to the geostrophic velocity fields is computed to ensure continuity with classical geostrophy. The friction velocity field, $u_{f}$, is calculated through an iterative method (Snyder at al., 1979), in which the model is first solved with constant $u_{f}$, and then iterated using the velocity from the previous model run, along with any relevant climate related adjustment fields, as detailed below. This process is performed until successive solutions converge; in practice, this involved no more than 7 iterations per model. Thirteen models are run for both the SSH and $u_{g}$ models; 12 monthly determinations based on monthly averaged fields of the MADT dataset, and one annual determination based on the overall average of the MADT dataset for all available years.

\subsubsection{Bottom drag model methodology}

\subsection{Modified 'law of the wall'}

In the following sections, we will detail how to generate a spatially-variable drag coefficient, $C_{d}$, using a modified law of the wall formulation appropriate to the stratified ocean (Perlin et al., 2005) to represent seasonally variable stratification which will be used to explore the mechanisms behind seasonal changes in the tides. The general form of the law of the wall is written as: 


$$
\frac{d u}{d z}=\frac{u^{*}}{l}
$$

where $u$ is the vertical velocity profile, $z$ indicates the vertical coordinate in reference to the ocean bottom, $u^{*}$ is the friction velocity (distinct from the "friction velocity" in the OTIS tide model mentioned earlier, $\left.u_{f}\right)$, also expressible as $u^{* 2}=\operatorname{sqrt}(\tau / \rho)$, and $/$ is the 'mixing length', an appropriate length scale that allows one to scale the velocity gradient in terms of the friction velocity.

The governing equation for momentum in the $x$ direction of a turbulent flow takes the form:

$$
u_{t}+u u_{x}+v u_{y}+w u_{z}=-\frac{P_{x}}{\rho}+\left(v u_{z}\right)_{z}
$$

where subscripts indicate partial derivatives, $P_{x}$ is the horizontal pressure gradient, $\rho$ is the reference density of the ocean $\left(\sim 1024 \mathrm{~kg} / \mathrm{m}^{3}\right)$, and $v$ is the eddy viscosity. Assuming steady-state $\left(u_{t}=0\right)$, and neglecting advective terms leaves a balance between the along-channel pressure gradient and the vertical divergence of the turbulent stress:

$$
\frac{1}{\rho} \frac{\partial P}{\partial x}=\frac{\partial}{\partial z}\left(v \frac{\partial u}{\partial z}\right)
$$

The eddy viscosity, $u$, is defined as the product of the friction velocity and the appropriate mixing length:

$$
v=u^{*} l
$$


The water column is considered to have three layers in this analysis: (a) the layer closest to the bottom is the viscous sublayer; (b) above this is the 'traditional' logarithmic layer; and (c) above this will be a stratification layer, where / will be related to the Ozmidov length, $I_{o z}$ (Ozmidov, 1965), defined as:

$$
l_{o z}=\left[v\left(\frac{\partial u}{\partial z}\right)^{2} N^{-3}\right]^{1 / 2}
$$

where $N$ is the Brunt-Väisälä, or buoyancy frequency, the angular frequency at which a vertically displaced parcel will oscillate within a statically stable environment, is determined from the annual and seasonal climatology of the 2013 World Ocean Atlas (WOA13).

The friction velocity is determined by the stress at the bottom (from Eq. (34)), which can be expressed in terms of the pressure gradient by vertically integrating Eq. (36):

$$
\left(u^{*}\right)^{2}=-\frac{H}{\rho} \frac{\partial P}{\partial x} .
$$

The mixing length is scaled in a way that limits the eddy size at both the top and bottom of the water column and incorporates the Ozmidov length scale. It is further scaled by including dependence on the gradient Richardson number $R i_{g}\left(R i_{g}=\right.$ $N^{2} /\left(|d u / d z|^{2}\right)$, based on the methods of Louis (1979) which were applied to atmospheric flows. 


$$
\begin{aligned}
& l *=\kappa z\left(1-\frac{z}{H}\right) \quad \text { (unstratified ocean) } \\
& l * *=\frac{l * l_{o z}}{l *+l_{o z}} \quad \text { (modified law of the wall) } \\
& l=l * *\left(\frac{1}{1+8 R i_{g}}\right) \quad \text { (stratified ocean, Louis, 1979), }
\end{aligned}
$$

where the Von Karman constant, $k$, is equal to 0.41 (Hinze, 1975). Buoyancy frequency $(N)$ is determined from WOA13 $T$ and $S$ data at a resolution of $(1 / 4)^{\circ}$, and the system of Eqs. (36), (37), (38), and (40a-c) is solved recursively via numerical methods (described in detail below) at every grid point in our domain to achieve a velocity profile in the vertical, subject to the two boundary conditions of no-slip at the bottom, i.e., $u(z=0)=0$, and no stress at the surface, i.e., $d U(z=H) / d z=0$. The first iteration of Eq. (40b) assumes an Ozmidov length scale of the water depth, $H$. From this first calculation, the vertical velocity profile is found using the buoyancy frequency profile, the friction velocity, and the eddy viscosity, by way of matrix inversion. Then, the vertical divergence of the turbulent stress $(d u / d z)$ is calculated via finite-differences, which allows a re-calculation of the Ozmidov length, $I_{o z}$, using Eq. (38a), which is then reinserted into Eq. (40b).

The result of the second iterations of Eq. (40b) is then inserted into Eq. (40c) to find the new value of I that considers the Richardson number scaling, which allows a new value of the eddy viscosity, which allows a new solution for the vertical velocity profile. This allows a recalculation of the vertical turbulent stress, which then allows a 
recalculation of the Richardson number. This process is continued until the solution converges completely; in practice, no more than 17 iterations were required. The modified bottom drag coefficient, $C_{d}$, is defined in terms of the vertical average of the velocity profile, $\bar{u}=\frac{1}{H} \int_{-H}^{0} u(z) d z$, and the friction velocity as:

$$
C_{d}=\frac{u^{*}}{\bar{u}^{2}}
$$

This quantity is calculated at all grid cells, and the effect of this modification on the tidal solution is explored for all months of the year.

\subsection{Numerical solution}

Using Eq. (39) to rewrite the left hand side, numerical solutions of Eq. (36) are found in the form:

$$
\frac{\left(u^{*}\right)^{2}}{H}=\frac{1}{\Delta z}\left[v_{i+1 / 2}\left(\frac{u_{i-1}-u_{i}}{\Delta z}\right)-v_{i-1 / 2}\left(\frac{u_{i}-u_{i-1}}{\Delta z}\right)\right]
$$

where $\Delta z$ is the vertical increment of water depth, $z, H$ is total water depth, and $v$ is the eddy viscosity, $u=u^{*}$; discretized by:

$$
\begin{aligned}
& l_{i+1 / 2}=\frac{l_{i+1 / 2}^{*_{o z_{i+1 / 2}}}}{l_{i+1 / 2}+l_{o z_{i+1 / 2}}}, \\
& l_{o z_{i+1 / 2}}=\left(v_{i+1 / 2}\left(\frac{u_{i+1}-u_{i}}{\Delta z}\right)_{i+1 / 2} N^{-3}\right)_{i+1 / 2}^{1 / 2},
\end{aligned}
$$

with: 


$$
v_{i+1 / 2}=u^{*} l_{i+1 / 2}
$$

The buoyancy frequency, $N$, is approximated numerically by:

$$
N_{i+1 / 2}^{2}=-\frac{g}{\rho_{0}}\left(\frac{\rho_{i+1}-\rho_{i}}{\Delta z}\right)
$$

Eqs. (40a-c) are also discretized in a similar manner (not shown). Note that a staggered grid is used where $u$ is defined at grid nodes, and $v$ is defined at $1 / 2$ nodes. Boundary conditions are: no-slip at the bottom, i.e., $u(z=0)=0$, and no stress at the free surface, i.e., $d U(z=H) / d z=0$. In practice, buoyancy frequency is calculated from the Ocean Data Viewer (ODV) software, which is then interpolated horizontally onto the OTIS grid and vertically onto a $\Delta z$ grid. This formulation yields a matrix system that, when inverted, will give a solution for $u$, from which $C_{d}$ can be determined from Eq. (41). The choice of pressure gradient, $P_{x}$, is based on scaling that allowed a realistic range of variability. Large choices of $P_{x}$ result in a $C_{d}$ with a small range of values, and small values of $P_{x}$ yield a larger range of values of $C_{d}$. For our purposes, a constant value of $P_{x}=0.01 \mathrm{~m}$ is used. The variation of $C_{d}$ with varied $H$ and $N$ is given in Figure 60 for this value of $P_{x}$. Smaller values of $C_{d}$ are found for deep water locations, and for shallow-water locations with stable stratification (larger $N$ ). 


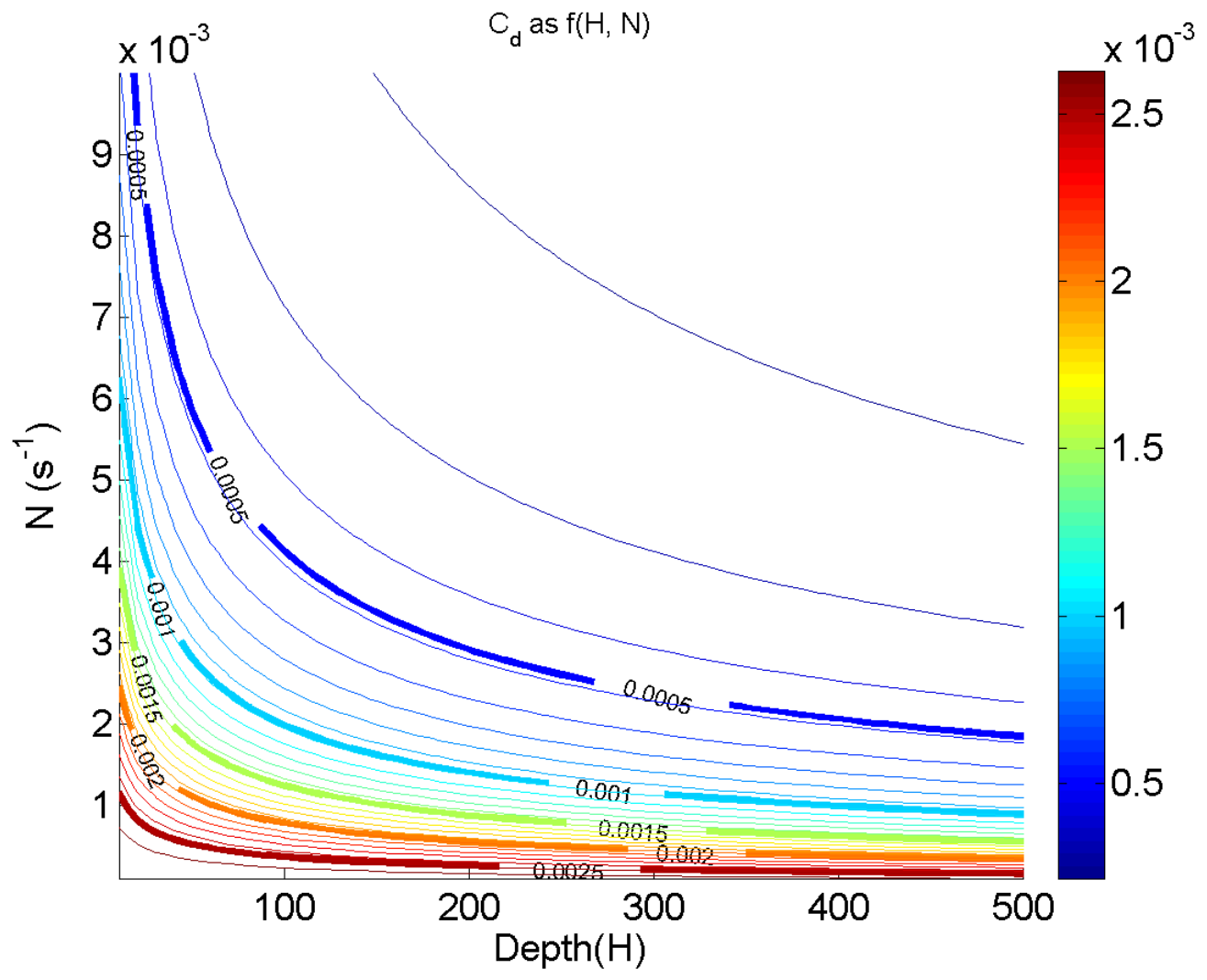

Figure 60 The variability of the (dimensionless) drag coefficient, $C_{d}$, with varied water depth $(H)$, and buoyancy frequency $(N)$ for a value of $P_{x}=0.01 \mathrm{~m}$. 


\subsection{Linearization of friction and model calibration}

This spatially-variable drag coefficient is then inserted into OTIS as a dimensionless modification of the global $C_{d}$ used in the $\lambda$ terms in Eqs. (8a-c), using its inherent linearization of friction. The linearization operation is done to approximate the behavior of the quadratic friction terms in the shallow water equations. OTIS uses a linearization scheme based on Snyder et al., (1979), which utilizes an expansion of the bottom friction term in the shallow water equations, and successively approximates the friction velocity field, using the solution of one iteration as the input for the next iteration, until successive solutions adequately converge. In practice, seven iterations were sufficient for all model runs. The form of this expansion of frictional terms changes the dissipation coefficient operator in Eqs. (33a-c) to:

$$
\lambda(r)=\frac{C_{d}}{H}\left(r_{0}+r_{1}\left|u_{f}\right|+r_{2}\left|u_{f}\right|^{2}+\ldots\right)
$$

where the $r_{i}^{\prime}$ s are numerical coefficients of this expansion. In Snyder et al., (1979), this expansion used no more than the quadratic term, the effects of which proved to be negligible for their study area. In default operation, OTIS only retains $r_{1}$, recreating Eq. (33d). In our analyses of spatially-variable bottom drag, the fields of $C_{d}$ found from Eq. (41) are made more or less sensitive to the stratification-induced seasonal changes by retaining the constant $\left(r_{0}\right)$ and linear $\left(r_{1}\right)$ coefficient terms of Eq. (46), and the magnitudes of $r_{o}$ and $r_{1}$ are numerically adjusted in OTIS in the form: 


$$
\lambda(r)=\frac{C_{d}}{H}\left(r_{0}+r_{1}\left|u_{f}\right|\right) \quad .
$$

Calibration runs of the drag coefficient model were made by comparing the mean amplitudes of model outputs to direct tide gauge measurements for different $\left(r_{0}, r_{1}\right)$ combinations. Values of $r_{0}, r_{1}$ are chosen between 0.001 and 1.0. Smaller choices of $r_{0}$ and $r_{1}$ generally yield greater sensitivity of tidal response to variability in $C_{d}$. However, if the value of $r_{0}$ is sufficiently large (greater than 0.5 ), the effect of the $r_{1}$ coefficient becomes negligible, and calibrations yield nearly identical results for all chosen values of $r_{1}$. Conversely, if $r_{0}$ and $r_{1}$ are very small, the sensitivity of the model becomes inordinately large. However, for small values of $r_{0}$ and large values of $r_{1}(\sim 1.0)$, sensitivity also decreases, but not as greatly as the previous case (large $r_{0}$; small $r_{1}$ ). Thus, $r_{0}$ is more of a controlling factor on the model sensitivity than $r_{1}$. The RMSE of the difference of modelled minus observed was compared for all gauges for both diurnal and semidiurnal constituents. A "best" set of tuning values, which consistently keep the RMSE below $0.08 \mathrm{~m}$ for all constituents at all locations (which was less than the RMSE found from the spatially constant calibrations described above), was found to be: $r_{o}=$ $0.1 ; r_{1}=0.5$.

\subsubsection{Ekman velocity determination}

The last model modification involves the consideration of the Ekman velocity due to wind-induced transport, as prescribed by Eq. (28). An Ekman balance (Ekman, 
1905 ) is achieved in conditions of steady winds, a reasonable assumption for monsoon conditions. Wind stress data is taken from the ECMWF climate reanalysis products, which provides a pre-calculated wind stress product at a resolution of $(1 / 8)^{\circ}$. Since the model domain straddles the Equator, the Coriolis term will vanish there. To prevent the calculated Ekman velocity from being discontinuous at the equator, an additional term, identical to $\lambda$ in Eq. (33d), is added which incorporates bed friction effects:

$$
\begin{aligned}
& -f v_{E}=\frac{\tau_{x}}{H \rho}-\frac{C_{d}\left|u_{f g}\right|}{H} u_{E} \\
& f u_{E}=\frac{\tau_{y}}{H \rho}-\frac{C_{d}\left|u_{f g}\right|}{H} v_{E}
\end{aligned}
$$

The frictional terms are only significant when $f$ is small, within $2^{\circ}$ of the equator. These equations are coupled, and can be solved via inversion of a 2 by 2 matrix. The equations are rewritten as:

$$
\left|\mathbf{u}_{E}\right|=\sqrt{\left(u_{E}^{2}+v_{E}^{2}\right)}
$$

and it is this absolute velocity that will be added into the model. The friction velocity, $u_{f g}$, used in Eq. (48) is not equivalent to $u^{*}$; it is the seasonal field of the absolute geostrophic velocity (as defined above in section 5.3.6, and by Eq. (27)). As with all previous modifications, thirteen models are run; twelve monthly determinations for 
monthly averaged wind stress data, and one annual determination based on the overall time average of all wind stress data.

\subsection{Results}

\subsubsection{Seasonal variability of tides}

Semidiurnal and diurnal tidal amplitudes and phases at the 20 gauges are fitted to Eq. (32), yielding a constant value, $a_{0}$, as the mean value of the tide, annual harmonics, $a_{1}, b_{1}$, semi-annual harmonics, $a_{2}, b_{2}$, and root mean-squared residual error (RMSE). The magnitudes of the annual and semi-annual harmonics are defined as: $M_{a}=$ $\operatorname{sqrt}\left(a_{1}^{2}+b_{1}^{2}\right)$, and $\mathrm{M}_{\mathrm{sa}}=\operatorname{sqrt}\left(a_{2}^{2}+b_{2}^{2}\right)$, respectively, which give a measure of the relative importance of the seasonal variability of tidal constituents for each gauge location. Tables 20-23 show the fit results for all locations, listing $M_{2}, K_{1}, O_{1}$, and $S_{2}$, respectively.

The results of the coherence calculations at the annual band between the monsoon (represented by the WNPMI) and tidal variability is reported in Table 24 for all amplitudes, and an example map of the coherence distributions for $\mathrm{M}_{2}$ amplitudes is shown in Figure 61. Correlations of tidal phase with the WNPMI at the annual band is reported in Table $25 . \mathrm{M}_{2}$ and $\mathrm{S}_{2}$ amplitude coherence is stronger in the Malacca Strait, as is the semidiurnal phase coherence. $K_{1}$ is moderately coherent for amplitudes and for phases, but $\mathrm{O}_{1}$ is more strongly correlated for both amplitudes and phases. In the Gulf of Thailand there is strong amplitude and phase coherence for $M_{2}$ and $K_{1}$, and $S_{2}$ 
and $\mathrm{O}_{1}$ are moderately coherent. In the South China Sea, coherence is somewhat weaker than other locales in both amplitudes and phases, and very weak correlations are seen in all constituents in the Java Sea with the exception of the $K_{1}$ amplitude.

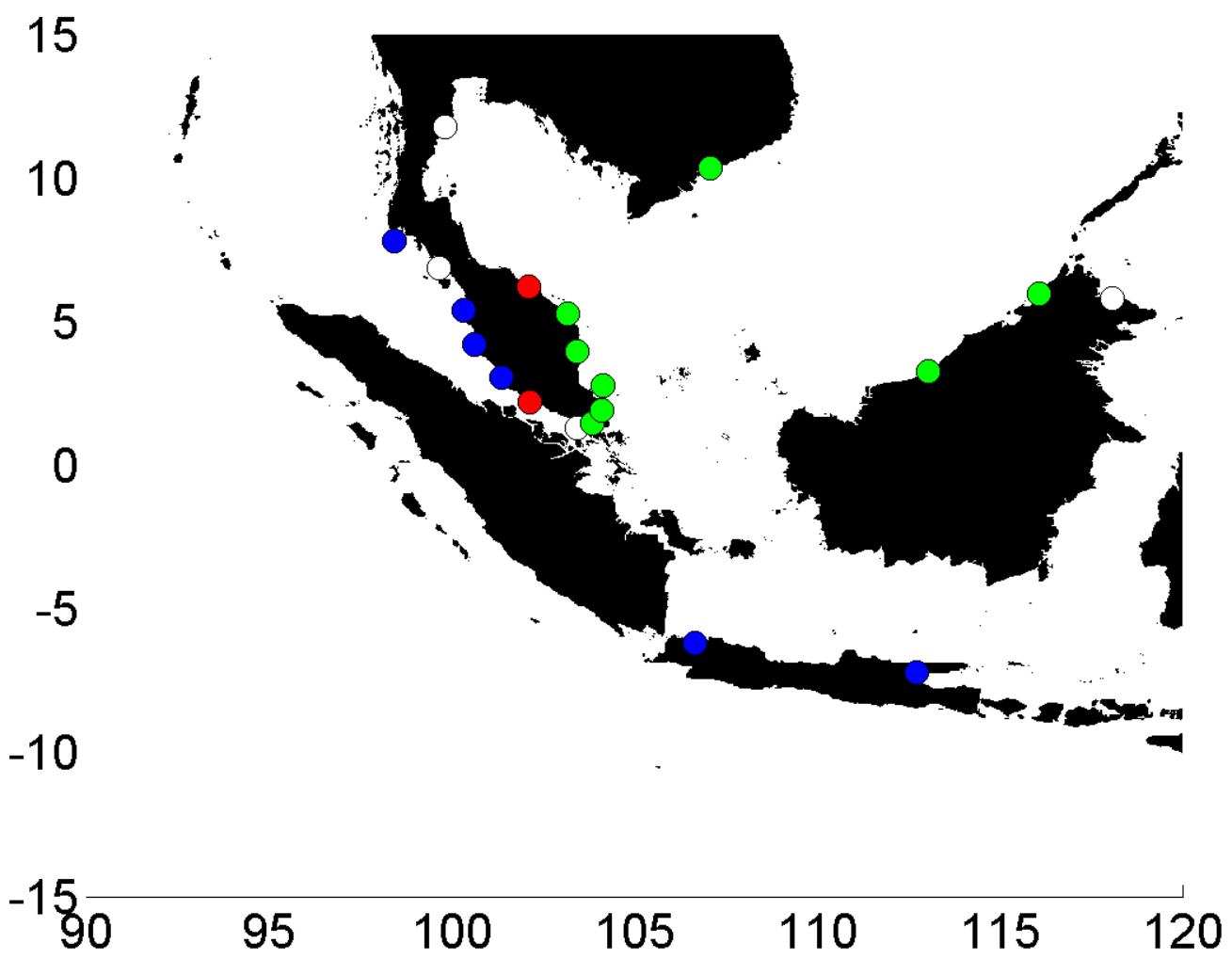

Figure 61 Map of annual coherences of $M_{2}$ amplitudes with the Western North Pacific Monsoon Index (WNPMI). Color of the dots indicates the correlation value found at the annual frequency band; white is a correlation of $0-0.25$, blue is $0.25-0.50$, red is $0.5-$ 0.75 , and green is greater than 0.75 . The $x$ and $y$ axes are latitude and longitude, respectively. 


\subsubsection{South China Sea}

The seasonal tidal variability in the SCS is small at both annual and semi-annual bands (10 mm or less), with the notable exception of Vung Tau, VTM. Here, seasonal variability is large (200 mm or more), and annual and semi-annual harmonics are of comparable magnitude for all tidal amplitudes. There is a strong bias in the semi-annual behavior towards the later part of the year for all but $S_{2}$, as the peak in fall is much more pronounced than that in spring. The phase variability for the semidiurnal constituents is over 5 degrees semi-annually. Figure 62 (a-d) shows the variability for $M_{2}$ and $K_{1}$ amplitudes and phases at Vung Tau, fitted with Eq. (32).

\subsubsection{Java Sea}

There are only two stations available to analyze in the Java Sea, Surabaya, IND in the south central Java Sea, and Jakarta, IND in the far western Java Sea. There is not any strong seasonal pattern for semidiurnal amplitudes, but $\mathrm{K}_{1}$ has a large annual and semiannual variation at both gauges. Seasonality is also moderate at Surabaya in $\mathrm{O}_{1}$. Phase variations are generally small, but $\mathrm{M}_{2}$ and $\mathrm{S}_{2}$ have a significant annual modulations.

Figure $63(a-d)$ shows the variability for $M_{2}$ and $K_{1}$ amplitudes and phases at Surabaya, fitted with Eq. (32). 

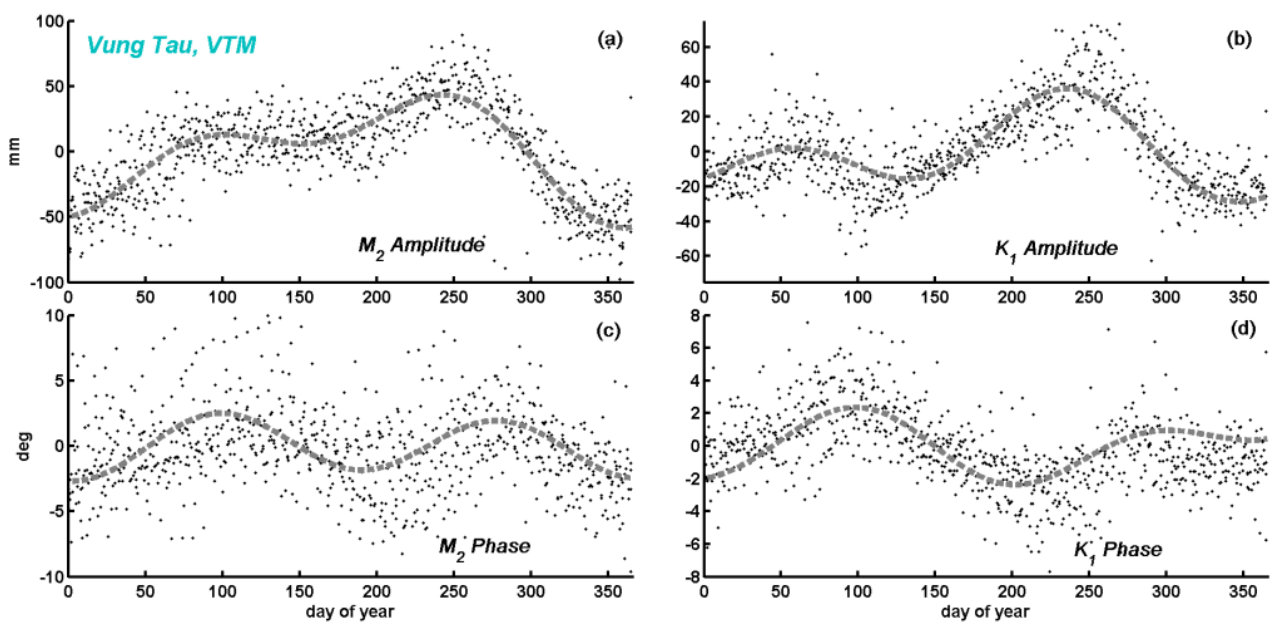

Figure 62 South China Sea example tidal variability with harmonic fits of Eq. (32) applied (grey dashed lines). The amplitude ( $a$ and $b$ ) and phase ( $c$ and d) variability at Vung Tau, Vietnam is shown for the $M_{2}$ and $K_{1}$ constituents.
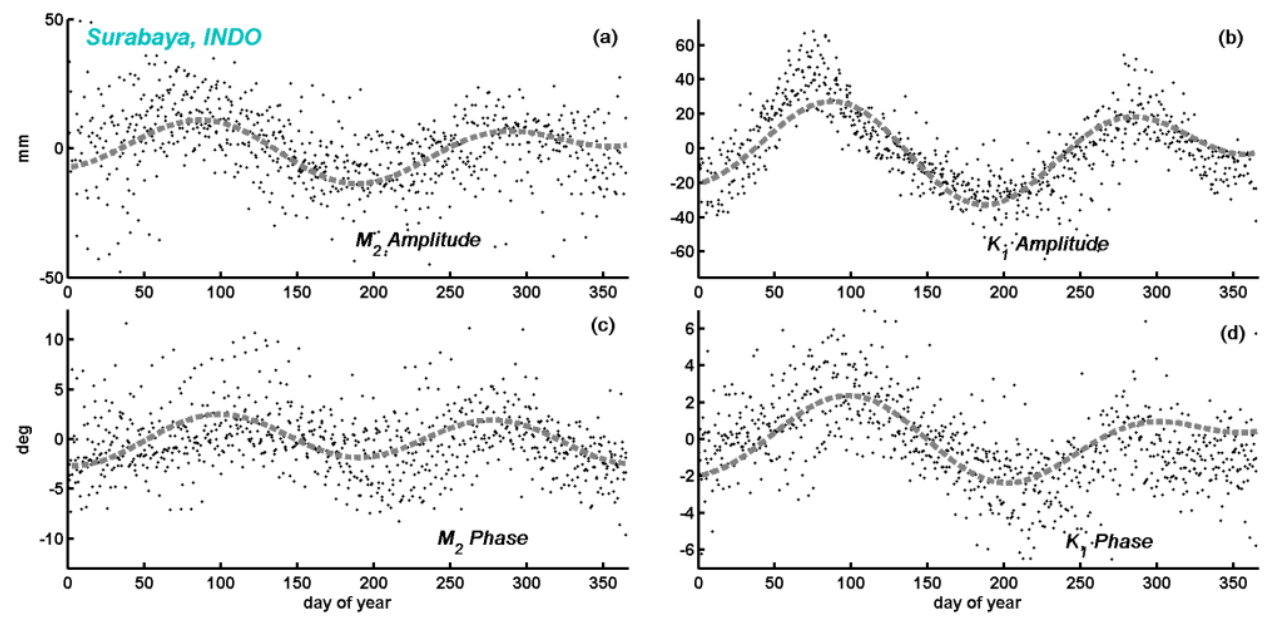

Figure 63 Java Sea example tidal variability with harmonic fits of Eq. (32) applied (grey dashed lines). The amplitude ( $a$ and $b$ ) and phase ( $c$ and d) variability at Surabaya, Indonesia is shown for the $\mathrm{M}_{2}$ and $\mathrm{K}_{1}$ constituents. 


\subsubsection{Gulf of Thailand}

Seasonal variability in the southern part of the Gulf is larger than anywhere else in the study domain for semidiurnal amplitudes. $S_{2}$ shows variability that is mainly semiannual, but $\mathrm{M}_{2}$ shows nearly equal semi-annual and annual magnitudes. Phase variability for both semidiurnals can reach 5 degrees or more. $\mathrm{K}_{1}$ and $\mathrm{O}_{1}$ both exhibit a mix of annual and semi-annual variability in amplitude; $\mathrm{K}_{1}$ variability is larger than $\mathrm{O}_{1}$, but $K_{1}$ mean amplitudes are also larger, so both diurnal tides have a similar relative variation. Diurnal phase variability is generally mild. Figure 64 (a-d) shows the variability for $M_{2}$ and $K_{1}$ amplitudes and phases at Sedili, MLY, fitted with Eq. (32).

\subsubsection{Malacca Strait}

In the Malacca Strait, diurnal amplitudes are lower, but the tidal variability of the diurnal constituents is remarkable. $\mathrm{O}_{1}$ amplitudes vary semi-annually by as much as 25 $\mathrm{mm}$, and in some locations, are nearly $50 \%$ of the mean tide. $\mathrm{O}_{1}$ phases also vary strongly at the semi-annual band, up to 40 degrees. The $K_{1}$ variability in amplitude and phase is typified by a mixed pattern of annual and semi-annual behavior, with very steep transitions occurring around August/September and around February/March at Keling, Langkawi, Penang, and Kukup, MLY. Lumut and Kelang also have the sharp transition in the later part of the year, but not the earlier peak. Figure $65(a-d)$ shows an example of this variability for $\mathrm{M}_{2}$ and $\mathrm{K}_{1}$ amplitudes and phases, shown at Lumut, MLY, fitted with Eq. (32). 

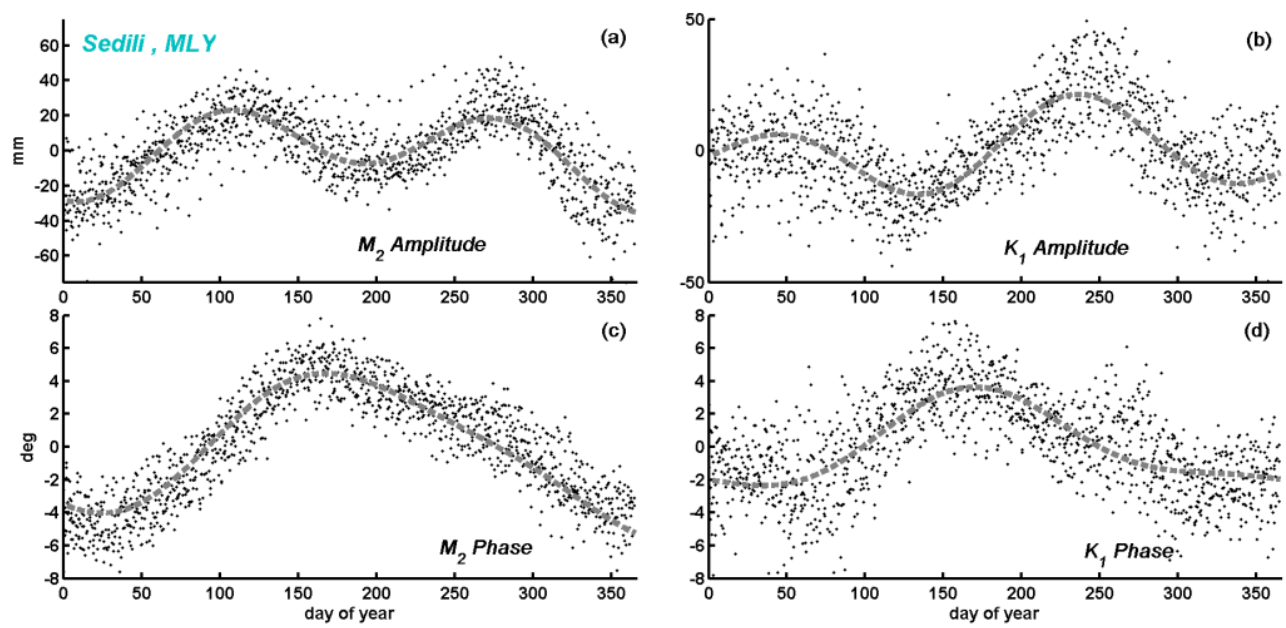

Figure 64 Gulf of Thailand example tidal variability with harmonic fits of Eq. (32) applied (dashed grey lines). The amplitude ( $a$ and $b$ ) and phase ( $c$ and d) variability at Sedili, Malaysia is shown for the $\mathrm{M}_{2}$ and $\mathrm{K}_{1}$ constituents.
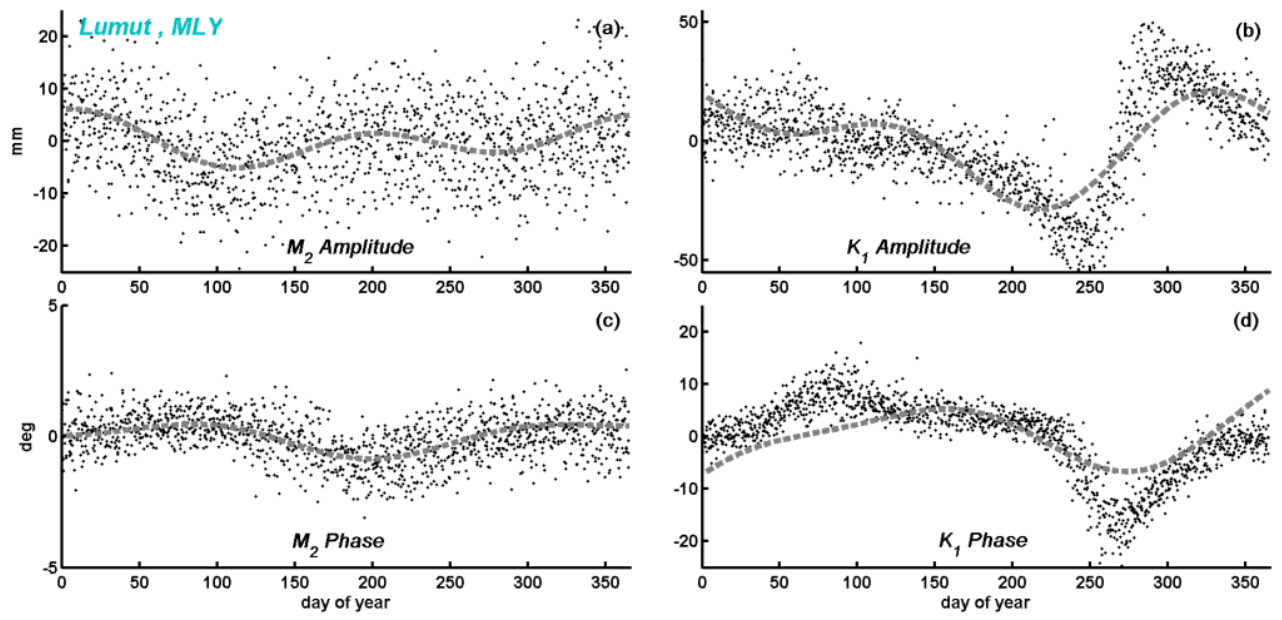

Figure 65 Malacca Strait example tidal variability with harmonic fits of Eq. (32) applied (dashed grey lines). The amplitude ( $a$ and $b$ ) and phase ( $c$ and d) variability at Lumut, Malaysia is shown for the $\mathrm{M}_{2}$ and $\mathrm{K}_{1}$ constituents. 


\subsubsection{Seasonal variability of physical properties}

\subsubsection{Seasonal variability of sea surface height}

Selections of the seasonal fields of SSH interpolated to the native OTIS resolution are shown in Figure 66. Four months are shown; the maximum extent of each monsoon phase (January and July), and the inter-monsoon periods (April and October). Sea level is highest in the Gulf of Thailand during January (Fig. 66(a)), and lower in the South China Sea and Malacca Strait. By April (Fig. 66(b)), sea level is fairly even across the region. In July (Fig. 66(c)), the situation seen in February is now reversed, with higher sea levels seen in the eastern SCS and in the Malacca Strait. By October (Fig. 66(d)), northern monsoon conditions are returning, and sea levels are higher again in the GOT. This is also the time of highest sea level in the Malacca Strait. 


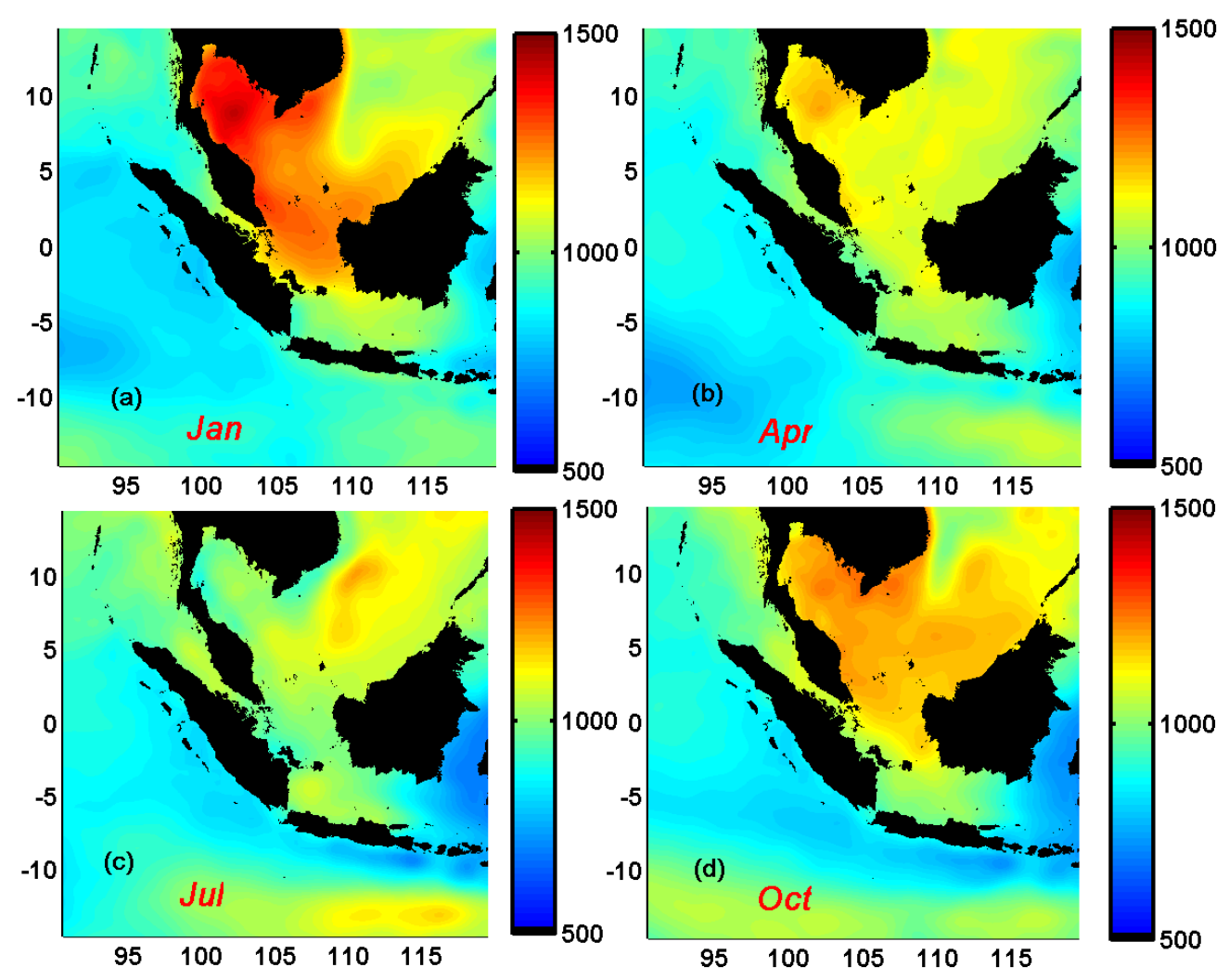

Figure 66 Seasonal fields of sea surface height (SSH) variability, in units of $\mathrm{mm}$, assimilated from AVISO. Four months are shown: January (a), April (b), July (c), and October (d). 


\subsubsection{Seasonal variability of geostrophic currents}

Seasonal fields of the absolute value of geostrophic currents are shown in Figure 67. Geostrophic currents in January (Fig. 67(a)) are largest in the Malacca Strait, along the southeastern coast of China, and on both sides of the northern Malay Peninsula, including the north GOT. In April (Fig. 67(b)), geostrophic currents are small, with the exceptions of the eastern Java Sea, and the southeastern tip of the Malay Peninsula, which persist through July (Fig. 67 (c)). August also sees an increase in geostrophic currents off the coast of Vietnam and China, which increases through October (Fig. 67 (d)), at which time the currents in the Malacca Strait again begin to increase. It is also apparent that geostrophic currents are always large east of Borneo in the Makassar Strait, but this is due to the constant throughput of water masses, and does not affect the dynamics near any tide gauges in this study. Temporal patterns at most locations are more annual than semi-annual. Note that this study only considers the absolute value of horizontal geostrophic currents, therefore the directions of currents are not indicated in Figure 67. For a good visual representation of the seasonal surface current circulation patterns, see Wyrtki (1961), plates 1-6. 

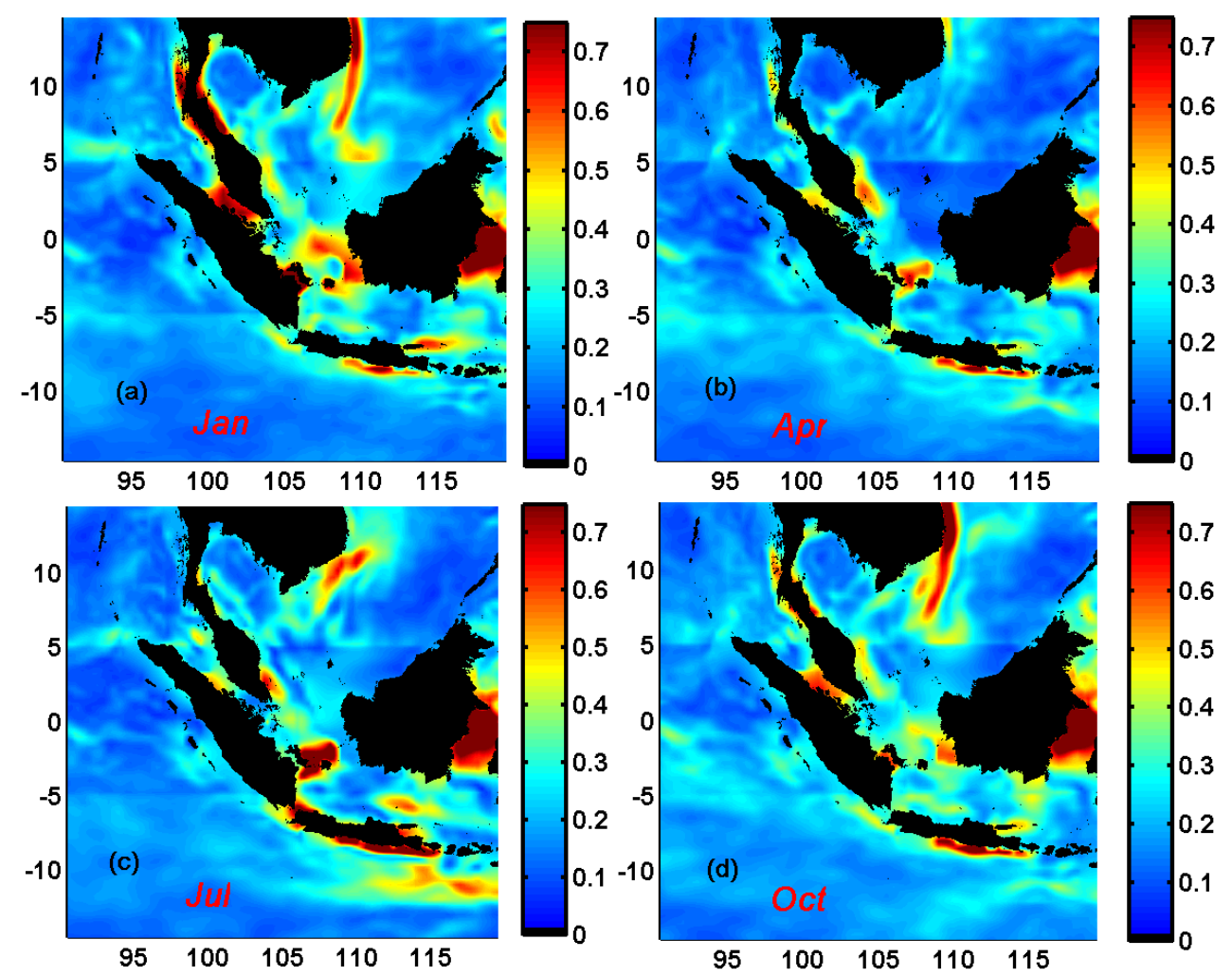

Figure 67 Seasonal fields of geostrophic velocity $\left(u_{g}\right)$ variability, in units of $\mathrm{ms}^{-1}$, assimilated from AVISO. Four months are shown: January (a), April (b), July (c), and October (d). 


\subsubsection{Seasonal variability of stratification}

In Figure 68, four seasons of stratification-sensitive bottom drag $\left(C_{d}\right)$

modifications are shown. It is readily apparent that the modifications to the effective drag coefficient are only a factor in shallow water areas, and the deep open-ocean shows little variation. As the model modifications are divided by water depth, this is not surprising. The scale of the plots shows the value of the dimensionless bottom drag coefficient, $C_{d}$, in parts per thousand.

In January (Fig.68 (a)), $C_{d}$ is largest in the southern Malacca Strait, the western GOT, the northern Java Sea, and between Sumatra and Borneo. In April (Fig.68 (b)), stratification has diminished in the GOT and Malacca Strait, though is still large at the tip of Singapore. Values are also large in the Java Sea. In July (Fig.68 (c)), increased $C_{d}$ is observed over the majority of the Gulf of Thailand, Java Sea, and the Malacca Strait. In October (Fig.68 (d)), the pattern is similar to July, though much diminished in intensity. 

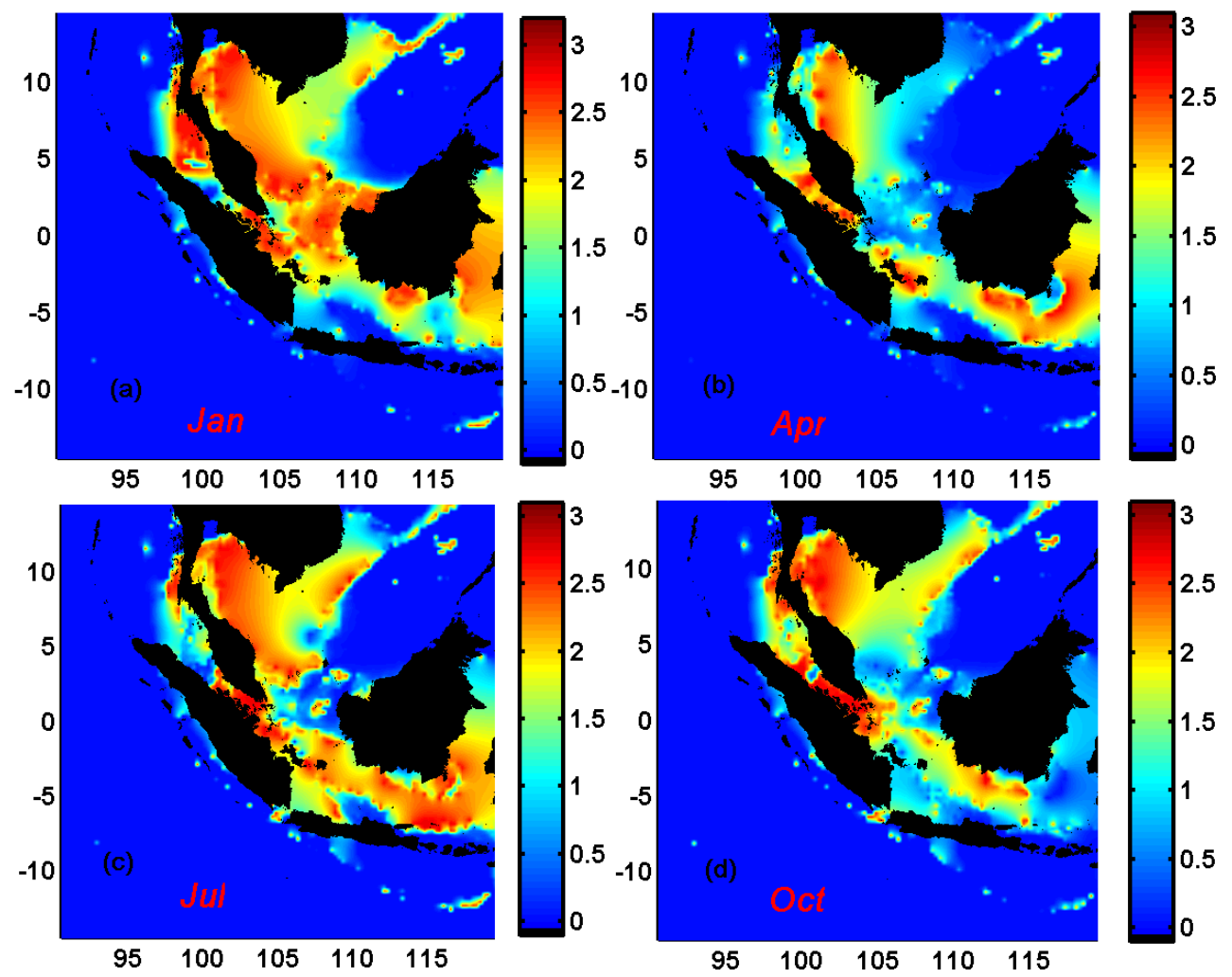

Figure 68 Seasonal fields of effective bottom drag $\left(C_{d}\right)$ variability (unitless), calculated using data assimilated from the World Ocean Atlas 2013 dataset (WOA13). Four months are shown: January (a), April (b), July (c), and October (d). 


\subsubsection{Seasonal variability of Ekman velocity}

Absolute Ekman velocity seasonal fields are shown in Figure 69. Four seasons are shown; units are in $\mathrm{ms}^{-1}$. As was true for the geostrophic current and bottom drag coefficient fields, only shallow water locations show any significant modification in Ekman velocity, since water depth affects the solutions. In January (Fig.69 (a)) and in July (Fig.69 (c)) when the monsoon winds are blowing strong, large values of Ekman transport are seen near the Mekong delta in Vietnam, around the southern tip of the Malay Peninsula, between Sumatra and Java, and in the Java Sea. The intensity is generally greater in July, with additional Ekman transport occurring in the northern Gulf of Thailand. During April (Fig.69 (b)) and October (Fig.69 (d)) when the monsoons winds have died down, Ekman transport is virtually negligible at most locations. This switching pattern produces a semi-annual behavior. 

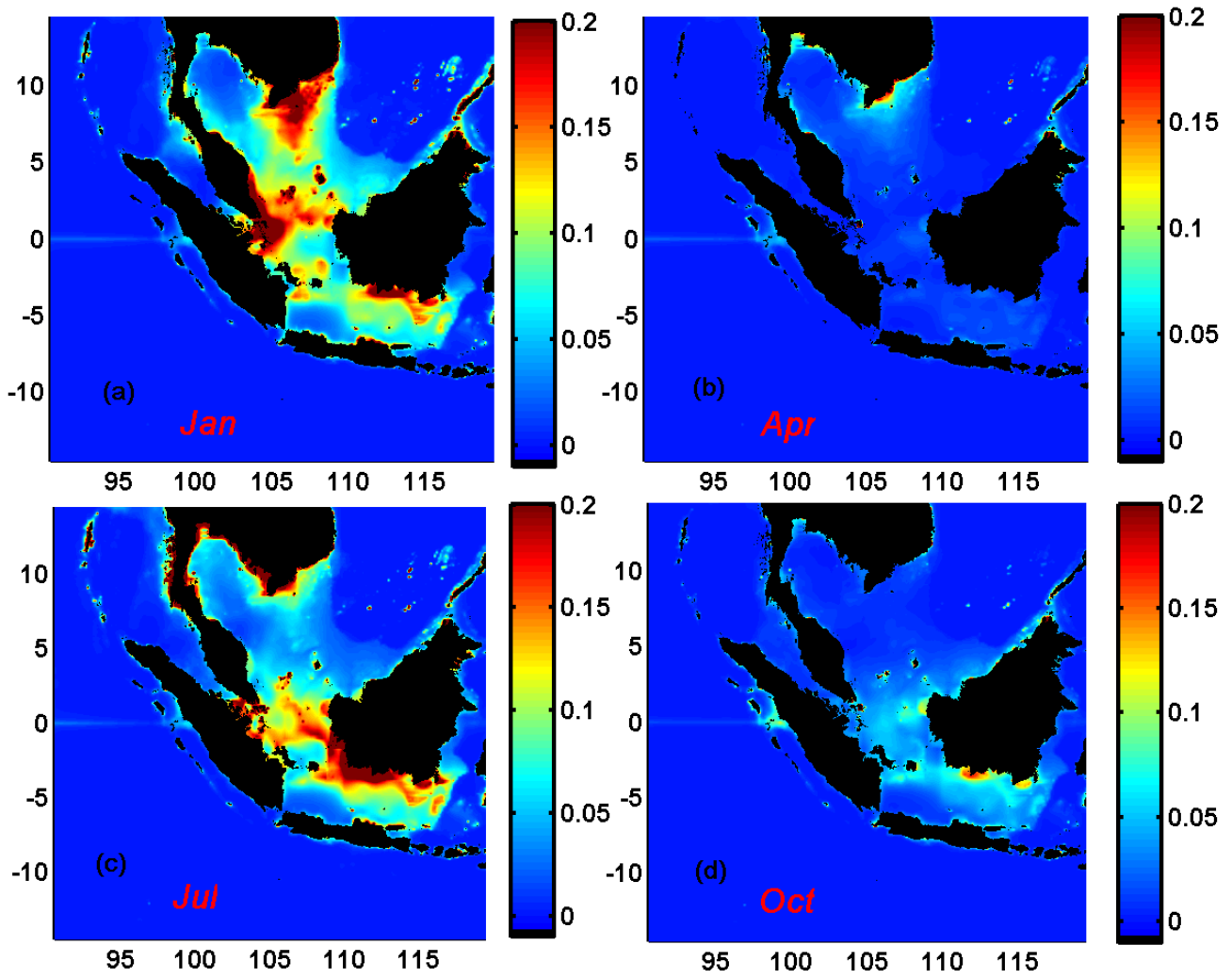

Figure 69 Seasonal fields of Ekman velocity variability, in units of $\mathrm{ms}^{-1}$, calculated using data assimilated from ECMWF. Four months are shown: January (a), April (b), July (c), and October (d). 


\subsubsection{Seasonal variability of physical properties by region}

The previous set of figures documents the spatial patterns of physical property variability, but only four months are shown, which does not give a complete temporal picture of variability. To better understand the seasonal variability within each subregion, the monthly variability is extracted for the grid cells surrounding each gauge location for the seasonal fluctuations in sea surface height ( $\mathrm{SSH})$, dimensionless effective drag coefficient $\left(C_{d}\right)$, geostrophic velocity $\left(u_{g}\right)$, and Ekman velocity $\left(u_{e}\right)$. Figure 70 shows this variability for each region. Results are shown for near Vung Tau, VTM, in the South China Sea (first column), Jakarta, IND, in the Java Sea (second column), Sedili, MLY in the Gulf of Thailand (third column), and Lumut, MLY in the Malacca Strait (last column). SSH is plotted in blue in the first row, $C_{d}$, as red in the second row, $u_{g}$, as green in the third row, and $u_{e}$ as black in the bottom row. The SCS and GOT exhibit a strong annual pattern in $\mathrm{SSH}$, with a maximum found in January, and minimum in June/July. The Java Sea is slightly semi-annual, with a larger maximum in May, and a lesser peak in November. Minima are found in March and September. The Malacca Strait is also semiannual, but with two equal maxima in May and November, a deep minimum in March, and a lesser minimum in September. The temporal patterns in $C_{d}$ are less distinct, but are approximately annual in the SCS, and semi-annual/annual mixed elsewhere. Geostrophic velocities are annual in the Java Sea and Gulf of Thailand, both of these have an extended minima during November to March, and a maxima during August in the Java Sea, and in May in the GOT. The magnitude of $u_{g}$ in the Java Sea is about twice 
that of the GOT. In the greater SCS and within the Malacca Strait, geostrophic velocities are of the same magnitude and mainly semi-annual, with a large maximum in December/January, and a lesser maximum in June/July. Both regions have weak minima in spring and fall months. Finally, the variability in Ekman velocity is mixed semi-annual in the SCS, the JS, and the GOT, with larger maxima in December/January, and lesser maxima in June or July. In the SCS, the lesser peak is nearly the same magnitude of the greater peak. Only within the Malacca Strait is this pattern different, being of small magnitude and mainly annual, with a maximum from June-August, and lower values seen at most other times. 

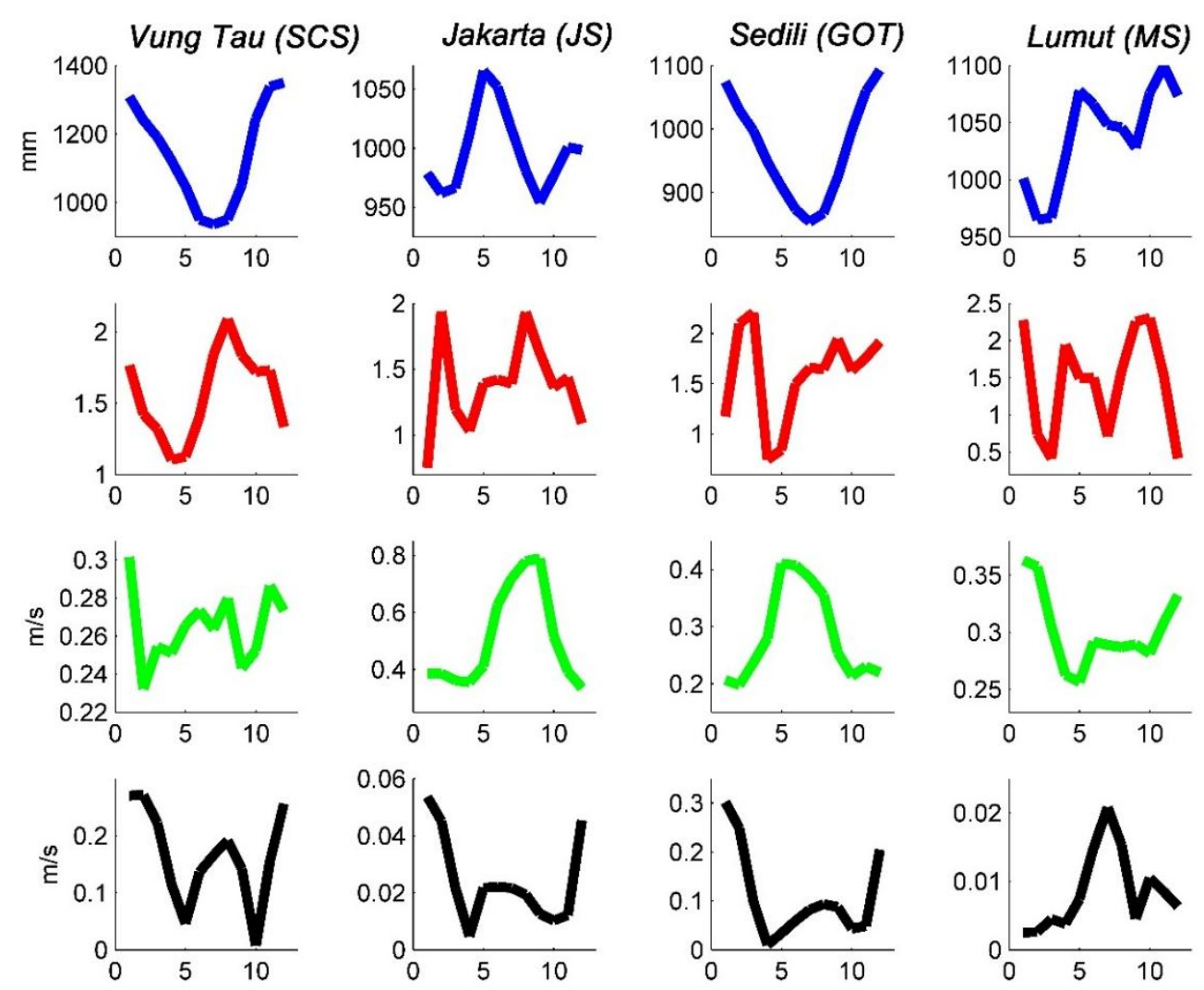

Figure $\mathbf{7 0}$ Time series of all relevant seasonal variability in physical properties at four locations in the model domain: Vung Tau, VTM, in the SCS; Jakarta, IND, in the JS; Sedili, MLY, in the GOT; and Lumut, MLY, in the MS. SSH variability is plotted as blue lines in the first row in units of millimeters, bottom drag $\left(C_{d}\right)$ variability is plotted as red lines in the second row (dimensionless), Ekman velocity $\left(u_{e}\right)$ variability is plotted as green lines in the third row, and geostrophic velocity $\left(u_{g}\right)$ is plotted as black lines in the bottom row. Note that different vertical scales are used. 


\subsubsection{Model results}

\subsubsection{SSH model results}

The first of the model results shown are those due to a seasonal change in sea surface height. Figure 71 shows the seasonal adjustments of the $M_{2}$ tidal amplitudes in January, April, July, and October. It is seen that tidal amplitudes are larger than the annual average during January and October, and less than the annual averages during April and July. In all temporal cases, the geographical distribution of significant change is mainly centered in the Gulf of Thailand, and near the Mekong delta. However, the magnitudes of all changes are very small, no more than $10 \mathrm{~mm}$ at any location in any season. Figure 72 shows the corresponding seasonal changes in the $\mathrm{K}_{1}$ tide. Similar to $\mathrm{M}_{2}$, all relevant adjustments occur in the Gulf of Thailand or nearby, but in the diurnal case, no change is greater than $5 \mathrm{~mm}$. The $S_{2}$ amplitude patterns are similar in temporal and spatial distribution to $\mathrm{M}_{2}$ and $\mathrm{O}_{1}$ is similar to $\mathrm{K}_{1}$, but these changes are even smaller, and are not shown. The effect on the model of a variation in mean sea level was a naïve hypothesis, and was not expected to produce the same magnitude of changes as the other three model runs. From these model results, this expectation is confirmed, and no further attention will be given to the tidal adjustments due to seasonal SSH. 


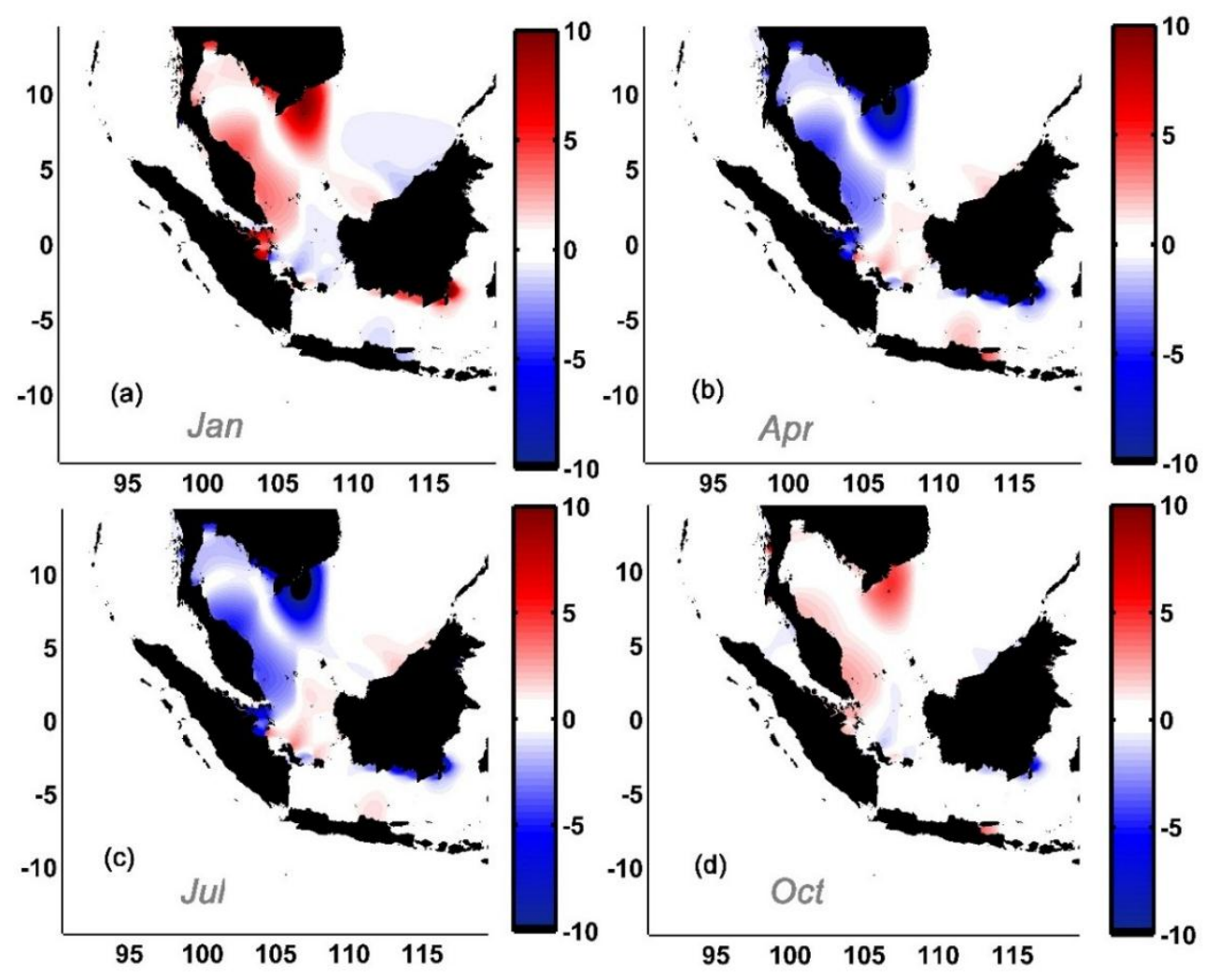

Figure 71 Modelled adjustments of the $M_{2}$ tidal amplitudes due to the seasonal changes in SSH in: January (a), April (b), July (c), and October (d). The $\mathrm{x}$ and $\mathrm{y}$ axes are latitude and longitude, and color bar units are in millimeters. 

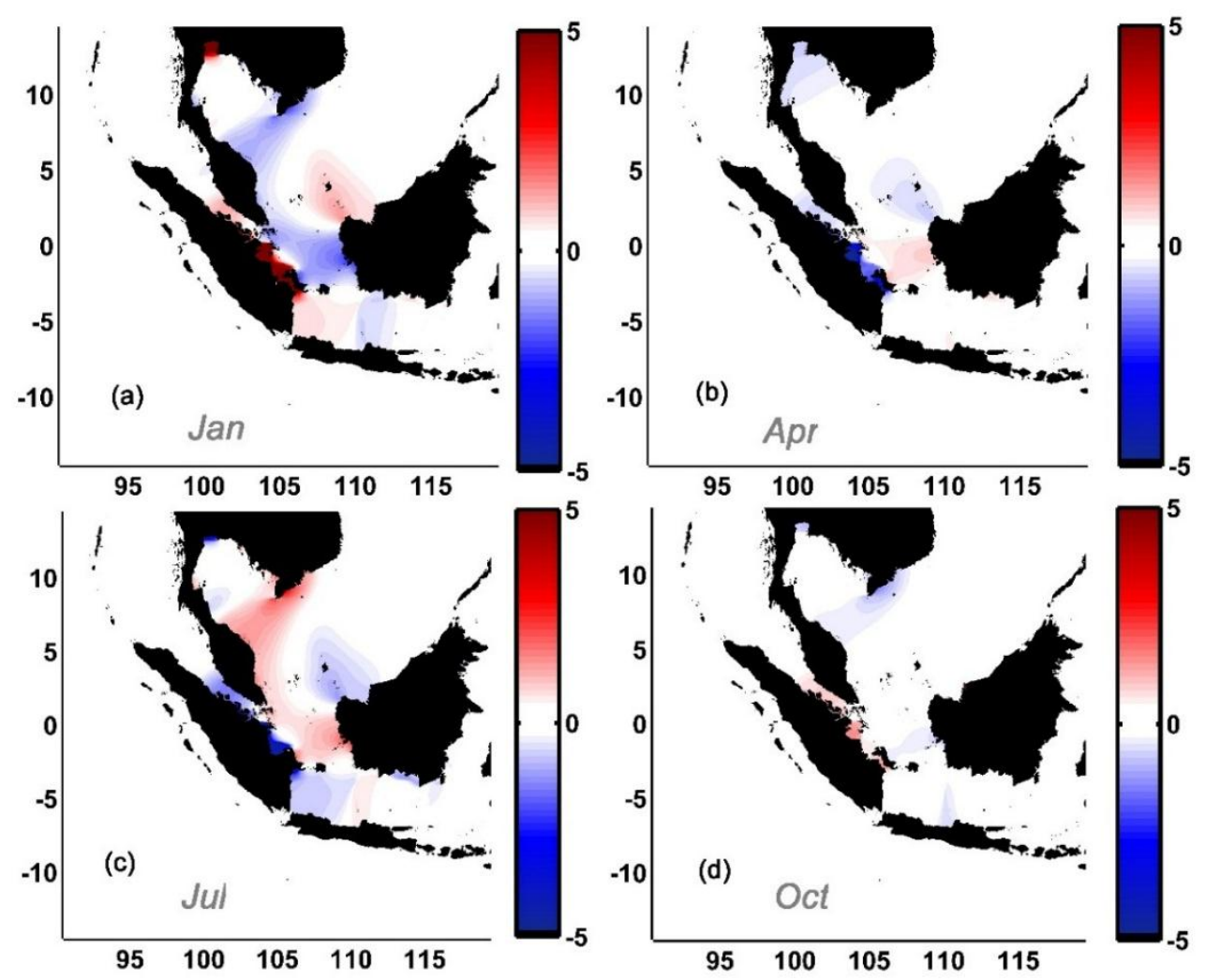

Figure 72 Modelled adjustments of the $K_{1}$ tidal amplitudes due to the seasonal changes in SSH in: January (a), April (b), July (c), and October (d). The $x$ and y axes are latitude and longitude, and color bar units are in millimeters. 


\subsubsection{Geostrophic velocity model results}

The geostrophic velocity model produces a much more spatially and temporally varied solution than the previous perturbations of water depth. Figure 73 shows the $M_{2}$ amplitude departures from annual averages in January, April, July, and October. In the eastern SCS, there are slightly lowered amplitudes in January, April, and October, but near the Mekong in the western SCS, there are increased tidal amplitudes at these times, and lowered amplitudes in July. In the GOT, maximum positive amplitude departures from annual averages are in April and maximum negative departures are in July. The behavior of tidal amplitudes in the Malacca Strait are mixed and semi-annual prominent, with a steep and reversing gradient pattern within a very small geographical area, with the maximum positive and negative adjustments occurring near the tip of the Malay Peninsula. The northern Java Sea near the southern coast of Borneo shows some interesting positive adjustments in April and negative adjustments in October, unfortunately, there are no tide gauges in this area to compare to. Figure 74 shows the $\mathrm{K}_{1}$ amplitude adjustments. Changes in the diurnal tide are weakly semi-annual in the majority of the GOT, however, the changes are greater in the far northern and southern parts of the Gulf. In the northern Malacca Strait, amplitude adjustments are positive in January, and negative at other times; in the southern Strait, the pattern is reversed. In the center of the Strait, very little change is seen at all. The northwestern and eastern Java Sea show very broad areas of strong seasonal change, with strong maxima in April and October. Figure 75 shows the $S_{2}$ results, which generally follow the patterns of $M_{2}$, 
with reduced magnitudes of variation. Figure 76 shows the $\mathrm{O}_{1}$ results, which are similar to $K_{1}$ in the Java Sea, where a large amplitude adjustment is seen in April and. Unlike $K_{1}$, the $\mathrm{O}_{1}$ variability in the GOT and Malacca Strait are mostly uniform across each subregion, and is nearly everywhere semi-annual in behavior.

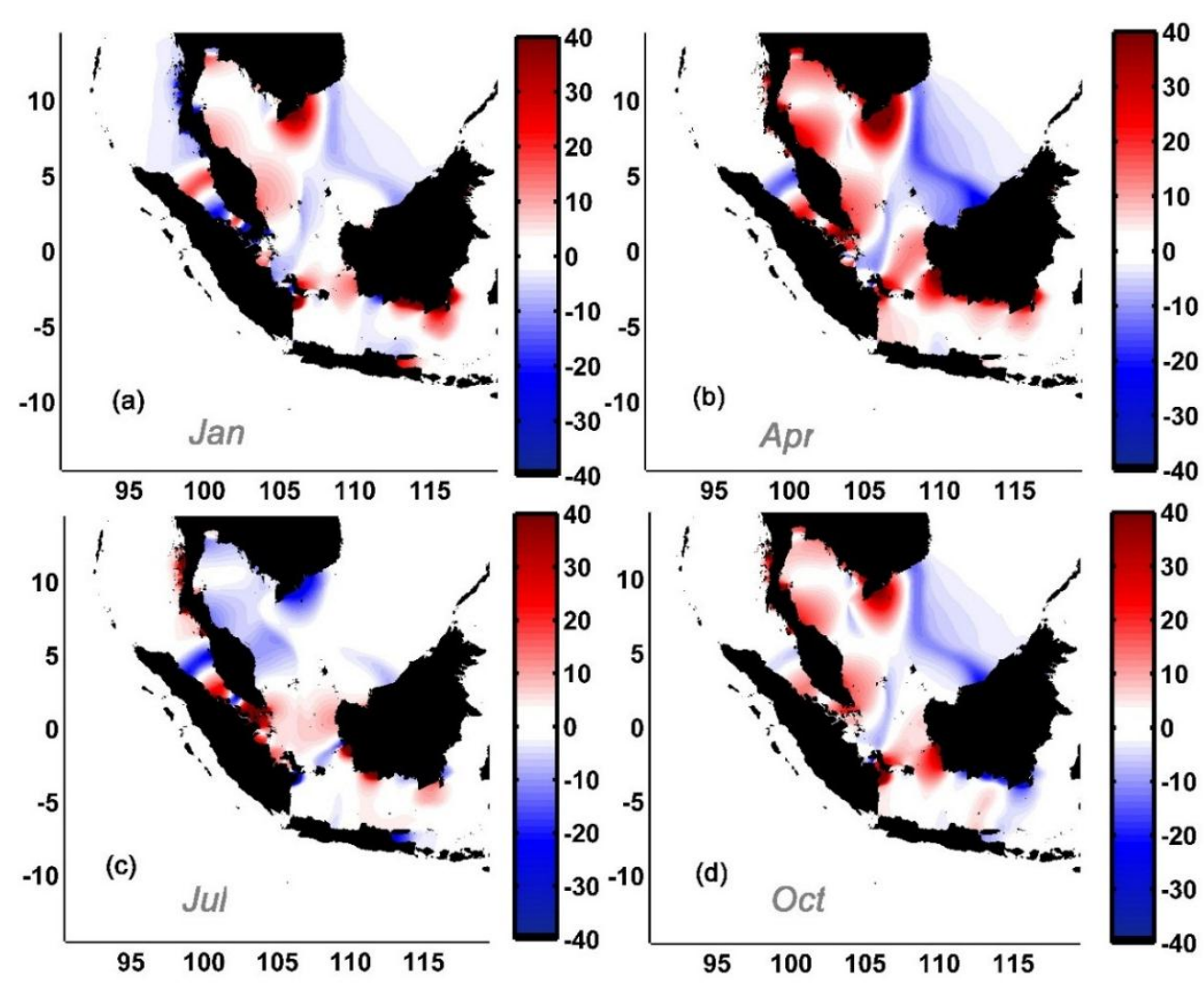

Figure 73 Modelled adjustments of the $\mathrm{M}_{2}$ tidal amplitudes due to the seasonal changes in geostrophic velocity in: January (a), April (b), July (c), and October (d). The $x$ and $y$ axes are latitude and longitude, and color bar units are in millimeters. 


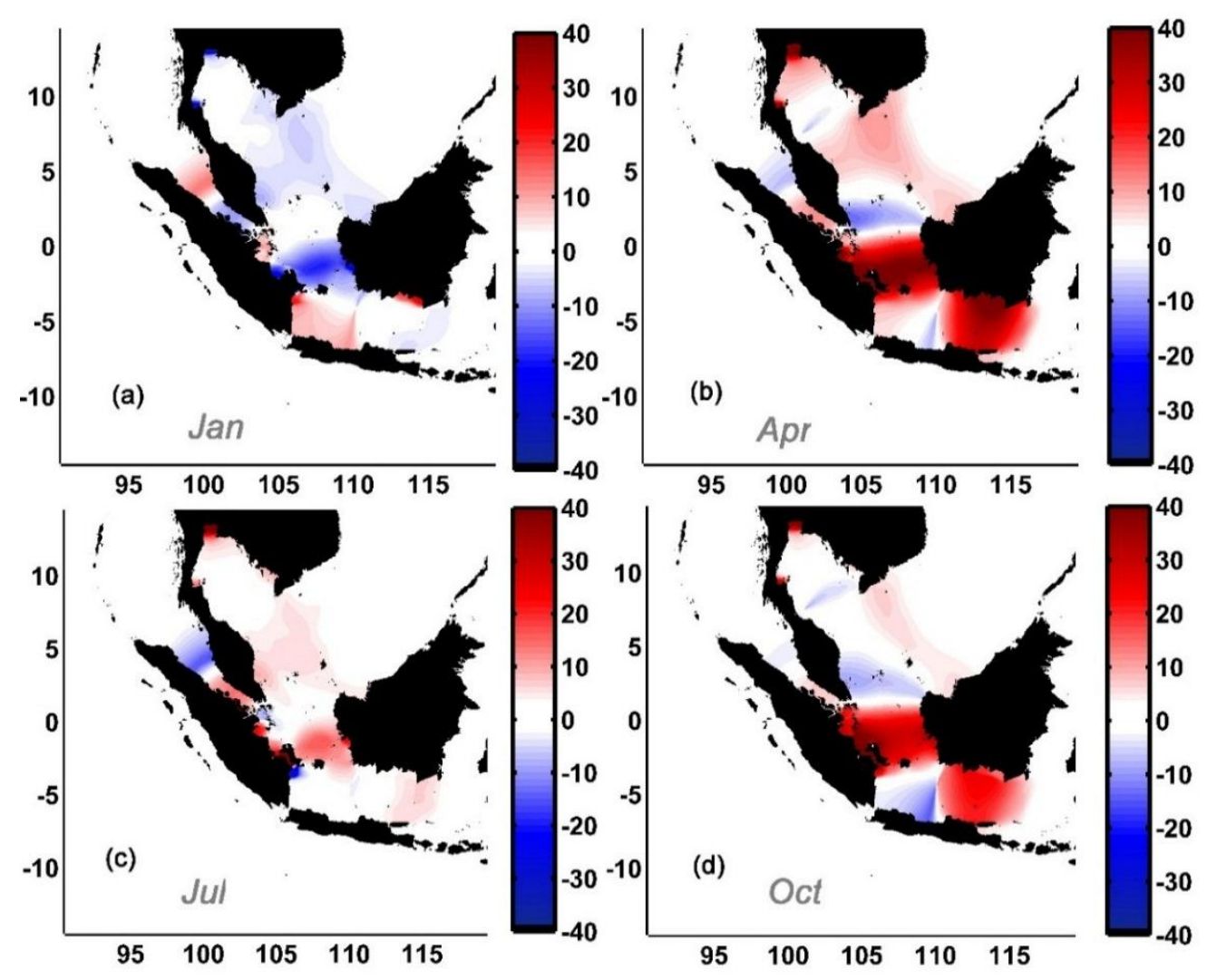

Figure 74 Modelled adjustments of the $K_{1}$ tidal amplitudes due to the seasonal changes in geostrophic velocity in: January (a), April (b), July (c), and October (d). The x and y axes are latitude and longitude, and color bar units are in millimeters. 


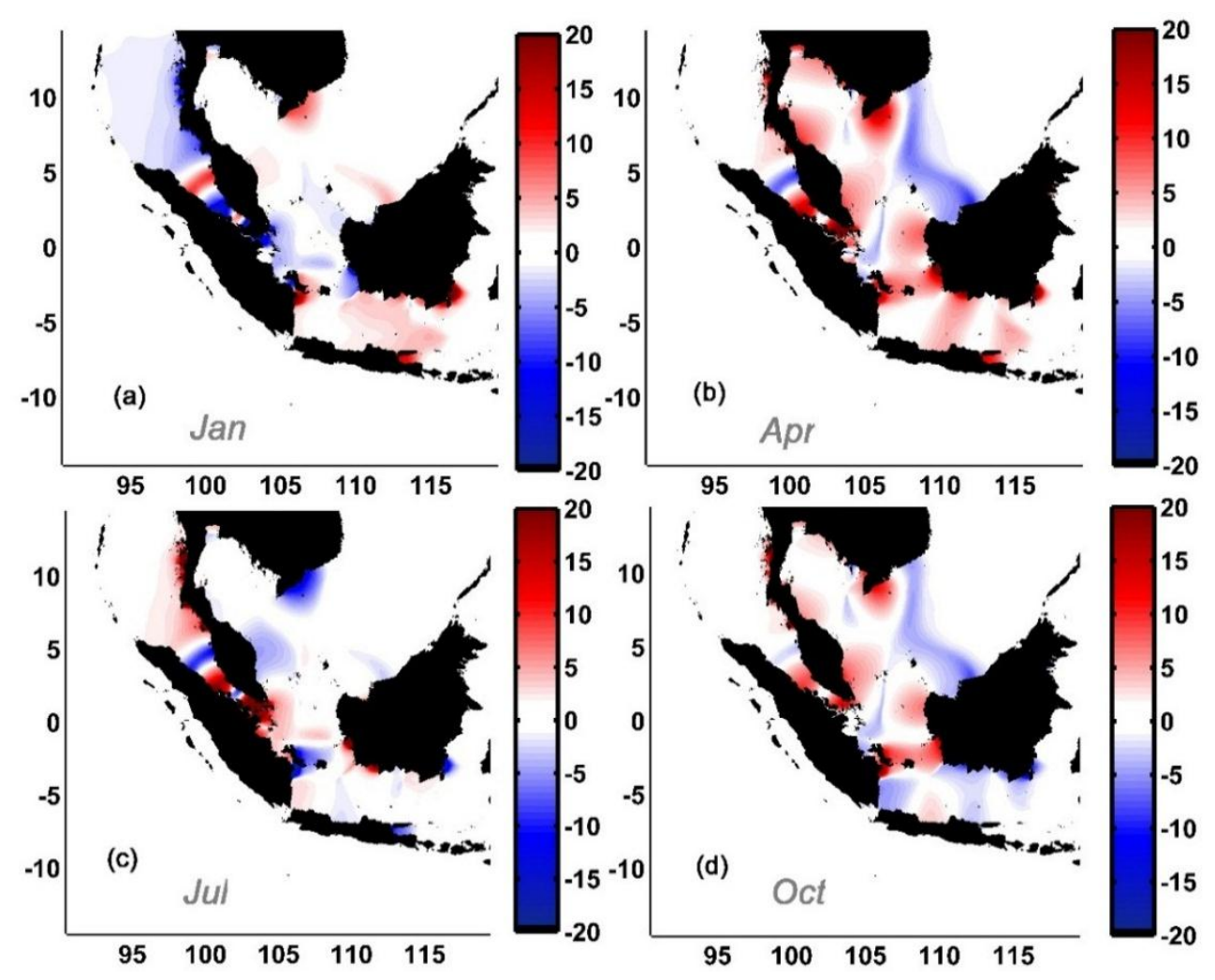

Figure 75 Modelled adjustments of the $S_{2}$ tidal amplitudes due to the seasonal changes in geostrophic velocity in: January (a), April (b), July (c), and October (d). The x and y axes are latitude and longitude, and color bar units are in millimeters. 


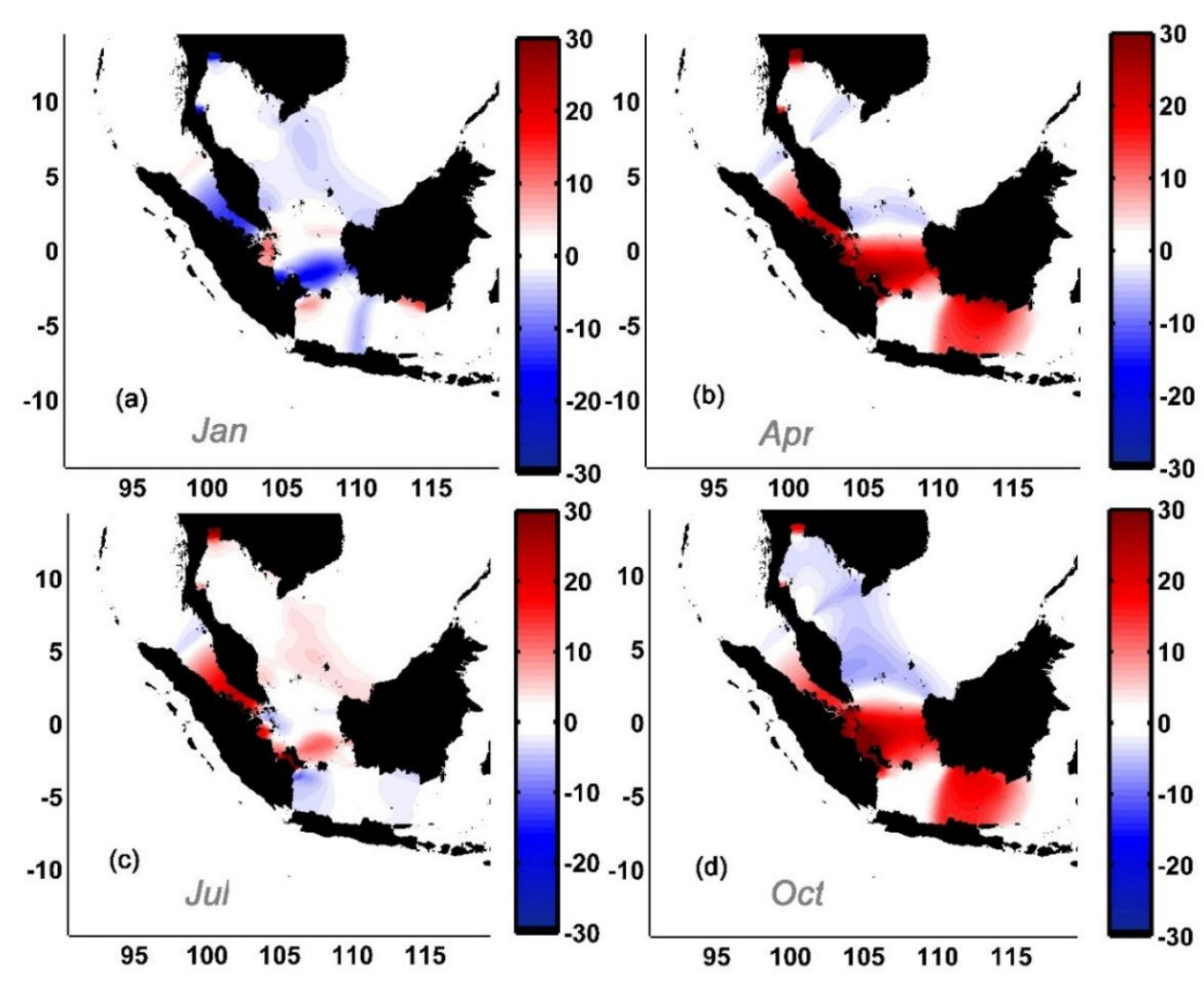

Figure 76 Modelled adjustments of the $\mathrm{O}_{1}$ tidal amplitudes due to the seasonal changes in geostrophic velocity in: January (a), April (b), July (c), and October (d). The $x$ and y axes are latitude and longitude, and color bar units are in millimeters. 


\subsubsection{Drag coefficient model results}

Figure 77 shows the model response of the seasonally variable bottom drag for $M_{2}$. The variation in stratification affects almost the entire shallow water area of the model domain, with a complex spatial pattern, and a much larger range of variation than the previous models. Model response in deep water locations is negligible, as the variation in $C_{d}$ is also small. The seasonal behavior in the northern GOT, the Java Sea, and the central SCS tends to be reversed from that seen in the southern GOT and off the southwestern corner of Borneo. Within the Malacca Strait, a generally semi-annual and spatially complex pattern is seen. Additionally, there is a very large positive amplification not seen in the previous models off the far northwestern coast of Thailand, near the tide gauge at Ko Taphao Noi. Figure 78 presents the $K_{1}$ results. The magnitude of seasonal stratification-induced tidal variation is of the same magnitude as the $M_{2}$ changes, but the spatial patterns are broader in nature. Amplitudes are higher than annual averages in April, and lower than annual averages in January, July, and October in the northern Java Sea, northern and southern GOT, and near Singapore. In the Malacca Strait, this yearly pattern is reversed in most parts, and also in the central Gulf of Thailand, near where a diurnal amphidromic point lies. Figure 79 shows $\mathrm{S}_{2}$, which has responses that are about half the magnitude and spatially and temporally similar to $M_{2}$, with the exception of the Java Sea, where the response is homogeneously semi-annual, with maxima in April and October, and minima in January and July. Figure 80 shows $\mathrm{O}_{1}$ model responses. Seasonal changes are equal in magnitude to $\mathrm{K}_{1}$ changes, 
but with differences in spatial distribution. Positive amplitude departures from annual averages are seen in most of the Gulf of Thailand in January and April, with lowered amplitudes seen in the other months shown. In the western Java Sea there are positive adjustments in April and July, negative in January and October. In the eastern Java Sea, and in between Borneo and Sumatra, there are slight positive departures during October, and negative departures at all other times.

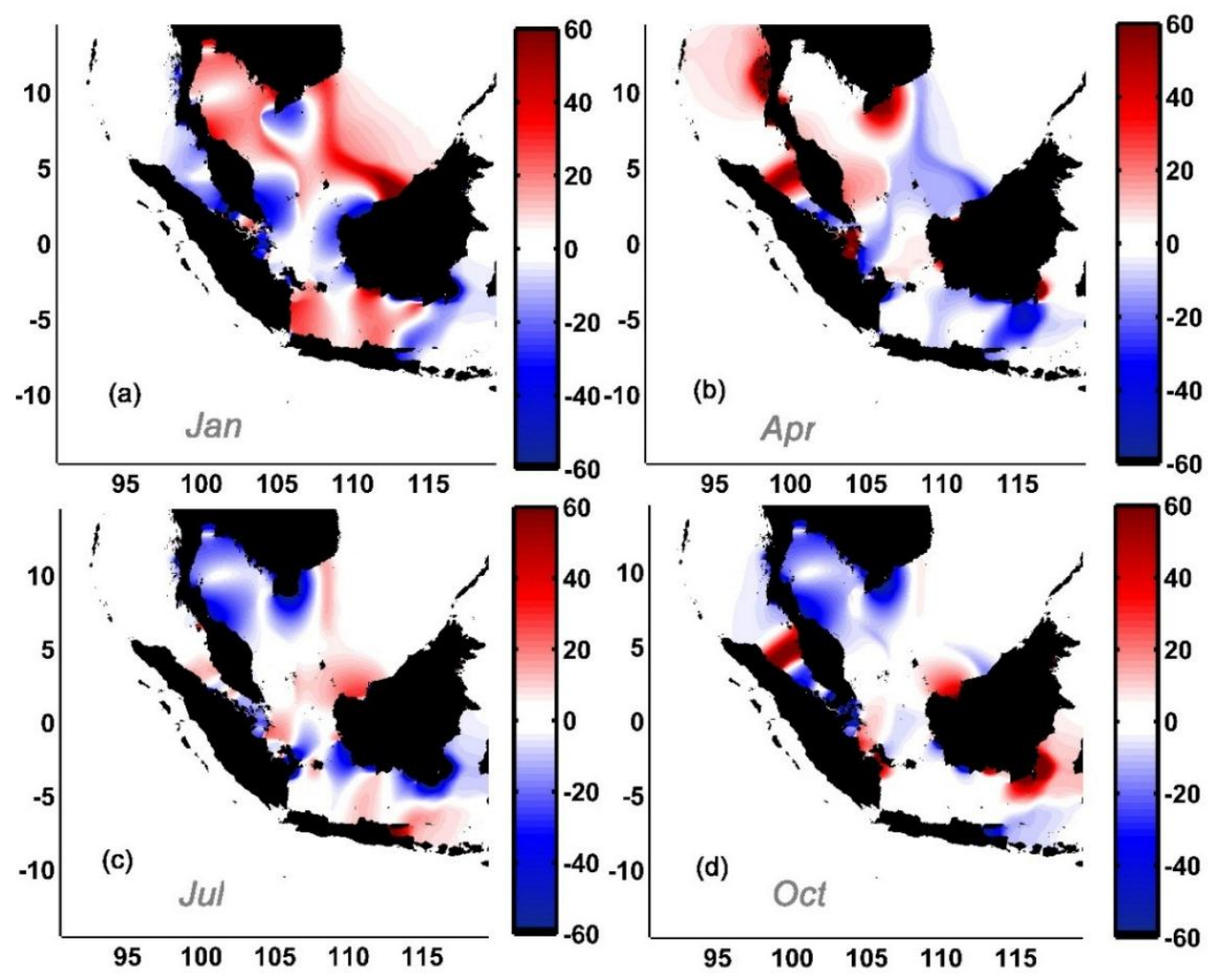

Figure 77 Modelled adjustments of the $M_{2}$ tidal amplitudes due to the seasonal changes in bottom drag $\left(C_{d}\right)$ in: January (a), April (b), July (c), and October (d). The $x$ and $y$ axes are latitude and longitude, and color bar units are in millimeters. 


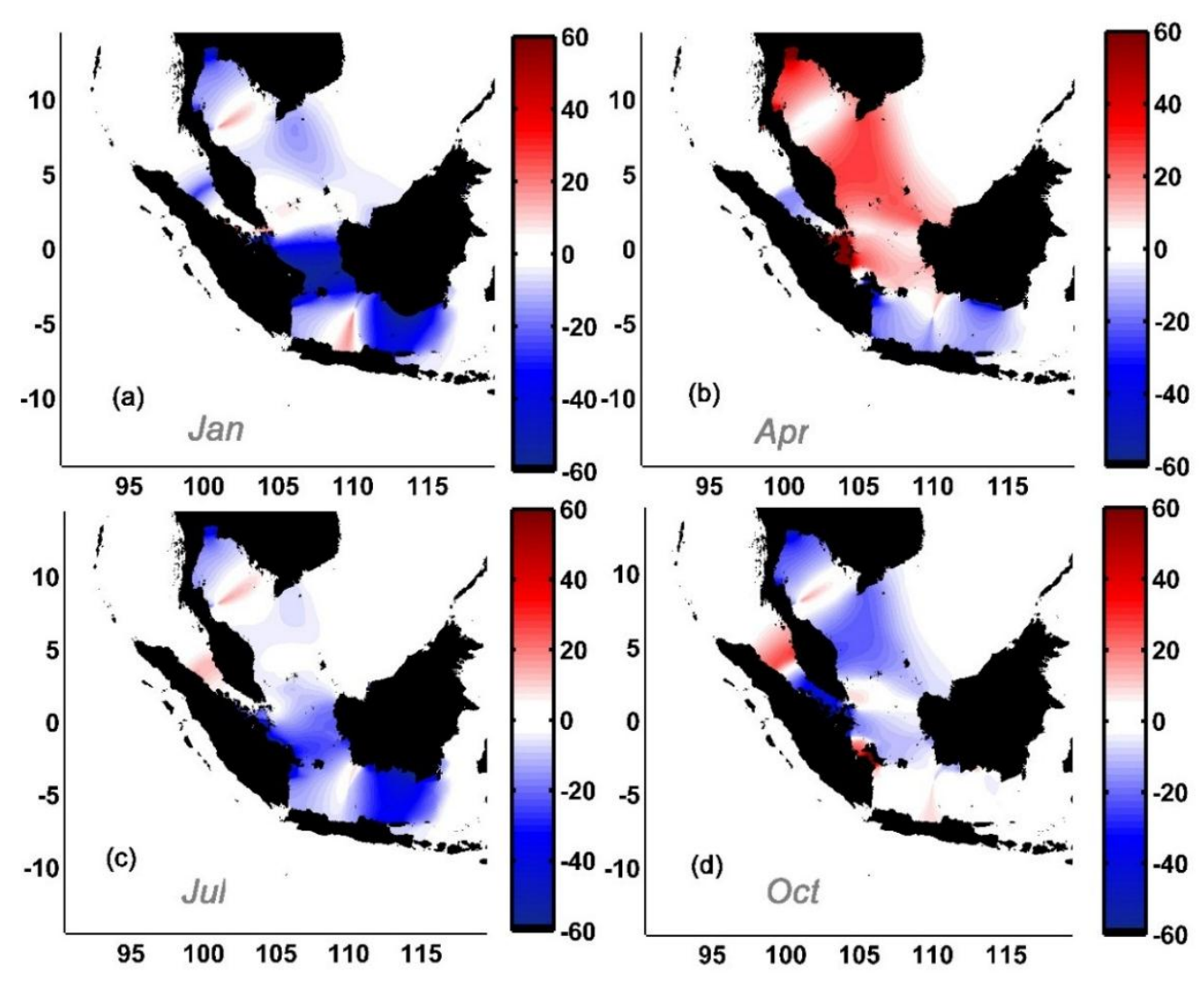

Figure 78 Modelled adjustments of the $K_{1}$ tidal amplitudes due to the seasonal changes in bottom drag $\left(C_{d}\right)$ in: January (a), April (b), July (c), and October (d). The $x$ and y axes are latitude and longitude, and color bar units are in millimeters. 


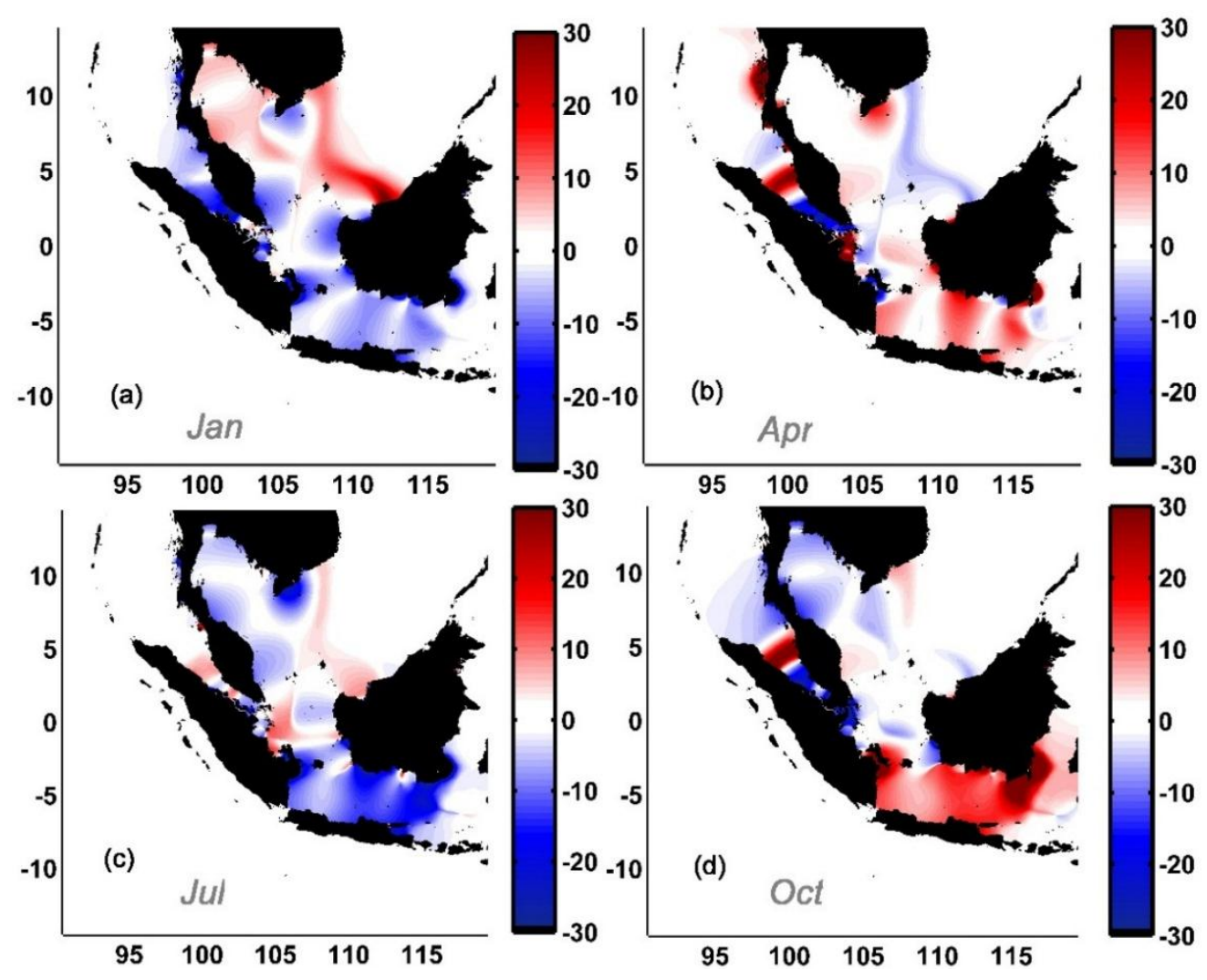

Figure 79 Modelled adjustments of the $S_{2}$ tidal amplitudes due to the seasonal changes in bottom drag $\left(C_{d}\right)$ in: January (a), April (b), July (c), and October (d). The $x$ and y axes are latitude and longitude, and color bar units are in millimeters. 


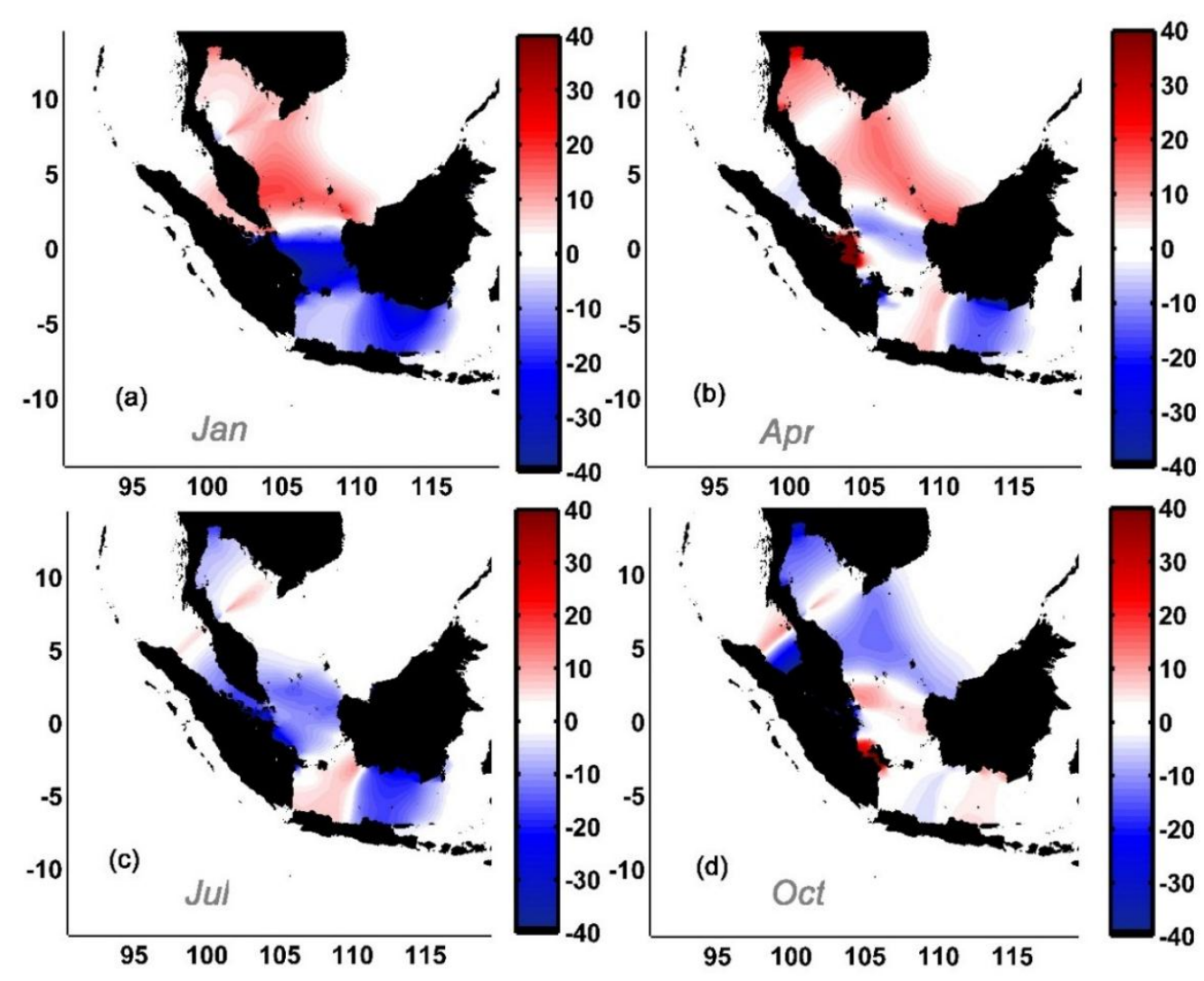

Figure 80 Modelled adjustments of the $\mathrm{O}_{1}$ tidal amplitudes due to the seasonal changes in bottom drag $\left(C_{d}\right)$ in: January (a), April (b), July (c), and October (d). The $x$ and y axes are latitude and longitude, and color bar units are in millimeters. 


\subsubsection{Ekman velocity model results}

Figure 81 shows the $M_{2}$ model response for the Ekman velocity model

modifications. Ekman forcing is only relevant during times of persistent winds, i.e., during the northeast monsoon in winter, and the southwest monsoon in summer, therefore, any modifications to the tidal amplitudes are only apparent during January and July. The spatial pattern is nearly identical in both windy seasons, with negative adjustments in the Gulf of Thailand and in the northwest and eastern Java Sea, and positive adjustments in the western South China Sea and central Java Sea. Figure 82 shows the $K_{1}$ results from Ekman forcing. Again, the only significant adjustments are found in January and July, and the entire shallow water region undergoes negative amplitude adjustments from annual averages, with the exception of the tip of the Malay Peninsula, which has a slight positive adjustment. Figure 83 shows the $S_{2}$ results, which exhibits a nearly identical spatial and temporal pattern as $M_{2}$, with approximately half the range of seasonal variation. Figure 84 shows the $\mathrm{O}_{1}$ results, which are spatially similar to $K_{1}$, except that the region of positive variability seen in January and July off the southeastern tip of the Malay Peninsula is much larger in extent. Areas of negative adjustment in the GOT, Malacca Strait and Java Sea are identical in pattern, and approximately half the range of seasonal variability. 


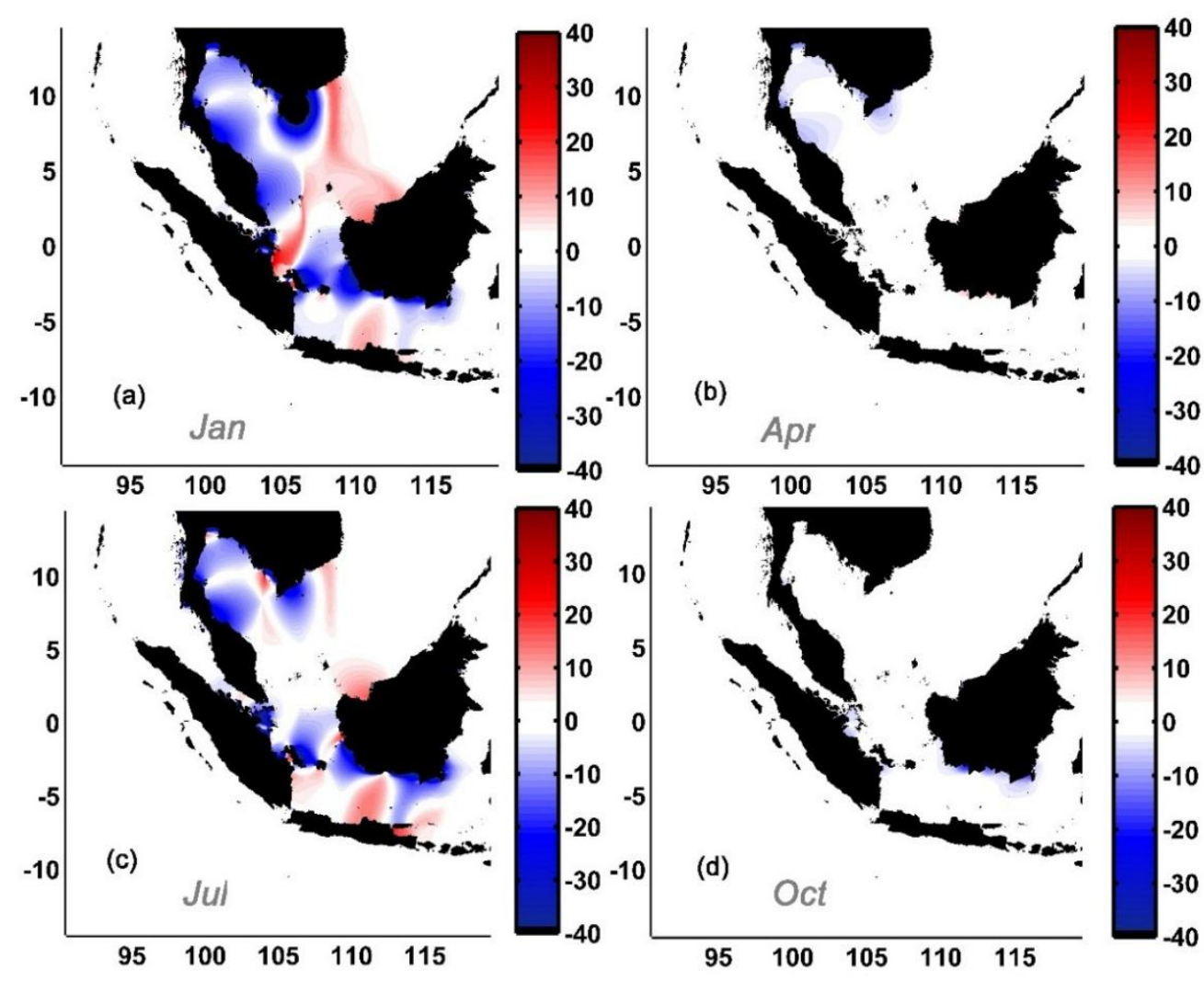

Figure 81 Modelled adjustments of the $M_{2}$ tidal amplitudes due to the seasonal changes in Ekman velocity $\left(u_{e}\right)$ in: January (a), April (b), July (c), and October (d). The $x$ and y axes are latitude and longitude, and color bar units are in millimeters. 


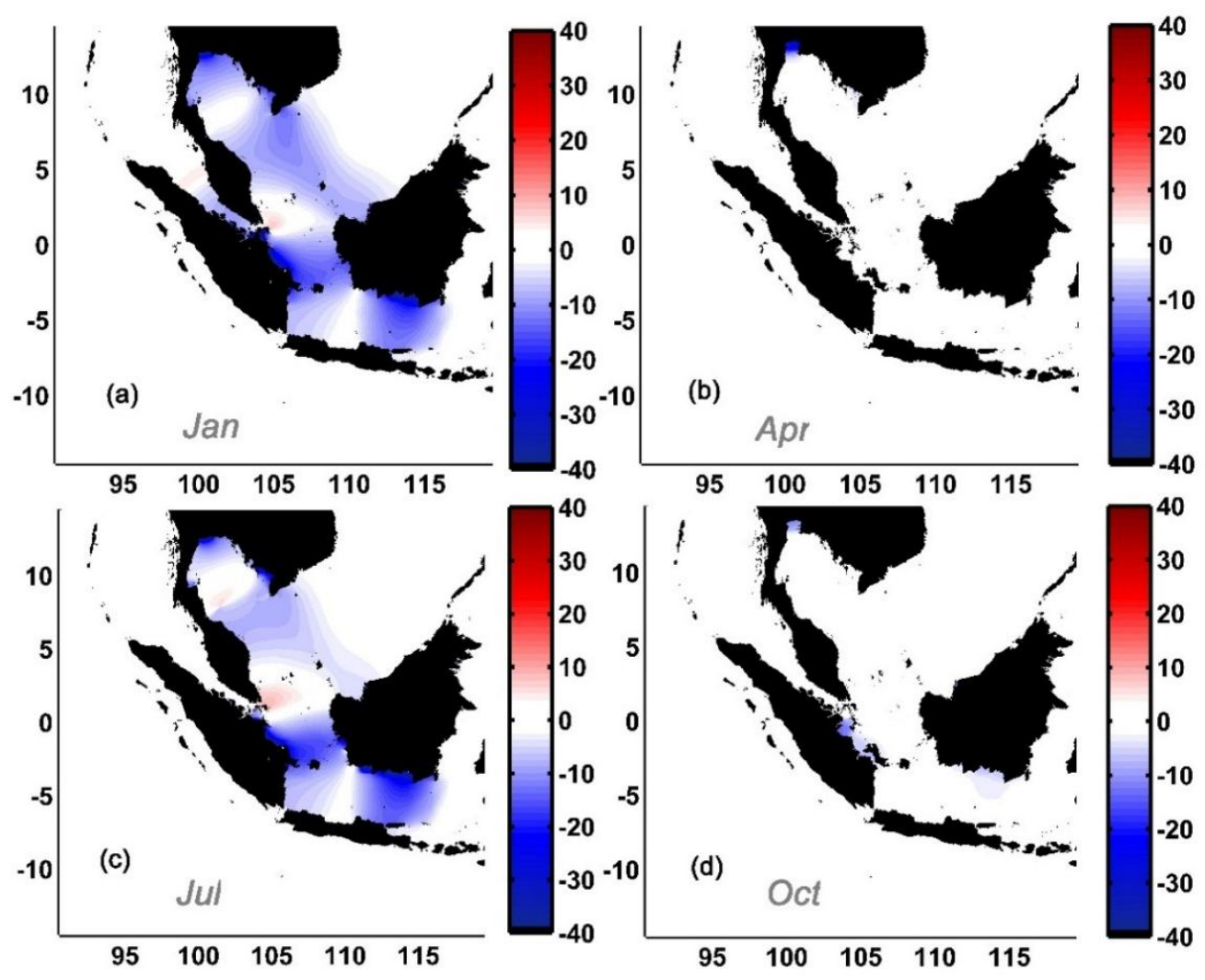

Figure 82 Modelled adjustments of the $K_{1}$ tidal amplitudes due to the seasonal changes in Ekman velocity $\left(u_{e}\right)$ in: January (a), April (b), July (c), and October (d). The $x$ and y axes are latitude and longitude, and color bar units are in millimeters. 


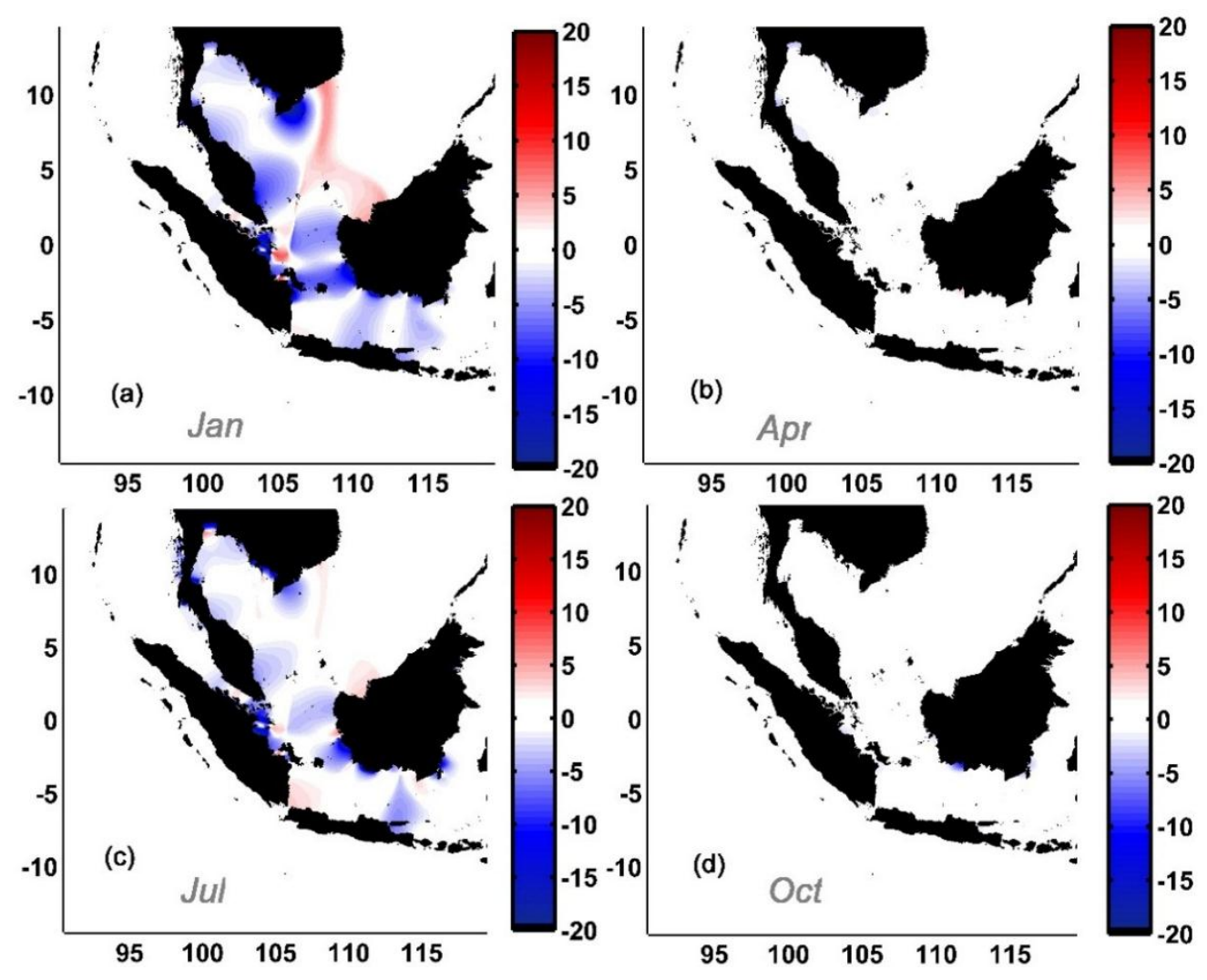

Figure 83 Modelled adjustments of the $S_{2}$ tidal amplitudes due to the seasonal changes in Ekman velocity $\left(u_{e}\right)$ in: January (a), April (b), July (c), and October (d). The $x$ and y axes are latitude and longitude, and color bar units are in millimeters. 


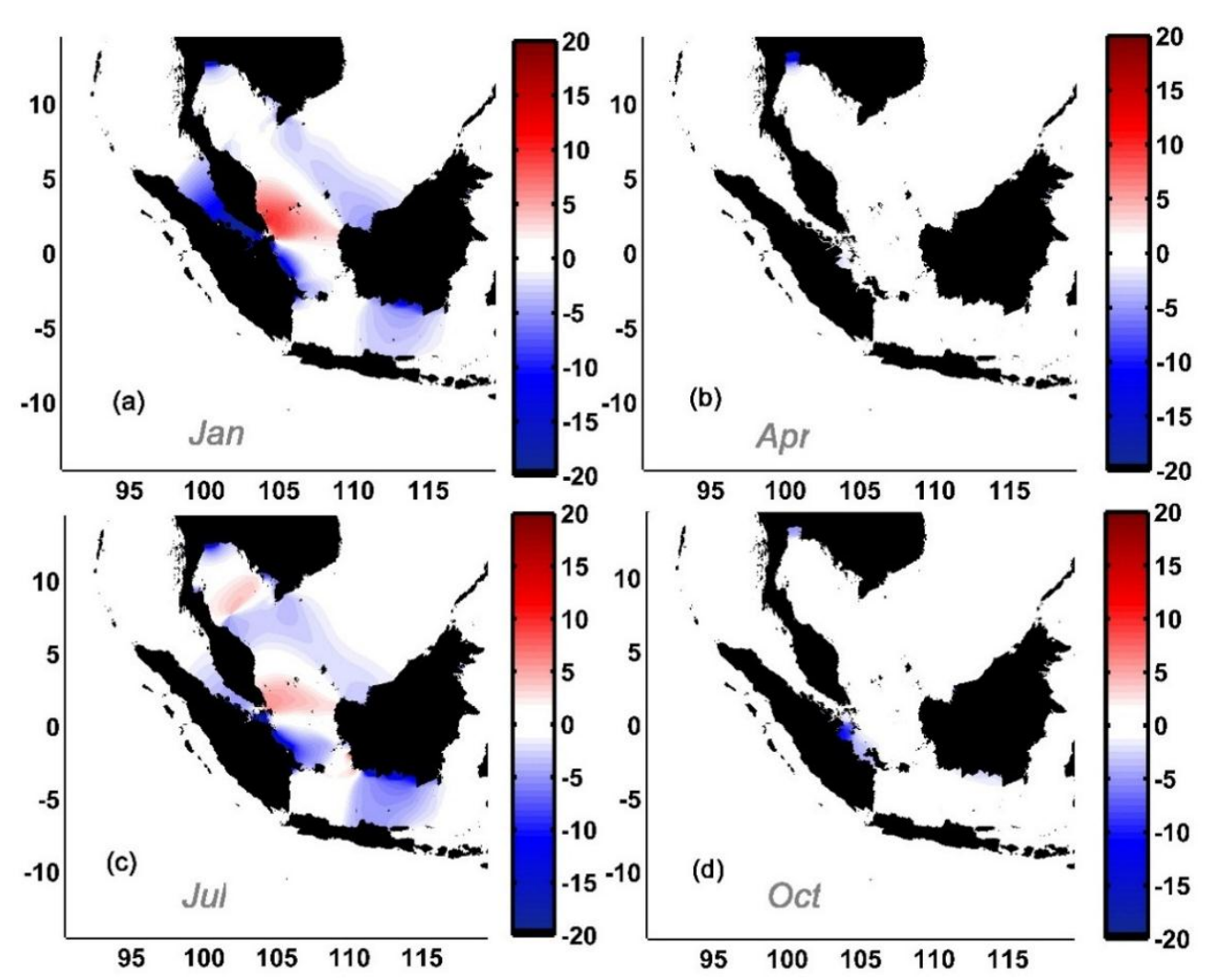

Figure 84 Modelled adjustments of the $\mathrm{O}_{1}$ tidal amplitudes due to the seasonal changes in Ekman velocity $\left(u_{e}\right)$ in: January (a), April (b), July (c), and October (d). The $x$ and y axes are latitude and longitude, and color bar units are in millimeters. 


\subsubsection{Modelled vs. observed at tide gauges}

The previous sets of figures highlighted the spatial patterns of the model responses, next to be shown will be the temporal patterns at individual gauges for all the model responses. The seasonally variable SSH models, whose effects were shown above to be negligible, will not be considered in this step, but all other models results will be considered. For all monthly model runs, the amplitude and phase difference from the annual average at each tide gauge was determined by extracting data from the difference fields shown above at the nearest neighboring grid cells to the coordinates of the tide gauges. In some cases where gauges are located within embayments or in harbors the model returned no data as it considers those cells to be land, in those cases the locations were shifted to the nearest valid offshore grid cells. All values on the $1 / 30^{\circ}$ resolution grid were averaged over a footprint of 25 grid cells. Choosing a single grid cell may yield an inaccurate response at near-coastal locations, but averaging over too large of an area might obscure the observation of the desired variability. First to be shown will be some example plots, and then all results will be disseminated statistically and discussed. Figures $85-88$ show the individual model results at the same locations shown in Figures 61-64. For all plots, grey dashed lines indicate true fits to observed data based on Eq. (32). Blue lines show the results of the changing bottom drag $\left(C_{d}\right)$ forcing, green lines are the results of the changing Ekman forcing $\left(u_{e}\right)$, and red lines are the changing geostrophic velocity forcing $\left(u_{g}\right)$. Changes to amplitude for $M_{2}$ and $K_{1}$ are 
plotted in (a) and (b) of each plot, and changes to phase for $\mathrm{M}_{2}$ and $\mathrm{K}_{1}$ are plotted in (c) and (d).

Figure 85 shows the results at Vung Tau, VTM in the South China Sea. The adjustments to the $\mathrm{M}_{2}$ amplitude from the drag coefficient are much larger than the observed changes, and in the second half of the year are reversed from what is observed. The Ekman and geostrophic forcing results show the same semi-annual pattern as the observed data, and are a closer fit, though the Ekman results tend to underestimate the observed changes, and the geostrophic results overestimate. For $\mathrm{K}_{1}$ the model responses were much smaller; only the drag coefficient results are of the same order as the observed changes, but are inverted in behavior from the observed data. Virtually no changes were seen in the phase of $M_{2}$ and $K_{1}$ in the model.

Figure 86 shows the results in the Java Sea at Surabaya, IND. The $M_{2}$ amplitude is nearly reconstructed by the geostrophic model response from about March through September, and in other months, the Ekman forcing is a better fit. The drag coefficient perturbations largely overestimate and invert from the observed behavior. There is a very weak response in all models of $\mathrm{K}_{1}$ amplitude, and all fall short of explaining the observed semidiurnal variability. Phase results for both also show little to no changes, but similar to the SCS results, observed variability in phases is also weak and nearly insignificant. 

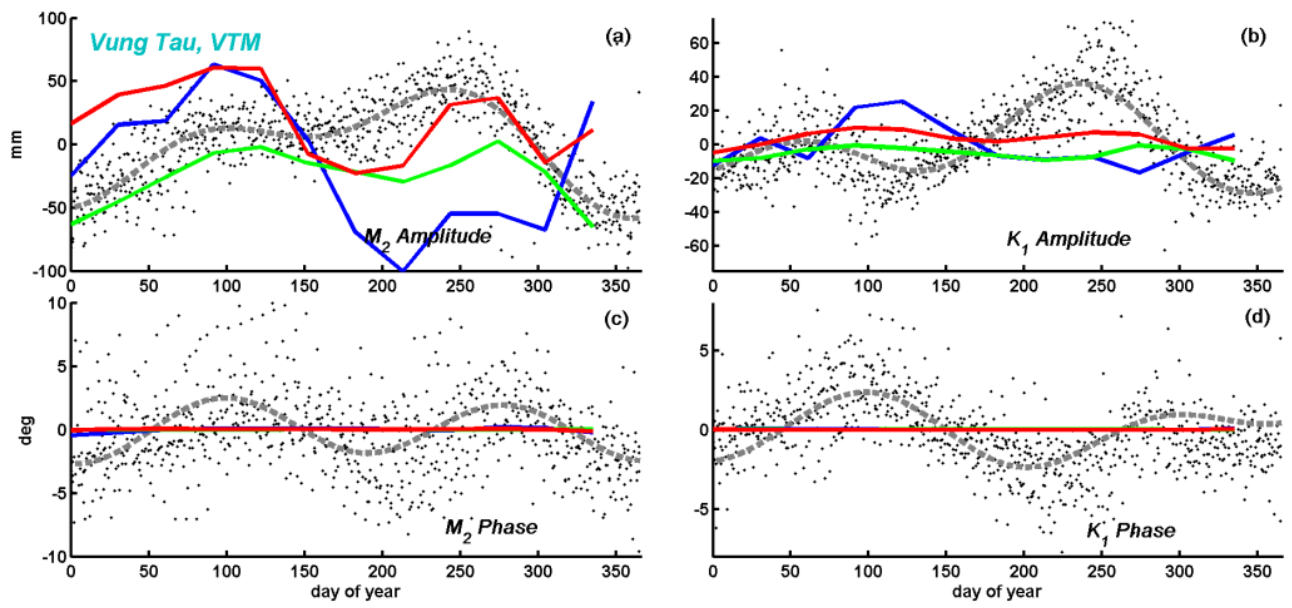

Figure 85 South China Sea tidal variability with modelled results overlain. The harmonic fits of Eq. (32) are shown as heavy grey dashed lines, the bottom drag $\left(C_{d}\right)$ model response is plotted as blue, Ekman velocity $\left(u_{e}\right)$ model response is plotted in green, and geostrophic velocity $\left(u_{g}\right)$ model response is plotted in red. The amplitude ( $a$ and $b$ ) and phase ( $c$ and d) variability at Vung Tau, VTM, is shown for the $\mathrm{M}_{2}$ and $\mathrm{K}_{1}$ constituents.
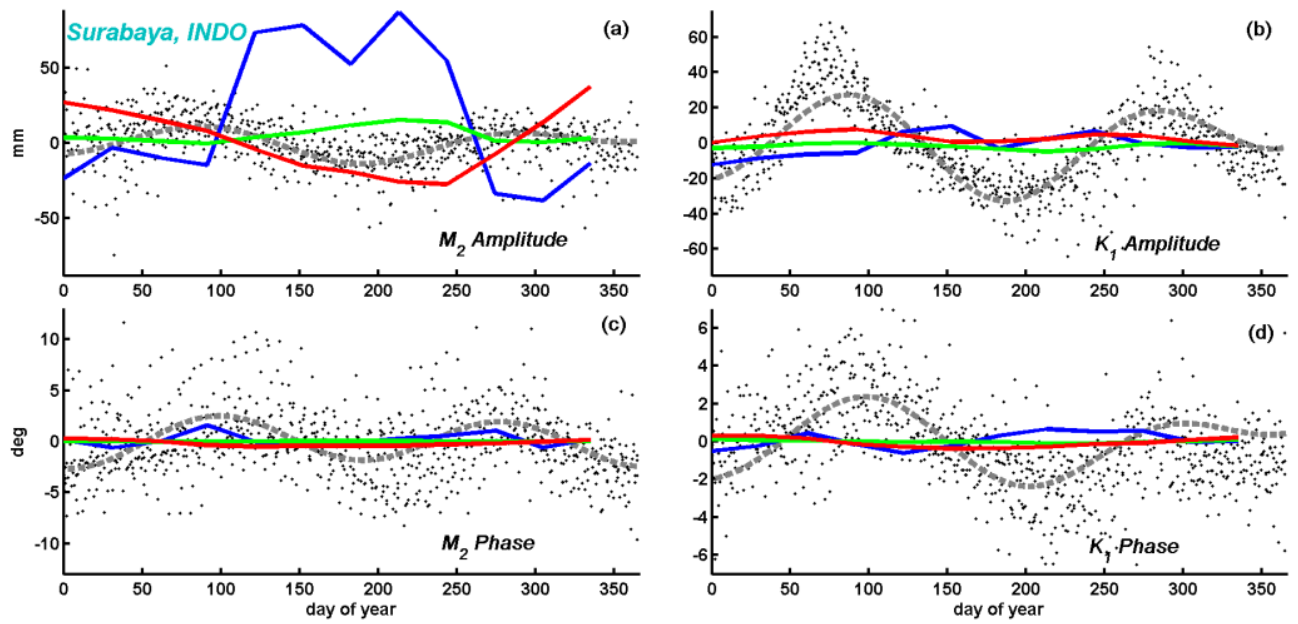

Figure 86 Java Sea tidal variability with modelled results overlain. The harmonic fits of Eq. (32) are shown as heavy grey dashed lines, the bottom drag $\left(C_{d}\right)$ model response is plotted as blue, Ekman velocity $\left(u_{e}\right)$ model response is plotted in green, and geostrophic velocity $\left(u_{g}\right)$ model response is plotted in red. The amplitude ( $\mathrm{a}$ and $\mathrm{b}$ ) and phase (c and d) variability at Surabaya, IND, shown for the $M_{2}$ and $K_{1}$ constituents. 
Figure 87 gives the results in the Gulf of Thailand at Sedili, MLY. The semidiurnal pattern in $\mathrm{M}_{2}$ amplitude is moderately reconstructed in both geostrophic velocity and drag coefficient models; the geostrophic velocity fits well during both maxima (March and September) but does not capture the minima in January and July as well as the drag coefficient model does. However, the bottom drag model does not match the second maximum in September. Ekman forcing effects are negligible for $\mathrm{M}_{2}$. For $\mathrm{K}_{1}$ amplitude, the bottom drag model shows the largest response and the best recreation of observed behavior from January through August. For the remainder of the year, the Ekman forcing plays a larger role, yet still does not fully reconstruct the maxima in September. Phase variability at Sedili is observed to be dominantly annual. Model results for Ekman and geostrophic velocity forcing are more dominantly semi-annual. Only the bottom drag model shows an annual response, and is approximately of the same order as observed changes, but is delayed from the peak in observed phase variability by about two months. For $\mathrm{K}_{1}$ phase variability, which is also predominantly annual in the observed data, the same response is seen in the models as $M_{2}$ phase; geostrophic and Ekman forcing responses are small and semi-annual, and bottom drag responses are annual but delayed.

Figure 88 shows the results at Lumut, MLY. The observed seasonal behavior of the $\mathrm{M}_{2}$ amplitude and phase here is very weak. The bottom drag model, however, yields large and anomalous responses in amplitude and phase, much greater than the observed changes. The amplitude response for geostrophic and Ekman velocity forcing 
is very weak, but the phase response shows a semi-annual cycle larger than observed changes. The observed $K_{1}$ amplitude and phases at gauges in this region show some of the most anomalous behavior in in the study area, with steep pulses of negative and positive changes. None of the models were able to adequately capture these temporal characteristics. 

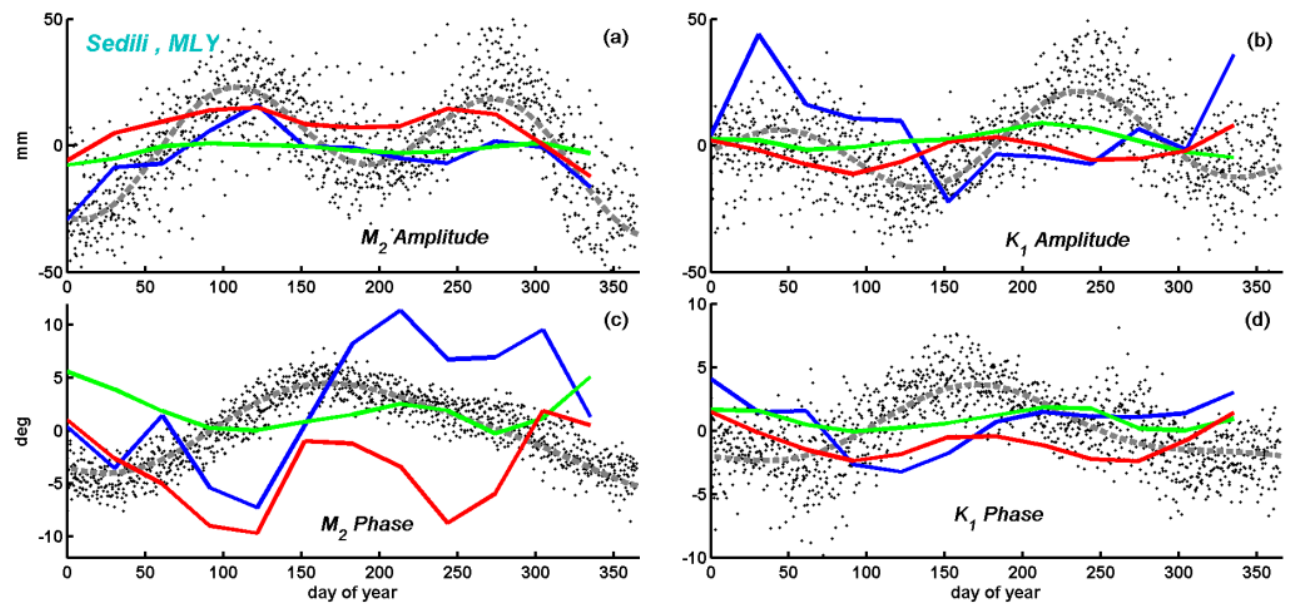

Figure 87 Gulf of Thailand tidal variability with modelled results overlain. The harmonic fits of Eq. (32) are shown as heavy dashed grey lines, the bottom drag $\left(C_{d}\right)$ model response is plotted as blue, Ekman velocity $\left(u_{e}\right)$ model response is plotted in green, and geostrophic velocity $\left(u_{g}\right)$ model response is plotted in red. The amplitude ( $a$ and $b$ ) and phase (c and d) variability at Sedili, MLY, is shown for the $M_{2}$ and $K_{1}$ constituents.
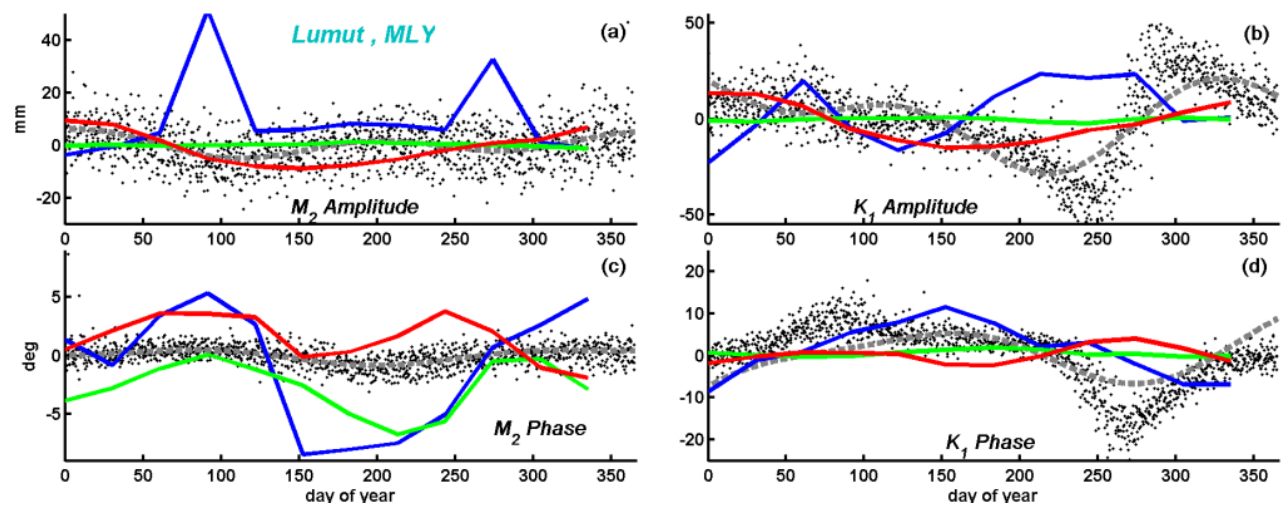

Figure 88 Malacca Strait tidal variability with modelled results overlain. The harmonic fits of Eq. (32) are shown as heavy dashed grey lines, the bottom drag $\left(C_{d}\right)$ model response is plotted as blue, Ekman velocity $\left(u_{e}\right)$ model response is plotted in green, and geostrophic velocity $\left(u_{g}\right)$ model response is plotted in red. The amplitude ( $a$ and $b$ ) and phase ( $c$ and d) variability at Lumut, MLY, is shown for the $M_{2}$ and $K_{1}$ constituents. 


\subsubsection{Coupled models and accuracy of tidal reproductions}

It can readily be seen from the plots above that the seasonal behavior of tides is complex both temporally and spatially. It has also been shown that the response of the models is time-dependent; some models best recreated the observed variability at some times of the year, and at other times, other models fit better. So far, the model results have only been considered individually, now the combined results will also be compared. In lieu of excessive plotting of all gauges and all constituents, model statistics will be calculated and reported in tables. There will be seven comparisons made for each tidal constituent at each gauge. First will be the individual results of the bottom drag $\left(C_{d}\right)$, Ekman velocity $\left(u_{e}\right)$, and geostrophic $\left(u_{g}\right)$ models, then the combined velocities $\left(u_{g}+u_{e}\right)$, the combined $\left(C_{d}+u_{g}\right)$ response, the combined $\left(C_{d}+u_{e}\right)$ response, and the combination of all three models $\left(C_{d}+u_{g}+u_{e}\right)$.

To compare model responses to the observed variability, linear regressions will be taken between the complex amplitudes of detrended observed variability and the detrended model responses. There are twelve determinations of amplitude and phase, one for each monthly model with the annual model response subtracted. These two time series can be combined into a single complex time series through Eq. (29). After this, the real and imaginary parts of $\boldsymbol{Z}(t)$ will be separated and combined into a single data set of 24 values for each observed constituent, and each model response. A robust linear regression is then applied to get estimates of the linear trend between the 
observed variability and each of the seven model results (dimensionless units), and the associated error bounds on the linear trends $(95 \% \mathrm{Cl})$. Regression results will be denoted tidal reconstruction factors (TRFs). TRF values will be a ratio of how well each model reconstructs the observed variability, with a value of 1.0 indicating a near-perfect correspondence, values greater than 1.0 indicating that the model generally overestimates the observed variability, and values from 0 to 1.0 indicating that the model generally underestimates the observed variability. Negative TRF values indicate that the model response is inverted from that of the observed variability, with a value of -1.0 indicating perfect reflection. Tables 26-29 ( $a$ and $b$; individual and combined model results, respectively) report the $M_{2}, S_{2}, K_{1}$, and $O_{1}$ regression values and errors $(95 \%$ confidence intervals). Positive TRF values greater than 0.1 and having a signal-to-noise ratio (SNR) of linear trend to error greater than 2.0 will be indicated by bold text in the tables, and significant negative (inverted) trends will be italicized.

\subsection{Discussion}

\subsubsection{Comparison of model results}

Table 26a shows the $\mathrm{M}_{2}$ amplitude model TRF results for individual model results, Table $26 \mathrm{~b}$ shows combined model results. In the Malacca Strait, three of eight stations including Singapore were best fit by the combination of Ekman and geostrophic velocities, though overestimated by a factor of +1.25 to +1.93 . The Ekman contribution is very small in the Strait, hence the null results for the Ekman forcing alone. The 
geostrophic model results for Singapore is remarkable, with a TRF of +1.33 , as it recreates quite well the strong annual cycle in the $M_{2}$ amplitudes observed there, in contrast to the decidedly semi-annual behavior seen at closely neighboring gauges in the GOT. Bottom drag was the best explanation at Penang, but at other locations in the Strait, the response of the bottom drag model is inverted and amplified compared to the observed variability, and errors are large in all bottom drag determinations. In the Gulf of Thailand, all models fit most gauges to some extent, but combined models were generally a better fit. A few gauges in the southern Gulf were partially recreated by the bottom drag model, but better results were found from the combined velocity models, and better still from all three models combined. In the northern Gulf at Ko Lak, THL, the Ekman forcing alone was the best fit, as determined by a TRF value of +0.65 . In the central Gulf, responses are significant but somewhat weaker. In the South China Sea, only Ekman forcing gave a good fit of $\mathrm{M}_{2}$ seasonality, and only at Vung Tau, VTM, and Bintulu, MLY. In the Java Sea, the response of the bottom drag model is amplified by about a factor of four at both gauges positive at Jakarta, IND, and negative at Surabaya, IND. There is a good reconstruction of the tidal variability at Surabaya for the combined velocity models. Very large model responses are observed at Vung Tau, and the Ekman response yielded a TRF value of +0.75 with a small relative error. However, no model responses can explain the variability around August, which is likely due to the high seasonal discharge of the Mekong River at this time. This situation is discussed in further detail below. 
Table 27a shows the $S_{2}$ amplitude model TRF results for individual model results, Table $27 \mathrm{~b}$ shows combined model results. As was seen with $\mathrm{M}_{2}$, four of eight gauges in the Malacca Strait show a good recreation from the combined velocity models, but the Ekman forcing effect is again very small. Bottom drag model response gives a decent response at Keling but is amplified by a factor of two. Penang, MLY, has a good response to the combined effect of all models, with a moderately sized error. The geostrophic velocity response in Singapore is also remarkable in $S_{2}$ as it was for $M_{2}$, with a TRF value near +1.0 and a moderate error. In the Gulf of Thailand, two of six gauges in the southern Gulf show good reconstructions from the combined response of all three models. Elsewhere, the majority of model responses were small with large errors and mainly inverted. A large seasonal cycle at Vung Tau, VTM, is present in $S_{2}$ as well, but different from $\mathrm{M}_{2}$. All model responses have satisfactory recreations at Vung Tau, but the best comparison to observed data is provided by the combined bottom drag, geostrophic velocity, and Ekman velocity forcing, which is only overestimated slightly, and has a low relative error. Elsewhere in the South China Sea, $\mathrm{S}_{2}$ model responses are virtually nil. In the Java Sea only the $S_{2}$ variability at Surabaya had good explanations by the model response, with the best result found from the combined Ekman and geostrophic velocity forcing.

Table 28a gives the $K_{1}$ amplitude model TRF results for individual model results, Table 28b gives combined model results. Weak but significant trends are found in the northern Malacca Strait from the geostrophic model response, and at Kukup, MLY, the 
best explanation comes from the bottom drag model. Ekman response is mainly negligible, though it has a weak but significant response in Singapore. In the Gulf of Thailand, the response of the bottom drag model is inverted at all gauges. Weak positive reconstructions are found at Sedili and Tioman, MLY, for the Ekman model response, and at Getting, MLY, for the combined velocities. In the SCS, Vung Tau's large $\mathrm{K}_{1}$ tidal variability is not well explained by any model combination, and elsewhere in the SCS and the Java Sea, model responses are negligible with the exception of Bintulu, MLY, which has moderate negative responses in most models. In the Java Sea, both gauges show very weak positive reconstructions from the combined velocity model.

Table 29a shows the $O_{1}$ amplitude model TRF results for individual model results, Table $29 \mathrm{~b}$ shows combined models. Seasonal variability of $\mathrm{O}_{1}$ in the Malacca Strait is strongly semidiurnal at all locations, and is best explained at the two northern and three southern gauges in the Strait by the combined velocity models, but model responses are indeterminate in the middle parts of the Strait. The bottom drag model results are moderate but negative (inverted) at most locations. In the Gulf of Thailand, the three southern gauges are moderately fit by the combined velocity models, but northern gauges show no satisfactory fits. In the South China Sea and the Java Sea, there is little to no model response anywhere with the exception of Vung Tau, where the observed seasonal variation is not explained by any model combination, and Jakarta, where a weak reconstruction is found by the geostrophic velocity model. 


\subsubsection{Summary of model results}

The $\mathrm{M}_{2}$ model tidal reconstruction factors (TRFs) are comparable to the observed tidal variability at 14 of 20 tide gauges, and at nine for $S_{2}$. The $K_{1}$ model TRFs compared well to the observed variability at 11 gauges, ten for $\mathrm{O}_{1}$. Overall, the best explanations for the observed tidal variability of diurnal and semidiurnal tidal amplitude seasonality are the model responses due to the combined Ekman velocity forcing and geostrophic velocity forcing, though the combined effect of both velocities and bottom drag was a better fit at some stations. Tidal variability is better explained in the Gulf of Thailand than in the other sub-regions. The bottom drag model alone yielded some good responses of the observed data at some times of the year, but not at others, as stratification is stronger in the spring inter-monsoonal periods than the autumn intermonsoonal time. The Ekman velocity model responses were limited to specific locations, and only had a large effect during winter and summer monsoon, when winds were strong. In the narrow Malacca Strait, the effect of Ekman forcing is virtually nonexistent for all modelled constituents.

In terms of the original hypotheses, a better explanation is provided by the second hypothesis $(\mathrm{H} 2)$ than the first $(\mathrm{H} 1)$ or third $(\mathrm{H} 3)$, in that the influence of non-tidal velocity is more important to tidal variability than the influence of stratification or the changes in total water level induced by seasonal MSL changes. However, the inclusion of stratification does improve the model results at a limited number of stations, mainly 
in the Southern GOT. In general, shallow-water regions of the study domain showed the greatest range of seasonal variability, as compared to deeper-water stations. In addition, shallow-water regions showed the largest variability in the model representations, as all model adjustments were highly sensitive to water depth, particularly the drag coefficient model.

\subsubsection{Limitations of model results}

The responses of the models are dependent on the forcing mechanisms integrated into the model via field variables. The majority of regions where significant changes in tidal amplitudes and phases occur are in shallow water regions. All of the models used here are sensitive to water depth, as $H$ occurs in the denominator of the $\lambda$ term used in field adjustments (33d). This sensitivity to depth is also a probable source of error in model accuracy, given the inaccuracy in bathymetry in some regions (Figs 59a and 59b). In very shallow water, the effect of forcing mechanisms may therefore be artificially amplified or damped. Additionally, the climatic variables used to produce the field adjustments in the models are sparse near coastlines, which can cause model results to compare poorly with tide gauge properties. Furthermore, all sources of climate data used have a much coarser resolution than the model bathymetry $\left(1 / 4^{\circ} \mathrm{vs}\right.$. $1 / 30^{\circ}$ ) and each data source places the coastlines in slightly different locations. All these fields were carefully interpolated to the native model resolution, but some data may be nonexistent or spurious near the coasts. This is particularly true in the Malacca 
Strait and near Singapore, which is very shallow and narrow, in some places only $\sim 1 / 2^{\circ}$ wide. The complex topography and bathymetry in this region complicate the tidal solutions found from OTIS, which are underdetermined in narrow shallow regions such as the Malacca Strait.

The bottom drag model depends on an iterative finite-difference calculation using buoyancy frequency profiles $\left(N^{2}\right)$, which needs at least two values of $T$ and $S$ in the vertical direction. The vertical resolution of the WOA13 climate reanalysis is $5 \mathrm{~m}$, meaning that no data would be returned for any grid cell less than $10 \mathrm{~m}$ deep, and cells that were only $10 \mathrm{~m}$ deep would only yield one value of $N^{2}$, which is likely less accurate than the average of a vertical profile, and these inaccuracies may propagate through the iteration process. Thus, these shallow regions can produce wild fluctuations in $C_{d}$ model responses, which correspond to fluctuations in the monthly climatology. Similarly, the Ekman forcing added to the model is dependent on a surface wind stress reanalysis, which is calculated globally without indication of land nodes. Wind stresses tend to be large at land-sea interfaces, so misplacement of the coastlines in the interpolation of the wind stress data fields may yield incorrect results, particularly the narrow parts of the Malacca Strait. The location of the coastlines was determined from the ECMWF dataset by using comparing to parallel global datasets of soil moisture and soil temperature, and it was assumed that grid nodes with no soil data would be over the ocean, but this assumption may not hold at all locations. 
For the bottom drag model, the sensitivity of the model response of $C_{d}$ to changes in stratification is determined by Eq. (47), based on the methods of Snyder et al. (1979). Various calibrations of the coefficients in Eq. (47) were tried, but in all cases only one set of values $\left(r_{0}=0.1 ; r_{1}=0.5\right)$ were used over the entire model domain. As the modelling domain covers multiple sub-regions with different tidal regimes and geographical morphology, the use of global coefficients might overestimate the true effect of stratification in some regions, and underestimate it in others. Furthermore, the sensitivity of the model response to stratification is often temporally variable, because stratification is strong during some parts of the year, and at other times, other mechanisms are more dominant. A spatially and temporally variable set of sensitivity coefficients based on a closer study of each gauge location may yield some improvements to the bottom drag model results, and is considered for future efforts.

Sparse data, erroneous bathymetry, and calculation artifacts aside, another reason for model mismatch with data might be due to unmodeled processes. The model used is a barotropic solver, and therefore, some baroclinic effects cannot be captured such as internal tide generation in nearby seas, or by possible baroclinic river effects due to seasonal discharge, such as in Vung Tau, VTM, near the mouth of the Mekong River. Another baroclinic interaction that is not modeled is the resonant triad interaction, a non-linear, energy exchanging coupling of three waves. This situation was explored in Devlin et al., (2014) for the case of the $M_{2}, K_{1}$, and $O_{1}$ tidal waves in the Solomon Sea. The tides in the Malacca Strait and the Gulf of Thailand have similar magnitudes for 
these three constituents, and resonant triad interactions could occur. Furthermore, if resonant triads are active in the Malacca Strait, which is semidiurnal dominant, this may help explain the large variability of the relatively weaker $\mathrm{K}_{1}$ and $\mathrm{O}_{1}$ constituents in the Strait. This determination would require a finer resolution, fully three dimensional model, and is beyond the scope of the present study.

Finally, storminess is another factor not studied that may have an effect on tidal variability. Storminess, which may drive fluctuations of water levels on a daily scale, is not resolved in a monthly analysis, and may be a partial explanation for tidal behavior not explained by the models (e.g., Bromirski et al., 2011).

\subsubsection{Effect of river discharge on tidal seasonality}

The tidal variability of all constituents at Vung Tau, near the Mekong River delta is among the largest in the study domain, and no other tide gauge in the South China Sea exhibits a similar magnitude of seasonality. Furthermore, none of the models employed were able to adequately recreate the observed variability, as can be seen from Figure 85 . Seasonal behavior in the first part of the year can be explained by the models, but the large peak around August is not. It is probable that the observed seasonality here is caused by a riverine mechanism. This mechanism is explored qualitatively by considering the river discharge of the Mekong, which has an average discharge of $16,000 \mathrm{~m}^{3} \mathrm{~s}^{-1}$, and maximum discharge of $39,000 \mathrm{~m}^{3} \mathrm{~s}^{-1}$. A selection of weekly flow data from the Mekong over six years $(2001,2002,2004-2007)$ provided by 
the Mekong River Delta Commission is shown in Figure 89, along with the average flow over these years (heavy black dashed line). It can readily be seen that there are two distinct high-flow seasons in the Mekong, first a weaker and more variable flow season in January/February, and a stronger and more constant flow season in August/September. The latter corresponds to both the maximum extent of the monsoon, and also the peak in tidal amplitude seasonality unexplained by all barotropic tidal models. The tidal variability at Vung Tau unexplained by the model is therefore thought to be due to a baroclinic river effect. A similar conclusion is made by (Guo et al., 2015) in a study of the tides near the Yangtze River, which also are observed to be larger around the time of greatest river discharge (see also Kulkulka \& Jay, 2003, and Moftakhari et al., 2013, 2016. Since both $\mathrm{K}_{1}$ and $\mathrm{M}_{2}$ are larger when the flow (and hence the friction) are large, this may also be due to internal tide variability.

Another region of anomalous tidal variability is in the Malacca Strait for the $\mathrm{K}_{1}$ constituent, which shows a steep seasonal transition in amplitude and phase (Figure 88, (b), and (d)). Both the Malaysian and Indonesian sides of the Strait have many small rivers with relatively low annual mean flows that exhibit a similar degree of seasonality in response to monsoon related precipitation patterns. There is, unfortunately, no weekly or daily flow data for any of the rivers in the region for comparison purposes. Some limited monthly average flow data was found from the RIVDAS project (Vörösmarty et al., 1998) for selected rivers in Malaysia and Thailand up to 1991, but no data are available for Indonesia. 


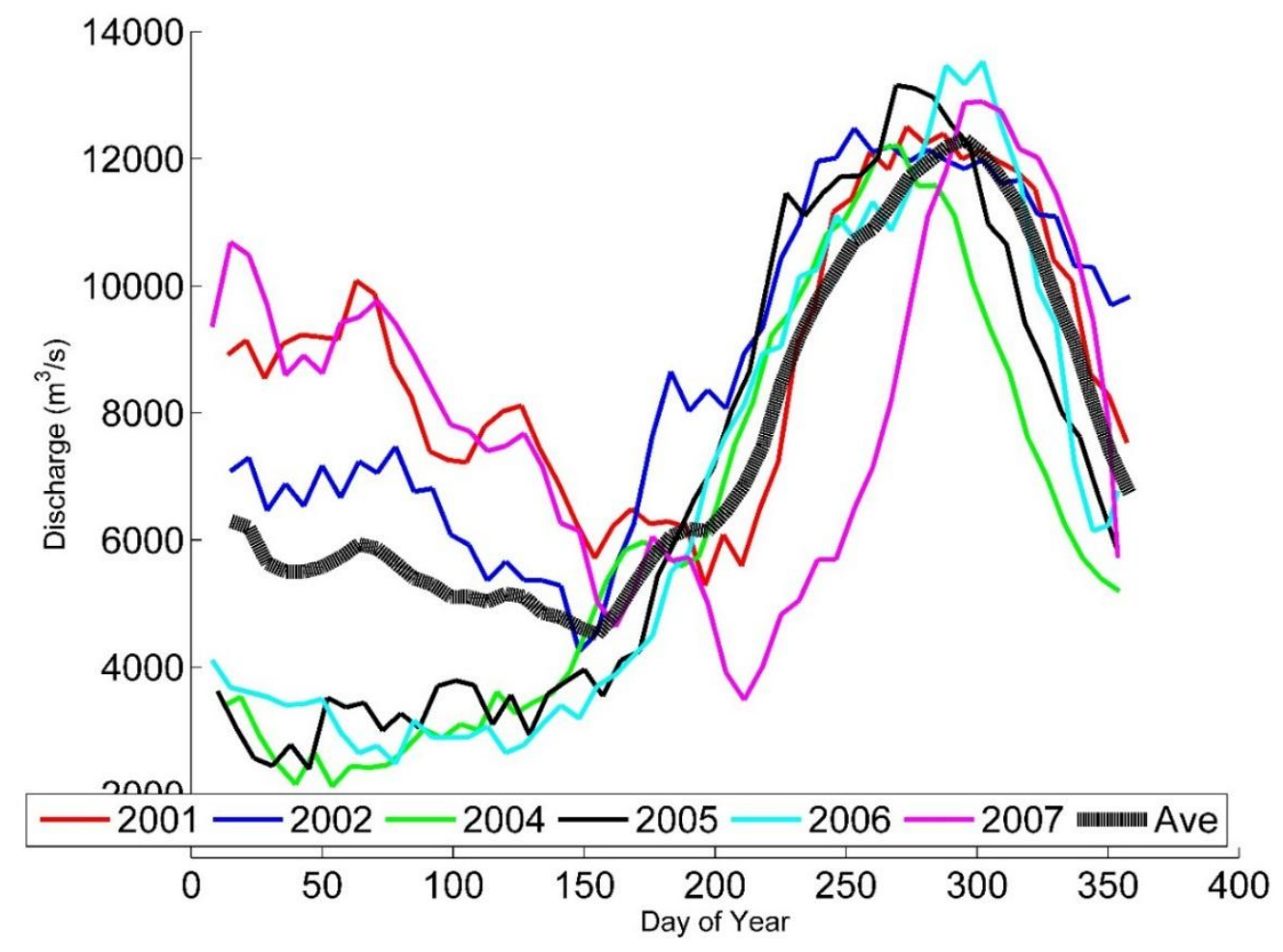

Figure 89 Weekly averaged discharge data of the Mekong River for the years: 2001, 2002, 2004-2007. Colored lines correspond to individual flow year, heavy dashed black line is the average flow over all these years. 


\subsection{Conclusions}

Diurnal and semidiurnal tidal amplitudes and phases exhibit a high degree of seasonality at $\mathbf{2 0}$ gauges in the Southeast Asian waters located in the Malacca Strait, the Gulf of Thailand, the South China Sea, and the Java Sea. The magnitude of $\mathrm{M}_{2}$ tidal variability is generally about twice that of $S_{2}$, and $K_{1}$ is about twice that of $\mathrm{O}_{1}$. Additionally, the majority of the observed tidal variability is coherent with the Western North Pacific Monsoon Index (WNPMI) at the annual frequency band, with strong correlations in the majority of the Malacca Strait and all of the Gulf of Thailand, moderate correlations in the South China Sea, and weak correlations in the Java Sea. Possible mechanisms leading to the observed variability were explored through the use of a barotropic ocean model (OTIS). The forcing mechanisms explored were: seasonal changes in mean sea level (SSH), geostrophic velocity $\left(u_{g}\right)$, bottom drag $\left(C_{d}\right)$ as a proxy for stratification, and Ekman velocity $\left(u_{e}\right)$. The model responses due to SSH changes were negligible in all locations at all times. The $C_{d}$ model alone yielded a better fit in the first half of the year, but did not perform as well after July, suggesting that stratification has more effect on tidal variability during winter and spring. Ekman transport is important only during monsoon seasons and for shallow regions, and is of very small magnitude in narrow passages such as the Malacca Strait. The majority of the best fits were produced by the geostrophic velocities, the combination of the two velocity model responses, or in a few locations, the combination of both velocities and bottom drag. 
Based on the regressions between the complex amplitudes of observed tidal variability and the complex amplitudes of model responses (TRFs), it was found that 14 of 20 gauges were able to be at least partially reconstructed for $M_{2}$, nine for $S_{2}, 11$ for $K_{1}$, and ten for $\mathrm{O}_{1}$

Model responses were ubiquitously larger in shallow water locations than in deep ocean locations. The best model reconstructions for all constituents were in the Gulf of Thailand, with the semidiurnal models performing better than diurnal models. Tidal variability in the South China Sea and Java Sea is generally small, and the semidiurnal model response was generally more accurate than the diurnal response. The exception to this was Vung Tau, VTM, which has large tidal variability not fully explained by any barotropic model combination. This is thought to be due to a baroclinic effect of river discharge from the Mekong not captured in the model. Results in the Malacca Strait are mixed and less reliable, with some constituents at some gauges being well explained, and others not, particularly the $K_{1}$ amplitudes and phases. It is possible that this variability is also due to river flow mechanisms not accurately captured by the model, though there is very little flow data in the region to make an accurate comparison. Furthermore, climate parameters that the model adjustment relies on may have unreliable data in this shallow narrow region.

Overall, this study showed that even though seasonal tidal variability is spatially and temporally complex and caused by multiple mechanisms, barotropic models can 
reconstruct much of the yearly variability at the locations examined, especially when the influence of multiple mechanisms are considered. The hypothesis of monsoonal dynamics being the causative factor is supported, as areas where the tidal variability was strongly correlated to the WNPMI were regions where models based on monsoon mechanisms had the most success in reconstructing the observed variability. Further work to improve this study would include the utilization of a higher resolution, fully three dimensional baroclinic model that could include riverine and internal tide mechanisms. 
Table 19 Tide gauges used in Part III of this study. Gauge names are listed, along with country, latitude and longitude, starting and ending year of record analyzed, and relevant metadata about the gauge environment. Locations are shown in Figures 54, $55 a$, and 55b.

\begin{tabular}{|c|c|c|c|c|c|c|}
\hline station & country & latitude & longitude & start year & end year & location \\
\hline MALACCA STRAIT & & & & & & \\
\hline Ko Taphao Noi & Thailand & $7.82^{\circ} \mathrm{N}$ & $98.42^{\circ} \mathrm{E}$ & 1985 & 2014 & bay \\
\hline Langkawi & Malaysia & $6.87^{\circ} \mathrm{N}$ & $99.67^{\circ} \mathrm{E}$ & 1985 & 2014 & island \\
\hline Penang & Malaysia & $5.42^{\circ} \mathrm{N}$ & $100.35^{\circ} \mathrm{E}$ & 1984 & 2014 & island \\
\hline Lumut & Malaysia & $4.23^{\circ} \mathrm{N}$ & $100.62^{\circ} \mathrm{E}$ & 1984 & 2014 & coastal \\
\hline Kelang & Malaysia & $3.05^{\circ} \mathrm{N}$ & $101.37^{\circ} \mathrm{E}$ & 1983 & 2014 & coastal \\
\hline Keling & Malaysia & $2.22^{\circ} \mathrm{N}$ & $102.15^{\circ} \mathrm{E}$ & 1984 & 2014 & coastal \\
\hline Kukup & Malaysia & $1.33^{\circ} \mathrm{N}$ & $103.45^{\circ} \mathrm{E}$ & 1985 & 2014 & island \\
\hline Tanjong Pagar & Singapore & $1.47^{\circ} \mathrm{N}$ & $103.84^{\circ} \mathrm{E}$ & 1988 & 2014 & harbor \\
\hline GULF OF THAILAND & & & & & & \\
\hline Sedili & Malaysia & $1.94^{\circ} \mathrm{N}$ & $104.12^{\circ} \mathrm{E}$ & 1986 & 2014 & bay \\
\hline Tioman & Malaysia & $2.8^{\circ} \mathrm{N}$ & $104.14^{\circ} \mathrm{E}$ & 1985 & 2014 & island \\
\hline Kuantan & Malaysia & $3.98^{\circ} \mathrm{N}$ & $104.44^{\circ} \mathrm{E}$ & 1983 & 2014 & coastal \\
\hline Cendering & Malaysia & $5.27^{\circ} \mathrm{N}$ & $103.18^{\circ} \mathrm{E}$ & 1984 & 2014 & coastal \\
\hline Getting & Malaysia & $6.23^{\circ} \mathrm{N}$ & $102.11^{\circ} \mathrm{E}$ & 1986 & 2014 & coastal \\
\hline Ko Lak & Thailand & $11.8^{\circ} \mathrm{N}$ & $99.82^{\circ} \mathrm{E}$ & 1985 & 2014 & coastal \\
\hline SOUTH CHINA SEA & & & & & & \\
\hline Vung Tau & Vietnam & $10.34^{\circ} \mathrm{N}$ & $107.07^{\circ} \mathrm{E}$ & 1986 & 2002 & estuary \\
\hline Bintulu & Malaysia & $3.26^{\circ} \mathrm{N}$ & $113.06^{\circ} \mathrm{E}$ & 1992 & 2014 & coastal \\
\hline Kota Kinabulu & Malaysia & $5.98^{\circ} \mathrm{N}$ & $116.07^{\circ} \mathrm{E}$ & 1987 & 2014 & coastal \\
\hline Sandakan & Malaysia & $5.82^{\circ} \mathrm{N}$ & $118.08^{\circ} \mathrm{E}$ & 1993 & 2014 & coastal \\
\hline JAVA SEA & & & & & & \\
\hline Jakarta & Indonesia & $6.17^{\circ} \mathrm{S}$ & $106.67^{\circ} \mathrm{E}$ & 1984 & 2004 & coastal \\
\hline Surabaya & Indonesia & $7.22^{\circ} \mathrm{S}$ & $112.73^{\circ} \mathrm{E}$ & 1984 & 2004 & bay \\
\hline
\end{tabular}


Table $20 \mathrm{M}_{2}$ amplitude and phase fitting harmonics. Mean values of tides are shown $\left(a_{0}\right)$, annual magnitudes $\left(M_{a}=\left(a_{1}^{2}+b_{1}^{2}\right)^{1 / 2}\right.$, and semiannual magnitudes $\left(M_{s a}=\left(a_{2}{ }^{2}+\right.\right.$ $\left.b_{2}{ }^{2}\right)^{1 / 2}$. Amplitude harmonics are in units of millimeters $(\mathrm{mm})$, and phase harmonics are in units of degrees (deg).

\begin{tabular}{|c|c|c|c|c|c|c|c|c|}
\hline $\mathbf{M}_{2}$ & & AMPS & $(\mathrm{mm})$ & & & PHASES & (deg) & \\
\hline station & $a_{0}$ & $M_{a}$ & $M_{s a}$ & RMSE & $a_{0}$ & $M_{a}$ & $M_{s a}$ & RMSE \\
\hline \multicolumn{9}{|l|}{ MALLACA STRAIT } \\
\hline Ko Taphao Noi, THL & 784.0 & 3.5 & 0.5 & 16.8 & -63.6 & 0.2 & 0.3 & 2.0 \\
\hline Langkawi, MLY & 802.8 & 3.1 & 3.0 & 10.7 & -42.4 & 0.2 & 0.7 & 0.9 \\
\hline Penang, MLY & 613.6 & 2.6 & 8.8 & 12.8 & -6.5 & 0.5 & 0.7 & 1.0 \\
\hline Lumut, MLY & 740.9 & 2.7 & 3.4 & 9.7 & 82.7 & 0.6 & 0.3 & 0.8 \\
\hline Kelang, MLY & 1368.0 & 6.6 & 5.7 & 20.1 & 126.8 & 0.4 & 0.7 & 0.9 \\
\hline Keling, MLY & 607.9 & 4.9 & 8.8 & 9.7 & 200.6 & 0.9 & 0.1 & 1.4 \\
\hline Kukup, MLY & 932.5 & 1.2 & 16.0 & 14.3 & -61.1 & 0.8 & 0.6 & 0.9 \\
\hline Tanjong Pagar, SNG & 792.5 & 24.1 & 9.0 & 11.4 & -60.4 & 0.2 & 0.8 & 1.5 \\
\hline \multicolumn{9}{|l|}{ GULF OF THAILAND } \\
\hline Sedili, MLY & 552.1 & 12.7 & 19.8 & 14.5 & -92.2 & 4.4 & 0.8 & 1.3 \\
\hline Tioman, MLY & 588.6 & 16.6 & 22.2 & 16.3 & -111.1 & 3.4 & 0.9 & 1.2 \\
\hline Kuantan, MLY & 522.3 & 19.7 & 21.9 & 15.2 & -124.3 & 2.2 & 0.9 & 1.4 \\
\hline Cendering, MLY & 295.6 & 7.8 & 10.3 & 8.9 & -146.9 & 3.1 & 0.7 & 1.5 \\
\hline Getting, MLY & 162.0 & 6.0 & 8.0 & 11.7 & -131.9 & 3.2 & 0.4 & 6.1 \\
\hline Ko Lak, THL & 63.2 & 1.4 & 5.4 & 7.6 & 135.0 & 4.8 & 2.2 & 14.4 \\
\hline \multicolumn{9}{|l|}{ SOUTH CHINA SEA } \\
\hline Vung Tau, VTM & 766.4 & 35.4 & 22.6 & 23.5 & 49.4 & 0.5 & 2.2 & 5.6 \\
\hline Bintulu, MLY & 189.4 & 9.4 & 3.3 & 8.1 & 47.5 & 2.0 & 1.8 & 2.4 \\
\hline Kota Kinabulu, MLY & 233.8 & 3.7 & 0.8 & 4.3 & -40.5 & 0.6 & 0.4 & 1.3 \\
\hline Sandakan, MLY & 415.1 & 0.8 & 4.3 & 12.7 & -38.4 & 1.3 & 1.3 & 5.8 \\
\hline \multicolumn{9}{|l|}{ JAVA SEA } \\
\hline Jakarta, IND & 62.4 & 3.5 & 1.5 & 8.9 & -3.2 & 27.7 & 8.3 & 28.5 \\
\hline Surabaya, IND & 344.2 & 7.0 & 8.3 & 17.1 & -19.3 & 1.6 & 0.5 & 6.5 \\
\hline
\end{tabular}


Table $21 S_{2}$ amplitude and phase fitting harmonics. Mean values of tides are shown $\left(a_{0}\right)$, annual magnitudes $\left(M_{a}=\left(a_{1}^{2}+b_{1}^{2}\right)^{1 / 2}\right.$, and semiannual magnitudes $\left(M_{s a}=\left(a_{2}^{2}+b_{2}^{2}\right)^{1 / 2}\right.$. Amplitude harmonics are in units of millimeters $(\mathrm{mm})$, and phase harmonics are in units of degrees (deg).

\begin{tabular}{|c|c|c|c|c|c|c|c|c|}
\hline $\mathbf{S}_{2}$ & & AMPS & $(\mathrm{mm})$ & & & PHASES & (deg) & \\
\hline station & $a_{0}$ & $M_{a}$ & $M_{s a}$ & RMSE & $a_{0}$ & $M_{a}$ & $M_{s a}$ & RMSE \\
\hline \multicolumn{9}{|l|}{ MALLACA STRAIT } \\
\hline Ko Taphao Noi, THL & 408.3 & 0.9 & 12.7 & 11.9 & -27.8 & 0.2 & 2.1 & 2.1 \\
\hline Langkawi, MLY & 456.1 & 2.2 & 12.0 & 10.0 & -4.4 & 0.0 & 2.0 & 1.5 \\
\hline Penang, MLY & 373.2 & 0.9 & 9.1 & 9.3 & 27.6 & 0.2 & 1.7 & 1.5 \\
\hline Lumut, MLY & 360.2 & 2.7 & 10.7 & 8.0 & 117.1 & 0.1 & 1.6 & 1.3 \\
\hline Kelang, MLY & 703.8 & 4.5 & 21.8 & 14.7 & 168.2 & 0.4 & 2.0 & 1.5 \\
\hline Keling, MLY & 303.4 & 2.3 & 7.3 & 7.9 & -119.7 & 0.4 & 2.1 & 1.9 \\
\hline Kukup, MLY & 436.9 & 2.8 & 19.6 & 12.2 & -15.8 & 0.5 & 2.6 & 1.6 \\
\hline Tanjong Pagar, SNG & 331.6 & 5.5 & 11.8 & 10.9 & -13.8 & 1.2 & 2.1 & 2.4 \\
\hline \multicolumn{9}{|l|}{ GULF OF THAILAND } \\
\hline Sedili, MLY & 165.7 & 3.9 & 17.0 & 10.2 & -43.5 & 8.4 & 6.1 & 3.8 \\
\hline Tioman, MLY & 188.7 & 5.7 & 20.8 & 9.9 & -68.2 & 7.1 & 5.8 & 3.2 \\
\hline Kuantan, MLY & 179.2 & 5.7 & 19.0 & 9.4 & -84.4 & 5.3 & 5.3 & 3.2 \\
\hline Cendering, MLY & 122.0 & 2.7 & 2.5 & 6.4 & -110.5 & 4.9 & 1.2 & 3.3 \\
\hline Getting, MLY & 80.4 & 1.9 & 4.6 & 8.6 & -100.2 & 2.5 & 4.2 & 9.1 \\
\hline Ko Lak, THL & 18.9 & 2.4 & 2.5 & 8.1 & 184.2 & 5.1 & 15.9 & 36.3 \\
\hline \multicolumn{9}{|l|}{ SOUTH CHINA SEA } \\
\hline Vung Tau, VTM & 298.4 & 3.1 & 20.6 & 20.8 & 85.3 & 0.8 & 5.2 & 6.1 \\
\hline Bintulu, MLY & 62.4 & 0.4 & 8.4 & 5.4 & 31.2 & 4.3 & 7.4 & 5.2 \\
\hline Kota Kinabulu, MLY & 105.6 & 1.0 & 3.3 & 3.8 & -13.0 & 1.1 & 1.9 & 2.2 \\
\hline Sandakan, MLY & 235.4 & 6.1 & 9.0 & 8.0 & -5.1 & 0.8 & 1.6 & 2.3 \\
\hline \multicolumn{9}{|l|}{ JAVA SEA } \\
\hline Jakarta, IND & 57.0 & 2.7 & 7.9 & 9.4 & -66.5 & 12.4 & 8.0 & 31.0 \\
\hline Surabaya, IND & 218.0 & 6.0 & 7.6 & 14.2 & -10.9 & 1.7 & 1.9 & 5.0 \\
\hline
\end{tabular}


Table $22 \mathrm{~K}_{1}$ amplitude and phase fitting harmonics. Mean values of tides are shown $\left(a_{0}\right)$, annual magnitudes $\left(M_{a}=\left(a_{1}^{2}+b_{1}^{2}\right)^{1 / 2}\right.$, and semiannual magnitudes $\left(M_{s a}=\left(a_{2}{ }^{2}+\right.\right.$ $\left.b_{2}^{2}\right)^{1 / 2}$. Amplitude harmonics are in units of millimeters $(\mathrm{mm})$, and phase harmonics are in units of degrees (deg).

\begin{tabular}{|c|c|c|c|c|c|c|c|c|}
\hline $\mathbf{K}_{1}$ & & AMPS & $(\mathrm{mm})$ & & & PHASES & (deg) & \\
\hline station & $a_{0}$ & $M_{a}$ & $M_{s a}$ & RMSE & $a_{0}$ & $M_{a}$ & $M_{s a}$ & RMSE \\
\hline \multicolumn{9}{|l|}{ MALLACA STRAIT } \\
\hline Ko Taphao Noi, THL & 136.6 & 9.6 & 4.0 & 6.4 & -36.8 & 4.3 & 2.0 & 3.0 \\
\hline Langkawi, MLY & 176.2 & 12.2 & 5.6 & 7.6 & -28.3 & 5.4 & 1.7 & 2.8 \\
\hline Penang, MLY & 208.6 & 19.4 & 5.6 & 10.0 & -22.6 & 7.2 & 1.1 & 3.0 \\
\hline Lumut, MLY & 228.0 & 17.3 & 12.8 & 13.3 & -12.2 & 8.4 & 2.5 & 3.6 \\
\hline Kelang, MLY & 202.1 & 24.7 & 15.5 & 16.9 & 6.5 & 11.8 & 4.3 & 5.6 \\
\hline Keling, MLY & 103.5 & 33.8 & 14.0 & 16.8 & -224.5 & 21.7 & 9.8 & 14.0 \\
\hline Kukup, MLY & 273.2 & 19.8 & 11.5 & 13.6 & -213.6 & 9.3 & 3.9 & 2.9 \\
\hline Tanjong Pagar, SNG & 319.9 & 7.6 & 16.4 & 13.3 & 95.8 & 5.7 & 3.0 & 3.2 \\
\hline \multicolumn{9}{|l|}{ GULF OF THAILAND } \\
\hline Sedili, MLY & 374 & 10.0 & 12.9 & 13.0 & 30.1 & 2.8 & 0.9 & 2.2 \\
\hline Tioman, MLY & 488.3 & 9.9 & 14.5 & 12.3 & 7.2 & 1.1 & 1.4 & 2.0 \\
\hline Kuantan, MLY & 561.7 & 12.8 & 19.9 & 12.5 & -3.8 & 0.5 & 1.4 & 1.9 \\
\hline Cendering, MLY & 522.6 & 12.7 & 21.8 & 12.2 & -14.3 & 0.4 & 1.5 & 2.0 \\
\hline Getting, MLY & 262.5 & 15.5 & 19.2 & 14.4 & -23.6 & 1.6 & 2.5 & 4.0 \\
\hline Ko Lak, THL & 530.1 & 9.6 & 24.1 & 21.0 & -199.0 & 0.9 & 0.8 & 3.2 \\
\hline \multicolumn{9}{|l|}{ SOUTH CHINA SEA } \\
\hline Vung Tau, VTM & 615.5 & 20.0 & 18.0 & 17.2 & -44.5 & 1.6 & 1.5 & 3.8 \\
\hline Bintulu, MLY & 434.7 & 7.5 & 8.7 & 19.5 & -47.7 & 1.9 & 1.5 & 1.7 \\
\hline Kota Kinabulu, MLY & 371.7 & 2.1 & 10.4 & 7.2 & -50.2 & 1.0 & 1.8 & 1.2 \\
\hline Sandakan, MLY & 368.1 & 6.3 & 7.0 & 9.3 & -37.3 & 2.7 & 0.4 & 1.6 \\
\hline \multicolumn{9}{|l|}{ JAVA SEA } \\
\hline Jakarta, IND & 268.1 & 20.8 & 16.2 & 11.6 & -38.4 & 3.8 & 1.4 & 4.7 \\
\hline Surabaya, IND & 485.7 & 14.2 & 22.0 & 14.6 & 138.7 & 1.9 & 0.6 & 3.3 \\
\hline
\end{tabular}


Table $23 \mathrm{O}_{1}$ amplitude and phase fitting harmonics. Mean values of tides are shown $\left(a_{0}\right)$, annual magnitudes $\left(M_{a}=\left(a_{1}^{2}+b_{1}^{2}\right)^{1 / 2}\right.$, and semiannual magnitudes $\left(M_{s a}=\left(a_{2}^{2}+\right.\right.$ $\left.b_{2}^{2}\right)^{1 / 2}$. Amplitude harmonics are in units of millimeters $(\mathrm{mm})$, and phase harmonics are in units of degrees (deg).

\begin{tabular}{|c|c|c|c|c|c|c|c|c|}
\hline $\mathbf{O}_{1}$ & & AMPS & $(\mathrm{mm})$ & & & PHASES & (deg) & \\
\hline station & $a_{0}$ & $M_{a}$ & $M_{s a}$ & RMSE & $a_{0}$ & $M_{a}$ & $M_{s a}$ & RMSE \\
\hline \multicolumn{9}{|l|}{ MALLACA STRAIT } \\
\hline Ko Taphao Noi, THL & 50.8 & 3.2 & 3.5 & 5.7 & -70.5 & 3.2 & 3.7 & 6.4 \\
\hline Langkawi, MLY & 54.8 & 0.8 & 8.4 & 5.9 & -75.8 & 2.6 & 9.4 & 6.7 \\
\hline Penang, MLY & 54.6 & 1.8 & 12.3 & 7.2 & -80.1 & 4.0 & 15.1 & 8.1 \\
\hline Lumut, MLY & 38.5 & 4.4 & 18.1 & 9.2 & -96.6 & 8.0 & 43.5 & 31.8 \\
\hline Kelang, MLY & 46.2 & 9.5 & 25.7 & 12.7 & -212.7 & 12.8 & 37.6 & 27.7 \\
\hline Keling, MLY & 223.8 & 8.7 & 21.1 & 13.6 & -224.4 & 4.1 & 2.8 & 3.1 \\
\hline Kukup, MLY & 264.4 & 11.7 & 24.5 & 13.8 & -249.0 & 1.9 & 4.1 & 3.1 \\
\hline Tanjong Pagar, SNG & 312.4 & 10.9 & 12.5 & 14.6 & 51.0 & 2.3 & 2.9 & 2.9 \\
\hline \multicolumn{9}{|l|}{ GULF OF THAILAND } \\
\hline Sedili, MLY & 318.7 & 7.1 & 8.4 & 12.8 & -3.0 & 3.1 & 1.3 & 2.3 \\
\hline Tioman, MLY & 357.0 & 5.9 & 10.4 & 12.8 & -25.1 & 2.0 & 1.9 & 2.1 \\
\hline Kuantan, MLY & 376.9 & 6.2 & 9.8 & 11.7 & -38.4 & 0.6 & 2.8 & 2.0 \\
\hline Cendering, MLY & 320.1 & 2.9 & 7.2 & 10.4 & -51.9 & 0.2 & 3.4 & 2.2 \\
\hline Getting, MLY & 136.3 & 3.9 & 7.3 & 10.6 & -66.8 & 1.3 & 5.4 & 4.8 \\
\hline Ko Lak, THL & 348.4 & 3.6 & 7.4 & 16.7 & -240.6 & 1.0 & 2.5 & 5.1 \\
\hline \multicolumn{9}{|l|}{ SOUTH CHINA SEA } \\
\hline Vung Tau, VTM & 466.2 & 15.7 & 16.4 & 14.8 & -86.7 & 1.3 & 2.2 & 3.2 \\
\hline Bintulu, MLY & 350.2 & 8.0 & 8.3 & 20.2 & -88.1 & 1.5 & 1.7 & 2.4 \\
\hline Kota Kinabulu, MLY & 320.8 & 3.5 & 7.9 & 7.2 & -90.4 & 0.8 & 1.4 & 1.5 \\
\hline Sandakan, MLY & 328.6 & 7.5 & 15.0 & 11.3 & -72.3 & 1.7 & 3.0 & 5.8 \\
\hline \multicolumn{9}{|l|}{ JAVA SEA } \\
\hline Jakarta, IND & 140.4 & 3.9 & 5.8 & 13.3 & -50.5 & 3.3 & 0.2 & 10.7 \\
\hline Surabaya, IND & 271.8 & 10.4 & 11.2 & 14.3 & 99.7 & 1.5 & 3.7 & 5.8 \\
\hline
\end{tabular}


Table 24 Annual coherence of tidal amplitudes with the Western North Pacific Monsoon Index (WNPMI).

\begin{tabular}{|c|c|c|c|c|}
\hline amps & $\mathbf{M}_{2}$ Amp & $\mathbf{S}_{2}$ Amp & $\mathrm{K}_{1}$ Amp & $\mathbf{O}_{1}$ Amp \\
\hline MALACCA STRAIT & & & & \\
\hline Ko Taphao Noi, THL & 0.36 & 0.02 & 0.66 & 0.32 \\
\hline Langkawi, MLY & 0.25 & 0.20 & 0.66 & 0.04 \\
\hline Penang, MLY & 0.16 & 0.08 & 0.72 & 0.28 \\
\hline Lumut, MLY & 0.30 & 0.49 & 0.64 & 0.37 \\
\hline Kelang, MLY & 0.33 & 0.47 & 0.64 & 0.32 \\
\hline Keling, MLY & 0.49 & 0.29 & 0.70 & 0.67 \\
\hline Kukup, MLY & 0.05 & 0.29 & 0.69 & 0.57 \\
\hline Tanjong Pagar, SNG & 0.61 & 0.39 & 0.22 & 0.59 \\
\hline GULF OF THAILAND & & & & \\
\hline Sedili, MLY & 0.66 & 0.39 & 0.51 & 0.42 \\
\hline Tioman, MLY & 0.68 & 0.34 & 0.58 & 0.29 \\
\hline Kuantan, MLY & 0.61 & 0.54 & 0.58 & 0.46 \\
\hline Cendering, MLY & 0.58 & 0.31 & 0.66 & 0.26 \\
\hline Getting, MLY & 0.54 & 0.10 & 0.68 & 0.27 \\
\hline Ko Lak, THL & 0.20 & 0.23 & 0.23 & 0.09 \\
\hline SOUTH CHINA SEA & & & & \\
\hline Vung Tau, VTM & 0.25 & 0.32 & 0.21 & 0.28 \\
\hline Bintulu, MLY & 0.40 & 0.55 & 0.46 & 0.39 \\
\hline Kota Kinabulu, MLY & 0.50 & 0.36 & 0.22 & 0.28 \\
\hline Sandakan, MLY & 0.54 & 0.44 & 0.16 & 0.30 \\
\hline JAVA SEA & & & & \\
\hline Jakarta, IND & 0.27 & 0.33 & 0.44 & 0.36 \\
\hline Surabaya, IND & 0.08 & 0.45 & 0.71 & 0.07 \\
\hline
\end{tabular}


Table 25 Annual coherence of tidal phases with the Western North Pacific Monsoon Index (WNPMI).

\begin{tabular}{|c|c|c|c|c|}
\hline phase & M $_{2}$ Phase & S2 $_{2}$ Phase & K $_{1}$ Phase & $\mathbf{O}_{1}$ Phase \\
\hline MALACCA STRAIT & & & & \\
\hline Ko Taphao Noi, THL & 0.02 & 0.04 & 0.64 & 0.43 \\
\hline Langkawi, MLY & 0.16 & 0.01 & 0.73 & 0.51 \\
\hline Penang, MLY & 0.46 & 0.17 & 0.78 & 0.56 \\
\hline Lumut, MLY & 0.52 & 0.04 & 0.75 & 0.18 \\
\hline Kelang, MLY & 0.35 & 0.33 & 0.71 & 0.06 \\
\hline Keling, MLY & 0.03 & 0.19 & 0.59 & 0.62 \\
\hline Kukup, MLY & 0.49 & 0.19 & 0.66 & 0.03 \\
\hline Tanjong Pagar, SNG & 0.10 & 0.33 & 0.10 & 0.42 \\
\hline GULF OF THAILAND & & & & \\
\hline Sedili, MLY & 0.69 & 0.66 & 0.71 & 0.62 \\
\hline Tioman, MLY & 0.62 & 0.57 & 0.50 & 0.49 \\
\hline Kuantan, MLY & 0.64 & 0.59 & 0.31 & 0.34 \\
\hline Cendering, MLY & 0.06 & 0.71 & 0.09 & 0.02 \\
\hline Getting, MLY & 0.49 & 0.52 & 0.50 & 0.28 \\
\hline Ko Lak, THL & 0.33 & 0.01 & 0.14 & 0.03 \\
\hline SOUTH CHINA SEA & & & & \\
\hline Vung Tau, VTM & 0.12 & 0.18 & 0.25 & 0.42 \\
\hline Bintulu, MLY & 0.62 & 0.47 & 0.69 & 0.45 \\
\hline Kota Kinabulu, MLY & 0.21 & 0.49 & 0.55 & 0.62 \\
\hline Sandakan, MLY & 0.25 & 0.23 & 0.29 & 0.18 \\
\hline JAVA SEA & & & & \\
\hline Jakarta, IND & 0.27 & 0.12 & 0.05 & 0.08 \\
\hline Surabaya, IND & 0.17 & 0.27 & 0.28 & 0.25 \\
\hline
\end{tabular}


Table 26a $\mathrm{M}_{2}$ Model Responses. Values shown indicate the slope relation between the complex observed tidal seasonality and the complex model responses, in dimensionless units, for each individual model response, along with the associated errors of the slope determinations ( $95 \%$ confidence interval). Statistically significant trends are defined as those whose signal-to-noise ratio (SNR) is greater than 2.0. Bold text indicates statistically significant model reconstructions, and italicized text indicates significant but inverted model reconstructions.

\begin{tabular}{|c|c|c|c|}
\hline & $C_{d}$ & $u_{e}$ & $u_{g}$ \\
\hline \multicolumn{4}{|l|}{$\underline{M S}$} \\
\hline Ko Taphao Noi, THL & $-4.50 \pm 1.32$ & $-0.30 \pm 0.13$ & $2.34 \pm 0.87$ \\
\hline Langkawi, MLY & $-0.74 \pm 0.54$ & $0.10 \pm 0.05$ & $-0.10 \pm 0.44$ \\
\hline Penang, MLY & $1.74 \pm 0.73$ & $-0.01 \pm 0.01$ & $0.28 \pm 0.37$ \\
\hline Lumut, $M L Y$ & $-1.99 \pm 0.86$ & $-0.06 \pm 0.03$ & $1.50 \pm 0.34$ \\
\hline Kelang, MLY & $0.69 \pm 0.85$ & $-0.08 \pm 0.04$ & $-1.57 \pm 0.29$ \\
\hline Keling, MLY & $0.21 \pm 0.78$ & $0.01 \pm 0.02$ & $0.57 \pm 0.34$ \\
\hline Kukup, MLY & $0.65 \pm 0.50$ & $-0.11 \pm 0.07$ & $-1.18 \pm 1.07$ \\
\hline Tanjong Pagar, SNG & $0.10 \pm 0.21$ & $-0.03 \pm 0.04$ & $1.33 \pm 0.16$ \\
\hline \multicolumn{4}{|l|}{ GOT } \\
\hline Sedili, MLY & $0.43 \pm 0.13$ & $0.12 \pm 0.03$ & $0.49 \pm 0.06$ \\
\hline Tioman, $M L Y$ & $0.35 \pm 0.08$ & $0.26 \pm 0.03$ & $0.40 \pm 0.05$ \\
\hline Kuantan, $M L Y$ & $0.07 \pm 0.07$ & $0.26 \pm 0.06$ & $0.20 \pm 0.07$ \\
\hline Cendering, MLY & $-0.05 \pm 0.09$ & $0.36 \pm 0.08$ & $0.02 \pm 0.09$ \\
\hline Getting, MLY & $-0.33 \pm 0.30$ & $0.28 \pm 0.09$ & $0.12 \pm 0.10$ \\
\hline Ko Lak, THL & $-0.08 \pm 0.88$ & $0.65 \pm 0.14$ & $1.22 \pm 0.33$ \\
\hline \multicolumn{4}{|l|}{$\underline{S C S}$} \\
\hline Vung Tau, VTM & $-0.60 \pm 0.23$ & $0.75 \pm 0.09$ & $0.29 \pm 0.27$ \\
\hline Bintulu, MLY & $1.40 \pm 1.52$ & $0.25 \pm 0.07$ & $0.28 \pm 0.33$ \\
\hline Kota Kinabulu, MLY & $-0.08 \pm 0.07$ & $-0.09 \pm 0.03$ & $0.09 \pm 0.06$ \\
\hline Sandakan, MLY & $-0.01 \pm 0.01$ & $0.01 \pm 0.01$ & $0.01 \pm 0.01$ \\
\hline \multicolumn{4}{|l|}{$\underline{J S}$} \\
\hline Jakarta, IND & $4.29 \pm 1.49$ & $-0.44 \pm 0.17$ & $-0.48 \pm 0.23$ \\
\hline Surabaya, IND & $-3.53 \pm 0.77$ & $-0.46 \pm 0.11$ & $1.26 \pm 0.57$ \\
\hline
\end{tabular}


Table 26b M2 Model Responses. Values shown indicate the slope relation between the complex observed tidal seasonality and the complex model responses, in dimensionless units, for combined model responses, along with the associated errors of the slope determinations ( $95 \%$ confidence interval). Statistically significant trends are defined as those whose signal-to-noise ratio (SNR) is greater than 2.0. Bold text indicates statistically significant model reconstructions, and italicized text indicates significant but inverted model reconstructions.

\begin{tabular}{|c|c|c|c|c|}
\hline & $u_{g}+u_{e}$ & $C_{d}+u_{g}$ & $c_{d}+u_{e}$ & $c_{d}+u_{e}+u_{g}$ \\
\hline \multicolumn{5}{|l|}{$\underline{M S}$} \\
\hline Ko Taphao Noi, THL & $1.93 \pm 0.81$ & $-1.14 \pm 2.10$ & $-5.08 \pm 1.30$ & $-1.98 \pm 1.92$ \\
\hline Langkawi, MLY & $0.01 \pm 0.40$ & $-0.73 \pm 0.91$ & $-0.59 \pm 0.55$ & $-0.70 \pm 0.85$ \\
\hline Penang, MLY & $0.35 \pm 0.36$ & $2.07 \pm 1.20$ & $1.74 \pm 0.79$ & $2.03 \pm 1.19$ \\
\hline Lumut, MLY & $1.42 \pm 0.32$ & $-0.29 \pm 0.94$ & $-2.16 \pm 0.85$ & $-0.39 \pm 0.94$ \\
\hline Kelang, MLY & $-1.72 \pm 0.28$ & $-1.70 \pm 0.59$ & $0.52 \pm 0.90$ & $-1.81 \pm 0.58$ \\
\hline Keling, MLY & $0.54 \pm 0.33$ & $-0.55 \pm 1.30$ & $0.19 \pm 0.77$ & $-0.55 \pm 1.30$ \\
\hline Kukup, MLY & $-1.13 \pm 1.01$ & $1.76 \pm 1.41$ & $0.56 \pm 0.50$ & $2.13 \pm 1.23$ \\
\hline Tanjong Pagar, SNG & $1.28 \pm 0.17$ & $1.28 \pm 0.29$ & $0.10 \pm 0.19$ & $1.24 \pm 0.30$ \\
\hline \multicolumn{5}{|l|}{$\underline{G O T}$} \\
\hline Sedili, MLY & $0.56 \pm 0.07$ & $0.80 \pm 0.14$ & $0.55 \pm 0.16$ & $0.97 \pm 0.19$ \\
\hline Tioman, $M L Y$ & $0.62 \pm 0.08$ & $0.70 \pm 0.14$ & $0.56 \pm 0.15$ & $0.97 \pm 0.16$ \\
\hline Kuantan, $M L Y$ & $0.38 \pm 0.07$ & $0.25 \pm 0.10$ & $0.37 \pm 0.10$ & $0.46 \pm 0.12$ \\
\hline Cendering, MLY & $0.36 \pm 0.06$ & $0.17 \pm 0.15$ & $0.27 \pm 0.13$ & $0.34 \pm 0.12$ \\
\hline Getting, MLY & $0.39 \pm 0.15$ & $-0.22 \pm 0.38$ & $-0.02 \pm 0.29$ & $0.09 \pm 0.38$ \\
\hline Ko Lak, THL & $1.75 \pm 0.36$ & $1.10 \pm 1.08$ & $0.48 \pm 0.83$ & $1.52 \pm 1.06$ \\
\hline \multicolumn{5}{|l|}{$\underline{S C S}$} \\
\hline Vung Tau, VTM & $0.63 \pm 0.19$ & $-0.11 \pm 0.35$ & $-0.44 \pm 0.28$ & $0.08 \pm 0.39$ \\
\hline Bintulu, MLY & $0.53 \pm 0.34$ & $1.49 \pm 1.69$ & $1.62 \pm 1.61$ & $1.67 \pm 1.76$ \\
\hline Kota Kinabulu, MLY & $0.01 \pm 0.08$ & $-0.09 \pm 01.2$ & $-0.04 \pm 0.08$ & $-0.10 \pm 0.14$ \\
\hline Sandakan, MLY & $0.01 \pm 0.01$ & $-0.01 \pm 0.01$ & $-0.01 \pm 0.01$ & $-0.01 \pm 0.01$ \\
\hline \multicolumn{5}{|l|}{$\underline{J S}$} \\
\hline Jakarta, IND & $-1.18 \pm 0.58$ & $3.43 \pm 1.41$ & $2.66 \pm 1.05$ & $2.67 \pm 1.27$ \\
\hline Surabaya, IND & $1.09 \pm 0.35$ & $-3.45 \pm 0.60$ & $-4.14 \pm 0.82$ & $-3.60 \pm 0.70$ \\
\hline
\end{tabular}


Table 27a $\mathrm{S}_{2}$ Model Responses. Values shown indicate the slope relation between the complex observed tidal seasonality and the complex model responses, in dimensionless units, for each individual model response, along with the associated errors of the slope determinations ( $95 \%$ confidence interval). Statistically significant trends are defined as those whose signal-to-noise ratio (SNR) is greater than 2.0. Bold text indicates statistically significant model reconstructions, and italicized text indicates significant but inverted model reconstructions.

\begin{tabular}{|c|c|c|c|}
\hline & $C_{d}$ & $u_{e}$ & $u_{g}$ \\
\hline \multicolumn{4}{|l|}{$\underline{M S}$} \\
\hline Ko Taphao Noi, THL & $-0.37 \pm 0.10$ & $-0.01 \pm 0.02$ & $-0.48 \pm 0.11$ \\
\hline Langkawi, MLY & $-0.25 \pm 0.18$ & $0.01 \pm 0.01$ & $0.28 \pm 0.13$ \\
\hline Penang, MLY & $0.80 \pm 0.35$ & $0.03 \pm 0.01$ & $0.68 \pm 0.14$ \\
\hline Lumut, $M L Y$ & $0.13 \pm 0.18$ & $0.01 \pm 0.01$ & $0.33 \pm 0.12$ \\
\hline Kelang, MLY & $-0.57 \pm 0.15$ & $0.01 \pm 0.01$ & $-0.37 \pm 0.11$ \\
\hline Keling, MLY & $1.90 \pm 0.63$ & $0.08 \pm 0.02$ & $-0.40 \pm 0.15$ \\
\hline Kukup, MLY & $-0.71 \pm 0.34$ & $0.03 \pm 0.04$ & $-0.60 \pm 0.55$ \\
\hline Tanjong Pagar, SNG & $-0.39 \pm 0.28$ & $0.02 \pm 0.03$ & $0.96 \pm 0.31$ \\
\hline \multicolumn{4}{|l|}{$\underline{G O T}$} \\
\hline Sedili, MLY & $-0.06 \pm 0.06$ & $0.01 \pm 0.03$ & $0.01 \pm 0.06$ \\
\hline Tioman, $M L Y$ & $0.12 \pm 0.11$ & $0.06 \pm 0.06$ & $0.20 \pm 0.03$ \\
\hline Kuantan, $M L Y$ & $0.24 \pm 0.05$ & $0.11 \pm 0.05$ & $0.26 \pm 0.03$ \\
\hline Cendering, $M L Y$ & $-0.26 \pm 0.18$ & $-0.55 \pm 0.09$ & $0.04 \pm 0.16$ \\
\hline Getting, MLY & $-0.28 \pm 0.13$ & $-0.05 \pm 0.05$ & $-0.25 \pm 0.08$ \\
\hline Ko Lak, THL & $0.48 \pm 0.34$ & $-0.19 \pm 0.07$ & $-0.37 \pm 0.17$ \\
\hline \multicolumn{4}{|l|}{$\underline{S C S}$} \\
\hline Vung Tau, VTM & $0.45 \pm 0.10$ & $0.28 \pm 0.04$ & $0.42 \pm 0.12$ \\
\hline Bintulu, MLY & $-0.25 \pm 0.18$ & $0.03 \pm 0.01$ & $0.02 \pm 0.08$ \\
\hline Kota Kinabulu, MLY & $-0.08 \pm 0.01$ & $-0.01 \pm 0.01$ & $0.01 \pm 0.01$ \\
\hline Sandakan, MLY & $0.01 \pm 0.01$ & $0.01 \pm 0.01$ & $0.01 \pm 0.01$ \\
\hline \multicolumn{4}{|l|}{$\underline{J S}$} \\
\hline Jakarta, IND & $-0.48 \pm 0.39$ & $0.06 \pm 0.07$ & $-0.01 \pm 0.05$ \\
\hline Surabaya, IND & $1.39 \pm-0.21$ & $0.19 \pm 0.05$ & $0.76 \pm 0.18$ \\
\hline
\end{tabular}


Table 27b $\mathrm{S}_{2}$ Model Responses. Values shown indicate the slope relation between the complex observed tidal seasonality and the complex model responses, in dimensionless units, for combined model responses, along with the associated errors of the slope determinations (95\% confidence interval). Statistically significant trends are defined as those whose signal-to-noise ratio (SNR) is greater than 2.0. Bold text indicates statistically significant model reconstructions, and italicized text indicates significant but inverted model reconstructions.

\begin{tabular}{|c|c|c|c|c|}
\hline & $u_{g}+u_{e}$ & $C_{d}+u_{g}$ & $c_{d}+u_{e}$ & $c_{d}+u_{e}+u_{g}$ \\
\hline \multicolumn{5}{|l|}{$\underline{M S}$} \\
\hline Ko Taphao Noi, THL & $-0.41 \pm 0.10$ & $-0.09 \pm 0.14$ & $-0.48 \pm 0.11$ & $-0.14 \pm 0.13$ \\
\hline Langkawi, MLY & $0.27 \pm 0.12$ & $-0.11 \pm 0.17$ & $-0.26 \pm 0.15$ & $-0.15 \pm 0.20$ \\
\hline Penang, MLY & $0.69 \pm 0.14$ & $0.92 \pm 0.32$ & $0.91 \pm 0.33$ & $0.94 \pm 0.32$ \\
\hline Lumut, MLY & $0.33 \pm 0.11$ & $0.40 \pm 0.22$ & $0.13 \pm 0.18$ & $0.39 \pm 0.22$ \\
\hline Kelang, MLY & $-0.32 \pm 0.11$ & $-0.18 \pm 0.15$ & $-0.58 \pm 0.15$ & $-0.18 \pm 0.15$ \\
\hline Keling, MLY & $-0.30 \pm 0.15$ & $2.23 \pm 0.42$ & $2.00 \pm 0.65$ & $2.31 \pm 0.41$ \\
\hline Kukup, MLY & $-0.22 \pm 0.51$ & $-1.49 \pm 0.35$ & $-0.59 \pm 0.31$ & $-1.43 \pm 0.33$ \\
\hline Tanjong Pagar, SNG & $0.97 \pm 0.29$ & $0.08 \pm 0.46$ & $-0.30 \pm 0.23$ & $0.07 \pm 0.48$ \\
\hline \multicolumn{5}{|l|}{$\underline{G O T}$} \\
\hline Sedili, MLY & $0.01 \pm 0.06$ & $-0.04 \pm 0.10$ & $-0.06 \pm 0.07$ & $-0.05 \pm 0.11$ \\
\hline Tioman, $M L Y$ & $0.24 \pm 0.08$ & $0.33 \pm 0.13$ & $0.20 \pm 0.13$ & $0.40 \pm 0.16$ \\
\hline Kuantan, $M L Y$ & $0.33 \pm 0.05$ & $0.48 \pm 0.07$ & $0.30 \pm 0.08$ & $0.57 \pm 0.11$ \\
\hline Cendering, $M L Y$ & $-0.02 \pm 0.28$ & $0.54 \pm 0.30$ & $0.05 \pm 0.18$ & $0.04 \pm 0.29$ \\
\hline Getting, MLY & $-0.32 \pm 0.09$ & $-0.41 \pm 0.17$ & $-0.15 \pm 0.11$ & $-0.71 \pm 0.16$ \\
\hline Ko Lak, THL & $-0.46 \pm 0.16$ & $0.45 \pm 0.36$ & $0.39 \pm 0.30$ & $0.42 \pm 0.33$ \\
\hline \multicolumn{5}{|l|}{$\underline{S C S}$} \\
\hline Vung Tau, VTM & $0.65 \pm 0.05$ & $0.85 \pm 0.14$ & $0.75 \pm 0.12$ & $1.15 \pm 0.14$ \\
\hline Bintulu, MLY & $0.09 \pm 0.08$ & $-0.16 \pm 0.22$ & $-0.22 \pm 0.17$ & $-0.12 \pm 0.22$ \\
\hline Kota Kinabulu, MLY & $-0.01 \pm 0.01$ & $-0.05 \pm 0.01$ & $-0.08 \pm 0.02$ & $-0.09 \pm 0.01$ \\
\hline Sandakan, MLY & $0.01 \pm 0.01$ & $0.01 \pm 0.01$ & $0.01 \pm 0.01$ & $0.01 \pm 0.01$ \\
\hline \multicolumn{5}{|l|}{$\underline{J S}$} \\
\hline Jakarta, IND & $0.02 \pm 0.07$ & $-0.39 \pm 0.32$ & $-0.35 \pm 0.32$ & $-0.24 \pm 0.25$ \\
\hline Surabaya, IND & $0.94 \pm 0.20$ & $0.92 \pm 0.31$ & $1.22 \pm 0.44$ & $0.90 \pm 0.35$ \\
\hline
\end{tabular}


Table 28a $\mathrm{K}_{1}$ Model Responses. Values shown indicate the slope relation between the complex observed tidal seasonality and the complex model responses, in dimensionless units, for each individual model response, along with the associated errors of the slope determinations ( $95 \%$ confidence interval). Statistically significant trends are defined as those whose signal-to-noise ratio (SNR) is greater than 2.0. Bold text indicates statistically significant model reconstructions, and italicized text indicates significant but inverted model reconstructions.

\begin{tabular}{|c|c|c|c|}
\hline & $C_{d}$ & $u_{e}$ & $u_{g}$ \\
\hline \multicolumn{4}{|l|}{$\underline{M S}$} \\
\hline Ko Taphao Noi, THL & $0.05 \pm 0.08$ & $0.01 \pm 0.01$ & $0.09 \pm 0.02$ \\
\hline Langkawi, MLY & $0.01 \pm 0.11$ & $0.01 \pm 0.01$ & $0.12 \pm 0.03$ \\
\hline Penang, MLY & $-0.38 \pm 0.26$ & $0.06 \pm 0.02$ & $0.37 \pm 0.12$ \\
\hline Lumut, $M L Y$ & $-0.62 \pm 0.19$ & $0.04 \pm 0.01$ & $0.45 \pm 0.13$ \\
\hline Kelang, MLY & $0.08 \pm 0.10$ & $-0.02 \pm 0.02$ & $-0.16 \pm 0.03$ \\
\hline Keling, MLY & $0.31 \pm 0.33$ & $-0.02 \pm 0.03$ & $-0.18 \pm 0.18$ \\
\hline Kukup, MLY & $0.73 \pm 0.33$ & $-0.17 \pm 0.06$ & $-0.01 \pm 0.06$ \\
\hline Tanjong Pagar, SNG & $-0.13 \pm 0.07$ & $0.12 \pm 0.02$ & $0.05 \pm 0.03$ \\
\hline \multicolumn{4}{|l|}{ GOT } \\
\hline Sedili, MLY & $-0.39 \pm 0.30$ & $0.33 \pm 0.04$ & $0.22 \pm 0.07$ \\
\hline Tioman, $M L Y$ & $-0.63 \pm 0.31$ & $0.18 \pm 0.04$ & $-0.17 \pm 0.07$ \\
\hline Kuantan, $M L Y$ & $-0.55 \pm 0.22$ & $0.02 \pm 0.02$ & $0.03 \pm 0.05$ \\
\hline Cendering, MLY & $-0.46 \pm 0.16$ & $-0.02 \pm 0.03$ & $-0.04 \pm 0.04$ \\
\hline Getting, MLY & $-0.23 \pm 0.08$ & $0.06 \pm 0.02$ & $0.11 \pm 0.01$ \\
\hline Ko Lak, THL & $-0.42 \pm 0.18$ & $-0.03 \pm 0.04$ & $0.05 \pm 0.03$ \\
\hline \multicolumn{4}{|l|}{$\underline{S C S}$} \\
\hline Vung Tau, VTM & $-0.23 \pm 0.09$ & $-0.11 \pm 0.03$ & $0.16 \pm 0.04$ \\
\hline Bintulu, MLY & $-0.49 \pm 0.06$ & $-0.11 \pm 0.02$ & $0.04 \pm 0.04$ \\
\hline Kota Kinabulu, MLY & $0.01 \pm 0.02$ & $-0.03 \pm 0.01$ & $0.01 \pm 0.01$ \\
\hline Sandakan, MLY & $0.01 \pm 0.01$ & $0.01 \pm 0.01$ & $0.01 \pm 0.01$ \\
\hline \multicolumn{4}{|l|}{$\underline{J S}$} \\
\hline Jakarta, IND & $-0.13 \pm 0.06$ & $0.01 \pm 0.02$ & $0.10 \pm 0.03$ \\
\hline Surabaya, IND & $-0.10 \pm 0.05$ & $0.06 \pm 0.01$ & $0.09 \pm 0.02$ \\
\hline
\end{tabular}


Table 28b K 1 Model Responses. Values shown indicate the slope relation between the complex observed tidal seasonality and the complex model responses, in dimensionless units, for combined model responses, along with the associated errors of the slope determinations ( $95 \%$ confidence interval). Statistically significant trends are defined as those whose signal-to-noise ratio (SNR) is greater than 2.0. Bold text indicates statistically significant model reconstructions, and italicized text indicates significant but inverted model reconstructions.

\begin{tabular}{|c|c|c|c|c|}
\hline & $u_{g}+u_{e}$ & $c_{d}+u_{g}$ & $c_{d}+u_{e}$ & $c_{d}+u_{e}+u_{g}$ \\
\hline \multicolumn{5}{|l|}{$\underline{M S}$} \\
\hline Ko Taphao Noi, THL & $0.01 \pm 0.02$ & $0.09 \pm 0.04$ & $0.05 \pm 0.08$ & $0.09 \pm 0.04$ \\
\hline Langkawi, MLY & $0.15 \pm 0.04$ & $-0.01 \pm 0.06$ & $0.03 \pm 0.10$ & $0.19 \pm 0.06$ \\
\hline Penang, MLY & $0.46 \pm 0.14$ & $-0.12 \pm 0.23$ & $-0.37 \pm 0.18$ & $0.01 \pm 0.28$ \\
\hline Lumut, $M L Y$ & $0.46 \pm 0.10$ & $-0.21 \pm 0.21$ & $-0.57 \pm 0.18$ & $-0.16 \pm 0.22$ \\
\hline Kelang, MLY & $-0.22 \pm 0.05$ & $-0.08 \pm 0.09$ & $0.01 \pm 0.09$ & $-0.18 \pm 0.10$ \\
\hline Keling, MLY & $-0.28 \pm 0.26$ & $0.02 \pm 0.20$ & $0.16 \pm 0.23$ & $-0.14 \pm 0.23$ \\
\hline Kukup, MLY & $-0.22 \pm 0.09$ & $0.75 \pm 0.36$ & $0.74 \pm 0.32$ & $0.71 \pm 0.38$ \\
\hline Tanjong Pagar, SNG & $0.11 \pm 0.02$ & $-0.12 \pm 0.08$ & $-0.13 \pm 0.08$ & $0.05 \pm 0.07$ \\
\hline \multicolumn{5}{|l|}{$\underline{G O T}$} \\
\hline Sedili, MLY & $0.28 \pm 0.07$ & $-0.15 \pm 0.31$ & $-0.14 \pm 0.25$ & $0.03 \pm 0.26$ \\
\hline Tioman & $0.12 \pm 0.16$ & $-0.61 \pm 0.27$ & $-0.54 \pm 0.26$ & $-0.49 \pm 0.25$ \\
\hline Kuantan, MLY & $0.25 \pm 0.06$ & $-0.49 \pm 0.20$ & $-0.56 \pm 0.21$ & $-0.49 \pm 0.20$ \\
\hline Cendering, $M L Y$ & $-0.03 \pm 0.05$ & $-0.08 \pm 0.22$ & $-0.53 \pm 0.15$ & $-0.05 \pm 0.22$ \\
\hline Getting, MLY & $0.15 \pm 0.02$ & $-0.15 \pm 0.08$ & $-0.14 \pm 0.08$ & $-0.13 \pm 0.09$ \\
\hline Ko Lak, THL & $0.01 \pm 0.06$ & $-0.38 \pm 0.20$ & $-0.48 \pm 0.19$ & $-0.43 \pm 0.21$ \\
\hline \multicolumn{5}{|l|}{$\underline{S C S}$} \\
\hline Vung Tau, VTM & $0.01 \pm 0.10$ & $-0.17 \pm 0.12$ & $-0.34 \pm 0.10$ & $-0.18 \pm 0.18$ \\
\hline Bintulu, MLY & $-0.20 \pm 0.05$ & $-0.57 \pm 0.13$ & $-0.58 \pm 0.07$ & $-0.46 \pm 0.10$ \\
\hline Kota Kinabulu, MLY & $-0.03 \pm 0.01$ & $0.02 \pm 0.02$ & $-0.03 \pm 0.02$ & $-0.02 \pm 0.03$ \\
\hline Sandakan, MLY & $0.01 \pm 0.01$ & $0.01 \pm 0.01$ & $0.01 \pm 0.01$ & $0.01 \pm 0.01$ \\
\hline \multicolumn{5}{|l|}{$\underline{J S}$} \\
\hline Jakarta, IND & $0.11 \pm 0.04$ & $0.09 \pm 0.06$ & $-0.11 \pm 0.06$ & $0.06 \pm 0.06$ \\
\hline Surabaya, IND & $0.15 \pm 0.02$ & $0.01 \pm 0.06$ & $-0.02 \pm 0.05$ & $0.08 \pm 0.06$ \\
\hline
\end{tabular}


Table 29a $\mathrm{O}_{1}$ Model Responses. Values shown indicate the slope relation between the complex observed tidal seasonality and the complex model responses, in dimensionless units, for each individual model response, along with the associated errors of the slope determinations ( $95 \%$ confidence interval). Statistically significant trends are defined as those whose signal-to-noise ratio (SNR) is greater than 2.0. Bold text indicates statistically significant model reconstructions, and italicized text indicates significant but inverted model reconstructions.

\begin{tabular}{|c|c|c|c|}
\hline & $C_{d}$ & $u_{e}$ & $u_{g}$ \\
\hline \multicolumn{4}{|l|}{$\underline{M S}$} \\
\hline Ko Taphao Noi, THL & $0.20 \pm 0.16$ & $-0.01 \pm 0.01$ & $-0.13 \pm 0.03$ \\
\hline Langkawi, MLY & $0.23 \pm 0.20$ & $0.04 \pm 0.03$ & $0.19 \pm 0.08$ \\
\hline Penang, MLY & $-0.14 \pm 0.40$ & $-0.07 \pm 0.05$ & $0.23 \pm 0.08$ \\
\hline Lumut, $M L Y$ & $-0.47 \pm 0.38$ & $0.01 \pm 0.03$ & $0.12 \pm 0.13$ \\
\hline Kelang, MLY & $0.27 \pm 0.52$ & $0.08 \pm 0.07$ & $0.32 \pm 0.25$ \\
\hline Keling, MLY & $-1.23 \pm 0.20$ & $0.11 \pm 0.04$ & $0.11 \pm 0.12$ \\
\hline Kukup, MLY & $-0.80 \pm 0.09$ & $0.08 \pm 0.02$ & $0.10 \pm 0.04$ \\
\hline Tanjong Pagar, SNG & $-0.58 \pm 0.10$ & $0.10 \pm 0.01$ & $0.04 \pm 0.01$ \\
\hline \multicolumn{4}{|l|}{ GOT } \\
\hline Sedili, MLY & $-0.83 \pm 0.28$ & $0.31 \pm 0.04$ & $0.09 \pm 0.04$ \\
\hline Tioman, $M L Y$ & $-0.75 \pm 0.49$ & $0.26 \pm 0.11$ & $0.40 \pm 0.06$ \\
\hline Kuantan, $M L Y$ & $-0.60 \pm 0.40$ & $0.20 \pm 0.03$ & $0.35 \pm 0.06$ \\
\hline Cendering, MLY & $-0.48 \pm 0.49$ & $0.06 \pm 0.03$ & $0.08 \pm 0.19$ \\
\hline Getting, MLY & $-0.21 \pm 0.11$ & $0.01 \pm 0.02$ & $0.10 \pm 0.03$ \\
\hline Ko Lak, THL & $0.41 \pm 0.44$ & $-0.07 \pm 0.05$ & $-0.20 \pm 0.08$ \\
\hline \multicolumn{4}{|l|}{$\underline{S C S}$} \\
\hline Vung Tau, VTM & $-0.15 \pm 0.05$ & $-0.02 \pm 0.01$ & $0.08 \pm 0.02$ \\
\hline Bintulu, MLY & $0.06 \pm 0.05$ & $-0.06 \pm 0.01$ & $0.06 \pm 0.01$ \\
\hline Kota Kinabulu, MLY & $-0.01 \pm 0.03$ & $0.01 \pm 0.01$ & $0.01 \pm 0.01$ \\
\hline Sandakan, MLY & $0.01 \pm 0.01$ & $0.01 \pm 0.01$ & $0.01 \pm 0.01$ \\
\hline \multicolumn{4}{|l|}{$\underline{J S}$} \\
\hline Jakarta, IND & $-0.44 \pm 0.15$ & $-0.05 \pm 0.04$ & $0.32 \pm 0.09$ \\
\hline Surabaya, IND & $0.07 \pm 0.02$ & $-0.01 \pm 0.01$ & $0.03 \pm 0.02$ \\
\hline
\end{tabular}


Table 29b O $\mathrm{O}_{1}$ Model Responses. Values shown indicate the slope relation between the complex observed tidal seasonality and the complex model responses, in dimensionless units, for combined model responses, along with the associated errors of the slope determinations ( $95 \%$ confidence interval). Statistically significant trends are defined as those whose signal-to-noise ratio (SNR) is greater than 2.0. Bold text indicates statistically significant model reconstructions, and italicized text indicates significant but inverted model reconstructions.

\begin{tabular}{|c|c|c|c|c|}
\hline & $u_{g}+u_{e}$ & $C_{d}+u_{g}$ & $c_{d}+u_{e}$ & $c_{d}+u_{e}+u_{g}$ \\
\hline \multicolumn{5}{|l|}{$\underline{M S}$} \\
\hline Ko Taphao Noi, THL & $-0.13 \pm 0.04$ & $0.15 \pm 0.07$ & $0.17 \pm 0.15$ & $0.16 \pm 0.07$ \\
\hline Langkawi, MLY & $0.27 \pm 0.09$ & $0.23 \pm 0.10$ & $0.27 \pm 0.20$ & $0.28 \pm 0.01$ \\
\hline Penang, MLY & $0.23 \pm 0.12$ & $0.06 \pm 0.23$ & $-0.23 \pm 0.20$ & $-0.13 \pm 0.24$ \\
\hline Lumut, $M L Y$ & $0.15 \pm 0.16$ & $-0.29 \pm 0.29$ & $-0.48 \pm 0.37$ & $-0.29 \pm 0.23$ \\
\hline Kelang, MLY & $0.43 \pm 0.27$ & $0.62 \pm 0.57$ & $0.36 \pm 0.53$ & $0.71 \pm 0.58$ \\
\hline Keling, MLY & $0.25 \pm 0.15$ & $-1.00 \pm 0.19$ & $-0.96 \pm 0.26$ & $-0.95 \pm 0.21$ \\
\hline Kukup, MLY & $0.19 \pm 0.06$ & $-0.71 \pm 0.11$ & $-0.74 \pm 0.11$ & $-0.68 \pm 0.13$ \\
\hline Tanjong Pagar, SNG & $0.14 \pm 0.02$ & $-0.54 \pm 0.10$ & $-0.46 \pm 0.11$ & $-0.43 \pm 0.10$ \\
\hline \multicolumn{5}{|l|}{$\underline{G O T}$} \\
\hline Sedili, MLY & $0.36 \pm 0.07$ & $-0.85 \pm 0.32$ & $-0.42 \pm 0.30$ & $-0.39 \pm 0.32$ \\
\hline Tioman, $M L Y$ & $0.49 \pm 0.04$ & $-0.31 \pm 0.52$ & $-0.69 \pm 0.44$ & $-0.16 \pm 0.50$ \\
\hline Kuantan, $M L Y$ & $0.44 \pm 0.06$ & $-0.26 \pm 0.37$ & $-0.44 \pm 0.42$ & $-0.10 \pm 0.43$ \\
\hline Cendering, $M L Y$ & $0.14 \pm 0.16$ & $-0.38 \pm 0.51$ & $-0.41 \pm 0.48$ & $-0.32 \pm 0.50$ \\
\hline Getting, MLY & $0.06 \pm 0.06$ & $-0.24 \pm 0.11$ & $-0.28 \pm 0.11$ & $-0.20 \pm 0.10$ \\
\hline Ko Lak, THL & $-0.11 \pm 0.08$ & $0.58 \pm 0.46$ & $-0.93 \pm 0.42$ & $0.39 \pm 0.43$ \\
\hline \multicolumn{5}{|l|}{$\underline{S C S}$} \\
\hline Vung Tau, VTM & $0.06 \pm 0.02$ & $-0.07 \pm 0.06$ & $-0.16 \pm 0.05$ & $-0.10 \pm 0.05$ \\
\hline Bintulu, MLY & $-0.01 \pm 0.02$ & $0.09 \pm 0.10$ & $0.02 \pm 0.05$ & $0.05 \pm 0.10$ \\
\hline Kota Kinabulu, MLY & $-0.01 \pm 0.01$ & $-0.02 \pm 0.02$ & $-0.05 \pm 0.02$ & $-0.04 \pm 0.02$ \\
\hline Sandakan, MLY & $0.01 \pm 0.01$ & $0.01 \pm 0.01$ & $0.01 \pm 0.01$ & $0.01 \pm 0.01$ \\
\hline \multicolumn{5}{|l|}{$\underline{J S}$} \\
\hline Jakarta, IND & $0.30 \pm 0.06$ & $-0.24 \pm 0.08$ & $-0.77 \pm 0.21$ & $-0.34 \pm 0.10$ \\
\hline Surabaya, IND & $0.03 \pm 0.02$ & $0.08 \pm 0.02$ & $0.06 \pm 0.02$ & $0.08 \pm 0.03$ \\
\hline
\end{tabular}




\section{Chapter 6: Concluding Chapter}

Ocean tides, thought for centuries to be a stationary process because of their close connection to the predictable celestial clockwork of gravitational attraction, are now known to be changing worldwide. No consensus has been reached regarding the causes of observed tidal changes, in part because there are apparently multiple mechanisms. One commonality, however, are the concurrent changes in mean sea level (MSL). This study shows that short term rises in sea levels and tidal properties interact in a complex manner, potentially leading, along some coasts, to increased future coastal inundation and its consequences. The short term fluctuations suggest that long-term changes in sea level may also drive long-term shifts in tidal properties and MSL. The relationships between the detrended short-term (seasonal to decadal) tidal variability, and the short-term MSL variability are named tidal anomaly trends (TATs).

The goal of this study was to quantify and catalogue changes in tides across the Pacific Ocean and determine possible mechanisms behind the observed variability. Part I accomplishes the former, whereas Parts II and III investigate the latter. This study has endeavored to improve the knowledge of dynamic tide theory by examining TATs at yearly and monthly time scales, and then attempting to determine causative factors. It is unlikely that MSL rise is the sole cause of global tidal evolution, however, changes are correlated on multiple time scales, and therefore, the changes in both may be related to the same intermediate mechanisms, such as stratification and background vorticity. The 
technique of comparing detrended short-term oceanic variability in such a manner is a new contribution to the field of tidal oceanography.

In Part I of this study, "Tidal variability in the Pacific", a survey of 153 tide gauges in the Pacific Ocean was presented. Tidal anomaly trends (TATs), defined from regressions against the yearly MSL variability (detrended from the mean) of the yearly variability in tidal admittance amplitudes and phase differences (similarly detrended) were documented for the four strongest tidal components, two semidiurnal $\left(\mathrm{M}_{2}\right.$ and $\left.\mathrm{S}_{2}\right)$, and two diurnal ( $\mathrm{K}_{1}$ and $\left.\mathrm{O}_{1}\right)$. The amplitude tidal anomaly trends (A-TATs) are found to be significant ( $S N R>2.0$ ) at the majority (93 and 82) of 153 tide gauges examined for $M_{2}$ and $\mathrm{K}_{1}$, and greater than $40 \%$ of all gauges in $\mathrm{O}_{1}$ and $\mathrm{S}_{2}$ (59 and 66 , respectively). The phase tidal anomaly trends (P-TATs) were found to be significant at 55 and 47 gauges for $M_{2}$ and $S_{2}$, and at 42 and 61 gauges for $K_{1}$ and $O_{1}$. Yearly TATs of note were mostly regional in scale, such as the strong negative A-TATs observed at US tide gauges situated in river estuaries, the anomalous pattern of TATs seen in and around Tokyo harbor, and the very negative semidiurnal A-TATs at Puerto Montt, Chile, thought to be a resonant effect. The largest portion of tide gauges observed to have significant TATs were found in the Southwest Pacific, where MSL rates are larger than anywhere else in the world. The coincidence of the tidal and MSL variations (possible causal), suggested that this region warranted closer investigation. This provided the motivation for Part II. 
Seasonal (monthly) variability of TATs, denoted seasonal tidal anomaly trends (STATs) were also documented in Part I. Tidal seasonality is small or absent at most gauges in the Pacific Ocean, but about a quarter of all gauges do show significant seasonality, as defined by statistically significant annual and semi-annual TAT modulations. Certain northern US and Canadian gauges show seasonality, likely influenced by seasonal river flow. However, the greatest concentration of strong tidal seasonality occurs in Southeast Asia at gauges located in Malaysia, Thailand, Vietnam, and Indonesia. The seasonality of constituent amplitudes in Malaysia is exceptionally strong and coherent, as is most of the phase seasonality. This area is under the influence of the yearly monsoon system, which is a likely causal mechanism for observed tidal seasonality, via the seasonal patterns of winds and rains that typify a monsoon system. These seasonal dynamics provided the motivation for Part III.

In Part II, entitled "Can tidal perturbations associated with sea level variations in the Western Pacific Ocean be used to understand future effects of tidal evolution?" (Devlin et al., 2014), the yearly TAT variability at 26 gauges in the Southwest Pacific was analyzed in detail. More than half of this set of tide gauges exhibited significant $\mathrm{M}_{2}$ and $\mathrm{K}_{1}$ A-TATs and P-TATs. The connection to changes in shallow-water overtides, the El Niño Southern Oscillation, and thermocline depth were found to be causative mechanisms of tidal variability in the Solomon Sea. Furthermore, the tidal variability relationship to MSL variability was seen to be different during different epochs of time (pre-1993 and post-1993) at some gauges in Australia; this division was chosen due to 
the observed change in MSL rates in the Western Pacific at this time (Merrifield, 2011). Finally, the dynamics of resonant triad interactions, a nonlinear coupling phenomenon between the $M_{2}, K_{1}$, and $\mathrm{O}_{1}$ tides, was also found to be part of the explanation of tidal variability in the Solomon Sea.

Long-term trends (LTTs) in tidal properties were compared to the short-term variability in the Western Pacific (yearly TATs), but the two metrics do not show any obvious causal connection; at some locations the direction of change is correlated (e.g., positive LTT; positive TAT), but at other it is anti-correlated (e.g., positive LTT; negative TAT). Comparison of time periods before and after 1993 shows considerable temporal variability. However, complex spatial patterns, differences between constituents, and differences between TATs and trends make it difficult to draw conclusions regarding causes of tidal evolution. This suggests that multiple dynamics are active in different parts of the frequency spectrum, and as of yet, no significant prediction about the future behavior of tidal constituents may be inferred from the analysis of interannual tidal and MSL fluctuations. Thus, the question posed in the title must be answered in the negative, and the predicted change in total water levels (tides + sea level) by 2100 (Part I) requires further investigation.

Though conclusive answers cannot be provided for the observed tidal changes the entire domain, there are a few sub-regions of the study that can be adequately explained at the yearly time scale, specifically, the eastern coast of Australia, and the 
Solomon Sea. For the Australian coast, which includes the Great Barrier Reef, a frictional mechanism, combined with a "back-effect" of continental shelf dynamics is likely (Arbic, 2009). Changes in ORs over time suggest a frictional component to changing tides in the region of study. Particularly over the Australian shelf, this appears to have a regional rather than local origin. The similarity in trends between coastal and island stations gives some support to the hypothesis that changes may be driven by continental shelf processes, which can have a back-effect upon open-ocean trends (Arbic and Garrett, 2010). Comparison of TATs for the pre- and post-1993 periods shows the trends have changed for many Australian shelf stations, including sign reversals.

In the Solomon Sea, the observed TATs are caused by a complex interaction of mechanisms. Astronomically forced tides and frictional shallow-water overtides are closely anti-correlated, particularly during times of extreme ENSO events. The $\mathrm{M}_{2}$ and $\mathrm{S}_{2}$ constituents are strongly (positively) correlated with nearby thermocline depth in the region surrounding the Solomon Islands as well as with MSL, and diurnal tides show a negative (decreasing) response to increasing MSL and deepening thermocline. Thus, changing friction appears to be the most likely agent of large-scale tidal evolution here. Additionally, tide data from gauges in the Solomon Sea exhibit a resonant triad interaction. Triad interactions of the diurnal and semidiurnal tides $\left(\mathrm{K}_{1}, \mathrm{O}_{1}\right.$, and $\left.\mathrm{M}_{2}\right)$ may both be mediated by and enhanced by variations in thermocline properties (Ball, 1964). The strength of these interactions can be modulated by changing water depth (MSL), 
which changes bottom friction, and also by the deepening of the thermocline, which changes both surface-layer depth and stratification. Triads can involve a transfer of tidal energy across multiple frequencies, as illustrated by the analyses of the Honiara and Rabaul gauge records in the Solomon Sea. Whether triad interactions are relevant on a regional basis, or only locally important, remains unclear. The situation in the Solomon Sea suggests that $M_{2}$ tides are involved in both the resonant and frictional triads. This results in large $( \pm 30 \%)$ interannual fluctuations of $\mathrm{M}_{2}$ amplitudes.

Finally, in Part III, "Seasonality of tides in Southeast Asia", the seasonal variability of tidal anomaly trends (STATs) was examined for twenty tide gauges in the Southeast Asian waters. The observed $M_{2}$ seasonality is about twice that of $S_{2}$, and $K_{1}$ is about twice that of $\mathrm{O}_{1}$. Most of the observed tidal variability is coherent with the Western North Pacific Monsoon Index (WNPMI) in the annual frequency band, with strong correlations in the majority of the Malacca Strait and all of the Gulf of Thailand, moderate correlations in the South China Sea, and weak correlations in the Java Sea. Based on these connections, the observed tidal variability was hypothesized to have a monsoon-related cause, and these were explored by way of a barotropic tide model (OTIS). Forcing mechanisms accessible in the barotropic model were seasonal changes in mean sea level (SSH); geostrophic velocity $\left(u_{g}\right)$; stratification, which influences bottom drag $\left(C_{d}\right)$; and Ekman velocity $\left(u_{e}\right)$. These mechanisms may act alone, or may all contribute to the observed tidal seasonality. Frictional stresses can be modulated by SSH, non-tidal currents $\left(u_{g}\right.$ and $u_{E}$ ), and stratification (through its influence on $C_{d}$ ). SSH 
can also act independently via the continuity equation. However, though the observed behavior may also be due in part to baroclinic mechanisms like internal tides and changes in steric heights, this is beyond the scope of this work.

The model responses due to SSH changes were negligible at all locations at all times. The $C_{d}$ model alone yielded a better fit in the first half of the year, but not as good after July, suggesting that stratification has more effect on tidal variability during winter and spring. Ekman transport is important only during monsoon seasons and for shallow regions, and is of very small magnitude in narrow passages such as the Malacca Strait. The mechanisms were evaluated by compared observed annual and semi-annual cycles to the modeled annual and semi-annual cycles, as modulated by SSH, $u_{g}, u_{E}$, and $C_{d .}$. The majority of the best fits were produced by the geostrophic velocities, the combination of the two velocity model responses, or in a few locations, the combination of velocities and bottom drag. Around half of all gauges were able to be at least partially reconstructed for $\mathrm{M}_{2}, \mathrm{~S}_{2}, \mathrm{~K}_{1}$, and $\mathrm{O}_{1}$. Model responses were ubiquitously larger in shallow water locations than in deep ocean locations. The best model reconstructions for all constituents were in the Gulf of Thailand. Tidal variability in the South China Sea and Java Sea is generally small, and the semidiurnal model response was generally more accurately modeled than the diurnal response. Vung Tau, Vietnam was a notable exception, as the large tidal variability here is not fully explained by any barotropic model combination. I suggest that tidal variability at this station is due to the 
barotropic and baroclinic effects of river discharge from the Mekong, which are not captured in the model. Results in the Malacca Strait are mixed, with some constituents at some gauges being well explained, and others not, particularly for the $K_{1}$ amplitudes and phases. It is possible that this variability is also due to river flow mechanisms not accurately captured by the model, though there is very little flow data in the region to allow comparisons, and the climate data on which model adjustments are based may be unreliable in this shallow narrow region.

Part III showed that even though seasonal tidal variability is spatially and temporally complex and caused by multiple mechanisms, a barotropic model can recreate some of the yearly variability at the locations examined, especially when the influence of multiple mechanisms are considered. The hypothesis of monsoonal dynamics being the causative factor is supported. Areas where the tidal variability is strongly correlated to the WNPMI are regions where models based on monsoon mechanisms had the most success in reconstructing the observed variability.

While this study did not conclusively resolve the causes of tidal variability, it has achieved significant results. The motivations of this work were twofold: (a) to document the tidal variability of the Pacific; and (b) to explain the causes of the variability. The first of these goals was achieved, and the second goal met with locationspecific, but nonetheless significant, success. The catalogue of tidal response to MSL variability at multiple time scales provided by this work may assist in future predictions 
of high-water events and formulation of coastal planning strategies. Further accomplishments of this study were the development of the methodology of tidal anomaly trends (TATs) and seasonal tidal anomaly trends (STATs) to compare and contrast tidal fluctuations with MSL variability is a new contribution to the field of oceanography, as well as the analysis of resonant triad relationships between the $M_{2}$, $\mathrm{K}_{1}$, and $\mathrm{O}_{1}$ tides in the Solomon Sea. Resonant triads are non-linear harmonic interactions of multiple wave modes observed in many other fields of physics, yet not observed in such a tidal context before. Success can also be claimed in the utilization of a barotropic model to explain parts of the observed seasonal tidal variability in Southeast Asia, a region of complex atmospheric and oceanic dynamics that is experiencing some of the largest rates of MSL rise as well as the largest tidal seasonal tidal variability in the Pacific.

I conclude in closing that the long-term changes in tides, as well as the shortterm fluctuations, may be as important to future water levels as the rise in MSL in some regions. Over three centuries after Newton first explained the tides, many questions are still unresolved. It is likely that no single global explanation will be found. Yet it is hoped that the work presented here will help to advance the knowledge of tidal and water level dynamics, which will help in efficient future planning of coastal areas, and may even save lives, particularly in the Southwest Pacific. This region is also one of the most populous on Earth, and is likely to experience the damaging effects of increased high water levels before other parts of the globe, making accurate knowledge of these 
regional dynamics vital to the health of coastal infrastructure and the welfare of coastal inhabitants. 


\section{References}

Ablain M, Cazenave A, Larnicol G, Balmaseda M, Cipollini P, Faugère Y, Fernandes MJ, Henry O, Johannessen, JA. Knudsen P, and Andersen O (2015) Improved sea level record over the satellite altimetry era (1993-2010) from the climate change initiative project. Ocean Science, 11(1), pp.67-82.

Aiken CM (2008) Barotropic tides of the Chilean Inland Sea and their sensitivity to basin geometry. Journal of Geophysical Research: Oceans, 113(C8).

Alcock G and Pugh DT (1980) Observations of tides in the Bristol Channel and Severn Estuary. Inst. Oceanographic Sciences Report No. 112.

Amin M (1983) On perturbations of harmonic constants in the Thames

Estuary. Geophysical Journal International, 73(3), pp.587-603.

Arbic BK (2005) Atmospheric forcing of the oceanic semidiurnal tide, Geophys. Res. Lett., 32, L02610, DOI: 10.1029/2004GL021668

Arbic BK, Karsten RH, Garrett C (2009) On tidal resonance in the global ocean and the back-effect of coastal tides upon open-ocean tides, Atmosphere-Ocean 47 (4) , 239266, DOI:10.3137/OC311.2009

Arbic BK and Garrett C (2010) A coupled oscillator model of shelf and ocean tides Cont. Shelf Res. 30 (6), 564-574, DOI: 10.1016/j.csr.2009.07.008

Armstrong JA, Bloembergen N, Ducuing J, Pershan PS (1962) Interactions between light waves in a nonlinear dielectric, Phys. Rev. 127, 1918-1939, DOI:

10.1103/PhysRev.127.1918

Ashok K, Behera SK, Rao SA, Weng H and Yamagata T (2007) El Niño Modoki and its possible teleconnection. Journal of Geophysical Research: Oceans, 112(C11).

Ball FK (1964) Energy transfer between external and internal gravity waves. J. Fluid Mech. 19 (3), 465

Bowen AJ (1972) The tidal regime of the River Thames; long-term trends and their possible causes. Philosophical Transactions of the Royal Society of London A:

Mathematical, Physical and Engineering Sciences, 272(1221), pp.187-199. 
Bretherton FP (1964) Resonant interactions between waves J. Fluid Mech., 20, 457-479, DOI: 10.1017/S0022112064001355

Bromirski PD, Miller AJ, Flick RE, Auad G (2011) Dynamical suppression of sea level rise along the Pacific coast of North America: Indications for imminent acceleration., Jour. Of GeoPhys. Res. 116, CO7005, DOI: 10.1029/2010JC006759

Cáceres M, Valle-Levinson A and Atkinson L (2003) Observations of cross-channel structure of flow in an energetic tidal channel. Journal of Geophysical Research: Oceans, 108(C4).

Carter GS, Gregg MC (2006) Persistent near-diurnal internal waves observed above a site of $\mathrm{M}_{2}$ barotropic-to-baroclinic conversion, Jour. of phys. Oceanogr. 36(6), 11361147, DOI: 10.1175/JPO2884.1

Carlson JA, Jaffe A and Wiles A (2006) The millennium prize problems. American Mathematical Soc.

Cartwright DE, Tayler RJ (1971) New computations of the tide-generating potential, Geophysical Journal of the Royal Astronomical Society, 23, 45-74, DOI: 10.1111/j.1365246X.1971.tb01803.x

Cartwright DE (1972) Secular changes in the oceanic tides at Brest, 17111936. Geophysical Journal International, 30(4), pp.433-449.

Cartwright DE, Edden AC (1973) Corrected tables of tidal harmonics Geophys. Res. Lett. 33, 253-264, DOI: 10.1111/j.1365-246X.1973.tb03420.x

Cartwright DE (1977) Oceanic tides. Reports on Progress in Physics, 40(6), p.665. Cartwright DE and Amin MM (1986) The variances of tidal harmonics. Deutsche Hydrografische Zeitschrift, 39(6), pp.235-253.

Cartwright DE and Melchior P (1999) Tides: a scientific history (Vol. 7). Cambridge: Cambridge University Press.

Cazenave A, Nerem RS (2004) Present-day sea level change: observations and causes, Reviews of Geophysics, 42, RG3001, 1-20, DOI: 10.1029/2003RG000139 
Chambers DP, Merrifield MA and Nerem RS (2012) Is there a 60-year oscillation in global mean sea level? Geophysical Research Letters, 39(18).

Chao SY, Ko DS, Lien RC, and Shaw PT (2007) Assessing the west ridge of Luzon Strait as an internal wave mediator. Journal of Oceanography, 63(6), pp.897-911.

Chen M, Murali K, Khoo BC, Lou J and Kumar K (2005) Circulation modelling in the Strait of Singapore. Journal of coastal research, pp.960-972.

Chiswell, SM (1994) Vertical structure of the baroclinic tides in the central North Pacific subtropical gyre, Jour. Of Phys. Oceanogr. 24, 2032-2039, DOI: 10.1175/15200485(1994)24[2032: VSOTBT] 2.0.CO; 2

Church JA, NJ White, R Coleman, K Layback, JX Mitrovica (2004) Estimates of the regional distribution of sea level rise over the 1950-2000 period, J. Clim., 17, 2609-2625, doi:10.1175/1520-0442(2004)

Church JA and White NJ (2006) A 20th century acceleration in global sea level rise, Geophys. Res. Lett., 33, L01602, DOI: 10.1029/2005GL024826

Church, JA and White, NJ (2011) Sea level Rise from the Late 19th to the Early 21st Century. Surv. Geophys., DOI 10.1007/s10712-011-9119-1

Church JA, Roemmich D, Domingues CM, Willis JK, White NJ, Gilson JE, Stammer D, Köhl A, Chambers DP, Landerer FW, Marotzke J, Gregory JM, Tatsuo Suzuki, Cazenave A, Pi.-Y. Le Traon, (2011) Ocean Temperature and Salinity Contributions to Global and Regional Sea level Change, in Understanding Sea level Rise and Variability, WileyBlackwell, Oxford, pp. 143-176, DOI: 10.1029/2007E0040008 Colossi JA and Munk W (2006) Tales of the Venerable Honolulu Tide Gauge, J. Phys. Oceanogr., 36, 967-996, DOI: 10.1175/JPO2876.1 Corkan RH (1934) An annual perturbation in the range of tide Proceedings of the Royal Society of London. Series A, Containing Papers of a Mathematical and Physical Character, 144(853), pp.537-559. Craik, ADD (1985) Wave Interactions and Fluid Flows, Cambridge Univ. Press, Cambridge, U. K, ISBN: 978-0521368292 
DeConto RM and Pollard D (2016) Contribution of Antarctica to past and future sea level rise. Nature, 531(7596), pp.591-597.

Dee DP, Uppala SM, Simmons AJ, Berrisford P, Poli P, Kobayashi S, Andrae U, Balmaseda MA, Balsamo G, Bauer P, Bechtold P, Beljaars ACM, van de Berg L, Bidlot J, Bormann N, Delsol C, Dragani R, Fuentes M, Geer AJ, Haimberger L, Healy SB, Hersbach H, Hólm EV, Isaksen L, Kållberg P, Köhler M, Matricardi M, McNally AP, Monge-Sanz BM, Morcrette JJ, Park BK, Peubey C, de Rosnay P, Tavolato C, Thépaut, JN and Vitart F (2011), The ERAInterim reanalysis: configuration and performance of the data assimilation system. Q.J.R. Meteorol. Soc., 137: 553-597. doi: 10.1002/qj.828

Devlin AT, Jay DA, Talke SA, and Zaron E. (2014). Can tidal perturbations associated with sea level variations in the Western Pacific Ocean be used to understand future effects of tidal evolution? Ocean Dynamics, 64(8), 1093-1120. DOI: 10.1007/s10236-014-0741-6 Di Lorenzo E, Schneider N, Cobb KM, Franks PJS, Chhak K, Miller AJ, McWilliams JC, Bograd, SJ, Arango H, Curchitser E, and Powell TM (2008) North Pacific Gyre Oscillation links ocean climate and ecosystem change. Geophysical Research Letters, 35(8).

Di Lorenzo E, Cobb KM, Furtado JC, Schneider N, Anderson BT, Bracco A, Alexander MA and Vimont DJ (2010) Central Pacific El Niño and decadal climate change in the North Pacific Ocean. Nature Geoscience, 3(11), pp.762-765.

Ding, X, J Chao, D Zheng, and Y Chen (2001). Long-term sea level changes in Hong Kong from tide-gauge records. Journal of Coastal Research, pp.749-754.

Ding, X, D Zheng, WT Wong, KW Li, W Chen and P Zhong (2004), July. Recent sea level variations in Southern China from tide gauge observations. In Proceedings of the AsiaPacific Space Geodynamics Symposium, Singapore (pp. 126-136).

Domingues CM, Church JA, White NJ, Glecker PJ, Wijffels SE, Barker PM, Dunn JR (2008) Improved estimates of upper-ocean warming and multi-decadal sea level rise, Nature, 453, 1090-1094, DOI: :10.1038/nature07080

Dushaw BD, Cornuelle BD, Worcester PF, Howe BM, Luther DS (1995) Barotropic and baroclinic tides in the central North Pacific Ocean determined from long-range 
reciprocal acoustic transmissions, Jour. Of Phys. Oceangr. 25, 631-647, DOI:

10.1175/1520-0485(1995)025<0631: BABTIT>2.0.CO; 2

Egbert GD, Bennett AF, and Foreman MG (1994) TOPEX/POSEIDON tides estimated using a global inverse model.

Egbert GD and Erofeeva SY (2002) Efficient inverse modeling of Barotropic Ocean tides, J. Atm. and Ocean. Tech., 19, 18 (204), DOI: 10.1175/1520-0426(2002)019<0183:

EIMOBO>2.0.CO; 2

Egbert GD and Erofeeva SY (2010) OTIS (OSU Tidal Inversion Software) TPXO7.2. College of Oceanic and Atmospheric Sciences, Oregon State University, Corvallis, Oregon, http://volkov.oce.orst.edu/tides/otis.html

Ekman VW (1905) On the influence of the earth's rotation on ocean currents. Ark. Mat. Astron. Fys., 2, pp.1-53.

Faughn JL (1974) Naga Expedition: station index and data. Scripps Institution of Oceanography.

Feng X, and Tsimplis MN (2014) Sea level extremes at the coasts of China, J. Geophys. Res. Oceans, 119, 1593-1608, doi: 10.1002/2013JC009607

Feng X Tsimplis MN and Woodworth PL (2015) Nodal variations and long-term changes in the main tides on the coasts of China. Journal of Geophysical Research: Oceans, 120(2), pp.1215-1232.

Fisher RL, Jantsch MJ, and Comer RL (1982) General Bathymetric chart of the Oceans (GEBCO). Canadian Hydrographic Service, Ottawa, Canada.

Flick RE, Murray JF, Ewing LC (2003) Trends in United States Tidal Datum Statistics and Tide Range, J. Waterway, Port, Coastal and Ocean Eng. Amer. Soc. Civil Eng., 129(4): 155-164, DOI: 10.1061/ ASCE10733-950X 20031129:4 1551

Frelich MH and Guza RT (1984) Nonlinear effects on shoaling surface gravity waves. Philosophical Transactions of the Royal Society of London A: Mathematical, Physical and Engineering Sciences, 311(1515), pp.1-41. 
Gerkema T, Staquet C, and Bouruet-Aubertot P (2006) Decay of semidiurnal internal-tide beams due to subharmonic resonance, Geophys. Res. Lett., 33, L08604, DOI:

$10.1029 / 2005$ GL025105

Gill, AE (1982) Atmosphere-ocean dynamics (Vol. 30), Academic press, ISBN: 9780122835223

Godin G (1985) Modification of river tides by the discharge. Journal of waterway, port, coastal, and ocean engineering, 111(2), pp.257-274.

Godin $\mathrm{G}$ (1986) Is the abnormal response of the tide at the frequency of $S_{2}$ really due to radiational effects? Continental Shelf Research, 6(5), pp.615-625.

Godin G (1991) Frictional effects in river tides. Tidal hydrodynamics, 379, p.402.

Guo L, van der Wegen M, Jay DA, Matte P, Wang ZB, Roelvink D, and He Q (2015) Rivertide dynamics: Exploration of nonstationary and nonlinear tidal behavior in the Yangtze River estuary, J. Geophys. Res. Oceans, 120, 3499-3521, doi: 10.1002/2014JC010491. Gutzwiller MC (1998) Moon-Earth-Sun: The oldest three-body problem. Reviews of Modern Physics, 70(2), p.589.

Haigh I, Nicholls R, Wells N (2010) Assessing changes in extreme sea levels:

Applications to the English Channel, 1900-2006, Cont. Sh. Res. 30, 1042-1055, DOI:

10.1016/j.csr.2010.02.002

Hamlington, BD, RR Leben, RS Nerem, W Han, KY Kim (2011) Reconstructing sea level using cyclostationary empirical orthogonal functions, J. Geophys. Res., 116, C12015, doi: $10.1029 / 2011 J C 007529$

Hartmann T and Wenzel HG (1995) The HW95 tidal potential catalogue. Geophysical Research Letters, 22(24), pp.3553-3556.

Hibiya, T., M. Nagasawa, and Y. Niwa (2002) Nonlinear energy transfer within the oceanic internal wave spectrum at mid and high latitudes, J. Geophys. Res., 107(C11), 3207, DOI: 10.1029/2001JC001210

Hinze JO (1959) Turbulence, 1975. New York. 
Hirst AC and Godfrey JS (1993) The role of Indonesian throughflow in a global ocean GCM. Journal of Physical Oceanography, 23(6), pp.1057-1086 Holleman RC and MT Stacey (2014) Coupling of sea level rise, tidal amplification, and inundation. Journal of Physical Oceanography, 44(5), pp.1439-1455.

Holgate SJ (2007) On the decadal rates of sea level change during the twentieth century. Geophysical research letters, 34(1).

Holleman, RC and MT Stacey (2014) Coupling of sea level rise, tidal amplification, and inundation. Journal of Physical Oceanography, 44(5), pp.1439-1455.

Horsburgh KL, Wilson C (2007) Tide-surge interaction and its role in the distribution of surge residuals in the North Sea, Jour. of Geophys. Res. 112, C08003,

DOI: $10.1029 / 2006 J C 004033$

Huang NE, Shen Z, Long SR, Wu MC, Shih HH, Zheng Q, Yen NC, Tung CC, Liu HH (1998) The empirical mode decomposition and the Hilbert spectrum for nonlinear and non-stationary time-series analysis Proc. R. Soc. Lond. A. 454, 903-995, DOI:

10.1098/rspa.1998.0193

Huang NE, Wu Z (2008) A review on Hilbert-Huang Transform: Method and its application to geophysical studies, Rev. of GeoPhys. 46, RG2006, 1-23,

DOI: $10.1029 / 2007 R G 000228$

Huber PJ Robust Statistics Hoboken, NJ: John Wiley \& Sons, Inc., 1981 DOI: 10.1137/1.9781611970036.fm

Hughes TP, Baird AH, Bellwood DR, Card M, Connolly, SR, Folke C, Grosberg R, HoeghGuldberg O, Jackson JBC, Kleypas J, Lough JM, Marshall P, Nystrom M, Palumbi SR, Pandolfi JM, Rosen B, Roughgarden J (2003) Climate Change, Human Impacts, and the Resilience of Coral Reefs, Science 301, 929, DOI: 10.1126/science.1085046 Hughes TP, Graham NAJ, Jackson JBC, Mumby PJ, Steneck RS (2010) Rising to the challenge of sustaining coral reef resilience, Trends in Ecology and Evolution, 25, 11, DOI: 10.1016/j.tree.2010.07.011 
Hunter JR (1975) A note on quadratic friction in the presence of tides Estuarine and Coastal Marine Science, 3(4), pp.473-475.

Hunter J (2010) Estimating sea level extremes under conditions of uncertain sea level rise. Climatic Change, 99(3-4), pp.331-350.

Jan S, Chern CS, Wang J, and Chao SY (2007) Generation of diurnal K1 internal tide in the Luzon Strait and its influence on surface tide in the South China Sea. Journal of Geophysical Research: Oceans, 112(C6).

Jay DA (1991) Green's law revisited: Tidal long-wave propagation in channels with strong topography.

Jay DA (2009) Evolution of tidal amplitudes in the eastern Pacific Ocean, Geophys. Res. Lett., 36, L04603, DOI: 10.1029/2008GL036185

Jay DA, Leffler K, Degens S, (2011) Long-term evolution of Columbia River tides, ASCE Journal of Waterway, Port, Coastal, and Ocean Engineering, 137: 182-191; DOI:

10.1061/(ASCE)WW.1943- 5460.0000082

Jevrejeva S, Grinsted A, Moore JC, and Holgate S (2006) Nonlinear trends and multiyear cycles in sea level records. Journal of Geophysical Research: Oceans, 111(C9).

Kang SK, Chung JY, Lee SR, and Yum KD (1995) Seasonal variability of the $M_{2}$ tide in the seas adjacent to Korea. Continental Shelf Research, 15(9), pp.1087-1113.

Kaup DJ (1980) A method for solving the separable initial value problem of the full three dimensional three-wave interaction, Stud. Appl. Math, 62, 75-83

Kohl A, Stammer D, and Cornuelle B (2007) Interannual to decadal changes in the ECCO Global Synthesis. J. Phys.Oceanogr., 37, 313-337, DOI: 10.1175/JP03014.1 Kolker AS and Hameed S (2007) Meteorologically driven trends in sea level rise. Geophysical Research Letters, 34(23).

Kukulka, T., and Jay DA, (2003) Impacts of Columbia River discharge on salmonid habitat II. Changes in shallow-water habitat, J. Geophys. Res. 108, 3294 DOI: 10.1029/2003JC001829. 
Lagerloef GSE, GT Mitchum, RB Lukas, PP Niiler (1999) Tropical Pacific near-surface currents estimated from altimeter, wind, and drifter data, J. Geophys. Res., 104, 2331323326

Lamb KG (2007) Tidally generated near-resonant internal wave triads at a shelf break, Geophys. Res. Lett. 34, L18607, DOI: 10.1029/2007GL030825

Leeuwenburgh O, Andersen OB, and Huess V (1999) Seasonal tide variations from tide gauges and altimetry. Physics and Chemistry of the Earth, Part A: Solid Earth and Geodesy, 24(4), pp.403-406.

Leffler KE, Jay DA (2009) Enhancing tidal harmonic analysis: Robust solutions, Cont. Shelf Res., 29.1, 78-88, DOI: 10.1016/j.csr.2008.04.011

Legg S, J Klymak (2008) internal hydraulic jumps and overturning generated by tidal flow over a tall steep ridge, J. Phys. Oceangr., 38, 1949-1964

Lelong MP, Kunze E (2013) Can barotropic tide-eddy interactions excite internal waves? Journal of Fluid Mechanics, 721, 1-27, DOI: 10.1017/jfm.2013.1

Levitus S, Antonov JI, Baranova OK, Boyer TP, Coleman CL, Garcia HE, Grodsky AI, Johnson DR, Locarnini RA, Mishonov AV, and Reagan JR (2013) The world ocean database. Data Science Journal, 12(0), pp.WDS229-WDS234.

Livezey, RE and WY Chen, (1983) Statistical field significance and its determination by Monte Carlo techniques. Mon. Wea. Review, 111, 46-59, DOI: 10.1175/1520-

0493(1983)111<0046: SFSAID>2.0.CO; 2

Locarnini RA, Mishonov AV, Antonov JI, Boyer TP, Garcia HE, Baranova OK, Zweng MM and Johnson DR (2010) World Ocean Atlas 2009, S. Levitus, Ed. NOAA Atlas NESDIS 67, U.S. Gov. Printing Office, Wash., D.C., 184 pp

Lombard A, Garric G, Penduff T (2009) Regional patterns of observed sea level change: Insights from a 1/48 global ocean/sea-ice hindcast, Ocean Dyn., 59, 433-449, DOI:

$10.1007 / \mathrm{s} 10236-008-0161-6$

Louis, JF (1979) A parametric model of vertical eddy fluxes in the atmosphere. Boundary-Layer Meteorology, 17(2), pp.187-202. 
McPhaden, MJ (1999) Genesis and evolution of the 1997-98 El Niño Science 283.5404 950-954.

MacKinnon, J. A., and K. B. Winters (2005) Subtropical catastrophe: Significant loss of low-mode tidal energy at 28.9N, Geophys. Res. Lett., 2, L15605,

DOI: 10.1029/2005GL023376

Madden RA and Julian PR (1971) Detection of a 40-50 day oscillation in the zonal wind in the tropical Pacific. Journal of the Atmospheric Sciences, 28(5), pp.702-708.

Mantua NJ, Hare SR, Zhang Y, Wallace JM, and Francis RC (1997) A Pacific interdecadal climate oscillation with impacts on salmon production. Bulletin of the American Meteorological Society, 78(6), pp.1069-1079.

Mantua NJ, and Hare SR (2002) The Pacific decadal oscillation. Journal of oceanography, 58(1), pp.35-44.

Mawdsley, RJ, ID Haigh, and NC Wells (2015). Global secular changes in different tidal high water, low water and range levels. Earth's Future, 3(2), pp.66-81.

Meinshausen M, Smith SJ, Calvin K, Daniel JS, Kainuma MLT, Lamarque JF, Matsumoto K, Montzka SA, Raper SCB, Riahi K, and Thomson AGJMV (2011) The RCP greenhouse gas concentrations and their extensions from 1765 to 2300. Climatic change, 109(1-2), pp.213-241.

Merrifield MA, Merrifield ST and Mitchum GT (2009) An anomalous recent acceleration of global sea level rise. Journal of Climate, 22(21), pp.5772-5781.

Merrifield MA (2011) A shift in Western tropical Pacific sea level trends during the 1990s, Jour. of Climate, 24, 4126-4138, DOI: 10.1175/2011JCLI3932.1

Millero FJ, Rainer F, Wright DG, McDougall TJ (2008) The composition of standard seawater and the definition of the reference-composition salinity scale, Deep Sea Res. Part 1, 55, 1, 50-72, DOI:10.1016/j.dsr.2007.10.001

Min-sheng $\mathrm{H}$ (2000) The development of ports in Japan and its economic development. WORLD REGIONAL STUDIES, 3, p.007. 
Mitchum GT, Chiswell SM (2000) Coherence of internal tide modulations along the Hawaiian ridge J. Geophys. Res., 105(C12), 28653-28661, DOI: 10.1029/2000JC900140 Mizuno K and White WB (1983) Annual and interannual variability in the Kuroshio Current system. Journal of physical oceanography, 13(10), pp.1847-1867.

Moftakhari HR, Jay DA, Talke SA, Kukulka T and Bromirski PD (2013) A novel approach to flow estimation in tidal rivers. Water Resources Research, 49(8), pp.4817-4832. Moftakhari HR, Jay DA, and Talke SA (2016) Estimating river discharge using multipletide gauges distributed along a channel. Journal of Geophysical Research: Oceans. Müller M, Arbic BK, Mitrovica J (2011a) Secular trends in ocean tides: observations and model results. J. Geophys. Res., 116, C05 013, DOI: 10.1029/2010JC006387 Müller M (2011b) Rapid change in semi-diurnal tides in the North Atlantic since 1980. Geophysical Research Letters, 38(11).

Müller M, Cherniawsky JY, Foreman MGG and Storch JS (2012a) Global M2 internal tide and its seasonal variability from high resolution ocean circulation and tide modeling. Geophysical Research Letters, 39(19).

Müller M (2012b) The influence of changing stratification conditions on barotropic tidal transport. Contin. Shelf Res., 47 (15), 107-188, DOI: 10.1016/j.csr.2012.07.003 Munk WH and Cartwright DE (1966) Tidal spectroscopy and prediction. Philosophical Transactions of the Royal Society of London A: Mathematical, Physical and Engineering Sciences, 259(1105), pp.533-581.

National Research Council (2012) Sea level Rise for the Coasts of California, Oregon, and Washington: Past, Present, and Future. National Academies Press

Nerem RS, Chambers DP, Leuliette EW, Mitchum GT, Giese BS (1999) Variations in global mean sea level associated with the 1997-1998 ENSO event: Implications for measuring long term sea level change, Geophys. Res. Lett. 26(19), 3005-3008,

DOI: 10.1029/1999GL002311

Newman M, Compo GP, and Alexander MA (2003) ENSO-forced variability of the Pacific decadal oscillation. Journal of Climate, 16(23), pp.3853-3857. 
Nicholls, RJ, A Cazenave (2010) Sea level rise and its impacts on coastal zones, Science 18, June 2010: 328, 5985 pp.1517-1520 DOI: 10.1126/science.1185782

Niwa $Y$ and Hibiya T (2004) Three-dimensional numerical simulation of M2 internal tides in the East China Sea. Journal of Geophysical Research: Oceans, 109(C4).

Ozmidov RV (1965) On the turbulent exchange in a stably stratified ocean, Izv. Acad. Sci. USSR, Atmos. Oceanic Phys, 1, pp.861-871.

Pantoja S, Iriarte JL, and Daneri G (2011) Oceanography of the Chilean Patagonia. Parker, Bruce (1991) Tidal Hydrodynamics, John Wiley and Sons, NY, 1-883, ISBN: 9780471514985

Pawlowicz R, Beardsley B, and Lentz S (2002) Classical tidal harmonic analysis including error estimates in MATLAB using T_TIDE, Computers and Geosciences, 28, 8, 929-937 Perlin, A, Moum JN, Klymak JM, Levine MD, Boyd T and Kosro PM, (2005) A modified law-of-the-wall applied to oceanic bottom boundary layers. Journal of Geophysical Research: Oceans, 110(C10).

Pfeffer WT, Harper JT, O’Neel S (2008) Kinematic constraints on glacier contributions to $21^{\text {st }}$ century sea level rise, Science, $321,1340-1343$

Pickering MD ,Wells NC, Horsburgh KJ, Green JAM (2012) The impact of future sea level rise on the European Shelf tides, Cont. Sh. Res. 35, 1-15, DOI:

10.1016/j.csr.2011.11.011

Pugh DT and Vassie JM (1976) Tide and surge propagation off-shore in the Dowsing region of the North Sea. Deutsche Hydrografische Zeitschrift, 29(5), pp.163-213. Pugh DT (1987) Tides, surges and mean sea level: a handbook for engineers and scientists, Wiley, Chichester, 472pp, ISBN: 978-0471915058 Pugh DT (2004) Changing sea levels. Effects of tides, weather and climate. Cambridge University Press, 280pp, ISBN: 978-0521532181

Pugh D and Woodworth P (2014) Sea level science: understanding tides, surges, tsunamis and mean sea level changes. Cambridge University Press. 
Rahmstorf S (2007) A semi-empirical approach to projecting future sea level rise.

Science, 315, 268-370

Rainville L, R Pinkel (2006) Propagation of low-mode internal waves through the ocean, J. Phys. Oceangr., 36, 6, 1220-1236, DOI: 10.1175/JPO2882.1

Rasheed AS, and Chua VP (2014) Secular trends in tidal parameters along the coast of Japan. Atmosphere-Ocean, 52(2), pp.155-168.

Ray RD, Mitchum GT (1996) Surface manifestations of internal tides generated near Hawaii. Geophys. Res. Letters 23, 2101-2104, DOI: 10.1029/96GL02050

Ray RD, Mitchum GT (1997) Surface manifestations of internal tides in the deep ocean: observations from altimetry and island gauges, Prog. Oceanography, 40,135-162, DOI: 10.1016/S0079-6611(97)00025-6

Ray RD (2001) Comparisons of global analyses and station observations of the $\mathrm{S}_{2}$ barometric tide Geophys. Res. Lett. 28, 21-24, DOI: 10.1016/S1364-6826(01)00018-9 Ray RD (2006) Secular changes of the M2 tide in the Gulf of Maine, Cont. Shelf. Res., 26(3), 422-427, DOI: 10.1016/j.csr.2005.12.005

Ray RD (2009) Secular changes in the solar semidiurnal tide of the Western North Atlantic Ocean, Geophysical Research Letters, 36, L19601, DOI: 10.1029/2009GL040217 Ray RD, Egbert GD, and Erofeeva SY (2011) Tide predictions in shelf and coastal waters: Status and prospects. In Coastal altimetry (pp. 191-216). Springer Berlin Heidelberg. Rizal S, Setiawan I, Iskandar T, Ilhamsyah Y, Wahid MA and Musman M (2010) Currents simulation in the Malacca Straits by using three-dimensional numerical model. Sains Malaysiana, 39(4), pp.519-524.

Rizal S, Damm P, Wahid MA, Sundermann J, Ilhamsyah Y and Iskandar T (2012) General circulation in the Malacca strait and Andaman Sea: a numerical model study. American Journal of Environmental Sciences, 8(5), p.479.

Rohling EJ, Grant K, Hemleben CH, Siddall M, Hoogakker BAA, Bolshaw M, Kucera M (2008) High rates of sea level rise during the last interglacial period. Nature Geoscience 1, 38 - 42 doi:10.1038/ngeo.2007.28 
Ropelewski CF, Halpert MS (1987) Global and regional scale precipitation patterns associated with the El Niño/ Southern Oscillation, Monthly Weather Review, 115, 16061626

Sallenger Jr. AH, Doran KS, and Howd PA (2012) Hotspot of accelerated sea level rise on the Atlantic coast of North America. Nature Climate Change 2.12 (2012): 884-888.

Schneider N and Cornuelle BD (2005) The forcing of the pacific decadal oscillation. Journal of Climate, 18(21), pp.4355-4373.

Simmons WF (1969, April) A variational method for weak resonant wave interactions. In Proceedings of the Royal Society of London A: Mathematical, Physical and Engineering Sciences (Vol. 309, No. 1499, pp. 551-577), The Royal Society.

Skiba AW, Zeng L, Arbic BK, Müller M and Godwin WJ (2013) On the resonance and shelf/open-ocean coupling of the global diurnal tides. Journal of Physical Oceanography, 43(7), pp.1301-1324. Smith WH and Sandwell DT (1994) Bathymetric prediction from dense satellite altimetry and sparse shipboard bathymetry. Journal of Geophysical Research: Solid Earth, 99(B11), pp.21803-21824.

Smith WH and Sandwell DT (1997) Global sea floor topography from satellite altimetry and ship depth soundings. Science, 277(5334), pp.1956-1962.

Snyder RL, Sidjabat M and Filloux JH (1979) A study of tides, setup and bottom friction in a shallow semi-enclosed basin, Part II: Tidal model and comparison with data. Journal of Physical Oceanography, 9(1), pp.170-188.

Talke SA, P Orton, and DA Jay, (2014). Increasing storm tides in New York Harbor, 18442013. Geophysical Research Letters, 41(9), pp.3149-3155.

Temam R (2001) Navier-Stokes equations: theory and numerical analysis (Vol. 343). American Mathematical Society.

Timmermann A, McGregor S, Jin FF (2010) Wind effects on past and future regional sea level trends in the southern Indo-Pacific. J. Climate, 23, 4429-4437, DOI:

10.1175/2010JCLI3519.1 
Trenberth KE, David PS and Caron JM (2000) The global monsoon as seen through the divergent atmospheric circulation. J. Climate 13, 22, 3969-3993 DOI: 10.1175/15200442

Vellinga NE, Hoitink AJF, van der Vegt M, Zhang W, and Hoekstra P (2014), Human impacts on tides overwhelm the effect of sea level rise on extreme water levels in the Rhine-Meuse delta, Coastal Eng., 90, 40-50.

Vörösmarty CJ, Fekete B and Tucker BA (1998) River Discharge Database, Version 1.1 (RivDIS v1.0 supplement). Available through the Institute for the Study of Earth, Oceans, and Space / University of New Hampshire, Durham NH (USA).

Wang B, and Fan Z (1999). Choice of South Asian summer monsoon indices. Bull. of the Am. Meteor. Society, 80(4), 629-638. DOI: 10.1175/1520-0477

Webster PJ, and Yang S (1992) Monsoon and ENSO: Selectively interactive systems. Quarterly Journal of the Royal Meteorological Society, 118(507), 877-926, DOI: 10.1002/qj.49711850705

Weiland J Wilhelmsson H. (1977) Coherent non-linear interaction of waves in plasmas, Pergamon Press, ISBN: 978-0080209647

White WB, Cayan DR, Dettinger MD, Auad G (2001) Sources of global warming in the upper ocean temperature during El Niño, J. Geophys. Res., 106(C3), DOI:

10.1029/1999JC000130

Wolanski, E (1994) Physical oceanographic processes of the Great Barrier Reef, CRC Press, 208pp, ISBN: 0849380472

Wood FJ (1986) Tidal dynamics: Coastal flooding and cycles of gravitational force.

Woodworth PL, White NJ, Jevrejeva S, Holgate SJ, Church JA and Gehrels WR (2009)

Evidence for the accelerations of sea level on multi-decade and century timescales. International Journal of Climatology, 29(6), pp.777-789.

Woodworth PL (2010) A survey of recent changes in the main components of the ocean tide, Continental Shelf Research, 30(15), 1680-1691, DOI: 10.1016/j.csr.2010.07.002 
Wu Z Huang NE (2009) Ensemble empirical mode decomposition: A noise-assisted dataanalysis method, Advances in Adaptive Data Analysis, 1(1), 1-41

Wyrtki K (1961) Physical oceanography of the Southeast Asian waters. Scripps Institution of Oceanography.

Xie XH, Chen GY, Shang XD, Fang WD (2008) Evolution of the semidiurnal (M2) internal tide on the continental slope of the northern South China Sea, Geophys. Res. Lett., 35, L13604, DOI: 10.1029/2008GL034179

Yanagi T and Takao T (1998) Clockwise phase propagation of semi-diurnal tides in the Gulf of Thailand. Journal of Oceanography, 54(2), pp.143-150.

Zakharov VE, Manakov SV (1973) Resonant interaction of wave packets in nonlinear media, Soviet Phys. - J.T.E.P. Lett. 18, 243-247

Zaron ED and Jay DA (2014) An analysis of secular change in tides at open-ocean sites in the Pacific. Journal of Physical Oceanography, 44(7), pp.1704-1726.

Zetler BD (1971), Radiational ocean tides along the coasts of the United States, J. Phys. Oceanogr., 1, 34-38. 
Appendix A: Supplementary Figures for Part I (Chapter 3)

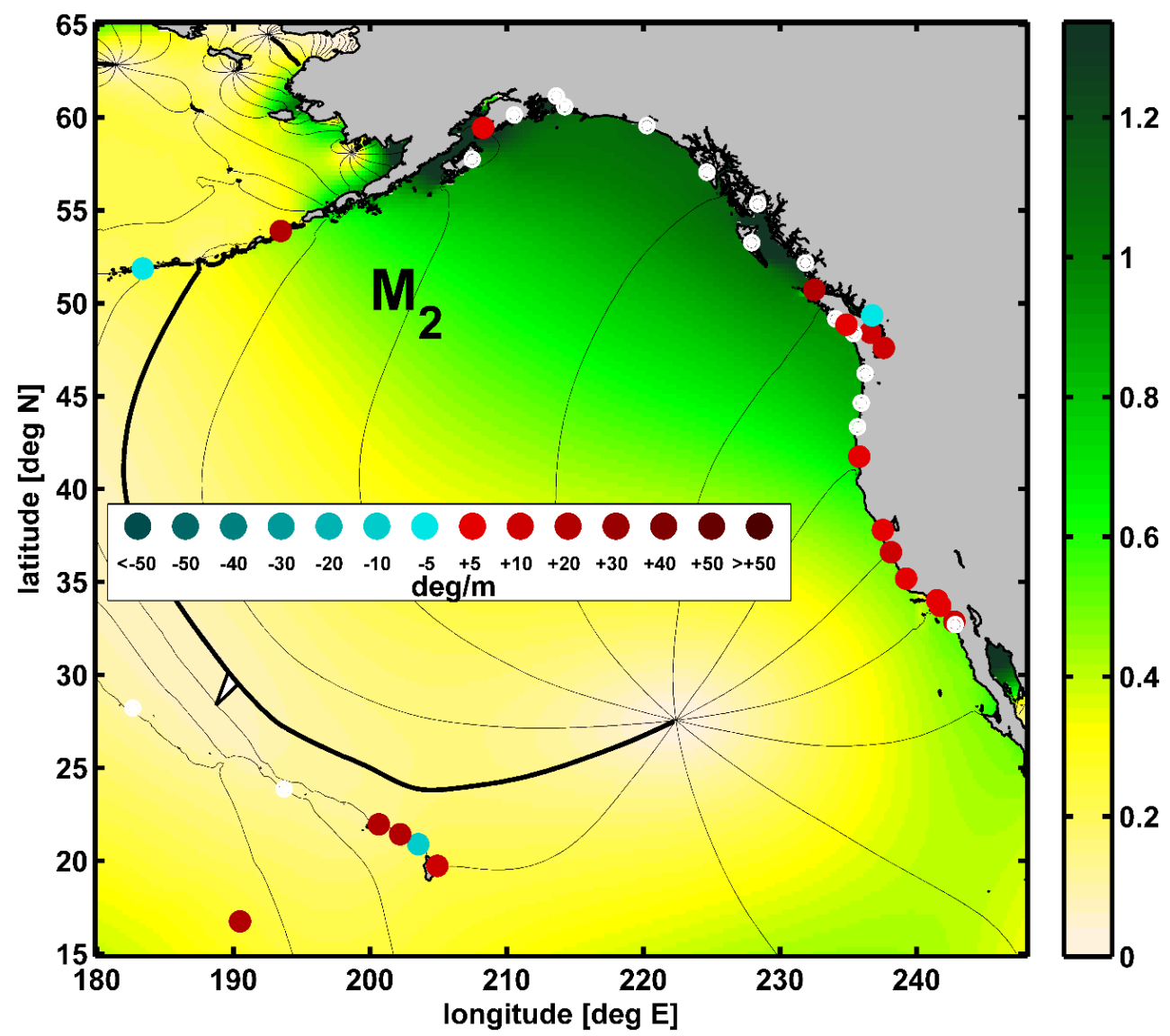

Figure $\mathbf{A} 1 \mathrm{M}_{2}$ P-TAT map in Northeast Pacific, showing changes in phase (per $\mathrm{m} \mathrm{MSL}$ rise). Map backgrounds show mean tidal amplitudes (meters) over the entire time record (color scale) and phases (solid lines), from the ocean tidal model of TPXO7.2, (Egbert and Erofeeva, 2002, 2010). Red and blue colored markers show positive and negative P-TATs, respectively. The magnitudes are indicated by color intensity, as shown by legend at the bottom, in units of degrees of tidal phase change per meter of sea level rise $\left(\mathrm{degm}^{-1}\right)$. To avoid potentially spurious results due to large percentage changes in small constituents, P-TATs are only plotted if the ratio of the $95 \%$ confidence limit of the trends to the errors has an SNR $>2$. Statistically insignificant values are indicated by white circles. 


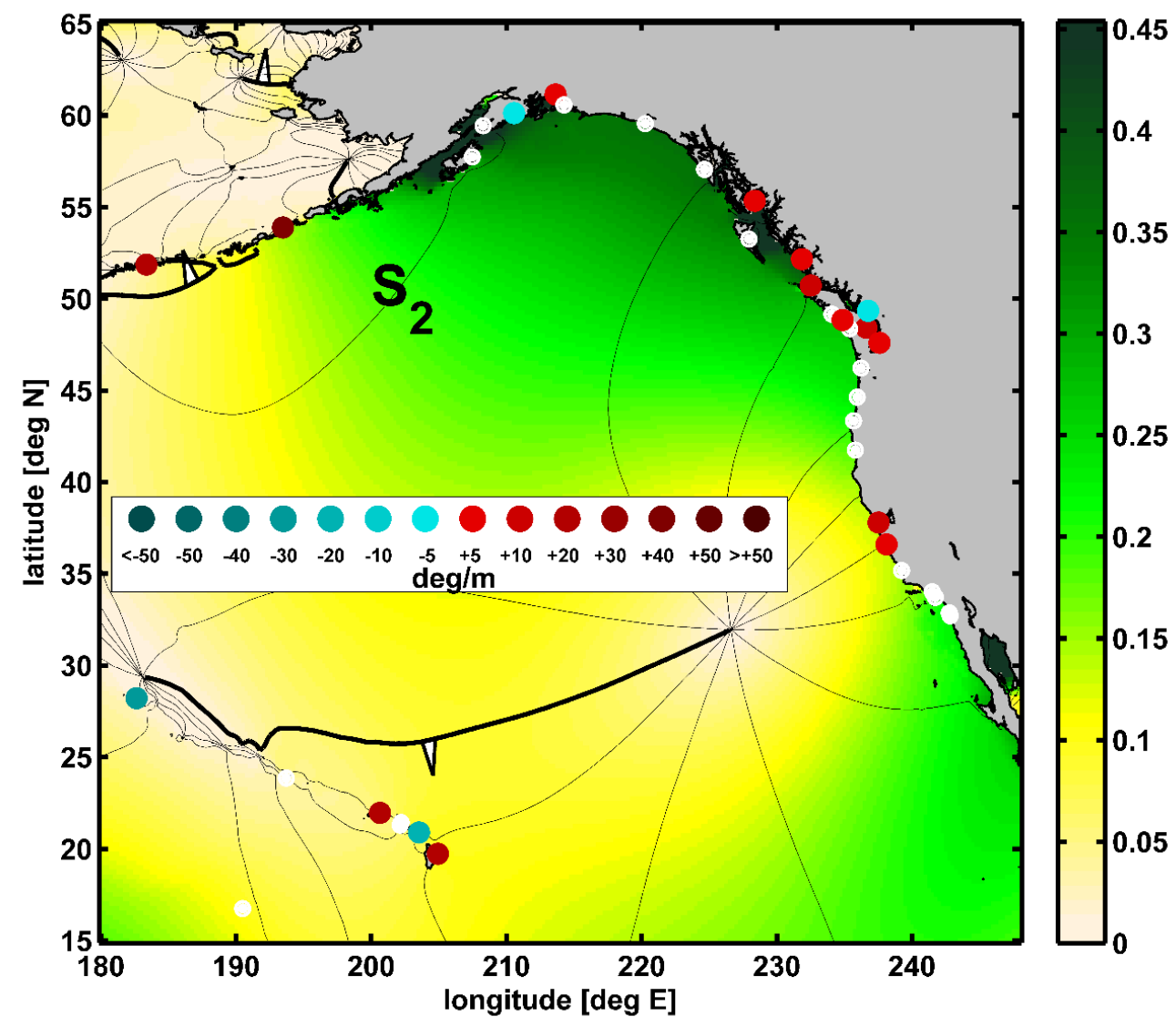

Figure A2 $\mathrm{S}_{2}$ P-TAT map in Northeast Pacific showing changes in phase anomaly trends (for a 1 meter MSL rise); symbols are as in Figure A1, and units are degm ${ }^{-1}$. 


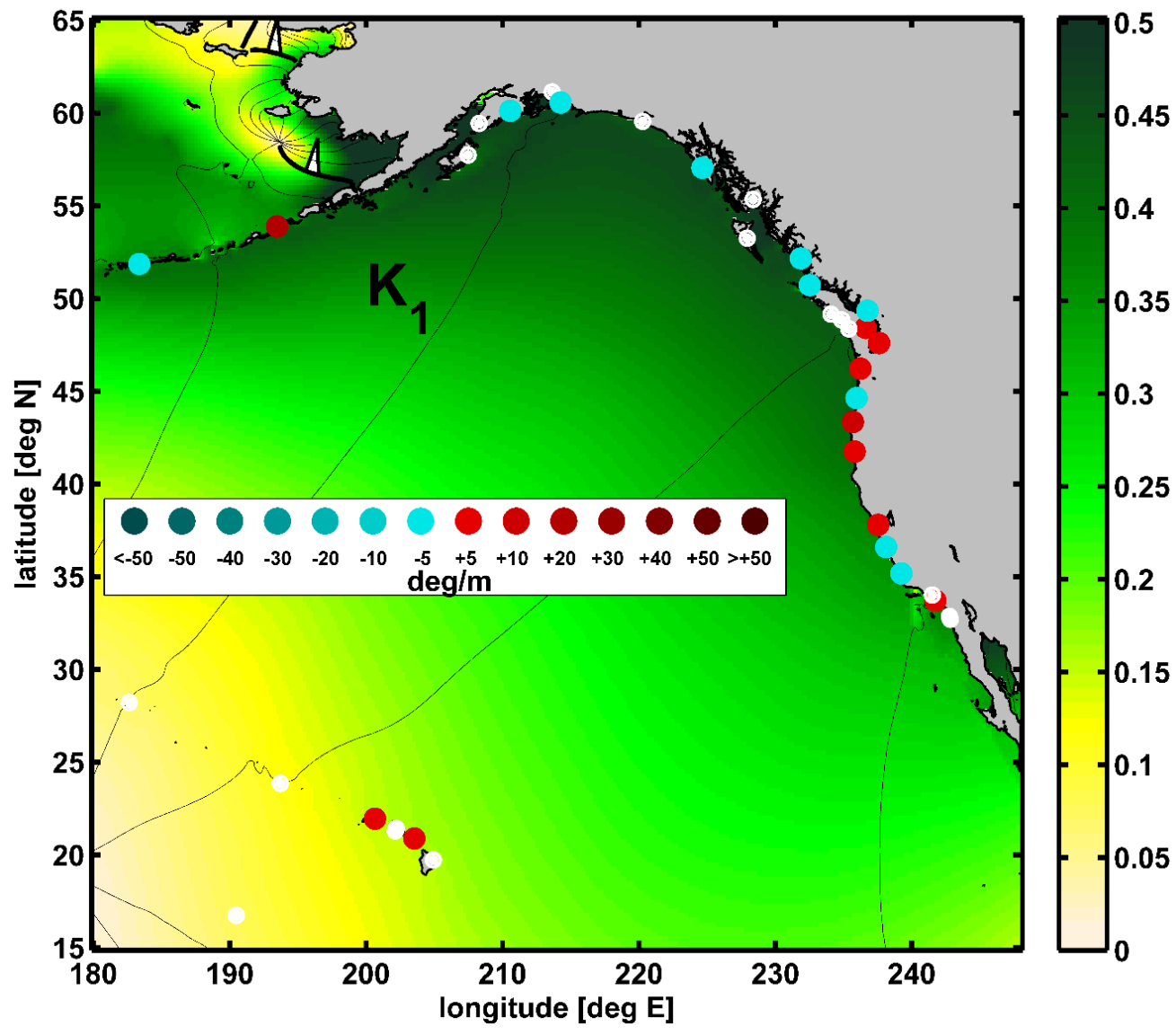

Figure A3 $\mathrm{K}_{1}$ P-TAT map in Northeast Pacific showing changes in phase anomaly trends (for a 1 meter MSL rise); symbols are as in Figure A1, and units are degm ${ }^{-1}$. 


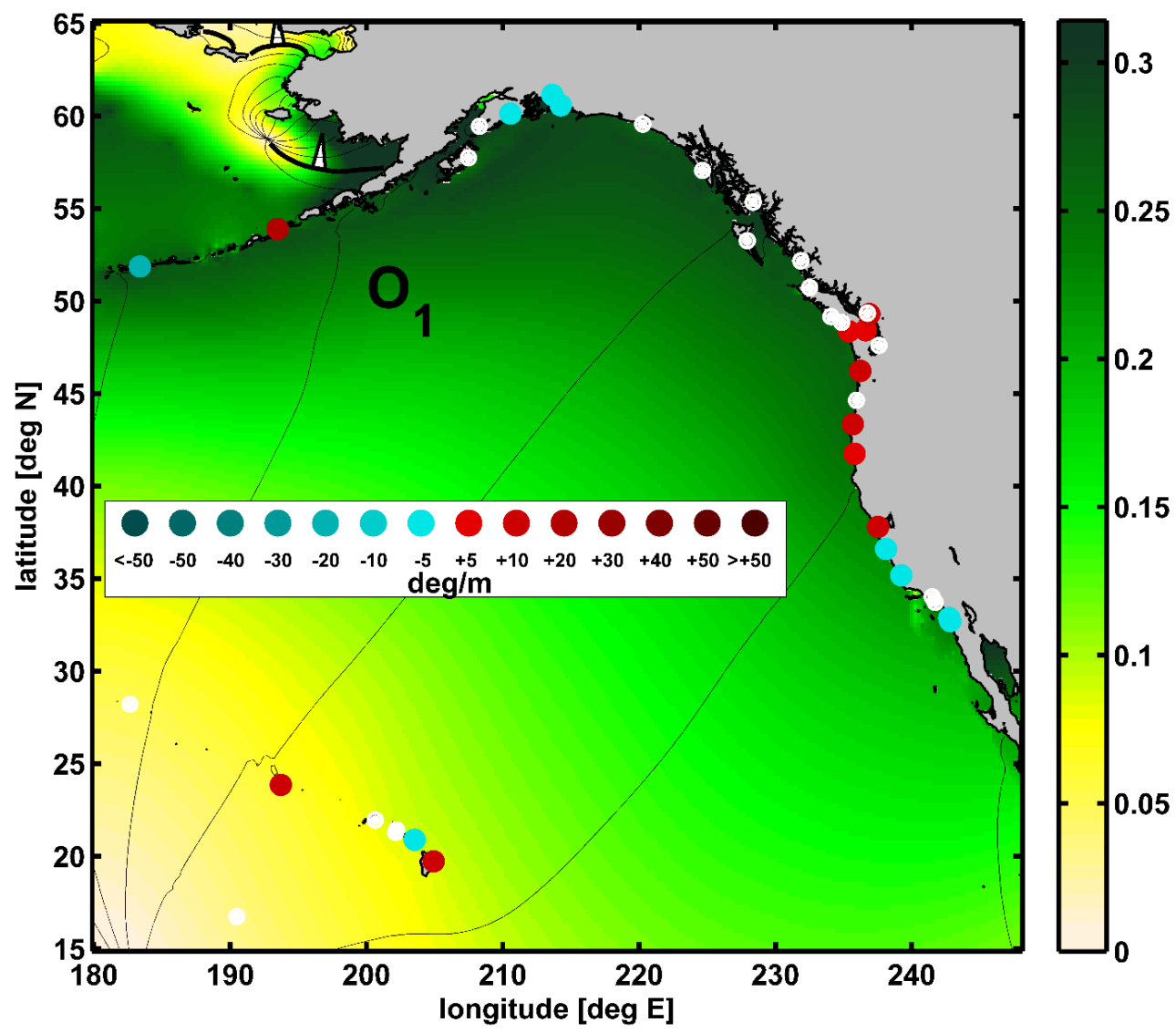

Figure A4 $\mathrm{O}_{1}$ P-TAT map in Northeast Pacific showing changes in phase anomaly trends (for a 1 meter MSL rise); symbols are as in Figure A1, and units are degm ${ }^{-1}$. 


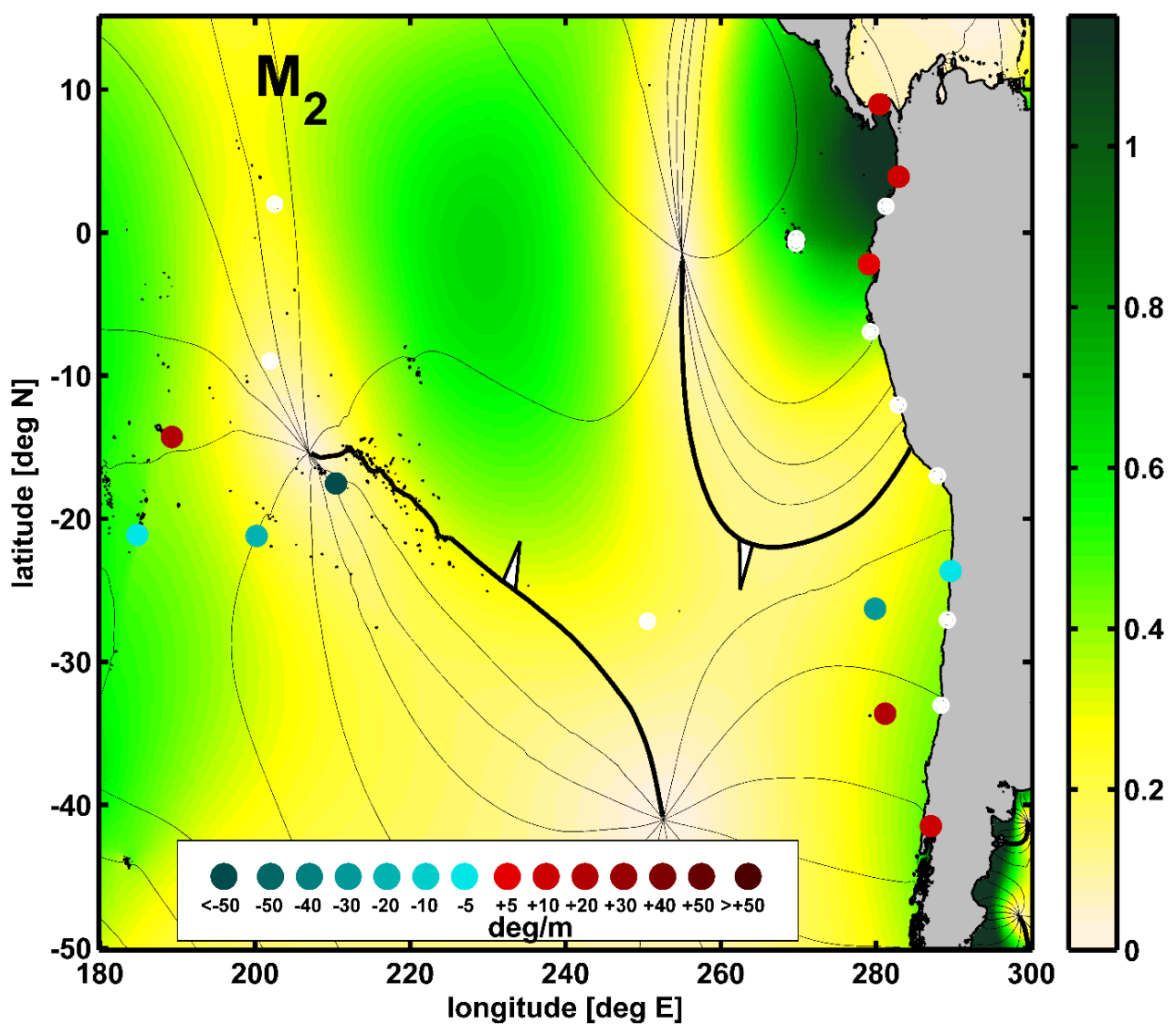

Figure A5 $\mathrm{M}_{2}$ P-TAT map in Southeast Pacific showing changes in phase anomaly trends (for a 1 meter MSL rise); symbols are as in Figure A1, and units are degm ${ }^{-1}$. 


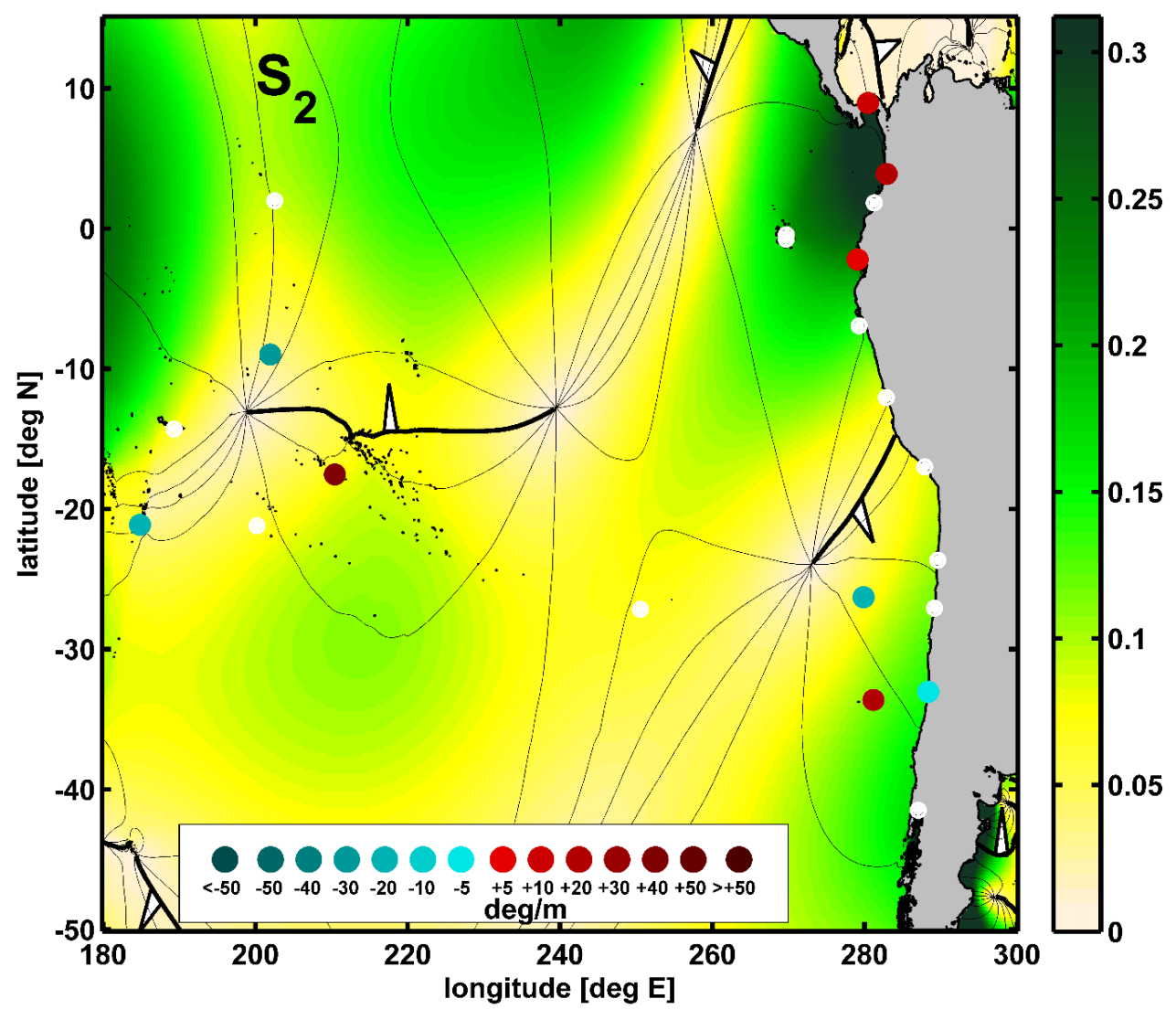

Figure A6 $\mathrm{S}_{2}$ P-TAT map in Southeast Pacific showing changes in phase anomaly trends (for a 1 meter MSL rise); symbols are as in Figure A1, and units are $\operatorname{degm}^{-1}$. 


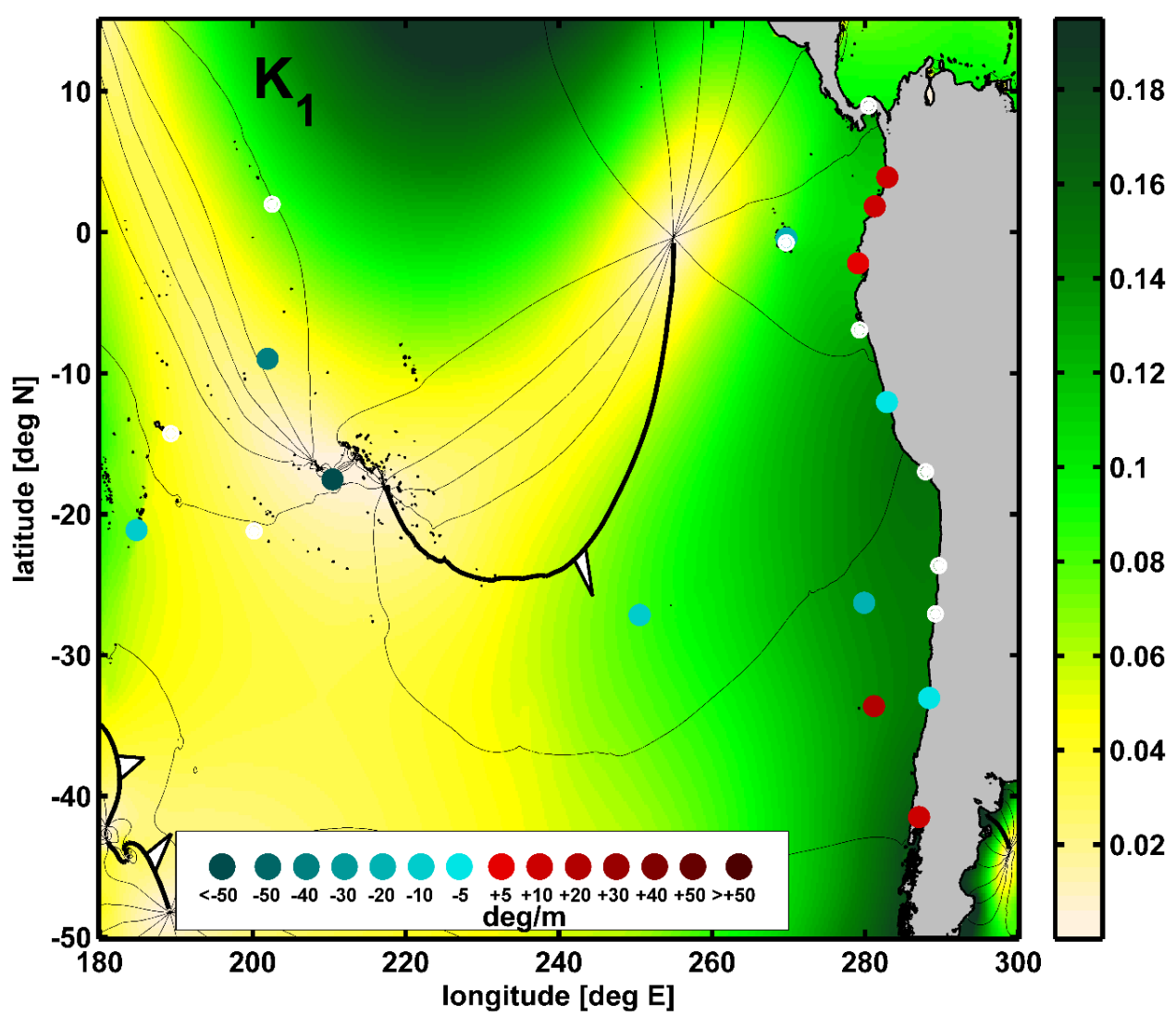

Figure A7 $\mathrm{K}_{1}$ P-TAT map in Southeast Pacific showing changes in phase anomaly trends (for a 1 meter MSL rise); symbols are as in Figure A1, and units are $\operatorname{degm}^{-1}$. 


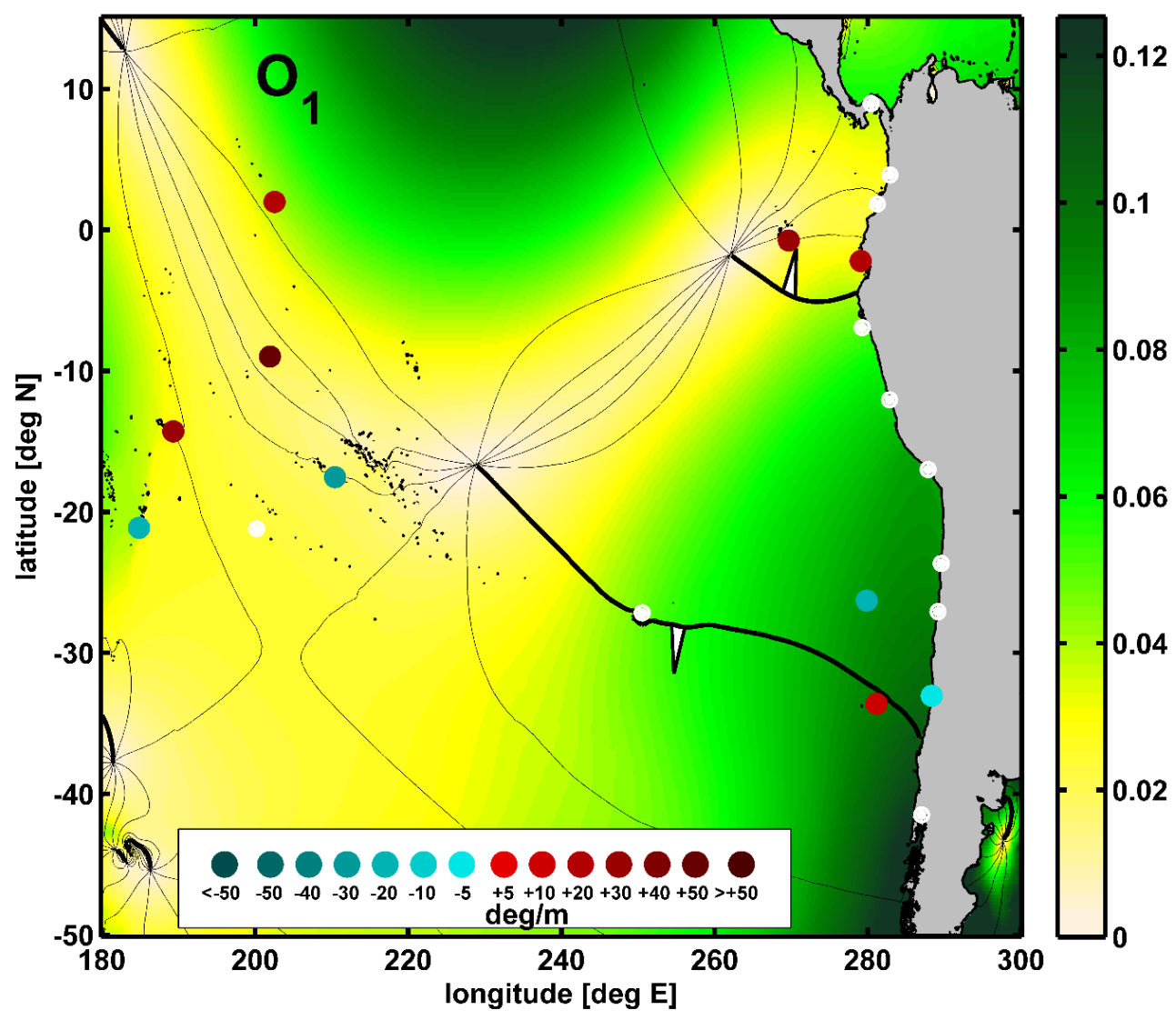

Figure $\mathrm{A} 8 \mathrm{O}_{1}$ P-TAT map in Southeast Pacific showing changes in phase anomaly trends (for a 1 meter MSL rise); symbols are as in Figure A1, and units are degm ${ }^{-1}$. 


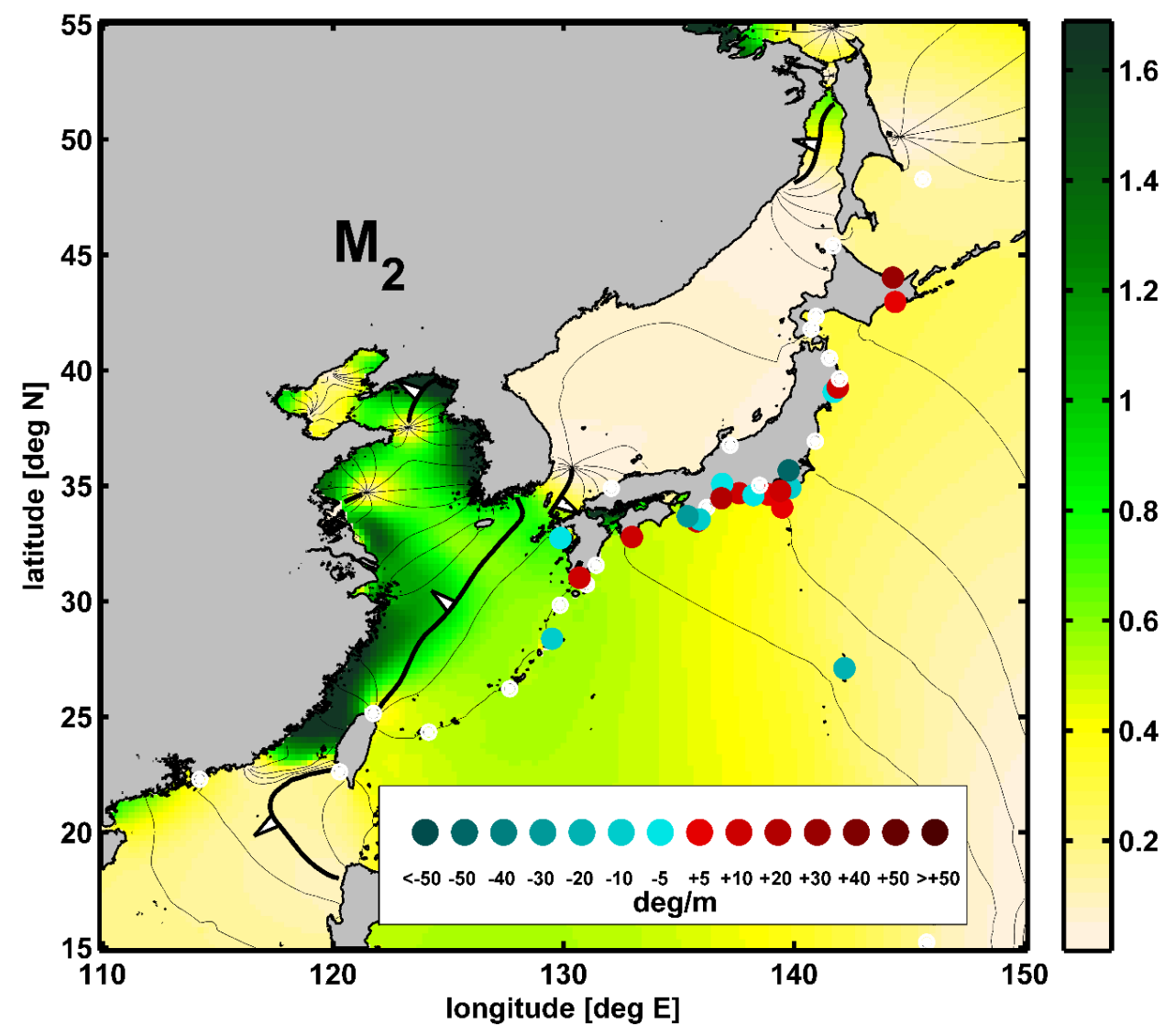

Figure $\mathrm{A} 9 \mathrm{M}_{2}$ P-TAT map in Northwest Pacific showing changes in phase anomaly trends (for a 1 meter MSL rise); symbols are as in Figure A1, and units are degm-1. 


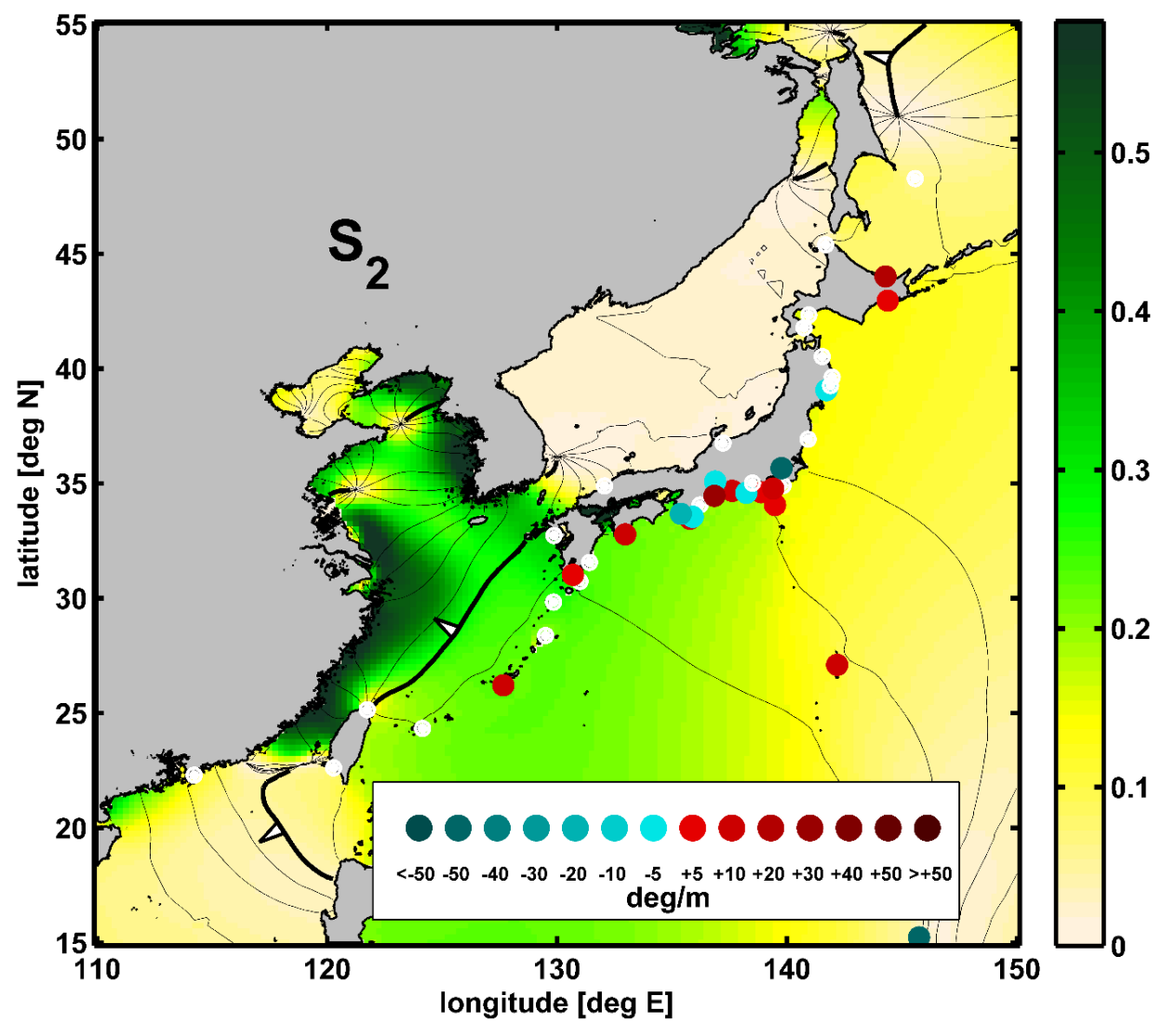

Figure A10 $\mathrm{S}_{2}$ P-TAT map in Northwest Pacific showing changes in phase anomaly trends (for a 1 meter MSL rise); symbols are as in Figure A1, and units are $\operatorname{degm}^{-1}$. 


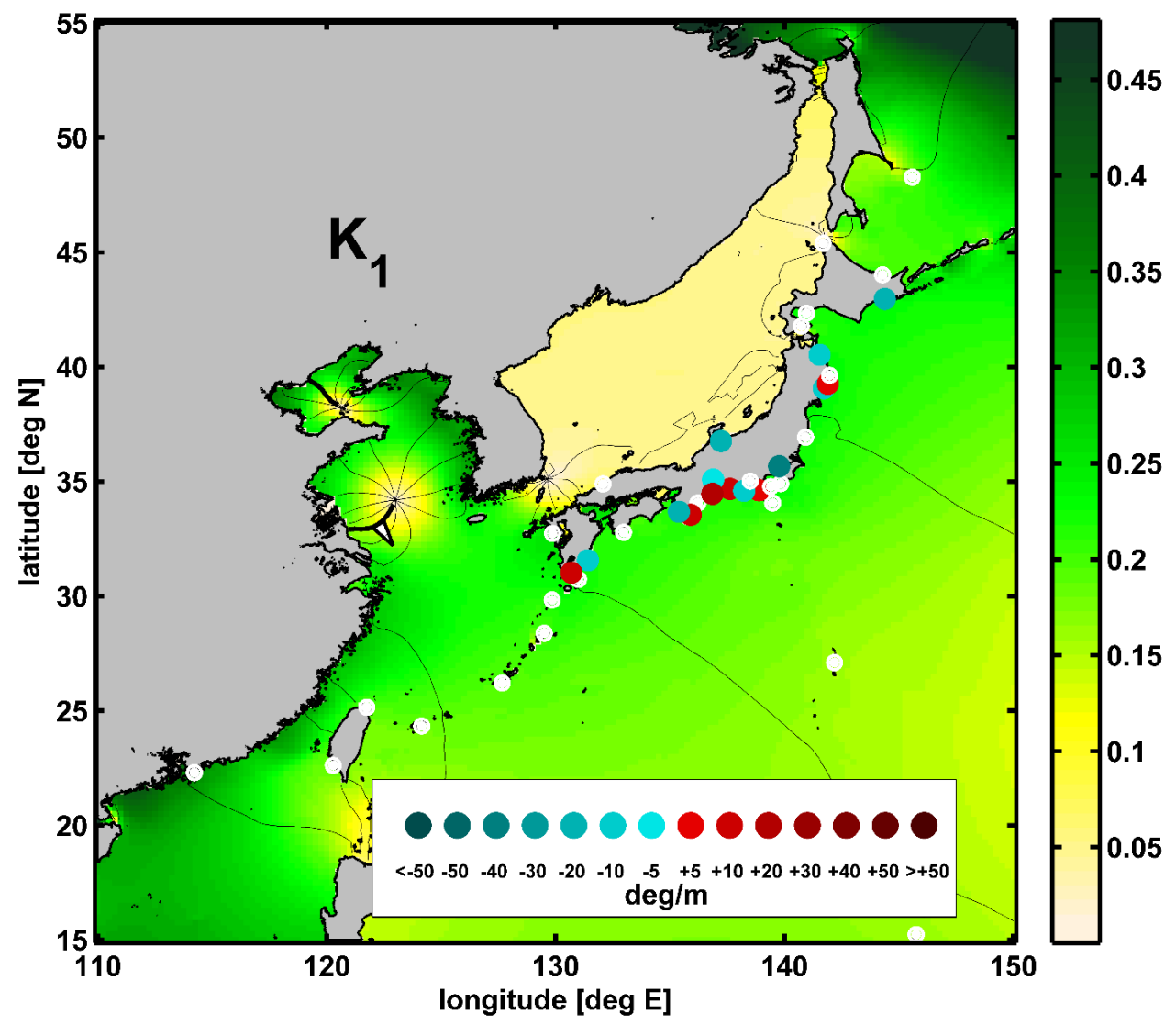

Figure A11 $\mathrm{K}_{1}$ P-TAT map in Northwest Pacific showing changes in phase anomaly trends (for a 1 meter MSL rise); symbols are as in Figure A1, and units are $\operatorname{degm}^{-1}$. 


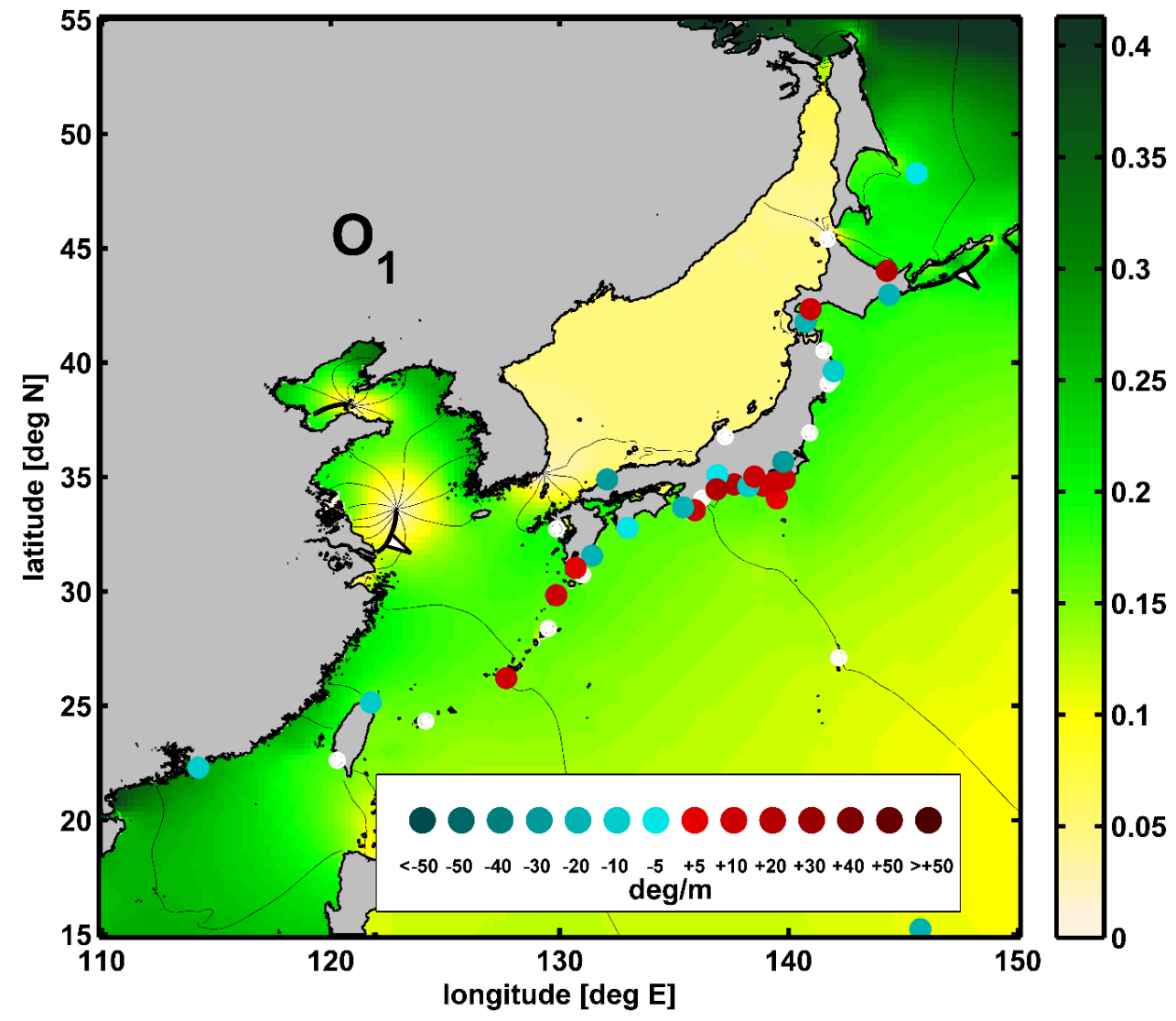

Figure A12 $\mathrm{O}_{1}$ P-TAT map in Northwest Pacific showing changes in phase anomaly trends (for a 1 meter MSL rise); symbols are as in Figure A1, and units are $\operatorname{degm}^{-1}$. 


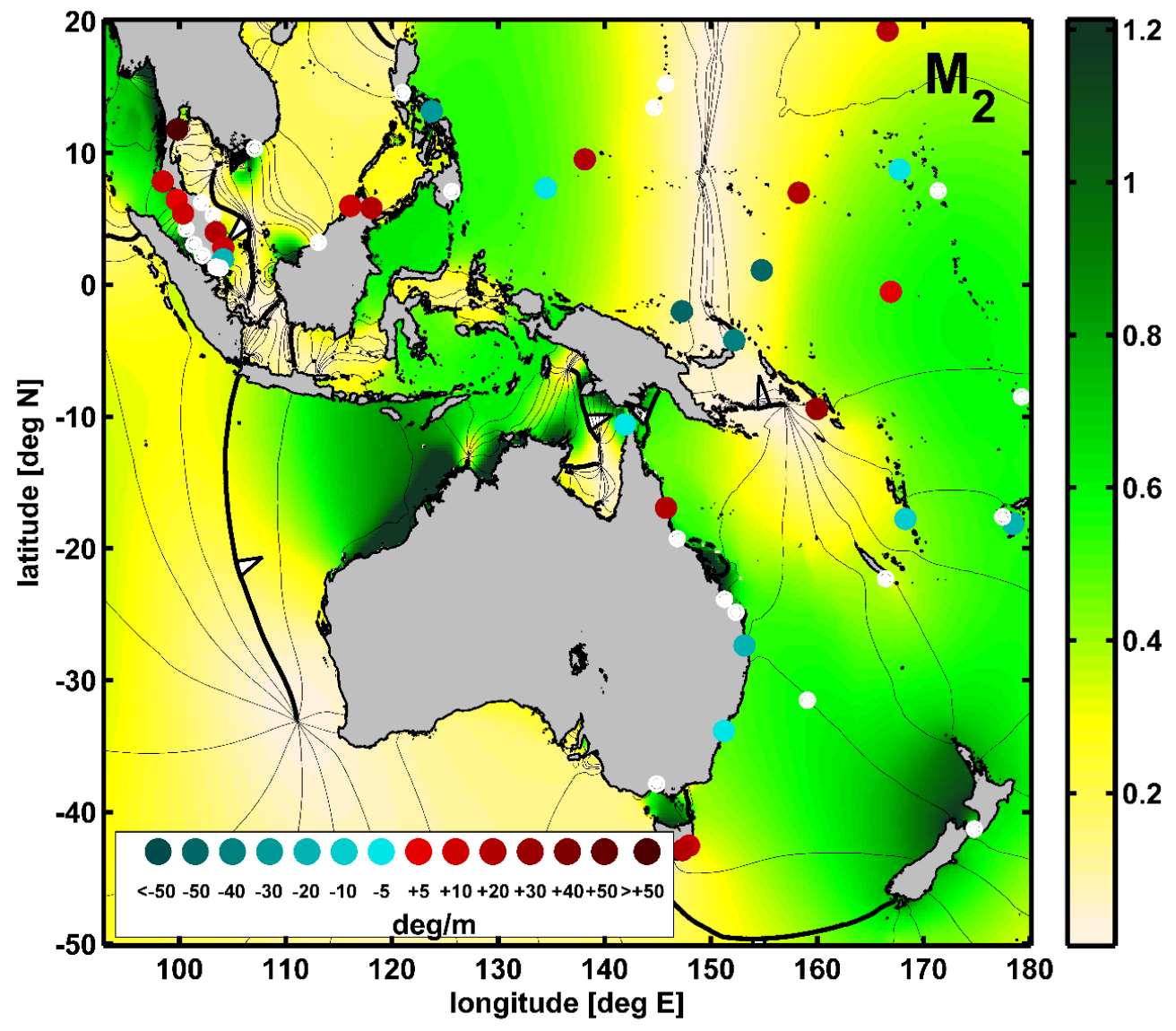

Figure A13 $\mathrm{M}_{2}$ P-TAT map in Southwest Pacific showing changes in phase anomaly trends (for a 1 meter MSL rise); symbols are as in Figure A1, and units are degm ${ }^{-1}$. 


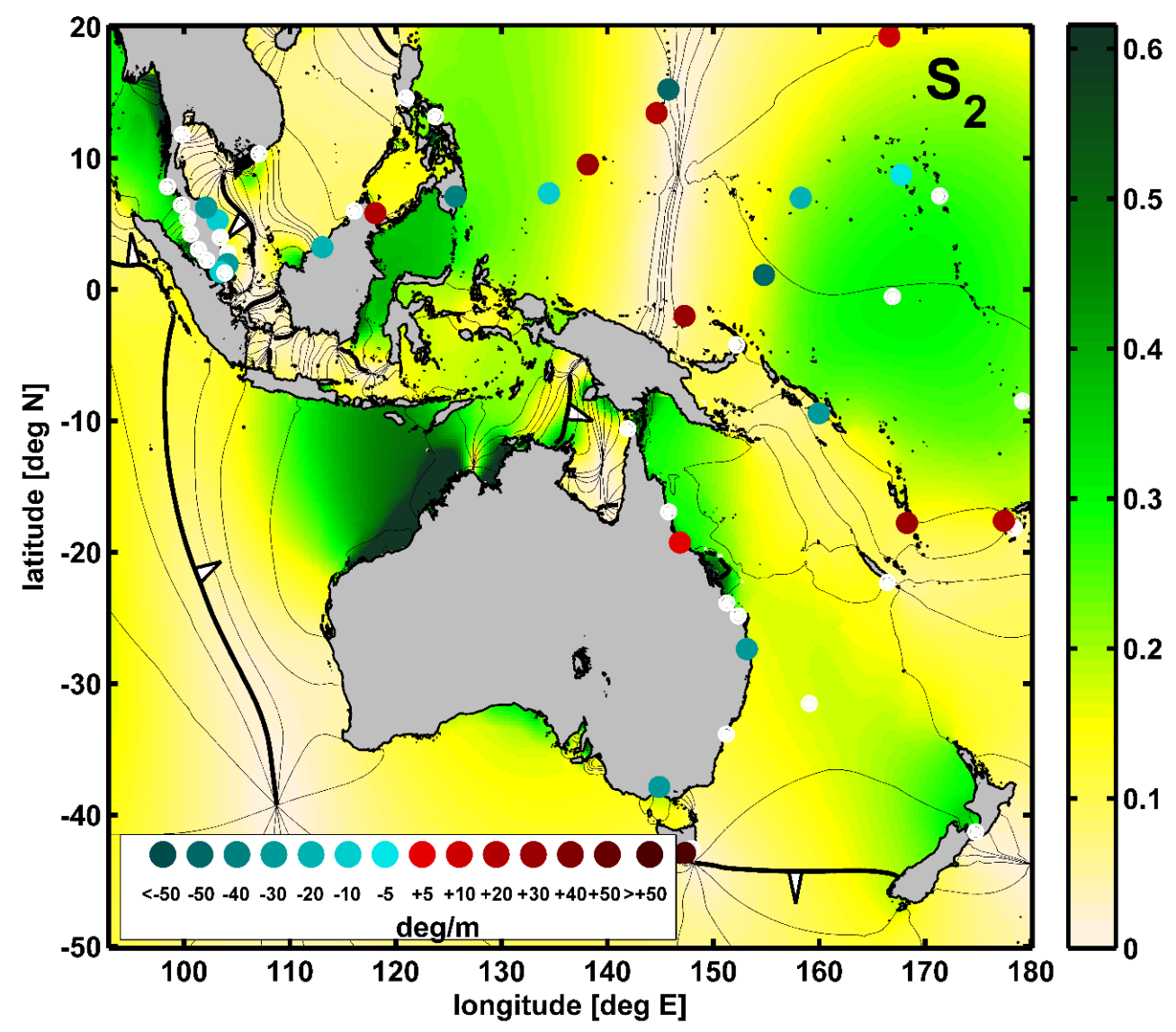

Figure A14 $\mathrm{S}_{2}$ P-TAT map in Southwest Pacific showing changes in phase anomaly trends (for a 1 meter MSL rise); symbols are as in Figure A1, and units are degm ${ }^{-1}$. 


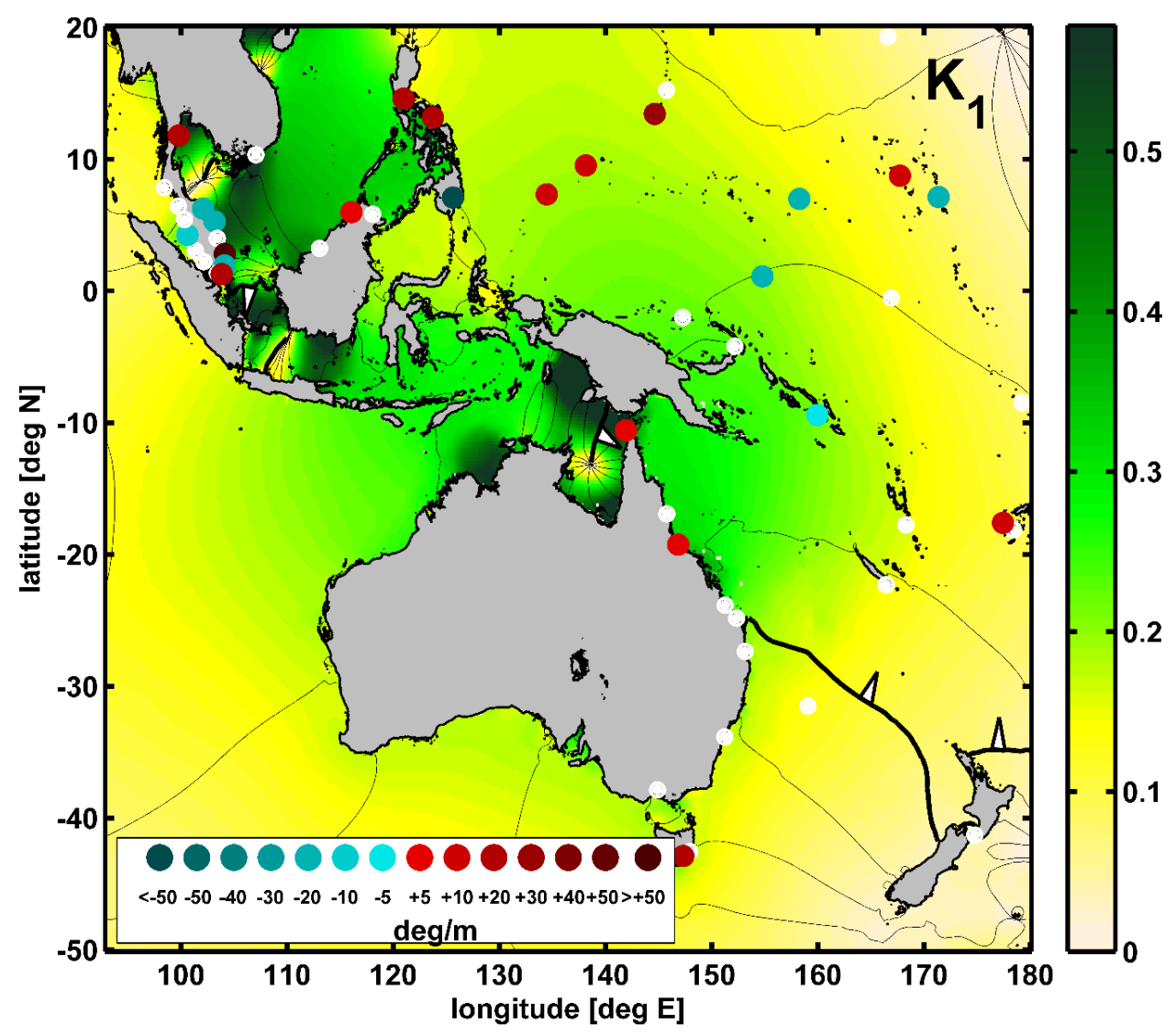

Figure A15 $\mathrm{K}_{1}$ P-TAT map in Southwest Pacific showing changes in phase anomaly trends (for a 1 meter MSL rise); symbols are as in Figure A1, and units are $\operatorname{degm}^{-1}$. 


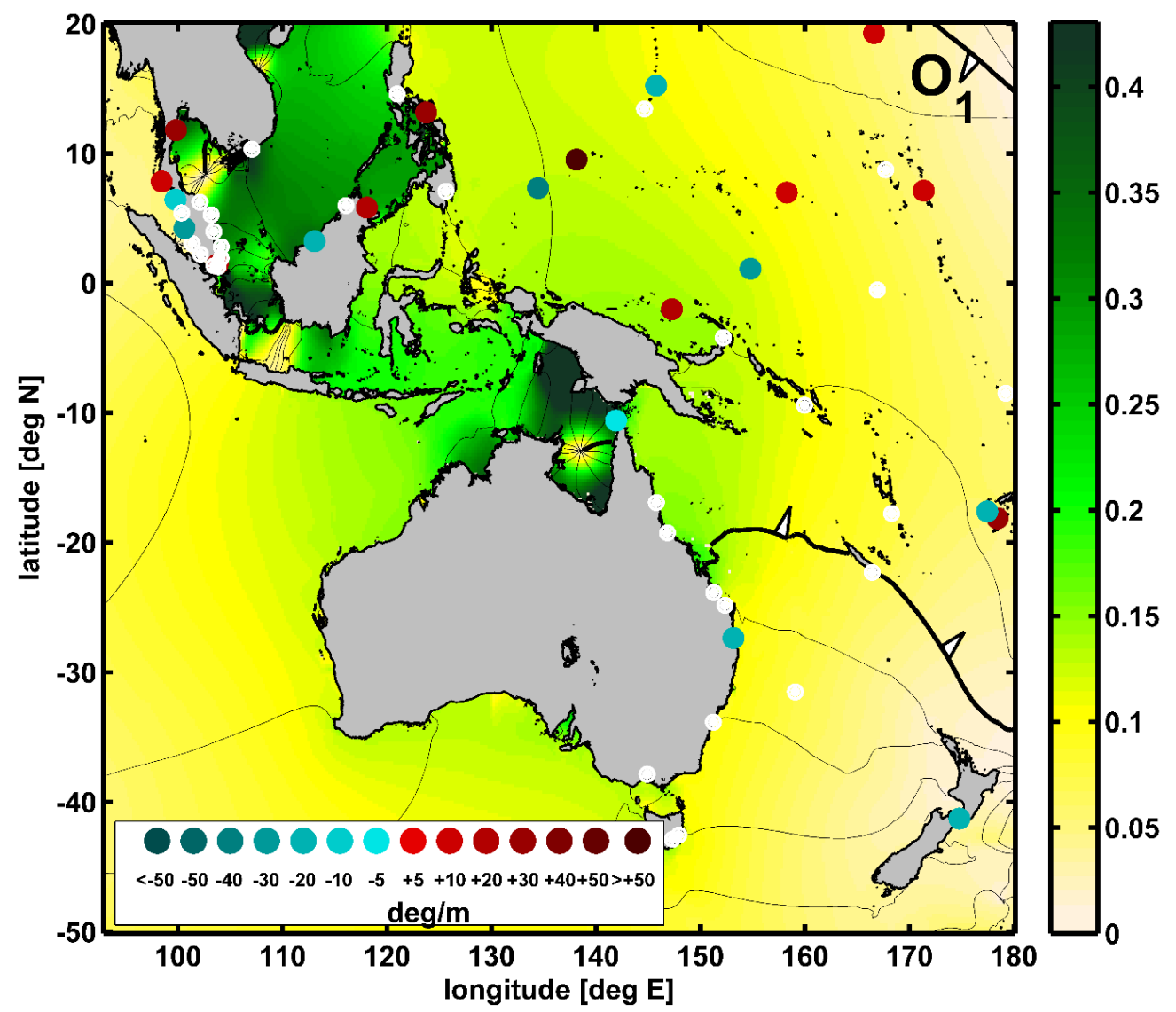

Figure A16 $\mathrm{O}_{1}$ P-TAT map in Southwest Pacific showing changes in phase anomaly trends (for a 1 meter MSL rise); symbols are as in Figure A1, and units are degm ${ }^{-1}$. 


\section{Appendix B: Supplementary Figures for Part II (Chapter 4)}
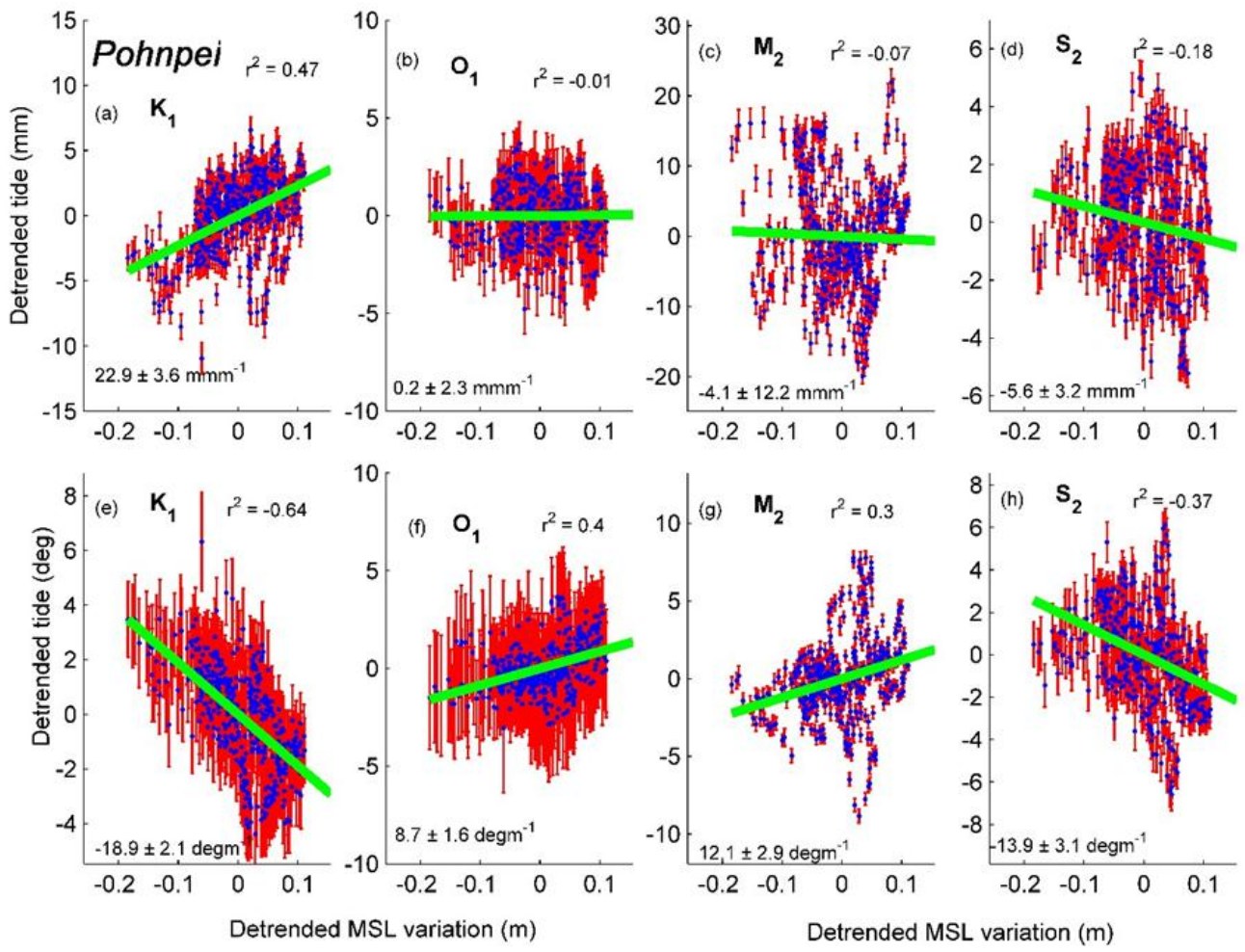

Figure B1-1 Pohnpei: amplitude anomaly trends (A-TATs) for (a) $\mathrm{K}_{1}$; (b) $\mathrm{O}_{1}$; (c) $\mathrm{M}_{2}$; (d) $\mathrm{S}_{2}$; and phase anomaly trend (P-TATs) for (e) $\mathrm{K}_{1}$; (f) $\mathrm{O}_{1}$; (g) $\mathrm{M}_{2}$; and (h) $\mathrm{S}_{2}$. The red bars show $95 \%$ confidence limits on each annual estimate. The green line is the robust linear regression trend, in $\mathrm{mmm}^{-1}$ or degm ${ }^{-1}$, as shown as text, with $95 \%$ confidence limits on the anomaly trend. Significance is indicated by $r^{2}$ values within each subplot. 

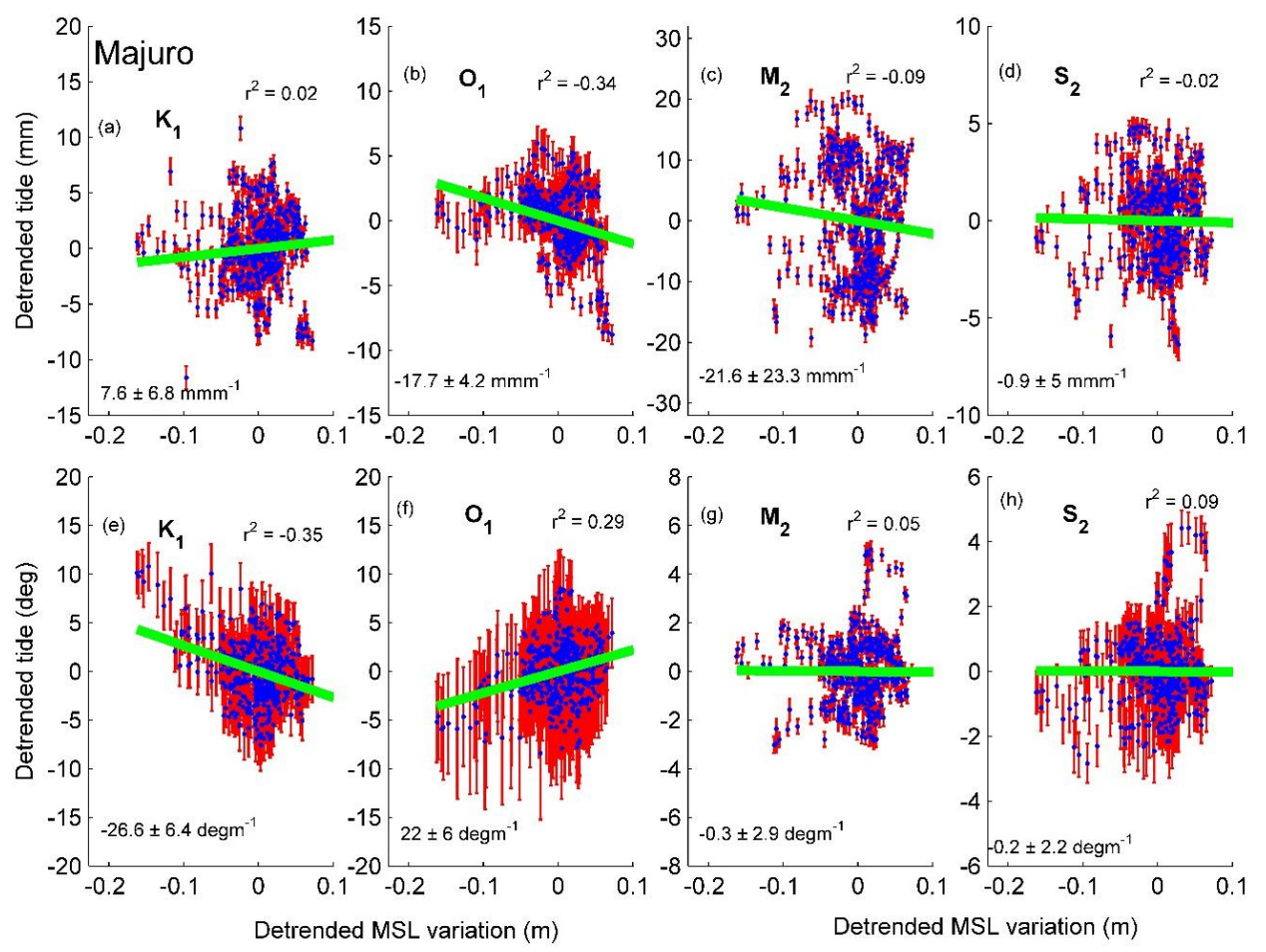

Figure B1-2 Majuro: amplitude anomaly trends (A-TATs) for (a) $\mathrm{K}_{1}$; (b) $\mathrm{O}_{1}$; (c) $\mathrm{M}_{2}$; (d) $\mathrm{S}_{2}$; and phase anomaly trend (P-TATs) for (e) $\mathrm{K}_{1} ;$ (f) $\mathrm{O}_{1} ;(\mathrm{g}) \mathrm{M}_{2}$; and (h) $\mathrm{S}_{2}$. The red bars show $95 \%$ confidence limits on each annual estimate. The green line is the robust linear regression trend, in $\mathrm{mmm}^{-1}$ or degm ${ }^{-1}$, as shown as text, with $95 \%$ confidence limits on the anomaly trend. Significance is indicated by $r^{2}$ values within each subplot. 

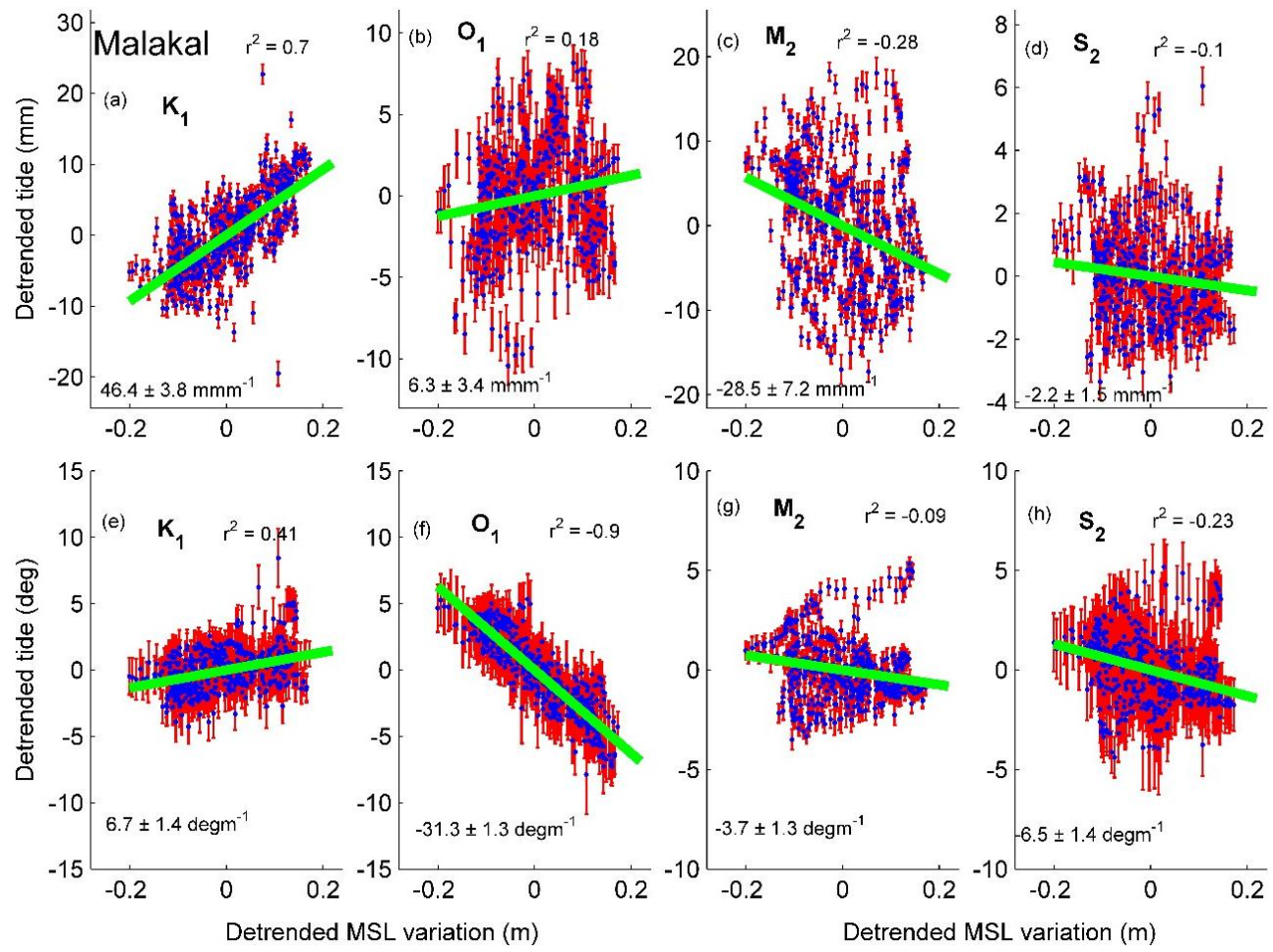

Figure B1-3 Malakal: amplitude anomaly trends (A-TATs) for (a) $\mathrm{K}_{1}$; (b) $\mathrm{O}_{1}$; (c) $\mathrm{M}_{2}$; (d) $\mathrm{S}_{2}$; and phase anomaly trend (P-TATs) for (e) $\mathrm{K}_{1} ;(\mathrm{f}) \mathrm{O}_{1} ;(\mathrm{g}) \mathrm{M}_{2}$; and $(\mathrm{h}) \mathrm{S}_{2}$. The red bars show $95 \%$ confidence limits on each annual estimate. The green line is the robust linear regression trend, in $\mathrm{mmm}^{-1}$ or degm ${ }^{-1}$, as shown as text, with $95 \%$ confidence limits on the anomaly trend. Significance is indicated by $r^{2}$ values within each subplot. 

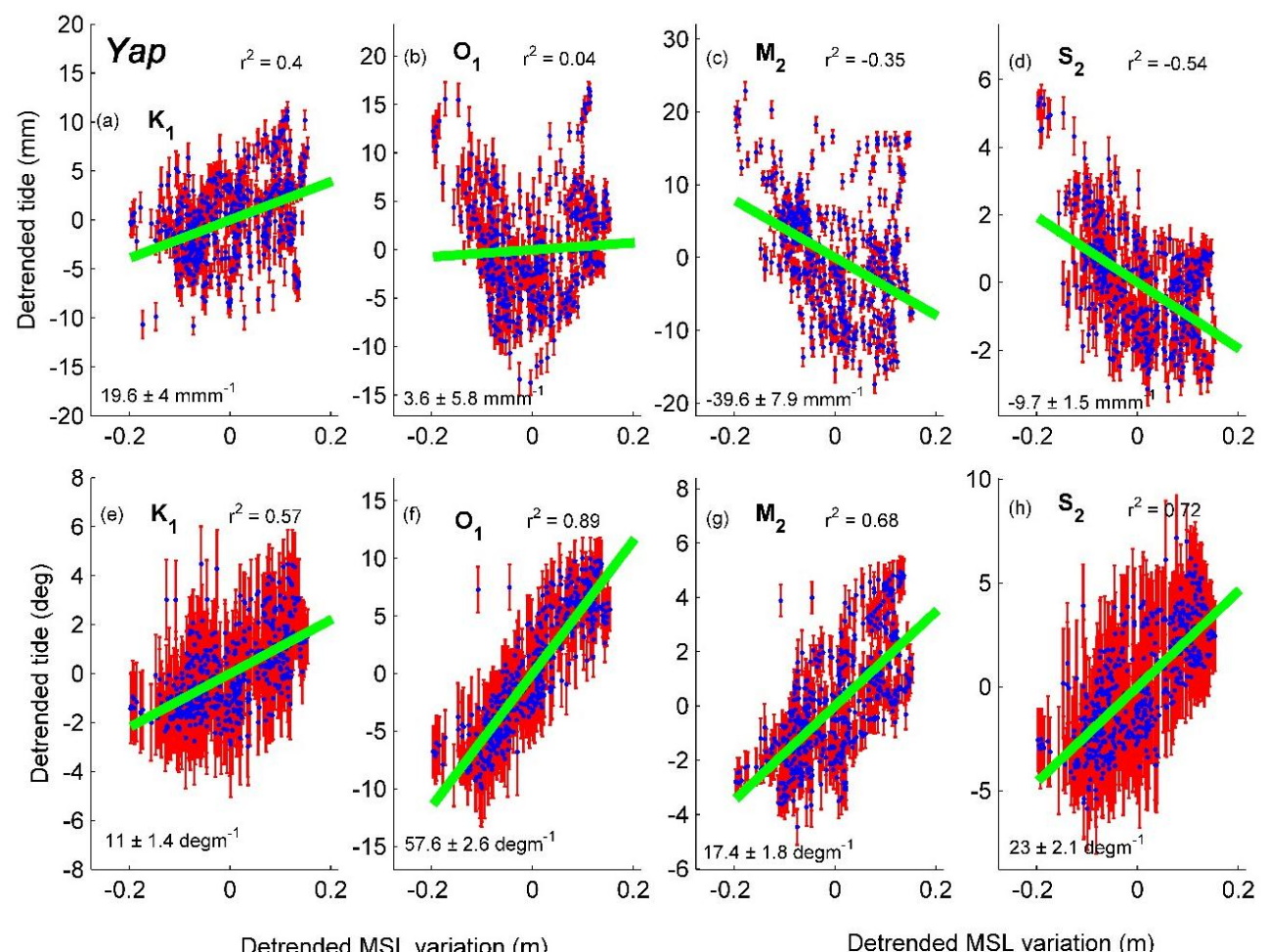

Figure B1-4 Yap: amplitude anomaly trends (A-TATs) for (a) $\mathrm{K}_{1}$; (b) $\mathrm{O}_{1}$; (c) $\mathrm{M}_{2}$; (d) $\mathrm{S}_{2}$; and phase anomaly trend (P-TATs) for (e) $\mathrm{K}_{1} ;(\mathrm{f}) \mathrm{O}_{1} ;(\mathrm{g}) \mathrm{M}_{2}$; and $(\mathrm{h}) \mathrm{S}_{2}$. The red bars show $95 \%$ confidence limits on each annual estimate. The green line is the robust linear regression trend, in $\mathrm{mmm}^{-1}$ or degm ${ }^{-1}$, as shown as text, with $95 \%$ confidence limits on the anomaly trend. Significance is indicated by $r^{2}$ values within each subplot. 

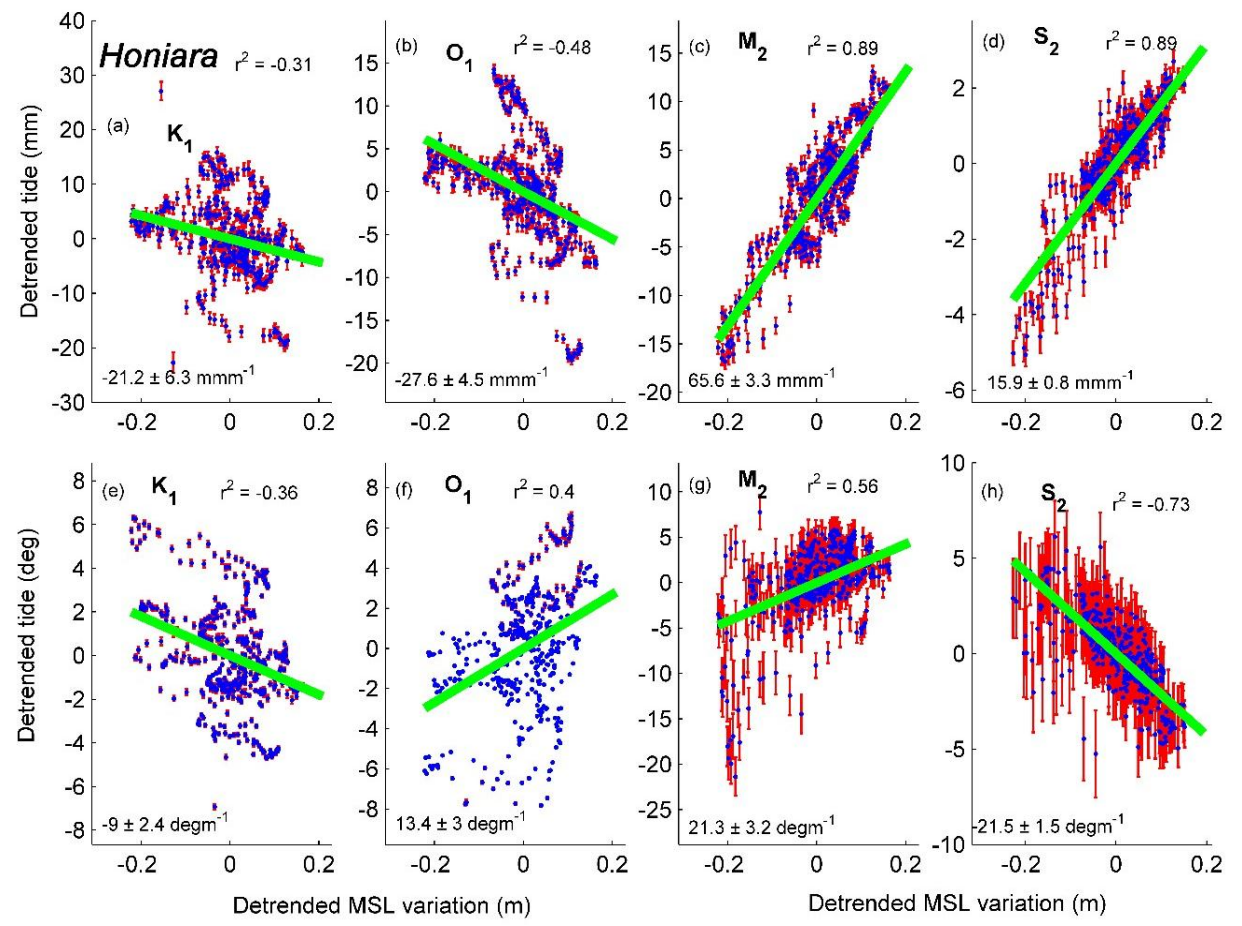

Figure B1-5 Honiara: amplitude anomaly trends (A-TATs) for (a) $\mathrm{K}_{1}$; (b) $\mathrm{O}_{1}$; (c) $\mathrm{M}_{2}$; (d) $\mathrm{S}_{2}$; and phase anomaly trend (P-TATs) for (e) $\mathrm{K}_{1}$; (f) $\mathrm{O}_{1}$; (g) $\mathrm{M}_{2}$; and (h) $\mathrm{S}_{2}$. The red bars show $95 \%$ confidence limits on each annual estimate. The green line is the robust linear regression trend, in $\mathrm{mmm}^{-1}$ or degm ${ }^{-1}$, as shown as text, with $95 \%$ confidence limits on the anomaly trend. Significance is indicated by $r^{2}$ values within each subplot. 

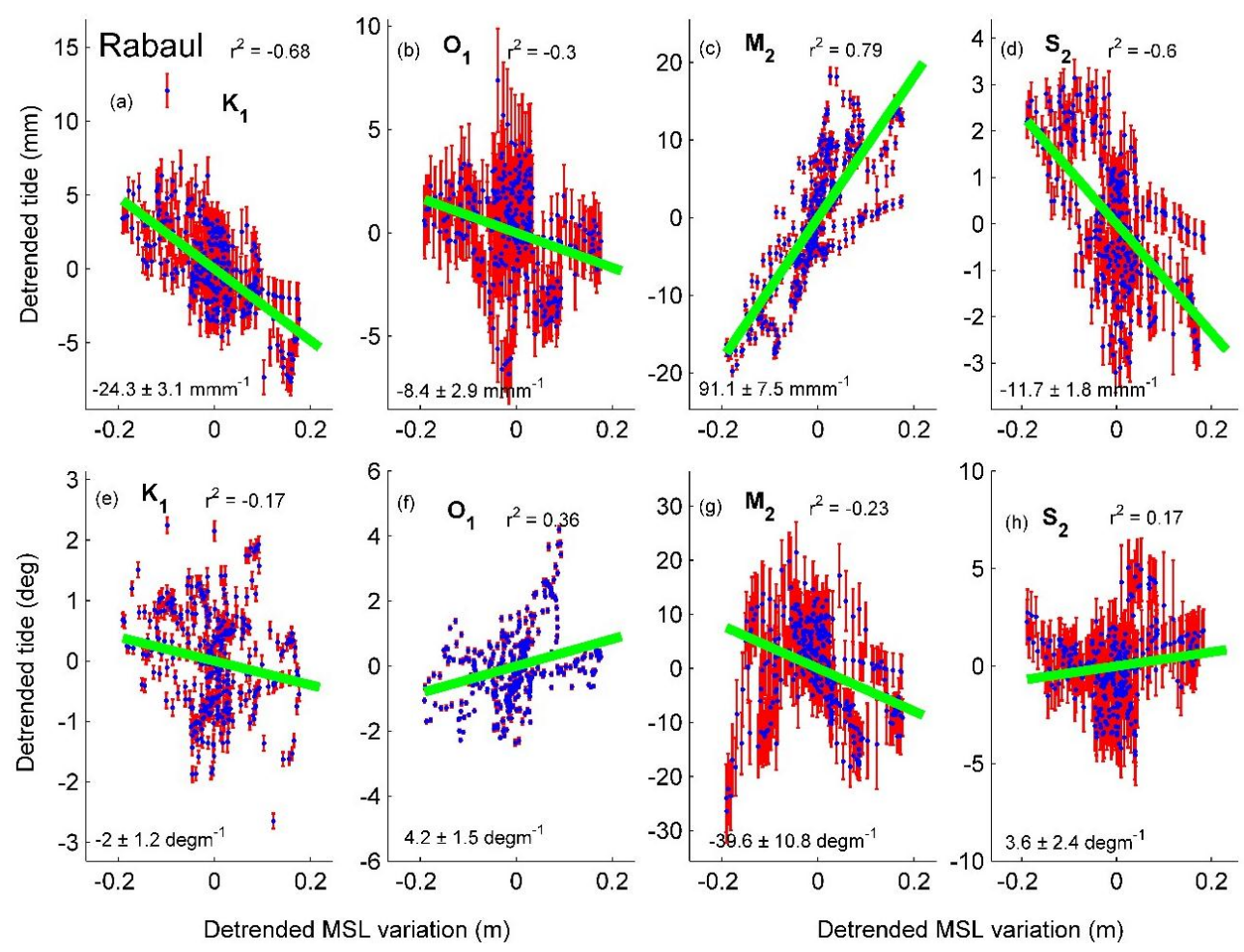

Figure B1-6 Rabaul: amplitude anomaly trends (A-TATs) for (a) $\mathrm{K}_{1}$; (b) $\mathrm{O}_{1}$; (c) $\mathrm{M}_{2}$; (d) $\mathrm{S}_{2}$; and phase anomaly trend (P-TATs) for (e) $\mathrm{K}_{1} ;$ (f) $\mathrm{O}_{1} ;(\mathrm{g}) \mathrm{M}_{2}$; and (h) $\mathrm{S}_{2}$. The red bars show $95 \%$ confidence limits on each annual estimate. The green line is the robust linear regression trend, in $\mathrm{mmm}^{-1}$ or degm ${ }^{-1}$, as shown as text, with $95 \%$ confidence limits on the anomaly trend. Significance is indicated by $r^{2}$ values within each subplot. 

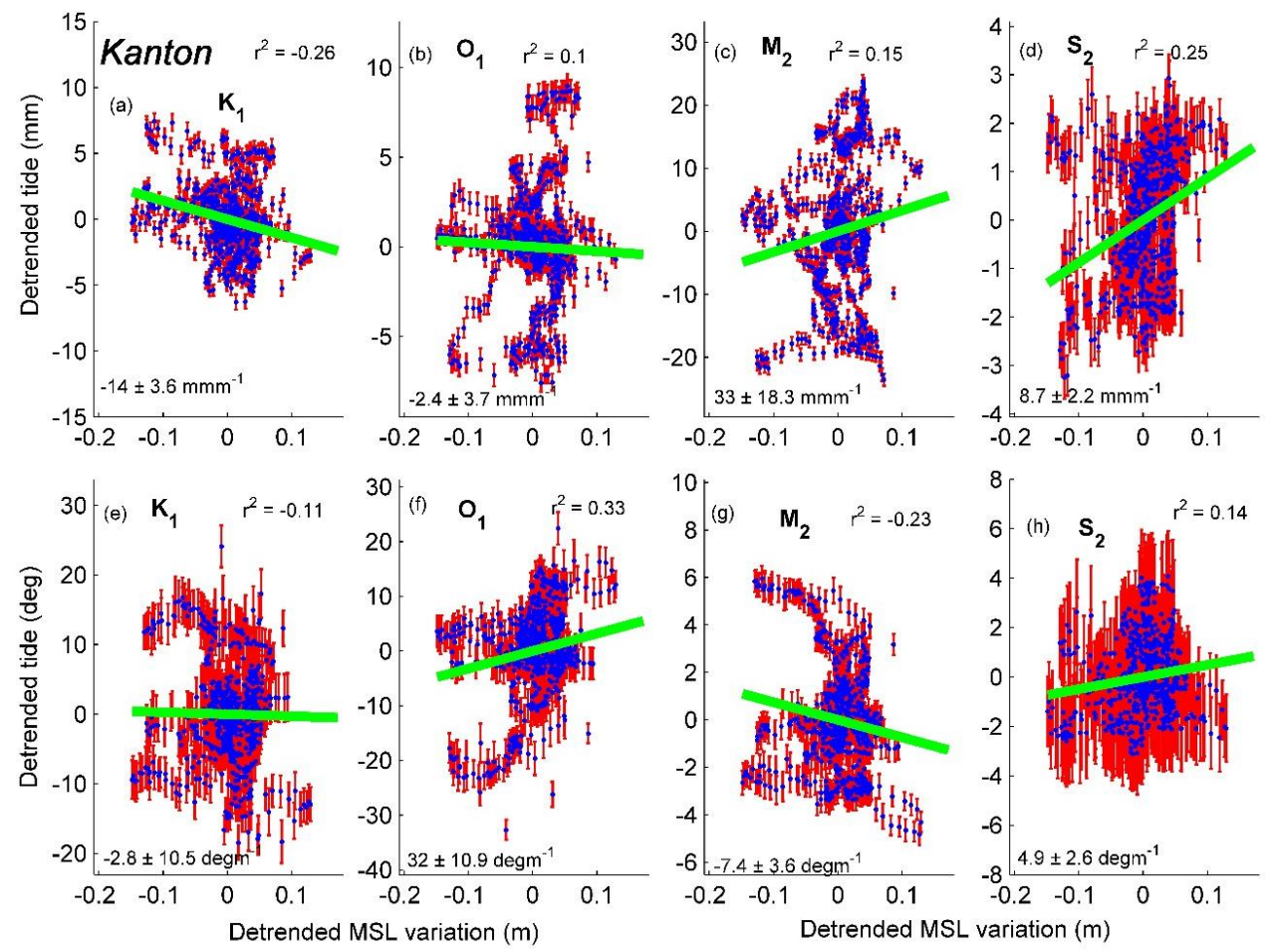

Figure B1-7 Kanton: amplitude anomaly trends (A-TATs) for (a) $\mathrm{K}_{1}$; (b) $\mathrm{O}_{1}$; (c) $\mathrm{M}_{2}$; (d) $\mathrm{S}_{2}$; and phase anomaly trend (P-TATs) for (e) $\mathrm{K}_{1}$; (f) $\mathrm{O}_{1} ;(\mathrm{g}) \mathrm{M}_{2}$; and (h) $\mathrm{S}_{2}$. The red bars show $95 \%$ confidence limits on each annual estimate. The green line is the robust linear regression trend, in $\mathrm{mmm}^{-1}$ or degm ${ }^{-1}$, as shown as text, with $95 \%$ confidence limits on the anomaly trend. Significance is indicated by $r^{2}$ values within each subplot. 

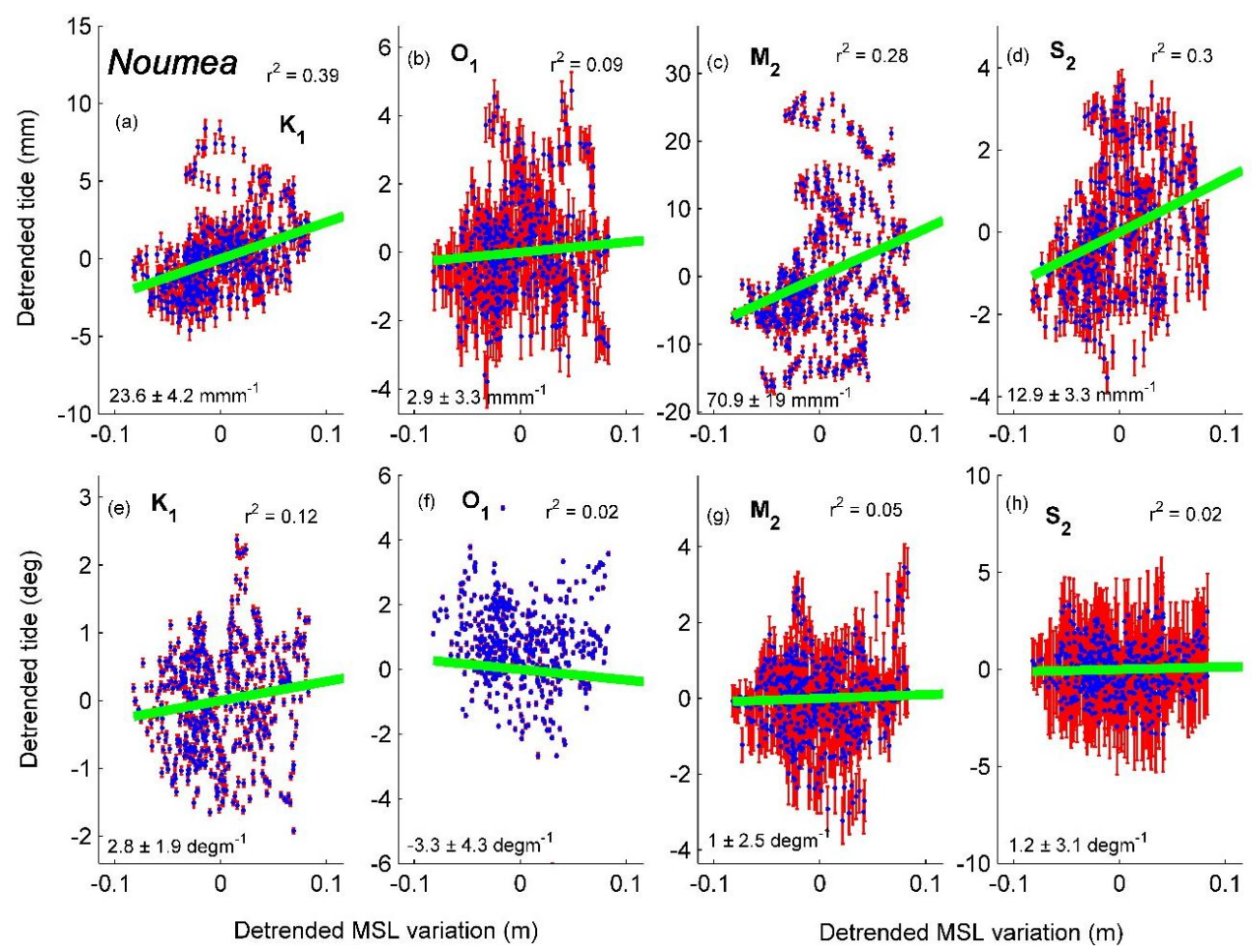

Figure B1-8 Noumea: amplitude anomaly trends (A-TATs) for (a) $\mathrm{K}_{1}$; (b) $\mathrm{O}_{1}$; (c) $\mathrm{M}_{2}$; (d) $\mathrm{S}_{2}$; and phase anomaly trend (P-TATs) for (e) $\mathrm{K}_{1}$; (f) $\mathrm{O}_{1} ;$ (g) $\mathrm{M}_{2}$; and (h) $\mathrm{S}_{2}$. The red bars show $95 \%$ confidence limits on each annual estimate. The green line is the robust linear regression trend, in $\mathrm{mmm}^{-1}$ or degm ${ }^{-1}$, as shown as text, with $95 \%$ confidence limits on the anomaly trend. Significance is indicated by $r^{2}$ values within each subplot. 

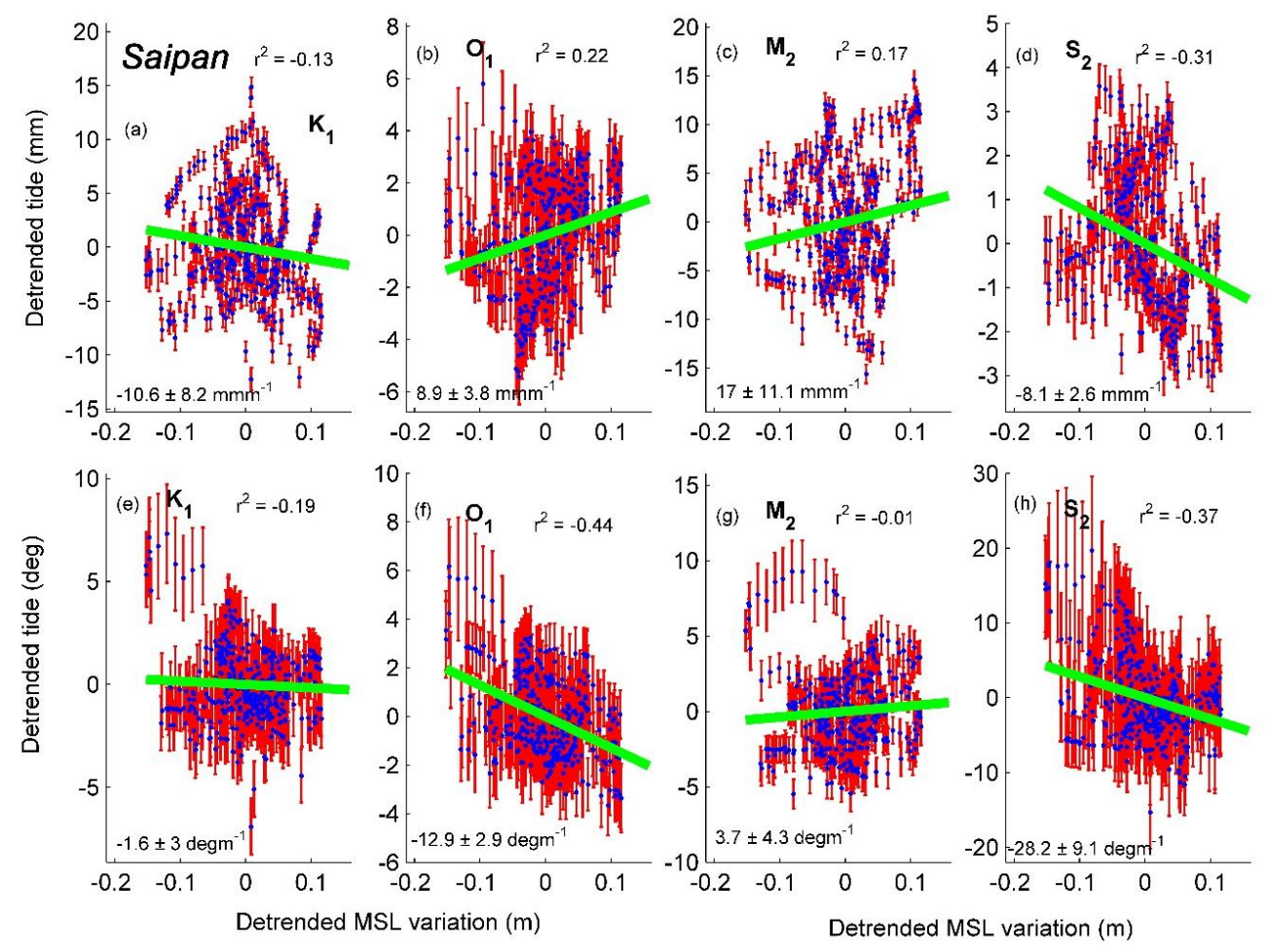

Figure B1-9 Saipan amplitude anomaly trends (A-TATs) for (a) $\mathrm{K}_{1}$; (b) $\mathrm{O}_{1}$; (c) $\mathrm{M}_{2}$; (d) $\mathrm{S}_{2}$; and phase anomaly trend (P-TATs) for (e) $\mathrm{K}_{1} ;$ (f) $\mathrm{O}_{1} ;(\mathrm{g}) \mathrm{M}_{2}$; and $(\mathrm{h}) \mathrm{S}_{2}$. The red bars show $95 \%$ confidence limits on each annual estimate. The green line is the robust linear regression trend, in $\mathrm{mmm}^{-1}$ or degm ${ }^{-1}$, as shown as text, with $95 \%$ confidence limits on the anomaly trend. Significance is indicated by $r^{2}$ values within each subplot. 

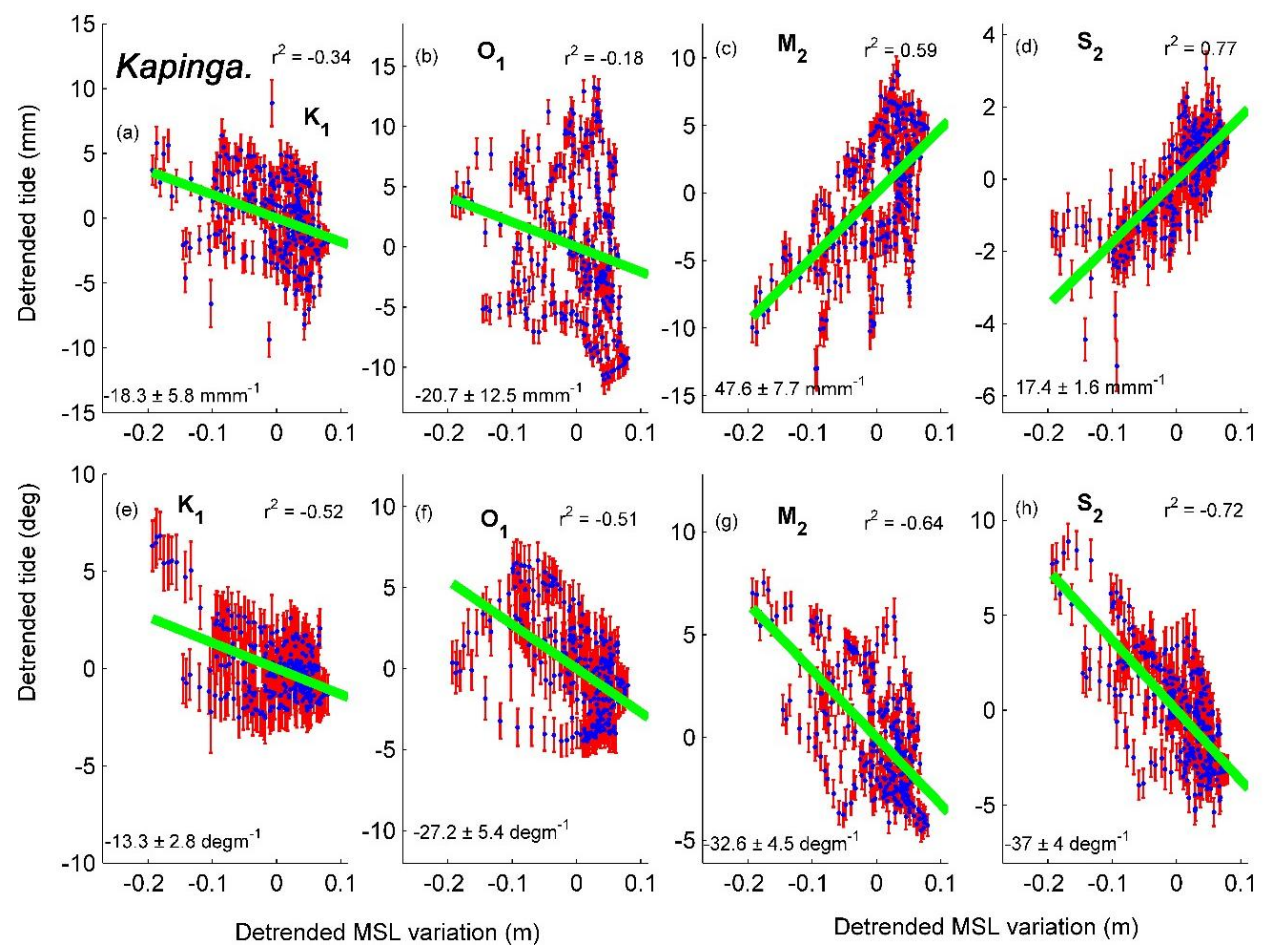

Figure B1-10 Kapingamarangi: amplitude anomaly trends (A-TATs) for (a) $\mathrm{K}_{1} ;(\mathrm{b}) \mathrm{O}_{1} ;$ (c) $\mathrm{M}_{2}$; (d) $\mathrm{S}_{2}$; and phase anomaly trend (P-TATs) for (e) $\mathrm{K}_{1}$; (f) $\mathrm{O}_{1}$; (g) $\mathrm{M}_{2}$; and (h) $\mathrm{S}_{2}$. The red bars show $95 \%$ confidence limits on each annual estimate. The green line is the robust linear regression trend, in $\mathrm{mmm}^{-1}$ or degm ${ }^{-1}$, as shown as text, with $95 \%$ confidence limits on the anomaly trend. Significance is indicated by $r^{2}$ values within each subplot. 

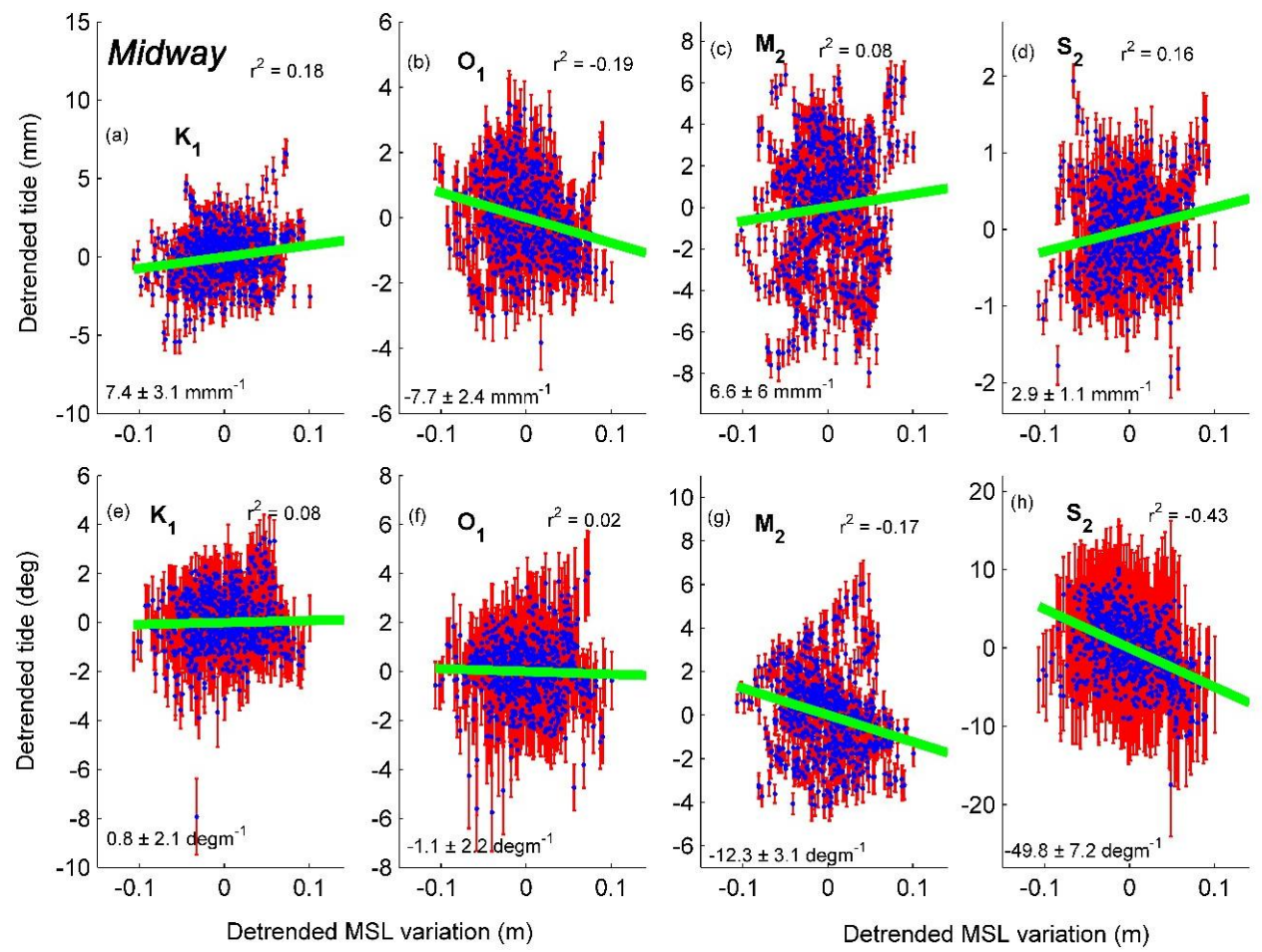

Figure B1-11 Midway: amplitude anomaly trends (A-TATs) for (a) $\mathrm{K}_{1}$; (b) $\mathrm{O}_{1}$; (c) $\mathrm{M}_{2}$; (d) $\mathrm{S}_{2}$; and phase anomaly trend (P-TATs) for (e) $\mathrm{K}_{1} ;$ (f) $\mathrm{O}_{1} ;(\mathrm{g}) \mathrm{M}_{2}$; and (h) $\mathrm{S}_{2}$. The red bars show $95 \%$ confidence limits on each annual estimate. The green line is the robust linear regression trend, in $\mathrm{mmm}^{-1}$ or degm ${ }^{-1}$, as shown as text, with $95 \%$ confidence limits on the anomaly trend. Significance is indicated by $r^{2}$ values within each subplot. 

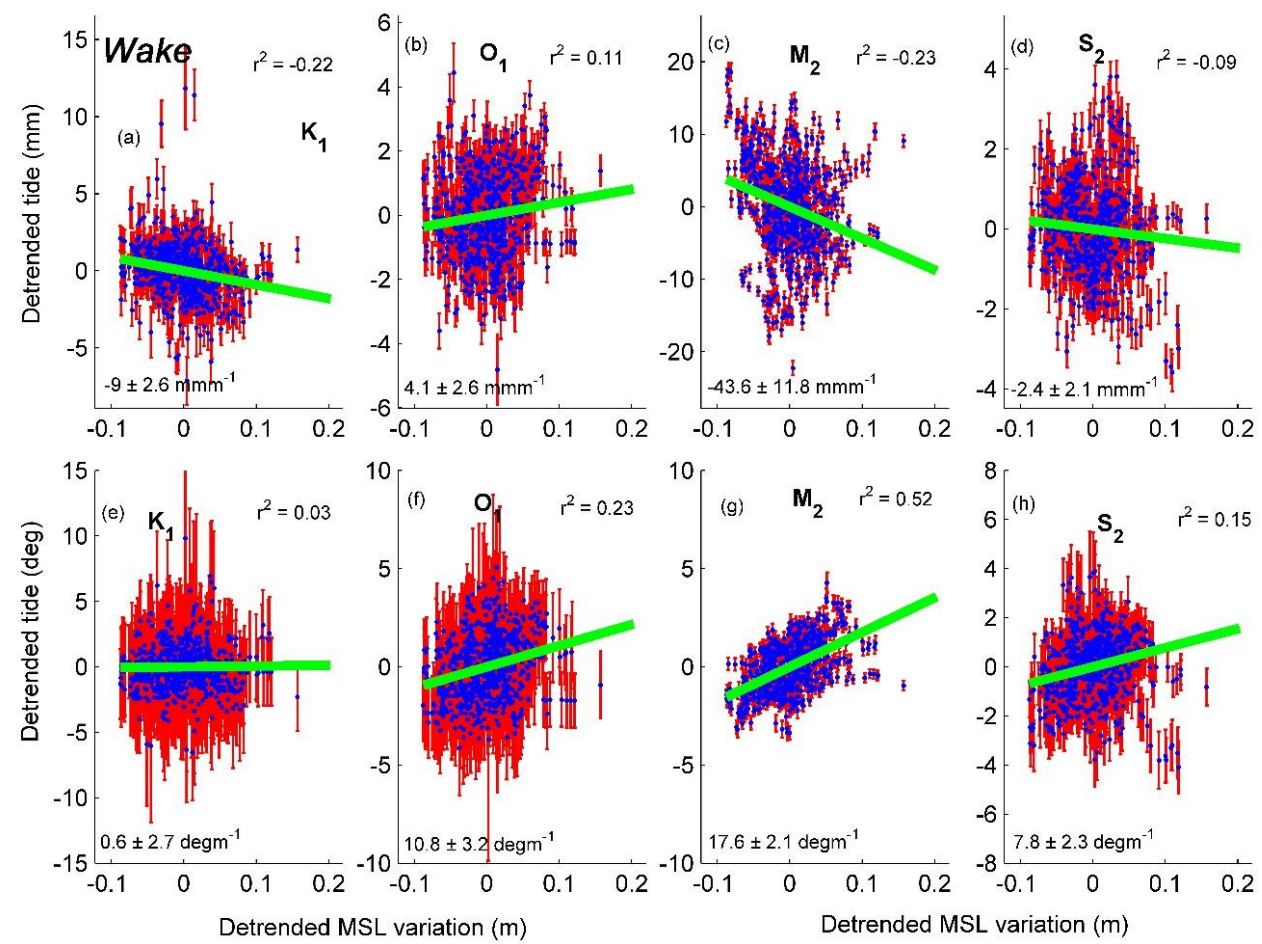

Figure B1-12 Wake: amplitude anomaly trends (A-TATs) for (a) $\mathrm{K}_{1}$; (b) $\mathrm{O}_{1}$; (c) $\mathrm{M}_{2}$; (d) $\mathrm{S}_{2}$; and phase anomaly trend (P-TATs) for (e) $\mathrm{K}_{1} ;(\mathrm{f}) \mathrm{O}_{1} ;(\mathrm{g}) \mathrm{M}_{2}$; and $(\mathrm{h}) \mathrm{S}_{2}$. The red bars show $95 \%$ confidence limits on each annual estimate. The green line is the robust linear regression trend, in $\mathrm{mmm}^{-1}$ or degm ${ }^{-1}$, as shown as text, with $95 \%$ confidence limits on the anomaly trend. Significance is indicated by $r^{2}$ values within each subplot. 

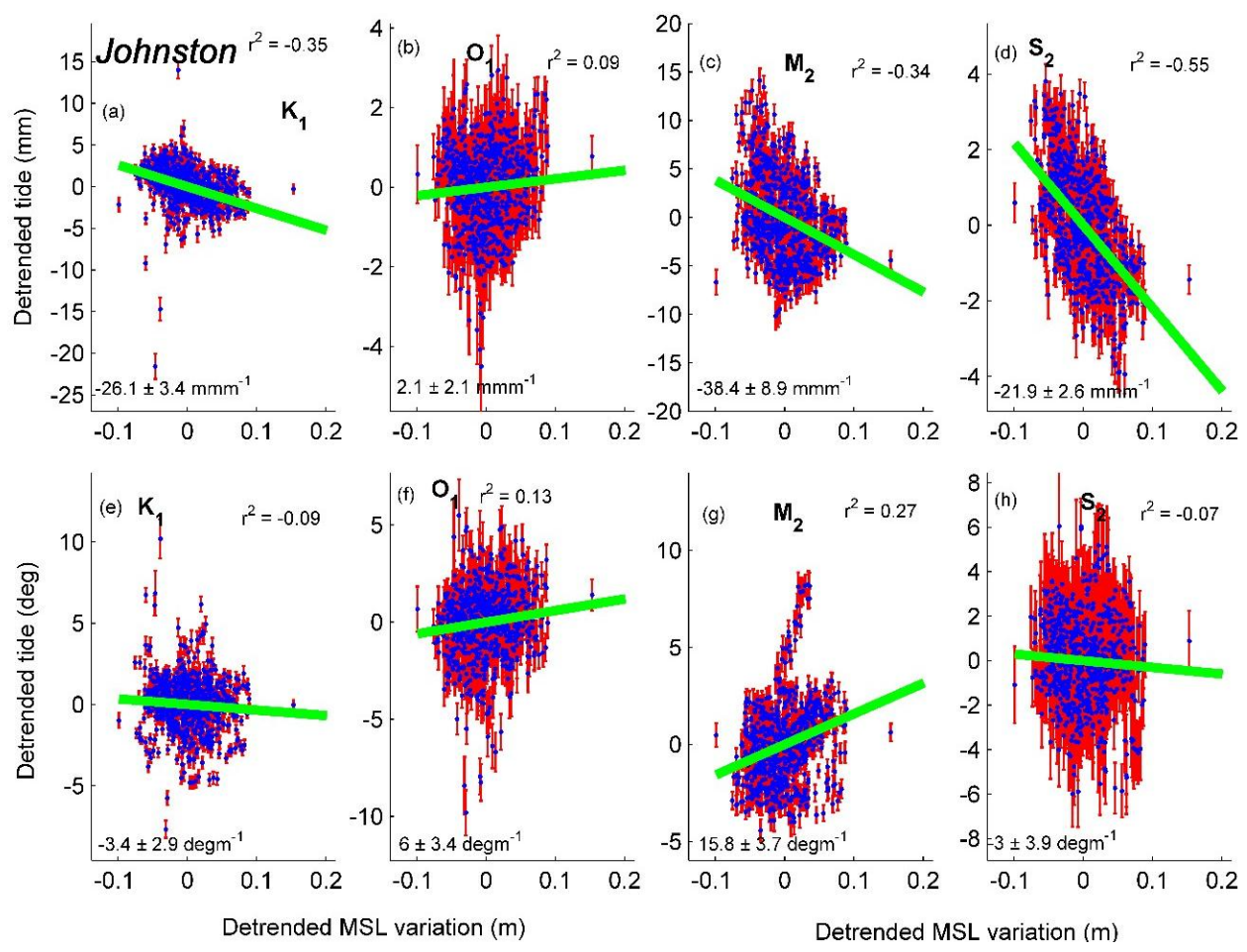

Figure B1-13 Johnston: amplitude anomaly trends (A-TATs) for (a) $\mathrm{K}_{1}$; (b) $\mathrm{O}_{1}$; (c) $\mathrm{M}_{2}$; (d) $\mathrm{S}_{2}$; and phase anomaly trend (P-TATs) for (e) $\mathrm{K}_{1}$; (f) $\mathrm{O}_{1}$; (g) $\mathrm{M}_{2}$; and (h) $\mathrm{S}_{2}$. The red bars show $95 \%$ confidence limits on each annual estimate. The green line is the robust linear regression trend, in $\mathrm{mmm}^{-1}$ or degm $\mathrm{m}^{-1}$, as shown as text, with $95 \%$ confidence limits on the anomaly trend. Significance is indicated by $r^{2}$ values within each subplot. 

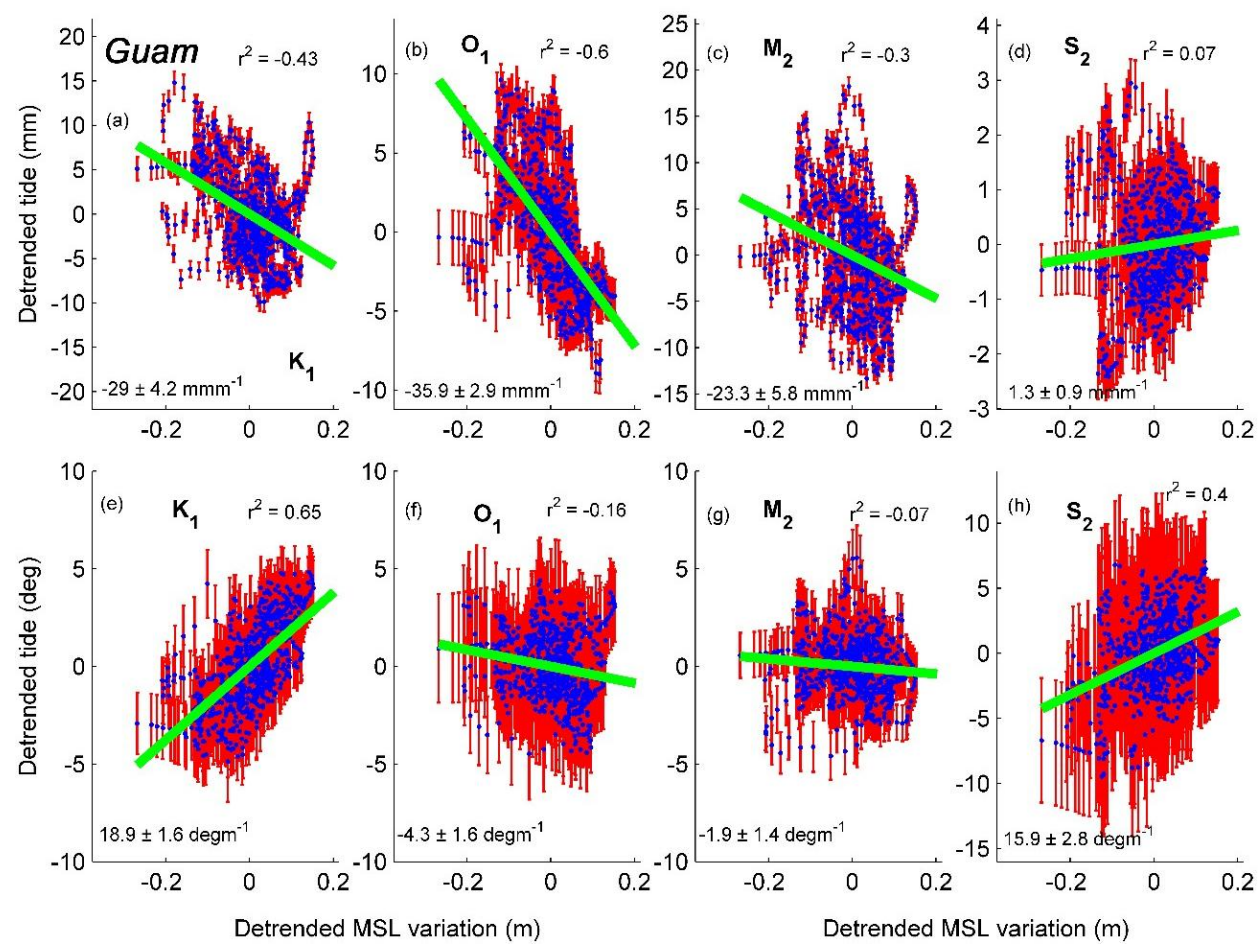

Figure B1-14 Guam: amplitude anomaly trends (A-TATs) for (a) $\mathrm{K}_{1}$; (b) $\mathrm{O}_{1}$; (c) $\mathrm{M}_{2}$; (d) $\mathrm{S}_{2}$; and phase anomaly trend (P-TATs) for (e) $\mathrm{K}_{1}$; (f) $\mathrm{O}_{1} ;$ (g) $\mathrm{M}_{2}$; and (h) $\mathrm{S}_{2}$. The red bars show $95 \%$ confidence limits on each annual estimate. The green line is the robust linear regression trend, in $\mathrm{mmm}^{-1}$ or degm ${ }^{-1}$, as shown as text, with $95 \%$ confidence limits on the anomaly trend. Significance is indicated by $r^{2}$ values within each subplot. 

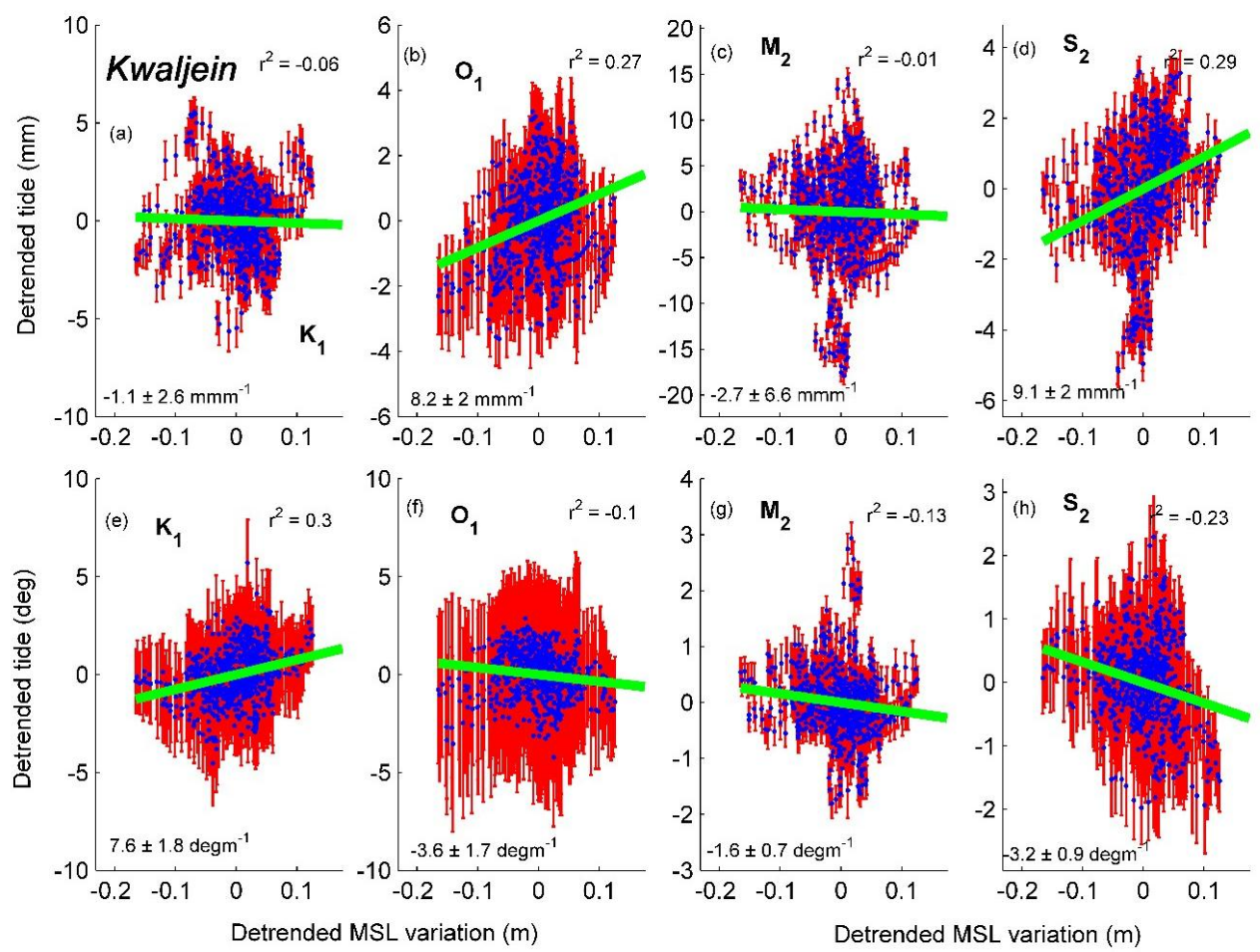

Figure B1-15 Kwajalein: amplitude anomaly trends (A-TATs) for (a) $\mathrm{K}_{1}$; (b) $\mathrm{O}_{1}$; (c) $\mathrm{M}_{2}$; (d) $\mathrm{S}_{2}$; and phase anomaly trend (P-TATs) for (e) $\mathrm{K}_{1}$; (f) $\mathrm{O}_{1}$; (g) $\mathrm{M}_{2}$; and (h) $\mathrm{S}_{2}$. The red bars show $95 \%$ confidence limits on each annual estimate. The green line is the robust linear regression trend, in $\mathrm{mmm}^{-1}$ or degm $\mathrm{m}^{-1}$, as shown as text, with $95 \%$ confidence limits on the anomaly trend. Significance is indicated by $r^{2}$ values within each subplot. 

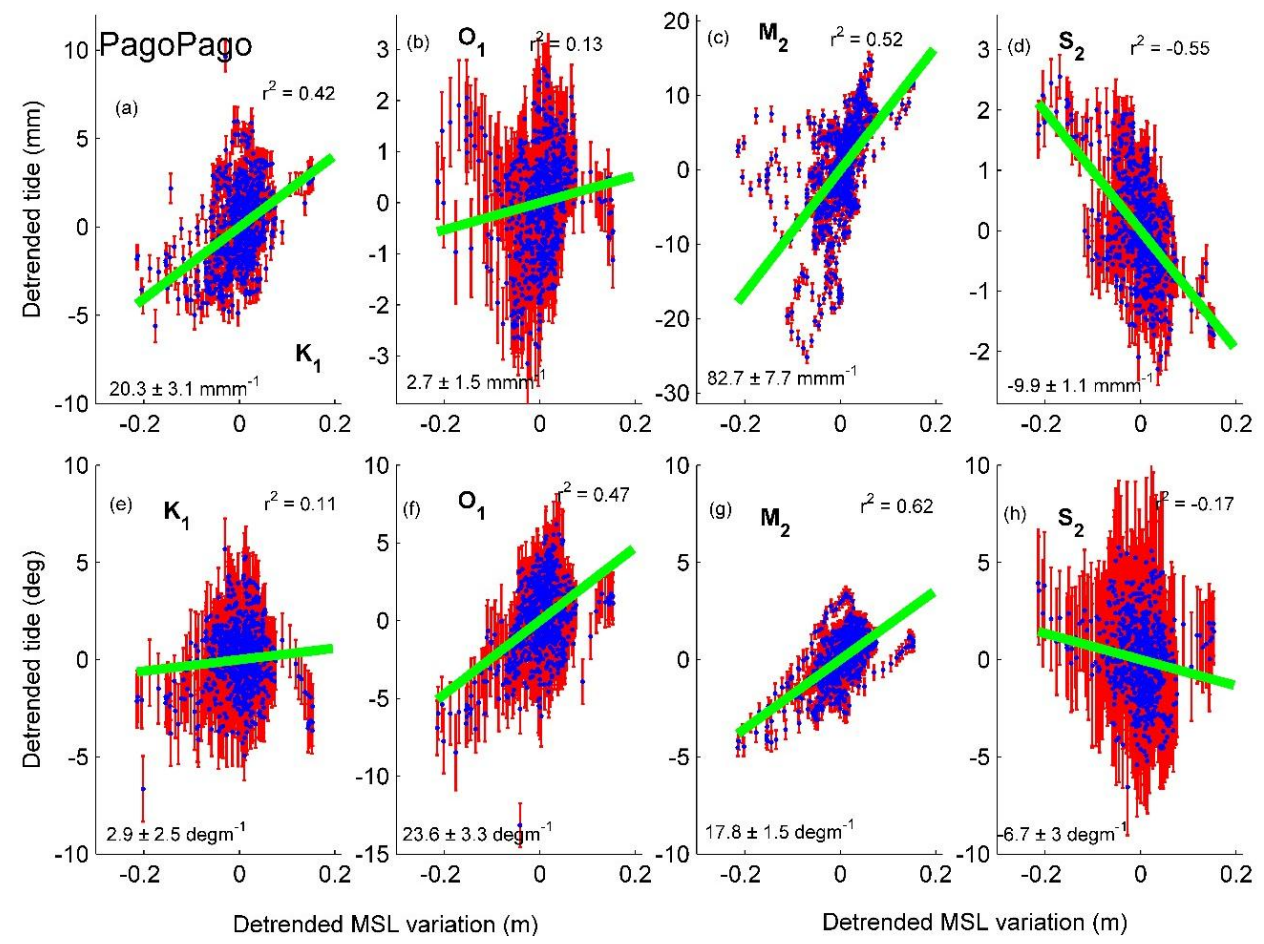

Figure B1-16 Pago Pago: amplitude anomaly trends (A-TATs) for (a) $\mathrm{K}_{1}$; (b) $\mathrm{O}_{1}$; (c) $\mathrm{M}_{2}$; (d) $\mathrm{S}_{2}$; and phase anomaly trend (P-TATs) for (e) $\mathrm{K}_{1}$; (f) $\mathrm{O}_{1}$; (g) $\mathrm{M}_{2}$; and (h) $\mathrm{S}_{2}$. The red bars show $95 \%$ confidence limits on each annual estimate. The green line is the robust linear regression trend, in $\mathrm{mmm}^{-1}$ or degm ${ }^{-1}$, as shown as text, with $95 \%$ confidence limits on the anomaly trend. Significance is indicated by $r^{2}$ values within each subplot. 

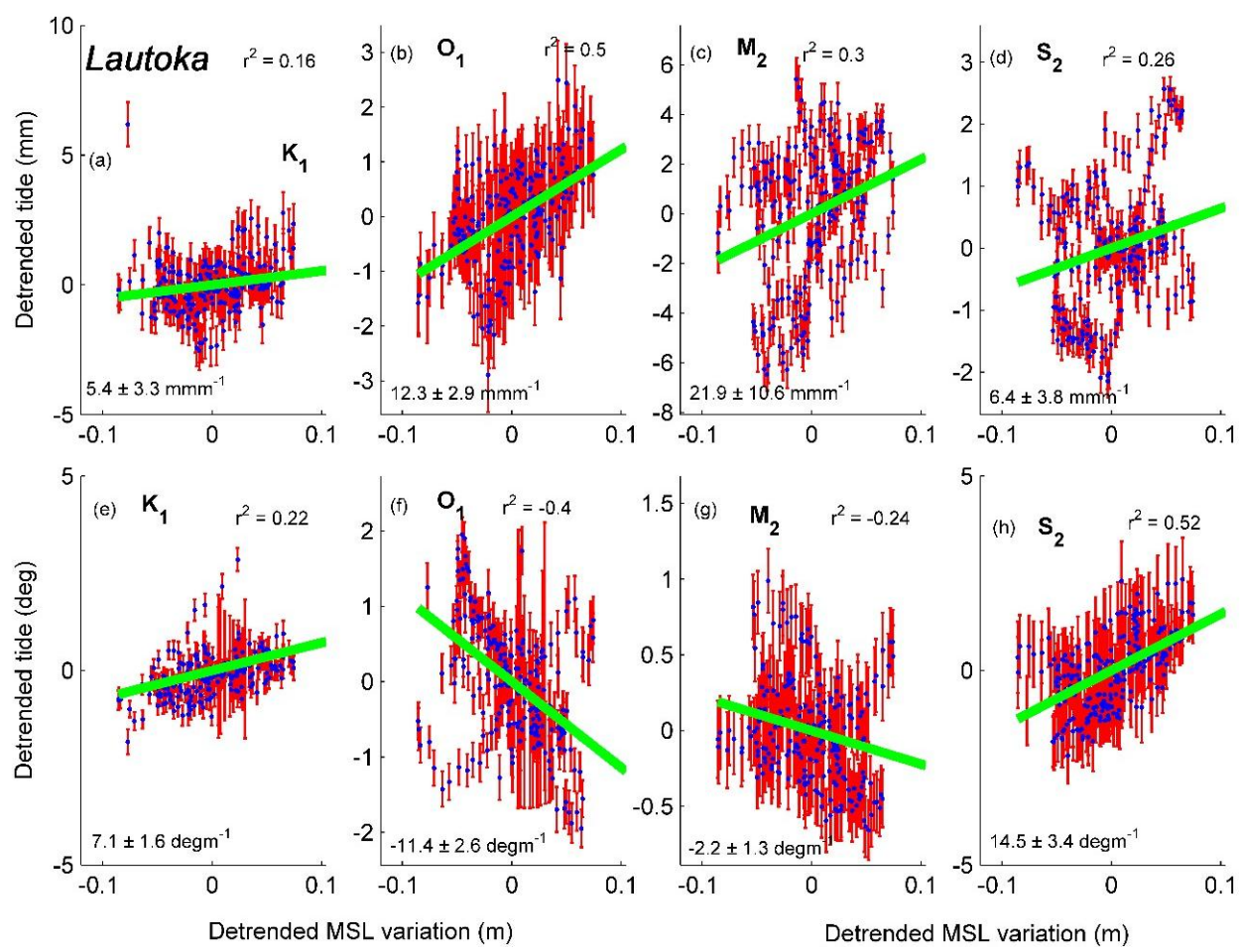

Figure B1-17 Lautoka: amplitude anomaly trends (A-TATs) for (a) $\mathrm{K}_{1}$; (b) $\mathrm{O}_{1}$; (c) $\mathrm{M}_{2}$; (d) $\mathrm{S}_{2}$; and phase anomaly trend (P-TATs) for (e) $\mathrm{K}_{1}$; (f) $\mathrm{O}_{1} ;(\mathrm{g}) \mathrm{M}_{2}$; and (h) $\mathrm{S}_{2}$. The red bars show $95 \%$ confidence limits on each annual estimate. The green line is the robust linear regression trend, in $\mathrm{mmm}^{-1}$ or degm ${ }^{-1}$, as shown as text, with $95 \%$ confidence limits on the anomaly trend. Significance is indicated by $r^{2}$ values within each subplot. 

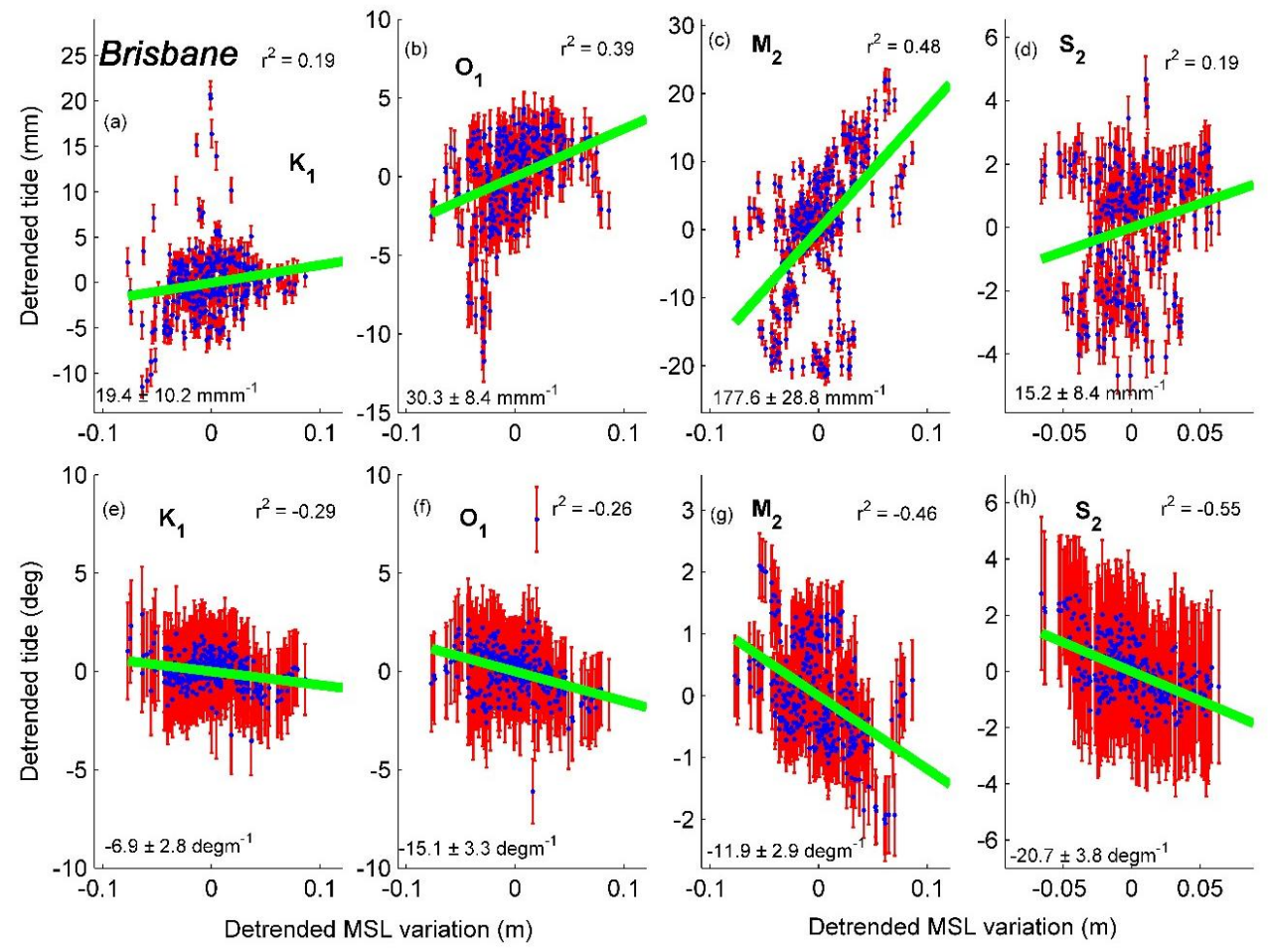

Figure B1-18 Brisbane: amplitude anomaly trends (A-TATs) for (a) $\mathrm{K}_{1}$; (b) $\mathrm{O}_{1}$; (c) $\mathrm{M}_{2}$; (d) $\mathrm{S}_{2}$; and phase anomaly trend (P-TATs) for (e) $\mathrm{K}_{1} ;$ (f) $\mathrm{O}_{1} ;(\mathrm{g}) \mathrm{M}_{2}$; and (h) $\mathrm{S}_{2}$. The red bars show $95 \%$ confidence limits on each annual estimate. The green line is the robust linear regression trend, in $\mathrm{mmm}^{-1}$ or degm ${ }^{-1}$, as shown as text, with $95 \%$ confidence limits on the anomaly trend. Significance is indicated by $r^{2}$ values within each subplot. 

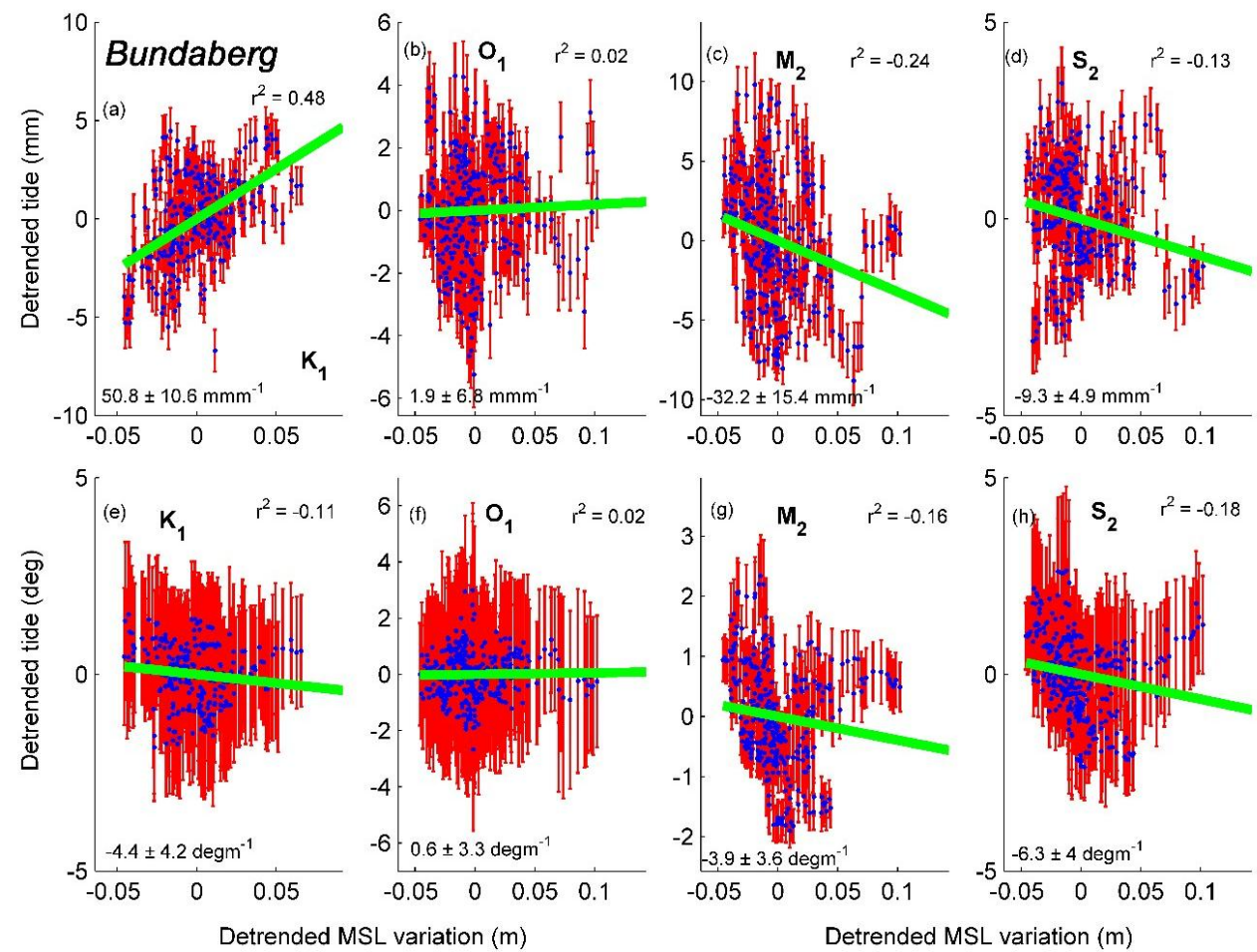

Figure B1-19 Bundaberg: amplitude anomaly trends (A-TATs) for (a) $\mathrm{K}_{1}$; (b) $\mathrm{O}_{1}$; (c) $\mathrm{M}_{2}$; (d) $\mathrm{S}_{2}$; and phase anomaly trend (P-TATs) for (e) $\mathrm{K}_{1}$; (f) $\mathrm{O}_{1} ;$ (g) $\mathrm{M}_{2}$; and (h) $\mathrm{S}_{2}$. The red bars show $95 \%$ confidence limits on each annual estimate. The green line is the robust linear regression trend, in $\mathrm{mmm}^{-1}$ or degm ${ }^{-1}$, as shown as text, with $95 \%$ confidence limits on the anomaly trend. Significance is indicated by $r^{2}$ values within each subplot. 

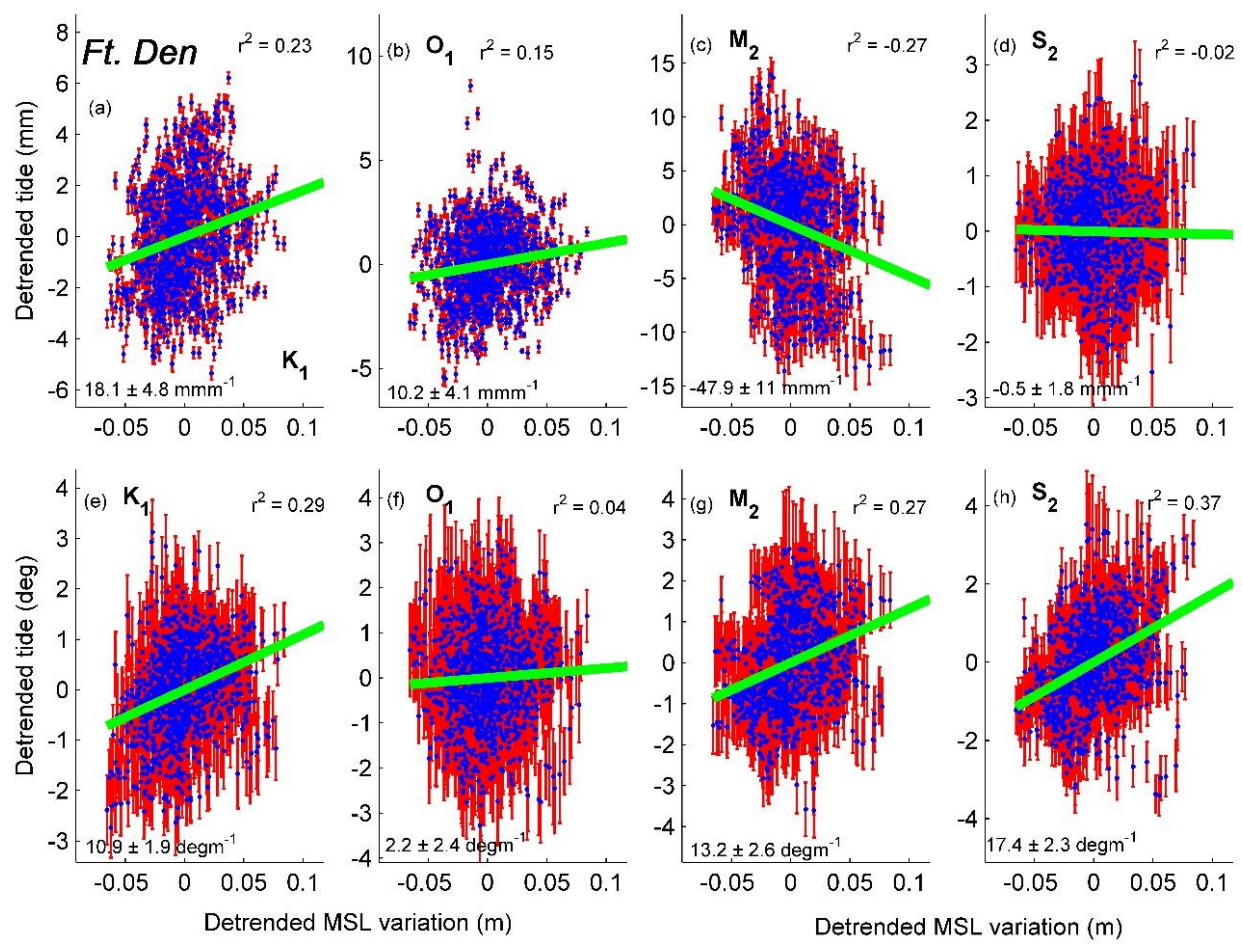

Figure B1-20 Fort Denison (Sydney Harbor): amplitude anomaly trends (A-TATs) for (a) $\mathrm{K}_{1}$; (b) $\mathrm{O}_{1}$; (c) $\mathrm{M}_{2}$; (d) $\mathrm{S}_{2}$; and phase anomaly trend (P-TATs) for (e) $\mathrm{K}_{1}$; (f) $\mathrm{O}_{1}$; (g) $\mathrm{M}_{2}$; and $(h) S_{2}$. The red bars show 95\% confidence limits on each annual estimate. The green line is the robust linear regression trend, in $\mathrm{mmm}^{-1}$ or degm ${ }^{-1}$, as shown as text, with $95 \%$ confidence limits on the anomaly trend. Significance is indicated by $r^{2}$ values within each subplot. 

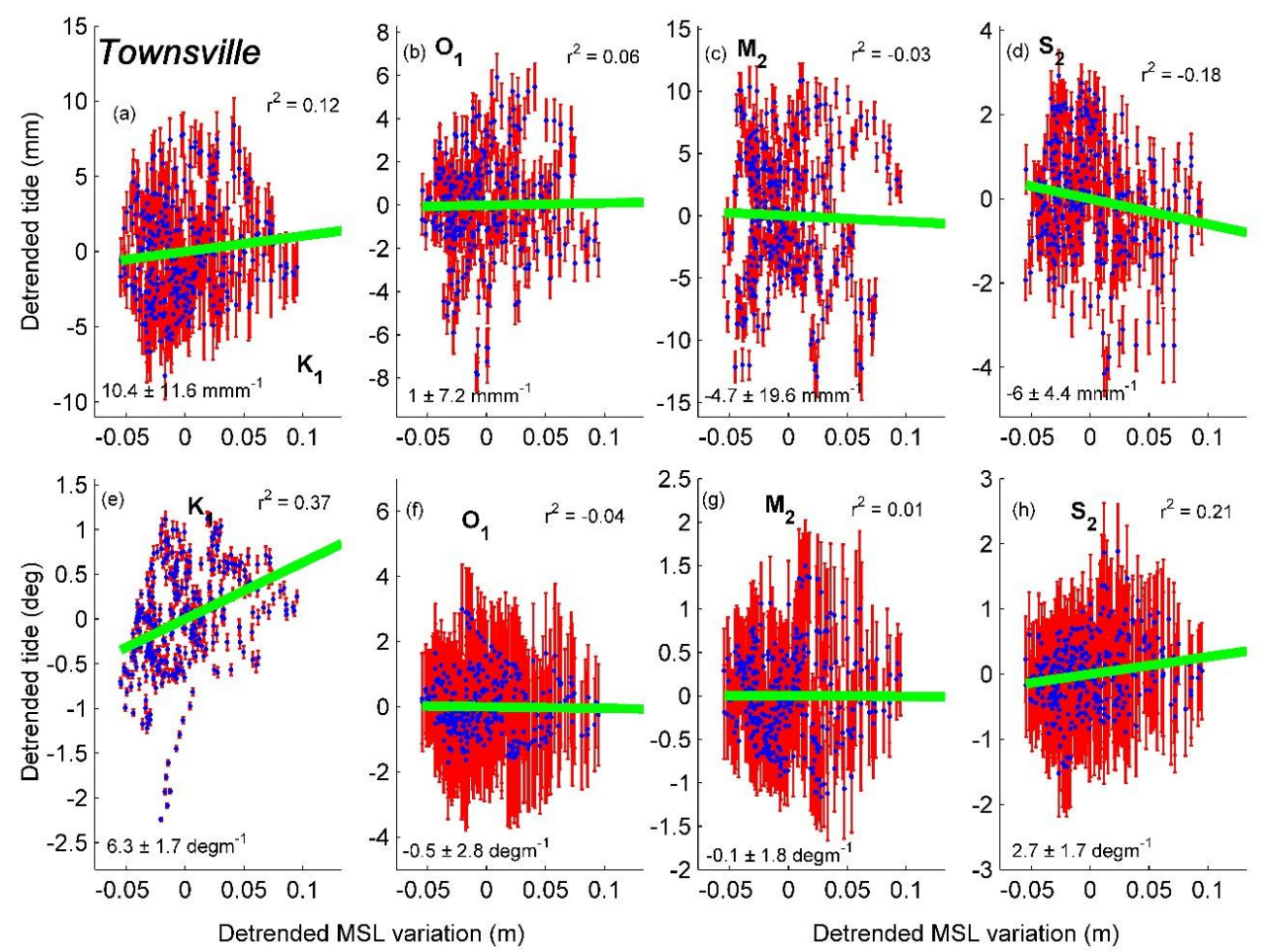

Figure B1-21 Townsville: amplitude anomaly trends (A-TATs) for (a) $\mathrm{K}_{1}$; (b) $\mathrm{O}_{1}$; (c) $\mathrm{M}_{2}$; (d) $\mathrm{S}_{2}$; and phase anomaly trend (P-TATs) for (e) $\mathrm{K}_{1}$; (f) $\mathrm{O}_{1} ;$ (g) $\mathrm{M}_{2}$; and (h) $\mathrm{S}_{2}$. The red bars show $95 \%$ confidence limits on each annual estimate. The green line is the robust linear regression trend, in $\mathrm{mmm}^{-1}$ or degm ${ }^{-1}$, as shown as text, with $95 \%$ confidence limits on the anomaly trend. Significance is indicated by $r^{2}$ values within each subplot. 

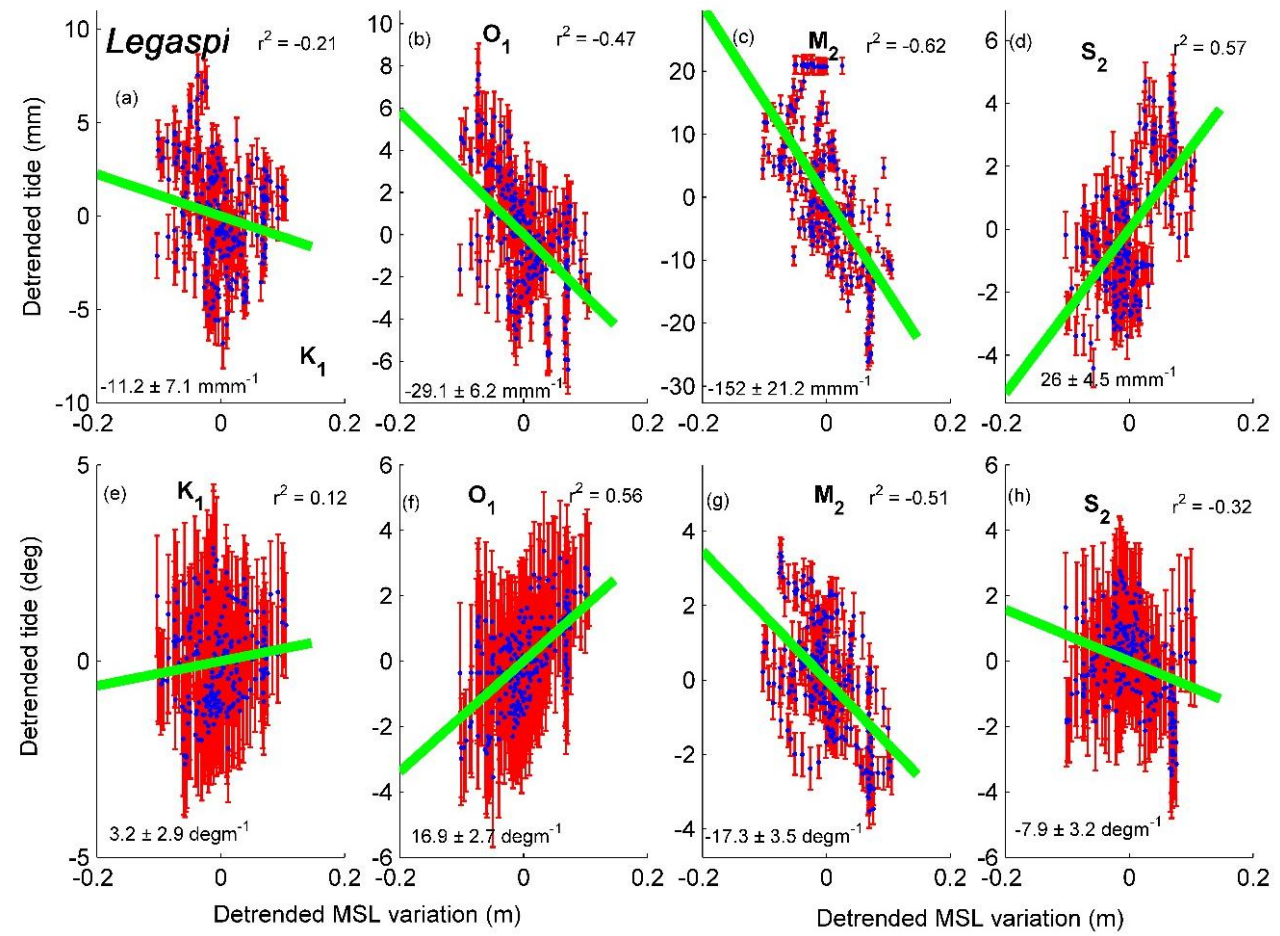

Figure B1-22 Legaspi: amplitude anomaly trends (A-TATs) for (a) $\mathrm{K}_{1}$; (b) $\mathrm{O}_{1}$; (c) $\mathrm{M}_{2}$; (d) $\mathrm{S}_{2}$; and phase anomaly trend (P-TATs) for (e) $\mathrm{K}_{1}$; (f) $\mathrm{O}_{1} ;(\mathrm{g}) \mathrm{M}_{2}$; and (h) $\mathrm{S}_{2}$. The red bars show $95 \%$ confidence limits on each annual estimate. The green line is the robust linear regression trend, in $\mathrm{mmm}^{-1}$ or degm ${ }^{-1}$, as shown as text, with $95 \%$ confidence limits on the anomaly trend. Significance is indicated by $r^{2}$ values within each subplot. 

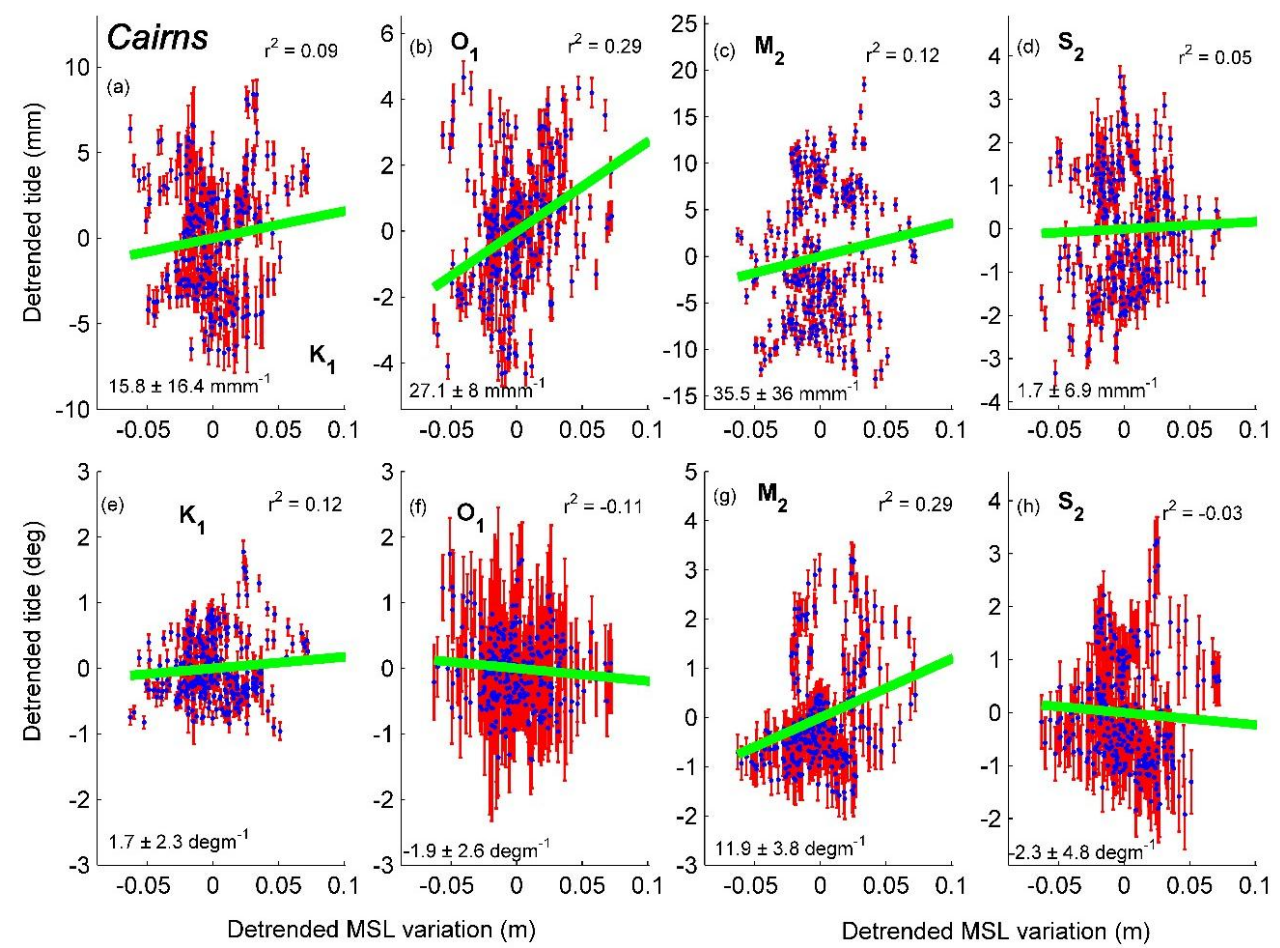

Figure B1-23 Cairns: amplitude anomaly trends (A-TATs) for (a) $\mathrm{K}_{1}$; (b) $\mathrm{O}_{1}$; (c) $\mathrm{M}_{2}$; (d) $\mathrm{S}_{2}$; and phase anomaly trend (P-TATs) for (e) $\mathrm{K}_{1}$; (f) $\mathrm{O}_{1}$; (g) $\mathrm{M}_{2}$; and (h) $\mathrm{S}_{2}$. The red bars show $95 \%$ confidence limits on each annual estimate. The green line is the robust linear regression trend, in $\mathrm{mmm}^{-1}$ or degm ${ }^{-1}$, as shown as text, with $95 \%$ confidence limits on the anomaly trend. Significance is indicated by $r^{2}$ values within each subplot. 

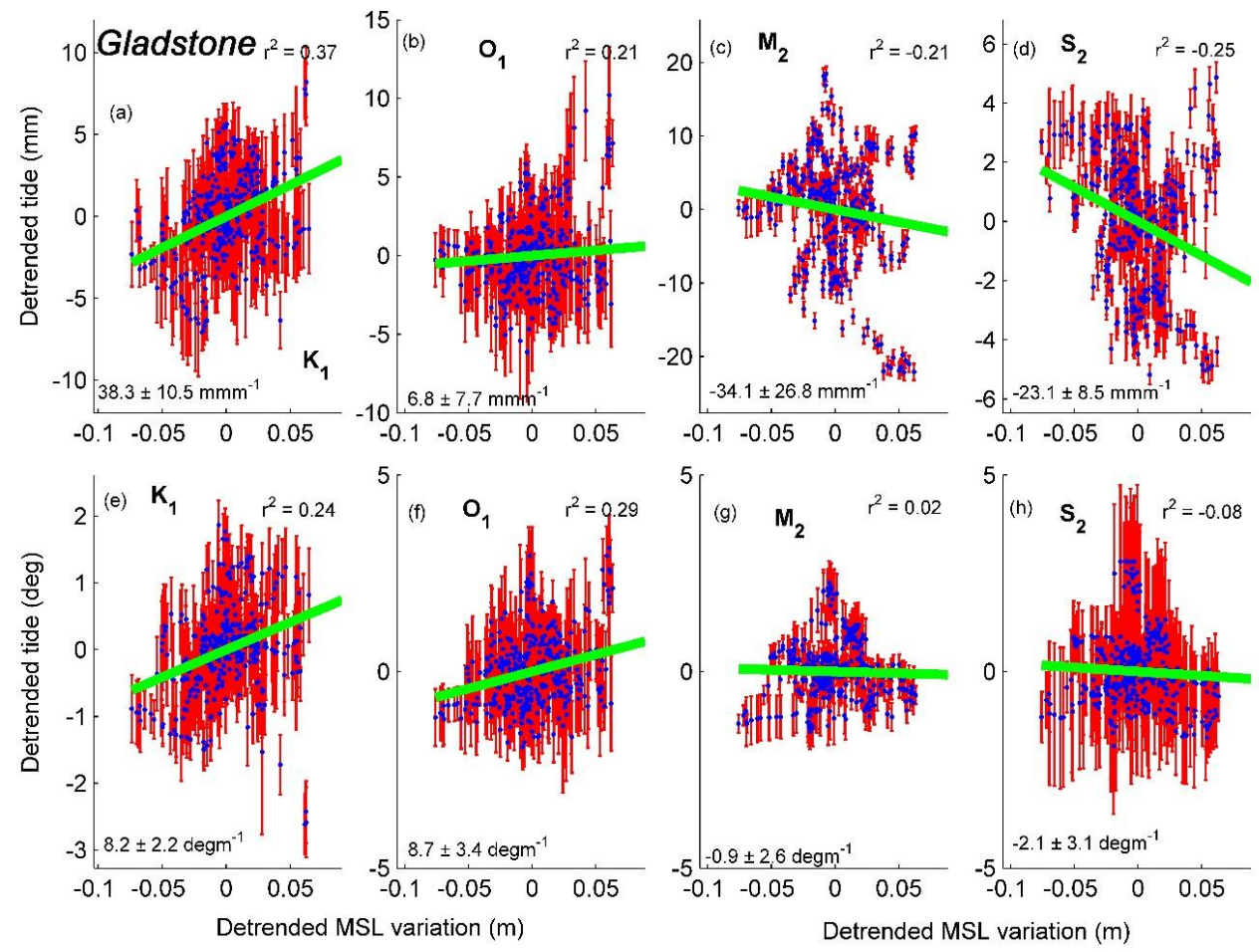

Figure B1-24 Gladstone: amplitude anomaly trends (A-TATs) for (a) $\mathrm{K}_{1}$; (b) $\mathrm{O}_{1}$; (c) $\mathrm{M}_{2}$; (d) $\mathrm{S}_{2}$; and phase anomaly trend (P-TATs) for (e) $\mathrm{K}_{1}$; (f) $\mathrm{O}_{1}$; (g) $\mathrm{M}_{2}$; and (h) $\mathrm{S}_{2}$. The red bars show $95 \%$ confidence limits on each annual estimate. The green line is the robust linear regression trend, in $\mathrm{mmm}^{-1}$ or degm $\mathrm{m}^{-1}$, as shown as text, with $95 \%$ confidence limits on the anomaly trend. Significance is indicated by $r^{2}$ values within each subplot. 

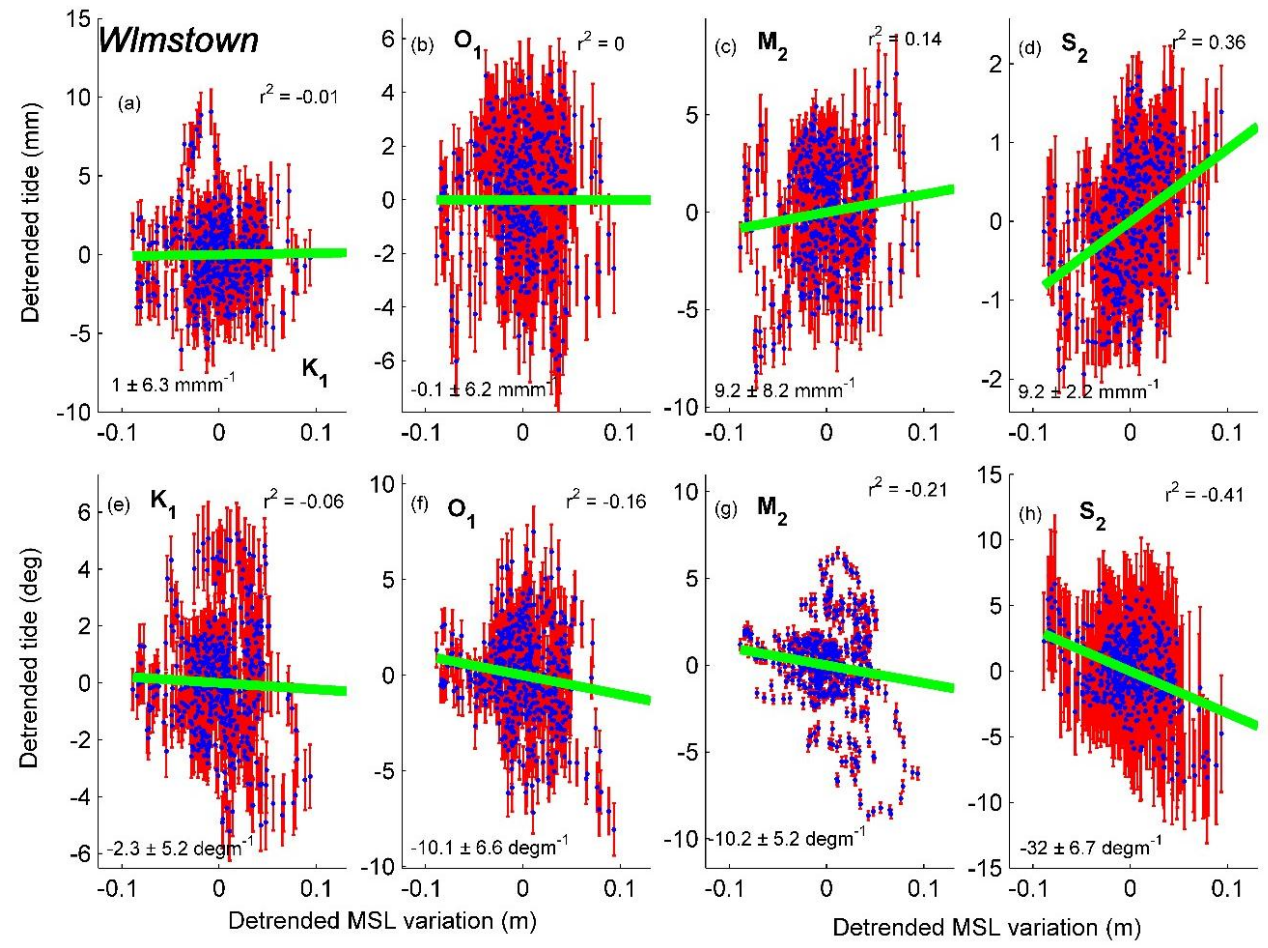

Figure B1-25 Williamstown: amplitude anomaly trends (A-TATs) for (a) $\mathrm{K}_{1}$; (b) $\mathrm{O}_{1}$; (c) $\mathrm{M}_{2}$; (d) $\mathrm{S}_{2}$; and phase anomaly trend (P-TATs) for (e) $\mathrm{K}_{1}$; (f) $\mathrm{O}_{1} ;$ (g) $\mathrm{M}_{2}$; and (h) $\mathrm{S}_{2}$. The red bars show $95 \%$ confidence limits on each annual estimate. The green line is the robust linear regression trend, in $\mathrm{mmm}^{-1}$ or degm ${ }^{-1}$, as shown as text, with $95 \%$ confidence limits on the anomaly trend. Significance is indicated by $r^{2}$ values within each subplot. 

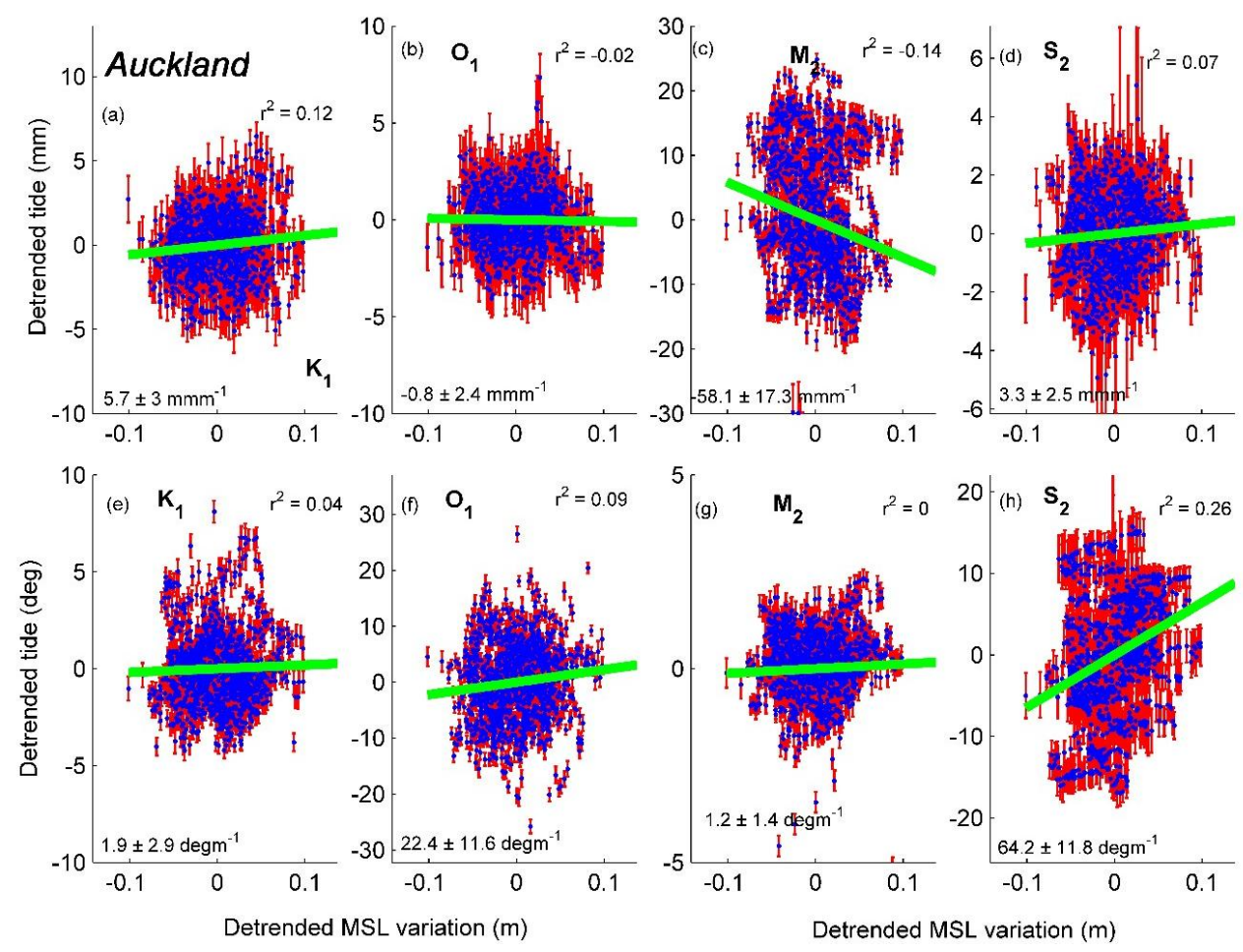

Figure B1-26 Auckland: amplitude anomaly trends (A-TATs) for (a) $\mathrm{K}_{1}$; (b) $\mathrm{O}_{1}$; (c) $\mathrm{M}_{2}$; (d) $\mathrm{S}_{2}$; and phase anomaly trend (P-TATs) for (e) $\mathrm{K}_{1}$; (f) $\mathrm{O}_{1} ;$ (g) $\mathrm{M}_{2}$; and (h) $\mathrm{S}_{2}$. The red bars show $95 \%$ confidence limits on each annual estimate. The green line is the robust linear regression trend, in $\mathrm{mmm}^{-1}$ or degm ${ }^{-1}$, as shown as text, with $95 \%$ confidence limits on the anomaly trend. Significance is indicated by $r^{2}$ values within each subplot. 


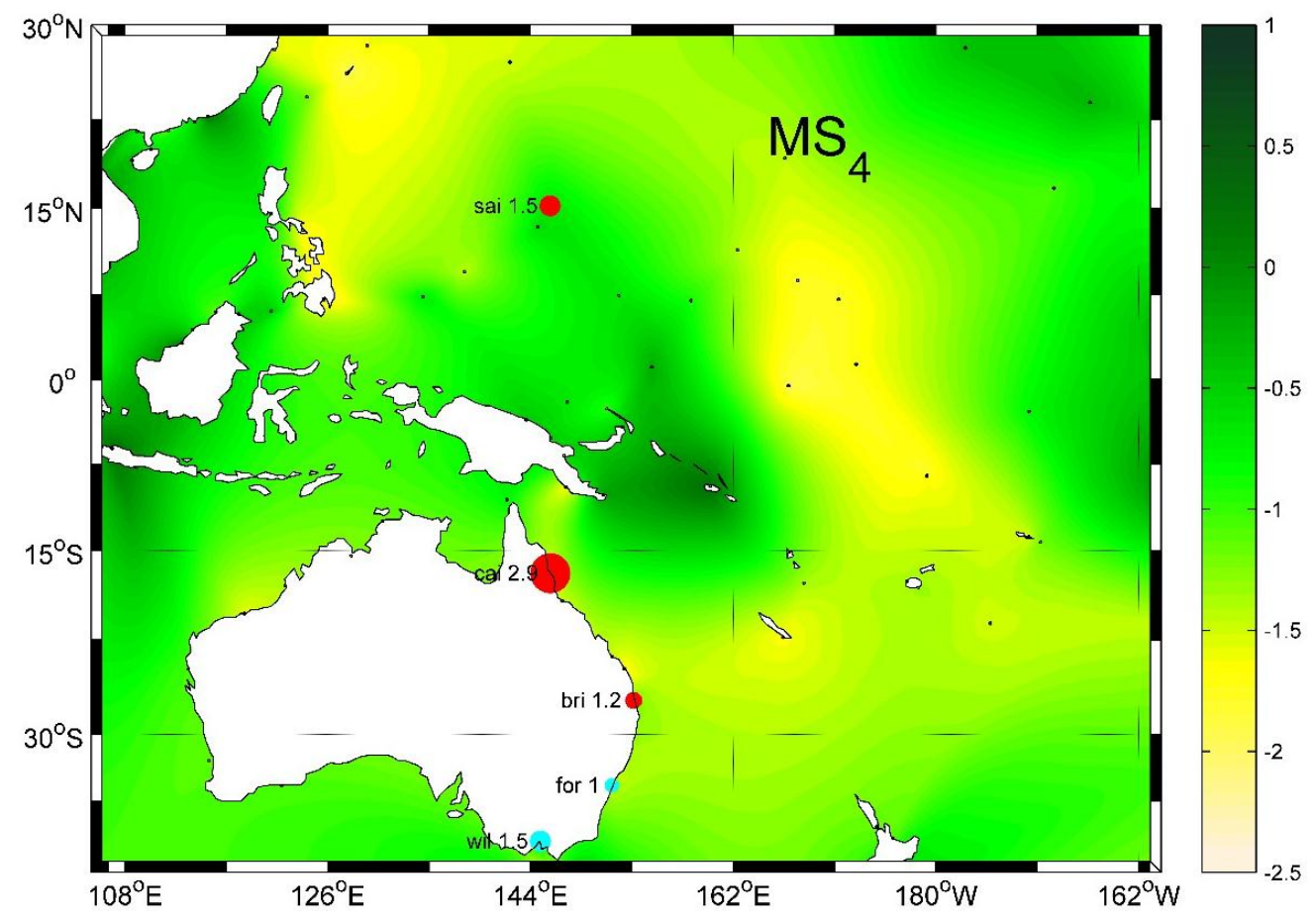

Figure B2 Overtide ratios (ORs) for: $\mathrm{MS}_{4} /\left(\mathrm{M}_{2} * \mathrm{~S}_{2}\right)$; the greenscale background represent the mean OR on a logarithmic scale in units of $\mathrm{m}^{-1}$. For stations that show a significant change over time in this ratio, numbers and colored (red for positive change, light blue for negative change) markers indicate change in the ORs, expressed as percentage change per year. 


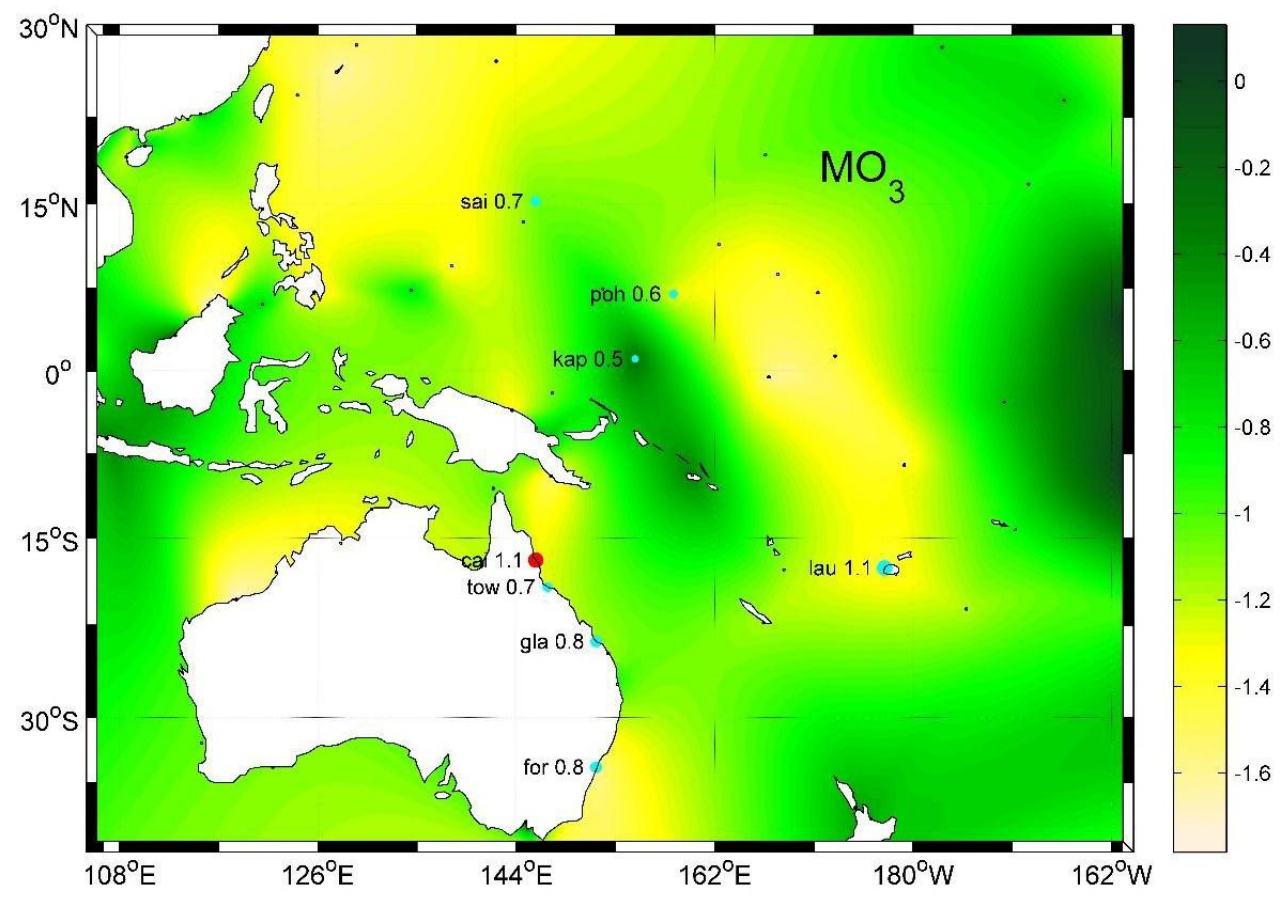

Figure $\mathrm{B3}$ Overtide ratios (ORs) for: $\mathrm{MO}_{3} /\left(\mathrm{M}_{2} * \mathrm{O}_{1}\right)$; the greenscale background represent the mean OR on a logarithmic scale in units of $\mathrm{m}^{-1}$. For stations that show a significant change over time in this ratio, numbers and colored (red for positive change, light blue for negative change) markers indicate change in the ORs, expressed as percentage change per year. 